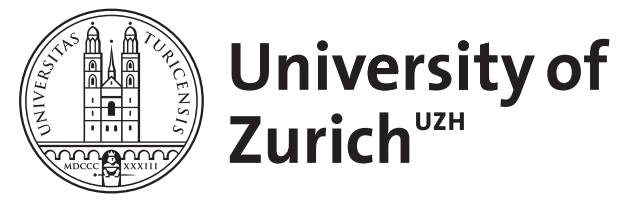

Zurich Open Repository and Archive

University of Zurich

University Library

Strickhofstrasse 39

CH-8057 Zurich

www.zora.uzh.ch

Year: 1982

\title{
Der Dekalog: Seine späten Fassungen, die originale Komposition und seine Vorstufen
}

\author{
Hossfeld, Frank-Lothar
}

Posted at the Zurich Open Repository and Archive, University of Zurich

ZORA URL: https://doi.org/10.5167/uzh-157928

Monograph

Published Version

Originally published at:

Hossfeld, Frank-Lothar (1982). Der Dekalog: Seine späten Fassungen, die originale Komposition und seine Vorstufen. Freiburg, Switzerland / Göttingen, Germany: Universitätsverlag / Vandenhoeck Ruprecht. 
HOSSFELD · DER DEKALOG 
Im Auftrag des Biblischen Institutes der Universität Freiburg Schweiz und des Seminars für Biblische Zeitgeschichte der Universität Münster herausgegeben von Othmar Keel, unter Mitarbeit von Bernard Trémel und Erich Zenger

Frank-Lothar Hossfeld, Jahrgang 1942, Studium der Theologie in Trier, Würzburg und Regensburg, 1966 Priesterweihe in Trier und anschließend Tätigkeit in der Pfarrseelsorge, 1967 Lizentiat der Theologie, 1976 Promotion in Regensburg, 19.81 Habilitation in Münster, seit 1973 Wissenschaftlicher Assistent am Seminar für Biblische Zeitgeschichte und Biblische Hilfswissenschaften des Fachbereichs Katholische Theologie der Universität Münster. Wichtige Veröffentlichungen: Prophet gegen Prophet (1973); Der Prophet vor dem Tribunal (ZAW 86, 1974); Untersuchungen zu Komposition und Theologie des Ezechielbuches (1977). 


\title{
ORBIS BIBLICUS ET ORIENTALIS 45
}

\author{
FRANK-LOTHAR HOSSFELD
}

\section{DER DEKALOG}

Seine späten Fassungen, die originale Komposition und seine Vorstufen

UNIVERSITÄTSVERLAG FREIBURG SCHWEIZ VANDENHOECK \& RUPRECHT GÖTTINGEN 1982 
CIP-Kurztitelaufnabme der Deutschen Bibliothek

Hossfeld, Frank-Lothar:

Der Dekalog: seine späten Fassungen, die orig. Komposition und seine Vorstufen / Frank-Lothar Hossfeld. Freiburg (Schweiz): Universitätsverlag;

Göttingen: Vandenhoeck und Ruprecht, 1982.

(Orbis biblicus et orientalis; 45)

ISBN 3-7278-0258-8 (Universitätsverlag)

ISBN 3-525-53663-1 (Vandenhoeck und Ruprecht)

(c) 1982 by Universitätsverlag Freiburg Schweiz

Paulusdruckerei Freiburg Schweiz 




\section{Vorwort}

Die vorliegende Untersuchung wurde im Sommer 1981 vom Fachbereich Katholische Theologie der Universität Münster als Habilitationsschrift angenommen. Für den Druck wurde sie geringfügig bearbeitet.

Mein besonderer Dank gilt den beiden Gutachtern der Arbeit, den Professoren Dr. Erich Zenger und Dr. Peter Weimar. In Anregung, Ermunterung und Kritik hat der "genius loci" vielfachen Einfluß ausgeübt und so Arbeit und Autor geprägt. Die individuelle Lebenszäsur einer Habilitation gibt mir die Gelegenheit, mich an die persönliche Förderung meines verehrten Lehrers Prof.Dr. Heinrich Groß zu erinnern und dankbar Rückschau zu halten.

Durch das freundschaftliche Entgegenkommen des Herausgebers, Prof.Dr. Othmar Keel, kann die Arbeit in der Reihe Orbis Biblicus et Orientalis erscheinen. Die Mitarbeiter beider Lehrstühle haben zügig Korrektur gelesen. Dr. Paul Deselaers hat trotz eigener Belastung den wissenschaftlichen Apparat vereinheitlicht und die Endredaktion betreut. Frau Elfriede Brüing hat mit gewohnter Akkuratesse und entlastender Schnelligkeit die Druckvorlage erstellt. Innen allen danke ich von Herzen.

Muinster, im Januar 1982 

KAPITEL 1: Thesen zum Stellenwert und zur Durchführung eines synoptischen Vergleichs der beiden Dekalogfassungen

KAPITEL 2: Der synoptische Vergleich im Einzelnen

2.1 Der erste Unterschied: Das waw im Bilderverbot Exkurs: Die Reihungen von Ty und

2.2 Der zweite Unterschied: Asyndese (Ex 20,5) oder Polysyndese (Dtn 5,9) in der Generationsreihe des Bilderverbots

2.3 Der synoptische Vergleich beim Sabbatgebot 33

2.4 Der synoptische Vergleich beim Elterngebot

2.5 Der Unterschied im Verbot des Falschzeugnisses

(Ex 20,16/Dtn 5,20)

2.6 Die synoptischen Differenzen im Dekalogschluß

(Ex 20,17/Dtn 5,21)

2.7 Die Polysyndese (Dtn 5,17-21) gegen die Asyndese (Ex 20,2-17) in der Prohibitivverknūpfung

Exkurs: Literarkritik zu Dtn 9,7b - 10,11

2.8 Gesamtergebnis des synoptischen Vergleichs

KAPITEL 3: Der Dekalog im Kontext der Sinaitheophanie

3.2 Die Dekalogeinleitung in Ex 19,25 und 20,1

Der Dekalograhmen in Ex 20,18-21 
4.7 Schichtungen innerhalb des Dekalogs 240

4.7.1 Einleitung und Forschungsüberblick 240

4.7.2 Das Verbot vom MiBbrauch des Jahwenamens

4.7.3 Das Sabbatgebot (Dtn 5.12-15) 247

4.7.4 Das Elterngebot (Dtn 5,16) 252

4.7.5 Die Verschmelzung von Fremagötter- und Bilder-

verbot durch Dtn 5,9a 259

4.7.6 Ergebnis 262

4.8 Die originale Komposition und mögliche Vorstufen 262

4.8.1 Der erste Teil des Rahmens (Dtn 5,6) 264

4.8.2 Das Fremdgötterverbot (Dtn 5,7) 266

4.8.3 Das Bilderverbot (Dtn 5,8) 268

4.8.4 Der zweite Teil des Rahmens (Dtn 5,9b.10) 274

4.8.5 Die Kurzprohibitive (Dtn 5,17-19) 276

$\begin{array}{ll}\text { 4.8.6 Die durch objekte erweiterten Prohibitive } & 278 \\ \text { (Dtn 5,20-21) }\end{array}$

4.8.7 Exkurs: Die These von der Umsetzung des Dekalogs in die Kasuistik der vordtn Biarta-Gesetze 279

4.8.8 Der Numeruswechsel vom Rahmen zum Dekalog-Grundtext 286

$\begin{array}{lll}4.8 .9 & \text { Ergebnis } & 281\end{array}$

KAPITEL 5: Biographie des Dekalogs 283

LITERATURVERZEICHNIS $\quad 285$

$\begin{array}{lr}\text { REGISTER DER BIBELSTELLEN } & 304\end{array}$ 


\section{EINLEITUNG}

Die Dignität und Wirkung des Dekalogs erläutern, heißt Eulen nach Athen tragen. Hier kommt es darauf an, von den spezifischen Fragen zu sprechen, die er an den Exegeten richtet. An erster Stelle steht das Problem der Doppelüberlieferung. So wenig wie man auf die Frage des Schriftgelehrten nach dem allerersten Gebot eine Antwort Jesu mit zwei Geboten erwartet (Mk 12. 28-34), genau so irritiert die Doppelüberlieferung des Dekalogs. Vom Anspruch des Dekalogs her, allein gebietendes Wort Jahwes zu sein, legt sich eine Doppelüberlieferung nicht nahe. Im Unterschied zu anderen Textdubletten des Alten Testaments wie Z.B. den beiden Schöpfungsberichten oder den drei Ahnfraugeschichten in der Genesis steigern die beiden Dekaloge das Maß der Kongruenz, so daß sich die Frage nach ihrer Beziehung zueinander in besonderer Weise stellt. Die Dekaloge oder Dekalogfassungen stehen je für sich in voneinander entfernten und selbständigen Kontexten. Darin wird ihnen jeweils eine zentrale Position zugewiesen. Die Frage des gegenseitigen Verhältnisses weitet sich dementsprechend aus auf die Beziehungen der selbständigen Kontexte zueinander. Insofern die jeweiligen Kontexte zu gewichtigen Teilen des Pentateuch gehören, betritt man bei deren Analyse das weite und schwer überschaubare Gebiet der Pentateuchkritik, gehen also Positionen zur Entstehung des Pentateuch in die Analyse ein. Zugleich steht der Dekalog als geschlossenes Rechtskorpus neben anderen Rechtskorpora wie Bundesbuch, Privilegrecht (Ex 34), Deuteronomium und Heiligkeitsgesetz. Deren Interdependenz und Zuordnung zum Dekalog spielen in der Dekalogexegese eine große Rolle. Weil der Dekalog als typischer Vertreter für die Reihung von Rechtssätzen gilt, hat die Diskussion um die Gattungen des alttestamentlichen Rechts sich auf ihn konzentriert und in ihm das Konstruktionsmodell für die Organisation der alttestamentlichen Rechtsmaterialien gesehen. Bei dieser Problemlage wundert es nicht, daß die Dekalogfrage eine Fülle von Stellung- 
nahmen provoziert oder zumindest in vielen Fällen von exegetischen Positionen mitbetroffen ist. Nebenher wird die Bemühung der Exegeten verständlich, durch Rekonstruktion eines Urdekalogs und dessen grobe zeitliche Ansetzung, einen Fixpunkt zu gewinnen, um den Problemdruck zu verringern.

Im folgenden sollen nicht die einzelnen Lösungsvorschläge der chronologischen Reihenfolge nach vorgeführt werden. Dafür sei auf die Forschungsberichte verwiesen ${ }^{1}$. Der grobe Oberblick hebt auf die Methode ab, mit der die Probleme angegangen wurden und bleibende Resultate der Forschung erreicht wurden. Die vorliegende Arbeit will diese Ergebnisse kontinuierlich integrieren, weder wiederholen noch einfach zurückweisen.

Das Stadium der frühen Literarkritik in der Dekalogexegese im Laufe der Mitte und zweiten Hälfte des 19. Jh.s löst das Problem der Doppelüberlieferung durch die Annahme eines Urdekalogs, der beiden Dekalogfassungen in Ex 20 und Dtn 5 vorausliegt. Unter der Führung von Ewald werden die beiden Dekalogfassungen miteinander verglichen. Die identischen Teile - zumeist die Anfangssätze der Einzelgebote - ergeben den festliegenden Urdekalog, die divergierenden Passagen entstammen den verschiedenen Quellen, die den Urdekalog in ihre Schicht aufnehmen und bearbeiten. Seit Goethe und dann Wellhausen die Aufmerksamkeit auf einen weiteren Dekalog in Ex 34 lenkten, ist jede der traditionellen Quellen an einem Dekalog beteiligt: Zum Jahwisten gehört der sogenannte "kultische Dekalog" von Ex 34 und zum Elohisten der "ethische Dekalog" von Ex 20. Der Jehowist bearbeitet bzw. "deuteronomisiert" den "ethischen Dekalog". Das Deuteronomium übernimmt ihn nach Dtn 5 und erweitert ihn. Schließlich hinterläßt der Pentateuchredaktor in Ex 20 seine Spuren. Ein großer Teil der Unterschiede zwischen den beiden Fassungen des ("ethischen") Dekalogs in Ex 20 und Dtn 5 - aber eben nur ein Teil - wird auf diese Weise erklärt. Der Kontext der jeweiligen Fassungen bleibt im Blick. Opposition gegen den Urdekalog und seine ältere elohistische Fassung meldet sich seit Fr. Delitzsch zu Wort ${ }^{2}$. Für inn exi-

1 Vgl. für die Literatur des 19. Jh.s und den wogenden streit um die richtige Einteilung des Dekalogs DILLMANN/RYSSEL, Exodus, $221 \mathrm{ff}$; dann später KÖHLER, Der Dekalog; STAMM, DreiBig Jahre; DERS./ANDREW, Commandments; ZENGER, Dekalogforschung; BOECKER, Recht und Gesetz, 166ff.179; und schließlich die umfassende Besprechung von SCHOTTROFF, Recht.

2 DERS., Genesis, 19f. In seiner Nachfolge vor allem MEISNER, Der Dekalog, bes. $8 f$. 
stiert nur eine jehowistisch-deuteronomische Form als älteste Gestalt des Dekalogs. Damit kommt die Debatte um die mosaische Verfasserschaft des Urdekalogs und um die quellenkritische Einordnung seiner Fassungen erst richtig in Gang. Pauschal gesagt: Auf der einen Seite setzt man den Urdekalog früh an und verfolgt sein literarisches Anwachsen. Auf der anderen Seite hält man den gesamten Dekalog für ein spätes Produkt, ein compendium legis, das sowohl in Ex 20 wie in Dtn 5 von Redaktoren eingeschoben wurde.

Der Streit führt im anschließenden Stadium der Formkritik ab dem zweiten Jahrzehnt des 20. Jh.s zu einer Gegenreaktion. Der synoptische Vergleich der Dekalogfassungen tritt in den Hintergrund, des Zanks um die quellenkritische Zuordnung ist man überdrüssig ${ }^{3}$. Seit Schmidt konzentriert man sich auf den formkritisch-begründeten Urdekalog, eine Reihe von gleichmäßig gebauten und metrisch gleichgestalteten Rechtssätzen. Der Urdekalog wird zum Musterexemplar der weiter verbreiteten Gattung "Rechtssatzreihe" des sogenannten "apodiktischen Rechts". Das Alter dieses Urdekalogs ohne seine Ergänzungen macht keine so großen Sorgen mehr, da nach formkritischem oder besser formgeschichtlichem Verständnis die kleine, einfache und wuchtige Form am historischen Anfang der Gattung steht. Der Dekalog tritt aus seiner Isolierung als literarisches Produkt heraus in den Kontakt mit analog gebauten Reihen der großen Rechtskorpora im Alten Testament. Damit wechselt er seinen bisher bevorzugten Aufenthaltsort. Vom Schreibtisch der Verfasser der Quellenschriften und Redaktoren wandert er aus in die zeitenüberdauernde Verkündigung des Rechts, sei es im Kult als "leges sacrae", sei es in der Predigt oder in der außerkultischen Lehre. Spezifische Spannungen in nerhalb des (Ur-)Dekalogs werden neu entdeckt und rücken in den Vordergrund der Debatte: die Diskrepanz zwischen der faktischen Zahl der Gebotssätze im Dekalog und der angegebenen Zehnzahl, die man auch an parallelen Rechtssatzreihen als gattungstypisch festzustellen meint. Ferner der Wechsel in der Qualität der Sätze von vorherrschender Negation zu Position. Schließlich der Unterschied in der Länge der einzelnen Sätze, vor allem der zwischen den objektlosen Kurzprohibitiven und den in der Mehrzahl vorhandenen Prohibitiven mit Objekt.

3 Am deutlichsten ist das bei KÖHLER, Der Dekalog, 163 abzulesen. 
Der Wandel zu einer neuen Phase der Dekalogexegese tritt ein, seit es Gerstenberger zu Beginn der sechziger Jahre gelungen ist, das Diktat der Zehnernorm für die Reihung von Prohibitiven zu durchbrechen und damit auch die Gattung einer Großreihe von zehn oder zwölf Rechtssätzen in Frage zu stellen. Die Prohibitive treten - wie die weitere Forschung zeigt - ursprünglich in Kleinreihen auf, entweder in Dreiergruppierungen oder in Paaren oder sogar als Singles. Ihre anfängliche Heimat ist das vorstaatliche Sippenethos; später werden sie in das Standesethos der führenden Schicht übernommen und in deren Schule gepflegt bzw. Weitergegeben. Für den Dekalog ist damit das latente Problem des Sprecherwechsels zutage getreten: Wer ist Träger oder bevollmächtigter Verkünder der Prohibitive? Jahwe oder eine menschliche Autorität? Da sich die Gattung "Rechtssatzreihe" als Großreihe auflöst, kommt eine Großreihe wie der (Ur-)Dekalog nur mehr sekundär durch Komposition zustande. In Frage steht dann weiter das Ausmaß der Komposition. Besteht die Kompositionsleistung nur im Arrangement von vorgegebenen $\mathrm{Kleinreihen} \mathrm{oder} \mathrm{steigert} \mathrm{sie} \mathrm{ihren} \mathrm{Anteil,} \mathrm{indem} \mathrm{sie} \mathrm{Kleinreihen}$ und verstreute Einzelprohibitive zusammenstellt, oder erfaßt sie sogar die Produktion von einzelnen Prohibitiven? Am Ende steht die grundsätzliche Frage, was überhaupt der Komposition vorgegeben ist. So muß bei jedem Prohibitiv geprüft werden, ob die alttestamentliche Rechtsüberlieferung - und ausgeweitet auch die übrige Literatur - den Prohibitiv als autarkes Einzelexemplar, als Teil einer vorgegebenen Gruppe oder als Kunstprodukt eines Autors ausweist. Der neue Ansatz des dritten Stadiums der Dekalogexegese hat mittlerweile dazu geführt, daß keine der für ursprünglich gehaltenen klassischen Zehnerreihen den Ansturm überlebt hat. Zuletzt ist die Zehnerreihe in Lev 18,7-18 gefallen, die Elliger noch als den ältesten Kern des Abschnitts herausgearbeitet hatte ${ }^{4}$. Wenn die Komposition die einzelnen Prohibitive tangiert, dann steht auch deren Verhältnis zu den bislang für sekundär gehaltenen Ergänzungen erneut zur Debatte. Und über das Problem der Ergänzungen und die Frage, wer die Komposition und wer die Ergänzungen vorgenommen hat, drängt sich dann die Suche nach einer Zuordnung zum unmittelbaren literarischen Kontext auf.

4 HALBE, Inzestverbote, weist nach, daß der Grundtext des Abschnitts, eine Satzgruppe aus fünf oder sechs begründeten Sätzen, erst sekundär zum Dekalog ausgebaut wurde. 
Das Durchlaufen der formkritischen Fragestellung hat zuletzt zu einer Zertrümmerung der Urdekaloghypothese geführt. Das Instrumentarium der Analyse hat sich verfeinert, der Fragehorizont geweitet. Probleme, wie sie ähnlich die alten Literarkritiker quälten, sind wieder aufgetaucht: Wer, in welcher Form, mit welchen Mitteln und Vorgaben hat den oder die Dekaloge erstellt?

Diese Untersuchung legt den masoretischen Text zugrunde. Sie geht vom Endtext aus und versucht, alle Spannungen und Brüche in methodischer Rückfrage zu den Anfängen aufzuhellen. Endtext bedeutet im Falle des Dekalogs die beiden Dekalogfassungen als autarke Texte. Kap. 1 erläutert die Prinzipien des synoptischen Vergleichs, Kap. 2 führt ihn durch und nimmt vor allem das Gespräch mit der bisherigen Dekalogforschung auf. Kap. 3 stellt die Exodusfassung in ihren Kontext. Kap. 4 konzentriert sich auf Dtn 5 und seine Beziehungen zum Buch Dtn. Kap. 5 bietet eine pauschale Zusammenfassung. 


\section{KAPITEL 1}

Thesen zum Stellenwert und zur Durchführung eines synoptischen Vergleichs der beiden Dekalogfassungen

1.1 Der Ansatz der Dekalogexegese kann nicht bei einer katechetischen Kurzfassung des Dekalogs liegen, wie es bei E. Bertheau oder K. Koch der Fall ist ${ }^{1}$.

1.2 Die Dekalogexegese hat bei dem markanten Faktum der Doppelüberlieferung anzusetzen, daß der eine Dekalog in zwei verschiedenen Fassungen an zwei verschiedenen Stellen des Pentateuch überl iefert ist.

1.3 Ohne eine Vorentscheidung über den jeweiligen Kontextbezug zu fällen, empfiehlt es sich aus arbeitstechnischen Gründen, die beiden Fassungen vorerst aus ihrem Kontext herauszulösen und synoptisch miteinander zu vergleichen.

1.4 Die vorläufige Herauslösung ist insofern gerechtfertigt, da an beiden Stellen der Dekalog als selbständiges Zitat vom Kontext abgegrenzt wird ${ }^{2}$.

1.5 Der Eigenständigkeit des Dekalogs korrespondiert sein späteres Eigenleben in Gottesdienst und Gebet der Frommen zur Zeit des zweiten Tempels, das mit einiger historischer Sicherheit seit dem 2. Jh.v.Chr. belegt

1 BERTHEAU, Die sieben Gruppen; KOCH, Formgeschichte, 1 off.

2 Vgl. NOTH, Exodus, 124; PERLITT, Bundestheologie, $91 \mathrm{f}$. 
ist. So wird schon für diese Zeit seine gemeinjüdische, liturgische Sonderstellung bewiesen durch den Papyrus Nash, durch die Qumranphylakterien ${ }^{3}$ und durch die samaritanischen Dekaloginschriften ${ }^{4}$.

1.6 Der synoptische Vergleich betrachtet die herausgelösten Dekalogfassungen als je eigene Texteinheiten, deren Individualität durch die Differenzen bestimmt wird. Damit werden die Unterschiede weder als Unfälle der Textüberlieferung noch als beliebige Variationen der Dekalogpredigt interpretiert, sondern bis zum Beweis des Gegenteils als gewollte Abweichungen, die je für sich in jeder Dekalogfassung eine Rolle spielen. Qualifizierende Einteilungen in größere und kleinere Unterschiede werden damit obsolet.

1.7 Solche Wertung der Unterschiede legt sich nahe, wenn man die Textüberlieferung der Dekalogfassungen betrachtet: Die späten Dekalogfassungen wie der Papyrus Nash, die samaritanischen Dekaloginschriften und die Qumran-Phylakterien bieten einen "unierten Text", der die beiden Fassungen von Ex 20 und Dtn 5 verarbeitet ${ }^{5}$. Ebenso gleichen die alten Versionen wie die LXX und der Sam die beiden Fassungen einander an 6 . Der Grundsatz von N. Lohfink ist voll zu unterstreichen: "Da auch in MT, Sam und den alten ubersetzungen eine Tendenz zur Harmonisierung vorausgesetzt werden darf, sind nach dem Prinzip der lectio difficilior die Varianten zu beachten, die bei beiden Fassungen auseinandertreiben" 7 . Was bei Lohfink primär textkritisch gemeint ist, kann in Richtung auf die Wertung von Differenzen der beiden Fassungen verlängert werden. Gegenüber einer vereinheitlichenden Textüberlieferung müssen die Differenzen um so mehr auffallen und die Konservierung der Unterschiede im MT gewuirdigt werden!

1.8 Eine zweite Oberlegung zielt in die gleiche Richtung: Der Kontext von Ex 20 und Dtn 5 - ganz gleich auf welche Weise er zustande gekommen ist - weist dem Dekalog eine besondere Rolle zu. Er sticht vom Kontext

3 SCHNEIDER, Dekalog; VERMES, Decalogue.

4 DEXINGER, Garizimgebot.

5 Vgl. CHARLES, Decalogue XIII-XXXIII; JEPSEN, Beiträge,275ff; WÜRTHWEIN, Text, 37; STAMM, Dekalogforschung, $197 f$.

6 Vgl. DEXINGER, Garizimgebot, $124 \mathrm{ff}$.

7 LOHFINK, Dekalogfassung,17 A 6 . 
$a b$ als Gottesrede, deren Ende gegenüber der nachfolgenden Moserede eigens hervorgehoben und begründet wird (Ex 20,19; Dtn 5,22f). Das betonte Ende macht die vorausgehenden Jahweworte ("und Jahwe sagte diese Worte und sonst nichts") um so kostbarer. Die von den Hörern befürchtete todbringende Wirkung steigert den numinosen Charakter der "zehn Worte". Somit impliziert der Sprecherwechsel von Jahwe zu Mose ein kanonisches Gefälle. Unabhängig davon, wie man das Verhältnis der beiden Dekalogfassungen konstruiert, fallen im Blick auf die kanonische Würde jeder Fassung die Differenzen um so stärker auf. Die Heiligkeit des Dekalogs hätte ihn eigentlich vor Textveränderungen schützen müssen! Deshalb wiederholen wir das Postulat: Jeder auch nur scheinbar kleinste Unterschied verlangt eine angemessene Erklärung! Allerdings fallen die beiden orthographischen Varianten, der Unterschied zwischen Plene- und Defektivschreibung im Falle von אב(I) (Ex 20,5//Dtn 5,9) und $T(1)$ ( $ת$ (I) 20, $12 / / \operatorname{Dtn} 5,16)$, aus der Erklärung heraus, da sie semantisch nichts entscheiden. 
KAPITEL 2

Der synoptische Vergleich im Einzelnen

\subsection{Der erste Unterschied: Das Wow im Bilderverbot (Ex 20,4// Dtn 5,8)}

In beiden Dekalogfassungen des Bilderverbots besteht die Hauptschwierigkeit im syntaktischen Anschluß der nominalen Relativsätze an ihr Beziehungswort. Das Beziehungswort steht in einer Konstruktverbindung mit כל als nomen regens im sta.t. constr. und תמונה als nomen rectum im Absolutus. So wie der Text sich jetzt bietet, ist das Beziehungswort der Relativsätze המונה. Dem Sinn nach ist aber die umgekehrte Stellung gefordert mit תמונה im Constructus und כל als unmittelbar vorausgehendem Beziehungswort im Absolutus; eine analog sinnvolle und stilistisch glatte lösung bieten Dtn 4,16.23.25. Eine Textkonjektur im letzteren Sinne aber verwehrt die einhellige oberlieferung in beiden Fassungen ${ }^{8}$.

Die zweite Schwierigkeit betrifft die synoptische Differenz, den syntaktischen Anschluß der eben erwähnten Konstruktverbindung an das vorausgehende Akkusativobjekt des Prohibitivs. Ex 20,4 verbindet mit 1-copulativum und erhält ein zweites synonymes Akkusativobjekt zum Prohibitiv, das allerdings durch die Näherbestimmung כל vom ersten Akkusativobjekt abgehoben wird. Dtn 5,8 setzt die Konstruktverbindung asyndetisch daneben und versteht sie als explikative Apposition zum ersten Akkusativobjekt des Prohibitivs ${ }^{9}$. Die Exegeten haben öfters versucht, beide Schwierigkeiten in einem Zuge zu lösen:

Der erste Lösungstyp faßt die Konstruktverbindung als Subjekt eines zusammengesetzten Nominalsatzes auf, dessen verbales Prädikat in Ex 20,5a//Dtn 5,9a nachfolgt. Die pluralen Personalpronomina des selbständigen Prädikatsatzes verweisen in einer constructio ad sensum auf das betont vorangestellte Subjekt zurück.

8 ZIMMERLI, Das zweite Gebot, 235 A 3; CHILDS, Exodus, $387 \mathrm{f}$.

9 Vgl. ZIMMERLI, Das zweite Gebot, 235 A 3; KRUYSWIJK, Beeld, 62. 
Dabei wird entweder die Asyndese des Dtn vorgezogen und die Syndese von Ex 20 abgelehnt ${ }^{10}$ oder das eine wie das andere als irrelevant bezeichnet ${ }^{11}$. An die letztere Position knüpft eine Gruppe von Exegeten an, die ebenso die Konstruktverbindung mit den Relativsätzen zur Glosse stempelt und Syndese wie Asyndese gleichermaßen als Explikation erklärt und damit den Unterschied für "sachlich bedeutungslos" hält ${ }^{12}$.

Diese Lösung scheitert am überweiten Abstand zwischen Subjekt und verbalem Prädikatsatz und an der Divergenz von femininem Subjekt und maskulinen rückweisenden Personalpronomina. Wird darüber hinaus der linterschied nivelliert, verstößt ein solches Vorgehen gegen die Prinzipien des synoptischen Vergleichs.

Der zweite Lösungstyp verbindet das erste Akkusativobjekt mit der nachfolgenden Konstrukt-Verbindung zu einer Konstruktus-Kette "Bild von jeglicher Gestalt, die ..." und scheidet das waw von Ex 20,4 als Textverderbnis aus 13 . Bei dieser Lösung ist das Eindringen des waw nicht zu erklären. Ferner gilt Dillmanns Einwand: "Aber da פסל nicht imago oder homoioma, sondern sculptile bedeutet, so ist sehr die Frage, ob man פסל תמונה im st.-c.-Verhältnis sagen konnte" 14 .

Der dritte Lösungstyp nimmt die Hauptschwierigkeit zum Anlaß für das Modell einer stufenweisen Ergänzung unter Priorität der Exodusfassung, so H. Holzinger: "פסל ist in Ex durch וכל תמונה, in Dtn durch die Formel תמונת כל אשר... ergänzt worden; das Novum in Dtn ist nach Ex übernommen und mechanisch an angehängt, endlich unter der Autorität von Ex תמונת כל ... das Dtn in geändert worden" 15 .

Wahrscheinlich ist die Annahme nicht zu vermeiden, daß der Text des Bilderverbots stufenweise angewachsen ist; allerdings scheinen der Ausgangspunkt, die Priorität von Ex 20 und die Vielzahl der Stufen bei diesem Typ mehr als fraglich!

10 EWALD, Geschichte, 227 A 2.

11 DILLMANN - RYSSEL, Exodus, 230; STRACK, Exodus, 226; KRUYSWIJK, Beeld, $65 \mathrm{ff}$.

12 MOWINCKEL, Décalogue, 63 A 1; V. REVENTLOW, Gebot, 24 und 31; LOHFINK, Dekalogfassung, 25; PHILLIPS, Criminal Law, 51; SMEND, 2 Mose 20,4-6, 282; zuletzt FLOSS, Jahwe dienen, 236-247, bes. $240 f$.

13 Wellhausen, ${ }^{4}$ Composition, 89 A 1; OETTLI, Deuteronomium, 39; HEMPEL, Schichten, 161; SCHMIDT, Mose, 78 A 2; STAMM, Dekalogforschung, 8 A 3; NIELSEN, Zehn Gebote, 34. DILLMANN-RYSSEL, Exodus, 230. 
Der vierte Lösungstyp geht von zwei unterschiedlichen Bedeutungen von תמונה aus: Gestaltung im Sinne von Beschaffenheit (Ex 20,4; Dtn 4,16.23.25) und Gestalt im konkreten Sinne von Erscheinung (Num 12,8; Dtn 4,12.15; 5,8). Die konkrete Bedeutung in Dtn 5,8 senkt die Schwierigkeit des relativen Anschlusses und läßt sich mit פסל in einer Konstruktkette verbinden (vgl. den zweiten Lösungstyp). Die Abweichung in Ex 20,4 erklärt sich als "Brachylogie" durch sekundäres Eindringen des waw mit dem Ziel, die beiden Ausdrucksweisen, nämlich die des Dtn "Gestalt, die ..." mit der des Ex "Gestaltung von etwas", zu verschmelzen. "Der im Dtn stehende Wortlaut konnte ergänzungsbedürftig erscheinen, indem das Verbot von plastischen (durch Schnitzen, Behauen, Meisseln hergestellten) Darstellungen auch auf gegossene Götterbilder ausgedehnt werden sollte" 16 .

Fraglich ist bei diesem Lösungstyp, ob die beiden Dekalogfassungen in der Bedeutung von nמונה auseinandergehalten werden können. Für die Möglichkeit einer "Brachylogie" wird auf die Konstruktionsparallele 1 Sam 13,21a verwiesen, die aber wegen unsicherer Textlage ausfällt ${ }^{17}$. Nicht erklärt wird, warum das sekundäre waw nur in Ex 20,4 eingedrungen ist, obwohl doch gerade Dtn 5,8 ergänzungsbedürftig erschien.

Aus dem Forschungsüberblick ergeben sich einige Konsequenzen:

Erstens kann der schwierige syntaktische Anschluß der Relativsätze an כל kaum anders als durch stufenweises Wachstum erklärt werden; d.h. die Konstruktverbindung und die Relativsätze sind nicht von einer Hand in einem Zuge niedergeschrieben worden. Die weitere Klärung dieses Wachstumsprozesses tangiert nicht den synoptischen Vergleich und kann aufgeschoben werden.

Zweitens kommt es in der Frage des Unterschieds zwischen Syndese und Asyndese gemäß den einleitenden Grundsätzen weder in Frage, die eine Dekalogfassung gegen die andere auszuspielen, noch den Unterschied zu nivellieren bzw. für bedeutungslos zu erklären. Dieses Problem wird dann gelöst, wenn für den Unterschied triftige Gründe angegeben werden können, d.h. wenn die beiden Fassungen je für sich ausgelegt werden 18 .

15 HOLZINGER, Exodus, 71; ZIMMERLI, Das zweite Gebot, 235 A 3 scheint sich an HOLZINGER anzuschließen.

16 KÖNIG, Deuteronomium, 87; vgl. DERS., Dekalog, 367-369.

17 STOEBE, Samuelbücher, 255.

18 NIELSEN, Zehn Gebote, 34; CAzELLES, Décalogue, 15 deuten die Möglichkeit an, ohne sie konsequent zu verfolgen. 
Drittens funktioniert die von Zimmerli erstmals aufgewiesene Verbindung von Ex 20,5a//Dtn 5,9a zum Fremdgötterverbot ${ }^{19}$ und die dadurch intendierte Unterordnung des Bilderverbots unter das Fremdgötterverbot nur für die Deuteronomiumfassung. Nur hier schlagen die Personalpronomina von Dtn 5,9a die Brücke zurück zu den Fremdgöttern von Dtn 5,7, weil die asyndetische, explikative Apposition in Dtn 5,8 den Brückenschlag nicht unterbricht. Es sei daran erinnert, daß wir beim synoptischen Vergleich nur auf der Ebene des Endtextes argumentieren vor aller literarkritischen Trennung.

Dagegen wird in der Exodusfassung der Prohibitiv von 20,4 mit seinem maskulinen Akkusativobjekt (das Singularetantum פסל) durch das waw um ein zweites (feminines) Akkusativobjekt כל תמונה erweitert. Die maskulinen Personalpronomina von 20,5 a verweisen hier notwendigerweise auf die beiden objekte des Prohibitivs von 20,4. Der Brückenschlag und damit die Unterordnung des Bilderverbots unter das Fremdgötterverbot kommen nicht zustande.

Somit ist der erste Unterschied der beiden Dekalogfassungen im Rahmen der je eigenen Dekalogkonzeption zu interpretieren. Die Deuteronomiumfassung versteht das Bilderverbot unter dem Primat des Fremdgötterverbots und zieht die beiden zu einem Verbot zusammen. Die Exodusfassung verzichtet auf solche Verklammerung und bietet zwei Verbote mit eigenem Schwergewicht.

Für die Interpretation wie die zeitliche Priorität einer der beiden Fassungen des Bilderverbots kann eine knappe Untersuchung der formelhaften Reihung

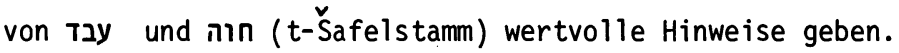

Exkurs: Die Reihungen von עבד 20

Grundlegend ist die Differenzierung in eine Reihenbildung mit 1. עבד und 2. חוה und deren Umkehrung mit 1. עבד מוה . Die erste Reihung ist 15 mal in dtn-dtr Schrifttum belegt; hinzuzunehmen ist die zerdehnte Stelle Jer 8,2 aus der Hand der dtr Bearbeitung des Jeremiabuches. Die zweite Reihung, die wir im Dekalog vorfinden, kommt mit den beiden Dekalogstellen auf insgesamt 12 Belege.

19 ZIMMERLI, Das zweite Gebot, 236-238; die modifizierende Kritik von FLOSS, Jahwe dienen, hat daran nichts ändern können, vgl. s.u.! FOHRER, Recht, 131 A 33, deutet wohl ebenso an, daB ZIMMERLIs Interpretation des zweiten Gebots in Ex 20 keine Basis im Text hat.

20 Sie sind mehrmals mit wachśender Akribie untersucht worden von: ZIMMERLI, Das Zweite Gebot, 237f. In Auseinandersetzung mit ZIMMERLI von FLOSS, Jahwe dienen, 168-180. Ebenso LOHFINK, Dekaloganfang, bes. 108f. Zu n im Einzelnen vgl. HALBE, Privilegrecht, $119 \mathrm{ff}$ und PREUSS, Art. An, ThWAT II, 784-794. 
Floss ist in der zeitlichen Vorordnung der ersten Reihe vor der zweiten zuzustimmen 21 . Die breitere Streuung im $\operatorname{Dtn}(8,19 ; 11,16 ; 17,3 ; 29,25)$ gegenüber den eindeutig späten Belegen der zweiten Reihe wie Dtn 4,19;30,17 spricht für das höhere Alter der ersten Reihe, obwohl sie auch nicht zu den ältesten Schichten der dtn Paränese und Gesetzeskommentierung zu gehören scheint. Für die erste Reihe könnte deren profane Verwendung in Gen 27:29 als Inspirationsquelle gedient haben. Bei der zweiten Reihe sieht Floss den literarischen Erstbeleg in 2 Kön 21,3 (Verfasser des DtrG) ${ }^{22}$. Die Umkehrung der ersten Reihe zur zweiten wurde vom Autor des DtrG ad locum geschaffen, um den unter Manasse eindringenden Astralkult zu beschreiben; dies erreichte er, indem er das konkrete, auf fremdkultische Handlungen anspielende חוה an die erste Stelle setzte.

Ober das Objekt der Gestirngötter sind dann auch die anderen Objekte der zweiten Reihe, wie die Fremdgötter, angezogen worden. Bei dieser Rekonstruktion der Entwicklung verdient Floss weniger Gefolgschaft. Die zweite Reihung bietet acht Belege mit den Fremdgöttern als objekt (Ex 20,5// Dtn 5,9; 30, 17; 1 Kön 9,9 // 2 Chr 7,22; 2 Kön 17,35; Jer 22,9 und Ex 23,24); dem stehen drei Belege mit Gestirngöttern als Objekt gegenüber (Dtn 4,19; 2 Kön 21,3 // $2 \mathrm{Chr}$ 33,3), hinzu kommt 2 Kön 17,16 (exilische Redaktion des DtrG) mit den Gestirngöttern und Baal als objekt. Die Zuweisung aller Belege zu Schichtungen des dtr Schrifttums erlaubt keine Präferenz für die Gruppe mit den Gestirngöttern als objekt im Sinne von Floss. Eher legt die statistische Verteilung und die Nähe zur älteren ersten Reihung den Dekalog als Umschaltstelle nahe. Unter Einfluß von Ex 34,14 hat der Verfasser von Ex 20,5a // Dtn 5,9a die erste Reihung umgekehrt und das konkret gemeinte חוה von Ex 34,14 an die erste Stelle gerückt. Der Impuls von Ex 34 her liegt nahe, zumal dieses Kapitel auf den Dekalog noch an anderen Stellen eingewirkt hat. Die Kombination der zweiten Reihung mit den Gestirngöttern erscheint deshalb als Konkretisierung der allgemeinen Fremdgötter, wobei für diese Dreiergruppe, aber nur für diese, 2 Kön 21,3 den Rang des Erstbelegs behalten kann. Die Deuteronomiumfassung des Dekalogs mit ihrem Brückenschlag von den Doppelprohibitiven (der zweiten Reihung) zum Fremdgötterverbot paßt in den Rahmen der Formel mit den Fremdgöttern als bevorzugtem Objekt. Die Exodusfassung sprengt diesen Rahmen, indem sie die Bilder an die Stelle der Fremdgötter setzt.

21 FLOSS, Jahwe dienen, 170.

22 DERS., 436-440.545-547. 
Darin ist die Exodusfassung singulär. Eine zeitliche Ortung eines solchen Vorgehens gelingt nicht über die zweite R:ihung, dafür aber durch die Betrachtung der Einzelglieder bzw. der Einzelverben in ihrer Verbindung mit dem Objekt "Bilder". Für עבד ist die Kombination mit פסל oder auch atypisch ${ }^{23}$. Nur dreimal ist eine solche Verbindung belegt (Ps 97,7; 2 Kön 17,41; $2 \mathrm{Chr} 33,22)$; alle Belege gehören in die exilisch-nachexilische Zeit.

Für nוה sind in analoger Kombination 10 Stellen anzuführen (Ex 32,8; Lev 26,1 ; Jes 2,8.20; 44,15.17; 46,6; Jer 1,16; Mich 5,12; Ps 106,19). Auch sie gehören in die exilisch-nachexilische Zeit.

Somit kommt der Exkurs zu dem Ergebnis, daß Ex 20,5a der Götterbildpolemik aus dem Deuterojesajabuch nahesteht ${ }^{24}$. Zugleich ist erwiesen, daß in Bezug auf das Biiderverbot die Deuteronomiumfassung älter ist als die Exodusfassung.

\subsection{Der zweite Unterschied: Asyndese (Ex 20,5) oder Polysyndese (Dtn 5,9)} in der Generationenreihe des Bilderverbots

Die stiefmütterliche Behandlung, die dieser Unterschied bisher im synoptischen Vergleich oder in Abhandlungen zum Thema der Stelle erfahren hat, zeigt an, daß mit bestimmter. Feineinstellung gearbeitet werden muß. Meistens wurde der Unterschied übergangen ${ }^{25}$. Bei einigen Exegeten wird er notiert, aber nicht erklärt ${ }^{26}$. Andere nehmen ihn ebenso wahr und versuchen eine halbherzige schnelle Erklärung: rhetorisch-stilistische Erweiterung bzw. Vervollkommnung der älteren Exodusfassung durch das Deuteronomium 27 . Einen Schritt wei-

23 Vgl. FLoSs, Jahwe dienen, 156-161.541f.

24 Zur Einordnung als Nachtrag zur Verkündigung Deuterojesajas jetzt: KIESOW, Jesajabuch, 159 A 2.

25 ROST, Schuld der Väter, 229: "Der einzige Unterschied der beiden Parallelen (Ex 20,5// Dtn 5,9) besteht in einer defective-Schreibung im Exodus". SCHARBERT, Formgeschichte sowie DENTAN, Exodus 34,6f, bes. 38.48 A 2, nehmen die Differenz nicht zur Kenntnis.

26 DILLMANN - RYSSEL, Exodus, 231; GOLDMANN, The Ten Commandments, 35; CHILDS, Exodus, 388.

27 So E. KÖNIG, Deuteronomium, $91 \mathrm{f}$; in seinem Gefolge: STAMM, Dekalogforschung, 7f; er rechnet den Unterschied unter die "drei kleineren Differenzen im Wortlaut des zweiten Gebotes" und ordnet ihn ein in die "13 Zusätze, welche Dtn 5 über Ex 20 hinaus hat". Ihm schließen sich übereinstimmend REVENTLOW, Gebot, $23 f$ sowie LOHFINK, Dekalogfassung, 25, an. Auf der einen Seite erscheint der Unterschied, "sachlich bedeutungslos", auf der anderen Seite, "zeigt er aber doch einen Entwicklungsfortschritt von Ex zu Dtn". 
ter führen jene, die in Ex 20,5 unter בנים die "Nachkommen" verstehen und darauf asyndetisch die näherbestimmende Apposition "an der dritten und vierten Generation" folgen lassen. In Dtn 5,9 sehen sie dagegen eine geschlossene Reihe, die von den Vätern bis zu den Urenkeln führt ${ }^{28}$.

Damit geben diese Exegeten der obigen Differenz der Dekalogfassungen mehr Gewicht, können aber nicht die entsprechenden Motive für die Differenz angeben.

Grundsätzlich bieten sich die folgenden beiden Lösungsmöglichkeiten an: Einmal nimmt man stilistische Variation an. Der Dtn-Dekalog bietet dann die im Alten Testament übliche polysyndetische Reihung. Demgegenüber zieht der ExDekalog eine Reihung vor, bei der erst die letzten beiden Glieder einer Reihe verbunden werden ${ }^{29}$. Eine solche stilistische Variation genügt den oben aufgestellten Prinzipien des synoptischen Vergleichs nicht! Zugleich widerspricht die vom üblichen abweichende Reihung des Ex-Dekalogs der Polysyndese der beiden Dekalogfassungen in den Aufzählungen des Sabbatgebotes und Begehrensverbotes.

Daher verbleibt nur die zweite Lösungsmöglichkeit: Hinter der Differenz steckt eine verschiedene Auffassung der Generationenreihe! Ihr kann man nur auf die Spur kommen, wenn die einschlägigen Parallelen berücksichtigt werden. Der schnelle Durchlauf durch die Parallelstellen zu שלשים bzw. רבעים offenbart eine typische Unsicherheit: Welche Generation ist eigentlich gemeint?

Einige Exegeten bestehen auf dem Verständnis von "Enkel" bzw. "Urenkel" und berufen sich auf den Dekalog und Num 14,18 ${ }^{30}$. Andere votieren unter dem Einfluß von Ex 34,7 für die Bedeutung Urenkel / Ur-Urenkel 31 . Und wieder andere schließen einen Kompromiß und lassen beide Bedeutungen nebeneinander stehen ${ }^{32}$. Die Verschiedenheit wurze1t in einer unterschiedlichen Zählung. Rost behauptet: "denn im allgemeinen zählt der alte Israelite das Ausgangs-

28 GESENIUS-BUHL, Handwörterbuch, 839 deutet ein solches Verständnis an. JACOB, Exodus, $887 f$ und NIELSEN, Zehn Gebote, 35, beschreiben diese Auffassung deutlicher. Weil sich nach seiner Meinung Ex 34,7 und Dtn 5,9 in der Zählung widersprechen bzw. שלשים mal als Urenkel mal als Enkel verstehen, entscheidet sich NIELSEN für die Lesung von Ex 20,5, wohingegen er den Text von Dtn 5,9 verwirft.

29 Vgl. GES. -K. S. $506 \mathrm{~N} 1$.

3o So KÖNIG, Syntax $\S 337$ e, ebenso ROST, Schuld der Vätex und MOWINCKEL, Décalogue, 26.

31 So GESENIUS-BUHL, 839 und FREEDMAN-LUNDBOM, Art. רור, ThWAT II, 181-194 bes. 186 .

32 KBL 983; DILLMANN-RYSSEL, Exodus, 231; JEPSEN, Beiträge, 289 A 7. 
glied mit:das sind in diesem Falle die Väter" 33 . Freedman-Lundbom stellen die Gegenthese auf ${ }^{34}$ : "Außerdem so 11 daran erinnert werden, daß die Israeliten das Zählen in Generationen nicht mit dem Vater, sondern mit dem Sohn begannen". Welche These ist falsch? Oder kann zwischen den Gegensätzen vermittelt werden? Die jeweiligen Positionen hängen vom unmittelbaren Verständnis der einschlägigen Stellen und vom Verhältnis dieser Stellen zueinander $a b$, d.h. von ihrer literarkritisch-redaktionskritischen Zuweisung.

Wir erweitern bei der folgenden Untersuchung die einschlägigen Stellen um jene Parallelen, die uns helfen können, die Frage nach der Zählung zu entscheiden. Dabei spielt die Unterscheidung zwischen Zahlwort und dem vom Zahlwort abgeleiteten Nomen keine Rolle ${ }^{35}$.

Gen 50,23:

Strittig ist, wie die Genitivverbindung בני שלשים aufzufassen ist, Angehörige oder Söhne der dritten Generation. Wir entscheiden uns für den genet. appositionis 36 "Angehörige der dritten Generation". In der Frage, ob der Vater (hier: Josef) mitgezählt oder ausgeschlossen wird, entscheidet V. 23a nichts. V. 23b allerdings erwähnt vier Generationen (Josef, Manasse, Machir und dessen Söhne). Nur unter der Bedingung der Parallelität der Halbverse - das überleitende $ם \lambda$ würde dafür sprechen -- kann man dann rückschließen, daß es sich bei den "Angehörigen der dritten Generation" um Josefs Urenkel (über Ephraim) handelt, also die Angabe "dritte Generation" hier den Vater nicht mitzählt 37 .

\section{Ex 34,7:}

Der Vers gehört zum Selbsthymnus Jahwes in Ex 34,6f, der wegen seiner ausgebauten Formeln eine Schluisselposition innehat. Die literarkritische Zuweisung drifțet heute mehr denn je auseinander ${ }^{38}$.

Wir verzichten deshalb auf eine quel lenkritisc:he Einordnung des gesamten Hymnus und rechnen mit sukzessiven Erweiterungen bzw. Auffüllungen eines

33 ROST, Schuld der Väter, 229.

34 DERS., Art, TוT, ThWAT II, 186.

35 Anders bei SEGERT, Glied, 37-39, der nur auf die abgeleiteten Nomina abhebt.

36 Mit DELITZSCH, Genesis, 537 und Ges.-K. § 128 gegen RUPPERT, Josefserzählung, 199 A 26.

37 Ebenso parallelisiert LOWENTHAL, Joseph Narrative, 158 . Die Habilitationsschrift von SCHMITT, Josephsgeschichte, gibt darüber keine Auskunft, vgl. die synopse s. 53. 
"Basis-Hymnus", was bei der reihenden Konstruktion von Hymnen leicht möglich ist. Deshalb konzentrieren wir uns auf den Partizipialsatz "der heimsucht die Schuld der Väter an den Söhnen und Enkeln, an der dritten und vierten Generation". Die Streuung weist den Satz als Formel aus (außer den Dekalogstellen und Ex 34,6f noch: Num 14,18; Dtn 7,9f; Jer 32,18). Die Redewendung, daß Jahwe die Schuld heimsucht, ist schon im authentischen Vers Am 3,2 bezeugt. Für die späteren Schichten des deuteronomistischen Schrifttums wie in Dtn 7,9f und Jer 32,18 (Jer D) wird unter dem Einfluß von Dtn 24,16 (vgl. 2 Kön 14,5f) die solidarische Haftung der Generationen zum Problem und deshalb die Heimsuchung an den Söhnen dadurch abgeschwächt, daß man auf die Generationenreihe keinen Wert mehr legt ${ }^{39}$.

In exilisch-nachexilischer Zeit konstatiert man die eigene wie die Schuld der Väter ( $\mathrm{Klgl} \mathrm{5,7;} \mathrm{Lev} \mathrm{26,39f} \mathrm{und} \mathrm{Jes} \mathrm{65,7)} \mathrm{oder} \mathrm{hat} \mathrm{sich} \mathrm{mit} \mathrm{massiver}$ Polemik gegen die Kollektivhaftung auseinanderzusetzen wie in Jer $31,29 f$ (Jer D) und Ez 18 (Prophetenschule). Insofern widerraten das "geistige K1 ima" und das oben festgestellte Gefälle im dtn-dtr Schrifttum einer exilischnachexilischen Ansetzung des Partizipialsatzes von Ex $34,7 \mathrm{~b}$ 40. Für das relativ hohe Alter d.h. vorexilische Entstehung spricht auch die gegenüber den Parallelen singuläre Konstruktion der Generationenreihe; sie besteht aus vier Elementen (Söhne, Enkel, dritte, vierte Generation), die durch Syndese zwischen dem ersten und zweiten wie dem dritten und vierten Element zu zwei Paaren geordnet werden. Die Asyndese in der Mitte garantiert die Paarigkeit. Wer im zweiten Paar d.h. in der dritten und vierten Generation Urenkel bzw. Ur-Urenkel entdeckt, interpretiert die Aufzählung als durchlaufende Reihe und übersieht die Asyndese ${ }^{41}$. Um der Konstruktion gerecht zu werden, ist daher "Anadiplosis iterata" bzw. eine "Catena" anzunehmen, bei der das letzte Glied eines Satzes oder Satzteils mit dem ersten des nächsten identisch

38 Hier eine grobe Übersicht über neuere Positionen:

SCHARBERT, Formgeschichte, 131: Jahwist; ZENGER, Sinaitheophanie, 148ff: Elohist; CHILDS, Exodus, 610: Jehowist; HALBE, Privilegrecht, 280-286: Jehowist; PERLITT, Bundestheologie, 213-216: deuteronomistisch; ZENGER, Exodus, 242ff: nachexilische Theologie.

39 Ebenso KNIERIM, Sünde, $204 \mathrm{ff}$; er plädiert deswegen für ein relativ hohes Alter von Ex 34,7b. Das exilisch-nachexilische Echo auf Dtn 7,9ff in Neh 1,5; Dan 9,4; 1 Kön 8,23// 2 Chr 6,14 verzichtet ganz auf den Gedanken der solidarischen Haftung, vgl. SCHARBERT, Formgeschichte, $136 \mathrm{f}$.

$40 \mathrm{Vgl}$. LOHFINK, Dekaloganfang, 1०2f; eine partielle Auffüllung mit dem Einschub "und an den Enkeln" - so ROST, Schuld der väter, 229 - verbietet sich aus den gleichen Gründen.

41 Vgl. Anm. 31 und 32. 
ist und sich zu einer Kette verbindet, eine Stilform, die wir z.B. bei Genealogien wie Gen 4,17f oder Mt 1,2-16 antreffen ${ }^{42}$.

Demnach sind in Ex 34,7 Enkel und dritte Generation identisch. Daraus folgt, daß hier die Angabe "Dritte Generation" den Vater mitzählt.

Von Ex 34,7 her erschließt sich auch die Parallele Dtn 5,9. Die polysyndetische Reihe des Dtn-Dekalogs nimmt Ex 34,7 auf; sie verzichtet auf die Stilform der Catena, referiert aber eine sachlich identische Generationenreihe von vier Gliedern: Väter, Söhne, Enke1, Urenkel! Die Polysyndese sichert die sachliche Identität mit Ex 34,7. Also wird auch in Dtn 5,9 der Vater mitgezählt.

\section{Num $14,17 f$}

hängt nach eigenen Angaben von Ex $34,6 f$ ab und versteht sich als Zitat. $0 b$ das Zitat bewußt verkürzt oder in der Kurzform auf den ehemaligen Grundtext von Ex 34,6f ohne spätere Auffüllungen hinweist, kann hier offen bleiben. Die literarkritische Zuweisung ist einheitlicher als bei der vorhergehenden Stelle. Die Verse gehören zu einem Einschub Num 14,11-23(25) wahrschein1ich aus deuteronomistischer Hand ${ }^{43}$. Der uns interessierende Partizipialsatz wird in derselben syntaktischen Form geboten wie in Ex 20,5 mit der asyndetisch angeschlossenen Apposition "an der dritten und vierten Generation". Die Erklärungen für die syntaktische Form schieben wir auf, bis wir alle Parallelen geprüft haben.

Ijob 42,16

gehört zum Schluß der alten Ijobnovelle. Wie ein Patriarch (vgl. Gen 50,23) schaut Ijob auf ein erfülltes Leben und sieht vier Geschlechter bzw. Generationen seiner Nachkommen. Der Vers bietet keine lückenlose Reihe; er nennt nur das Familienoberhaupt Ijob, die Kinder und Enkel und schließlich die summarische Angabe "vier Geschlechter".

Sie wird aus der Ijobnovelle verständlich: In der Generationenfolge werden die umgekommenen Söhne und Töchter (Ijob 1,18f) zu den Nachkommen der späteren Lebenszeit (Ijob $42,12 f$ ) hinzugerechnet ${ }^{44}$. Damit kommt man auf vier Generationen nur, wenn bei dieser Angabe der Vater/Ijob mitgezählt wird.

42 Vgl. KÖNIG, Stilistik, 3o4; er führt als weitere Beispiele Joel 1,3 und Ps 115,14 an. Zur Erläuterung der Stilform s. auch: LAUSBERG, Rhetorik, $\S 256$ und BÜHLMANN-SCHERER, Stilfiguren, 26.

43 So NOTH, Numeri, $96 \mathrm{f}$ und SMEND, Entstehung des AT, 68. Jetzt ebenso MITTMANN, Deuteronomium, $49 \mathrm{ff}$. 
Gen 15,16

gehört zu einem Kapitel mit verwirrend verwickelter Literarkritik. Einige Exegeten halten zu Recht die VV.13-16 für einen Einschub ${ }^{45}$. Innerhalb dieses Einschubs ¿wingt der Widerspruch in der Dauer des Agyptenaufenthaltes zwischen VV.13f und V.16 zu einer erneuten Abtrennung von V. 16. Der einleitende accusativus adverbialis 46 und der Plural der finiten Verbform zeigen deutlich, daß es in V.16 nicht um die vierte Generation von Abraham her, sondern um die vierte Generation der Nachkommen Abrahams in Agypten, also um Israel d.h. die Jakobsöhne geht ${ }^{47}$. Aussagetendenz und die sprachlich nächstverwandten Parallelen Lev 18,25-27; 20,22-24 ( $\left.\mathrm{PH}_{2}\right)$ legen für den Vers eine Verfasserschaft des Pentateuchredaktors nahe ${ }^{48}$. Aus dem Vers allein ist kein Hinweis auf die Zählung der Generationen zu gewinnen. Das ändert sich, wenn man den Stammbaum Aarons aus Ex 6,13-20 dazu in Beziehung setzt. Beide Textabschnitte, Gen 15,16 und Ex 6,13-27, stammen aus der Hand des Pentateuchredaktors; beide beschäftigen sich mit den Generationen der Israeliten in Agypten bis zum Auszug. Was Gen 15,16 summierend mit der "vierten Generation" angibt, das führt Ex 6,13ff konkret aus.

Der Stammbaum Aarons nennt fünf Generationen: Israel/Jakob, Levi, Kehat, Amram, Aaron und Mose. Die Auszugsgeneration ist dann die "vierte Generation", wenn der Stammvater Jakob/Israel nicht mitgezählt wird ${ }^{49}$.

\section{Kön 10,$30 ; 15,12$}

verhalten sich zueinander wie Voraussage und Erfüllung. Beide Male wird die Dauer der Jehudynastie mit vier Generationen angegeben. Dabei umfaßt die Jehudynastie fünf Glieder: Jehu, Joahas, Joasch, Jerobeam II., Secharja. Der Vater wird also auch hier nicht mitgezählt! W. Dietrich 50 hat nachgewie-

44 Vgl. FOHRER, Hiob, 545. Bestätigend für die Zuordnung von Ijob 42,16 s. WEIMAR, Ijobnovelle, z.B. $69 f$.

45 PERLITT, Bundestheologie, 72-77; VON RAD, Genesis, 145; ZIMMERLI, Abraham, 48f; WESTERMANN, Genesis, $269 f$.

46 GES. $-\mathrm{K} .$, § 118q.

47 Mit WEIMAR-ZENGER, Exodus, 117 und WESTERMANN, Genesis, 269 gegen HERRMANN, Geschichte Israels, 93 A 40 !

48 Vgl. V. SETERS, Abraham, 267 und WESTERMANN, Genesis, 270 .

49 Die Verbindung der beiden Texte deutet auch ZIMMERLI, Abraham, 58 an.

50 DIETRICH, Prophetie, $34 f$. 
sen, daß 2 Kön 10,30.31a; 13,4-6.23; 14,26f; 15,12 zu einer durchgehenden Kommentierung der Herrschaft der Jehudynastie aus der Hand des DtrN gehören, einem exilischen Redaktor des DtrG.

Dtn 23,9

erwähnt eine "dritte Generation". Die Stelle selbst wie der Kontext geben für unsere Fragestellung keine Antwort.

Das Gegeneinander der Ausgangsthesen kann nun aufgelöst werden: Eine ältere Zählweise rechnet bei den Generationenangaben den Vater mit; sie wird repräsentiert durch Ex 34,7; Dtn 5,9 und Ijob 42,16. Die jüngere Zählweise schließt den Vater aus; sie ist in exilisch-nachexilischen Texten wie 2 Kön 10,$30 ; 15,12$ und Gen 15,16 + Ex 6,13ff vertreten. Gen 50,23 ist nur bedingt dazuzurechnen ( $\mathrm{vgl}$. die Generationenreihen in Jos $7,16 \mathrm{ff}$ vier Generationen 1 Sam 9,1 [fünf] und Tob 1,1 [fünf]).

Zugleich haben wir den Schlüssel für die syntaktische Form der Generationenreihe in Ex 20,5 und Num 14,18 in der Hand: Die ältere Polysyndese wurde aufgegeben, weil die jüngere Zählweise die durchlaufende Reihe nicht mehr erlaubte.

Bei akribischer Konservierung des vorliegenden Partizipialsatzes tilgte man nur das erste waw der Deuteronomiumfassung.

Aus den בנים von Dtn 5,9 wurden die Nachkommen von Ex 20,5, die jetzt bis zur dritten und vierten Generation unter Ausschluß des Vaters heimgesucht werden. Die durch Asyndese abgehobene Apposition repräsentiert nun im Unterschied zur Deuteronomiumfassung das Schema " $X$ und $(X+1)$ " der Zahlensprüche. In juristischen Texten hat es die Bedeutung von " $X$ oder $(X+1)$ ". Im Falle von Ex 20,5 kommt wahrscheinlich noch die Konnotation hinzu, daß die"vierte Generation" das Maximum bedeutet im Sinne von "höchstens bis zur dritten oder vierten Generation" 51 . Die Untersuchung des zweiten Unterschiedes erreicht also folgendes Resultat: Sowohl der Dtn - wie der Ex-Dekalog zeigen am Unterschied ihre begründete Eigenheit. Die zeitliche Priorität liegt wieder beim Dtn-Dekalog!

51 JACKSON, Essays, 160: "The phrase means, at the most, 'to about the third or fourth generation' or the literal ' to the third or fourth generation'. What it does not mean is 'at least to the third generation' or 'to the third generation or further'." 


\subsection{Der synoptische Vergleich beim Sabbatgebot}

\subsubsection{Vorbemerkungen}

Das Sabbatgebot stellt den größten Teilabschnitt des Dekalogs dar; deshalb spiegelt sich in seiner wechselnden Interpretation die Auslegungsgeschichte des gesamten Dekalogs wider. Die jeweiligen Positionen zu Entstehung und Charakter des Dekalogs schlagen unmittelbar auf das Verständnis des Sabbatgebotes durch und vice versa: Positionen zur Entwicklung der Institution Sabbat infizieren die Interpretation der Dekaloge!

Eine weitere Besonderheit des Sabbatgebotes rangiert neben der erstgenannten: Das Sabbatgebot weist mit sechs die meisten Differenzen unter den Einzelgeboten zwischen beiden Fassungen auf. Naturgemäß konzentriert es bei einem synoptischen Vergleich die Aufmerksamkeit auf sich.

Die prominente Rolle des Sabbatgebotes für den Dekalog und die Bedeutung des Dekalogs für die Frage nach der Institution des Sabbat im Zeugnis des AT provozierten und provozieren eine fülle von Literatur.

Diese drei Gründe veranlassen einen gerafften Forschungsüberblick, der nicht so sehr die einzelnen Positionen referiert, sondern auf die angewandten Prinzipien der Exegese abhebt, um so die Grundlage für eine adäquate Behandlung der gehäuften Differenzen zu schaffen.

\subsubsection{Forschungsüberblick}

Monographien zum Dekalog aus der 1. Hälfte des 19. Jh.s wie die von Bertheau und Meier 52 übernehmen ohne Begründung die in der kirchlichen Katechese übliche Kurzfassung, bestehend aus dem ersten Satz jedes Einzelgebotes wahrscheinlich in der Voraussetzung, hier den Aussagekern oder das ursprüngliche Gebot vor sich zu haben. Der Rest der weiteren Sätze beim Sabbatgebot Ex 20,9f // Dtn 5,12-14 und die Begründungen Ex 20,11; Dtn 5,15 - wird pauschal weiteren Zusätzen zugewiesen.

Davon hebt sich die Phase der Literarkritik ab. Für sie entwickelt erstmals Ewald die Prinzipien der Dekalogexegese ${ }^{53}$. Demnach ergibt sich der mosaische Urdekalog aus dem synoptischen Vergleich der beiden Fassungen.

52 BERTHEAU, Die sieben Gruppen und MEIER, Die ursprüngliche Form.

53 EWALD, Geschichte, 2.Bd., $228 f$. 
Die Sätze oder Gebotsteile mit Differenzen zeigen die Flexibilität späterer Erweiterer. Der gleichsam klein;te, beiden Fassungen gemeinsame Nenner, offenbart den mosaischen Urdekalog, d.h. nur die kurzen Anfangssätze stammen von Mose; was darüber hinausgeht ist später hinzugefügt worden. Auf das Sabbatgebot angewandt, führt das bei Ewald zum Ergebnis: Ex 20,8 (du sollst des Sabbattages gedenken, ihn zu heiligen!) gilt ais Urgebot. Auch für die Anordnung der weiteren Zusätze wird Ewald maßgebend. Die Sabbatbegründung von Dtn 5,15 hält er für älter als die von Ex 20,11, die mit Rücksicht auf ihre Beziehungen zu Gen 2,1-3 seiner Meinung nach vom "Verfasser des Buches der Ursprünge" in Ex 20,11 eingetragen wurde.

Die weiteren Stellungnahmen der Literarkritiker halten an den Prinzipien von Ewald fest, präzisieren aber die Quellenzuweisung und differenzieren in den Zusätzen. So unterscheiden Wellhausen und Kuenen drei Stufen ${ }^{54}$ : einen ursprünglichen E-Dekalog, dann deuteronomische Zusätze wie die Aufzählung der vom Sabbat Betroffenen,ebenso die deuteronomisclie Begründung des Sabbats und schließ1ich Ex 20,11 vom Pentateuchredaktor stammend. Eine ganze Reihe von Literarkritikern schließen sich im großen und ganzen diesem Drei-Stufen-Modell an 55.

Ein kleinerer Teil von Literarkritikern lehnt dieses Modell ab. Entweder rechnen sie mit einer späten, exilischen Entstehung des gesamten Dekalogs und lassen sekundäre Zusätze nur im Fall der Sabbatbegründungen zu ${ }^{56}$ oder

54 WELLhAUSEN, Composition, 89; KUENEN, Einleitung, Bd. I, § 9 A 2. § 16 A 12 .

55 OETTLI, Deuteronomium, 40; STRACK, Exodus, 227; DILLMANN-RYSSEL, ExOdus, 233-238; HOLZINGER, Exodus, 74; HOLZINGER spaltet Ex 20,11 literarkritisch auf; V.11a gehört zum JE-Redaktor wegen einiger Abweichungen vom sprachgebrauch des $P ; V$. $11 \mathrm{~b}$ bleibt nach wie vor beim Pentateuchredaktor; HEMPEL, Schichten, 161; CHARLES, Decalogue, Introduction passim und Schautafel S.LV; CHARLES verfeinert das Drei-StufenModell zum Vier-Stufen-Modell: Ex 20,8 Urgebot zum Sabbat; erste Zusätze aus dem 10. Jh.v.Chr. in Ex 20,9f // Dtn 5,13f zu finden; deuteronomische Zusätze in Ex 20,9f // Dtn 5,13ff wie der Rückverweis oder die Wendung "der Fremde, der in deinen Toren ist" einschließlich der deuteronomischen Sabbatbegründung; zuletzt Ex 20,11 vom Pentateuchredaktor.

STEUERNAGEL, Deuteronomium, 22; MATTHES, Der Dekalog, bes. 31 ; beide halten die soziale Motivierung des Deuteronomiumdekalogs für älter als die von Ex 20,11, die vom Pentateuchredaktor stammt. 
sie erkennen Ex 20 insgesamt die zeitliche Priorität gegenüber Dtn 5 zu und macher: davon auch für Ex 20,11 keine Ausnahme 57 .

Die Aporie des literarkritischen Ansatzes wird gerade bミim Sabbatgebot deutlich. Das Prinzip des "kleinsten gemeinsamen Nenners" führt zu einem Urdekalog, der aus zehn knappen Anfangssätzen der Einzelgebote besteht. Nur weist das Sabbatgebot gerade im Einleitungssatz eine Differenz auf. Peters will die Aporie überwinden, indem er die Abweichung des Dtn als Schreibfehler eines Kopisten erklärt ${ }^{58}$. Rowley dagegen, ein später Nachfahre der al ten Literarkritiker, verficht konsequent das oben genannte Prinzip und verzichtet wegen der Differenz auf den Anfangssatz (Ex 20,8// Dtn 5,12a). Als das in beiden Fassungen Identische und damit mosaische Urgebot verbleibt dann die Vorschrift: Sechs Tage sollst du arbeiten und jedes Werk tun; der siebte Tag ist ein Ruhetag für Jahwe, deinen Gott ${ }^{59}$ ! Rowley erklärt nicht, warum nur beim Sabbatgebot die ursprüngliche Vorschrift vom Gebotsanfang wegrückt und warum sie sekundär ummantelt wird.

Die Phase der Formkritik löst die Literarkritik ab. H. Schmidi ist der erste ${ }^{60}$, der Gunkels formkritische Anregungen 61 in die Dekalogexegese einführt. Am Wortlaut des Urdekalogs der Literarkritiker ändert sich nicht viel; übernommen wird die Oberzeugung von den sekundären Wucherungen im Anschluß an die knappen Urgebote. Aber es wandelt sich das System der Begründung. Entscheidend ist nun die inhaltliche und stilistische Gleichförmigkeit der Einzelglieder. Weil das Sabbat- und das Elterngebot in der Kurzform des Urdekalogs der Literarkritiker aus der Verbotskette der Zehn Gebote herausfallen, scheidet $H$. Schmidt sie kurzerhand aus. Das Sabbatgebot hält er für eine exilische Einfügung durch einen Deuteronomisten in den mosaischen Urdekalog, die später noch mit unterschiedlichen Begründungen Dtn 5,14f bzw. Ex 20,11 ergänzt wurde ${ }^{62}$. Damit hat er die jahrzehntelange Diskussion um Alter und

57 DELITZSCH, Genesis, 19f, hält Ex 20 uneingeschränkt für den jehovistischdeuteronomischen Dekalog, der auf mosaischen Ursprung zurückgeht. Dtn 5, 15 reproduzierte frei den Exodusdekalog im Flusse rednerischer Paränese. Gen 2,2f seinerseits lehne sich an Ex 20,11 an. KöNIG, Deuteronomium, $91 \mathrm{f}$ hält die metaphysisch-religiöse Begründung von Ex 20,11 für früher als die geschichtlich-ethische von Dtn 5,15.

58 PETERS, The Ten Words, 143.

59 ROWLEY, Moise, lof und $32 \mathrm{ff}$.

60 SCHMIDT, Mose.

61 Vgl. GUNKEL, Die israelitische Literatur, bes. $24 \mathrm{f}$. 
Urform des Sabbatgebotes eröffnet, wobei die Frage der Erweiterungen der Urform völlig in den Hintergrund tritt. Von nun an scheiden sich an der Form des Sabbatgebotes die Geister. Im Namen der stilistischen Eeschlossenheit fordern einige Exegeten eine negative Urform (du sollst nicht irgendeine Arbeit tun am Sabbat!) ${ }^{63}$. Demgegenüber halten einige an der positiven Form von Ex 20,8 // Dtn 5,12 fest und stimmen mit H. Schmid't darin überein, das Sabbatgebot auch in seiner positiven Urform spät anzusetzen, weil sie den Dekalog insgesamt für ein spätes Produkt halten 64.

Die größte Gruppe von Exegeten ${ }^{65}$ vertritt nach wie vor die Auffassung der Literarkritiker: Der Anfangssatz von Ex 20,8// Dtn 5,12a als alte Urform des Sabbatgebotes. Dabei kann man den Dekalog als uniforme Zehnerreihe aufgeben und nur mehr kleinere, aber ebenso gleichgestaltete Gebotsgruppen annehmen.

Eine weitere Gruppe von Exegeten 66 löst sich von der Fixierung auf eine knappe Urform des Sabbatgebotes und stellt es in eine Reihe mit seinen Parallelen aus anderen "Gesetzeskorpora", den zweiteiligen Arbeitsverboten von Ex 23,12 und 34,21. Von diesen Parallelen her konzentriert sich die Aufmerksamkeit dieser Exegeten mehr auf den Kern des dekalogischen Sabbatgebotes als auf seinen Anfang.

62 Vgl. SCHNIDT, Mose, 8off und $106 \mathrm{f}$.

63 So als erster SELLIN, Geschichte, Teil I, 83f. Ihm folgen: ALT, Ursprünge, 318; RABAST, Das apodiktische Recht, 37f; NIELSEN, Zehn Gebote, 35ff; CAZELLES, Décalogue, 16f; ROBINSON, The Origin, 194f rechnet ein positives und negatives urgebot zu den Grundbausteinen des Sabbatgebotes.

64 MOWINCKEL, Décalogue, 75-98 und MEINHOLD, Der Dekalog.

65 So MENES, Die vorexilischen Gesetze, 46ff; KESZLER, Problematik des Dekalogs 9f; AUERBACH, Moses, 198. REVENTLOW, Gebot, 45-60; REVENTLOW allerdings verstrickt sich in widersprüche; auf Seite 48 übernimmt er die traditionelle Auffassung, vermutet dann aber auf Seite 56 im Urgebot einen Einleitungssatz zur Gesetzespredigt über den Sabbat; HAAG, Der Dekalog, 29; GERSTENBERGER, Wesen, 46.88; FOHRER, Recht, 133.138 A 51; NOTH, Exodus, 131f; GESE, Der Dekalog als Ganzheit, 67; JEPSEN, Beiträge, 292f; SCHMIDT, therlieferungsgeschichtliche Erwägungen, 208f; SCHÜNGEL-STRAUMANN, Der Dekalog, 72-79; HULST, Sabbatgebot, 154; MATHYS, Sabbatruhe, 244.

66 LURJE, Studien, 62f; KÖHLER, Der Dekalog, 180; SCHMÖKEL, Gebote, 368f; PATRICK, La formation littéraire, 246; PHILLIPS, Criminal Law, 64-79; TSEVAT, Biblical sabbath, 451; NEGRETTI, Il Settimo Giorno, 122ff; KOCH, Formgeschichte, 60.62; CHILDS, Exodus, $385 \mathrm{ff}$. 
Stellt man sich die Frage, was die Phase der Formkritik für die Auslegung des Sabbatgebotes einbrachte, dann können mehrere Punkte genannt werden: Durch die unterschiedlichen Vorschläge zur Urform wurde das eigene Modell vom Werden des Sabbatgebotes relativiert, nämlich ein ursprünglich knappes Kurzgebot (positiv oder negativ), das durch Zusätze bis zum vorliegenden Endtext erweitert wurde. Die Anbindung des Sabbatgebotes an die betreffenden Parallelen der anderen Rechtstexte wie Bundesbuch und Privilegrecht Ex 34 schärfte den Blick für die ursprünglichere Zweiteiligkeit des Sabbatgebotes, das keinen fixen Termin vorschreibt, sondern die Relation von Arbeit und Ruhe im Rhythmus von sechs zu einem Tag. Schließlich provozierte die analytische Aufsplitterung des umfangreichen Sabbatgebotes im Gegenzug die Frage nach der Synthese bzw. der Komposition, wie sie in der jüngsten Phase der Dekalogexegese greifbar scheint.

Diese Phase der Betonung der Komposition lehnt das Analysemodell der beiden vorhergehenden Phasen (Urgebot mit sukzessiven Erweiterungen) insofern $a b$, als nun das Sabbatgebot Produkt einer einzigen Komposition ist, die die älteren und vorliegenden Arbeitsverbote von Ex 23,$12 ; 34,21$ verarbeitet. Diese "neue Sehweise" kündigt sich für Dtn 5,12-14 bei Lohfink an ${ }^{67}$. Für Ex 20,8-11 wird sie bei Richter ${ }^{68}$ präzise dargestellt und bei Halbe 69 angedeutet; Andreasen referiert sie für beide Fassungen, spielt sie aber nicht konsequent durch, so daß sie für seine Darstellung der Entwicklung des Sabbat folgenlos bleibt ${ }^{70}$. Die neue Phase der Dekalogexegese bzw. der Interpretation des Sabbatgebotes betont das Faktum der Komposition, ohne den genauen Bauplan oder die Kompositionsabsicht anzugeben. Wenn für die Sabbatgebote beider Fassungen das Faktum der Komposition feststeht, wie verhalten sich die beiden Kompositionen zueinander? Ein systematischer Vergleich steht noch aus. Daraus ergibt sich die Arbeitsanweisung, daß die synoptischen Differenzen auch im Rahmen ihrer dazugehörigen Komposition erörtert werden müssen. Dahinter steht also die Hypothese, daß die Differenzen nicht Nebenprodukte eines schwer durchschaubaren Erweiterungsprozesses sind, sondern Er-

67 LOHFINK, Dekalogfassung, 17-32. LOHFINK hängt mit halbem Herzen noch am alten Modell und rechnet mit Vorstufen des Sabbatgebotes in Ex 20,810, vgl. a.a.0., 22f; der Schwerpunkt seiner Ausführungen liegt aber bei der Komposition der Endredaktion.

68 RICHTER, Recht, 102-104.

69 HALBE, Privilegrecht, 185-192.

7o ANDREASEN, Sabbath, 244; DERS., Recent Studies. 
gebnisse jeweils einer anderen Komposition. Wir beginnen deshalb den synoptischen Vergleich beim Sabbatgebot mit einem Vergleich der Kompositionen, der nur auf das Gerüst der Komposition abhebt, ohne in die Einzelinterpretation einzusteigen.

\subsubsection{Vergleich der Kompositionen Ex 20,8-11 und Dtn 5,12-15}

Für Dtn 5,12-15 hat Lohfink auf die doppelte äußere Rahmung hingewiesen und die weitere Forschung hat diese Beobachtung nicht bestritten 71 . Im gerahmten Inneren sorgen bestimmte Konstruktionselemente für die notwendige Verklammerung. Die Konstruktverbindung יום השבת dürfte wohl hier ihren ältesten Beleg haben, da alle weiteren Fundstellen dem Dekalogvorkommen nachzuordnen sind ${ }^{72}$. Als Neuschöpfung fordert sie erhöhte Aufmerksamkeit. Wir verstehen sie als Kürzel für die Fusion vom siebten Tage mit dem Sabbat, die im Dekalog gleich zu Anfang auf den nachfolgenden Nominalsatz verweist, der den siebten Tag mit dem Sabbat, dem Vollmondtag, identifiziert ${ }^{73}$.

Die auf die Rahmung V.12 folgenden vier Sätze VV.13.14a verarbeiten das von seiner Natur aus zweiteilige Arbeitsverbot von Ex $23,12 a ; 34,21^{74}$. Die Aufspaltung des zweiteiligen Arbeitsverbotes und dessen Ausbau zu einer Vierergruppe mit je zwei Satzpaaren ist eine gezielte Konstruktion mit dem Aussageschwerpunkt auf dem dritten Satz, dem Nominalsatz mit seiner Gleichsetzung von siebtem Tag und Sabbat. Die anschließende Aufzählung der vom Sabbattag Betroffenen mit dem nachfolgenden Finalsatz bearbeiten Dtn 16 und Ex 23, $12 b$ - sind also über gemeinsame Vorlagen mit den vorausgehenden Sätzen verbunden. Der Finalsatz fungiert als Umschaltstelle: Er wiederholt Elemente der Aufzählung der vom Sabbattag Betroffenen und leitet über zum dreiteili-

71 LOHFINK, Dekalogfassung, 21; seine chiastische Gliederung des Sabbatgebotes im Sinne einer konzentrischen Struktur (vgl. NEGRETTI, Il Settimo Giorno, 131f) bleibt eine Unterstellung, die MITTMANN, Deuteronomium, 135f, berechtigt kritisiert hat; aber auch er respektiert die Rahmenelemente VV.12.15b.

72 Vgl. Ex 31,$15 ; 35,3 ;$ Lev 24,$8 ;$ Num 15,$32 ; 28,9 ;$ Jer $17,19-27 ;$ Ez $46,1.4$. 12 ; Ps 92,1 ; Neh 10,32; 13,15ff; alle Stellen gehören zur exilisch-nachexilischen Literatur; vgl. RICHTER, Recht, 102 A 201 und ROBINSON, The Origin, 217 .

73 Wir schließen uns der Richtung der Exegeten an, die eine ursprünglich d.h. zur Zeit der Staatlichkeit Israels bestehende Trennung von Sabbat als Vollmondtag und dem siebten Tag als Ruhetag annehmen; vgl. MEINHOLD, Zur Sabbatfrage; ebenso LEMAIRE, Le Sabbiat; desgleichen die Dissertation von ROBINSON, The Origin, passim. Wir kommen später darauf zurück! 
gen "Klischee deuteronomischer Gesetzeskommentierung" (וכרת כי) ... Narrativ mit Jahwe als Subjekt ... על כו mit abschließendem Rückgriff auf ein vorhergehendes Gebot). Der dritte Teil des Klischees ist hier im Sabbatgebot besonders gestaltet: Er schärft das Tun der Vorschrift allgemein ein und spielt zugleich zitierend auf den Anfang des Sabbatgebotes an. Beide Formen des Rückgriffs treten sonst im Dtn getrennt auf ${ }^{75}$. Damit sind einige Anhaltspunkte gegeben, Dtn 5,12-15 als geschlossene Komposition zu verstehen. Logische Spannungen, die zu einer literarkritischen Trennung zwingen, liegen nicht vor. Wer sie dennoch behauptet, muß prüfen, ob er nicht Dtn 5,12-15 von Ex 20,8-11 her liest und letztere Stelle zum Maßstab erhebt!

Ahnlich wie Dtn 5,12-15 ist auch Ex 20,8-11 gerahmt, was die Forschung schon seit längerem beobachtet hat ${ }^{76}$. Die oben für Dtn 5,12-15 angegebenen Konstruktionsklammern bis zum Ende der Aufzählung der vom Sabbattag Betroffenen gelten auch für Ex 20,8-11. Innerhalb der Rahmung wird der Lebensrhythmus des Israeliten mit dem Jahwes bei der Schöpfung parallelisiert, indem zweimal das Schema "sechs Tage - der/am siebte(n) Tag" abläuft 77. Trotz der relativ geschlossenen Konstruktion von Ex 20,8-11 fallen einige Unebenheiten auf. Dtn 5,12-15 gebraucht durchgehend die für die Dtn-Paränese typische Rede von "Jahwe, dein Gott" (insgesamt viermal). Dagegen wechse1t Ex 20,8-11 vom "Jahwe, dein Gott" in 20,10 zum appositionsiosen zweimaligen "Jahwe" in 20,11. In der größeren Konsequenz von Dtn 5,12-15 liegt ein Hinweis darauf, daß diese Verse eine Primärkomposition darste1len, während das Sabbatgebot im Exodusdekalog sowohl auf seinen Vorgänger im Dtn und auf eine andere Sprechweise Rücksicht nimmt. Eine weitere Beobachtung flankiert den vorhergehenden Hinweis. In der Dtn-Fassung hat der כy-Satz seine bestimmte Funktion ${ }^{78}$. Er dient der abschließenden Rahmung, die jedesmal nach Gesetzeserläuterungen sowohl auf den Akt der Promulgation als auch auf den Inhalt der Vorschrift abhebt ${ }^{79}$. In Ex 20,11b verhält sich dieser Satz sperrig zum Kontext. Er stößt sich mit dem begrün-

75 Zu den Belegen s.u. bei der Darstellung der Komposition von Ex 20,8-11.

76 ZIMMERLI, Das zweite Gebot, 234; NIELSEN, Zehn Gebote, 37f; LOHFINK, Dekalogfassung, 23 A 22; RICHTER, Recht, 102-104; HALBE, Privilegrecht, $188 \mathrm{f}$.

77 Vgl. LOHFINK, Dekalogfassung, 23 A 22; ZENGER, Sinai, 66.232.

78 Vgl. MERENDINO, Gesetz, 113.

79 Abschließender כ כy-Satz mit Zitat der Ausgangsvorschrift: Dtn 15,11 zitiert 15,8; Dtn 19,7 zitiert 19,2; Num 18,24 zitiert 18,20.23; Lev 17,12 zitiert 17,10; abschließender כy-Satz mit allgemeinem Rückverweis: Dtn 15,15; Dtn 24,18b; 24,22b. 
denden כי כי V.11a, das von seinen einschlägigen Parallelen her besser ausgewiesen ist ${ }^{80}$. Der zu erwartende Rekurs auf den Promulgationsakt findet in Ex 20,11b nicht statt. Schließlich setzt der כy-Satz seinem semantischen Gehalt nach die vorausgehende Begründung von V.11a fort, genauso wie es Gen 2,2f vorführt ${ }^{81}$. Die Konjunktion כל בוberlagert V.11b mit einem begründenden Charakter, um inn zum rahmenden Abschluß umzustilisieren; damit ahmt sie Dtn 5,15b nach. Aus beiden Hinweisen schlußfolgern wir, daß die Komposition Ex 20,8-11 diejenige von Dtn 5,12-15 zur Vorlage nimmt und ihre eigene neue Aussage in das vorgegebene Gerüst einbaut.

\subsubsection{Der erste synoptische Unterschied im Einleitungsverb:}

ז in Ex 20,8 und in Dtn 5,12

Hier hat die bisherige Forschung alle logisch möglichen Positionen erwogen. Die größte Gruppe von Exegeten hält זכר für älter und nimmt eine sekundäre Anderung zu שמר an, we שמר den Befehlston verschärft und keine Ausnahme mehr zuläßt ${ }^{82}$ oder weil שמר für den Sprachgebrauch des Dtn typisch ist und zugleich Rücksicht auf die festliegende Bedeutung von זכר in Dtn 5,15 nimmt ${ }^{83}$. Die konträre Gegenposition (שמר älter, זכר jünger) kommt zahlenmäßig schwächer zu Wort ${ }^{84}$. Die Not der Forschungslage veranlaßt einige, sich nicht zu entscheiden oder die Differenz in ihrer Bedeutung herunterzuspielen ${ }^{85}$. Andere halten שמר üur sinngleich, so daß der Wechsel keinen Bedeutungsunterschied mit sich bringt ${ }^{86}$. Nur müssen dann andere Gründe angeführt werden, warum ein Wechsel vorgenommen wurde, obwohl beide termini äquivalent sind.

$80 \mathrm{Vgl}$. Gen 2,3 und Ex 31,17b; dazu STECK, Schöpfungsbericht, 190.

81 Ähnlich argumentieren: HULST, Sabbatgebot, 163 und NEGRETTI, Il Settimo Giorno,160; die Ausführungen von NIELSEN, Zehn Gebote, $37 \mathrm{f}$ gehen an der Sache vorbei!

82 KÖNIG, Deuteronomium, 92; KESZLER, Problematik des Dekalogs, 9f; RICHTER, Recht, 103; KOCH, Formgeschichte, 57; ROBINSON, The Origin, 190.

83 DILLMANN-RYSSEL, Exodus, 235; NIELSEN, Zehn Gebote, 35ff; MITTMANN, Deuteronomium, 141f; LOHFINK, Dekalogfassung, $22 f$ sieht darin, daß שמר in den "umfassenden Formzusammenhang" von Dtn 5,12-15 gehört, ein Motiv für die Änderung, während umgekehrt für eine Änderung von שמר zu kein Motiv ausfindig gemacht werden kann; NEGRETTI, Il settimo Giorno, 131 schließt sich ihm an. Wie sich zeigen wird, kann gerade für eine sekundäre Änderung von שמר ז זכר ein Motiv angegeben werden und damit die obige Position unterwandert werden.

84 Vgl. KÖHLER, Der Dekalog, 180: Tר/gedenken setze ein langes Bestehen der Sabbatinstitution voraus und sei später als der sachgemäße Terminus שמר/beobachten. 
Jüngere Untersuchungen, vor allem zu זכר, erlauben eine Neuorientierung 87. Wir setzen bei Dtn 5,12 ein und rekapitulieren die schon erwähnten Einsichten, warum an dieser Stelle שמר gewählt wurde. Auf Grund der festen Paarung mit שמר nun die äußere Inklusion des Dtn-Sabbatgebotes. Zugleich setzt es sich ab von זכר in Dtn 5,15, das in der dtn Paränese die Bedeutung von "sich erinnern" übernimmt und zwar ein "sich erinnern" an Erfahrungen der Vergangenheit ${ }^{89}$. Bei dieser scharfen Trennung zwischen שמר und זכר ist es - diachron betrachtet - nicht geblieben. So kann זכר zunehmend mit שמר semantisch gleichwertig werden ${ }^{90}$, sei es daß es in Parallele zu שמר tritt (Pss 103,18; 119,55; Num 15,39f) oder wie שמר durch nachfolgenden Infinitiv final auf ein bestimmtes Tun ausgerichtet wird (PSS 103,18; 109,16; [Ex 20,8]) oder daß es, vom Kontext her geurteilt, die gleiche Funktion wie שמר übernimmt (Jos 1.13; Mal 3,22). Die angegebenen Belege weisen alle in exilisch-nachexilische Zeit. In die gleiche Richtung zeigen die einschlägigen Parallelen von Ex 20,8 (זכר mit einem kultischen Termin als Objekt) wie Ex 13,3; Dtn 16,3 und Est 9,28 91 .

זכר besitzt an den eben genannten Stellen die Konnotationen von "gedenken" und "beachten" bzw. "einhalten" 92.

85 So STAMM, Dekalogforschung, 8f; REVENTLOW, Gebot, 24; HULST, Sabbatgebot, 158f; SCHÜNGEL-STRAUMANN, Der Dekalog, 26.72f; ANDREASEN, Sabbath, 83.

86 Vgl. STEUERNAGEL, Deuteronomium, 22; NOTH, Exodus, 131; MITTMANN, Deuteronomium, 141; HALBE, Privilegrecht, 188.

87 GROSS, Zur Wurzel זכר, 227-237; SCHOTTROFF, 'Gedenken'; DERS., Art. זכר, THAT I, 507-518; EISING, Art. זכ, ThWAT II, 571-593.

$88 \mathrm{Vgl}$. die Stellen bei LOHFINK, Hauptgebot, 68-70; LANGLAMET, Israel, 328 A 43.44 .

$89 \mathrm{Vgl}$. SCHOTTROFF, Gedenken, 117-125.

90 Vgl. THAT I, 510 .

91 CALOZ, Ex XIII, 3-16, hat für den ganzen Abschnitt protodeuteronomischen Charakter nachweisen wollen; aber seine Analyse leidet unter einem atomisierendem Sprachvergleich und der aus Eissfeldts Hexateuchsynopse übernommenen Hypothese einer Laienquelle. HALBE, Passa-Massot, $158 \mathrm{f}$ vermutet mit guten Gründen in Ex 13,3 eine nachträgliche Einleitung, die vor den Abschnitt W.4-10 gesetzt wurde, als dieser in die vorlage VV.1-2.11-16 eingeschaltet wurde. Das läuft darauf hinaus, in 13,3 den spätesten Teil eines u.U. mehrfach geschichteten dtr Abschnitts $\mathrm{zu}$ sehen.

Für Dtn 16,3b hat HALBE, Passa-Massot, 157f.167 herausgearbeitet, daB dieser versteil mit dem verwandten V.8 zur letzten Bearbeitungsstufe von Dtn 16,1-8 gehört, die "in priesterlicher Tradition zu Hause" ist.

92 Vgl. SCHOTTROFF, Gedenken, 125f.275; ebenso ThWAT II, 576. 
Diese Bedeutung in Bezug auf kultische Einrichtungen greift das Nomen זכרוו auf; die Belege beschränken sich ebenso auf exilisch-nachexilisches Schrifttum 93 .

Der Oberblick verschafft uns auch ein Motiv für die sekundäre Abwandlung des ursprünglichen זכר zu שמר: Der Autor des Sabbatgebotes Ex 20,8-11 greift einen Terminus auf, der den Aspekt des kultischen Gedächtnisses mit dem permanenter Observanz verbindet. Der Sabbat ist eine dem Menschen im Schöpfungssabbat vorgegebene Institution - daran hat der Mensch bei jedem Sabbat zu denken und diesen Tag einzuhalten ${ }^{94}$ !

\subsubsection{Der aweite Unterschied: Asyndese zwischen dem dritten und vierten} Glied in der Aufzählung der vom Sabbattag Betroffenen bei der Exodusfassung gegenüber konsequenter Syndese in der Dtn-Fassung

Dieser wenig bemerkte Unterschied ist schwer zu erklären. Wenn man nicht textkritisch mit Haplographie in Ex 20,10 arbeiten wi11, bleiben nur folgende Lösungsmöglichkeiten: Der Autor des Sabbatgebotes in Ex 20 intendierte eine Gruppen- oder Paarbildung in der Aufzählung. In diesem Fall müßten sich aber Syndese und Asyndese abwechseln, was hier nicht stattfindet. Auch die nächste Möglichkeit von konsequenter Asyndese mit abschließender Syndese, wie sie eine Parallelreihe aus den Maribriefen bietet ${ }^{95}$, kommt hier nicht in Betracht. Auf dem Hintergrund, daß bei solchen Reihungen Syndese zu erwarten ist wie in der Dtn-Fassung oder in Ex 20,17, bleibt nur die Vermutung, die auch die alten Literarkritiker anstellten ${ }^{96}$, daß der Autor die Reihe in zwei Teile aufspalten wollte: der erste Teil für die blutsverwandte Familie im engen Sinne, der zweite Teil für die Gruppe der zum Eigentum gehörenden dienenden Wesen. Die Parallelen in Bezug auf die Großreihe sind zu spärlich und dieses Phänomen zu singulär, um aus der Asyndese auf eine bestimmte Tendenz eines Autors schließen zu können. Ob hier die Forderungen von Lev 26,44-46.47-49 mit ihrer scharfen Trennung zwischen Blutsverwandten und Sklaven einschlägig sind, kann eben nur vermutet werden. Der synoptische Vergleich bleibt in diesem Fall unentschieden.

93 Spätes dtr Schrifttum: Ex 13,9; 17,14 (zum dtr Charakter dieser Stelle jüngst: VALENTIN, Aaron, 147.164); Jos 4,7; Priesterliches Schrifttum: Ex 12,14; Lev 23,24; Num 17,5 und Jes 57,8 wie Neh 2,20; vgl. SCHOTTROFF, Gedenken, 341; THAT I, 517; ThWAT II, 589.

94 KÖHLER, Der Dekalog, s.o. A 84 erhält insofern recht, als eine Institution vorausgesetzt wird; aber nicht der "normale" Sabbat, sondern der Schöpfungssabbat, wie es ja auch die Begründung Ex 20,11 erläutert.

95 Vgl. ARM II 99,8-9. 
2.3.6 Der dritte Unterschied in der Aufzählung der Tiere bei der Reihe der vom Sabbat Betroffenen

Bei all denen, die von dieser Differenz Notiz nehmen, bleibt die Meinung konstant: Ex 20,10 bietet die kürzere und ursprünglichere Aufzählung der vom Sabbat Betroffenen, Dtn 5,14 dagegen füllt sekundär auf 97! Lohfink kann darüber hinaus Angaben zum Vorgehen des Redaktors der Deuteronomiumfassung machen: Er habe aus stereotypen Wortpaarungen wie etwa "Sohn und Tochter", "Sklave und Sklavin" oder "Rind und Esel", die je nach Umständen kombiniert werden können, ausgewählt und im Hinblick auf den letzten Satz des Dekalogs die Stichwortentsprechung "Rind und Esel" eingefügt ${ }^{98}$. Ohne an dem obigen Urteil zu rütteln, sind aber auch Beobachtungen gemacht worden, die Zweifel am angenommenen Gefälle von der Exodusfassung zur Deuteronomiumfassung aufkommen lassen. So vermutet Dillmann-Ryssel ${ }^{99}$ im Wortpaar "Rind und Esel" wegen der guten Bezeugung im Bundesbuch die ältere "Formel", die in der Deuteronomiumfassung mit dem jüngeren Ausdruck "Vieh" kombiniert worden sei.

Reventlow 100 sieht hinter Ex 20,10.17 eine alte Reihe aus priesterlichem Listenwissen, die die Prediger in Dtn 5,14 aufgegriffen und vollständiger zitiert haben. Bei einigen wird der Einfluß von Ex 23,12 auf Dtn 5,14 erkannt und von dort her die Ergänzung erklärt ${ }^{101}$. Richter geht einen Schritt weiter und konstatiert Ex 23,12 auch als Vorlage der Reihung in Ex 20,10, wobei dann Dtn später die Vollständigkeit der Vorlage Ex 23,12 "restauriert" habe ${ }^{102}$. Ninmt man noch die seit Wellhausen 103 nicht verschüttete Auffassung hinzu, daß die Aufzählung in Ex 20,10 Formulierungen aus dem Dtn enthalte ${ }^{104}$, dann erstaunt es, daß alle genannten Beobachtungen nicht zur Umkeh-

96 Vgl. OETTLI, Deuteronomium, 40; STRACK, Exodus, 227; DILLMANN-RYSSEL, Exodus, 236; JACCB, Exodus, 846.

97 OETTLI, Deuteronomium, 40; KÖNIG, Deuteronomium, 92; STAMM, Dekalogforschung, 8f; NIELSEN, Zehn Gebote, 35ff; ANDREASEN, Sabbath, 84; ROBINson, The Origin, 190.

98 LOHFINK, Dekalogfassung, 23f bes. 23 A 24; MITTMANN, Deuteronomium, 142 A 31 dämpft LOHFINKs Vorschlag $a b$ und will einen primären AnstoB vom Dekalogende her nicht zulassen, weil der sachliche Bezug fehlt. DILLMANN-RYSSEL, Exodus, 236.

100 DERS., Gebot, 56f.92.

101 JACOB, EXodus, 891; NEGRETTI, Il Settimo Giorno, 129; MITTMANN, Deuteronomium, 142 .

102 DERS., Recht, 103.

103 DERS., Composition, 89. 
rung des Gefälles geführt haben. Es muß an der Schwierigkeit gelegen haben, das Mehr an Text in Dtn 5,14 anders als durch sekundäre Erweiterung zu erklären!

Beide Fassungen präsentieren eine Liste von Sabbatteilnehmern, die in ihrem Aufbau bzw. Typ einer Liste von Kultteilnehmern entspricht, wie sie im Dtn heimisch ist: Beginn mit Anrede an den freien Vollbürger ("Du"), Fortsetzung mit der eigenen Familie und den personae miserabiles, an deren letztes Glied sich der Relativsatz אשר בשעריך anhängt ${ }^{105 .}$

Nun springt sofort ins Auge, daß beide Dekaloge die Haustiere in die Aufzählung aufnehmen. Neben diesem Faktum überrascht weiterhin deren Position innerhalb der Liste vor dem letzten Glied der Kultteilnehmerliste. Denn verglichen mit anderen Aufzählungen über Besitz oder Bewohner, die Mensch und Tier aufreihen, steht das Vieh entweder voran ( $\mathrm{vgl}$. Gen 32,6) oder es folgt nach (vgl. die Bannerzählungen Jos 6,$21 ; 7,24 ; 1$ Sam 15,3;22,19), oder es rahmt die Menschen ein (Gen 12,16b), nie mittendrin! Das läßt sich nur erklären mit dem oben erwähnten Bezug zu Ex 23,12b. Diese Zweckangabe des Arbeitsverbots V.12 steht unter bestimmten Formzwängen ${ }^{106}$ : Zunächst fällt die konsequente Parallelisierung der Zweckangabe auf. Die Objekte werden nicht von einem Verb abhängig gemacht, sondern in singulärer Parallelisierung auf die beiden bedeutungsgleichen Verben נפש und נוח H-Stamm verteilt. Um die Balance der Halbverse zu wahren, bildet die zweite Hälfte des Verbes den für das Bundesbuch singulären Terminus בן אמתך, obwohl im Bundesbuch sonst nur das fixe Wortpaar אמה/עבד auftaucht ${ }^{107}$; wir dürfen annehmen, daß die obige singuläre Konstruktverbindung hier die abhängigen Personen "Sklave und Sklavin" vertritt. Die Zweiteiligkeit der Zweckangabe ergibt sich aus der Zweiteiligkeit der vorausgehenden Brachjahrvorschrift wie des Arbeitsver-

$104 \mathrm{Vgl}$. KOCH, Formgeschichte, 60.

105 Nach MERENDINO, Gesetz, $136 \mathrm{f}$ liegt der Ursprung aller Belege in Dtn 16, 14 vor; es ist zugleich der Beleg mit den meisten (neun) Gliedern; sekundär kopiert in 16,11; reduziert in 12,12.18; "Sohn und Tochter" sowie "Knecht und Magd" zusammengefaßt durch den Begriff "Haus" in 14,26f; 26,11 .

106 Die folgenden Beobachtungen erfolgen im Anschluß an RICHTER, Recht, 92 und HALBE, Privilegrecht, 420.445, ohne des letzteren indirekte Voraussetzung eines hohen Alters für die Reihungen der Dekaloge zu übernehmen.

107 Die Stellen: Ex 21,20.26f.32 und die zusammenordnung der Paragraphen über Sklave Ex 21,2-6 und Sklavin 21,7-12. 
bots und ist ebenso in Ex 23,11aßr, einem wahrscheinlich sekundären Interpretament der Brachjahrvorschrift anzutreffen; dort werden analog zu 23,12b die "Armen deines Volkes" und die "Tiere des Feldes" parallelisiert. Stichwortbezüge (גש und gleicherweise kompositorische Rücksicht auf $23,9 b \alpha$ erzwingen die Nachordnung der Menschen in 23,12b und die Verlegung von הגר ans Satzende. Sowohl die Kultteilnehmerliste aus dem Dtn mit dem durch den Relativsatz gekennzeichneten letzten Glied, ein Vertreter der personae miserabiles, als auch die Vorlage Ex 23,12b konvergieren in der Endposition des גר. Als der Autor des Sabbatgebotes von Dtn 5,12-15 die Kultteilnehmerliste mit seiner Vorlage Ex 23,12b zu seiner Reihe der vom Sabbat Betroffenen kombinierte, konnte er die Haustiere nicht übergehen; er nahm sie auf und postierte sie vor das schon festliegende Schlußglied seiner Kette.

Bei diesen Zusammenhängen steht Dtn 5,14 in engerem Verhältnis zu Ex 23,12 als seinerseits Ex 20,10. Das Verhältnis im Falle von Dtn 5,14 wird nicht nur bestimmt durch die summarische Erwähnung von "Vieh" und die Position dieser Erwähnung in der Liste, sondern auch durch die Stichworte שור und חמור. Von daher stellt sich die Frage dieser synoptischen Differenz nun anders: Warum hat Ex 20,10 trotz vorliegender Beziehungen zu Ex 23,12b diese Stichworte unterdrückt? Ein Blick auf betreffende Tierreihungen kann darüber Aufschluß geben.

Das Wortpaar nמור/שור fungiert seit alten Zeiten als Paradigma für die Gesamtheit der Haustiere ${ }^{108}$. Dieses Paar kann zu einer ebenso gut belegten Trias von Rind/Esel/Schaf aufgestockt werden; שמור/שור stehen dann für das Großvieh, שה als pars pro toto für das Kleinvieh ${ }^{109}$. Die gleiche Trias wird äquivalent variiert dadurch, daß der Kollektivbegriff צאן den Einzelbegriff שה ersetzt 110. In Ex 22,9 wird die erste Trias durch וכל בהמה ergänzt; offensichtlich soll hier der Oberbegriff בהמה Groß- und Kleinvieh einschließen 111, um am Ende der Trias sicherzustellen, daß kein Haustier von der Verordnung ausgeschlossen wird ${ }^{112}$. In Dtn 28,31 gehört die zwei-

108 AuBer den Dekalogstellen folgende Belege: Ex 21,33; 23,4.12; Dtn 22,4. 10; 1 Sam 12,3; Jes 1,$3 ; 32,20 ;$ Ijob 24,3; vgl. IN DER SMITTEN, Art. רמור, ThWAT II, 1036-1042.1039; MORAN, The Conclusion, 550f.

109 Ex 22,3.8; (34,19f); Jos 6,21; Ri 6,4; (1 Sam 15,3); 1 Sam 22,19.

110 Gen 32,$6 ; \operatorname{Dtn} 28,31$; Jos 7,24 .

111 Vgl. BOTTERWECK, Art. בהמה, ThWAT I, 523-536.530.

112 Der Wechsel von der Partikel 1 zur Syndese vor dem letzten Glied von Ex 22,9 kann eine sekundäre Auffüllung aus tutioristischen Gründen signalisieren analog derjenigen, die HALBE, Privilegrecht, $176 f$ für Ex 34, $19 \mathrm{ba}$ festgestellt hat. 
te Trias zum Grundbestand des Kapitels aus vorexilischer Zeit ${ }^{113}$. Die sinnverwandte Wendung "Frucht deines Viehs" in Dtn 28,4.11.51 ist spätere Auffüllung aus der Hand des Deuteronomisten oder der inm nahestehenden "Schule", desgleichen die davon abhängige Spezialisierung "Wurf deiner Rinder (אלפים) und Zuwachs deines Kleinviehs (צאן)" in Dtn 28,4.18.51 114. Aus diesen Tierreihungen entnehmen wir die Information, daß die Aufzählung von Dtn 5,14 "dein Rind und dein Esel und all dein Vieh" ein fortgeschrittenes Stadium Jל בהמה mit Reihenbildung präsentiert, wobei das alte Wortpaar שמור שור vervollständigt wird, um alle möglichen Haustiere einzuschließen.

Es bleibt aber nach wie vor die Reduktion auf בהמה allein in Ex 20,10 zu erklären. Lev 26,6aßb.7 115 bringt uns auf die Spur einer Lösung. Der Anhang zur Sabbatjahrvorschrift verarbeitet einerseits die Brachjahrvorschrift von Ex 23,11 und verbindet wie diese Vorlage Mensch und Tier ${ }^{116}$; andererseits gestaltet der Anhang aus. Die Betroffenen sind wie in Dtn 5,14 bzw. Ex 20,10 der angeredete Vollbürger, Sklave und Sklavin, Lohnarbeiter und Beisasse als modifizierte "personae miserabiles" mit anschließendem Partizipialsatz statt des uns bekannten Relativsatzes und dann über die Vorlage Ex 23,11 hinausgehend neben den wilden Tieren noch die Haustiere. Wie in Ex 20,10 werden die Haustiere nur mehr mit dem Oberbegriff בהמה erfaßt (vgl. Lev 1,2 und $27,26)$. Das leitet uns weiter zum Schöpfungsbericht von $\mathrm{p}^{g}$, wo in Gen 1:2426 dreimal von בהמה!) als den Haustieren die Rede ist ${ }^{117}$. Daraus kann man schließen, daß Ex 20, lodie Liste von Dtn 5,14 auf בהמה reduzierte, ohne den Sinn der Liste zu verfälschen. Die Reduktion lag nahe, weil sie dem Sprachgebrauch des priesterlichen Schöpfungsberichtes folgt, den der Autor des Sabbatgebotes Ex 20,8-11 schon von der Einleitung V.8 und von der Fortsetzung in V.11 her im Blick hat. Eine analoge Reduktion belegt deutlich die Neufassung der Bauernregel Dtn 22,9-11 in Lev 19,19.

113 PLÖGER, Deuteronomium, 154f.190-192 spricht von "dt. Zeit" und hält auch ein älteres Stadium für möglich.

114 Vgl. PLÖGER, Deuteronomium, 143f.171-173.

115 Nach ELLIGER, Leviticus, 344 ist die stelle ein zusatz zu $\mathrm{Ph}_{1}$.

116 Vgl. ELLIGER, Leviticus, 350.

117 Vgl. CLARK, Animal Series, 433-449; ThWAT I, 525f; STECK, Schöpfungsbericht, 124 . 


\subsubsection{Der vierte Unterschied: Der überschüssige Finalsatz in Dtn 5,14}

Beim Oberblick über die Forschung zu diesem Punkt gehen wir von jener Gruppe von Exegeten aus, die den Finalsatz als einen weiteren, zunächst einmal autarken Zusatz versteht, dem auf der Seite der Exodusfassung eine Leerstelle entspricht; erst später hat dann dieser einzelne Zusatz die Sabbatbegründung von Dtn 5,15 nach sich gezogen 118 .

Dieser Meinung widerspricht jene Gruppe, die den Finalsatz und die anschliessende Begründung einer einzigen Hand zuschreibt, weil beide eng zusammengehören ${ }^{119}$. Quer durch beide Gruppen geht der Hinweis auf die starke Beziehung des Finalsatzes zu Ex 23,12 ${ }^{120}$. Seit Köhler 121 ist das Mißtrauen gegen Dtn 5,14f als Begründung nicht verschwunden, weil diese Begründung zum Sabbatgebot in Spannung zu stehen scheint und in sich selbst unausgeglichen wirkt, sei es daß eine Begründung des Sabbattages nicht vorliegt, sondern eher der Sabbat der Feier der Erlösung dient ${ }^{122}$, sei es daß der Hinweis auf den Exodus nur das Ruhen des Sklaven motiviert, aber nicht das des Freien oder der Haustiere ${ }^{123}$, oder sei es schließlich daß sogar innerhalb der Begründung ein literarischer Bruch existiert zwischen einem ersten sozial ausgerichteten Zuwachs (Finalsatz mit anschließender Reminiszenz an den Agyptenaufenthalt in 5,14.15a ) und der späteren heilsgeschichtlichen Begründung des gesamten Sabbatgebotes in V.15aßrb. ${ }^{124}$.

118 So CHARLES, Decalogue, Introduction XXXIXf und LV; STAMM, Dekalogforschung, 8. REVENTLOW, Gebot, 57f; ANDREASEN, Sabbath, 83.133f; SCHÜNGELSTRAUMANN, Der Dekalog, 75f; NEGRETTI, Il Settimo Giorno, $130 \mathrm{f}$; KOCH, Formgeschichte, 57; ROBINSON, The Origin, 156.190; MITTMANN, Deuterono-

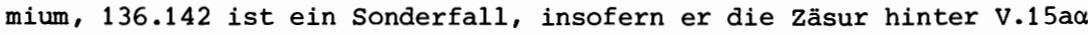
setzt; dazu s.u.!

119 KUENEN, Einleitung § 9 A 2, 160; STEUERNAGEL, Deuteronomium, 22; JENNI, Begründung des Sabbatgebotes, 5.15; NIELSEN, Zehn Gebote,36; HULST, Sabbatgebot, 158; LOHFINK, Dekalogfassung, 22; RICHTER, Recht, 103.143; MATHYS, Sabbatruhe, 251 .

120 STEUERNAGEL, Deuteronomium, 22; MENES, Die vorexilischen Gesetze, 47; JENNI, Begründung des Sabbatgebotes, 16; RICHTER, Recht, 103; TSEVAT, Biblical Sabbath, 449f; SCHÚNGEL-STRAUMANN, Der Dekalog, 75f; NEGRETTI, Il Settimo Giorno, 130f; ROBINSON, The Origin, 190.

121 DERS., Der Dekalog, 171: "Die deuteronomische (Begründung) ist schlecht. Sie erklärt ja nur, warum der Sklave ruhen soll, aber nicht, warum auch der freie Hebräer".

122 So HULST, Sabbatgebot, $155 f$.

123 Mit KÖHLER s.o. A 121 auch JENNI, Begründung des Sabbatgebotes, 18 und TSEVAT, Biblical Sabbath, 45of. 
Wir knüpfen an das an, was wir bisher schon zur Komposition beobachtet und bei der Analyse der vorhergehenden Differenzen gefunden haben. Der Autor des Sabbatgebotes hat für Dtn 5,14 die Vorlage Ex 23,12b aufgegriffen und deren soziale Motivierung mit der langen Liste der Sabbatteilnehmer zur Sprache gebracht. Ohne Zweifel hat er mit der Einleitung der Zweckangabe (Finalpartikel + Verb) Ex 23,12b kopiert. Aus welchem Grund aber hat er noch einmal auf denselben Vers rekurriert? Warum werden aus der Liste die drei Elemente Sklave/Sklavin/angeredeter Freier wiederholt, welche Rolle spielt dabei der Freie, der doch in Ex 23,12b nicht auftaucht?

Die Prohibitive (Ex 22,20; 23,9) und Injunktive (Dtn 10,19; Lev 19,33f) zum גר werden alle auf dieselbe Weise begründet: "denn גרים wart ihr im Lande Agypten". Das Stichwort verklammert beide Sätze und macht dadurch den nervus rerum aus. Ohne es offen auszusprechen, argumentiert die Verklammerung mit der Goldenen Regel, die sie hier an die Agyptenerfahrung der Angeredeten anbindet. Paraphrasiert lautet das etwa: Behandelt den Fremdling so, wie auch inr behandelt werden wolltet, als ihr Fremdlinge in Agypten wart! 125

Dieser Zusammenhänge ist sich auch das Freilassungsgesetz Dtn 15,12-15 bewußt, wenn es mit dem oben erwähnten dreiteiligen paränetischen Schema abschließt und dabei das Stichwort עב עבִד

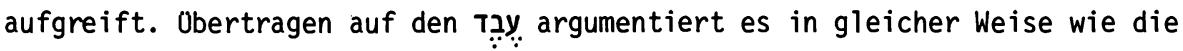
obigen Anweisungen zum $\lambda$; nur wird hier die Argumentation zum Schlußschema ausgebaut und durch den Rekurs auf den Exodus verstärkt, der dem genius loci entsprechend als befreiender Rechtsakt Jahwes (Loskauf) interpretiert wird. Von diesem Ursprung her wird die Argumentation schematisch, aber durchaus sinnentsprechend, auf humanitäre Bestimmungen zugunsten Benachteiligter übertragen wie in Dtn 24,17f.21f; und vgl. 16,11f ${ }^{126}$. Dieser Einblick in

124 MITTMANN, Deuteronomium, 136.142.

125 Vgl. RǗCKER, Die Begründungen, 8-10; zu den Begründungen des Bundesbuches: BEYERLIN, Bundesbuch, 9-29. Der volle Wortlaut der Goldenen Regel taucht singulär für das AT in Tob 4,15 auf. Zu Stellenwert und Traditionsgeschichte vgl. jetzt: DESELAERS, Tobit, bes. A 16 in Teil III, Kap. II.

126 Vgl. MERENDINO, Gesetz, 114.306f; zum Fehlen des 2. Teils vom dreiteiligen Schema in Dtn 24,22 DERS., a.a.0., 308; für Dtn 16,12 schlieBt er (a.a.o., 135f) eine gleichartige Verknüpfung nicht aus; zum ganzen Schema noch SCHOTTROFF, Gedenken, 117-121. 
die Mechanismen der Begründungen ermöglicht, die obigen Ausgangsfragen zu beantworten. Der Autor von Dtn 5,12-15 möchte wie seine Vorlage Ex 23,12 sein Sabbatgebot ebenso sozial motivieren. Er verquickt dazu den Finalsatz der Vorlage mit dem dreiteiligen paränetischen Schema; insofern beginnt die schon in der Liste der Sabbatteilnehmer vorbereitete soziale Motivierung expressis verbis mit dem Finalsatz; das erkennt Ex 20,8-11, wenn es mit seiner neuen Begründung unmittelbar hinter der Aufzählung ansetzt und den Finalsatz nicht übernimmt. Beim Einleiten der sozialen Motivierung weiß der Autor von Dtn 5,12-15 um die Stichwortentsprechung bei den Begründungen einiger humanitärer Gebote und Verbote. Er wiederholt deshalb aus der Liste das fixierte Wortpaar אמה/עבד, das inm das notwendige Stichwort liefert, wiederum in sinngemäßer Obereinstimmung mit Ex 23,12b.

Zugleich will er die Einseitigkeit der sozialen Motivierung von Ex 23,12 verhindern und fügt das im Vergleich mit der Vorlage überschießende כמוך hinzu. Im Sabbatgebot sind Freie und Abhängige gleichgestellt ${ }^{127}$. Damit verschiebt sich die Funktion der sozialen Motivierung. Sie hat jetzt nicht mehr die Aufgabe, den Freien zu menschenwürdigem Verhalten gegenüber den Abhängigen zu bewegen, sondern auch zu menschenwürdigem Verhalten sich selbst gegenüber; d.h. die soziale Motivierung bewegt sich in Richtung auf eine Begründung des Sabbatgebotes überhaupt. Die Schwierigkeiten mit Dtn 5,14f sind nicht wie bei Mittmann literarkritisch aufzulösen ${ }^{128}$; sie ergeben sich aus dem divergenten Material, das hier zu einer neuen eigenständigen Komposition verarbeitet wird. Für den synoptischen Vergleich resultiert aus der Behandlung dieser Differenz, daß sie keine Differenz im Sinne der oben genannten ersten Gruppe von Exegeten darstellt, der dann in der Exodusfassung eine Leerstelle bzw. Fehlanzeige "korrespondiert", sondern daß sie zur Begründung des Sabbatgebotes in Dtn 5 gehört und mit dieser Begründung zusammen derjenigen der Exodusfassung gegenübergestel1t werden muß!

\subsubsection{Der fünfte Unterschied: Die individuellen Sabbatbegrïndungen}

Die Stellungnahmen zur meistdiskutierten Differenz innerhalb des Sabbatgebotes lassen sich grob auf zwei Positionen verteilen: Die erste Position

127 Vgl. JENNI, Begründung des Sabbatgebotes, 17; TSEVAT, Biblical Sabbath, 450 A 7.

128 MITTMANN, Deuteronomium, s.o. A 124, übersieht die innere Konstruktion; er zerreißt das dreiteilige paränetische Schema und dessen natürliche Verklammerung mit dem Finalsatz. 
hält die Sabbatbegründung des Dtn für älter als die von Ex 20,11. Kernpunkt der Argumentation ist die Abhängigkeit des Verses vom Schöpfungsbericht der Priesterschrift; bei vorausgesetzter Nachordnung von $P$ hinter $D$ folgt daraus, daß Ex 20,11 zuletzt dem Dekalog hinzugefügt wurde ${ }^{129}$. Die zweite Position bezweifelt diese Abhängigkeit: entweder kehrt sie das Abhängigkeitsverhältnis um und gibt Ex 20,11 die Priorität vor Dtn 5,14f und dem Schöpfungsbericht von $P{ }^{130}$, oder sie gesteht innerhalb von Ex 20,11 nur partiell Abhängigkeit von $P$ zu und kommt deshalb zu einer literarkritischen Trennung der beiden Vershälften ${ }^{131}$, oder sie ebnet die Priorität der einen vor der anderen Begründung ein und erklärt beide gleichermaßen zu späten Zusätzen 132 .

Der Forschungsüberblick gibt den Hinweis, daß das Problem dieser synoptischen Differenz von Ex 20,11 her entschieden werden muß; zumal die bisherige Behandlung von Dtn 5:14f in keinem Punkt eine Priorität von Ex 20,11 gefordert hat. Im Gegenteil, der Kompositionsvergleich hat eine strukturelle Abhängigkeit von Dtn 5,12-15 nahegelegt. Deshalb bieten wir im folgenden eine knappe, kursorische Analyse von Ex 20,11:

Wie schon beim Kompositionsvergleich erwähnt, hat der Begründungssatz, eingeleitet mit 2 , innerhalb der Sabbaterwähnungen von $\mathrm{P}$ seinen festen $\mathrm{Platz}$. Auch die Wahl des Verbes עשה spricht nicht gegen, sondern für eine Beziehung zum Schöpfungsbericht von $\mathrm{pg}^{g}$, der neben ברא auch für die Schöpfer-

129 Vgl. EWALD, Geschichte, 228f; WELLHAUSEN, Composition, 89; KUENEN, Einleitung, 160; DILLMANN-RYSSEL, Exodus, 219f.237f; STEUERNAGEL, Deuteronomium, 22; MATTHES, Der Dekalog, 31; HEMPEL, Schichten,161; SCHMIDT, Mose, 106f; MENES, Die vorexilischen Gesetze, 47; KÖHLER, Der Dekalog, 171 ; ROWLEY, Moise, lof; STAMM, Dekalogforschung, 7ff; FOHRER, Recht, 132f; NOTH, Exodus, $131 \mathrm{f}$; LOHFINK, Dekalogfassung, 22f ; JEPSEN, Beiträge, 292f; SCHÜNGEL-STRAUMANN, Der Dekalog,78f sieht Parallelen, möchte aber keine direkte literarische Abhängigkeit annehmen; CHILDS, Exodus, $415 f$ möchte zwischen Gen 1,1-2,4a und Ex 20,8-11 nur die Abhängigkeit von einer gemeinsamen Sabbattradition gelten lassen; MITTMANN, Deuteronomium, 144 A 43; JENNI, Begründung des Sabbatgebotes, 2of; HULST, Sabbatgebot, $160-163$.

130 So DELITZSCH, Genesis, 19f; KÖNIG, Deuteronomium, 92; LURJE, Studien, 63; REVENTLOW, Gebot, 57ff; PATRICK, La formation littéraire, 246 hält auf Grund hermeneutischer Prämissen die religiöse Begründung für ursprünglicher als die soziale; NIELSEN, Zehn Gebote, 35ff; RICHTER, Recht, 103 räumt allerdings auf Seite 143 die Möglichkeit der ersten Position ein; MATHYS, Sabbatruhe, 252f; ANDREASEN, Sabbath, 244 A 3.

131 HOLzINGER, Exodus, 74 läßt Abhängigkeit von Gen 2,2f nur für V.11b gelten; V.11a bleibt wegen der Differenzen Gut des älteren jehovistischen Redaktors; NEGRETTI, Il Settimo Giorno, 155-160 kommt zu ăhnlichen Ergebnissen: V.11a vorpriesterlich und V.11b von Gen $2,2 \mathrm{f}$ abhängig.

132 So MOWINCKEL, Décalogue, 75-98; ROBINSON, The Origin, 196-276. 
tätigkeit Jahwes einsetzt ${ }^{133}$. Allerdings scheint sich in der Wahl der objekte von עשה eine Divergenz in der Einteilung der Welt zu offenbaren. Während der Schöpfungsbericht wie auch Ex 31,17b die Zweiteilung in Himmel und Erde bevorzugen, taucht hier die Trias Himmel - Erde - Meer auf. Beide Einteilungen sind traditionel1 ${ }^{134}$. Auch der Schöpfungsbericht kennt die Dreiteilung sowohl in den Benennungen Himmel V.8a, Erde und Meer V.loa wie in den Aufzählungen der Tiere VV.26b.28b ${ }^{135}$. Damit hebt sich diese Divergenz zwischen Sabbatbegründung und Schöpfungsbericht auf.

Weiterhin fällt in Ex 20,11a die Verteilung der Trias auf vier Objekte auf (Himmel - Erde - Meer - alles, was in ihnen ist); darin bricht eine poetische Einteilung in zwei parallele Stichen durch, wie sie einige nachexilische Psalmen pflegen (Pss 69,35; 96,11; die nahen Verwandten Pss135,6; $146,6)$ neben der hymnischen Kette von Neh 9,6. Der Schöpfungsbericht bot Ex 20,11a sowohl eine Zwei- wie eine Dreiteilung an. Ex 20,11a hat die Dreiteilung gewählt. Sie ergab sich durch Vermittlung der Tierreihen Gen 1,26b. 28b, die der Autor von Ex 20,8-11 ja schon bei seiner Liste der Sabbatteilnehmer berücksichtigt hatte ${ }^{136}$. Schließlich legte ebenso die Dreiteilung von Ex 20,4// Dtn 5,8 diese Wahl nahe. Die poetische Einkleidung im Stile nachexilischer Parallelen unterstreicht den späten Standort des Autors.

Der Satz Ex 20,11aß ist mit Gen 2,2ba identisch bis auf das Verb, hier נוח dort שבת. Liegt ein trennender Unterschied vor 137 oder hat der Autor des Sabbatgebotes Ex 20,8-11 unter Bezug auf Gen 2,2f den Unterschied bewußt in Kauf genommen ${ }^{138}$ ? Wir entscheiden uns für die zweite Möglichkeit. Der verwandte "priesterschriftlich orientierte Zusatz" Ex $31,17 \mathrm{~b}$ setzt wie Ex 20,11

133 Vgl. STECK, Schöpfungsbericht, 63 A 224 (Lit.!); zur Auseinandersetzung mit SCHMIDT, Schöpfungsgeschichte, um Wort- und Tatbericht STECK, 26 A 85 und 198 A 836; zur Wurzel ברא jetzt: ANGERSTORFER, Der Schöpfergott, $201 \mathrm{f}$.

134 Vgl. NEGRETTI, Il Settimo Giorno, 156 A 19 und STECK, Schöpfungsbericht, 182 A 771 (Lit.!).

135 Vgl. CLARK, Animal Series, 437-444 und STECK, Schöpfungsbericht, 151 A 615.182 A 771.189 A 799.

136 S.o. den dritten Unterschied!

137 So die Exegeten der obigen zweiten Position und SCHMIDT, Schöpfungsgeschichte, $71 \mathrm{f}$.

138 So HULST, Sabbatgebot, $162 f$ und STECK, Schöpfungsbericht, 189 A 799. 
Gen 1,1-2,4a voraus, wählt שבח als Verb des Ruhens und ergänzt es mit dem seltenen נפש/N-Stamm (Jahwe als Subjekt).

Solches Vorgehen signalisiert konservative Haltung gegenüber dem Schöpfungsbericht und zugleich Wissen um die Vorgeschichte des Sabbatgebotes, ohne das die Obernahme von נפש/N-Stamm aus Ex 23,12 nicht erklärt werden kann. Die gleiche Haltung ist hinter Ex 20,11aß zu vermuten. Der Autor des Sabbatgebotes Ex 20,8-11 übernimmt נוח als Verb, weil er sich auch seinen weiteren Vorlagen Ex 23,12b und Dtn 5,14 verpflichtet weiß!

Die singuläre Verknüpfung von Segnen und Heiligen Jahwes ist in Gen 2,3 aus der Gesamtkonzeption des Schöpfungsberichtes von $\mathrm{pg}$ konstruiert worden; Ex $20,11 b$ hat sie übernommen ${ }^{139}$. Das unterschiedliche objekt der Verben, in Gen 2,3 der "siebte Tag", in Ex 20,11b der "Sabbattag" ergibt sich aus dem Kontext: Der Schöpfungsbericht muß das Wochenschema betonen 140 , während Ex 20,11b kompositionsgerecht die Einleitung des Sabbatgebotes zitiert.

Eine weitere Beobachtung und deren Auswertung flankieren die bisherige Argumentation. Ex 20,11 wechselt zweimal zwischen ausdrücklicher und impliziter Nennung des Subjektes "Jahwe" ebenso wie Gen 2,2f. Dieser syntaktische Befund, bei $P$ häufiger anzutreffen 141 , ist auch an den beiden Stellen des Schöpfungsberichtes modal aufzulösen ${ }^{142}$. Für Ex 20,11 funktioniert eine modale Auflösung nur beim zweiten Male in V.11b; in V.11a muß es bei der einfachen syndetischen Parataxe bleiben. Das spricht a fortiori dafür, daß Ex 20,11 den Stil von Gen 2,2f nur kopiert bzw. unter Stilzwang dieser Vorlage steht.

Im übrigen ordnet sich die Absicht von Ex 20,11. ein menschliches Verhalten durch eine vorbildhafte Aktion Jahwes zu begründen, bruchlos in die Argumentation mit der imitatio dei ein, wie wir sie vornehmlich im priesterlichen Schrifttum finden 143 . Es besteht also kein Grund, die Position der ersten Gruppe von Exegeten für diese Differenz zu verlassen. Ex 20,11 ist von sei-

139 Vgl. STECK, Schöpfungsbericht, 189 A 799 und 193ff; als späteres Echo Sir 33,7-9.

$140 \mathrm{Vgl}$. STECK, Schöpfungsbericht, $196 \mathrm{f}$.

141 BEYER, Althebräische Syntax, 90 A 70.

142 STECK, Schöpfungsbericht, 186 A $787 f$ und 194.

143 Vgl. ROBINSON, The Origin, 369-371 und folgende Stellen: Ex $31,17 \mathrm{~b} ;$ Lev 11,$44 ; 19,2 ; 20,7.26$; Num 9,15-23. 
nen Vorlagen Ex 23,12, Dtn 5,12-15 und Gen 1,1-2,4a abhängig und damit diesen zeitlich nachzuordnen.

In Stil und Aussage teilt es den Standort nachexilischer,priesterlicher Redaktoren!

\subsubsection{Der sechste Unterschied: Der doppelte Rückverweis in der Deutero- nomizmfassung des Sabbatgebotes}

Bei dieser letzten und vielleicht auch schwierigsten synoptischen Differenz im Sabbatgebot haben die Exegeten keine entgegengesetzten Positionen entwickelt. Wenn sie von der Differenz überhaupt Notiz nahmen, haben sie diese mit unterschiedlicher Intensität behandelt. Weil dem doppelten Rückverweis von Dtn 5,12-15 in Ex 20,8-11 nichts entspricht, war man leicht versucht, diese Differenz schnell beiseite zu schieben. Dementsprechend notiert eine erste Gruppe von Exegeten den Rückverweis nur als typischen formelhaften Zusatz, wie es dem Sprachgebrauch des Dtn entspricht ${ }^{144}$. Die nächste Gruppe interpretiert die Formel meist im übertragenen Sinne; sie dient nun der paränetischen Verstärkung bzw. der Einschärfung des Gesetzes ${ }^{145}$. Andere nehmen die Formel immerhin beim Wort und deuten sie als Hinweis auf den Exodusdekalog; allerdings bleibt ungeklärt, warum die Formel gerade und nur beim Sabbat- und Elterngebot auftaucht ${ }^{146}$. Einen Erkenntnisfortschritt bringt die neuere Deuteronomiumforschung. Sie versteht die Formel wörtlich als perfektischen Promulgationssatz, der im Dtn die Aufgabe übernimmt, auf die schon ergangene Gesetzespromulgation am Horeb zurückzuweisen 147 .

144 Vgl. DILLMANN-RYSSEL, Exodus, 219; CHARLES, Decalogue, Introduction XL; ROWLEY, Moise, 11; RICHTER, Recht, 103; PHILLIPS, Criminal Law, 69; HULST, Sabbatgebot, 154; ANDREASEN, Sabbath, 83f.132.

145 Vgl. OETTLI, Deuteronomium, 40; KÖNIG, Dekalog, 378; STEUERNAGEL, Deuteronomium, 22; STAMM, Dekalogforschung, 8; REVENTLOW, Gebot, 56; NIELSEN, Zehn Gebote, 35f; NEGRETTI, Il Settimo Giorno, 131 ; SCHÜNGEL-STRAUMANN, Der Dekalog, 7o und 76; KOCH, Formgeschichte, 57; ROBINSON, The Origin, 190; MITTMANN, Deuteronomium, $134 \mathrm{f}$.

146 So KÖNIG, Deuteronomium, 89; JAKOB, Exodus, 889; MILGROM, Profane Slaughter, 4f; DERS., A formulaic key, 42-47.123f.

147 MORAN, Background of The Love of God, 86; LoHFINK, Hauptgebot, 6of; DERS., Dekalogfassung, 29f; BRAULIK, Ausdrücke für "Gesetz", $41 \mathrm{f} \mathrm{mit}$ der differenziertesten Sichtung aller Stellen. 
Von nun an ist der Rückverweis nicht mehr nur ein synoptisches Problem, sondern ein internes Problem der Dekalogfassung von Dtn 5 selbst. Nach Ausweis des dortigen Kontextes ergeht der Dekalog als "erstmalige und grundlegende Gesetzesverkündigung aus dem Munde Jahwes" 148 . Dem widerspricht der Rückverweis auf eine dem Dekalog vorausgehende Gesetzesverkündigung ${ }^{149}$. Lohfink hat als einziger den Widerspruch aufzulösen versucht ${ }^{150}$. Nach ihm erklärt sich der Rückverweis aus den spezifischen Produktionsbedingungen des "Sabbatdekalogs"; der Rückverweis zeigt das Selbstverständnis dieses Dekalogs als Sekundärform an, die einen ursprünglichen Dekalog mit einem anderen Hauptgebot an derselben Stelle verdrängt hat. Demnach sichert der Rückverweis die Kontinuität zwischen der ursprünglichen, älteren Dekalogform und dem neuen Stellvertreter. Der Rückverweis wurde beim Sabbat- und Elterngebot angebracht, weil hier "echte Eingriffe - in den älteren Bestand vorgenommen wurden".

Lohfink scheint den Rückverweis diachron auf der Achse der sich an ein und derselben Stelle ablösenden Dekalogformen zu interpretieren. Das steht aber im Gegensatz zur Funktion des Rückverweises im Dtn, der sich immer auch synchron auf der Ebene des vorliegenden Kontextes auf eine Vorschrift an anderer (meist vorausgehender) Stelle bezieht, entweder auf eine Vorschrift innerhalb oder ein Gesetz außerhalb des Dtn ${ }^{151}$. Lohfink extrapoliert den Rückverweis von seinem punktuellen Einsatzort (Sabbat-, Elterngebot) auf die Gesamtheit des Dekalogs. Das geschieht unter den Bedingungen eines zentrierten "Sabbatdekalogs" und der oben angegebenen maximalen Eingriffe in Sabbatund Elterngebot. Selbst wenn wir Lohfinks Voraussetzung von einem sekundären Deuteronomiumdekalog teilen, gibt es neben den Eingriffen in Sabbat- und Elterngebot noch andere Eingriffe wie z.B. im Begehrensverbot, die ebenso massiv sind und keinen Rückverweis haben - überhaupt scheint eine Gewichtung der

148 LOHFINK, Dekalogfassung, 29.

149 MITTMANN, Deuteronomium, $134 \mathrm{f}$ nimmt an, daß die Rede von Jahwe in dritter Person in Dtn 5,11-16 Jahwes Urheberschaft bei den Geboten verdunkelte und den Rekurs auf sein Befehlen veranlaßte; das mag sein, erklärt aber nicht, wie es überhaupt zum Bruch in der Ichrede kam. Wir werden später diese wichtige Frage aufgreifen, weil sie jetzt nicht unmittelbar den synoptischen Vergleich tangiert!

150 DERS., Dekalogfassung, 29f, insbesondere A 43.

151 LOHFINK, Hauptgebot, 6of. Dieses Faktum hat jetzt SKWERES, Rückverweise, nachgewiesen. Er spricht von literarischen Rückverweisen, d.h. Rückverweisen auf Texte; DERS., a.a.0., 24.77f.197. Die Bezugstexte sind innerhalb wie außerhalb des Dtn zu finden. Im Fall der Dekalogrückverweise geht er davon aus, daß die betreffenden Dekaloggebote im Exodusdekalog älter sind und die Rückverweise des Deuteronomiumdeka- 
Unterschiede schwierig, bevor nicht alle Differenzen erfaßt sind, wobei selbst anscheinend kleinere Unterschiede große Bedeutung haben können wie etwa das waw im Bilderverbot.

Wir mustern noch einmal die zuständigen Parallelen durch; es kommen nur jene Rückverweise in Frage, an denen Mose der Sprecher ${ }^{152}$, Jahwe das Subjekt von צוD-Stamm und das Volk der angeredete Adressat ist. Von den neun parallelen Rückverweisen sind fünf von einem Ausdruck für "Gesetz" abhängig und beziehen sich dadurch ziemlich eindeutig auf den Dekalog von Dtn $5{ }^{153}$; zweien fehlt das Bezugswort, aber der Kontext legt sie ebenso auf den Dekalog fest ${ }^{154}$; einmal umfaßt der Rückverweis das ganze deuteronomische Gesetz unter Einschluß des Dekalogs ${ }^{155}$. Die verbleibende Parallele Dtn 20,17 steht den Rückverweisen im Dekalog besonders nahe. Neben der wörtlichen Obereinstimmung fehlt hier wie dort ein Bezugswort, das den Rückverweis festlegt. Die Bezugsgröße ist vielmehr eine unmittelbar vorausgehende Einzelvorschrift, im Falle von Dtn 20,17 ein Jahwegebot zur Vernichtung aller Völker der Völkerliste in demselben Vers. Zuerst geht der Rückverweis von Dtn 20,17 auf Dtn 7,1f, wo aber Mose spricht und nicht Jahwe, was der Rückverweis eigentlich fordert. Demnach dient Dtn 7,1f nur als Brückenstelle, die zu den Jahweverheißungen von Ex $34,11 \mathrm{~b} .12 .15$ (vgl. Ex 23,31b.32) vermittelt und diese mit dem Verb als Jahwegebot interpretiert ${ }^{156}$.

logs sich deshalb auf ihre älteren vorgänger beziehen. Da aber in Dtn 5 der Dekalog Jahwerede ist, können die Rückverweise im Text eines dtn Autors noch nicht gestanden haben. Sie gehören zur Nachgeschichte des Dtn-Dekalogs, indem "spätere varianten des Dekalogs in das Buch eindrangen". Aus diesem Grunde schließt er Dtn 5,12.16 aus der Analyse dtn Rückverweistechnik aus. - Er lehnt sich an LOHFINKs Vorschlag an und verschiebt das Problem an die Nachfahren. Warum sollte für sie der Dekalog seine Qualität als Jahwerede verloren haben? Warum wurden die Rückverweise gerade am Eltern- und Sabbatgebot angebracht? Mit SKWERES gegen ihn selbst ist es sachgerechter, die dekalogischen Rückverweise genau so $\mathrm{zu}$ behandeln wie alle anderen, als literarische Bezüge auf andere Texte. Wenn der Exodusdekalog nicht in Frage kommen kann, müssen andere Texte gesucht werden (vgl. SKWERES, Rückverweise, 182-184).

152 So fordern es für die Dekalogstellen Dtn 5,12.15.16 der nähere (Dtn 5) und der weitere Kontext, d.h. das ganze Dtn; die Stellen, an denen ein Erzähler (Dtn 1,3; 34,9) oder die Väter (Dtn 6,24f) oder der Sohn (6, 2o) oder das Volk (Dtn 1,$41 ; 26,13 f$ ) sprechen, scheiden aus dem vergleich aus.

153 So $\operatorname{Dtn} 4,13 ; 5,33 ; 6,17 ; 9,16 ; 13,6$.

154 Dtn 4,$23 ; 5,32$.

155 Dtn 28,45; vgl. LOHFINK, Hauptgebot, 61.

156 Vgl. LOHFINK, Hauptgebot, 61 und mit größerer Entschiedenheit DERS., Art. םาח, ThWAT III, 192-213.209; SKWERES, Rückverweise, 43-47 erwägt dieselbe Erklärung. 
Ein solcher Rückverweis auf Gesetze außerhalb des Dtn ist noch in 24,8 belegt, wo Mose Subjekt des Befehlens ist ${ }^{156 a}$. Aus dem Vergleich ergibt sich der Schluß:Die Rückverweise im Dekalog beziehen sich jeweils auf entsprechende einzelne Jahwegebote außerhalb des Dtn. Für das Sabbatgebot Dtn 5,1215 liegt der Bezugspunkt auf der Hand: die Arbeitsverbote in Ex 34,21a und vor allem in Ex 23,12. Die letztere Stelle hat Dtn 5,12-15 ja als Vorlage benutzt und kommentiert. Insofern kommt in den Rückverweisen des Deuteronomiumdekalogs das Selbstverständnis zu Wort, Sekundärfassung zu sein, aber nicht des ganzen Dekalogs, sondern nur des Einzelgebots!

Mit obiger Interpretation der Rückverweise können wir nun auch erklären, warum die Rückverweise in den entsprechenden Einzelgeboten von Ex 20 fehlen bzw. dorthin nicht übernommen wurden. Die Position von Ex 20 im Pentateuch macht die Rückverweise überflüssig, weil die betreffenden Einzelgebote dieser Dekalogfassung den dazugehörigen Bezugspunkten im Bundesbuch oder im "Privilegrecht Jahwes" von Ex 34 vorausgehen. Die Dekalogfassung von Dtn 5 mußte wegen ihrer Position im Pentateuch auf den vorhergehenden Kontext Rücksicht nehmen, während Ex 20 sich diese Rücksicht sparen konnte. Die Sabbatpassagen von Ex 16 stehen in keiner Konkurrenz zu Ex 20 dergestalt, daß Ex 20 auf bestimmte "Vorläufer" in Ex 16 rekurrieren müßte 157 .

Die letzte Differenz im Sabbatgebot macht deutlich, wie der synoptische Vergleich mit Fragen der Beziehungen der Dekaloge zu ihrem Kontext verknüpft ist. Der Exodusdekalog zeigt sich auf diesem Problemfeld weniger "belastet", was für die bisherige Exegese Signum seines relativ höheren Alters war. Wir meinen bei näherem Zusehen, gerade darin die Merkmale eines Spätprodukts erkennen zu können!

$156 \mathrm{a}$ Zu allen außerdtn Rückverweisen auch mit anderen verben jetzt: SKWERES, Rückverweise, 86-197.

157 Unabhängig von aller literarkritischen Schichtung des Kapitels bieten die in Frage kommenden verse Ex 16,23.25f.29 Kommentare und Anordnungen des Mose anläßlich der doppelten Mannaration am sechsten Tage, enthalten also keine Promulgation von Jahwegeboten, auf die dann der Dekalog von Ex 20 sich zu beziehen hätte. Während das Sabbatgebot der Dekaloge das zweiteilige Arbeitsverbot ausdrücklich erwähnt, wird in Ex 16,26.29b.3o nur darauf angespielt. Zur Literarkritik vgl. RUPRECHT , Mannawunder; ROBINSON, The origin, 270-276; ZENGER, Exodus, $163 \mathrm{ff}$ und die Literaturübersicht mit Tabellen zur Schichtung bei FUHS, Qadeš-Materialien. 


\subsubsection{Ergebnis}

Der synoptische Vergleich der Sabbatgebote füht zu folgendem Ergebnis: Beide Sabbatgebote sind komplexe, in sich geschlossene Kompositionen von jeweils einer Hand. Jede interpretiert und verarbeitet auf ihre Weise die aus der Tradition bekannten zweiteiligen Arbeitsverbote von Ex 23,12 und 34,21. Jede identifiziert den "siebten Tag" mit dem "Sabbat" und fusioniert diese zwei bisher getrennten Institutionen. In der relativen Chronologie hat Dtn 5,12-15 die Priorität vor Ex 20,8-11!

\subsection{Der synoptische Vergleich beim. Elterngebot}

\subsubsection{Forschungsüberblick}

Neben dem Sabbatgebot hat das Elterngebot wegen seines Inhalts, seiner form und seiner synoptischen Unterschiede viel Aufmerksamkeit gefunden. Allerdings hat das Gebiet des synoptischen Vergleichs den Exegeten nicht viel Kopfzerbrechen bereitet. Mit ungebrochener Kontinuität seit Beginn einer intensiveren wissenschaftlichen Beschäftigung mit dem Dekalog hat beim Elterngebot die kürzere Exodusfassung Vorrang vor der späteren und erweiternden Deuteronomiumfassung. Viele Exegeten nehmen darum von den synoptischen Unterschieden nur schwach Notiz und sprechen global von späteren Zusätzen im Deuteronomium ${ }^{158}$. Einige geben präzisere Stellungnahmen zu den einzelnen Unterschieden $a b$, wahren dabei aber immer die Priorität der Exodusfassung ${ }^{159}$. Eine größere Gruppe von Exegeten konzentriert sich auf den einleitenden Gebotssatz und behandelt die Motivierung demgegenuiber zweitrangig ${ }^{160}$. Seit H. Schmidt ${ }^{161}$ das Elterngebot als unpassend in Form, Inhalt und Adressaten aus dem Urdekalog gestrichen und die Debatte um die drei Punkte eröffnet hat,

158 So MEIER, Die ursprüngliche Form, 50-54; EWALD, Geschichte, 2. Bd. 229 A 2; DILLMANN-RYSSEL, Exodus, 239; STEUERNAGEL, Deuteronomium, 22; ROWLEY, Moise, 11; RICHTER, Recht, 104f; JEPSEN, Beiträge, 282; SCHULZ, Todesrecht, 53; KOCH, Formgeschichte, 57; CHILDS, Exodus, 388; ALBERTZ, Elterngebot, $351 \mathrm{f}$.

159 KÖNIG, Dekalog, 378; CHARLES, Decalogue, XXIVf und XXXV; STAMM, Dekalogforschung, DLF 8; REVENTLOW, Gebot, 24.68; GAMBERONI, Elterngebot, 162f; NIELSEN, Zehn Gebote, 38; LOHFINK, Dekalogfassung, 3of; SCHÜNGEL-STRAUMANN, Der Dekalog, 26.67-72; MITTMANN, Deuteronomium, $134 \mathrm{ff}$.

$160 \mathrm{Vgl}$. HOLZINGER, Exodus, 74f; NOTH, Exodus, 133; FOHRER, Recht, 131; ALBERTZ, Elterngebot, 353 .

161 SCHMIDT, Mose, $81 \mathrm{ff.105f.}$ 
wird der einleitende Gebotssatz zum Zentrum der Analyse; der motivierende Finalsatz tritt völlig in den Hintergrund, auf ihn wird keine Rücksicht genommen 162 .

Demgegenüber bleibt die Zahl der Exegeten klein, die das Elterngebot vom Finalsatz bzw. der Motivierung her interpretieren. Für Delitzsch und in seiner Nachfolge Meisner ist der Finalsatz Signum für die"jehovistisch-deuteronomische Beschaffenheit des Dekalogs" bzw. für den Autor des Dekalogs, nämlich D ${ }^{163}$. Kremers 164 hält die Motivierung, bei inm auch "Verheißung" genannt, zwar für keinen integrierenden Bestandteil des Gebotes, aber für ein altes Traditionsgut mit "Sitz im Leben" im Bundeserneuerungsfest in Sichem. Dort ist sie mit dem Dekalog von Ex 20 verwachsen und dann in alle Schichten des Dtn eingedrungen, wo sie weiter ausgebaut wurde. In ihrem jeweiligen Kontext übernimmt sie die Aufgabe, Gebotsreihen abzuschließen. Ergo gehört sie im Dekalog nicht nur zum Elterngebot, sondern zeigt das Ende der ersten Tafel an. Damit stehen die Eltern im Dekalog auf seiten Gottes, nicht auf seiten der Menschen. Als Stellvertreter Gottes sollen sie im Rahmen der Familie und Sippe wie Prediger, Lehrer und Priester amtieren ${ }^{165}$. Nachdem Dürr 166 für die "Segensverheißung" des Elterngebotes die Frage aufgeworfen hatte, ob sie an das Volk als Ganzes oder an den Einzelnen gerichtet sei, und sich für die erste Alternative entschieden hatte, wirkte seine Fragestellung nach und führte dazu, die Motivierung selbst aufzuspalten in Teilstücke, die ursprünglich zum Gebot dazugehören, und solche, die später

162 So bei: SELLIN, Geschichte I, 84; JIRKU, Das weltliche Recht, 154; KÖHLER, Der Dekalog, $181 \mathrm{f}$; ALT, Ursprünge, KS I, 318.320; RABAST, Das apodiktische Recht, 37f; SCHMÖKEL, Gebote, 376; KESZLER,Problematik des Dekalogs, 1of; PATRICK, La formation littéraire, 243f; GERSTENBERGER, Wesen, 46.78.88; GESE, Der Dekalog als Ganzheit, 67.76; SCHMIDT, Überlieferungsgeschichtliche Erwägungen, 209f; H.P. MUULLER, Zur Verkündigung der Zehn Gebote, $525 \mathrm{f}$.

163 DELITZSCH, Genesis, 19; MEISNER, Der Dekalog, 4-8.

164 KREMERS, Stellung des Elterngebotes.

165 Bei aller differenzierten Analyse der VerheiBung hat die Untersuchung von KREMERS zwei Schwachstellen: Von den Variationen in der Formulierung der Verheißung im Dtn wagt er den formkritischen Rückschluß auf "eine alte liturgische Verheißung". Geprägte Wendungen werden behandelt wie Formeln mit einem gemeinsamen "Sitz im Leben". Zweitens wird die Funktion der Verheißung ungenau geschildert: Sie kann Gebotsreihen abschließen, muß es aber nicht! Dazu s.u.!

166 DƯRR, Wertung des Lebens, bes. 21-30. 
dazugewachsen sind wie der Bezug auf das verheißene Land ${ }^{167}$. Bei Gamberoni wird die als relativ alt eingeschätzte Verbindung von Gebot und Motivierung aufgegeben. Beide Teile verselbständigen sich. Ihre spätere Verknüpfung wird zu einer Angelegenheit deuteronomischer Redaktionen ${ }^{168}$. Die Motivierung wird mittlerweile in ihrer Autonomie anerkannt. Als ihre Heimat hat sich das Dtn herausgeschält, so daß sich weitere Untersuchungen wie die von Lohfink und Albertz mit ihr allein beschäftigen können, ohne daß dabei dem Elterngebot im Dekalog ein besonderes Gewicht zukommt ${ }^{169}$.

Der grobe Oberblick über die bisherige Forschung zum Elterngebot zeigt die neuralgischen Punkte. Nach wie vor ungeklärt ist das Verhältnis von Gebot und Motivierung bzw. Segenshinweis. Liegt hier eine redaktionelle Verknüpfung ehemals selbständiger Teile vor oder sind beide gleichzeitig miteinander entstanden bzw. komponiert worden? Obwohl sich - gerade bei der letzten Gruppe von Exegeten - die Erkenntnis herausbildete, daß der Segenshinweis seinen Schwerpunkt im Deuteronomium hat und daß auch die Form von Ex 20,12 nur über die Vermittlung des Dtn entstanden sein kann 170, hat diese Erkenntnis in der jüngeren Dekaloginterpretation nicht zur Anfrage an das traditionelle Gefälle geführt, die Exodusfassung sei älter als die Deuteronomiumfassung.

Wir konzentrieren uns im folgenden zuerst auf den synoptischen Unterschied im Segenshinweis, behandeln dann das Problem des Rückverweises und erörtern

166 DURR, Wertung des Lebens, bes. 21-3o.

167 So verfahren MENES, Die vorexilischen Gesetze, 47; RICHTER, Recht, 104; BERGER, Gesetzesauslegung, $278 f$.

168 GAMBERONI, Elterngebot, 165-169.

169 LOHFINK, Hauptgebot, 52f.83f;er führt für die Motivierung im AnschluB an Vorschriften den terminus technicus "Segenshinweis" ein (81); ALBERTZ, Persönliche Frömmigkeit, 165-178.

170 So wird häufiger die auffällige Singularität des Segenshinweises von Ex 20,12 im Rahmen des Tetrateuch festgestellt; doch diese Beobachtung bleibt ohne Folgen; vgl. DURR, Wertung des Lebens, 23; KREMERS, Stellung des Elterngebotes, 148; GAMBERONI, Elterngebot, 163; BERGER, Gesetzesauslegung, 278 und schließlich RUCKER, Die Begründungen, $105 f$. 
zum Schluß die Konsequenzen aus dem synoptischen Vergleich für eine Interpretation des Elterngebotes.

\subsubsection{Die Differenz im Segenshiraveis:}

\subsubsection{Die bisherigen Argumente}

Keine besondere Aufmerksamkeit erfährt diese Differenz von jenen Exegeten, die den Finalsatz über das "Wohlergehen" als schlichte Erweiterung oder gar als kommentierende Glosse im Laufe der Dekalogüberlieferung deuten ${ }^{171}$. Mehr Gewicht erhält die Erweiterung bei denen, die darin eine konsequente, predigtartige Ausmalung oder gezielte Präzisierung des Motivs vom "langen Leben" durch das Dtn sehen ${ }^{172}$. Der Stellenwert der sogenannten Erweiterung wird gesteigert bei Lohfink ${ }^{173}$. Ausgehend von der engen Verknüpfung der "Zusage langen Lebens" mit dem Begriff der אדמה in der älteren Exodusfassung interpretiert er das Dazwischentreten der Erweiterung als bewußte Trennung der ursprünglichen Verknüpfung und nimmt darin ein Zeichen für die Exilssituation seines Sabbatdekalogs wahr, wo man sich nur noch Wohlergehen in Verbindung mit der אדמה vorstellen konnte, aber ohne eine zeitliche Aussage. Schüngel-Straumann hat Lohfinks Erklärung übernommen ${ }^{174}$. Mittmann 175 schließlich nennt drei Gründe für den sekundären Charakter der zweiten Zweckbestimmung: das Fehlen in Ex 20,12; die stilistisch schwerfällige Wiederholung der Konjunktion למען; die Zugehörigkeit zu seiner singularischen Redaktionsschicht, die von der den Dekalog zitierenden Grundschicht von Dtn 5 abgehoben werden muß.

\subsubsection{Diskussion der vorgebrachten Argumente}

Die kürzere Exodusfassung kann in diesem Zusammenhang nicht ohne die Gefahr einer petitio principii ins Feld geführt werden, denn zuerst muß das Abhängigkeitsverhältnis der beiden Fassungen geklärt werden, bevor mit einer Fassung argumentiert wird.

$171 \mathrm{Vgl}$. oben A 159.

172 So z.B. bei: REVENTLOW, Gebot, 24.67f; GAMBERONI, Elterngebot, 163; BERGER, Gesetzesauslegung, 279.

173 LOHFINK, Dekalogfassung, 3of.

174 SCHÜNGEL-STRAUMANN, Der Dekalog, $71 \mathrm{f}$.

175 MITTMANN, Deuteronomium, 136. 
Lohfink interpretiert das syntaktische Faktum, daß der Satz über das Wohlergehen dazwischentritt, semantisch; damit legt er zugleich die inhaltliche Bedeutung dieses Satzes fest. Denn seiner trennenden Funktion kann der Satz über das Wohlergehen nur nachkommen, wenn er sich gegenüber dem Vorgänger über das "lange Leben" inhaltlich mindestens neutral verhält. Dem widerspricht die Meinung der Exegeten, die in der Aussage über das Wohlergehen eine Entfaltung derjenigen über das "lange Leben" sehen. Auf semantischer Ebene ist ihnen zuzustimmen ${ }^{176}$. Langes Leben und Wohlergehen bzw. Glück und Gesundheit stellen grundlegende, allgemeinguiltige Wünsche des Menschen dar, die der Sache nach zusammgenhören 177.

Von Mittmanns Gründen bleiben nach obiger Bemerkung noch zwei übrig. Seine Zuweisung der zweiten Zweckbestimmung allein zu Passagen mit singularischer Anrede (d.h. zu seiner fünften Schicht) extrapoliert ungeprüft das an überwiegend erzählenden Texten gewonnene redaktionskritische Schichtenmodell auf paränetische und gesetzgeberische Partien des Dtn. Ebenso hat Braulik von der Methode her grundsätzlich das Vorgehen und die Ergebnisse Mittmanns für Dtn 4 in Frage gestel1t ${ }^{178}$. Da der Numeruswechsel, so wie Mittmann ihn für das Dtn konsequent als wichtiges literarisches Kriterium einsetzt, nicht angewendet werden kann, scheidet dieses Argument aus. Somit kann sich der sekundäre Charakter der zweiten Zweckbestimmung nur noch auf die "stilistisch schwerfällige Wiederholung der Konjunktion למע"stützen. Zu Recht wirft Braulik den stilistischen Werturteilen Mittmanns subjektiv-äs thetisches Empfinden vor, das gerade den Finalsatzperioden des Dtn nicht gerecht wird. In unserem Falle der Wiederholung von למעו verrät sich Mittmann durch inkonsequenten Gebrauch seiner Stilkriterien ${ }^{180}$. Im übrigen belegen lite-

176 Vgl. die Kritik PLÖGERs an LOHFINK in: PLÖGER, Deuteronomium, 95.

177 Vgl. STOEBE, Art. טוב, THAT I, 654 und ALBERTZ, Persönliche Frömmigkeit, $171 \mathrm{f}$. Den Zusammenhang bezeugen im AT: Gen 12,13, wo im verdeut-

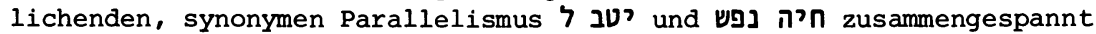
werden - vgl. WEIMAR, Redaktionsgeschichte des Pentateuch, 8, der die Stelle dem Jehowisten zuweist; Jer 38,20; ebenso Dtn 4,40; 5,16 (33); 6,$24 ; 22,7$; das zusammengehen von Lebenslänge und Lebensqualität in nicht formelhaften Ausdrücken belegen: Spr 3,2.16 und 1 Kön 3,11 (dtr).

178 BRAULIK, Literarkritik, 353-355.379.381ff.

179 DERS., Literarkritik, 382.

180 In Dtn 4,40 wird ein finales אשר durch ein zweites ולמען weitergeführt, ohne daß MITTMANN literarkritisch aufspaltet; DERS., Deuteronomium, 124; in Dtn $6,2 \mathrm{~b}$, beim zweiten Zwecksatz,spielt das Stilkriterium für die $\mathrm{Ab}-$ trennung des Halbverses keine Rolle, a.a.0., 140. 
rarkritisch einheitliche Stellen, daß die Reihung der Finalkonjunktion gerade bei späten Passagen des deuteronomisch-deuteronomistischen Schrifttums möglich ist, zumal gerade dann, wenn ein Subjektwechsel vom ersten zum zweiten Finalsatz die Wiederholung nahelegt ${ }^{181}$.

Nach dieser knappen Auseinandersetzung stehen wir wieder bei dem traditionellen und konstanten Argument: Der längere Text der Deuteronomiumfassung ist durch Erweiterung des kürzeren und zugleich älteren Textes der Exodusfassung entstanden. Wie verträgt sich aber das angenommene höhere Alter des Segenshinweises in Ex 20,12 mit der oben schon angesprochenen Beheimatung des Segenshinweises im Dtn? Um diese Frage zu klären, setzen wir beim Segenshinweis von Ex 20,12 an und fragen nach seinem Verhältnis zum Dtn!

\subsubsection{Ex 20,12b und seine Parallelen im Dtn}

Ex 20,12b kombiniert die Formel vom "Langmachen der Tage" (ארך/H-Stamm + ימים) mit der adverbialen Ortsbestimmung "auf dem Lande/Erdboden" ergänzt durch einen Relativsatz (hier die Landgabeformel in partizipialer Fassung). Dür 182 hat die Frage angerissen, wie denn die relative Bedeutung eines primär auf das Private ausgerichteten Einzelgebotes mit der politischen Existenz des Volkes im Gelobten Land zu verbinden sei. Menes ${ }^{183}$ hat die Fragestellung so entschieden, daß das Gebot und die individuell gemeinte Verheissung vom "Langmachen der Tage" ursprünglich vorgegeben waren und später durch den deuteronomischen Zusatz (Ortsbestimmung mit Landgabeformel im Relativsatz) zu einer nationalen Verheißung umgestempelt wurden. Richter ist inm darin gefolgt und hat zur Stuitzung noch auf die Eigenständigkeit der Formel vom "Langmachen der Tage" verwiesen 184 . Lohfink hat das Material für diese Formel auf das gesamte AT und altorientalische Parallelen ausgeweitet. Er vermutet die Heimat der Formel vor allem im weisheitlichen Bereich, aus dem sie die deuteronomischen Prediger übernommen haben ${ }^{185}$. A1bertz interpretiert den Vorgang religionssoziologisch: Die dtn Prediger haben unpolitische Segenszusagen der persönlichen Frömmigkeit aufgegriffen

181 Vgl. Ex 9,$16 ; 10,1 \mathrm{f} ; \operatorname{Dtn} 4,40 ;(6,2) ; 8,16 ; 11,8 \mathrm{f}$.

$182 \mathrm{Vgl}$. oben A 166 und DÜRR, Wertung des Lebens, 23f.29.

183 MENES, Die vorexilischen Gesetze, 47.

184 RICHTER, Recht, 104; ebenso BERGER, Gesetzesauslegung, $278 \mathrm{f}$.

185 LOHFINK, Hauptgebot, 83. 
und in die allgemeine Rettungsgeschichte des Volkes integriert. Das Familiäre wird mit der offiziellen Jahwereligion verschmolzen ${ }^{186}$. Demnach darf motivkritisch betrachtet das isolierte Vorkommen der Formel ohne Ortsbestimmung und Relativsatz als älter angesehen werden ${ }^{187}$, gegenüber der deuteronomisch erweiterten Wendung 188 . Besondere Bedeutung erlangt in diesem Zusammenhang Dtn 22,6f, die Vorschrift über den Schutz der Vogelmutter. Sie stellt innerhalb des Dtn die einzige Stelle dar, die in der Motivierung das ältere Stadium der Formel repräsentiert. Auch von seiten der Redaktionskritik wird das relativ hohe Alter der Vorschrift einschließlich Motivierung bestätigt ${ }^{189}$ : Damit bildet das Dtn selbst den Wachstumsprozeß bis zum ausgeformten Segenshinweis des Elterngebotes ab. Das hat zur Folge, daß der Segenshinweis von Ex 20,12 nur mit Hilfe von Dtn erklärt werden kann bzw. von dtn/dtr Autoren formuliert worden ist.

Nun kann man das alte Gefälle von der Exodus- zur Deuteronomiumfassung des Elterngebotes aufrechterhalten, indem man in der dtn/dtr Formulierung des Segenshinweises eine ältere Schicht wie in Ex 20,12 von einer jüngeren und erweiternden Schicht wie in Dtn 5,16 unterscheidet ${ }^{190}$. Die häufiger gemachte Beobachtung, daß die Formel vom "Langmachen der Tage" in Dtn immer die adverbiale Bestimung על האדמה nach sich zieht, scheint dem zu entsprechen ${ }^{191}$. Dieser Einordnung von Ex 20,12 läuft aber ein anderes Faktum zu-

186 ALBERTZ, Persönliche Frömmigkeit, $170 \mathrm{ff}$.

$187 \mathrm{Vgl}$. Dtn 22,7; (1 Kön 3,14) Jes 53,10; Spr 28,16; Koh 8,12f; daneben die Konstruktverbindung ארך ימים: Klgl 5,20; Ps 21,$5 ; 23,6 ; 91,16$; Ijob 12,12; Spr 3,2.16; mit רבה/Grundstamm: Spr 9,11; mit רבה/H-Stamm: Ijob 29,18; mit רבים: 1 Kön 3,11.

188 Dtn $4,26.40 ;(5,33) 11,9 ;(17,20)$ 30,18; 32,47; (Jos 24,$31 ; \operatorname{Ri} 2,7$ ) mit ארך ימים: Detn 30,20; mit רבה/Grundstamm: Dtn 11,21.

189 Gemäß MERENDINO, Gesetz, 256 hat der deuteronomische Redaktor die gesamte Einheit einschlieBlich Motivierung übernommen; nach SEITZ, Deuteronomium, 183.308ff hat die deuteronomische ubberarbeitung aus der Joschijazeit unter anderem dieses Gesetz eingebracht; für LOHFINK, Gott, 102 A 3 enthalten die Kapitel 21 und 22 Gesetzesmaterial, das am wenigsten umgeschmolzen ist. Wenn LOHFINK, a.a.o., $105 \mathrm{~A} 24$ vermutet, daß im Gesetz über die Vogelnester Dtn 22,7 eine bewußte Anspielung auf das Elterngebot vorliegt, stellt er, verleitet durch seine Dekalogthese, den Sachverhalt auf den Kopf und gleicht die letztere vermutung nicht mit der vorhergehenden Feststellung aus.

$190 \mathrm{Vgl}$. GAMBERONI, Elterngebot, 169 A 43.

191 Vgl. LOHFINK, Hauptgebot, 83 und PLÖGER, Deuteronomium, 126 mit allen Stellen; ebenso DIEPOLD, Israels Land, 76; sie hat ja wahrscheinlich LOHFINK zu seiner oben skizzierten Erklärung geführt; die Ausnahmen von der Regel wie in Dtn 4,$26 ; 5,33 ; 17,20$ oder Jos 24,$31 ; \mathrm{Ri} 2,7$ sind kontextbedingt. 
wider, auf das schon kremers aufmerksam gemacht hat ${ }^{192}$. Die Formel vom "Langmachen der Tage" hat an den meisten Stellen eine Person zum Subjekt ${ }^{193}$. An vier Stellen (Ex 20,12; Dtn 5,$16 ; 6,2 f ; 25,15)$ wird sie variiert und erhält "die Tage" zum Subjekt. Die beiden Stellen außerhalb der Dekaloge gehören zu relativ späten Schichten des Dtn ${ }^{194}$. Dieses Faktum erlaubt keine zeitliche Vorordnung der Exodusfassung und stuft sie zurück auf die Ebene von Dtn 5,16. Bezeichnenderweise hebt sich die finite Verbform unserer Formel in Ex 20,12; Dtn 5,16;6,2 jeweils durch das "Nun paragogicum" ab von der finiten Verbform in Dtn 25,15 ohne dieses "Nun" 195 . Die drei Stellen bilden also eine Gruppe gegenüber Dtn 25,15. Die relativische Landgabeformel knüpft im Dtn überwiegend an den Begriff אר ${ }^{196}$. Die Ausnahmen mit dem Bezugswort אדמה sind entweder auf sekundäre Verbindung mit dem Grundbestand (Dtn 21,1.23) zurückzuführen oder entspringen der Rücksicht auf die vorhergehende Redewendung (Ex 20,12; Dtn 4,40;5,16;25,15).

Ohne gewagte redaktionskritische Zuweisung unterstützen diese Tatbestände die Zugehörigkeit von Ex 20,12 zur Ebene von Dtn 5,16.

Wenn Ex 20,12 so eng an Dtn 5,16 heranrückt, dann kann in Umkehrung der bisherigen traditionellen Betrachtungsweise gerade von Dtn 5,16 her einiges Licht auf Ex 20,12 fallen.

192 Vgl. KREMERS, Stellung des Elterngebotes, 149; PLÖGER, Deuteronomium, 85f; THAT I, 719.

193 Siehe oben A 187.188.

194 Zu Dtn 6,2f vgl. EINHEITSÜBERSETZUNG der Heiligen Schrift, Das Alte Testament, Stuttgart 1974, 287; hier erscheint die Stelle als Erweiterung der überleitung 5,32-6,3 nach 6,4 hin, dem Eröffnungssatz einer frühen Ausgabe des dtn Gesetzes, vgl. LOHFINK, Gott, 108 A 30; nach MITTMANN, Deuteronomium, 14of, ist 6,2f paränetischer Kommentar zu V.1; der für uns wichtige v.2b ist Zuwachs zum Kommentar, d.h. in MITTMANNs Redaktionsmodell die letzte faBbare Schicht; nach LOPEZ, Analyse littéraire, 17f, sekundär und spät. Dtn 25,15b hat nach RICHter, Recht 113,dtn Gepräge; MERENDINO, Gesetz, 321 : deuteronomischer Redaktor; SEITZ, Deuteronomium, 186f: Motivation in 25,15f von dtn Sammler.

195 Zum "Nun paragogicum" vgl. MEYER II, § 63,5a und IRSIGLER, Einführung, $83 f$. 


\subsubsection{Der Segenshinweis in Dtn 5,16}

Spezifikum dieses Segenshinweises ist das Hinzutreten der Aussage über das Wohlergehen (כב ל ל Personalsuffix) zwischen die Formel vom "Langmachen/ sein der Tage" und der dazugehörigen adverbialen Ortsbestimmung. Zur vollständigen Beurteilung wird die adjektivische Variante (טוב ל + Personalsuffix) hinzugenommen, die ja nur eine Kurzform der verbalen Aussage darstellt ${ }^{197}$. Das Dtn zeigt wiederum Spuren der alltäglichen Verwendung vor allem in isolierten Vorkommen der Aussage ohne adverbiale Ergänzung oder Parallelformulierungen ${ }^{198}$. Die vordeuteronomische Koppelung von Wohlergehen und langem Leben (Gen 12,13// Jer 38,20) wird vom Dtn übernommen und modifiziert (טיה + טוב ל-D-Stamm mit Jahwe als Subjekt) in Dtn 6,24 oder mit der Form (ארך ימים + יטב ל-H-Stamm) in Dtn 22,7 - letztere Stelle hat ja auch bei der Formel vom "Langmachen der Tage" die Drehscheibe gespielt. Von hier aus gelangt die Aussage über das Wohlergehen in die relativ späten Stellen (Dtn 4,$40 ; 5,16.33 ; 6,2 f^{199}$ ), wo dann eine adverbiale ortsbestimmung hinzutritt. In diesem Zusammenhang fällt auf, daß bei der Koppelung der Aussagen über Wohlergehen und langes Leben diejenige über das Wohlergehen meistens die erste Stelle einnimmt ${ }^{200}$. Nur Dtn $5,16.33$ und $6,2 f$ erlauben sich, diese Reihenfolge aufzulösen 201.

Mit der Analyse des Segenshinweises von Dtn 5,16 haben sich vorher gemachte Vermutungen bestätigt und zu Ergebnissen verfestigt: Der Segenshinweis von Dtn 5,16 ist am groben Maßstab der Motivkritik und der Schichtung im Buch Dtn gemessen eine relativ späte Formulierung. Das gilt dann auch für den Segenshinweis von Ex 20,12, der mit dem von Dtn 5,16 eng verbunden ist.

197 Vgl. SEITZ, Deuteronomium, 109 und THAT I, 654.

198 ל טוב: Dtn 10,13; 15,16; 19,13; 23,17 (zur Übersetzung dieser letzten Stelle mit: wo er Lebensmöglichkeit hat! siehe THAT I, 654 und ThWAT III, 327); vgl. ferner: 1 Sam 16,16.23; Jer 22,15; 32,39; Ps 128,2; ל ' Dtn 5,29; 6,18; $12,25.28$; vgl. noch: Gen 40,14; 2 Kön 25,24; Jer 7,$23 ; 40,9 ; 42,6$; Rut 3,1 .

$199 \mathrm{Zu}$ den Schwierigkeiten in 6,2f mit dem Numeruswechsel und dem AnschluB der Landbeschreibungsformel "ein Land, das von Milch und Honig fließt" vgl. MITTMANN, Deuteronomium, 140f A 28.

$200 \mathrm{Vgl}$. Gen $12,13 / / \operatorname{Jer} 38,20 ; \operatorname{Dtn} 4,40(5,33) ; 6,24 ; 22,7$.

201 Dtn 5,33 bildet eine Dreiergruppe mit der Lebenszusage (היה/Grundstamm) an der spitze; 5,16 und 6,2f vertauschen die geläufigen Positionen. 
Die Verbindung von Ex 20,12 mit Dtn 5,16 erlaubt keine zeitliche Vorrangstellung der Exodusfassung vor der Deuteronomiumfassung. Ex 20,12 ist weder Zeuge eines älteren traditionskritischen Stadiums im Segenshinweis, noch Vertreter einer früheren deuteronomisch-deuteronomistischen Redaktion.

Auf diesem Hintergrund ist das Fehlen der Aussage über das Wohlergehen in Ex 20,12 als gewolltes Auslassen zu interpretieren. Das Auslassen zielt nicht auf den isolierten semantischen Gehalt der Aussage über das Wohlergehen; denn dafür hängen beide Aussagen über Lebenslänge und Wohlergehen zu eng zusammen (s.o.). Wer die Ansage vom "Wohlergehen auf dem Lande" vermeiden will, kann auch gleich das "lang sein der Tage auf dem Lande" streichen. Dann bleibt nur die Möglichkeit übrig, daß sich der Kontext von Ex 20,12 gegen das "Wohlergehen auf dem Lande" sperrt; d. $h$. von einem bestimmten Kontext her wird der zweite Finalsatz so aufgeladen, daß er der Formulierung, nicht der Sache nach in eben diesem Kontext unmöglich wird.

\subsubsection{Der sperrige Kontext zu einem in Ex 20,12 möglichen Finalsatz}

"damit es dir gut geht in dem Land, das Jahwe, dein Gott, dir gibt"

Hätte Ex 20,12 den zweiten Finalsatz mit dem anschließenden Relativsatz aus Dtn 5,16 übernommen, wäre es mit der Landgabeerzählung der $\mathrm{pg}$ in Konflikt geraten. Bei einem Redaktor, der mit der priesterschriftlichen Geschichtsdarstellung vertraut ist, muß der Relativsatz der zweiten Motivierung Assoziationen wecken zur "Landübergabeformel", die $\mathrm{Pg}$ in einem ausgeklügelten System vom Abrahambund (Gen 17,8) bis zu ihren Landgabegeschichten (Num 13,2; 20,$12 ; 27,12$ ) einsetzt. Dabei taucht die partizipiale Fassung der Formel nur in Num 13,2 auf und "scheint bewußt deshalb gewählt zu sein, um den Zug der Vertreter des Volkes zur Begutachtung des Landes (Num 13,2) als eine zeichenhafte Landgabe zu deuten, von der pg ja keinen ausgeführten Bericht bietet" 202 . Das divergierende Bezugswort der "Landübergabeformel", bei pg immer אדמה wie im Dekalog, bedeutet für die Assoziation kein Hindernis, da pg beide Begriffe promiscue gebrauchen kann 203.

202 WEIMAR, Untersuchungen, 110; zum ganzen System, a.a.0., 106-111.

203 Vgl. z.B. Gen 1 und STECK, Schöpfungsbericht, 124 A 487 und ELLIGER, Leviticus, 154 A 17; als einzige Ausnahme von der Regel vgl. $\mathrm{H}$ in Lev 20,24; weitere Stellen bei WEIMAR, Untersuchungen, $110 \mathrm{~A} 82.83$. 
Bei Obernahme des zweiten Finalsatzes stellt sich für den obigen Redaktor unweigerlich eine zweite Assoziation ein, die ihn wiederum zur Kundschaftererzählung von Pg in Num 13,1-14,38* führt ${ }^{204}$. Die Kundschaftergeschichte schildert die Sünde des auserwählten Volkes in ihren stellvertretenden Führern bei der Begutachtung und Bewertung von Jahwes größter Heilsgabe, des Landes Kanaan. Die Sünde liegt in der "Verleumdung des Landes". Die "Verleumdung" zielt auf die Guite oder Qualität des Landes, "ein Land, das seine Bewohner frißt, und die Leute, die wir darin gesehen haben, sind Riesen" (Num 13,32). Die Inhalte dieses Fehlurteils wie die Unfruchtbarkeit, Friedlosigkeit und tödliche Feindseligkeit des Landes 205 widersprechen diametral den Inhalten, die die Motivierung "damit es dir gut gehe auf dem Land/ Erdboden" voraussetzt bzw. umfaßt. Folgerichtig lautet das Gegenurteil von Josua und Kaleb in derselben Kundschaftergeschichte, Num 14,7: "Dieses Land ist wirklich sehr gut!" Unser Redaktor hat also vom Kontext der Priestergrundschrift her den zweiten Finalsatz des Elterngebotes als Anspielung auf das Thema der priesterschriftlichen Kundschaftererzählung verstehen müssen. Und diese Anspielung war ihm zuwider. Denn im E1terngebot von Dtn 5,16 wird die Verheißung des Wohlergehens dem Gebot final nach-bzw. untergeordnet; d.h. die Güte des Landes wird von der (menschlichen) Erfüllung des Gebotes abhängig gemacht ${ }^{206}$. Auf Ex 20,12 übertragen wäre diese Aussage im Kontext der Priestergrundschrift zwischen die unbedingte Zusage der Landgabe in Ex 6,8 und deren zeichenhafter Einlösung in der Kundschaftergeschichte plaziert worden 207 . In dieser Position und in dieser Formulierung mußte der Finalsatz mit dem Konzept von $\mathrm{p}^{g}$ in Konflikt geraten: Die Einflußnahme des "Faktors Mensch" über die Gebotserfüllung widerspricht der priesterlichen "Setzungsgeschichte" 208 , in der von Gott angekündigte Geschehnisse auch von ihm herbeigeführt werden. Die Konditionierung des Wohlergehens widerstreitet der feststehenden Qualität des Landes Kanaan 209 und reicht in gefährlicher Weise an den Straftatbestand der "Verleumdung des Landes" heran.

204 Zur priesterschriftlichen Kundschaftererzählung vgl. McEVENUE, The Narrative Style, 9o-144; WEIMAR, Untersuchungen, 151f; LOHFINK, Unsere großen wörter, 209-224.

205 MCEVENUE, The Narrative Style, 135 und WEIMAR, Freiheit, 89.

206 Vgl. DIEPOLD, Israels Land, $94 \mathrm{ff}$.

207 Vgl. WEIMAR, Untersuchungen, 150-153.

208 Vgl. STECK, Schöpfungsbericht, 51-55.

209 Hier sei an den konstatierenden Charakter der Urteile über das Land in der Kundschaftergeschichte erinnert; so auch McEVENUE, The Narrative Style, 121.125 ! 
Weil die Formulierung der zweiten Motivierung bei einem priesterschriftlich gebildeten Redaktor Assoziationen weckte, als er sie für Ex 20 übernahm und diese Assoziationen im Kontext der Priesterschrift Anstoß erregten, wurde die Formulierung als "corpus delicti" unterdrückt bzw. ausgelassen. Damit haben wir eine plausible Erklärung gefunden für den enigmatischen Tatbestand, daß der Segenshinweis von Ex 20,12 dem von Dtn 5,16 so stark gleicht, ohne inn vollständig zu kopieren. Ipso facto ist zugleich die zeitliche Priorität der Deuteronomiumfassung vor der Exodusfassung behauptet.

\subsubsection{Der zweite synoptische Unterschied: Das Fehlen des Rückverweises in Ex 20,12}

Im Prinzip sind das Verständnis des Rückverweises und sein Fehlen in der Exodusfassung oben bei der Behandlung des Sabbatgebotes unter 2.3.9 auch für das Elterngebot miterklärt worden. Der Rückverweis wird danach beim Wort genommen und tritt in die Funktion ein, auf der synchronen Textebene einen zurückliegenden Ausgangs text mit einem vorausgehenden Bezugstext zu verbinden. In dieser Funktion entspricht er einem bestimmten Selbstverständnis des deuteronomischen Gesetzes, auf ihm vorausliegende Gesetzeskorpora wie das Bundesbuch und das Privilegrecht Jahwes in Ex 34 expressis verbis Rücksicht zu nehmen. Der Dekalog von Ex 20 in seiner Frontstellung vor allen weiteren Gesetzeskorpora hat diese Ruicksicht nicht nötig und übergeht folgerichtig den Rückverweis der ihm vorliegenden Deuteronomiumfassung. Die oben unter 2.3.9 noch nicht berücksichtige, spezielle, jüngere Literatur zum Elterngebot trägt in Bezug auf den Rückverweis im El terngebot von Dtn 5,16, wenn überhaupt, keine neuen Gesichtspunkte ein 210 .

\subsubsection{Zwischenergebnis}

Für den synoptischen Vergleich hat sich beim Elterngebot ergeben: Beide Unterschiede entstanden dadurch, daß die ältere Deuteronomiumfassung nach Ex 20 übernommen und dabei wegen der Position von Ex 20 im Rahmen des Pentateuch sowohl um den Rückverweis wie um die Aussage über das Wohlergehen gekürzt wurde.

210 Mit der jüngeren Literatur ist gemeint: KREMERS, Stellung des Elterngebotes; GAMBERONI, Elterngebot, 162f; CONRAD, Die junge Generation; WOLFF, Anthropologie, 267; LANG, Altersversorgung; ALBERTZ, Elterngebot, 348ff. 


\subsubsection{Konsequenzen aus dem synoptischen Vergleich für die Interpretation} des Elterngebotes

Wenn Dtn 5,16 die ältere Fassung des Elterngebotes darste11t, muß sie zum Ausgangspunkt der Interpretation gemacht werden. Vor jeglicher Reduktion des Elterngebotes auf den einleitenden Gebotssatz ist Dtn 5,16 insgesamt daraufhin zu prifen, welche Hinweise die vorliegende Komposition des vollständigen Gebotstextes für das Verständnis des Elterngebotes geben kann.

Zuerst drängt sich die Frage auf, wohin der Rückverweis der Deuteronomiumfassung zielt! Da der Rückverweis die sachlich einschlägigen Parallelen in Lev 19,3; 20,9, die erst durch das Heiligkeitsgesetz in den Pentateuch integriert wurden, noch nicht vorliegen hatte, bleiben als einzige Bezugspunkte nur die Mōt-jūmāt-Sätze des Bundesbuches in Ex $21,15.17$ übrig $^{211}$.

Nun hat Schulz 212 die in Ex 21,12-17 auftretende Vierergruppe von Mōt-jümātSätzen auf drei reduziert und den Rechtssatz 21,15 zu einer "späteren Analogiebildung" nach 21,12 erklärt mit der rein kompositionstechnischen Funktion, bei der Einarbeitung der Reihe in das Bundesbuch einen festeren Zusammenhang herzustellen 213 . Die weitere Forschung zum sogenannten Todesrecht hat dem mit guten Gründen widersprochen und für die Beibehaltung der Vierergruppe und deren hohes Alter plädiert ${ }^{214}$. Mit Liedke ${ }^{215}$ halten wir die Vierer-

211 Damit schließen wir uns der Pentateuchhypothese von WELLHAUSEN an, die heutzutage stärker von jüdischen Gelehrten in Frage gestellt wird, vgl. z.B. WEINFELD, Deuteronomy, 179ff. Ohne Rücksicht auf den späteren Einschub von $\mathrm{H}$ hat auch JAKOB, Exodus, $893 \mathrm{f}$ den Rückverweis erklären wollen. Er soll nach seiner Meinung die Verschiedenheit der Verben in

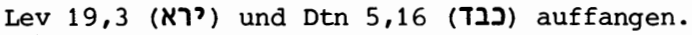

212 DERS., Todesrecht, $51 \mathrm{ff}$.

213 DERS., Todesrecht, 52 A 203. HALBE, Privilegrecht, 463 A 16 ist ihm darin gefolgt und hat die Begründung von SCHULz verstärkt, indem er die Analogiebildung mit der Redaktion in $21,13 \mathrm{f}$ verbindet, die das Anfangsglied vom Rest der Reihe wegdrängte und dieses Faktum im Gegenzug durch das neue Bindeglied 21,15 auffangen wollte.

214 zur generellen Kritik an SCHULz vgl. LIEDKE, Rechtssätze, 127-138, insbesondere 127 A 1 und 132 A 1; ebenso WAGNER, Rechtssätze, 16-31, insbesondere $24 \mathrm{~A} 41$. Im Einzelnen ist SCHULZ, Todesrecht, $51 \mathrm{f}$ zu kritisieren: 1. SCHULZ verwischt die Eigenständigkeit der in Ex 21,12 und 21,15 geschilderten Tatbestände und trimmt V.15 auf Totschlag. In die gleiche Richtung zielt die Kritik von WAGNER, Rechtssätze, 19 A 16. Der Tatbestand von V.15 (Schlagen ohne Todesfolge mit neuem objekt: Eltern) hat sein Eigengewicht, was durch die Parallele C H § 195 bestätigt wird, vgl. DRIVER/MILES, The Babylonian Laws, 411. 2. Das schwache Echo des alten Mōt-Satzes in den Rechtskorpora spricht nicht gegen ihn, zumal die zweiteilige partizipiale Weisheitssentenz von Spr 19,26 einen 
gruppe für (partizipiale) apodiktische Rechtssätze mit dem pater familias als setzender Autorität. Zwei Tatbestände gegen die Eltern werden indiziert: der handgreifliche Angriff auf die Eltern (Ex 21,15) und das primär verbale "Verächtlich-machen" der Eltern (Ex 21,17) 216. Der Rückverweis von Dtn 5,16 versteht die apodiktischen Rechtssätze als Jahwerede und stimmt darin überein mit dem redaktionellen Einschub Ex 21,13-14 217.

Mit der Ablehnung der Thesen von Schulz zu Ex 21,12-17 und dem Festhalten an zwei Tatbeständen in Bezug auf die Eltern kann der Rückverweis von Dtn 5,16 nun entweder selektiv nur einen Tatbestand und zwar den von Ex 21,17 im Auge haben oder bewußt beide Tatbestände einschließen bzw. durch den einleitenden Gebotssatz interpretieren wollen. Um diese Alternative zu entscheiden, muß die Bedeutung des Lexems כבד/D-Stamm untersucht werden. Damit stoßen wir in den Bereich des einleitenden Gebotssatzes vor, wo im Zuge "klassischer" Lösungsvorschläge Probleme der Lexembedeutung mit Fragen der syntaktischen Form verknüpft wurden. Im folgenden werden die Lösungsvorschläge kurz skizziert, aber nicht unter dem Aspekt der unterschiedlichen Ergebnisse ${ }^{218}$, sondern mit dem Schwerpunkt auf der Argumentation, die zu den unterschiedlichen Lösungen geführt hat ${ }^{219}$. Eine erste Gruppe von Exe-

ähnlichen Tatbestand wie Ex 21,15 verurteilt und ein Beispiel für die Gefährdung der Eltern liefert. 3. Das Rechtsparadigma Dtn 21,18-21 schildert in partizipialen Wendungen den generellen Sachverhalt des Ungehorsams und bietet damit keine Handhabe weder für noch gegen einen alten Mōt-Satz von Ex 21,15. Die Glosse V.2ob ist ein Zeugnis für die Assoziation mit Spr 23,21f, aber kein Zeichen für "Unsicherheit hinsichtlich des eigentlich strafwürdigen Vergehens des Sohnes" (SCHULz, Todesrecht, 51 ).

215 DERS., Rechtssätze, 130-135; vgl: zustimmend: BOECKER, Recht und Gesetz, 168-171; SCHOTTROFF, Recht, $25 \mathrm{f}$.

216 Vgl. LIEDKE, Rechtssätze, $134 f$ und WAGNER, Rechtssätze, 23 A 38 und 28.

217 Für spätere Redaktion bzw. Novellierung sprechen der Wechsel vom unpersönlichen kasuistischen Stil in die Jahwerede mit Ansprache der 2. pers.sg. und die sachliche Spannung zwischen der in VV.13f vorgenommenen Differenzierung in Mord und Totschlag und dem Fehlen dieser Differenzierung in Ex 21,19.23.29 - vgl. NOTH, Exodus, 145f und JACKSON, Essays, 91-93.

218 So bei ALBERTZ, Elterngebot, 348-351.

219 Manche Autoren verfechten ihre Position nicht mit einer logisch stringenten Argumentation, sondern mischen unterschiedliche Begründungen, die oft unverbunden nebeneinander stehen; in diesem Fall taucht ein Autor an mehreren stellen auf, oder es wird nur sein Schwerpunktargument erwähnt. 
geten 220 sieht in כבד/D-Stamm einen strikten Oppositionsbegriff zum קלל / D-Stamm von Ex 21,17. Dabei steckt besagte semantische Relation den Bedeutungsbereich von כבד/D-Stamm ab und je nach der vorausgesetzten Spannweite

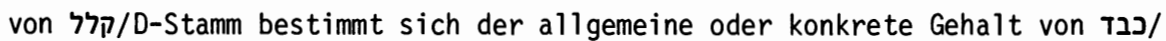
D-Stamm. Nach diesem Verständnis kann der Rückverweis von Dtn 5,16 nur auf Ex 21,17 zielen.

Die Feststellung der semantischen Opposition paßt zum umfassenderen Tatbestand, daß כבד sich in Wurzelbedeutung und semantischer Entwicklung oppositionell zu der von קלל verhält ${ }^{221}$. Nur bleibt es nicht bei dieser einen

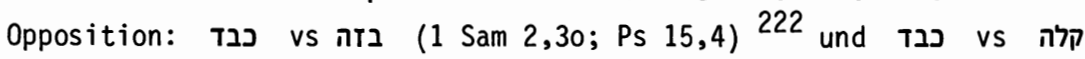
(Nebenform von קלל: Jes 3,5 ; Spr 12,$9 ; 13,18$ ). Im übrigen reicht die Beschreibung der semantischen Relation als Opposition nicht aus, weil - 1inguistisch betrachtet - die Opposition z.B. in kontradiktorische oder konträre Relationen differenziert werden muß ${ }^{223}$. Wenn wir letztere Differenzierung auf das Verhältnis von כבד/D-Stamm zu קלל/D-Stamm anwenden, können wir präzisieren: Beide Verben fungieren als zweistellige Prädikate (d.h. sie stellen eine Relation zwischen einem personalen Subjekt und einem personalen Objekt her) und stehen zueinander im Verhältnis einer konträren bzw. antonymischen Opposition, vergleichbar dem Verhältnis von "lieben" vs "hassen", "achten" vs "verachten", "erniedrigen" vs "erhöhen" im Deutschen 224 .

Eine zweite Gruppe von Exegeten ${ }^{225}$ setzt sich von der vorhergehenden ab und charakterisiert כבד כור liegt, keine konkreten Verhaltensweisen anzugeben. Tạ hebt auf die allgemeine Norm ab und bleibt gegenüber den zu verwirklichenden Formen der Norm

220 KÖHLER, Der Dekalog, 182; SELLIN, Geschichte, 84; PATRICK, La formation littéraire, 246 A 10; PHILLIPS, Criminal Law, 80; LANG, Altersversorgung, 152; MÜLLER, Zur Verkündigung der Zehn Gebote, $526 f$.

221 So KELLER, Art. קלל, THAT II, 641-647.642; vgl. noch RS 8. 145 mit Zeile 19 gegen Zeile 25 .

222 Vgl. ThWAT I, 582.

223 Die Unterscheidung stammt aus der Syllogismuslehre, vgl. STROMBACH, Die Gesetze, 52ff; von dort ist sie auf die Semantik angewendet worden: WUNDERLICH, Grundlagen, 3o2ff; TITZMANN, Strukturale Textanalyse, 104149; RIESENER, Stamm עבד, 74.

224 Vg̣l. TItzManN, Strukturale Textanalyse, $126 f f$.

225 HOLZINGER, Exodus, 74f; ALT, Ursprünge, 321 A 1; KESZLER,Problematik des Dekalogs, 1of; KREMERS, stellung des Elterngebotes, 158f; GAMBERONI, Elterngebot, 171; JEPSEN, Beiträge, 239f; BERGER, Gesetzesauslegung, 280; CHILDS, Exodus, 418; ALBERTZ, Elterngebot, 354-356 und BARTH, Elterngebot, $331 \mathrm{f}$. 
hin offen. Mit dieser Charakterisierung wird etwas angezeigt, was bei der ersten Gruppe zu kurz kam. Zwischen קלל/D-Stamm und כבד/D-Stamm besteht ein signifikanter Unterschied: קלל/D-Stamm beschreibt eine bestimmte Relation zwischen Personen und legt sich zugleich auf konkrete Aktionen fest, durch die die Relation nach außen feststellbar wird, nämlich überwiegend auf verbale Handlungen 226 . Auch כבד/D-Stamm qualifiziert eine bestimmte entgegengesetzte Relation unter Personen, aber es kann auf keine bestimmte konkrete, äußerliche Verhaltensweise eingegrenzt werden. Es verbleibt nicht im Raum der reinen Gesinnung, sondern verlangt verdeutlichende Außerungen; nur können diese je nach beteiligten Personen und Umständen wechseln (von "angemessener Bezahlung" bis zu "Gesten der Pietät" und "öffentlicher Anerkennung"). Im Sinne dieser größeren Flexibilität und offenheit gegenüber Konkretionen besitzt כבד/D-Stamm seine Allgemeinheit. Von daher kann das

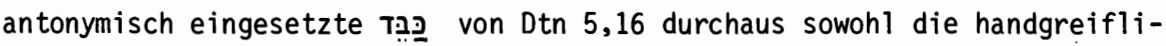
che wie verbale Aktion von Ex 21,15.17 umfassen. Der Rückverweis versteht dann den einleitenden Gebotssatz zu Recht als Interpretation der alten Mōt-jümāt-Sätze aus dem Bundesbuch.

Eine dritte Gruppe ${ }^{227}$ tritt ebenfalls für einen größeren Geltungsbereich des Elterngebotes ein. Allerdings argumentiert sie nicht so sehr semantisch, sondern überwiegend syntaktisch. Sie geht davon aus, daß ursprünglich ein Prohibitiv zum Elternfluch oder eine gesetzliche Verurteilung wie in Ex 21,17 oder Dtn 27,16 vorgelegen hat. Die negativ formulierte Vorlage bzw. das Verbot ist dann sekundär in die Position des Elterngebotes verwandelt worden, um in der positiven Fassung eine Ausweitung des Geltungsbereiches bzw. die angestrebte Allgemeingültigkeit zu erreichen. Wenn die Außerungen der betreffenden Exegeten auch nicht immer eindeutig sind, so beanspruchen sie zumindest, den syntaktischen wechsel von Verbot zu Gebot im Dekalog zu erklären 228.

226 Vgl. STECK, Genesis 12,1-3, 530 A 19; KELLER, Art. קלל, $643 f$.

227 ALT, Ursprünge, 321 A 1; RABAST, Das apodiktische Recht, 37; STAMM, Dekalogforschung, 52; NIELSEN, Zehn Gebote, 9of; FOHRER, Recht, 139; SCHULZ, Todesrecht, 54; SCHMIDT, Überlieferungsgeschichtliche Erwägungen 208-210; CHILDS, Exodus, 418; BARTH, Elterngebot, 332.

228 Das hebräische Negationsmorphem לא verbindet sich wie das deutsche "nicht" vorwiegend mit verben, aber auch mit Substantiven, vgl. RICHTER, Grammatik, 35. Die Negation und die dazugehörige Affirmation, wobei letztere als "Null-Morphem" realisiert wird, bilden zusammen ein Paradigma der Syntax, vgl. WEINRICH, Sprache in Texten, $78 f$. 
Die entscheidende Frage ist: Kann die syntaktische Umsetzung des Verbots in ein Gebot die angegebene Ausweitung bewirken? Wenn wir auf die Voraussetzung einer sekundären Umsetzung des Verbots in ein Gebot eingehen ${ }^{229}$, müßten zwei Operationen unternommen werden: eine syntaktische, die die $\mathrm{Ne}-$ gation tilgte, und eine semantische, die ein konträres/antonymisches VerbLexem wählte. Die Tilgung der Negation vermag die ihr aufgebürdete Last nicht zu tragen. Bei der These wird der Sachverhalt auf den Kopf gestellt. Denn nur das Setzen der Negation erweitert die Möglichkeiten, nicht deren Tilgung! Wird ein Prädikat bzw. ein Verb von der Position in die Negation gebracht, dann umfaßt die Negation mehrere Fälle: "Er flucht nicht" impliziert gegenüber "er flucht" die Möglichkeit jeder anderen Tätigkeit, einschließlich der Enthaltung von jeder Art von Tätigkeit. "Du sollst die Eltern achten" fordert eine bestimmte Relation, während die Negation "du sollst die Eltern nicht achten" sowohl das konträre Gegenteil (die Verachtung der Eltern) wie den Fall der Indifferenz (die Gleichguiltigkeit gegenüber den Eltern) umspannt 230 .

Demnach kann die syntaktische Umsetzung bzw. die Tilgung der Negation die oben genannte Ausweitung nicht bewirken. Die intendierte Allgemeinguiltigkeit kommt nur als Ergebnis der vorher beschriebenen semantischen Operation zustande. Damit ist auch die Frage nach den Motiven des Wechsels vom Verbot zum Gebot im Rahmen des Dekalogs wieder offen ${ }^{231}$.

229 Die Voraussetzung wird von jenen nicht geteilt, die neben den Verboten gleichberechtigte und ebenso ursprüngliche Gebote annehmen: GERSTENBERGER, Wesen, 43-5o; HAAG, Der Dekalog, 2o; FOHRER, Recht, 137f; RICHTER, Recht, 104ff; GESE, Der Dekalog als Ganzheit, $66 \mathrm{f} \mathrm{A} \mathrm{12;} \mathrm{SCHÜN-}$ GEL-STRAUMANN, Der Dekalog, 32.67.

$230 \mathrm{zu}$ diesem Sachverhalt vgl. TITZMANN, Strukturale Textanalyse, $123.127 \mathrm{f}$.

231 RICHTER, Recht, 88-91 will die Gebote als eigene Gattung von den Verboten abheben. Seine Argumentation ist in sich nicht schlüssig. Er nennt drei Konstitutiva der selbständigen Gattung "Gebot": Das Fehlen der Negation לא, eine bestimmte Verbalform (Präfixkonjugation-Langform mit dem Aspekt des "heischenden Präsens") und ein bestimmter Inhalt (Regelung von Fest- und opfervorschriften). Aber der Inhalt der "Gebote" läßt sich nicht in dieser Weise festlegen, zumal die Inhalte zwischen Verbot und Gebot austauschbar sind. Die PräfixkonjugationLangform ist Konstitutivum sowohl beim Verbot im Prohibitiv wie beim Gebot im Injunktiv (mit seinen subsidiären Verbalformen); das zeigt schon der Blick auf das akkadische "Vorbild", wo Prohibitiv und "heischendes Präsens" sich nur durch die Negation unterscheiden, vgl. v. SODEN, GAG $\S \S 78$, d.e; 81 . Dann verbleibt als drittes Unterscheidungsmerkmal für die Gattung "Gebot" nur das Fehlen der Negation לא, was aber nach eigenen Angaben "nicht zur Bestimmung der Form hinreicht" (RICHTER, Recht, 89). Zur Kritik vgl. GERSTENBERGER, Weisheit, 38; LIEDKE, Rechtssätze, 188 A 3; HALBE, Privilegrecht, 111 A 18. 


\subsubsection{Resultat}

Der synoptische Vergleich hat ergeben: Dtn 5,16 ist die ältere Fassung des Elterngebotes im Dekalog. Sie versteht sich selbst als Interpretation oder Novellierung vorgängiger Mōt-jümāt-Sätze bezüglich der Eltern, wie sie das Bundesbuch überliefert. Für die weitere Interpretation des Elterngebotes stellen sich folgende Anschlußfragen, die hier nur genannt, nicht behandelt werden können:

1. Wurde Dtn 5,16 von einem relativ späten Autor als geschlossenes Gebot komponiert und in den Dekalog eingesetzt oder ist es eine Bearbeitung eines ursprünglichen und alten Kurzgebotes ${ }^{232}$ ?

2. Damit hängt eine weitere Frage zusammen. Liegt im Elterngebot ein Gebot im strengen Sinne mit der subsidiären Verbalform des absoluten Infinitiv vor, das erst sekundär mit einer Begründung erweitert wurde, oder haben wir einen Imperativ vor uns ${ }^{233}$. der in einem Mahnspruch von vornherein mit einer Motivierung verknüpft war?

3. Schließlich muß die alte Frage beantwortet werden, wie es zu der im Dekalog auffälligen positiven Fassung gekommen ist?! Sie wird durch die Beantwortung der vorhergehenden Fragen mitentschieden:

Hängt es mit der gezielten Wahl des Lexems כבד/D-Stamm zusammen oder drückt sich darin eine größere Flexibilität aus, die in der Reihung von Prohibitiven auch Injunktive unterbringen konnte? Oder ist es ein Zeichen später Toleranz, die in der Folge der Gebote (Prohibitiv, Injunktiv) auch die Weisung bzw. die Mahnung (Vetitiv, Imperativ, Jussiv) aufnehmen konnte?

Die Beantwortung dieser Fragen gehört nicht mehr in den synoptischen Vergleich, der die Fragestellung aber entwickeln half. Die Lösung bleibt der Behandlung des Dekalogs in seiner älteren Deuteronomiumfassung vorbehal ten ${ }^{232 a}$.

232 Diese grundlegende Alternative hat ALBERTZ, Elterngebot, übergangen. Wertvoll ist sein Aufsatz darin, daß er einschlägiges Material aus dem Alten Orient sichtet und präsentiert. Die Verbindung dieses Materials mit dem atl. Befund scheint mir nicht gelungen! ALBERTZ nivelliert die synoptischen Unterschiede und steuert gleich auf den isolierten Gebotssatz zu. Dessen Verhältnis zu Lev 19,3 wird allzu schnell geklärt und beide werden zu Repräsentanten benachbarter Traditionen gemacht. Dabei kommt die Möglichkeit der Komposition nicht in den Blick und die Hinweise der Einzelstellen für eine Interpretation fallen unter den Tisch. Der allgemeine Gehalt der isolierten Einzelgebote wird ausdrücklich

$232 \mathrm{a} \mathrm{Vgl}$. unter $4.7 .4 \mathrm{~S}$. $252 \mathrm{ff}$. 
Der Unterschied betrifft die Differenz im nomen rectum der Konstruktverbindung in den genannten Versen (עד שוא עד gegen ge.

\subsubsection{Forschungsüberblick}

Einsam steht Steuernagel ${ }^{234}$ unter seinen Kollegen mit der Meinung, daß beide Konstruktverbindungen gleichbedeutend seien. Weil er die Abweichung nicht erklärt, wirkt seine Meinung wie ein Herunterspielen der Differenz. Als zufälligen Abschreibefehler früherer Kopisten erklären den Unterschied Peters und Rowley ${ }^{235}$. Ihr Vorschlag impliziert die Synonymität beider wendungen, so daß der Abschreiber sich keiner Sinnverschiebung bewußt wurde, denn diese hätte ihn auf seinen Fehler aufmerksam gemacht. In anderer Hinsicht nehmen Meier und Wellhausen eine Sonderstellung ein ${ }^{236}$ : Sie geben als einzige Dtn 5,20 mit עד שוא den Vorzug und halten das שד שד 20,16 für eine "bloße Erklärung". Die große Mehrzahl der Exegeten differenziert die Bedeutung der in Frage stehenden Lexeme. שקר (Lüge/Falschheit) ist der präzisere und konkretere Begriff gegenüber dem allgemeineren und dem Sinne nach weiteren שוא (das Sündige/Vergebliche) 237.

Die folgenden Exegeten erkennen die Differenz an, nur erklären sie ihre Genese unterschiedlich. Charles ${ }^{238}$ hält das Allgemeine und Unbestimmte für ursprünglich, die Präzisierung dagegen für sekundär bzw. später. Die meisten Exegeten polen das Gefälle um und stufen die verallgemeinernde Deuteromiumfassung als später ein ${ }^{239}$. Die Motive für die sekundäre Ausweitung hat

konstatiert, dann aber durch den altorientalischen, kulturellen Kontext aufgeladen und von dort her konkretisiert. Die Belege aus der Weisheitsliteratur werden nicht genügend erfaßt, so daß die zu beobachtende Entwicklung in den Forderungen von Verhaltensweisen gegenüber den Eltern nicht zur Sprache kommt; doch dazu s.u.!

233 Die finite Verbform כבד kann im D-Stamm rein morphologisch sowohl den absoluten Infinitiv wie den Imperativ sg. masc. bezeichnen.

234 STEUERNAGEL, Deuteronomium, 73.

235 PETERS, The Ten Words, 143; ROWLEY, Moise, 36 A 85.

236 MEIER, Die ursprüngliche Form, 27; WELLHAUSEN, Composition, 89 A 1.

237 So schon OETTLI, Deuteronomium, 41; STRACK, Exodus, 228.

238 CHARLES, Decalogue XIX, XXXV.

239 So DILLMANN-RYSSEL, Exodus, 219.233.240; HOLZINGER, Exodus, 75 vermutet für Dtn 5,20 den EinfluB von Ex 23,1a. 
König genau beschrieben,und seine Darstellung blieb bis heute einflußreich. Nicht nur der Fall der vorsätzlichen Lüge (Ex 20,16) sollte verboten werden, sondern auch der Fall der fahrlässigen Unwahrheit (Dtn 5,20), um vor Gericht einem Falschzeugen jede Ausflucht abzuschneiden ${ }^{240}$. Stamm hat Königs Meinung übernommen und für die neuere Dekalogforschung zur festen Basis gemacht ${ }^{241}$. Die traditionelle Argumentation stützt er durch ein weiteres Indiz: Die singuläre Formulierung von Dtn 5,20 weist auf eine sekundäre "Umoder Neuformung des alten Ausdrucks" hin. Stamms Schüler Klopfenstein baut in seiner Monographie "Die Lüge nach dem Alten Testament" auf der Ansicht seines Lehrers weiter auf, indem er die Argumente präziser faßt und vermehrt ${ }^{242}$. Sie lassen sich auf drei Punkte engfüren: 1 . Die Verallgemeinerung der Deuteronomiumfassung zielt sowohl auf eine "unausweichlichere Erfassung des Pseudozeugen" wie auf eine "Ausweitung des Verbotsbereichs über die (forensische) Situation selbst hinaus". 2. Die spätere Deuteronomiumfassung von 5,20 formuliert in Anlehnung an 5,11 (Verbot des Namensmißbrauches) und hat hier wie dort den meineidigen Zeugen im Auge. 3. Der שד שקר bringt mehr das Verhältnis des Zeugen zum Nächsten zur Sprache, trifft mehr die Funktion des Zeugen, während שוא mehr das Wesen des Zeugen charakterisiert und seine Qualität, seine Gesinnung bezeichnet.

Die Ergebnisse seiner Monographie hat Klopfenstein in die Artikel des THAT zu שקר integriert 243 . Die weitere Forschung knüpft durchweg an Stamm und Klopfenstein an ${ }^{244}$. Einige Exegeten dosieren ihre Zustimmung. Sie übernehmen entweder das Argument sekundärer Verallgemeinerung durch die Deuteronomiumfassung 245 oder votieren für eine spätere Angleichung der Ver-

240 KÖNIG, Dekalog, 378 sowie Deuteronomium, 92; der häufig zitierte Satz lautet: "Kein Zeuge sollte sich darauf berufen können, daß er nicht geradezu eine Lüge (שרו) gesagt, d.h. mit Wissen und Willen die Unwahrheit gesprochen habe".

241 STAMM, Dreißig Jahre, 199; DERS., Dekalogforschung, 9.59-62.

242 KLOPFENSTEIN, Lüge, bes. 18-21.

243 DERS., Art. כזב, THAT I, 817-823; Art. כחש, THAT I, 825-828; Art. שר , THAT II, $1010-1019$.

244 So REVENTLOW, Gebot, 25; LOHFINK, Dekalogfassung, 31 ; SCHREINER, Die Zehn Gebote, 6o; HYATT, Exodus, 215; SCHÛNGEL-STRAUMANN, Der Dekalog, 62-67; CHILDS, Exodus, 388.41off.425; MITTMANN, Deuteronomium, 142; MÜLLER, Zur Verkündigung der Zehn Gebote, 528.

$245 \mathrm{Vgl}$. SCHMIDT, Überlieferungsgeschichtliche Erwägungen, $203 \mathrm{ff}$. 
bote des Namensmißbrauches und des Falschzeugnisses in Dtn 5,20 246 oder schließen sich Klopfensteins Unterscheidung zwischen Funktionsbezeichnung und Wesensaussage an 247.

\subsubsection{AZlgemeine Bemerkungen zur Bedeutung von שוא.}

Die neueren semantischen Analysen zum Terminus stammen von Klopfenstein und Sawyer ${ }^{248}$. Klopfenstein verteilt die Konnotationen von שוא auf ein Spektrum, dessen Anfang die Bedeutung "Unhei1, Zauber, Böses" anzeigt; im breiten Mittelfeld liegt die Bedeutung "Lüge, Trug"; das gegenüberliegende Ende markiert die Bedeutung "Nichtigkeit, Leeres, Unreales". Im breiten Mittelfeld nähert sich die Bedeutung von שוא an die von שקר an.

Sawyer kappt das Spektrum nach seinen beiden Enden hin ab. Er zieht die einander gegenuiberliegenden Pole von "durch Zauberworte gewirktes Unheil" und von "Nichtigkeit" in Frage und hält an einer konstanten Bedeutung von "Trug, Falschheit, Unheil" in einem allgemeinen Sinne fest. Der eine Pol (Zauber) sei kaum zu beweisen, der andere (Nichtigkeit) sei über die vom Griechischen der LXX abhängige Vulgata mit vanum/vanitas induziert worden. Sawyers Umschreibung des Bedeutungsumfangs von שוא entspricht in etwa dem "Mittelfeld" bei Klopfenstein, das sich ja an den Bedeutungsbereich von שקר annähert. Von Sawyers Position her werden alle jene Erklärungsversuche zu dieser synoptischen Differenz in Frage gestellt, die auf der deutlichen semantischen Differenz der beiden Termini basieren ${ }^{249}$.

246 Zuerst bei JAKOB, Exodus, 895; PATRICK, La formation littéraire, 247; NIELSEN, Zehn Gebote, 39; BERGER, Gesetzesauslegung, 339; CHILDS, Exodus, 412; KOCH, Formgeschichte, 57.

247 So PHILlIPS, Criminal Law, 142-148.

248 KLOPFENSTEIN, Lüge, 315-320; SAWYER, Art. שוא, THAT II, 882-884.

249 Ähnlich wie SAWYER hat CAZELLES, Etudes, 85f, für שוא eine Grundbedeutung "Falschheit/Lüge" angenommen. Die Konnotation "Nichtigkeit", die die LXx übernehme, sei später und tauche erst mit den Propheten auf, während das Dtn sie nicht kenne. ANDREW, Falsehood, 433 sieht in שוא ein Wort, das mit denselben Implikationen gebraucht wird wie שקר. BERGER, Gesetzesauslegung, 339 konstatiert die "große inhaltliche Nähe" beider Termini und verweist auf funktionsgleiche Verwendung bei mißbräuchlicher Nennung des Jahwenamens, beim falschen Schwören und beim Einander-Betrügen. 
2.5.3 Auseinandersetzung mit den Argumenten in ihrer differenzierten Form bei Starm/Klopfenstein

Das Argument der späteren Verallgemeinerung in der Deuteronomiumfassung baut auf zwei Prämissen auf: dem größerenBedeutungsumfang von שוא - der steht aber nach den obigen Erwägungen in Frage - und der Annahme, daß die Verallgemeinerung Signum der sekundären Bearbeitung ist. Auch diese zweite Prämisse kann keine Sicherheit beanspruchen, weil die komplexe Rechtsentwicklung auch anders verlaufen kann und im Falle des Dekalogs von vornherein schon mit einer Tendenz zur Verallgemeinerung gerechnet werden kann.

Das Argument der sekundären Angleichung des Falschzeugnisses an das Namensmißbrauchverbot in Dtn 5,11 rechnet mit einer Entwicklung im Dekalogverständnis, die prinzipiell möglich ist. Nur muß dabei das ganze System der "Zehn Gebote" berücksichtigt werden; denn eine nachträgliche Angleichung bringt den Geltungsbereich mindestens zweier Gebote zur Deckung, was sich aber auf die festliegende Zehnzahl auswirken muß. Ohne Prüfung der Verschiebung im Gesamtsystem "Dekalog" ist die Hypothese nachträglicher Angleichung haltlos 250. Klopfenstein spürt den Widerstand zwischen dem traditionellen Argument der späteren Verallgemeinerung und dem neueren Argument der sekundären Angleichung, das ja auf eine Eingrenzung bzw. Präzisierung des verbotenen Tatbestandes hinausläuft, nämlich Meineid des Zeugen vor Gericht.

Mit einem "Wie dem auch sei" zieht er sich auf sein drittes Argument zurück. Hier muß gefragt werden, ob die Trennung zwischen Funktionsbezeichnung und Wesensaussage möglich und der Unterschied auf die beiden Termini zu verteilen ist, zumal derselbe Autor später so definieren kann: "Wo also שוא "Lüge" heißt, wird solche Unwahrheit - weit mehr als durch ihre theoretische Unstimmigkeit - durch ihre praktische Schädlichkeit und die faktische Verderbtheit der Person oder Sache, die sie qualifiziert, in ihrem Wesen geprägt" 251 .

Bei diesem dritten Argument beruft sich Klopfenstein in bezug auf das Dtn auf die (freilich sekundäre) "sonst zu beobachtende Tendenz zur Verinner-

250 Wie punktuell diese Erklärung ist, wird deutlich daran, daß man beim nachfolgenden Begehrensverbot üblicherweise derselben deuteronomischen Bearbeitung des Exodusdekalogs zutraut, daß sie nun ihre Vorlage ausdifferenziert zu zwei verschiedenen Geboten. Die Spannung zwischen beiden gegenläufigen Verfahren wird nicht diskutiert. SCHMIDT, Überlieferungsgeschichtliche Erwägungen, $203 \mathrm{~A} 1$, kritisiert das Argument vom allgemeinen Inhalt des Namensmißbrauchverbotes her, das weniger in der Lage gewesen sei, Dtn 5,20 zu beeinflussen. 
lichung der Urteile". Damit übernimmt er ein traditionelles Etikett, das König und Stamm der von ihnen für später gehaltenen Deuteronomiumfassung aufgeklebt haben 252 .

\subsubsection{Die Parallelen von Dtn 5, 20}

Wir prüfen nun das Vorkommen von שוא im Kontext der Rechtssprechung. Seit Holzinger ist immer wieder auf den Einfluß von Ex 23,1a auf Dtn 5,20 aufmerksam gemacht worden 253.

Der Prohibitiv V.1a verbietet das Vorbringen falscher Gerüchte. Der Kontext legt die Situation auf die Rechtsprechung fest. Wahrscheinlich sind sowohl Falschaussagen bei der Gerichtsverhandlung 254 wie "die Andichtung von Vergehen, die zu prozeßrechtlicher Verfolgung führen können" 255 , anvisiert. Noth macht auf die semantische, Cazelles auf die syntaktische Entsprechung des V.1 zu V.7 aufmerksam ("von einem betrügerischen Prozeß/Wort hal te dich fern!") 256 . Klopfenstein kommt bei seiner getrennten Analyse der VV. 1a.7a faktisch zur Identität der Aussagen in beiden Versteilen: Warnung vor falschem Zeugnis 257.

Die Beziehung beider Verse zueinander hat Auswirkungen für die Bedeutung

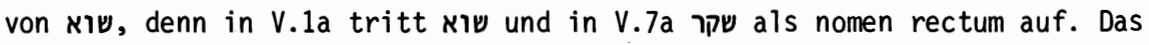
Verhältnis beider Termini wird unterschiedlich bestimmt, je nachdem welche Hypothese zur Textentstehung des Abschnitts 23,1-9 angenommen wird. Richter vermutet als Basistext eine Prohibitivreihe, die das Ethos einer führenden Schicht formuliert; Vetitive und Begründungen wie auch den Injunktiv V.7a rechnet er zur Erweiterung, der er schließlich auch noch VV.2f zuschlägt. Das Ausscheiden des Injunktivs geht auf das Konto seiner These von einer Sondergattung "Gebot", die wir nicht teilen ${ }^{258}$. Damit fällt für Richter der uns interessierende V.7a und dessen Verhältnis zu V.1a aus der näheren Betrachtung heraus.

251 KLOPFENSTEIN, Lüge, $319 f$.

252 Vgl. die zusammenfassende Charakterisierung ihres synoptischen Vergleichs bei LOHFINK, Dekalogfassung 18.

253 HOLZINGER, Exodus, 75; SCHMIDT, Überlieferungsgeschichtliche Erwägungen, 203; BERGER, Gesetzesauslegung,339; MITTMANN, Deuteronomium, 142.

254 So CAZELLES, Etudes, 86; NOTH, Exodus, 153; KLOPFENSTEIN, Lüge, 317.

255 RICHTER, Recht, 122; vgl. HALBE, Privilegrecht, 431.

256 NOTH, Exodus, 153; CAZELLES, Etudes, 89.

257 DERS., Lüge, 28.317.

258 Vgl. RICHTER, Recht, 60-62.86-88.121-124; zu unserer kritik s.o. A 231. 
Gerstenberger ${ }^{259}$ hält in 23,1-9 zwei selbständige Prohibitivreihen - unter seiner Gleichschaltung der grammatikalisch zu trennenden Formen Prohibitiv, Vetitiv, Injunktiv - für die Grundlage; beide Reihen 23,1-3.6-9 laufen parallel und behandeln das gleiche Thema: gerechtes Verhalten vor Gericht. Diese These impliziert eine semantische Analogie zwischen VV.1a.7a, ohne diese zu präzisieren.

Anders bei den Versuchen, in 23,1-9 eine durchlaufende, zusammengehörende Reihe zu entdecken. Hier zwingt die zugrundeliegende Hypothese zur Textentstehung, die Halbverse 1a.7a auseinander -, auf Eigenständigkeit hin zu interpretieren. Morgenstern deutet 23,1-3.6-9 als Gruppe von fünf "DoppelMiswōt", wobei - wie im Falle von 23,1 - jede "Doppel-Miswah" aus einem synthetischen Parallelismus besteht, dessen erste Hälfte in der zweiten Hälfte in puncto Strenge des Verbots gesteigert wird. Demnach bedeutet שמע שוא ein unbegründetes, unbewiesenes und haltloses Gerücht, das auch durch einen gutwilligen, aber schlechten Zeugen vorgebracht werden kann. Wohingegen der "Gewaltzeuge" der zweiten Hälfte, der mit dem "Lügenzeugen" identisch ist, den vorsätzlich falschen Zeugen bezeichnet. Nach dem gleichen Muster löst Morgenstern die Differenz zwischen Ex 20,16 und Dtn 5,20 auf. Die Deuteronomiumfassung unterscheide zwischen objektivem und subjektivem Falschzeugnis und zeige in ihrer juristischen Verfeinerung das spätere Stadium an 260 . Morgensterns These läuft in ihren Konsequenzen für das semantische Verhältnis von שוא und die Verhältnisbestimmung von König und Stamm hinaus: Dtn 5,20 erweitere vom vorsätzlichen Zeugen (Ex 20,16) zum fahrlässigen Zeugen. Seine These der "Doppel-Miswōt" scheitert an der mangelnden Differenzierung in den grammatischen Formen und an der Willkür der Ausscheidungen 261. Zu analogen Ergebnissen, ohne von Morgenstern Notiz zu nehmen, kommt McKay. Er greift Auerbachs Vorschlag vom einer Zehnergruppe von Gesetzen in 23,1-8 auf 262 und rekonstruiert einen Dekalog von zehn paarig angeordneten Prohivitiven. Dabei verbietet der erste Prohibitiv V.la die Wiederholung und Verbreitung falscher Gerüchte, während der siebte Prohibitiv V.7a das Aussprechen von vorsätzlichen Lügen anzielt ${ }^{263}$.

259 GERSTENBERGER, Wesen, 83f; zustimmend BOECKER, Recht, 177.

260 MORGENSTERN, Covenant, 88-90.93f bes. A 55.

261 Vgl. RICHTER, Recht, 87 A 139 und 123 A 12.

262 AUERBACH, Das Zehngebot.

263 McKAY, Exodus, bes. 318 A 1. 
Mckays Rekonstruktion trifft erst recht der Vorwurf, mit dem Text willkürlich umzuspringen. Der Vielfalt der grammatischen Formen und juristischen Gattungen sowie dem Zustand des MT am meisten gerecht wird die Erklärung Halbes ${ }^{264}$. Er beschreibt 23,1-7 als konzentrische Komposition um den Kern VV.4f mit einem herausgehobenen Schlußakzent in V.7bß. Innerhalb dieser Komposition übernehmen VV.1.7 die äußere Rahmung; dabei "ergänzen sich V.1a/7a aufs engste". Beide heben auf falsche Anklage in einem Lügenprozeß ab. Die Frage der vorgegebenen und dann verarbeiteten Rechtsmaterialien wie das Problem des Alters der Komposition kann hier nicht behandelt werden. Auf jeden Fall versteht die Komposition שקר und als synonyme Lexeme mit dem Inhalt von "Betrug bzw. Lüge". Ex 23,1 gilt darum als der erste Beleg dafür, daß שוא im Kontext der Rechtssprechung mit שקר synonym ist.

Hos 10,4: Der Satz אלות שוא ist schwer zu deuten, weil das Verb (hier: אלה Inf. abs.) אלה (ihn mit Vieldeutigkeit belastet. Rudolph versteht unter die Fremdverfluchung und Verwünschung; שוא erhält bei ihm dann fast adverbiale Bedeutung "zu Unrecht verfluchen" oder "haltlose Verwünschungen" an die Adresse der Gegner des Königs ${ }^{265}$. Als bedingte, im Eid enthaltene Selbstverfluchung bei Abschluß von Verträgen mit der hinterhältigen Absicht, den Eid zu brechen, deuten den Satz Scharbert, Keller und Wolff ${ }^{266}$; wohingegen Klopfenstein 267 diesen "Falscheid" in die Situation des Zeugen vor Gericht verlegt. Im Falle des Verständnisses im Sinne von Falscheid/Meineid würde sich שוא an die Bedeutung von שקר לשקר" im term. technicus (= lügenhaft schwören)" annähern.

In diesen Zusammenhang gehört eine weitere Stelle bei Hosea. Ihr fehlt zwar das Lexem שוא, dafür bietet sie aber den Inf. abs. von אלה und zeichnet sich durch enge Verwandtschaft mit den sozialen Prohibitiven des Dekalogs aus: Hos 4,2. Die besondere Schwierigkeit dieser Stelle liegt darin, daß

264 HALBE, Privilegrecht, 430-435.

265 RUDOLPH, Hosea, $193 \mathrm{f}$ bes. A 1; BRICHTO, Problem $39 \mathrm{f} .70$ scheint bei aller Unentschlossenheit in die gleiche Richtung zu tendieren.

266 SCHARBERT, ThWAT I, 282; KELLER, THAT I, 151; WOLFF, Hosea, 221.227. 267 DERS., Lüge, 20f.316f. 
fünf absolute Infinitive fünf gesonderte Vergehen nennen, wobei der erste Infinitiv von אלה für sich genommen eigentlich kein Vergehen anzeigt, da die "Verfluchung" durchaus legitim angewandt werden kann. Man hat mehrere Auswege aus dem Dilemma gesucht: Die Verknüpung der ersten beiden Infinitive zu einem einzigen Vergehen "Falschschwur" widerspricht der Konstruktion. H.Schmidtund Klopfenstein nehmen deshalb in 4,2 Breviloquenz für den vollen Ausdruck von $10,4 a a^{268}$. Die neueren Kommentare zu Hosea entdecken im ersten Infinitiv einen Verstoß gegen das Dekalogverbot des Namensmißbrauchs, ohne anzugeben, worin der Mißbrauch des göttlichen Namens besteht ${ }^{269}$; unter Anrufung Gottes einen Fluch gegen jemanden aussprechen, muß ja nicht ipso facto Mißbrauch des göttlichen Namens bedeuten! Folgender Ausweg scheint möglich: אלה bezeichnet hier den Ordalfluch eines Anklägers gegen einen Mitmenschen, der dadurch in den Verdacht eines Vergehens gerät; das läuft auf eine Anklage hinaus 270 , wobei der Ankläger unter dem Schutz der bedingten Verfluchung nicht zu seiner Anklage stehen muß, sondern es Gott übe läßt, sie zu beweisen. Das Illegitime an einem solchen Verfahren besteht dann darin, daß von ihm ein leichtfertiger und im konkreten Falle unberechtigter Gebrauch gemacht wird. Da an den einschlägigen Parallelen (Pss 10,7; 59,13; Ijob 31,30; vgl. 1 Kön 8,31) ebenso wie in Hos 4,2 vom Fluch bzw. Fluchen absolut gesprochen wird und der Kontext diese Tätigkeit negativ einfärbt, scheint dieses Verständnis hier zuzutreffen. Dann fällt Hos 4,2 als Beleg für שוא aus, bleibt aber für die sozialen Prohibitive wichtig.

Zwei weitere Fundorte für שוא bei Hosea besitzen ihre je eigenen Unsicherheiten. Hos 12,2a kommt als Beleg nur durch Textemendation nach LXX zustande, wofür neuere Kommentatoren eintreten ${ }^{271}$. Demzufolge bildet שוא zusammen mit כזב ein Hendiadyoin im Sinne von "Lug und Trug". Vom Kontext her ist die betrügerische Außenpolitik des Nordreiches angedeutet; שוא wäre mithin im Zusammenhang des Vertragrechts erwähnt ${ }^{272}$.

268 KLOPFENSTEIN, Lüge, 274f; SCHMIDT, Mose, 103 A 4.

269 So RUDOLPH, Hosea, 100; WOLFF, Hosea, 84; vgl. PHILLIPS, Criminal Law, $145 \mathrm{ff}$.

270 Vgl. BRICHTO, Problem, 56-59.63; SCHARBERT, ThWAT I, 281; KELLER, THAT I, 152 .

271 RUDOLPH, Hosea, 221 und DIEDRICH, Anspielungen, 27f; beide verteidigen die Lesart der LXX und halten den Text für authentisch im Gegensatz zu WOLFF, Hosea, 267, der den MT vorzieht, dann aber den Satz als interpretierende Glosse streicht.

272 Vgl. DIEDRICH, Anspielungen, $241 \mathrm{ff.250ff.}$ 
In Hos 12,12 fungiert שוא als Parallelbegriff zu און, der vor allem die Folge von און bezeichnet. Die übliche Festlegung der sündigen Aktivitäten auf kultische Vergehen ist nicht so eindeutig; es können auch soziale Vergehen gemeint sein 273. Dann bezieht sich שוא hier wie in Ijob 15,31 und Jes 30,28 auf das "Unheil/Böse", auf das unheilvolle Tätigkeiten hinführen.

Das Lexem שוא spielt also bei Hosea keine untergeordnete Rolle; es fällt auf durch seinen hohen Abstraktionsgrad, der eine Verwendung in unterschiedlichen Zusammenhängen zuläßt. Im Kontext der Rechtsprechung sind keine Konnotationen aufgefallen, die es von שקר signifikant unterscheiden.

In Spr 30,8 hängt das Verständnis der in V.8aa verwandten Begriffe שוא und von der Zuordnung zum Kontext ab. Wer die Bitte in V.8a als eigenständig betrachtet gegenüber der zweiten und dritten Bitte in V.8aß.b, die dann in V.9 kommentiert werden, der wird שוא und דבר כזב synonym nach Art von Hos 12,2 und Ez 13,6-9.19; 21,$34 ; 22,28$ verstehen ${ }^{274}$. Wer die erste Bitte mit dem Kommentar von V.9 verknüpft, wird שוא und דבר כזב auseinanderdividieren, sei es daß שוא nun die Gesinnung und דבר כזב die konkrete Folge der Gesinnung bedeutet oder daß das erste den Meineid bei der Ableugnung des Diebstahls bezeichnet (Bezug von שוא auf V.9b), während das zweite die Verleugnung Gottes im Auge hat (Bezug von דבר כזב auf V.9a) 275. Wir halten die zweite Lösung für allzu konstruiert. Die angegebenen Parallelen sprechen eher für Synonymie zwischen שוא und כזב.

Die erste Bitte von 30,8 gibt keinen Hinweis auf eine konkrete Situation, schließt damit aber zugleich die Situation der Rechtsprechung nicht aus.

An den beiden letzten Parallelen Ps 144,8.11 und Jes 59,3f ist sowohl der Kontext der Rechtsprechung als auch die Synonymität von שקר und verbuirgt.

Wir schließen die Prüfung der Parallelen mit dem Ergebnis: Im Kontext der Rechtsprechung ist שוא synonym mit שקר. Typische und beide Lexeme trennende Konnotationen sind nicht in diesem Zusammenhang auszumachen. Zugleich

273 Vgl. DIEDRICH, Anspielungen, 394.401.

274 Vgl. MCKANE, Proverbs, $649 f$.

275 KLOPFENSTEIN, Lüge, 218.265f. 
zwingen die Parallelen bzw. die Beziehungen von Dtn 5,20 zum Bundesbuch wie zu Hosea gerade nicht zu einer Spätdatierung der Deuteronomiumfassung.

\subsubsection{Die Singularität von Dtn 5,20}

Seit Stamm 276 wird die singuläre Konstruktverbindung שוא dem geläufigen terminus technicus עד עד gegenübergestellt. Die Singularität dient als Indiz"für eine Um- oder Neuformung des alten Ausdrucks" in Dtn 5.20. Nun kann die singuläre Formulierung durchaus eine spätere bewußte Abweichung von der Sprachnorm sein. Sie kann aber ebenso der Sprachnormierung durch einen terminus technicus vorausgehen wie auch jenes Stadium widerspiegeln, in dem die Normierung sich noch nicht durchgesetzt hat. Die Singularität der Formulierung allein kann über ihr Alter nichts aussagen, hat also keinen Wert als Indiz. Im Falle von Dtn 5,20 haben wir oben gesehen, daß die Parallelen ein hohes Alter zulassen. Was in diesem Zusammenhang eher auffällt - ganz gleich wie das Verhältnis der beiden Stellen geregelt wird ${ }^{277}$ ist die spannungsreiche Nähe von Dtn 5.20 zum Zeugengesetz in Dtn 19,16-19*. Trotz Kongruenz in der Sache und partieller wörtlicher Obereinstimmung weicht es in drei Punkten vom Dtn-Dekalog ab: Dem Jahwenamen in V.17 fehlt die für das Dtn einschließlich Dekalog typische Apposition "dein/euer Gott". Der "Nächste" wird mit אח statt mit רezeichnet (VV.18.19). Den "Falschzeugen" nennt das Gesetz עד שמס (VV.16.18).

Der Kern des Zeugengesetzes 278 hat Verbindungen zu Parallelen ${ }^{279}$, die zusammen mit den eben erwähnten Eigenheiten ein relativ hohes Alter des Zeugengesetzes möglich erscheinen lassen. Somit beherbergt das Buch Deutero-

276 S.o. unter 2.5.1; vgl. noch VAN OYEN, Ethik, 130; BERGER, Gesetzesauslegung, 339; SCHǗNGEL-STRAUMANN, Der Dekalog, 67; KLOPFENSTEIN, THAT II, 1013 .

277 Eine Spätansetzung der Deuteronomiumfassung müßte dann alle Differenzen sowohl zur vorgegebenen Exodusfassung wie zum deuteronomischen zeugengesetz in Dtn 19,16-19* erklären.

278 Gemeint ist damit der von der Sache her geforderte Grundtext, der auch von den unterschiedlichen Rekonstruktionen eines Basistextes bei MERENDINO, Gesetz,215f und SEITZ, Deuteronomium, 113-115 nicht angetastet wird; die These von STOEBE, Das achte Gebot, 12off zu Dtn 19,16ff wird bei BERGER, Gesetzesauslegung, $33 f$ berechtigterweise kritisiert.

279 Drei wörtliche übereinstimmungen mit Ps 27,12, zwei mit Spr 25,18 (hier:ער) und Spr 6,19 (hier: $n$ ), eine mit Spr 24,28 (BHS, hier: ער); 12,$17 ; 14,5 ; 19,5.9 ; \mathrm{vgl}$. noch $\operatorname{Spr} 14,25 ; 21,28$ - siehe dazu die Ausführungen von RICHTER, Recht und Ethos, $151 \mathrm{ff}$. 
nomium zwei eigenständige Gesetzesformulierungen zum Falschzeugen: Den mit dem Bundesbuch und Hosea verbundenen Prohibitiv Dtn 5,20 und das mit den Sprüchen verwandte Zeugengesetz Dtn 19,16-19*.

\subsubsection{Motive für eine Änderung durch Ex 20,16}

Wir gehen nun von einem relativ hohen Alter der Deuteronomiumfassung aus und fragt nach den Motiven für eine Abweichung der Exodusfassung. Sie können nicht in einer punktuellen, semantisch bedingten Variation des Prohibitivs liegen, weil sich diese mit der festgestellten Synonymie von שוא und שקר Kontext der Rechtsprechung stößt. Deshalb müssen die Motive in der Rücksicht auf die Gesamtkomposition des Dekalogs zu finden sein; d.h. der Exodusfassung kommt es darauf an, die Stichwortassoziation zwischen dem Verbot des Namensmißbrauches und dem des Falschzeugnisses zu unterbinden, ohne den Sinn des Falschzeugnisverbots zu verändern. Das Ziel des korrigierenden Eingriffs liegt nicht am Ort der Operation, sondern in der Rückwirkung auf das Verständnis vom Verbot des Namensmißbrauchs. Durch Tilgung der Stichwortassoziation werden die Beziehungen des Namensmißbrauchverbotes zum Bereich der Rechtsprechung gedämpft, wie sie z.B. in der Auslegung dieses Verbotes in Richtung auf Falschschwur und Meineid zutage treten 280 . Zugleich wird die Eigenständigkeit dieses Verbotes betont und im Rahmen seines allgemeinen Inhalts seine theologische Komponente unterstrichen. Eine ähnliche Tendenz finden wir in Lev 24,10-23 wieder. Eine späte P-Redaktion hat hier eine Gesetzesvorlage VV.15b-22 bearbeitet und mit einer Beispielerzählung VV.10$15 a .23$ aus der paradigmatisch gewordenen mosaischen Urzeit verbunden ${ }^{281}$. Dabei deutet sie den alten Straftatbestand des Gott-Verwünschens (Ex 22, 27) um in den neuen Tatbestand der Lästerung des Jahwenamens נקב in der nur hier belegten Bedeutung von "lästern" ${ }^{282}$ ). Die sekundäre Umdeutung enthält folgende Implikationen: קלל / קבר/lästern schwächt das vorgegebene

280 Vgl. V.RAD, THEOLOGIE I, 197.

281 Vgl. CHOLEWINSKI, Heiligkeitsgesetz, 95-100.

282 Vgl. ELLIGER, Leviticus, 335 A 9; wir schließen uns den literar- und traditionskritischen Argumenten von SCHULZ, Todesrecht, 42-46 gegen ELLIGER, Leviticus, 330-335 an. WEINGREEN, Case, 118-123 nimmt נקב jede pejorative Konnotation und übersetzt es mit "to utter the Name of God". Dadurch kommt er im Verein mit קלל auf einen Straftatbestand, der das wahllose, ohne triftigen Grund erfolgende Aussprechen des Namens Gottes anzeigt. Diese Auffassung versteht die Gotteslästerung in Lev 24,10-23 faktisch als Vorstufe zum Verbot der späteren jüdischen Ausleger, das Tetragramm auszusprechen. 
verwünschen $a b$. Der allgemeine Tatbestand der Schmähung Gottes wird auf den speziellen Fall des Umgangs mit dem Jahwenamen eingegrenzt. Der Jahwename erhält eine eigene Qualität, er wird hypostasiert und gesetzlich geschuitzt. Gerade in diesen Trend, aus traditionellen Gesetzesvorschriften den Gebrauch des Jahwenamens als gesonderten Bereich auszugrenzen, ordnen wir die Tendenz der Exodusfassung ein. Sie will also mehr die Scheu vor dem Jahwenamen einschärfen als das bekannte und im Falschzeugnisverbot eingeschlossene Vergehen des Meineids verbieten.

Eine analoge Entwicklung scheint sich in Lev 19,12 anzudeuten. Abweichend vom geläufigen Sprachgebrauch für "lügenhaft schwören" 283 tritt im Prohibitiv V.12a die breitere Wendung "bei meinem Namen lügenhaft schwören" auf (ebenso nur noch Sach 5,3f (BHS) ) ${ }^{284}$. Man könnte zuerst an eine ausführlichere Variation der knappen Ausgangswendung denken oder an eine mehr zufällige Verschmelzung der Rede "beim Namen Jahwes schwören" 285 mit dem Ausdruck "lügenhaft schwören". Allerdings hebt eine Erläuterung mit Numeruswechsel in 19,12b noch einmal auf den שahwes ab und deutet die Tat des vorausgehenden Prohibitivs als "Entweihen des Gottesnamens". Unabhängig davon,zu welcher Redaktion die Erläuterung V.12b gehört ${ }^{286}$, wird im Zusammenspiel von Prohibitiv und Erläuterung das Interesse am Jahwenamen deutlich. Der angezielte Bereich des Verbotes mit seiner Erläuterung ist: Meineid als Mißbrauch des Jahwenamens ${ }^{287}$. Von der beim Meineid nebeneinanderliegenden sozialen und theologischen Komponente erhält die theologische das obergewicht.

Damit läßt sich die jüngere Abweichung von Ex 20,16 einordnen: Sie dient einer verstärkt theologisch argumentierenden Revision überkommener Gesetzesmaterialien, wie wir sie in späten priesterlichen Redaktionen z.B. des Heiligkeitsgesetzes antreffen.

283 Vgl. Lev 5,22.24; Jer 5,2; 7,9; Mal 3,5; vgl. noch Lev 5,4; Pss 15,4; 24,4 - dazu GIESEN, Semantische Vorfragen, bes. 129-131.

284 JAGERSMA, Leviticus 19, $89 \mathrm{f}$ akzentuiert das ebenso.

285 Dtn 6,$13 ; 10,20$; Jes 48,1 ; Jer 12,16 .

286 JAGERSMA, Leviticus 19, 90.140f denkt an eine priesterliche Redaktion zum Ende des Exils; CHOLEWINSKI, Heiligkeitsgesetz, 45.344ff vermutet darin seinen der Hauptredaktion des $\mathrm{H}$ vorausgehenden priesterlichen Redaktor H 2, dem an einer "Grundordnung der wichtigsten Lebensbereiche Israels" gelegen war.

287 Vgl. JAGERSMA, Leviticus 19, 89f; CHOLEWINSKI, Heiligkeitsgesetz, 291. 
2.6. Die synoptischen Differenzen im Dekalogschluß

(Ex 20,17; Dtn 5,21)

\subsubsection{Einleitung}

Die beiden Standardschwierigkeiten der Dekalogexegese: die Diskrepanz zwischen der biblisch verankerten Zehnzahl und dem faktischen Gebotsüberschuß sowie die Häufung von synoptischen Unterschieden auch wieder gegen das Ende des Dekalogs hin, verursachen eine naturgemäße Problematisierung von Anfang und besonders Ende der Zehnerreihe. So nimmt es nicht wunder, daß der latente Kampf um die richtige Zählung bzw. um die angemesser:e Einteilung des Dekalogs und damit um das Verständnis bestimmter Einzelgebote bald aufbrandete - so vor allem in der 1. Hälfte des 19. Jh.s - und schon früh zu Lösungen führte, die ihrerseits die spezifischen Schwierigkeiten des Dekalogschlusses vor Augen führen 288.

Zwei Lösungen sollen paradigmatisch vorgestellt werden. Die erste stamt von E. Meier ${ }^{289}$. Er schließt sich an die jüdische Zählung an, die die Dekalogeinleitung als erstes Gebot auffaßt. Als zweite Prämisse nimmt er zwei kongruente, analog aufgebalite Pentaden aus Kurzgeboten an (Einleitung, Fremdgötter-, Bilder-, Namensmißbrauchverbot und Sabbatgebot; dann Elterngebot, Ehebruchs-, Tötungs-, Falschzeugnis- und Diebstahlsverbot). Daher ist für inn der Dekalogschluß sekundäre Ergänzung zum Urdekalog, aus der Zeit des seßhaften Lebens stammend; die Ergänzung erläutert das (Meiers letztes) Diebstahlsverbot. Konsequenterweise ist für ihn das Begehrensverbot kein Verbot einer Gesinnung, sondern einer Tat; und er kann zu seinen Gunsten eine Reihe von beachtenswerten Gründen anführen ${ }^{290}$. Der Antipode ist H. Ewald ${ }^{291}$. Für inn besteht der mosaische Urdekalog aus zehn kurzen Sätzen; er ist in der Exodusfassung zu finden. Wie bei Meier ist der Deka$\log$ aus zwei analogen Pentaden aufgebaut, wobei Ewald das je fünfte Gebot (Elterngebot/Begehrensverbot) von den vier zusammengehörigen Vorgängern absetzt. Das verbotene Begehren versteht er als Gesinnungsdelikt. Der Gesetzgeber hat sachlich richtig mit dem abschließenden Verbot der Gesinnung die

288 Literatur dazu bei: GEFFKEN, Einteilung; DILLMANN-RYSSEL, Exodus, $221 \mathrm{ff}$.

289 MEIER, Die ursprüngliche Form, bes. 7off. Sie wird ausführlich vorgestellt,weniger gewürdigt bei NIELSEN, Zehn Gebote, 18 A 6.64 .

$2 \% \mathrm{zu}$ den Gründen s.u.

291 EWALD, Geschichte Bd. 2, 27-31.224-232. 
Quelle der vorher indizierten Taten bezeichnet und den Dekalog abgerundet. Aus dieser Auffassung folgt: Der DekalogschluB in Ex 20,17 ist nur ein Gebot, dessen Urform in V.17a zu finden ist. Die für Mose "eigentümliche Redensart" V.17a wird in V.17b erläutert, indem erklärt wird, daß unter Haus "alle äußeren Güter" des Nächsten zu verstehen sind. Die Deuteronomiumfassung mischt in einem für sie typischen freieren Verfahren Erläuterung und Kurzgebot zusammen und interpretiert um. Der Begriff Haus erhält dabei eine ganz andere Bedeutung.

Die beiden skizzierten Lösungsversuche zeigen die Problemkreise an, die im Dekalogschluß miteinander verhakt sind und sich gegenseitig überlagern:

1. Wie verhalten sich die beiden Dekalogfassungen zueinander, d.h. wie sind die synoptischen Differenzen zu bewerten?

2. Welche Bedeutung haben die Objekte der Verben im DekalogschluB,insbesondere der Terminus "Haus"?

3. Enthält der Dekalogschluß ein oder zwei Gebote? Die Zugehörigkeit der Begehrensverbote zum Urdekalog ist seit $\mathrm{E}$. Meier nicht mehr in Frage gestellt worden.

4. Welchen Tatbestand beschreiben die Verben: eine Gesinnung oder eine Tat? Und in welchem Verhältnis steht der so beschriebene Tatbestand zu dem der vorausgehenden Kurzgebote?

Bei dieser Problemlage ist im weiteren Verlauf der Interpretation des Dekalogschlusses "kein Stein auf dem anderen geblieben".

Die unterschiedlichen Lösungsvorschläge haben jeweils bei einem der eben genannten Problemkreise angesetzt und unter Umständen zu den anderen Stellung genommen. Von den obigen Fragen ausgehend schlagen wir folgenden Aufriß vor: Ein erster Teil diskutiert die Lösungen der bisherigen Dekalogexegese, behandelt also die Antworten, die bislang auf die Ausgangsfragen gegeben wurden. Ein zweiter Teil erarbeitet den eigenen Lösungsvorschlag und gibt seine Antworten auf die ersten drei Fragen. Der dritte Teil dann beschreibt die Konsequenzen des Lösungsvorschlags und beantwortet damit die vierte Ausgangsfrage.

\subsubsection{Forschungsüberblick}

Der Obersichtlichkeit halber und dem ersten Analyseschritt gemäß beginnen wir die Darstellung mit dem synoptischen Vergleich. Wahrscheinlich wegen der komplexen Problemlage einerseits und seiner exegetischen Präzision im Vergleich zu seinen Vorgängern andererseits hat das Lösungsmodell Ewalds in seinen Grundzügen (Priorität der Exodusfassung mit der Urform des Begeh.- 
rensverbotes in V.17a, spätere Ergänzung durch V.17b und sekundäre Umdeutung beider Versteile der Exodusfassı.ng in Dtn 5,21) bis heute seine Vorherrschaft behauptet. Wir verfolgen darum Zustimmung, Modifikation und Ausbau dieses Modells bis zur Gegenwart. Die sich dabei ergebenden "Stammbäume" heute gängiger Meinungen stellen die Abhängigkeiten heraus und erleichtern das Auffinden versteckter Prämissen bzw. Vorentscheidungen. Im großen und ganzen haben Ewald eine große Reihe von Exegeten zugestimmt und vertreten sein Modell auch heute ${ }^{292}$. Anfragen an Ewalds Modell haben sich zuerst in Bezug auf seine Zuordnung von Ex 20,17a zu V.17b ergeben. Wenn V.17b die Urform des Gebotes in V.17a erläutert, wie ist dann die Wiederholung desselben Prohibitivs in V.17b zu erklären, und in welchem Verhältnis steht das Objekt des ersten Prohibitivs zu der syndetischen Reihe von Objekten des zweiten Prohibitivs?

\subsubsection{Die Wiederholung des Prohibitivs in Ex 20,17b}

Schon Bertheau hält die Trennung des Begehrensverbotes in zwei Verbote für willkürlich und von der Sache her für unangebracht ${ }^{293}$. Dillmann ${ }^{294}$ meint, daß die Verzweifachung des Begehrensverbotes nach den Objekten des Begehrens in sich selbst keinen zureichenden Grund hat, ja, mit dem Text der Exodusfassung geradezu unvereinbar ist. Die Verzweifachung in der Deuteronomiumfassung sei ein bloßer Notbehelf zur Erzielung der Zehnzahl. Herrmann 295 opponiert gegen die Zählung von V.17 als ein Gebot, denn V.17b steht neben V.17a im Wortlaut selbständig da, ohne Andeutung einer Abhängigkeit von V.17a; dem Inhalt nach gehört der Versteil aber zu V.17a, und V.17b bleibt

292 In chronologischer Reihenfolge: PETERS, The Ten Words, $141 \mathrm{ff}$; OETTLI, Deuteronomium, 41; STRACK, Exodus, 228; DILLMANN-RYSSEL, Exodus, 224. 240ff; HOLZINGER, Exodus, 75; KÖNIG, Dekalog, 377ff; STEUERNAGEL, Deuteronomium, 22; CHARLES, Decalogue, Einleitung S.XIXf. XXXV.XLVII; trotz mancher Kritik im Einzelnen Zustimmung zu den Grundzügen bei HERRMANN, Das zehnte Gebot; MOWINCKEL, Décalogue, 3.6; KÖHLER, Der Dekalog, 177 und 183; EBERHARTER, Der Dekalog, 53f; ALT, Verbot, 333ff; BEER, Exodus, 103; BOLLE, Bodenrecht, 4of; ROWLEY, Moise, 10; AUERBACH, Moses; STAMM, Dreißig Jahre, 199-3c4; DERS., Dekalogforschung, 9.55f; GESE, Der Dekalog als Ganzheit, 75; PATRICK, La formation littéraire, 246-248; HAAG, Der Dekalog, 19.33-35; NIELSEN, Zehn Gebote, 17f;39.82f; SCHREINER, Die Zehn Gebote, 62-66; FOHRER, Recht, 131f.136; NOTH, Exodus, 133f; JEPSEN, Beiträge, 294f; PHILLIPS, Criminal Law, 149-152; SCHMIDT, Überlieferungsgeschichtliche Erwägungen, 207f; BERGER, Gesetzesauslegung, 343-345; SCHÜNGEL-STRAUMANN, Der Dekalog, 56ff; KOCH, Formgeschichte, 58; CHILDS, Exodus, 426f; MÜLLER, Zur Verkündigung der Zehn Gebote, 527; MITTMANN, Deuteronomium, 142f; zu vergleichen noch HOFFNER, Art. בית, ThWAT I, 629-638, bes. 637f.

293 BERTHEAU, Die sieben Gruppen, 10-12.

294 DERS. , Exodus, 224. 
ergänzender Zusatz, der V.17a auf das gesamte Eigentum ausdehnt. Herrmann trifft eine gute Unterscheidung zwischen der formalen Autarkie von V.17b und der inhaltlichen Nähe beider Versteile, die durch den Begriff des Eigentums miteinander verbunden sind. Warum allerdings die Erläuterung in einem autarken Prohibitiv untergebracht wird, bleibt ungeklärt. Für Reventlow ist der formale Aspekt ausschlaggebend ${ }^{296}$. Er betont die Eigenständigkeit des zweiten Prohibitivs und teilt nur das erste objekt (Frau des Nächsten) zu; so erhält er eine Prohibitiv-Kurzreihe mit Thn, ähnlich den Reihen bei gleichbleibendem Verb aus Lev 18,20 und Dtn 27. Sie sei dann in beiden Dekalogfassungen jeweils im zweiten Glied aus einer vorgegebenen Besitzliste unterschiedlich ergänzt worden. Die Dekalogprediger, die für die Ergänzung aus der Besitzliste verantwortlich seien, sähen die Doppelprohibitive in eins. Reventlow tauscht für eine Lösung eine Reihe von neuen Schwierigkeiten ein. Er muß mit drei zufälligen Variationen arbeiten: Die sekundäre Deuteronomiumfassung vertauscht die Reihenfolge in der Prohibitivreihe; sie variiert den zweiten Prohibitiv; sie zitiert die Besitzliste aber vollständig, während in der Exodusfassung ein objekt einfach fortfällt. Deswegen ist Reventlows These pauschal abgelehnt worden ${ }^{297}$, und die weitere Forschung hat sie nicht übernommen. Sie ist auf den Spuren Ewalds weitergeschritten. Eine neue Nuance bringt Nielsen ${ }^{298}$ ein. Er hält die Teilung von V.17 formal gesehen für gerechtfertigt, sachlich aber undurchführbar, weil ja auch die VV.4-6 und 8-11 nicht in drei Gebote aufgeteilt werden. Bei dieser Argumentation übersieht er die individuelle syntaktischstilistische und semantische Gestaltung der angeführten Verse, die sie als Parallelen zu V.17a.b gerade nicht in Frage kommen lassen, so daß schließlich die Singularität von V.17 im Dekalog unterstrichen wird ${ }^{299}$.

295 DERS. , Das Zehnte Gebot, 7of.79-82.

296 REVENTLOW, Gebot, 90-92; vor ihm schon JIRKU, Das weltliche Recht, 15off; ebenso führt die Begehrensverbote als Gebotspaar auf GERSTENBERGER, Wesen, 88 .

297 So bei JEPSEN, Beiträge, 294.

298 DERS., Zehn Gebote, 17.

299 Vgl. SCHMIDT, tberlieferungsgeschichtliche Erwägungen, 207: " (Das Gebot) besteht ausnahmsweise aus zwei parallelen, syntaktisch voneinander unabhängigen Sätzen, die das Begehren des Hauses bzw. der zum Haus gehörenden Personen und Tiere untersagen". Ebenso CHILDS, Exodus, 425 . 
So stellt die Forschung das Auffällige der Wiederholung heraus, erklärt es aber nicht. Cazelles deutet als einziger eine gegenläufige Meinung an, indem er für die Exodusfassung eine punktuelle, sekundäre Vereinheitlichung des Vokabulars vermutet ${ }^{300}$. Allerdings wird die Frage der Priorität nicht ausdiskutiert und die eigene Meinung nicht auf ihre Konsequenzen bedacht.

\subsubsection{Bedeutung und Beziehung der Objekte zueinander in Ex 20,17}

Nachdem Ewald die Urform des Begehrensverbotes auf V.17a eingeschränkt hatte, geriet das Objekt des ersten Prohibitivs "das Haus deines Nächsten" ins Zentrum der Diskussion sowohl in Bezug auf seine kontextunabhängige Bedeutung als auch auf seine Bedeutung im Verhältnis zur Objektreihe des zweiten Prohibitivs.

Nicht ins Gewicht fallen die Versuche von Peters und Charles ${ }^{301}$, die die Urform des zehnten Gebots nur auf den Prohibitiv reduzieren und darin das Verbot der begehrlichen Gesinnung überhaupt entdecken. Eine weitere Variante vergleichbarer Reduktion bieten Sell in und Auerbach 302 .

Sie streichen das nomen rectum der Konstruktverbindung ("deines Nächsten") und machen aus dem Verbot eine Art Rekabitenregel: Du sollst kein Haus begehren bzw. für begehrenswert halten. Sie retten dadurch die Verfasserschaft des Mose, der von Kadesch aus mit Blick auf die bevorstehende Landnahme den Israeliten das nomadische Wüstenideal einschärft. Diese grundlose Reduktion ist von Lewy ausführlich widerlegt worden ${ }^{303}$. Auch in dieser Frage hat die Lösung Ewalds konsequent Schule gemacht. Dabei fungiert "Haus" als Bezeichnung für den gesamten Besitz, den Hausstand bzw. das Vermögen. Der Begriff "Haus" steht wie ein Hypersem, ein Oberbegriff, über den hierarchisch ihm untergeordneten Konkretionen von V.17b. Diese können ihn nur se-

300 CAZELles, Décalogue, 15: "(Ex 20) comporte comme l'autre le dédoublement du dernier interdit entre la "convoitise" de la femme et celle de la maison mais en unifiant le vocabulaire (Thn au lieu de la tout en conservant un texte ancien qui met la "maison" avant "la femme" (car la femme était primitivement comprise dans l'ensemble de la maison)." Vgl. noch DERS., Etudes, 19.

301 PETERS, The Ten Words, 141f; CHARLES, Decalogue,XLVII.

302 SELIIN, Geschichte I, 83; AUERBACH, Moses, $203 f$.

303 LEWY, Ursprung der Zehngebote, 313-316; LEWY schwenkt wieder zur Lösung Ewalds zurūck. 
kundär illustrieren und auseinanderfalten. Ewald hat reichl-ch Nachfolger gefunden ${ }^{304}$. In der Liste der Nachfolger ist Alt gesondert zu erwähnen, weil er intensiver die Objektreihe unter die Lupe genommen hat ${ }^{305}$. Nach inm verbietet das Diebstahlverbot das Stehlen des freien Mannes. Die Söhne werden dem Kreis der freien Männer zugerechnet. Demgegenüber verbietet das Begehrensverbot die Aneignung von Sachguitern und gewaltunterworfenen Menschen, die in ihren wesentlichen Kategorien (Frauen/Sklaven) genannt werden. Das Fehlen der Kinder (außer der Söhne) und des Grundbesitzes wird konstatiert und damit erklärt, daß die Reihe keine Vollständigkeit beabsichtigt. Hier offenbart sich ein Widerspruch. Die Reihe tendiert als "sekundäre Spezialisierung" mit ihrer Vielzahl von Einzelgliedern auf Totalität. Die Schiußformel "alles, was $X$ gehört" sagt über die Länge der Reihe nichts aus und kann deshalb weder für noch gegen die Vollständigkeit ins Feld geführt werden. Daß von den Sachgütern ein so bedeutender Bereich wie Grundbesitz fehlt, bleibt ein schwerwiegender fusfal1. Bei den gewaltunterworfenen Personen stellen die Frau und die Sklaven keineswegs die wesentlichsten Kategorien dar. Der Pater familias hat beschränkte Verfügungsgewalt über seine Frau, dagegen aber unbeschränkte über seine Kinder, die nach israelitischem Haftungsrecht verpfändet und sogar verkauft werden können (vgl. Gen 31,15; 2 Kön 4,1-7; Neh 5,1-5) 306 . Die Söhne zählen nicht per se zu den freien Männern. Hier muß mit 1 Sam 8,11b-17 zwischen den erwachsenen und selbständigen Söhnen und den zu den Kindern zählenden Söhnen unterschieden werden. Letztere sind unverheiratet und leben im Haus der Eltern ${ }^{307}$. Die Sklaven zu den gewaltunterworfenen Personen zu zählen, vereinfacht die Rechtsposition des Sklaven, der auch als Vermögenswert seines Besitzers betrachtet werden kann 308 .

304 OETTLI, Deuteronomium, 41; STRACK, Exodus, 228; DILLMANN-RYSSEL, Exodus, 240; MOWINCKEL, Décalogue, 3; GOLDMANN, The Ten Commandments, 189; PATRICK, La formation littéraire, 248; NIELSEN, Zehn Gebote, 82f; SCHREINER, Die Zehn Gebote, 63f; NOTH, Exodus, 134; und jüngst wieder CRÜSEMANN, Mann und Frau, 32. Bei ihm erhält Ex 20,17 signalwert für die juristische Stellung der Frau: Sie gehört zum Besitz des Mannes.

305 DERS., Verbot, 339f, bes. 339 A 1 und 340 A 1.

306 Vgl. KIPPENBERG, Religion, 27.56f.

307 Vgl. zur Stelle CRÜSEMANN, Widerstand, 66-73.

308 Das belegen Ex 21,20f und die Listen, die Vieh und Sklaven nebeneinander stellen; dazu s.u. 
Alt kann also die Objektreihe von V.17b nicht als Spezifizierung des Oberbegriffs "Haus" $\cong$ "Besitz" plausibel machen.

Der einflußreiche J.J. Stamm läßt zwei verschiedene Auffassungen unausgeglichen nebeneinanderstehen. In seinem Forschungsbericht wie in seiner Monographie ${ }^{309}$ votiert er auf der Linie Ewalds für die Bedeutung "Besitz", im Forschungsbericht an späterer Stelle 310 für den Inhalt "Familie, Hausgemeinschaft". Sein Vorschlag, für V.17b ein Wachstum über zwei Stufen anzunehmen, ändert an der Unausgeglichenheit nichts 311 .

Ein weiterer Versuch hat sich bemüht, die Lücken in den Besitzangaben zu erklären. Er sieht in V. 17b die Konkretion von Besitz aus der Situation des Halbnomaden, der nur bewegliche Habe sein eigen nenne ${ }^{312}$. Dieser Versuch scheitert an der Nennung von "Rind und Esel", denn die Tierhaltung von Großvieh ist nur bei Seßhaftigkeit möglich; Großvieh gehört nicht zur beweglichen Habe des Halbnomaden 313.

Eine letzte Bastion, die für "Haus" als Oberbegriff kämpft, findet sich in den theologischen Wörterbüchern ${ }^{314}$. Dabei werden Stellen ins Treffen geführt, die seit Dillmann als Belege haben herhalten müssen und die ebenso lange immer wieder in Frage gestellt worden sind ${ }^{315}$. Hier verdient die be-

309 DERS., DreiBig Jahre, 206 und Dekalogforschung, $55 f$.

310 DERS., DreiBig Jahre, 303f.

311 Die erste Stufe erstreckt sich auf die Objektreihe, die zweite umfaßt die SchluBformel, die sich wegen ihrer Allgemeinheit als das späteste Stück des Ganzen zu erkennen gibt. STAMM gibt keine Gründe für eine literarkritische und redaktionelle Aufspaltung von $\mathrm{V} .17 \mathrm{~b}$ an; er steht darin im Banne von SCHMIDT, Mose, mit ähnlicher Stufung. Mit MOWINCKEL, Décalogue, $6 \mathrm{f}$ ist dagegen an die Funktion der Schlußformel zu erinnern; sie will gerade pauschal Reihungen abschließen; eine redaktionelle Trennung erweist sich als überflüssig; näheres dazu s.u.

312 Die Vertreter dieser Lösung sind: BOLLE, Bodenrecht, 41; JEPSEN, Beiträge, 295 und MỨLLER, Zur Verkündigung der Zehn Gebote, 528.

313 Vgl. THIEL, Entwicklung, $142 \mathrm{f}$.

314 HOFFNER, Art. בית, ThWAT I, $637 f$ und JENNI, Art. בית, THAT I, 311.

$315 \mathrm{Zu}$ den Kritikern der Belege für den Oberbegriff "Haus" zählen: SCHMIDT, Mose, $91 \mathrm{ff}$; für HERRMANN, Das Zehnte Gebot, soll sein Fazit sprechen, das er nach Prüfung der Belege (75-77) formuliert: "Wo im AT bedeutet בית nachweislich 'Weib, Knecht und Magd, Ochs und Esel und alles, was einer besitzt', sei es ausschlieBlich, sei es einschlieBlich des Hauses selbst?" An HERRMANN hat sich REVENTLOW, Gebot, $87 \mathrm{f}$ angeschlossen. Von den wörterbüchern werden folgende Stellen aufgeführt: 
scheidenere Einteilung von HAL Vertrauen, die für בית die Bedeutung "Besitz Vermögen" im Unterschied zu älteren Wörterbüchern nicht mehr reklamiert ${ }^{316}$.

Wir kommen damit zu einem Zwischenergebnis: בית als Oberbegriff für "Besitz" läßt sich im AT nicht nachweisen. Selbst wenn man darauf eingeht, ergeben sich Schwierigkeiten bei der Zuordnung vom Oberbegriff in V.17a und der erläuternden Spezifizierung in V.17b, denn diese weist Lücken auf. Es fehlen neben der erwähnten Frau die Kinder, und es taucht expressis verbis kein Grundbesitz auf. Das "Haus" ist ja zum Oberbegriff abstrahiert; Wohnhaus und Grundstücke werden also nicht erwähnt. Ein Rückzug auf den verminderten Besitzstand von Halbnomaden wird dadurch abgeschnitten, daß der Bestand an Großvieh die Seßhaftigkeit voraussetzt. Auf diesem Hintergrund wird der Versuch verständlich, בית in V.17a nicht mehr über-, sondern nebenzuordnen und zum Anfangsglied einer Kette von semantisch gleichrangigen konבית kreten Objekten zu machen. Seltener sind dabei jene anzutreffen, die als "Familie" verstehen 317 . Der Umfang der im Begriff eingeschlossenen 0bjekte ist im Vergleich mit dem Oberbegriff "Besitz" herabgesetzt, aber immer noch zu abstrakt und umfassend. Die hebräische "extended family" beinhaltet Frauen, Kinder und abhängige Personen wie Kaufsklaven, Schuldsklaven,

Gen 15,2: Der"Sohn meines Hauses" bezeichnet hier den hausgeborenen Sklaven wie in V.3, vgl. WESTERMANN, Genesis, BK I, 2, $260 \mathrm{f}$ und unter"bitu"AHW I,133 A 7 sowie HAL I, 120 A 4;

Gen 30,30:Hier ist die zweite Bedeutung von "Haus", nämlich "Hausgemeinschaft, Familie" anzusetzen.

Est 8,1: Die Bedeutung "Haus und Inventar" scheint möglich, aber nicht notwendig.

Num: 22,18; 24,13: Wie die Parallelen des hyperbolischen Ausdrucks (Hld 8,7; 1 Kön 13,8) angeben und die geprägte Wendung selbst anzeigt ("das, was sein Haus anfüllt, Silber und Gold"), hat "Haus" hier die Bedeutung von Wohnhaus (mit Inventar?), vgl. GROSS, Bileam, 265.

Der Titel "אשר על הבית" kann nicht als Beleg herangezogen werden (Gen 43, $16.19 ; 44,1.4 ; \mathrm{vgl}$. Gen 41,40$)$. ב kann sich in dieser Kombination beziehen auf den (königlichen) Palast oder auf die (königliche) Familie ode: auf Grundbesitz, weil das Haus und das Grundstück, auf dem es steht, zusammengesehen werden; vgl. dazu HERRMANN, Das Zehnte Gebot, 76.78.81 und zum Titel insgesamgt METTINGER, Salomonic state, bes. 75f.109f; wir folgen METTINGER darin, "that Hebr. בית was sometimes used with reference to (landed) property, estate" (110), akzeptieren aber nicht die stellenangaben auf S. 75 und die Tendenz, בית zum abstrakten Begriff für Besitz zu stilisieren.

$316 \mathrm{Vgl}$. HAL I, $119 \mathrm{f}$ sub voce.

317 Zu STAMM vgl. A 310; HAAG, Der Dekalog, $33 f$ und KLEIN, Verbot, bes. 167. 
Lohnarbeiter, Kl ienten und Gäste ${ }^{318}$. Die In V.17b genannten Objekte "Frau" und "Sklave und Sklavin" passen gut dazu. Nur fehlen auch hier wieder die Söhne und Töchter. Ferner bleibt der Umbruch der Reihe in die Sachgüter ungeklärt. Schließlich ist kaum zu verstehen, warum die "sekundäre" Deuteronomiumfassung aus der gemischten Reihe (Familie - Sachgüter) eine reine Sachguiterreihe gestaltet. Als dritte Möglichkeit bleibt noch בית als Wohnhaus (vielleicht unter Einschluß des dazugehörigen Grundstücks) übrig. Diese Meinung hatte gegen starke Widerstände zu kämpfen. Denn zeitweise stand oder fiel mit dieser Bedeutung die mosaische Verfasserschaft des Urdekalogs. Wurde im 10. Gebot das Begehren des Wohnhauses verboten, dann war das ein sicherer Hinweis für die Seßhaftigkeit der Israeliten, die ihre Nomadenzeit mit den Zelten und mit Mose schon hinter sich gelassen hatten. Erst Greßmann ${ }^{319}$ brachte mit seiner Kadesch-Hypothese Entlastung. Altisrael und Mose haben während ihres längeren Wuistenaufenthaltes in der Oase Kadesch Wohnhäuser kennen gelernt. Also konnte das Begehrensverbot auch mit der angenommenen Bedeutung "Wohnhaus" im Urdekalog verbleiben. In entspannter Diskussion hat diese Bedeutung eine Reihe von Verfechtern gefunden ${ }^{320}$. Gegen בית als Wohnhaus ist nichts einzuwenden, nur bleiben die Anfragen an die Zusammenordnung mit den Objekten von V.17b bestehen. Bei "Sklave und Sklavin" überschneiden sich in der juristischen Betrachtung der sachliche und der personale Aspekt. Es besteht die Möglichkeit, daß sie z.B. in Besitzreihen auftauchen 321 . Eine Zusammenstellung von "Wohnhaus, Sklave und Sklavin" er-

318 Vgl. HOFFNER, Art. בית, ThWAT I, 636 und KIPPENBERG, Religion 27.40

319 DERS., Mose, 475.

320 MATTHES, Der Dekalog, $26 f$ und WITHLEY, Covenant, bes. 47 behandeln die Frage noch unter dem Aspekt der mosaischen verfasserschaft. SCHMIDT, Mose, $91 \mathrm{f}$ koppelt sein Votum mit einem komplizierten wachstumsprozeß von der Grundstufe "du sollst nicht begehren, was deinem Nächsten gehört" bis zum vorliegenden Endtext. Der angenommene Wachstumsproze $\beta$ ist mit vielen Unwägbarkeiten belastet und kann die synoptischen Unterschiede nicht erklären; HERRMANN, Das Zehnte Gebot, 79-82; REVENTLOW, Gebot, 87f; sein aus priesterlichem Wissen stammender Katalog (vgl. S. 56.91f) bleibt eine Chimäre. Sein Charakter (Art der Objekte) und seine Existenz lassen sich nicht belegen; REVENTLOW gebraucht ihn im Dekalog wie einen Joker; PHILLIPS, Criminal Law, 14.9.152; SCHMIDT, Überlieferungsgeschichtliche Erwägungen, 207f; SCHÜNGEL-STRAUMANN, Der Dekalog, 58f; DE MERODE - DE CROY, Rolle der Frau, 271 sieht in Ex 20,17 einen symptomatischen Ausdruck für die Rechtsstellung der Frau im Alten Testament: "Die Frau zählt mit dem Haus (und in Ex 20,17 sogar nach dem Haus) zu den Besitztümern ihres Mannes". Diese Sicht simplifiziert einen komplexen Tatbestand, dazu s.u. 
scheint von daher möglich. Die Frau gehört wie die Kinder zu den der Autorität des Pater familias unterworfenen Personen. In keiner Weise zählt sie aber zum Besitz wie die übrigen Objekte (Wohnhaus, Vieh und andere Mobilien) der Besitzreine ${ }^{322}$. Gerade bei einer Nebenordnung der Lexeme wie in Ex 20,17 muß das Auftauchen der Frau in einer Besitzreihe wie vor allem ihre Position hinter dem Wohnhaus (einschließlich des Grundstücks) auffallen. Insofern ist Ex 20,17 nicht typischer Ausdruck alttestamentlicher Hal tung gegenuiber der Frau, sondern ein singulärer Fall, der auf dem Hintergrund des im atl. Recht Oblichen erklärt werden muß. Bis jetzt konnte das Ewaldsche Lösungsmodell weder das Textwachstum von V.17a nach V.17b plausibel machen noch - damit zusammenhängend - die Exodusfassung als die ältere Ausgabe des Dekalogschlusses etablieren.

\subsubsection{Das Verhältnis der primären Exodusfassung zur sekundären Deutero-} nomiumfassung

Im Hinblick auf den sekundären Charakter der Deuteronomiumfassung hat das Ewaldsche Modell nur die allgemeine Richtung angegeben, nämlich Variation und freie Neuinterpretation. Die Begründungen im Einzelnen sind im Laufe der Dekalogforschung nachgeliefert und detailliert worden. Dabei hat sich ein Kanon von drei zu behandelnden Differenzen herausgebildet:

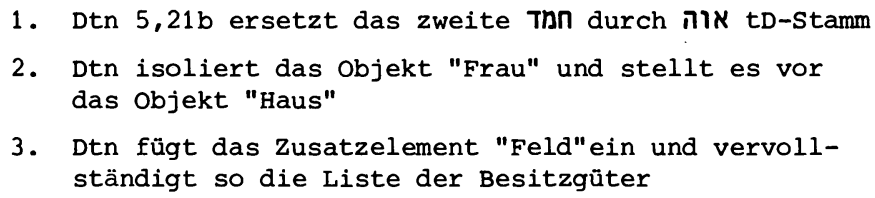

Anhand dieser Punkte soll die Forschung vorgestellt und geprüft werden.

\subsection{Das Verhältnis von אוה}

Man kann die Positionen der Forschung zu dieser Frage gleich zu drei Gruppen systematisieren. Die erste Gruppe von Exegeten geht von einer Synonymie der beiden Verben aus. Das Dtn hat dann eine rhetorisch bedingte Variation des Verbums vorgenommen, die als solche dem sekundären, von Predigern beein-

322 Vgl. MORAN, The Conclusion, 552: "For no more in Israel than at Ugarit was she (a man's wife) from a legal viewpoint a property in the same sense as other possessions; she was not, for example, subject to sale". 
flußten Charakter der Deuteronomiumfassung zugute zu halten ist ${ }^{323}$. Die zweite Gruppe entdeckt in der Deuteronomiumfassung eine Ausdifferenzierung des Begehrens auf der Ebene ethischer Abstraktion in Analogie zum Ehebruchsund Diebstahlsverbot. Die geschlechtliche Begierde wird von der Begierde nach Besitz geschieden ${ }^{324}$. Die dritte Gruppe wird von Stamm angeführt. Er knüpft noch an König an ${ }^{325}$, geht aber einen Schritt weiter ${ }^{326}$. Während חמה Intention und Aktion umfasse, hebe auf die Intention ohne die Aktion ab, sei ein "geistiges Begehren". Somit liege das Motiv der Variation in der fortschreitenden Spiritualisierung durch die Deuteronomiumfassung. Stamm hat sich mit seiner Meinung in der Dekalogforschung weitgehend. durchgesetzt 327 . - Neuere Untersuchungen zum Verhältnis der beiden Verben ergeben neue Gesichtspunkte ${ }^{328}$. In der Debatte um die Synonymie der beiden Verben hat sich der Tatbestand differenziert.

Stamm 329 weist darauf hin, daß beide Verben "begehren" bedeuten, wobei das Faktum von zwei Verben für eine Bedeutungsnuance zwischen ihnen spreche. Die Bedeutungsnuance definiert er durch das bei fehlende Moment der Aktion, die zur Erfüllung der Emotion führe. Moran sieht darin gerade den Bereich der Synonymie; beide Verben umfassen Emotion und Aktion zur Erfüllung der Emotion. Wie bei allen anderen Verben,die ein Wollen oder eine Emotion bezeichnen, müsse man Wunsch und Verwirklichung des Wunsches in einer Einheit zusammensehen. Deswegen müsse die Bedeutungsnuance anders beschrieben werden: Tn bezeichnet ein Begehren, das durch den Ge-

323 Vgl. OETTLI, Deuteronomium, 41; DILLMANN-RYSSEL, Exodus, 240; KÖNIG, Dekalog, 277f; CHARLES, Decalogue, XIX; KÖHLER, Der Dekalog, 177.183; JACOB, Exodus, 897; NIELSEN, Zehn Gebote, 39 ("was nicht nur eine stilistische Variation, sondern auch eine Verwässerung des verbots $\mathrm{zu}$ 'begehren' ist"); PHILLIPS, Criminal Law, 150.152 .

324 Vgl. HOLZINGER, Exodus, 75; JUNKER, Deuteronomium, 473; KOCH, Formgeschichte, 58; zur Kritik s. MITTMANN, Deuteronomium, 142 A 35.

325 Vgl. STAMM, DreiBig Jahre, 199.

326 DERS., Dreißig Jahre, 302 und Dekalogforschung, 56.59.

327 Zum Beleg die Liste seiner Nachfolger: GESE, Der Dekalog als Ganzheit, 75 A 42; REVENTLOW, Gebot, 87; HAAG, Der Dekalog, 35; SCHREINER, Die Zehn Gebote, 64; SCHMIDT, Ưberlieferungsgeschichtliche Erwägungen, 208; BERGER, Gesetzesauslegung, 344; SCHÜNGEL-STRAUMANN, Der Dekalog, 60; MITTMANN, Deuteronomium, $142 \mathrm{f}$.

328 Vgl. MORAN, Conclusion, 545-548; CHILDS, ExOdus, 526; GERSTENBERGER, Art. אוה, THAT I, 74-76; MAYER, Art. אוה, ThWAT I, 145-148; WALLIS, Art. Thn, ThWAT II, 1020-1032. DERS., Dekalogforschung, 56. 
sichtssinn stimuliert wird, אוה dagegen einen Wunsch, der durch ein inneres Bedürfnis, einen Trieb wie Hunger oder Durst geweckt wird ${ }^{330}$. Childs nimmt diese Unterscheidung etwas zurück. Er stimmt dem von Moran beschriebenen Bereich der Synonymie in etwa $z u$, geht dann aber doch wieder in die Richtung von Stamm. Wegen der häufigen Verbindung von אוה mit dem Subjekt אפש dindet er bei אוה die subjektive Seite der Emotion stärker betont als bei אמד, אוה die Gravitation auf Verwirklichung des Begehrens streichen möchte. Die Artikel der Wörterbücher betonen unisono die nahe Verwandtschaft der beiden Verben. Demnach kann sich die Ansicht von der Synonymie der beiden Verben unter anderem auf mehrere Beobachtungen berufen: auf eine enge Parallelisierung beider Verben wie in Gen 3,6, auf die identische Funktion bei Verwendung in analogem Kontext (vgl. Gen 2,9 mit Gen 3,6; Ps 68,17 mit Ps $132,13 f$; Ps 45,12 mit Spr 6,25) und schließlich auf das Faktum des Austausches im Dekalogschluß (vgl. Ex 20,17 mit Dtn 5,21) ${ }^{331}$. Die Synonymie umfaßt den komplexen Sachverhalt von stimulierender Emotion über Pläne und Aktionen bis zur Erfüllung der Emotion. Die Differenz zwischen den beiden Verben bzw. die Bedeutungsnuance liegt auf dem von Moran umschriebenen Gebiet ${ }^{332}$ : Th bezeichnet ein primär exogenes, visuell bedingtes Begehren, אוה dagegen ein primär endogenes, triebbedingtes Begehren 333 .

330 MORAN, Conclusion, 548 A 18.

331 Falls die Artikel auf den Dekalogschluß zu sprechen kommen, gelingt es ihnen nicht, die Synonymie festzuhalten und die Abweichung im Dtn zu erklären. MAYER, Art. אוה, 147f, argumentiert mit der formalen verwandtschaft des Prohibitivs Dtn 5,21b mit den Vetitiven in Spr 23, 3.6. Er vermutet den Einfluß der Weisheit auf das Dtn und schließt, "daß der apodiktische Rechtssatz von Deut in eine Lebensregel umgegossen worden ist". Solche Argumentation ist unhaltbar, weil sie grammatikalische Unterschiede verwischt und mit unklaren Gattungstermini durcheinanderwürfelt. Ein Prohibitiv bleibt ein Prohibitiv und wird durch wörtliche Anklänge an weisheitliche Vetitive keine "Lebensregel". Hier zeigt sich eher die Schwierigkeit, unter der Prämisse der älteren Exodusfassung eine Erklärung für die Abweichung in der Deuteronomiumfassung zu finden. WALLIS, Art. Thn, $1026 \mathrm{f}$ ist da konsequenter: "Warum Deut 5,21 an dieser Stelle das wahrscheinlich primäre אוה ersetzt, ist nicht ersichtlich".

332 CHILDS überzieht seinen Unterschied zu MORAN, denn seine Überlegungen gehen von denselben Fakten aus (Verbindung von אוה mit נפש) und führen im Grunde zu ähnlichen Akzentsetzungen.

333 Vgl. GERSTENBERger, Art. אוה, 75; MAYER, Art. 146; WOLFF, Anthropologie, 33; WALLIS, Art. Thn, 1024. 
Die oben genannte erste Gruppe von Exegeten geht zu Recht von der Synonymie der beiden Verben aus. Im Dekalogschluß ist weder vom Subjekt noch von den beiden Objekten her eine Differenzierung der Verben erfordert. Beide können das sexuelle Begehren bezeichnen. Beide können mit Immobilien und Sachgütern bzw. Gegenständen verbunden werden ${ }^{334}$. In der Konsequenz heißt das: Die Gruppe charakterisiert sachgerecht die Verschiedenheit der Verben als stilistische Variation. Nur indem sie diese als sekundïres Phänomen bewertet, übersteigt sie ihre Kompetenz.

Bei der zweiten Gruppe bleibt undeutlich, ob die Unterscheidung zwischen geschlechtlicher Begierde und Besitzgier an der Bedeutung des Verbs hängt oder am ganzen Satz mit den jeweils verschiedenen objekten. Im letzteren Fall setzt man wie bei der ersten Gruppe Synonymie voraus. Die zweite Gruppe also stellt sachgerecht die Unterschiedenheit des Begehrens voraus. Sie liegt falsch, wenn sie die Unterschiedenheit an der Verbbedeutung festmacht statt an den Objekten. Sie "trifft nicht ins Schwarze", wenn sie das Begehren auf die Emotion einschränkt und in der Ausdifferenzierung des Begehrens ein Zeichen nachträglicher Bearbeitung sieht. Die dritte Gruppe verzerrt den Bereich der Synonymie und verfehlt die Grenzlinie zwischen beiden Verben in Bezug auf Kongruenz und Differenz. Damit entfällt die Spiritualisierung als Motiv sekundärer Bearbeitung.

Somit ergibt die Diskussion der ersten synoptischen Differenz: Im Kontext des Dekalogschlusses sind die Verben אוה austauschbar. Dieser neutrale Sachverhalt begründet per se kein Gefälle von einer primären Exodusfassung zu einer sekundären Deuteronomiumfassung. Ebenso läßt er das Gegenteil zu, nämlich eine sekundäre Vereinheitlichung der Verben gegenüber einer primären Variation. Die Absicht der primären Variation hätte dann darin bestanden, bei analogem Tatbestand in den Verben die Eigenständigkeit der Verbote zu unterstreichen.

\subsection{Die Umstellung der Objekte "Frau" - "Haus"}

In der Frage der sekundären Umstellung der Objekte in der Deuteronomiumfassung ist die Forschung einhelliger Meinung. Schon in der Art, wie die Umstellung beschrieben wird, versteckt sich die Wertung. Die Frau wird aus dem Besitz herausgenommen und den Sachgütern vorangestellt. Der Vorgang

334 Vgl. zu dem in dieser Hinsicht selteneren אוה: neben Dtn 5,21 noch Gen 3,6; Ps 132,13f; Num 34,10 ist wie Spr 19,22 text1ich unsicher. 
wird durchgehend positiv charakterisiert: Die Frau werde als wertvollster Besitz ausgezeichnet. Die Frau werde vom Besitz getrennt und von einer Sache zur Person befördert. Darin zeigt sich das "Weiterschreiten der religiös-sittlichen Erziehung des Jahwevolkes", eine "die Stellung des Einzelnen mehr berücksichtigende Absicht" und eine für das Dtn kennzeichnende Tendenz, die Stellung der Frau anzuheben ${ }^{335}$. Anfragen oder Anmerkungen hat es nur zur Begründung des unbestrittenen, sekundären Charakters der Deuteronomiumfassung gegeben. So hat Junker zu Recht die für das Dtn typische Höherwertung der Frau in Frage gestel1t ${ }^{336}$. Das Dtn bewertet die Frau rechtlich als Eigentum des Mannes und spiegelt dasselbe Niveau der Auffassung wider wie das Bundesbuch und das übrige AT ${ }^{337}$. Darüber hinaus läßt z.B. das quantitative Ungleichgewicht familienrechtlicher Bestimmungen zwischen Bundesbuch und Deuteronomium keinen qualifizierenden Vergleich zu ${ }^{338}$. Interessant ist die Argumentation von Auerbach ${ }^{339}$. Er hält die Entwicklung von der Exodus- zur Deuteronomiumfassung deswegen für zutreffend, weil die anstößige Exodusfassung das Dtn zur Anderung drängte. Eine Umkehrung des Entwicklungsprozesses erscheint ihm unverständlich. Auerbach akzentuiert nach unserer Meinung zu Recht die Singularität der Exodusfassung und die"Normalität" der Deuteronomiumfassung. Wenn sich nun doch ein Grund für die Umkehrung finden läßt? Mittmann verstärkt das Votum für die juristische Angemessenheit der Deuteronomiumfassung. Sie empfinde richtig die Sonderstellung der Frau, die in zwei durch den Dekalog geschützte Lebenssphären hineingehöre: den Bereich des Besitzes und den der Familie ${ }^{340}$. Die von den Anmerkungen angedeuteten Linien sind weiter auszuziehen. Die Frau hat eine besondere soziale

335 Vgl. den Stammbaum: DILLMANN-RYSSEL, Exodus, 240; HOLZINGER, Exodus, 75; KÖNIG, Dekalog XII, 379; STEUERNAGEL, Deuteronomium, 22; CHARLES, Decalogue XIX; BEER, Exodus, 103; STAMM, Dekalogforschung, 9; HAAG, Der Dekalog, 19; SCHREINER, Die Zehn Gebote, 64; RICHTER, Recht, 130 A 27; PHILLIPS, Criminal Law, 152; SCHMIDT, Überlieferungsgeschichtliche Erwägungen, 208; BERGER, Gesetzesauslegung, 344; SCHÜNGEL-STRAUMANN, Der Dekalog, 59f; MITTMANN, Deuteronomium, $142 \mathrm{f}$.

336 DERS., Deuteronomium, 473.

337 Der Mann als Besitzer der Frau in: Gen 20,3; Ex 21,3.22; Dtn 22,22; 24,4; 2 Sam 11,26; zu Lev 21,4 vgl. ELLIGER, Leviticus, 279 z. Stelle.

338 Das Bundesbuch enthält zwei Bestimmungen familienrechtlicher Art: das Sklavinnenrecht Ex 21,7-11; den Fall der Verführung einer Jungfrau Ex 22,15f. Das Dtn steigert die Zahl und den Reichtum der Fälle: Dtn 15,74 (Aufnahme der Sklavin in die Familie); $21,10-14$ (Heirat der Kriegsgefangenen); 21,15-17 (Erbrecht des Erstgeborenen); 22,13-21.22.23-27. 28-29 (Beischlaf und Ehebruch); 23,1 (Blutschande); 24,1-4 (Wiederaufnahme einer Geschiedenen); 24,5 (Befreiung vom Kriegsdienst); 25,5-10 (Leviratsehe).

339 DERS., Moses, 202. 
Stellung inne. Einerseits gehört sie zum Eigentum des Mannes, andererseits kann von Besitz nur in einem uneigentlichen Sinne gesprochen werden. Diese Brechung in der Redeweise des AT wird zu oft übersehen. Besser spricht man von der Frau als einer Person, die männlicher Autorität unterworfen ist, und trennt sie von Sachbesitz. So wird die Frau nicht als Ware betrachtet mit Sachwert von Vieh, Mobiliar und Immobilien. Zwar bleibt sie passives Objekt gegenüber männlichen Entscheidungen, rutscht aber nicht in den Status einer Sklavin ab. Die eigene Tochter kann als Schuldsklavin und Nebenfrau verkauft werden (Ex 21,7-11), die eigene Frau aber nicht, selbst wenn sie als Kriegsgefangene Eigentum des Mannes geworden ist (Dtn 21,14) ${ }^{341}$. Es mag den Anschein haben, als ob im Kontext der Ehe gelegentlich von der Frau im Stile des Sachenrechts geredet wird, aber es hat eben nur den Anschein; die Frau tritt immer als Person auf ${ }^{342}$. Das gilt sowohl für Israels Dasein als Halbnomaden wie für die spätere Zeit der Seßhaftigkeit ${ }^{343}$. Demnach entspricht die Sonderstellung, die die Deuteronomiumfassung im Dekalogschluß der Frau zuweist, der Auffassung der alttestamentlichen Gesetzgebung. Weder kann mit Steuernagel von einer für das Dtn typischen Anhebung der sozialen Stellung der Frau gesprochen werden, noch vertritt Dtn 5,21 gegenüber der Exodusfassung eine fortgeschrittene, höhere Stufe in der Einschätzung der Frau. Umgekehrt fällt die Exodusfassung aus dem Rahmen, insofern sie die zu erwartende Sonderstellung der Frau aufgibt. Der von Auerbach vermißte Grund für die Veränderung in der Exodusfassung ist zu finden.

\subsection{Das überschüssige Element "Feld" in der Deuteronomiumfassung}

Auf der Linie des Ewaldschen Modells liegt es, daß die Forschung durchweg das Element "Feld" in Dtn 5,21b als Einschub behandelt. Die einen betonen mehr die Umdeutung des Oberbegriffs "Haus", die durch die Einfügung von "Feld" zustande kam ${ }^{344}$. Sie sind oben unter 2.6.2.2 widerlegt worden. Der

340 MITTMANN, Deuteronomium, 142.

341 Vgl. DE VAUX, Institutions I, $48 f .67$ und BOECKER, Recht und Gesetz, $96.138 f$.

342 Vgl. WOLFF, Anthropologie, 245.247.256; SCHARBERT, Ehe, bes. 224.

$343 \mathrm{Vgl}$. THIEL, Entwicklung, 206f.486ff.

344 DILLMANN-RYSSEL, Exodus, 240 und CHARLES, Decalogue, XIX. 
Großteil sieht darin eine spätere Vervollständigung und Anpassung des Besitzstandes, sei es aus der Zeit der Seßhaftigkeit, sei es unter Einfluß der Propheten, die für den Erhalt der נחלה eintreten (Hos 5,10; Mich 2,2; Jes 5,8$)^{345}$. Diejenigen, die mit der Zeit der Seßhaftigkeit argumentieren, übersehen, daß die Seßhaftigkeit mit "Rind und Esel" schon gegeben ist ${ }^{346}$. Ein Einfluß der Propheten bei der Zufügung scheint möglich. Nur hängt eine Entscheidung darüber zusammen mit der zeitlichen Ansetzung des Dekalogs und davon abhängig seiner Ergänzungen. Sie soll bei diesem Analyseschritt nicht entschieden werden. Der Vorschlag zwingt aber, die Besitzreihe des Dekalogs in den Kontext des AT und eventuell darüber hinaus in das sozial-geschichtliche Umfeld des Alten Orients zu stellen. Von vornherein soll eine versteckte Meinung gestellt und kritisiert werden. Das "Feld" als späteren Zusatz zu behandeln, entspringt oft der leitenden Ansicht, der Dekalog sei "juristisches Urgestein" aus der Nomadenzeit Altisraels, die keinen Ackerbau gekannt habe. Selbst wenn man den Dekalog als uralt einschätzt, bleibt die Frage, ob die Vorzeit des späteren seßhaften Israel mit der Charakterisierung "nomadisch" exakt beschrieben ist. Gemeint ist die Zeit der Patriarchen. Das Milieu, das ihre Erzählungen widerspiegeln, läßt sich als "halbnomadisch" bezeichnen: Die Lebensweise von Kleinviehnomaden in ständigem Kontakt mit Städten und Dörfern und selbst im Obergang zur Seßhaftigkeit. Die Wirtschaft solcher Halbnomaden basiert - pauschal gesagt - auf Kleinviehhaltung mit subsidiärem Ackerbau und bewegt sich hin auf Ackerbau mit subsidiärer Viehwirtschaft ${ }^{347}$. Bei diesem Befund muß das "Feld" nicht unbedingt erst später hinzugesetzt worden sein. Und wenn, wie Moran nachgewiesen hat ${ }^{348}$, Dtn 5,21b einem bestimmten altorientalischen Typ von Besitzliste entspricht, die Güter aufführt, die verkauft, getauscht oder geerbt werden konnten, dann schlägt die Frage um: Nicht - warum und wann wurde "Feld" in der Deuteronomiumfassung hinzugefügt, sondern - warum und wann wurde "Feld" in der Exodusfassung ausgelassen?

Der Forschungsüberblick hat die historische Bedeutung des Ewaldschen Modells beschrieben, es durchdiskutiert und in Frage gestellt. Damit ist das Terrain ausgekundschaftet, auf dem ein eigener Vorschlag zur Lösung aufgebaut werden kann.

345 So OETTLI, Deuteronomium, 41; HERRMANN, Das Zehnte Gebot, 77f; KÖHLER, Der Dekalog, 183; BOLLE, Bodenrecht, 41; JEPSEN, Beiträge, 294f; PHILLIPS, Criminal Law, 152; SCHMIDT, Überlieferungsgeschichtliche Erwägungen, 207; SCHÜNGEL-STRAUMANN, Der Dekalog,59f; MITTMANN, Deuteronomium, 142

$346 \mathrm{Vgl}$. oben A 312 . 


\subsubsection{Der eigene Lösungsvorschlag}

Der eigene Vorschlag liegt auf der Linie der bisher gefundenen Erklärungen zu den synoptischen Differenzen. Er arbeitet mit der Hypothese von der Priorität der Deuteronomiumfassung und knüpft an die obige Diskussion des Ewaldschen Modells an.

\subsubsection{Die syntaktische Verknüpfung in der Besitzliste}

Wir beginnen mit den Differenzen, die in der bisherigen Forschung stiefmütterlich behandelt wurden: den Unterschieden in der syntaktischen Verknüpfung der Objekte des zweiten Prohibitivs. Nach Dillmann ${ }^{349}$ besagen sie nicht viel und selbst bei Lohfink 350 werden sie zwar genau notiert, bleiben aber unerklärt. Als einziger arbeitet mit ihnen $B$. Jakob ${ }^{351}$, indem er die zweifache Asyndese in der Deuteronomiumfassung auf eine beabsichtigte Trennung der objekte zurückführt. Der von jeder Dekaloghypothese unbelastete Beobachter nimmt zuerst die konsequente Syndese in Ex 20,17b wahr; ihr gegenüber fällt ihm die unregelmäßige Asyndese zwischen erstem und zweitem wie zwischen viertem und fünftem Objekt in Dtn 5,21b auf. In einem Wechsel von Syndese und Asyndese hätte man die Absicht erkennen können, die Reihe in eine Abfolge von Paaren zu gliedern. So aber wird der in Dtn 5,21b fehlende Rhythmus durch kein Stilgesetz erklärt ${ }^{352}$. Es bleibt nur folgende Möglichkeit: Die im Hebräischen übliche Polysyndese von Ex 20,17b verweist auf sekundäre Glättung der primären "lectio difficilior" von Dtn 5,21b. Deren Unregelmäßigkeit zeigt Spuren des Wachstums zur jetzt vorliegenden Reihe mit sieben Gliedern. Als Stufen unter Anwendung des Sparsamkeitsprinzips sind denkbar: Eine ursprünglich sechsgliedrige Reihe mit Asyndese d.h. Zäsur in der Mitte zwischen "Sklavin" und "Rind" ist nachträglich durch die eingeschobene Glosse "Feld" erweitert worden. Allerdings würde man dann eher ein Nomen mit waw explicativum erwarten oder eine Anpassung an die Syndese,

347 Vgl. DE VAUX, Histoire, 213-223, bes. 220ff; ebenso THIEL, 142-173, bes. 164.169 .

348 DERS., Conclusion, 548-552.

349 DILLMANN-RYSSEL, Exodus, 240.

350 DERS., Dekalogfassung, 25.

351 DERS., Exodus, 897f.

$352 \mathrm{Vgl}$. zur Syndese und Asyndese bei Reihungen von Nomina GES-K $\S 154 \mathrm{a}$ N1a und JoÜoN, $\S 177$ o-r. 
weil "Feld" ja auch durch enklitisches Personalpronomen in die Reihe eingepaßt wurde. Oder eine ursprüngliche Dreierreihe mit waw copulativum beim letzten Glied (Haus, Feld und alles, was deinem Nächsten gehört) ist nachträglich durch die beiden Paare ("Sklave und Sklavin", "Rind und Esel") erweitert worden. Die Asyndese zwischen den beiden Paaren dient dann zur Trennung der beiden Paare. Eine Entscheidung kann nur die Prüfung einschlägiger Parallelreihen ergeben. Die Priorität der Deuteronomiumfassung vor der glättenden Exodusfassung wird von dieser Entscheidung nicht mehr berührt.

\subsubsection{Die Schlußvendung "alles, was NN gehört"}

Diese Schlußwendung war von H. Schmidt ${ }^{353}$ wegen ihrer Allgemeinheit als einziges objekt des letzten Prohibitivs zugelassen und von Stamm 354 eben wegen dieser Allgemeinheit als spätester Zusatz ausgewiesen worden. Mowinckel hat sie als Ende längerer Reihen verteidigt ${ }^{355}$. Die Wendung ist alttestamentlich so verfestigt ( 3 + אלר + NN/ePP), daß sie als Formel behandelt werden kann. Darüber hinaus ist sie im altorientalischen Umfeld verbreitet.

In den Amarnabriefen taucht sie in den Grußformeln auf, die über den angeredeten Adressaten hinaus erweitert sind und weitere Personen und sogar Besitz einschließen ${ }^{356}$. Hier steht sie (ana mimmuka $\cong$ alles, was dir gehört) hinter den Sachgütern und schließt die Reihe ab.

Im ugaritischen Briefformular finden wir das Analogon in der mehrgliedrigen Grußformel vom Typ: ana muhhi NN lü šulmu ana ... ana gabbi mimmu ša NN danniš (dannǐs) $1 \bar{u}$ šulmu $3 \dot{5} \dot{y}$. Hier endet ebenso die Reihe der Personen und Sachgüter in der Formel: ana gabbi mimmu Sa NN. Der Wechsel vom enklitischen Personalpronomen in der Formel der Amarnabriefe zum Relativsatz ist

353 DERS., Mose, 92.

354 DERS., Dreißig Jahre, 206 und Dekalogforschung, $55 \mathrm{f}$.

355 DERS., Décalogue, $6 \mathrm{f}$.

356 Die Stellen entsprechen dem Typ: ana kaక̌ lū šulumu ana ... ana mimmuka dannił danniక̌ lū Sulmu; zum Briefformular die Untersuchung von SALONEN, Höflichkeitsformeln; zu den Amarnabriefen ebd., 63-73ff, bes. Nr. 2 unter den Paradigma EA 19,5-8; ebenso KRISTENSEN, Formulas, bes. 152 A 71 .

357 KAISER nennt sie in seiner Untersuchung die "umgekehrte Grußformel", S. KAISER, Formular, 16f; vil. ferner SALONEN, Höflichkeitsformeln, 75; KRISTENSEN, Formulas, 152 A 70. 
durch den Titel bedingt, den der Angeredete gleich zu Beginn der Grußformel erhält und mit dem er auch in der durch Relativsatz erweiterten Schlußformel ausgezeichnet wird ${ }^{358}$.

Eine bescheidene Parallele in einer wesentlich kürzeren Grußformel, aber mit den uns interessierenden Bestandteilen bietet 1 Sam 25,5f im Gruß Davids an Nabal: "Heil sei dir, deinem Hause und allem, was dir gehört!"

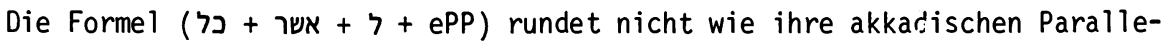
len eine Reihe $a b$, sondern ersetzt hier eine ganze Liste von Besitzgütern. Wie in den Amarnabriefen verbindet sie sich mit dem enklitischen Personapronomen.

Außerhalb der Grußformeln finden wir dieselbe Formel in derselben Funktion in Besitzreihen, wo sie Listen von unterschiedlicher Detaillierung abschließt. So ist sie in der Form "gabbu/i/a mimmi/ułu (= alles weitere, was ihm gehört) häufig in ugaritischen Kaufverträgen zu finden; sie bezieht sich vorwiegend auf Mobilien ${ }^{359}$, kann aber auch Immobilien einschliessen. In den Rechtsurkunden sichert sie $a b$, daß kein Besitzobjekt vom Rechtsgeschäft ausgeschlossen wird ${ }^{360}$.

Der atl. Befund fügt sich in das Bild ein.Die Formel (כל אלר + ePP) bezeichnet am Ende von Besitzreihen meist die Mobilien ${ }^{361}$. In den Erzählungen ist es schwieriger als in Rechtsurkunden, die Reichweite der Formel genau abzugrenzen. Mit dieser Einschränkung kann die Formel an einigen Stellen den Gesamtbesitz unter Einschluß der Immobilien meinen ${ }^{362}$. Naturgemäß umfaßt die Formel die Objekte, die ihr der nahe und weite Kontext übriggelassen bzw. zugewiesen hat.

358 Die Stellen gibt KRISTENSEN, Formulas 152 A 70 an; die häufigsten Titel sind: bëlu, sarru und కamsu.

359 So MENDELSOHN, Samuel's Denunciation, 20 A 15.

$360 \mathrm{zu}$ Funktion und Stellen vgl. MORAN, Conclusion, 550f; zu den dort in den Anmerkungen 27-29 genannten Stellen sind zu ergänzen: RS 17. 129 (PRU IV 167); RS 17. 355 (PRU IV 209); RS 17. 378A (PRU VI 48f).

361 Unter Mobilien werden Viehbesitz, Personal und Wertgegenstände verstanden; die angeführten Belege beanspruchen keine lückenlose Vollständigkeit: Gen 12,$20 ; 13,1 ; 24,2.35 \mathrm{f} ; 25,5 ; 31,21 ; 45,1$ of; $46,1.32$; 47,$1 ; \operatorname{Ex~} 9,19 ; \operatorname{Num} 1,50 ; 16,30.33 ; \operatorname{Dtn} 8,13 ;$ Jos $6,22.23 .25 ; 7,15.24$; 1 Sam 25,21; 2 Sam. 6,12//1 Chr 13,14; 1 Kön 20,4; Ijob 1,10-12.

362 Gen 20,7 $(31,1)$; 39,4-6; 2 Kön 8,6. 
Im Dekalogschluß paßt sich die Formel der Funktion an, die die altorientalischen und alttestamentlichen Parallelen angeben. Sie schließt die Reihen von Besitzgütern $a b$ und bezeichnet pauschal den Rest von Mobilien, den die vorausgehenden Glieder noch nicht genannt haben. Nur in einem Punkt weicht sie ab: Sie ersetzt das erwartete enklitische Personalpronomen durch dasselbe Nomen ("deines Nächsten"), das als nomen rectum zum ersten Objekt der Reihe hinzutritt. Syntaktisch zwingt nichts - auch nicht die Länge der Reihe - zur Aufgabe des pronominalen Rückverweises. Deshalb ist darin ein bewußt eingesetztes stilistisches Mittel zu sehen: Sei es daß die Reihe und damit der Dekalog volltönend mit Rücksicht auf die Konstruktverbindung des ersten objekts abgeschlossen werden soll; sei es, daß ein Gleichklang mit dem Schluß des vorausgehenden Prohibitivs beabsichtigt ist.

\subsubsection{Zwischenergebnis}

Die Diskussion des Ewaldschen Modells und die eigenen Beobachtungen zum Dekalogschluß haben bisher ergeben: Durch seine syntaktisch glattere Reihung erweist sich der Schluß der Exodusfassung (V.17b) als sekundär gegenüber der arhythmischen Fügung in der Deuteronomiumfassung (V.21b), die Spuren des Wachstums zeigt. In der semantischen Kohärenz der Reihe dagegen bietet die Exodusfassung einen gegenüber der Deuteronomiumfassung komplexen Tatbestand. Ihre Reihe, die eigentlich mit dem objekt des ersten Prohibitivs in V.17a beginnt, ist mit dem Objekt "Frau" belastet sowohl in Bezug auf dessen Position wie in Bezug auf dessen Auftauchen in der Besitzreihe überhaupt.

Demnach steht die Exodusfassung unter bestimmten Zwängen, die für die Deuteronomiumfassung mit ihrer einheitlichen Besitzreihe und der Trennung vom 0bjekt "Frau" nicht gelten. Wir sehen darin wiederum einen Hinweis auf die Priorität der Deuteronomiumfassung gegenüber der sekundären Exodusfassung. Ein Oberblick zu analogen Besitzreihen außerhalb und innerhalb des AT soll weiteren Aufschluß bringen und die Hypothese erhärten.

\subsubsection{Besitzreihen aus dem altorientalischen Umkreis des AT}

Es soll in keiner Weise an dieser Stelle das Material vollständig erfaßt werden, sondern nur bestimmte stereotype Reihungen genannt werden, die für einen Vergleich mit dem Dekalogschluß Gewinn bringen. 
Der Codex Hammurabi ( $\mathrm{CH})$ bezeichnet mit der festen Trias von eqlu, kīru, bītu (= Feld, Garten Haus) den Immobilienbesitz des Vollbürgers, sei es in privater Hand oder als Lehen (ilku) ${ }^{363}$. Die Trias dient daneben der Rechtssystematik im Codex selbst. $\mathrm{CH} \S 36$ bis 41 betreffen das ilku-Feld, den Garten und das Haus und leiten über zu den Paragraphen des privaten Vermögensrechts, die wiederum der Trias entsprechen, nach "Feld" (§§ 42-58), "Garten" ( $\S \S 59-66)$ und "Haus" (§§ 67-H/68) geordnet 364.

Die Mittelassyrischen Gesetze (MAG) führen statt der obigen Trias das Wortpaar "Feld und Haus" ein ${ }^{365}$, wobei der Terminus "eqlu/Feld" seinen Bedeutungsumfang ausweitet und im Gegensatz zum unkultivierten Land ("qaqquru") nun das kultivierte Grundstück bezeichnet; das mag das abgegrenzte urbare Ackerland sein oder mit Brunnen ausgestattet und mit Bäumen bepflanzt auch der Garten, wie er im zweiten Glied der Trias aus dem $\mathrm{CH}$ genannt wird ${ }^{366}$. Gelegentlich kann "eqlu" auch den gesamten Immobilienbesitz einschließen und für das Wortpaar "Feld und Haus" stellvertretend stehen 367 . Der Terminus "bîtu" muß seinerseits nicht auf das einzelne Gebäude beschränkt sein, sondern kann auch das dazugehörige Land einschließen im Sinne des deutschen "Haus und Hof" 368 . Das Neubabylonische Gesetzes fragment übernimmt das Wortpaar "Feld und Haus" in $\S 5$.

Für die ugaritischen Rechtsurkunden hat Moran das Material gesichtet ${ }^{369}$. Im Anschluß an und in Weiterführung von Nougayrol und Boyer ${ }^{370}$ unterscheidet er einen dreifachen Sprachgebrauch bei der Bezeichnung von Besitz: den gelegentlichen Solo-Gebrauch von "bitu" sowohl für das Wohnhaus als auch für ein Wohnhaus und das dazugehörige Land als auch für das Land

$363 \mathrm{CH} \S \S 30-32 \cdot 36-41.150 .165 ; \mathrm{vgl}$. DRIVER/MILES, Babylonian Laws I, 345. Die Reduktion der Trias auf das Duo "Feld, Garten", in $\mathrm{CH} \S \S 27$ bis 29 ist exklusiv gemeint und durch die spezifische Rechtslage verursacht, vgl. DRIVER/MILES, Babylonian Laws I, 116 und SZLECHTER, Effets, 23-25.26.32f.

364 Vgl. PETSCHOW, Codex Hammurabi, 153f; zu den sumerischen Vorgängern der Trias mit Stellen ebd., 153 A 40.

365 MAG Tafel; $\S 45$ und Tafel B $\S 6$.

366 DRIVER/MILES, Assyrian Laws, 259-262.293.

367 MAG Tafel A $\S 45 \mathrm{z} 64$; B $\S 6$ z 26; vgl. DRIVER/MILES, Assyrian Laws I, 306.486 .500 .

368 MAG, A $\S 46 ;$ vgl. DRIVER/MILES, Assyrian Laws I, 235.

369 MORAN, Conclusion, 549-552.

370 PRU III, 25 bes. A 4 ; 303 bes. A 1 . 
bzw. Grundstück. Dieser Sprachgebrauch läuft dem der Mittelassyrischen Gesetze parallel. Ebenso kann "eqlu" allein den Besitz bezeichnen, was wiederum den Sprachgebrauch der Mittelassyrischen Gesetze analog ist. Die zweite Verwendungsweise herrscht vor; sie spannt "Haus und Feld" zu einem festen Paar zusammen. Das Wortpaar ist die gängige Bezeichnung einer Besitzeinheit bzw. einer landwirtschaftlichen Latifundie. Man kann im Wortpaar ein Hendiadyoin gleich dem deutschen "Haus und Hof" sehen; dabei liegt im Wortpaar die Reihenfolge fest (umgekehrt zu der der MAG), wohingegen die Numeruskongruenz durchbrochen werden kann ${ }^{371}$. Die dritte Sprachregelung baut auf der zweiten auf. Sie setzt das Wortpaar "Haus und Feld" an die Spitze und ergänzt weitere Besitzguiter, indem sie entweder die oben schon vorgestellte Schlußformel anhängt oder einzelne tote und lebende Guiter aufzählt und dann mit der Schlußformel abrundet ${ }^{372}$.

Im Raum Palästina hat die Archäologie bisher nur mit wenig Vergleichsmaterial aufwarten können. Einschlägig ist eine akkadische Rechtsurkunde aus Hazor, die in die Zeit des 18.-16. Jh.s v.Chr. zu datieren ist. Drei Männer führen vor dem König einen Rechtsstreit mit einer Frau um "ein Haus und einen Garten im Stadtgebiet von Hazor und um einen Garten im Stadtgebiet von Giladima" (dinam igru ana biti u kiri ina Hazura u kiri ina Giladima). Die Herausgeber erwägen für das Logogramm E-ti (三 biti) die Lesung GANA ( $=$ eqlēti) 373. Beide Möglichkeiten "Feld und Garten" oder "Haus und Garten" zeigen eine gewisse Nähe zur Trias des $\mathrm{CH}$.

Der zweite Fund stammt aus Gezer zur Zeit der assyrischen Okkupation ${ }^{374}$. Die beiden Tafelfragmente von Kaufverträgen werden in die Jahre 649/648 v. Chr. datiert. Ihr Zustand erlaubt keine großen Rückschlüsse; trotzdem wird ihr Inhalt deutlich: Verkauf von Immobilien in privater Hand. Die erste Tafel spricht in $Z 3$ (Vorderseite) von "sina awelute bêlê bitê ekli"

371 Das Gebräuchliche ist die Kombination von Singular und Singular; daneben findet sich auch Plural + Plural z.B. RS $16.148+254$ B in $\mathrm{z} 6$ (PRU III 116); RS 16. 167 in Z 6 (PRU III 63); RS 17. $378 \mathrm{~A}$ in $\mathrm{Z} 16$ (PRU VI 48f); Singular + Plural z.B. RS 15. 90 in Z 20 (PRU III 54); RS 16. 267 in Z 12 (PRU III 110); RS 16. 166 in Z 4 (PRU III 48).

372 Vgl. MORAN, Conclusion, 549 A 27; zu ergänzen RS 17. 378 A (PRU VI 48f).

373 HALLO/RADMOR, Lawsuit, bes. 7 .

374 MACALISTER, Gezer, 22-31; vgl. GALLING, Präfekten, bes. 81-86. 
( zwei Besitzern von Häusern, Feld [ern]). Die zweite Tafel nennt in $Z$ If (Vorderseite)einen "Natanja, bel ekli ( Natanja, Besitzer eines Grundstücks). Eine Verbindung mit dem Sprachgebrauch der MAG kann in Frage kommen.

Der grobe Oberblick führt die Verbreitung und die Konstanz der stereotypen Besitzangaben vor Augen. Auf Grund analoger sozio-ökonomischer Bedingungen und der historisch-politischen Verflechtungen macht Palästina davon keine Ausnahme. Die alttestamentlichen Stereotype in den Besitzangaben werden weiteren Aufschluß geben.

\subsubsection{Die alttestamentlichen Reihen für Besitz}

Großreihen wie die im Dekalogschluß sind natürgemäß aus Einzel teilen zusammengesetzt, darüber hinaus zeigt die Syntax von Dtn 5.21b durch ihren Hinweis auf Wachstumsstufen der Reihe denselben Tatbestand an. Wir behandeln zuerst die Reihen mit Immobilien- und Sachbesitz und gehen dabei vom Einzelbegriff über die Kurzreihen zu den komplexen Großreihen vor.

Der Terminus שדה kann den Grundbesitz bzw. das Grundstück des Privatmannes bezeichnen ${ }^{375}$. Ebenso kann für die gleiche Bedeutung בית eintreten ${ }^{376 .}$ Beide Einzelbegriffe verbinden sich zu einem festen Wortpaar בית / שדה , das für das 8. Jh.v.Chr. und früher gut bezeugt ist ${ }^{377}$. Das Gerichtswort Jes 5,8-10 erwähnt das Wortpaar בית/ שדה durch Parallelismus membrorum zerteilt - nur im einleitenden Weheruf 5,8. Die Unheilsansage Jes 5,9f spielt darauf an und nennt die Häuser sowie "zehn Joch Rebland (כרם) neben dem "Chomär Saatgut". Nach dem Schema, daß die Strafe sich im Bereich der

375 Vgl. z.B. Gen 33,18; 1 Kön 2,26; Neh 13,10.

376 Dazu HAL I, 120 A 2; vgl. Hos 8,1; 9,15; 11,11 und die Kommentare von WOLFF, Hosea, 176.217.262 und RUDOLPH, Hosea, 162.188; desgleichen 1 Sam 25,1 vgl. STOEBE, Samuel, 446 und 1 Kön 2,34 vgl. NOTH, 1 Könige, $36 \mathrm{f}$ und WÜRTHWEIN, 1 Könige, 24. Mit METTINGER, Solomonic State, $73 \mathrm{ff}$ stimmen wir nur in der Meinung überein, die Bedeutung von בית auch auf Grundbesitz auszudehnen (s.o. A. 315). Seine Stellenangaben auf S. 75 können die Bedeutung "Besitz" nicht belegen und sind der falsche Ausgangspunkt zur Inhaltsbestimmung von . אשר על הבית. Die Einwände von KATZENSTEIN, The Royal Steward, 150f, Gen 44,1.4 aus der Josefsgeschichte für den Titel reklamieren zu können, bleiben bestehen. Die Josefsgeschichte insgesamt bietet keine Belege für בית in der Bedeutung von Gesamtbesitz. - Hier in dieser Anmerkung wird בית auch nur als das mit dem Wohnhaus verbundene Grundstück gefordert.

377 Gen 39,5; 2 Kön 8,3.5; Jes 5,8; Mich 2,2. 
Sünde auswirkt ${ }^{378}$, greift die Unheilsansage den Begriff "Haus" aus dem Weheruf wörtlich auf, zerlegt aber den Begriff "Feld" in die Spezifikationen von "Weinberg" und "Saatgut" (hier stellvertretend für Acker). Das Verständnis von "Feld" ähnelt dem von "eqlu" in den MAG ${ }^{379}$. Damit schlägt der בית - שדה 5ortgebrauch des Gerichtswortes Jes 5,8-10 eine Brücke vom Duo zur Trias בית - שדה - כרם und verweist zugleich auf die enge Verbindung von

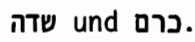

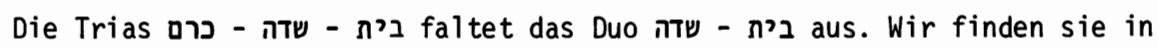
der Erzählung vom Ackerkauf des Jeremia Jer 32,15 - einer Zeichenhandlung, die eine künftige Belebung des Handelns mit Immobilien andeutet ${ }^{380}$. Sie taucht leicht variiert in der Rechabiterregel Jer 35,7.9 auf (Haus, Saat, Weinberg) ${ }^{381}$. Das "Lob der tüchtigen Hausfrau" 382 gibt in Spr 31,16 die Aktionsbereiche der selbständigen Hausfrau an und nennt nacheinander: Feld und Weinberg. Der häusliche Bereich wird öfters angesprochen, so in Spr 31,15.21.27, wobei der Begriff "Haus" zwischen den Bedeutungen für Familie und Wohnhaus pendelt. Die Nehemia-Denkschrift schildert soziale Konflikte und nennt in Neh 5,3.11 eine Gruppe, die ihren Grundbesitz den Gläubigern hat verpfänden müssen. Der Grundbesitz wird mit der umgestellten Trias umschrieben: "Felder, Weinberge,Häuser" ${ }^{383}$. Die späte redaktionelle Stelle Jes 32,12f läßt die Trias anklingen (Felder, Weinstock, Land, Häuser).

Das Duo ברם - בית in starrer Abfolge und fester Verbindung mit den Verben "bauen" und "pflanzen" ist von Bach untersucht und als Formel nachgewiesen

378 Zum Prinzip an dieser Stelle vgl. WILDBERGER, Jesaja I, 185 und FOHRER, Jesaja I, 80.

379 S.O. zu 2.6.3.4.

380 Zur Einordnung des Textes im Jeremiabuch vgl. THIEL, Redaktion, 111; FOHRER, Propheten, 156-158; zum Problem des Immobilienverkaufs KIPPENBERG, Religion, $33 f$.

381 Nach FOHRER, Propheten, Bd. 7, 141 ist der Zusatz "Feld" bei "Saat" in Jer 35,9 eine überflüssige Verdeutlichung.

382 CRÚSEMANN, Mann und Frau, 36 datiert das "Lob" in die persische Epoche.

383 Zur sozialgeschichtlichen Interpretation vgl. KIPPENBERG, Religion, 56ff; nach ihm (S. 57) bezeichnen die VV.3 und 11 dieselbe Gruppe; V.11 hat die Trias um das Glied $n^{T}$ T erweitert, wahrscheinlich unter dem Einfluß der nachfolgenden Pfänderreihe: Geld, Korn, Most, Öl; dabei stellt die Dreiergruppe "Korn, Mose, Öl" ein altbekanntes Klischee dar; dazu SEITZ, Deuteronomium, 286 A 129. 
worden, die im Milieu des freien, seßhaften Bauern entstanden ist ${ }^{384}$. Die ältesten Bezeugungen der zweigliedrigen, nicht erweiterten Formel dürften in Am 5,11385 und in Dtn 22,8f vorliegen ${ }^{386}$. Von den um ein Glied erweiterten Belegen sind die ehrwürdigsten Dtn $20,5-7 ; 28,30^{387}$.

In den alten Gesetzen wie Bundesbuch und Privilegrecht Jahwes von Ex 34 taucht für Grundbesitz und Grundstück zuerst einmal der Begriff אר auf. So heißt der Prohibitiv Ex 34,24b, der einer alten Bearbeitung des Privilegrechts Ex 34,12-26 zugehört: "Niemand soll nach deinem Land trachten!" Er verbietet, daß andere die Abwesenheit der Männer zu Zeiten der Wallfahrt dazu nutzen, "sich am heimatlichen Besitz der Pilger zu vergreifen" 388. Das 0bjekt ארץ hat hier die kleinräumige Bedeutung von Grundbesitz eines Einzelnen ${ }^{389}$. In gleicher Weise spricht die alte Vorschrift über die Ackerbrache in Ex 23,10-11aa nur von ארץ. Die Vorschrift ist wahrscheinlich schon früh durch V.11aßr.b ergänzt ${ }^{390}$ und auf die dazugehörigen Bereiche כרם und שדה מת מת braucht nicht eigens genannt zu werden; sachlich war es mit ארץ identisch und das "Feldgetier" von V.11ar hatte schon darauf angespielt.

Das Duo שדה - כרם steht auf eigenen Füßen. Gemessen an seinen Belegen zeigt es ein relativ hohes Alter und eine gewisse Konstanz ${ }^{391}$. Sachlich parallel

384 BACH, Bauen, 15-23.

385 Nach WOLFF, Amos, 29of im Kontext sekundärer, aber sonst autarker und authentischer Amosspruch.

386 An letzterer Stelle ist die Formel auf den ersten Blick nicht zu erkennen und darum auch bei $\mathrm{BACH}$ nicht einbezogen worden; sie dient hier der Verklammerung der Gesetze über Hausbau Dtn 22,8 mit dem "Bauernspiegel" 22,9-11, der in Lev 19,19 eine direkte Parallele hat. In Dtn 22,9 überschneidet sich die zweigliedrige Formel mit dem ersten Glied des Bauernspiegels, vgl. SEITZ, Deuteronomium, $250 \mathrm{f}$.

387 Die Stellen werden weiter unten analysiert.

388 So HALBE, Privilegrecht, 167; zur Stelle insgesamt wie zur Schichtung a.a.0., 161-170.207-210; HALBE rechnet den Prohibitiv zu seiner vorgegebenes Gut verarbeitenden "Wallfahrtsschicht".

389 Vgl. HALBE, Privilegrecht, 167 A 34; THAT I, 232 unter 3 d und ThWAT I, $431 \mathrm{f}$ unter 4 .

39o Nach HALBE, Privilegrecht, 444 f stammt die Ergänzung vom Verfasser seiner Grundschicht des BB.

391 Die Belege: Ex 22,4 (zum Wachstum dieses Paragraphen, der das Duo nur zu Beginn und am Schluß verwendet, s. CAZELlES, Études, 65); Lev 19,9f (CHOLEWINSKI, Heiligkeitsgesetz, 49.269f hält das Prohibitivpaar mit dem Duo für älter als Dtn 24,19-22); Lev 25,3f (Restitution der Ackerbrache von Ex 23,10f); Num 16,14; 20,17; 21,22; 1 Sam 8,15 (Variation mit "Pflanzungen - Weinberge"; Ergänzungen zum Grundtext nach STOEBE, 
dazu rangiert das Paar "Tenne - Kelter", mit dem man die Gesamtheit des Ernteertrages umschreibt ${ }^{392}$. Als umfassendste Beschreibung von Landbesitz aller Art unter den Agrarverhältnissen Palästinas fungiert die Trias שדה - כרם - דית אית Auch sie kann auf ein ehrwürdiges Alter verweisen ${ }^{393}$. Sie wirkt wie die vermögensrechtliche Umsetzung der schon erwähnten Dreiergruppe "Korn, Most, 01 ", die vor allem das Dtn durchzieht ${ }^{394}$. In die Trias eingeflossen ist das Wortpaar כרם / גפן - זית, das an wenigen Stellen auch isoliert auftritt, sich sonst aber mit der Trias verbindet oder in komplexen Großreihen mit anderen Gliedern zusammengebaut wird ${ }^{395}$.

Zum Schluß werden zwei Großreihen aufgeführt, die Immobilienbesitzer betreffen. Dtn 8,12f schildert die zivilisatorische Aktivität Israe1s, nachdem es von Jahwe ins Gelobte Land geführt wurde und den gratis geschenkten Reichtum angenommen hat. Was es auf der Basis der natürlichen Schätze dieses Landes durch Viehzucht und Handel erarbeitet, soll inm nicht Anlaß zur Hybris gegen Jahwe werden, der inm dazu die Kraft verliehen hat ${ }^{396}$. Dtn 8,12f gehört in den Kontext Dtn 8,7-18*, der wahrscheinlich einer vordeuteronomischen Redaktion zuzuweisen ist ${ }^{397}$. Die Reihe der Besitzgüter wird aufgelöst zu einer rhetorisch gestalteten Satzfolge mit Klimax und leitmotivischer Wiederholung des Verbs. Zusammengezogen umfaßt sie sechs Glieder: schöne Häuser, Groß- und Kleinvieh, Silber und Gold, dann die Schlußformel.

Samuel, 186 und CRÜSEMANN, Widerstand, 67f); 1 Sam 22,7; Mich 1,6; Neh 5,4 .

392 Num 18,27.30; Dtn 15,14; 16,13; 2 Kön 6,27; Hos 9,2; vgl. ThWAT II, 68 unter גר.

393 Vgl. Ex 23,1of (s.o.); 1 Sam 8,14 (CRÜSEMANN, Widerstand, 66-73 ordnet 1 Sam 8,11-17 in die frühe Königszeit ein); Dtn 24,19-21 und Dtn 28,38-40 (תT - כרם - vis - noch Mich 6,15 (PLÖGER, Deuteronomium, $191 \mathrm{f}$ ordnet die Reihe der vorexilischen Predigt zu).

394 "Korn, Most, öl" in: Dtn 7,13; 11,14; 12,17; 14,23; 18,4; 28,51; Hos $2,10.24$; Joel 2,19.

395 Die Angaben bei AHLSTRÖM, Art. nगT, Th WAT II, 564-569 sind nicht präzise und wenig geordnet; vgl. noch PLÖGER, Deuteronomium, 191 A 246; wir unterscheiden: das isolierte Vorkommen: (Ex 23,11 s.o.); Ri 15,5;

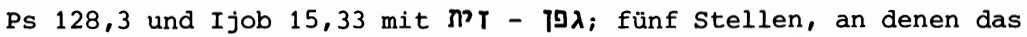
Wortpaar innerhalb der Trias שית - שרם - steht, s.0. A 393; neun Stellen, wo das Wortpaar in Großreihen auftritt: 2 Kön 5,26; 18,$32 ; \operatorname{Dtn} 6,1$ of $(8,8)$; Jos 24,13; Neh 9,25; Am 4,9; Hab 3,17; Hag 2,19 .

396 Vgl. LOHFINK, Höre, Israel, 81-85.

397 Zur Literarkritik und Schichtung jetzt: LOPEz, Analyse, bes. 488-501; DERS.., Tradition, bes. 60-81. 
Vom Aufbau und von den Eckgliedern her kommt sie dem Dekalogschluß Dtn 5,21b sehr nahe. Nur die Binnenpaare weichen ab, und der Land- bzw. Agrarbesitz wird ausgespart. Was Lopez zu Recht herausstreicht, sind die deutlichen Verbindungslinien zu Hos 2,$10 ; 8,14398$.

Von völlig anderem Charakter ist die reine Immobilienliste von Dtn 6,10f. Mit explikativer Asyndese angehängt erläutert sie den Einführungssatz V.1oa (Jahwe führt ins Verheißene Land). Die vier Einzelglieder der syndetischen Reihe (Städte, Häuser, Zisternen, Weinberge und olbäume) werden allesamt durch verneinte Relativsätze mit konstatierendem Perfekt näher gekennzeichnet ${ }^{399}$. In diesem Signum drückt sich auch der diametrale Gegensatz zur vorhergehenden Stelle Dtn 8,12f im Kontext von 8,7-18* aus. Wurden dort die kulturellen Leistungen Israels aufgelistet, so werden sie hier negiert. Israel "steigt ins gemachte Bett". Die Einrichtungen des Landes werden unversehrt übernommen, nur die Bevölkerung wird ausgewechselt ${ }^{400}$. Baltzer hat durch Heranziehen der ugaritischen Parallelen den Charakter der Liste erhel1t ${ }^{401}$. Die Listen entstammen den Schenkungsurkunden der Könige von Ugarit. Die zu verschenkenden Ländereien werden darin zuerst mit einem Begriff umfassend genannt und dann im Einzelnen durch eine Immobilienliste näher beschrieben, die ihre Einzelelemente mit Hilfe der akkadischen Präposition "qadu" aneinanderreint. Die Liste besteht nur aus Immobilien, die in der Weise eines Katasters nach Art und Umfang der zu vergebenden Ländereien genau festgelegt werden. Die Größe des überregionalen Immobilienbesitzes übersteigt den Umfang privater Transaktionen, deren Listen wir oben schon in Augenschein nahmen. Dem ugaritischen Prototyp kommt Dtn 6, lof am nächsten. Jos 24,13 nimmt 6,1 of interpretierend auf ${ }^{402}$. Das Gleiche gilt a fortiori für Neh 9,25.

398 Weitere Parallelen sind Hos 5,6; 8,4 - vgl. LOPEZ, Tradition, 60-63.

399 Vgl. die Analyse bei LOPEZ, Deutéronome, bes. 180-183.

400 LOPEZ, Analyse, 491-499 übersieht die Unterschiede und kommt so zu seiner Gleichstellung von Dtn 6,10-13 und 8,7-18*. LOHFINK, Art. םר, 209f ordnet die Stelle in die dtr an-Theologie ein. Dtn 6,10f kommt dabei Grundsatzcharakter zu. Redaktionskritisch setzt er die Stelle an für "die erste, wohl in den triumphalen Jahren Josias redigierte Fassung des DtrG" .

4O1 BALTZER, Bundesformular, 30; ebenso PLÖGER, Deuteronomium 89 und WEINFELD, Deuteronomy, $71 \mathrm{f}$ mit weiteren Parallelen aus hethitischen und assyrischen Schenkungsurkunden.

$4 \circ 2$ Zur Schwierigkeit, diese Stelle einzuordnen, vgl. McCARTHY, Treaty, 279-284 (protodeuteronomisch) und PERLITT, Bundestheologie, 239ff (deuteronomisch). 
Nachdem wir stereotype Reihungen für Besitz gemustert haben, fällt die Besitzguiterliste im Dekalogschluß (Dtn 5.21b) in vieler Hinsicht auf: Sie greift das obige alte Wortpaar "Haus - Feld" auf, wie es in den ugaritischen Kaufurkunden üblich und wie es in umgekehrter Abfolge aus den MAG bekannt ist. Als nächste alttestamentliche Parallele in puncto Aufbau und Eckglieder kam Dtn 8,12f in Frage. Das Fehlen weiterer Immobilien wie Feld, Weinberg, Olbaumpflanzung kann dort mit der Rücksicht auf Dtn 8,7f erklärt werden, wo auf sie in der hymnischen Landbeschreibung angespielt wird ("ein Land des Weizens, der Gerste, [des Weinstocks, des Feigen- und Granatbaums], ein Land des Olbaumfetts und des Honigs"). Im Dekalogschluß war eine solche Rücksicht überflüssig. Vom Bundesbuch, von manchen Texten der frühen Königszeit und vor allem vom dtn Gesetz her kommend, muß das Verschweigen von

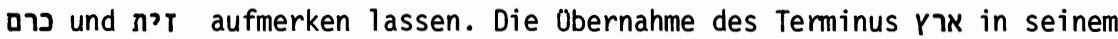
kleinräumigen Bedeutungsumfang lag nicht nahe, weil wahrscheinlich אר in seinem großräumigen Inhalt vom Kontext oder von der Tradition her die Oberhand gewonnen hatte. Aber die Erwähnung von "Olbaumpflanzung" und wenigstens "Weinberg" wäre angebracht gewesen. Nun erfordert die Bewirtschaftung beider bestimmte Voraussetzungen. Zwar ist die olbaumpflanzung nicht so arbeitsintensiv wie der Ackerbau, aber sie setzt Startkapital und Rücklagen voraus, da sie erst im zehnten Jahr nach der Pflanzung Erträge bringt. Folgerichtig bleibt der 01 ivenanbau Domäne der Reichen. Der Weinanbau verlangt mehr Arbeit als der Ackerbau (oft durch Sklaven geleistet) und ist nur bei hohen Investitionen möglich. Somit können inn wiederum nur Reiche unternehmen ${ }^{403}$. Es wäre nun möglich, daß der Dekalogschluß mit seiner Liste den Besitzdurchschnitt des Normalbürgers im Auge hat, der (mittlerweile?) unterhalb des Pegels "Feld, Weinberg, 0livenpflanzung" liegt und vom Standard des $B B$, der frühen Königszeit und des Dtn abweicht. Das setzt dann eine Gesellschaft voraus, in der eine relativ große und tonangebende Gruppe gleichsituierter Vollbürger in die $\mathrm{Klassen}$ arm und reich auseinandergedriftet ist. Die Sozialkritik der Propheten des 8. Jh.s spiegelt diesen Vorgang wider und prangert inn an als schleichende Enteignung der freien Bauernschaft. Der Dekalogschluß (Dtn 5.21b) würde auf die Schichtung der Gesellschaft dadurch eingehen, daß er die Besitzmarge senkt und das Ausmaß vor allem des Immobilienbesitzes verringert.

403 Vgl. KIPPENBERG, Typik, 28f; OHLER, Isxael, $193 \mathrm{ff}$. 


\subsubsection{Gemischte Reihen von Besitzgüterm}

Wir untersuchen nun Reihen, die Personen und andere Besitzobjekte nebeneinanderstellen. Dabei scheiden von vornherein jene Aufzählungen aus dem Vergleich aus, die im Kontext von Krieg oder aר-Vollzügen auflisten, was vor allem gegen die Bevölkerung von Ortschaften oder Städten unternommen und was erbeutet oder vernichtet wurde. Der Aussageschwerpunkt solcher Listen liegt in der Darstellung der totalen und restlos konsequenten Aktion; stilistisch wird das entweder durch Merismus (2.B. Jos 6,21) oder durch lückenlose Aufzählung der Einzelobjekte (2.B. Jos 7,24) dargestellt ${ }^{404}$.

Dagegen wirft eine Gruppe von Besitzreihen auf den Dekalogschluß neues Licht. Sie beschreibt den Besitzstand von wohlhabenden Bürgern, indem sie den Viehbestand, unter Umständen Wertgegenstände und Immobilien sowie Sklave und Sklavin aufführt ${ }^{405}$. An allen Stellen wird die Sklavin שחה genannt im Unterschied zum Sprachgebrauch der Gesetzbücher, wo dieselbe soziale Gruppe, nämlich die weibliche Sklavin, אמה gerufen wird. Riesener 406 hat daraus zu Recht die Differenzierung abgeleitet: Als שפחה wird die Sklavin unter dem Aspekt der Arbeitskraft, als organon gewertet. Sie zählt zum Besitz ihres Herrn bzw. ihrer Herrin. Als אמה betrachtet man sie im Hinblick auf ihre weiblichen Qualitäten (Schutzbedürftigkeit, Schwachheit, sexuelle Attraktivität usw.). Die Probe auf diese Unterscheidung liefert eine durchlaufende Prüfung aller Fundorte in den Gesetzbüchern. Ex 21, 7-11 und Dtn 15,12.17 behandeln den Fall der hebräischen Schuldsklavin, die zur Nebenfrau verkauft wurde. Die Rechtsbestimmungen über Körperverletzung mit ihrer formelhaften Redeweise von אמה geben für eine Probe aus sich heraus nichts her (Ex 21,20.26f.32). Obwoh1 Ex 23,12b unter eigenen Bedingungen produziert wurde, kann der Ausdruck בו־אמחך einige Hinweise geben ${ }^{407}$. Nach unserer

404 Vgl. noch: Gen 34,28f; Num 31,9f.17f.32-46; Dtn 2,34f; 3,6f; Ri $21,20 f$; 1 Sam 15,3; 22,19; 27,9.11 - Zum חרם LOHFINK, ThWAT III, 196.200; in die gleiche Gruppe gehören pauschale Gerichtsansagen gegen die Bevölkerung von Städten mitsamt ihrem Vieh und ihrem Besitz wie Jer 5,17; davon abhängig Dtn 28,49.52; Gericht gegen die Gesamtheit der Bevölkerung: Jer 6,$11 ; 14,16 ; 18,21 ; 38,23$; Ez 9,6 .

405 Gen 12,$16 ; 20,14 ; 24,35 ; 30,43 ; 32,6 ; 1$ Sam 8,16; 2 Kön 5,26; Koh 2,7 vgl. WEIMAR, Redaktionsgeschichte des Pentateuch, 10.

406 RIESENER, Stamm Tבע,76-83.

407 S.o. unter 2.3.6 auf S. ; FENSHAM, Son, 318.321 hält ihn an dieser Stelle für ein Synonym von $7 \mathbf{T}$; er berücksichtigt aber durchweg zuwenig die obige Differenzierung. 
Vermutung steht er an dieser Stelle als Kürzel für אמה עבד; wie dem auch sei, V.12b stellt 2 mit dem גו-אמת zusammen und trennt beide durch

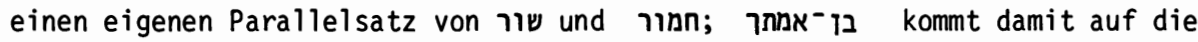
Seite der Großfamilie und ihrer Klientel zu stehen.

Als Nebenfrau des Besitzers oder eines seiner Söhne ist die אמה in die Großfamilie integriert, wie das die Kultteilnehmerliste im Dtn bezeugt ${ }^{408}$. Sie gehört zum "Haus" des Vollbürgers - so die Kurzfassung der Kultteilnehmerliste ${ }^{409}$. Lev 25,6f nimmt sie gleicherweise in die Familie des Pater familias auf. Nur in Lev 25,44b-46bd, einem pluralischen Zusatz zur singularischen Vorlage ${ }^{410}$, scheint sich die Differenzierung zu verwischen, denn עבד und אמה werden sehr stark unter dem Aspekt des Besitzes betrachtet ${ }^{411}$. In der Heimkehrerliste Esr 2.65 // Neh 7,67 rangieren עמה unter den heimkehrenden Personen, getrennt von den mitgeführten Tieren 412 .

Gegen diesen Hintergrund sticht die Reihe im Dekalogschluß ab. Sie nennt die Sklaven neben den Immobilien, dem Vieh und den Mobilien - fungiert also als reine Besitzgüterliste. Im Widerspruch zur obigen Differenzierung gebraucht sie im Wortpaar עבד - אמה den kontextfremden. Terminus שפחה . Wir werten diese semantische Spannung als weiteres Indiz für Wachstumsstufen der Reihe Dtn 5,21b. Ein Bearbeiter hat die ursprünglich knappere Liste mit dem Wortpaar עבד - עמה aufgefüllt. Entweder hat er sich dabei sklavisch an den vorherrschenden Sprachgebrauch der Gesetzbuicher gehal ten und dabei die Differenzierung übersehen oder die Unterschiede im Sprachgebrauch haben sich für ihn schon verschliffen 413 .

408 Dtn 5,$14 ; 12,12.18 ; 16,11.14 ;$ davon abhängig Ex 20,10.

409 Dtn 14,26 und 26,11 .

410 Nach ELLIGER, Leviticus, 348, $\mathrm{PH}_{2} ;$ nach CHOLEWINSKI, Heiligkeitsgesetz, 137, Hauptredaktion des ganzen HG.

411 HORST, Zwei Begriffe, 155f: Nur einmal (Lev 25,45f) werden verknechtete Personen als Objekte der אחin genannt.

412 Vgl. GALLING, Liste, bes. $100 f$.

413 CRÜSEMANN, Mann und Frau, $33 \mathrm{f}$ rechnet damit, daß in der älteren Zeit Sklaven und Sklavinnen weitgehend in die Großfamilien integriert waren, dieses aber sich im Laufe der zeit änderte, weil vor allem die Schuldsklaverei zunahm und die quantität eine Integration unmöglich machte. Allerdings läßt er bei seiner Darstellung die sprachliche Differenzierung außer acht und kann sie deshalb nicht juristisch auswerten. 


\subsubsection{Gemischte Reihen mit dem Einzelelement "Frau"}

Nachdem wir oben unter 2.6.2.3.2 die Nennung der "Frau" in Besitzguiterlisten problematisiert haben, sind jene Reihen von besonderem Interesse, die wie die Exodusfassung "Haus", "Frau" und andere Guiter nebeneinanderstellen.

Eine wichtige Parallele bieten die erweiterten Grußformeln aus den altorientalischen Briefformularen. Seit der mittelbabylonischen Sprachperiode tritt in den altorientalischen Briefen die Grußformel "ana kaša lù šulmu" (= Heil sei dir!) auf. Sie wird in der Folgezeit durch weitere Spezifizierungen ausgebaut. Für die Amarnabriefe unterscheidet Salonen drei Hauptformeln 414. Jede dieser Hauptformeln mit ihren Variationen wird durch eine Liste von weiteren Adressaten des Grußes ergänzt. Bei aller Variation bewahrt die Liste ein starres Gepräge. Die Einzelglieder stehen asyndetisch hintereinander und sind durch enklitisches Personalpronomen auf das zuerst angeredete "Du" bezogen. Die Liste schließt entweder ohne Kennzeichnung des letzten Gliedes oder mit Schlußsyndese oder mit der oben schon erwähnten Schlußformel. Am Kopf der Liste hinter dem einleitenden Gruß an den Adressaten steht in der Regel das Objekt "Haus"; dann folgt die Nennung von Personen, die zur Familie oder auch zum Hof des Adressaten gehören ${ }^{415}$. Den Schluß bildet die Erwähnung der Truppe, des Landes oder sogar des Besitzes, der durch die Schlußformel pauschal angeführt wird ${ }^{416}$. Je vornehmer der Empfänger, desto ausführlicher die Grußliste, die aber immer ihr Gerüst beibehält: Gruß an den Empfänger und an das "Haus" des Adressaten. Unter "Haus" wird die Familie verstanden, die dann immer mit den "Frauen" und weiteren Mitgliedern konkretisiert wird. Zum Schluß folgt die Truppe, da es sich zumeist um den Briefwechsel zwischen dem Pharao und den selbständigen Königen Vorderasiens handelt.

414 DERS., Höflichkeitsformeln, 63-66: Hauptformel A: ana kăsa...lū šulmu; Hauptformel B: ana mahrika lù šulmu, ana ... danni/eš lū šulmu; Hauptformel $C$ : ana muhhika lù sulmu, ana ... dannis lū sulmu.

415 Nach SALONEN, Höflichkeitsformeln, in Formel Nr. 1: deinen Frauen; Formel Nr. 2: deinen Frauen, deinen Kindern, deinen Großen; Variation von Formel Nr. 2: meiner Schwestern, deinen übrigen Frauen, deinen Kindern; Formel Nr. 3: deinen Frauen, deinen Kindern, deinen Großen; Formel Nr. 4: deinen Gattinnen, deinem Sohn, deinen Frauen.

416 Nach SALONEN, Höflichkeitsformeln, in Formel $\mathrm{Nr}$. 1: deinen Wagen und deinen Kriegern; Formel Nr. 2: deinen Pferden, deinen Wagen - die Position von "deinem Lande" kann wechseln vom Schluß zur Mitte und zum Anfang der Liste - alles, was dir gehört; Formel Nr. 3: deinen Pferden, deinen Wagen inmitten deiner Länder; Formel $\mathrm{Nr}$. 4: deinen Wagen, deinen vielen Pferden und in Ägypten, deinem Lande. 
In den akkadischen Briefen aus Ugarit ist das Aquivalent zu den eben besprochenen Formeln in der mehrgliedrigen Grußformel zu finden: "ana muḥ̣i NN 1ū šulmu, ana ... ana gabbi mimmū క̌a NN danniš (dannǐ̌) lū šulmu!" 417. Der mehrgliedrige Gruß umfaßt zumindest den Empfänger, sein Haus, seine Frauen und seinen Besitz, der durch die obligate Schlußformel immer mitgenannt wird. Die Reihe kann um das Land oder die Truppe erweitert werden. Im Unterschied zu den Amarnabriefen wird der Empfänger regelmäßig mit einem Titel (meist "bēlija") ausgezeichnet, der dann auch im Relativsatz der Schlußformel auftaucht.

Die Konstanz der Grußformel, wenn auch mit viel bescheidenerem Umfang in der Mehrgliedrigkeit, belegen zwei Briefe aus Arad, die in die Zeit um $600 \mathrm{v}$.Chr. datiert werden. In Arad 16,1-2 und Arad 21,1-2 heißt die einleitende Gruß-

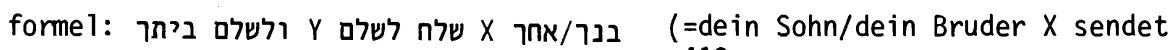
[hiermit] Grüße an [dich] $Y$ und dein Haus) 418.

Die alttestamentlichen Belege passen sich diesem Befund an. Das deutlichste Beispiel zeigt 1 Sam 25,5f im Gruß Davids an Nabal: "Grüße an dich und dein Haus und alles, was dir gehört!" 419.

Die Liste der Grußformeln läßt sich formalisieren und auf folgende abstrahierte Reihe bringen: An erster Stelle eine männliche Person, vertreten entweder durch ein selbständiges Personalpronomen oder durch einen Eigennamen oder durch einen Gattungsnamen; darauf folgt der Terminus "Haus", versehen mit enklitischem Personalpronomen, das sich auf das Eingangsnomen zurückbezieht; nach möglichen weiteren Gliedern endet die Reihe mit der Schlußformel (wiederum mit ePP). Die männliche Person repräsentiert den Pater familias; der Begriff "Haus" steht für die Familie bzw. Großfamilie, die auch stattdessen mit ihren Mitgliedern einzeln aufgeführt werden kann; die Schlußformel bezeichnet den Gesamtbesitz oder nach vorausgehenden Gütern den Restbesitz. Durch die Formalisierung können diesem Reihentyp auch Beispiele aus-

417 Vgl. SALONEN, Höflichkeitsformeln, 75f; KAISER, Formular, $17 f$, bes. A 38; KRISTENSEN, Formulas, 152, bes. A 70.

418 So PARDEE, Letters, 310f.318.325.

419 Dazu gehört auch die erweiterte Grußformel in ihrer Umformung zur Frage nach dem Ergehen (hier an einen weiblichen Adressaten) 2 Kön 4,26: "Geht es dir gut, deinem Manne, deinem Kinde?" - vgl. LANDE, Formelhafte Wendungen, 3-9; SCHMID, Schalom, 47-53. 
serhalb der Grußformeln zugeordnet werden. Diese Beispiele können vielgliedrig oder häufiger dreigliedrig sein ${ }^{420}$. Die Reihen verzichten auf Besitzangaben wie bei der Kultteilnehmerliste im Dtn (s.o.) und schrumpfen sogar bis auf zwei Glieder 421 .

Für den Dekalogschluß in der Exodusfassung entnehmen wir dem Oberblick folgende Informationen: Innerhalb von Reihen des oben beschriebenen Typs hat "Haus" die Bedeutung von Familie bzw. Hausgemeinschaft. Wenn die "Frau" genannt wird, zumal wenn sie dem Begriff "Haus" folgt, konkretisiert sie den umfassenderen Begriff "Haus" und zählt zur Familie und nicht zum Besitz. Die Exodusfassung entspricht nur scheinbar diesem Reihentyp. Ihr fehlt ein Konstitutivum, nämlich die Nennung des Pater familias oder des Vollbürgers im ersten Glied. Versuche, das dortige Nebeneinander von "Haus" und "Frau" durch das Verständnis von "Haus" als Oberbegriff,der Familie und Besitz umfaßt, zu rechtfertigen, sind damit obsolet geworden. Die Singularität der Exodusfassung tritt schärfer hervor. Sie steht schließlich noch einmal zur Debatte bei der letzten Gruppe von Vergleichstexten, die scheinbar wie die Exodusfassung die Frau neben andere Besitzgüter stellen und als "Wertobjekt" behandeln.

\subsubsection{Die Frou als "Wertobjekt"}

Zu diesen Texten zählt als erster Dtn 20,5-7. Er gehört zum Kern des Kriegsgesetzes von Dtn 20, ist eine metrisch streng aufgebaute Ansprache und wird

420 Sechsteilige Reihe: Gen 45,10; dreiteilige Reihe: Gen 45,11 (Zusammenfassung von Gen 45,10); Gen 12,20; 13,1; Ijob 1,10.

421 Gen 7,1; Jos 24,15; Dtn 15,20; 1 Sam 25,17; 27,3 ("ein jeder und sein Haus" wird anschließend konkretisiert durch "David und seine zwei Frauen"); 2 Sam 9,9; 1 Kön 16,3; 2 Kön 8,1f (die Rolle des Mannes ist hier durch eine Frau ersetzt); Mich 2,2. Unter Mißachtung des Reihentyps und der für das Gerichtswort kennzeichnenden elliptischen Parallelsätze hat ALT, Anteil des Königtums, 349 und DERS., Mich 2,15, 374 aus Mich 2,2 den Grundsatz des altisraelitischen Bodenrechts destilliert: "Ein Mann - ein Haus - eine גלה". Der Satz erhielt in der Folgezeit eine quasi-kanonische Würde, vgl. DONNER, Die soziale Botschaft, 241; THIEL, Entwicklung, 575; KIPPENBERG, Religion, 58; BOHLEN, Nabot, mit gewisser Distanz, 342f; SCHOTTROFF, Amos, 59; OHLER, Israel, 204f. Der Grundsatz insinuiert für "Haus" die Bedeutung Wohngebäude statt Familie (so mit Recht RUDOLPH, Micha, 53 A 5) und legt die נחלה einseitig auf Bodenbesitz fest. Mit THIEL, Entwicklung, 415 plädieren wir für einen weiteren נחלה-Begriff der Ackerland- und Hausbesitz einschließt, wenigstens gilt das schon für Mich 2,1-3. BOHLEN, Nabot, 333 trennt zu scharf. 
von neueren Exegeten unisono für relativ alt gehalten ${ }^{422}$. Drei Fälle begründen die Dispens vom Kriegsdienst: die Einweihung eines Hauses, die erste Nutzung eines Weinbergs und ein Verlöbnis im Sinne eines matrimonium ratum sed non consummatum. Der Grund, daß hier Haus, Weinberg und Frau nebeneinanderstehen, liegt nicht in der Einmaligkeit der drei Unternehmungen ${ }^{423}$, sondern in der "Neuheit" der Aktionen. Diese umgibt die Objekte mit einem sakralen Charakter und macht die mit ihnen Handelnden zu Tabupersonen ${ }^{424}$, die vom Heerbann ferngehalten werden müssen. Aus dem ursprünglichen Tertium comparationis, der Neuheit, ist im vorliegenden Text das Recht des Mannes auf Besitzergreifung und "Erstnutzung" geworden, das ihm der Kriegstod nicht streitig machen darf. Im jetzigen Kontext wird die Frau als Investitionsobjekt des Mannes mit dem Haus und dem Weinberg auf eine Stufe gestellt. Das deuteronomische Gesetz bringt aber eine solche Auffassung gleich wieder in Schwebe dadurch, daß es an anderer Stelle Dtn 24,5 wiederum die Freistellung vom Kriegsdienst vorschreibt, diesmal für den Neuvermählten. Trotz aller formalen und sachlichen Differenzen der beiden Kriegsgesetze ${ }^{425}$, die jeweils ihre ursprüngliche Selbständigkeit belegen, überschneiden sie sich so stark, daß ihre Aufnahme ins Gesetzbuch gezielte Absicht war. Das zweite Kriegsgesetz Dtn 24,5 hat seinen Platz im Kontext familienrechtlicher Vorschriften. Es betont das Recht der Frau auf sexuelle Befriedigung ( $v g 1$. Ex 21,10 für die Sklavin) und behandelt sie mithin als Person. Der Gesetzgeber würdigt im Nebeneinander der Kriegsgesetze die Sonderstellung der Frau, die einmal in einem bestimmten Eigentumsverhältnis zum Manne steht, ihm aber nicht wie andere Besitzgüter gehört. Die Frau bleibt juristisch gesehen Person, die der Gewalt des Mannes unterworfen ist.

Die antithetische Fluchreihe Dtn 28,30 erwähnt wieder die nun umgestellte Reihenfolge "Frau, Haus, Weinberg". Bisherigen Kommentatoren 426 ist die Abhängigkeit des $V .30$ von Dtn 20,5-7 entgangen. Während 20,5-7 konsequent

422 Vgl. VON RAD, Deuteronomium, 94f: vordeuteronomische Königszeit; MERENDINO, Gesetz, 224: Spruch prophetischer oder mantischer Herkunft; SEIT2, Deuteronomium, 162f: frühe Königszeit oder besser Epoche der Richter.

423 So BACH, Bauen, 2o.

424 vgl. NORTH, Art. שTח, ThWAT II, 759-780.779.

$425 \mathrm{Vgl}$. SEITZ, Deuteronomium, 122f.161.

426 So PLÖGER, Deuteronomium, 154ff.19of und SEITZ, Deuteronomium, 157. 285. 
konstruiert wurde, mangelt es V.30 an der ebenmäßigen Konstruktion. Die typische Antithese mit verneintem Verbalsatz wird im ersten Glied (beim Verlöbnis) aufgegeben zugunsten einer Verschärfung der Formulierung ins obszöne. Beim Element "Hausbau" wird der Aspekt der Neuheit abgestreift und die Situation durch einen blassen Ausdruck verallgemeinert. Der Autor von Dtn 28,30 hat 20,5-7 als Vorlage benuitzt und zu einer Fluchreihe abgewandelt. Damit erübrigt sich eine Diskussion der Reihe.

In der authentischen Strafansage Jer 6,11aß-12 427 heißt es im MT: "Es gehen ihre Häuser an andere über, Felder und Frauen zumal". Die Crux liegt darin, daß die "Frau" sowohl in der Gerichtsansage gegen die Bevölkerung, die nach Generationen aufgereint ist, auftritt $(6,11)$ wie in der anschliessenden Aufzählung des Besitzes (6.12). Um die Doppelung zu vermeiden, konjiziert Rudolph (vgl. BHS) über die Vermittlung der parallelen, aber sekundären Einheit 8,10-12 428 und streicht das 0bjekt "Frauen": "Es gehen ihre Häuser an andere über, ihre Felder an Eroberer". Wer am MT festhält, muß bedenken, daß nach ihm die "Frau" im Kontext der Bevölkerung und im Kontext der Besitzgüter erwähnt wird, ihr allein eine Doppelrolle zufällt. Im übrigen hebt die Strafansage auf Totalität ab, nicht auf Spezifizierung und Wertung der Besitzgüter 429.

Der Brief Jeremias an die babylonische Gola Jer $29,5 f^{430}$ fordert einleitend die Exilsgemeinde zu Häuserbau, Pflanzung von Gärten und Heirat zwecks Familiengründung auf. Man ist geneigt, in der Trias "Häuser, Gärten, Frauen" das Gerüst des Briefinhaltes zu sehen. Einige Gründe sprechen dagegen. Bei der durchlaufenden Syndese von Einzelsätzen innerhalb der gesamten Rede VV.5-7 bietet der Obergang von V.5 nach V.6 die einzige Asyndese. V.5 unterscheidet sich von V.6 semantisch; der erstere gebraucht überwiegend Nomina für unbelebte Konkreta, der zweite dagegen wählt Nomina für Personen. Das "Nehmen der Frauen" leitet eine neue Reihe von Kurzverbalsätzen ein, die sich alle mit Familiengründung auf drei Generationen hin beschäftigen. Die Wiedergabe des Briefinhaltes in Jer 29,28 zitiert wört-

427 RUDOLPH, Jeremia, 44; MEYER, Jeremia, 99-105.

428 Nach RUDOLPH, Jeremia, 63 und THIEL, Redaktion, 135 und MEYER, Jeremia, 104 sekundäres zitat von 6,13-15 mit der freien, punktuell auswählenden Überleitung von 8,10 .

429 Vgl. die oben erwähnten Gerichtsreihen; zum Wortpaar "Häuser-Felder" s.o. zu 2.6.3.5. 
lich V.5 und faßt V.6 mit eigener Wendung zusammen. Damit trennt der Brief des Jeremia deutlich zwischen einer Etablierung der Exulanten in puncto Besitz und der Familiengründung auf Dauer. Die Frau zählt weder zu einer Trias "Häuser, Gärten, Frauen", noch rangiert sie unter Besitz ${ }^{431}$. Das exilische Gedicht über den Sturz Babels Jes 13 beschreibt in V.16 die Schrecken des Jahwetages: "Ihre (Babels) Kinder werden zerschmettert vor ihren Augen, ihre Häuser geplündert und geschändet ihre Frauen". Hier fällt umgekehrt zur vorhergehenden Stelle die Nennung der Häuser innerhalb der Vergehen an der Bevölkerung auf ${ }^{432}$. Wenn Dtn 28,30 Einfluß ausübte ${ }^{433}$, sind die dortigen "Weinberge" übergangen worden. Auf jeden Fall kann diesem Text und dem von ihm abhängigen Sach 14,2 nichts über die Einschätzung der Frau entnommen werden. Beide Stellen gehören in die Gruppe pauschaler Gerichtsansagen, die mit traditionellen Topoi die Eroberung einer Stadt (Babel / Jerusalem) und die Vernichtung der Bevölkerung schildern.

In der Kriegsansprache Neh 4,8 macht Nehemia seinen Mitbürgern Mut und stachelt sie zum Widerstand auf gegen Störaktionen, die die Gegner des Mauerbaus von außen an die Stadt Jerusalem herantragen wollen: "Kämpft für eure Brüder, eure Söhne und eure Töchter, eure Frauen und eure Häuser!" Zwar werden hier die Frauen mit den Häusern zusammengestellt - unter letzteren sind am Ende der Reihe die Wohnhäuser und nicht die Familien zu verstehen -, aber der Aufruf tendiert auf Verteidigung der Stadt inklusive Familie und Besitz. Die Frau zählt dabei zur Familie.

Eine ähnliche Kombination von "Haus - Frau" bietet 2 Sam 12,8: "Ich gab dir das Haus deines Herrn und die Frauen deines Herrn in deinen Schoß". Ist hier mit Mettinger 434 unter Haus der Besitz Sauls und unter den Frauen ein Teil desselben oder mit Hertzberg ${ }^{435}$ der weibliche Teil der Sauliden, also die Familie verstanden? W. Dietrich beseitigt das Problem und konjiziert mit guten Gründen בת בת בית בית 436.

430 Die Verse sind der Kern des Grundtextes von Jer 29, nämlich 29,1.3-7; dazu vor allem SEIDL, Jeremia, 288-302.356-358.

431 Als Gerüst des Briefes hat Jeremia eher das Duo "Haus-Feld" oder "HausWeinberg" benützt, auf babylonische Verhältnisse zugeschnitten und durch den Gedanken der Familiengründung ausgebaut.

432 Deswegen möchte WILDBERGER, Jesaja II, 503 statt "ihre Häuser" lieber "ihre Jungfrauen" lesen; vgl. BHS zur Stelle.

433 So WILDBERGER, Jesaja II, $519 f$.

434 DERS., Solomonic State, 75.

435 DERS., Sammelbücher, 257. 
Eine enge Verbindung gehen "Erwerb einer Frau" und "Erwerb eines Ackers" im Buch Rut $(4,5.9 f)$ ein. Hier allerdings liegt das im individuellen Erzählinteresse des Autors begründet, der die Verknüpfung der beiden Rechtsinstitutionen des Levirats und der גאלה zum Thema der Novelle macht ${ }^{437 .}$

Für den Dekalogschluß in der Exodusfassung hat sich bei der letzten Gruppe kein vergleichbarer Text gefunden. Keiner stellt wie die Exodusfassung unkommentiert und ohne Relativierung die "Frau" mitten unter andere Besitzgüter. Die sich in den Gesetzbüchern widerspiegelnde passive Rolle der Frau darf nicht darauf hin mißdeutet werden, als sei sie für eine Sache wie jedes bel iebige andere Wertobjekt gehalten worden ${ }^{438}$. Demnach bringt die Deuteronomiumfassung mit ihrer Zweiteilung des Begehrensverbotes die Rechtsauffassung des AT zur Frau legitim zum Ausdruck: Die Frau ist vom Mann abhängig. In besonderer Weise besteht zwischen ihm und ihr ein Eigentumsverhältnis. Ihre Sonderstellung trennt sie deutlich vom übrigen Besitz. Damit formuliert die Deuteronomiumfassung das juristisch, was ein Zweizeiler aus der vorexilischen Sprüchesammlung Spr 19,14 volkstümlich umschreibt:

\footnotetext{
"Haus und Habe sind Erbe der Väter, aber von Jahwe ist eine verständige Frau!"
}

Umfang und Art der נחלה fallen einem quasi automatisch durch den Erbgang zu. Die Wahl der eigenen Frau ist dagegen an schwierige persönliche Entscheidungen gebunden, mit manchen Unwägbarkeiten belastet. Glückt sie, dann hat Jahwe mitgewirkt und gelenkt. Der Text betrachtet die Frau als Person und hebt sie vom Besitz ab.

2.6.3.9 Fazit: Die Exodusfassung als sekundäre Umarbeitung der primären Deuteronomiumfassung

Wir haben mittlerweile die Einschätzung der beiden Dekalogfassungen umgepolt. Der Dekalogschluß der Deuteronomiumfassung hat sich dem Aufbau und dem Sprachgebrauch nach als relativ alt erwiesen. Für die Exodusfassung hat sich

436 DERS., Prophetie, 129 bes. A 81; die Wendung "in deinen Schoß geben" verträgt sich nur mit Personen als Objekt; $\mathbf{I}$ schließt in diesem Falle die Frauen mit ein; eines der beiden objekte ist dann redundant; der Rückbezug in V.8b zielt auf die Femina von V.8ad: die Tochter und die Frauen.

437 Vgl. KIPPENBERG, Religion, 31.

438 Vgl. zu dieser wichtigen Unterscheidung die Analysen zur Form der Eheschließung und zur Terminologie des Ehekontraktes bei PLAUTZ, Eheschließung und SCHARBERT, Ehe. 
ihre vermutete Singularität bestätigt. Diese muß von der älteren Deuteronomiumfassung her erklärt werden. Von dort her gesehen ergeben sich die Besonderheiten der Exodusfassung aus der Novellierung des vorliegenden Deuteronomiumdekalogs in einem eigenen Exodusdekalog. Eine solche Novellierung steht unter spezifischen Zwängen. Sie versucht, zwischen Skylla und Charybdis Kurs zu halten. Als Skylla erweist sich die Würde des vorliegenden Deuteronomiumdekalogs, die die Möglichkeiten der Textveränderung einschränkt. Als Charybdis zeigt sich der Zwang zu novellierenden Eingriffen. Der Dekalogschluß der Exodusfassung ist deshalb ein Kompromiß, der mit einem Minimum an Variation des Deuteronomiumdekalogs die eigene Konzeption durchsetzt. Nachdem der Exodusdekalog die im Deuteronomiumdekalog vorhandene Verklammerung von Fremdgötter- und Bilderverbot zu einer Einheit aufgesprengt hat ${ }^{439}$, muß er diese Trennung in zwei Verbote am Anfang durch Vereinigung der zwei inm vorliegenden Begehrensverbote am Schluß kompensieren, weil er ja an der Dekalogkomposition von "zehn Worten" festhalten will. Diese Vereinigung gelingt inm mit geringen Mitteln. Strukturell beläßt er es bei der vorgegebenen Zweiteiligkeit, sorgt aber für thematische Einheit durch Wiederholung des ersten Prohibitivs.

Die Eigenständigkeit der beiden Begehrensverbote, die der Deuteronomiumdeka$\log$ durch Verwendung von Synonyma in den Verben erreichte, wird rückgängig gemacht. Auf der Linie der Vereinheitlichung im Exodusdekalog liegt konsequenterweise auch die Umstellung der Objekte. Das erste Objekt "Haus" des zweiten Prohibitivs in der Deuteronomiumfassung erhält die Frontstellung nach dem ersten Prohibitiv des Exodusdekalogs. Das Objekt "Frau" des ersten Prohibitivs der Deuteronomiumfassung wird zurückgenommen und dem objekt "Haus" nachgestellt. Denn thematisch betrachtet bilden in der Exodusfassung die Objekte der beiden identischen Prohibitive eine einzige objektreihe; folgerichtig hat die Dekalogexegese sie immer als eine Reihe interpretiert. Der zweite Prohibitiv in der Exodusfassung will überlesen werden; er ist eine Konzession an die zweiteilige Vorlage der Deuteronomiumfassung. Zugleich werden die Störungen in der Verknüpfung der objekte bei der Deuteronomiumfassung ("die Wachstumsspuren") mit Hilfe konsequenter Syndese beseitigt. So entsteht ein einziges Begehrensverbot, das auf keinen Bereich, den die Deuteronomiumfassung berücksichtigt, verzichtet. So gut es eben nur geht, wird der Dekalogschluß des Dtn in die Dekalognovelle des Ex hinübergerettet.

439 S.O. zu 2.1. 
Allerdings wird das erkauft, indem sich die Rechtsstellung der Frau verdunkelt und ipso facto der Terminus "Haus" in die Zweideutigkeit gerät; er oszilliert nun zwischen der Bedeutung "Hausgemeinschaft/Familie" und der von "Wohngebäude". Solche Opfer hat die Dekalognovelle zugunsten ihrer Isolierung bzw. Verselbständigung des Bilderverbotes gebracht. Eine letzte Eigenart der Exodusfassung ist bisher ausgespart worden. Sie streicht den Terminus "Feld" aus ihrer Objektreihe. Gemäß unserer bisherigen Hypothese, für die Dekalognovelle in Ex 20 einen priesterschriftlich beeinflußten Redaktor verantwortlich zu machen, suchen wir den Grund für die Streichung in sozio-ökonomischen Veränderungen der Zeit nach dem Exil. Sichere Angaben zu den Veränderungen der Besitzverhältnisse, wie sie durch die einschneidenden Ereignisse der Eroberung Jerusalems und der Exilierung verursacht wurden, sind spärlich gesät. Wir nennen hier drei mögliche Erklärungen, ohne sie gegeneinander auszuspielen:

1. Die babylonische Oberherrschaft rief durch ihre in 2 Kön 25,12// Jer 52,16 und Jer 39,10 berichteten Maßnahmen eine tiefgreifende Umstrukturierung der Besitzverhältnisse in Judäa hervor; deren Echo vom Standort der Exulanten in Babylon her gibt Ez 11,15; 33,24 wieder.

Die Babylonier gaben das eroberte und von den Deportierten verlassene Land an die ehemals Landbesitzlosen, den דלת (עם) Diese hatten nun den Auftrag, als "Sklaven auf Boden" für ihre Oberherren den Boden zu bewirtschaften, sei es als Ackerbauern oder Winzer. Privateigentum an Boden wurde eingeschränkt zugunsten eines überdimensional anwachsenden Staatseigentums. Ferner wurden künftige Konflikte vorprogrammiert: Zum einen der zwischen der Schicht der neuen Besitzer und den im Lande verbliebenen, entrechteten Vollbürgern, dem alten עם הארץ. Zum anderen der zwischen den ortsansässigen Einwohnern und den grundbesitzlosen Heimkehrern. Sach 5,1-4 könnte vielleicht mit dem Angriff auf Diebe und Meineidige jene Grundbesitzer meinen, die mit falschen Schwïren ihren Grundbesitz festzuhalten versuchen. Neh 5 wirft ein Schlaglicht auf den sozialen Konflikt. Der Grundbesitz ("Felder, Weinberge und Häuser") ist in der Hand der Oberschicht konzentriert, die Versklavung von Gemeindemitgliedern - hier "Brüder" genannt - greift um sich. Es könnte nun sein, daß die Exodusfassung auf die Auswirkungen der exilisch-nachexilischen Umschichtungen reagiert und das Ausmaß an Grundbesitz für den Durchschnittsbürger auf das Wohnhaus reduziert. Schwierigkeiten bereitet dabei - wie bei den folgenden Erklärungen auch - sowohl die präzise zeitliche Einordnung der Exodusfassung wie die lückenhafte Kenntnis der sozialen Entwicklung in persischer Zeit ${ }^{440}$. 
2. Nach dem Exil ist eine zuerst langsam wachsende Konzentration des öffentlichen Lebens auf die Stadt festzustellen, die ihre $\mathrm{Kl}$ imax in der hellenistischen Stadtkultur erreicht ${ }^{441}$. Die Exodusfassung könnte das einfangen, indem sie als Immobilienbesitz nur das Wohnhaus (in der Stadt) festhält, weil 2.B. bei aufkommender Münzwirtschaft Reichtum sich auch in Bargeldmengen ausdrücken kann und nicht mehr überwiegend in Grundstücken angelegt werden muß. Für diese Entwicklung gibt es mehrere Hinweise.

Nach Neh 7,4f; 11,1f vergrößert Nehemia die Bevölkerung Jerusalems durch Zwangsrekrutierung aus den uml iegenden Städten; er führt einen sogenannten "Synoikismos" durch 442 mit dem Ziel, Jerusalem als "städtisches Oberzentrum" für Juda aufzuwerten ${ }^{443}$. Innerhalb Jerusalems und anderer Städte wird es zu Zeiten der persischen Oberherrschaft zu einer Verlagerung der wirtschaftlichen Interessen gekommen sein. Handwerker und Händler gewinnen gegenüber den Bauern das Obergewicht ${ }^{444}$. Nehemia selbst könnte z.B. jenen neuen Typ von Stadtbürger vertreten, der kein Feld besitzt, was ausdrücklich für ihn und "seine Brüder" festgehalten wird (Neh 5,16).

Selbst dem bisher mittellosen ג $\lambda$ gelingt es in exilisch-nachexilischer Zeit, durch Handwerk und Handel zu Reichtum zu kommen, so daß er Gläubiger für verschuldete Israeliten werden kann ${ }^{445}$.

Neh 10,32 zeigt an, daß die Stadtgemeinde weniger Feldwirtschaft und Getreideanbau betreibt; sie kauft ihre Lebensmittel bei den עמי הארץ ein, also bei jenen, die nicht zur Heimkehrergemeinde gehören. Anpassung an die ausgreifende Stadtkultur kann sich schließlich auch in einigen Regelungen von Lev 25 widerspiegeln wie in der Sabbatjahranordnung von Lev 25,5 und in der unterschiedlichen Behandlung von Stadthaus und Landhaus bei den גאלה-Vorschriften Lev 25,29-31 446.

440 Vgl. WALLIS, Jobeljahr-Gesetz, 342; GUNNEWEG, Geschichte Israels, 116f; WEINBERG, Agrarverhältnisse; KIPPENBERG, Religion, 54-77.

441 Eine allgemeine Beschreibung bei OHLER, Israel, 152-174.

442 So HERRMANN, Geschichte Israels, 384.

443 In Neh 4,8 (s.o.) ruft er zur Verteidigung der stadt, ihrer Familien und Häuser, und nicht zur Verteidigung des Landes auf.

444 Vgl. SMITH, Entwicklungen, 320.

$445 \mathrm{Vgl}$. Lev 25,47f und Neh 5,8; dazu ELLIGER, Leviticus, 359.

446 Das rigorose Einhalten der Sabbatbrache war möglich, weil der Feldbesitz zurückgegangen war. Die Stadthäuser werden wohl deswegen so weitgehend von den Regelungen des Jobeljahrgesetzes ausgenommen, weil sich darin die ökonomischen Interessen von "Städtern" zu Wort melden, vgl. auch ELLIGER, Leviticus, 350.356. 
3. Die dritte Erklärung verdanken wir Kippenberg 447. Er vermutet zwischen dem 5. und 2. Jh.v.Chr. im judäischen Bergland eine Umwandlung von Ackerland in 01 ivenhaine und Weinberge. Das unrentable Ackerland und die hohen Abgaben zwangen die judäische Bevölkerung dazu, solche agrarischen Produkte wie 01 iven und Wein zu produzieren, die ihnen auf dem Markt im Tausch mehr Getreide einbrachten als ihr eigener Boden dafür hergab. Die Exodusfassung könnte darauf Rücksicht genommen haben, indem sie mit der Streichung von "Feld" den Hinweis auf den Ackerbau übergeht:

Somit können durch die Hypothese vom sekundären Charakter der Exodusfassung deren störende Eigenheiten besser erklärt werden als umgekehrt durch die bisherige Annahme, die Exodusfassung sei primär und deshalb Ausgangspunkt aller weiteren Interpretationen.

\subsubsection{Die Konsequenzen der eigenen Lösung}

Wenn wir von der Priorität der Deuteronomiumfassung ausgehen - unabhängig davon, ob sie im letzten Prohibitiv über eine oder zwei Stufen zum vorliegenden Endtext angewachsen ist - dann verstärkt sich die eingangs gestellte Ausgangsfrage. Die Alternative: Gesinnungs- oder Tatdelikt stellt sich für zwei Prohibitive. Das Problem der Oberschneidung mit den vorausgehenden Kurzgeboten verdoppelt sich. Es geht nicht nur um das Verhältnis von Diebstahls- und Begehrensverbot, sondern auch um das Verhältnis von Ehebruchsund Begehrensverbot, das auf die Frau des Nächsten bezogen ist. Beide Problembereiche (die Alternative und die Oberschneidung) sind von der Sache her verflochten und von der Forschung immer miteinander verkettet worden.

\subsubsection{Die Alternative: Gesinnungs- oder Tatdelikt}

Oben unter 2.6.2.3.1 haben wir herausgearbeitet, daß die Bedeutungsdifferenz zwischen אוה und fü den Dekalogschluß keine Rolle spielt. Vielmehr hat die ältere Dtnfassung bewußt von der Synonymie der beiden Verben Gebrauch gemacht. Deren Synonymie liegt in dem Bereich, der den gesamten Tatbestand "Begehren" umspannt, angefangen bei der stimulierenden Emotion bis hin zu deren Verwirklichung im konkreten Akt der Inbesitznahme. Damit gilt es, die obige Alternative für beide Verben gemeinsam zu entscheiden. Die Entscheidung hatte und hat einiges Gewicht für die Fragen, ob im AT

447 DERS., Religion $44 f$. 
schon die hohe Stufe der Gesinnungsethik erreicht ist und ob im Dekalog ein Kompendium sittlicher Grundnormen oder ein besonderer Strafrechtskodex mit juristisch zu beurteilenden vollendeten Taten vorliegt.

Gleich zu Anfang stellen wir eine bedeutende Auslegungstradition des 10. Gebots vor, der wir uns anschließen, weil sie auf der Linie der bisherigen Oberlegungen zur Synonymie der beiden Verben liegt und weil sie durch gute Gründe auch von außerhalb des Dekalogs gestützt ist. Diese Auslegungstradition geht auf die gestellte Alternative gar nicht ein, weil für sie der angezeigte Tatbestand in den Bereich der Gesinnung wie in den Bereich der Tat hineinreicht. Zu den prominenten frühen Vertretern dieser Tradition zählen Luther und Johannes Clericus ${ }^{448}$. Im 19. Jh. ist der zu Anfang erwähnte Meier dafür eingetreten und hat sein Urteil durch Parallelen erhärtet ${ }^{449}$. Nicht immer gelang es, zumal in der Diskussion, den Tatbestand ausbalanciert darzustellen und den Zusammenhang zwischen Emotion und Tat zu wahren. So geht Eerdmans zwar von der Einheit von "Begehren"und"Nehmen" aus, betont dann aber zu stark die Tat ${ }^{450}$. Ausgewogener stellt Herrmann den Sachverhalt dar ${ }^{451}$. Er arbeitet heraus, daß das Begehren eine Gravitation auf Handlungen hat, die zur Aneignung des Begehrten führen. Darin sind ihm viele gefolgt ${ }^{452}$. Moran hat für diese Bedeutung den Horizont erweitert. Er weist den Konnex von Affekt und Aktion in einigen altorientalischen Parallelen nach 453 und bringt den Tatbestand auf den Begriff: Wie alle Verben des Wol-

448 Vgl. HERRMANN, Das zehnte Gebot, 74f und WALLIS, Art. Thn, 1028; zur vorlaufenden, aber umstrittenen Interpretation im Talmud, bei Philo und Josephus vgl. JACKSON, Liability, 213-234 und WALLIS, Art. Th, 1029-1031.

449 DERS., Die ursprüngliche Form, 71 "Mit dem Begehren ist gar nicht der bloße wille als solcher, die böse innere Lust, oder überhaupt die Gesinnung gemeint, sondern es kann nur ein praktisches sein, das sich als wirkliches Streben nach Etwas äußert". Er verweist dann auf Parallelen, die in der weiteren Diskussion eine bedeutende Rolle spielen werden.

450 EERDMANS, Oorsprong, $26 f$.

451 DERS., das zehnte Gebot, $71 \mathrm{ff}$.

452 MENES, Die vorexilischen Gesetze, 5of; KÖHLER, Der Dekalog, 183; KESZLER, Problematik des Dekalogs, 13; STAMM, Dekalogforschung, 56f; GESE, Der Dekalog als Ganzheit, 75; REVENTLOW, Gebot, 86; NOTH, Exodus, 133; FOHRER, Recht, 136; SCHMIDT, Überlieferungsgeschichtliche Erwägungen, 208; RICHTER, Recht, 130 A 28; BERGER, Gesetzesauslegung, 344; SCHÜNGEL-STRAUMANN, Der Dekalog, 56f.

453 DERS., Conclusion, 546f; dazu gehören Gesetzestexte, Hymnen, Konfessionen und Beispiele aus der Briefliteratur; bei den Gesetzestexten kann 
lens implizieren Akte der Aneignung, ohne sie direkt zu bezeichnen ${ }^{454}$. In jüngeren Stellungnahmen wie $z . B$. den Wörterbüchern hat sich diese Meinung durchgesetzt ${ }^{455}$.

Ihr Vorteil bzw. ihre Verläßlichkeit liegt darin, daß sie überwiegend vom Dekalog unabhängig argumentiert; zugleich aber handelt sie sich die Schwierigkeit ein, zu erklären, warum der Dekalogschluß Verben wählt, die ihr Augenmerk auf den psychischen Bereich vor der Tat richten und deren Entstehen mitbedenken. Diese Besonderheit tritt schärfer hervor, wenn wir die alte Beobachtung einbeziehen, daß die Prohibitive des Dekalogschlusses keine einschlägigen, direkten Parallelen oder Vorbilder haben ${ }^{456}$.

$\mathrm{Zu}$ verstehen ist darum jene andere Auslegungstradition, die im 10. Gebot entschieden für den Tatbestand des Gesinnungsdelikts eintritt. Nur so sei der Dekalog als abgerundete Komposition zu akzeptieren, die am Schluß mit der Begierde die Quelle aller vorausgehenden bösen Taten verurteile. Nur so sei die Oberschneidung mit den vorausgehenden Prohibitiven zu vermeiden. Auch diese Auslegungstradition kann einen prächtigen "Stammbaum" aufweisen. Seine Wurzeln werden fassbar bei Ewald ${ }^{457}$. Dillmann und Holzinger haben die Konzeption präzisiert und viele Nachfolger bis in jünste Zeit gefunden ${ }^{458}$. Mit bewundernswerter Konstanz werden in der Diskussion jahrzehntelang die Argumente hin- und hergeschoben bzw. treu vererbt ${ }^{459}$. Die diffe-

$\mathrm{CH} \S 159$ ergänzt werden, der mit Synonyma den Konnex anspricht: "summa awilum ... ana sinnistim sanitim ubtallisma ana emisu maratka ul ahan iqtabi ( begehrt und zu seinem Schwiegervater: "Deine Tochter werde ich nicht nehmen" sagt").

454 SCHULZ, Todesrecht, 19 A 60, belegt, daß bei אהב grundsätzlich nicht zwischen Intention und Tat zu scheiden ist; für בחר unden vgl. WALLIS, Art. Thח, 1022 .

455 CHILDS, Exodus, 426f; GERSTENBERGER, Art. אוה; DERS., Art. Thח; KLEIN, Verbot, bes. 168f; MEYER, Art. אוה; WALlIS, Art. Tמד.

456 MEISNER, Der Dekalog, 35.

457 DERS., Geschichte, 230; vgl. PETERS, The Ten Words, $141 \mathrm{ff}$; OETTLI, Deuteronomium, 41 .

458 DILLMANN-RYSSEL, Exodus, 224.240; HOLZINGER, Exodus, 75; von den Nachfolgern unter anderen: MATTHES, Der Dekalog, 35-40; KÖNIG, Deuteronomium, 1917, 90; CHARLES, Decalogue, XLVII; SCHMIDT, Mose, 92; JIRKU, Das weltliche Recht, 150f; BEER, Exodus, 103; GOLDMANN, The Ten Commandments, 186f; PATRICK, La formation littéraire, 247f; PHILLIPS, Criminal Law, 150; und vor allem: JACKSON, Theft,148f; DERS., Liability, 204-213. 
renzierteste Diskussion vom Standpunkt der zweiten Auslegungstradition her führt Jackson. Er nähert sich der Meinung der ersten Gruppe an ${ }^{460}$, hält dann aber aus Gründen der Komposition im Falle des 10. Gebots am Konzept der Gedankensünde fest. Hier trage vor den Augen des göttlichen Richters der Mensch Verantwortung für seine geheimen Absichten und Gesinnungen. In der Rechtsgeschichte sei dieses Prinzip später in die menschliche Rechtssprechung übernommen worden 461 .

Wenn in bestimmtem Kontext wie z.B. Ex 34,24 die Meinung der ersten Auslegungstradition (nach Jackson) zutrifft, muß der spezifische Kontext des Dekalogs noch einmal überprüft werden, ob nicht auch er eine Lösung zuläßt, die an der Bedeutung von אוה / ohne Abstriche festhält und sich trotzdem in die Dekalogkomposition einfügt. Im übrigen tendiert die gesinnungsethische Interpretation dahin, den (die) Prohibitiv(e) im Dekalogschluß absolut zu setzen und dabei die konkreten Objekte, Personen wie Sachen, zu übersehen.

Die diametrale Opposition, daß beide Verben eine konkrete Tat bezeichnen, hat nur wenige Verfechter gefunden. Steuernagel 462 hält das "Begehren" für gleichbedeutend mit "Sich-anzueignen-versuchen". Die Oberschneidungen mit den Kurzgeboten nimmt er in Kauf, weil der (späte) Verfasser des Dekalogs

459 Sprechende Beispiele liefert die Behandlung der Stellen Dtn 7,25; Jos 7,21; Mich 2,2 als Belege für den Konnex von Begehren und Nehmen und von Spr 6,25 mit Verwendung von Thn ohne nachfolgendes "Nehmen". Was die erste Auslegungstradition als Hinweis auf den festen Zusammenhang wertet, deutete die zweite dialektisch um. Gerade der feste zusammenhang zeige die Notwendigkeit von zwei Verben, wobei thn nur die eine Seite, das "Begehren" meine. In Spr 6,25 liegt die crux in der adverbialen Ergänzung zu 7 Th "in deinem Herzen". Für die einen ist hier der Beweis zu finden, daß das konkret gemeinte thn die adverbiale Ergänzung braucht, um durch sie verinnerlicht zu werden. Für die anderen ist die adverbiale Ergänzung nur der explizite Ausdruck eines immer schon im Verb bezeichneten innerlichen Begehrens; vgl. dazu MEIER, Die ursprüngliche Form, 71; MATTHES, Der Dekalog, 79f; GOLDMANN, The Ten Commandments, 186ff; REVENTLOW, Gebot, 86; MORAN, Conclusion, 544; PHILLIPS, Criminal Law, 149f. Der letzte, PHILLIPS, sieht in thn eine Gedankensünde, scheidet das Verb aber als sekundäre spiritualisierung aus dem Dekalog aus, weil es in ein Strafgesetz nicht paßt. Was ursprünglich seine stelle eingenommen haben soll, bleibt offen. Vgl. schließlich noch die Diskussion bei JACKSON, Liability, $204 \mathrm{f}$.

460 DERS., Liability, 206: "The best that can be said of the interpretation of hamad as "to take" is that there is the possibility that the word can bear that meaning in some contexts".

461 DERS., Liability, $212 \mathrm{f}$.

462 DERS., Deuteronomium, $29 \mathrm{f}$. 
vorformulierte Sätze aufgenommen habe. Gerade an der Oberschneidung hat Alt Anstoß genommen ${ }^{463}$. Er übernimmt den Deutungsvorschlag Herrmanns, akzentuiert aber nur die Seite der Tat: "tätliche Machenschaften zur Aneignung fremden Eigentums"! Von daher kommt er zur "vollen Deckung" der Verben im Diebstahls - und Begehrensverbot und zu seiner Forderung nach Unterscheidung im Bereich der Objekte. Beim objektlosen Diebstahlverbot muß er ein solches Objekt rekonstruieren. Er differenziert schließlich zwischen einem ursprünglichen Verbot,den freien Israeliten zu kidnappen, und dem Verbot, sich dessen Sachguiter und die seiner Gewalt unterworfenen Personen anzueignen. Alts Lösung scheitert an der Vereinseitigung des Tatbestandes. Die Differenz der Verbote liegt mindestens auch in der unterschiedlichen Bedeutung der Verben. Sie scheitert wesentlich an seiner Basisprämisse eines gleichförmigen Urdekalogs, dessen Prohibitive alle aus Sachgründen mit einem Objekt ergänzt waren. Methodisch gesehen muß diese formkritische Annahme Hypothese bleiben, weil sie gegen den Text rekonstruiert. Die Hypothese fällt dahin, da die Zuversicht, Großreihen von gleichgebauten Prohibitiven zu entdecken, zusammengebrochen ist. Sie erweist sich als überflüssig, weil sie das Wachstum zum Endtext nicht widerspruchslos erklären kann, denn die sekundäre Verallgemeinerung durch Tilgung des Prohibitivobjekts verwischt die Differenz zwischen den Verboten. Diese läßt sich dann nur retten, wenn man ebenfalls eine sekundäre semantische Verschiebung in den Verbbedeutungen des Dekalogschlusses, nämlich eine fortschreitende Psychologisierung von אוה / ח אמד annimmt 464. Letztere Hilfshypothese fällt in sich zusammen, weil sie die Ausgangsbedeutung der fraglichen Verben verfehlt und die postulierte semantische Entwicklung nicht nachgewiesen werden kann 465 .

463 DERS., verbot, 333-340.

464 So ALT, Verbot, 339; NIELSEN, Zehn Gebote, $86 \mathrm{f}$.

465 ALTs Hypothese hat große Gefolgschaft gefunden, ist aber neuerdings mit guten Gründen auseinandergenommen und kritisiert worden von JACKSON, Liability, 207-209; HAMP, Art. $2 \mathrm{j}, 44$ schließt sich dem an; und zuletzt KLEIN, Verbot, 161-169; während wir die Gegenargumente von JACKSON restlos bejahen, können wir uns bei KLEIN nur mit zweien (b und d) von vier Gegengründen einverstanden erklären. RICHTER, Recht, $128 f$ A 23 meint, "Alts Annahme lasse sich zwar nicht streng beweisen", lege sich aber vom näheren Kontext der beiden Kurzprohibitive her nahe, die indirekt oder direkt das gleiche Objekt ("Mensch bzw. Mann") einschließen. Dahinter steht die Beobachtung, daß bei נאון und die verbbedeutung jeweils auch das Objekt festlegt (נאוא: ein geschlechtspolarer Partner; חา: ein Mensch) und beide Verben zu absoluter Verwendung neigen. Das transitive גנב hingegen verlangt ein Objekt. Deshalb muß die absolute Verwendung auffallen. Hier kann dann durch Weglassen eines ursprünglichen Objektes "Mensch" oder "Mann" verallgemeinert worden sein. An den 


\subsubsection{Das Problem der Uberschneidungen}

Die Erörterung der Alternative hat uns unmerklich zum abschließenden Problem der Oberschneidung geführt. Vor dessen Behandlung rekapitulieren wir kurz die Startposition. Auszugehen ist von dem vorliegenden Endtext. In bezug auf die Oberschneidungen bedeutet es, daß die Unterschiede zwischen den objektlosen Prohibitiven des Ehebruchs - und Diebstahlverbots und den mit objekten ausgestatteten Prohibitiven der Begehrensverbote liegen müssen. Der Tatbestandsbereich ist also einmal durch das Verb in absoluter Verwendung, das andere $\mathrm{Mal}$ durch das Verb mit beigegebenem Objekt definiert. Beide Bereiche müssen voll erfaßt und miteinander verglichen werden. Der Tatbestand bei den Verben des Begehrens darf unter dem Druck der Komposition nicht vorschnell einseitig verengt werden. Er ist so umfassend wie möglich anzusetzen als ein Begehren, das die Aktionen zu seiner Erfüllung impliziert.

\subsection{Die Uberschneidung zwischen Ehebruchsverbot und Begehrensverbot in beaug auf die Frau}

Wir zerlegen den Tatbestand des Prohibitivs לא / מנאף mit dem Ziel, seine Begrenzung zu erfassen und "Gesetzeslücken" zu entdecken. Der Prohibitiv richtet sich an den erwachsenen Mann und verbietet inm den Geschlechtsverkehr mit der Frau oder Verlobten eines anderen Mannes ${ }^{466}$. Während das Verb זנה immer mit femininem Subjekt gebraucht wird ${ }^{467}$, kann Mann wie Frau zum Subjekt haben. Seine semantische Spezialisierung wird deutlich im Vergleich mit dem analogen, aber weitaus häufigeren שכב עם / שת משת bieses be-

Beobachtungen ist nicht zu rütteln, nur stockt es bei den Schlußfolgerungen. Die Gleichheit der Objekte ist in den Kurzprohibitiven nicht gegeben. Der Dekalogprohibitiv mit נאר und männlichem Subjekt grenzt den objektbereich auf die Frau ein. Für den Dekalog und gerade auch für ALTs Annahme spielt der Statusunterschied zwischen freiem Mann und abhängiger Frau eine entscheidende Rolle. Die Vergleichsebene "Mensch" ist für diesen Prohibitiv zu hoch bzw. zu abstrakt angesetzt. Für nצר trifft diese Ebene zu (menschliches Objekt vs.tierisches objekt).Daß גנ "in keiner Weise das Objekt determiniert" trifft nicht zu (dazu s. u.). Sein Objektbereich umfaßt Personen, Tiere und Gegenstände. Nun ist nicht einzusehen, wie die an Unfang und Art verschiedenen Objektbereiche der Dekalog-Kurzprohibitive von נאף und רצו machbarschaftlichem Druck bei גנב die Reduktion seines Objektbereichs auf ein ursprüngliches "Mensch bzw. Mann" erreicht haben sollen. Ihre Tendenz zu absoluter Verwendung hat bei גנב den völligen Verzicht auf ein objekt forciert, aber keine spezialisierende Reduktion bewirkt. Ob der Dekalog bei dieser Entwicklung Vorreiter oder Erbe war, bleibt vorerst offen.

466 Definition nach ScHuLz, Todesrecht, 34.

467 Vgl. ERLANDSSON, Art. Tנה, bes. 616. 
zeichnet neutral den Beischlaf von Mann mit Frau, Mann mit Mann und Mensch mit Tier ${ }^{468}$. Demgegenüber grenzt נאף den Objektbereich auf Personen ein 469 und qualifiziert den Beischlaf moralisch wie juristisch als Ehebruch 470. Beide Verben beschreiben eine Aktion, die von Natur aus heimlich, unter Ausschluß der Offentlichkeit (Dtn 22,22) und ebenso okkasionell bzw. sporadisch stattfindet. An diesem Punkt wird die Begrenzung im Tatbestand deutlich: נאף erfaßt nicht die dauerhafte, illegitime Aneignung einer anderen Frau, die dem handelnden Mann nicht zugehört. Diese illegitime Aneignung kann geheim oder öffentlich vonstatten gehen. Sie kann mit unterschiedlicher Taktik und den verschiedensten Mitteln durchgeführt werden. In der patriarchalischen Gesellschaft Israels konnte das komplexe Eigentumsverhältnis zwischen Mann und Frau nicht nur durch ein Verbot punktueller Verletzungen geschützt werden.

Die auf Dauer hin angelegte Aufnahme der mobilen, geschlechtsreifen Frauen in die Gemeinschaft des Gatten wird im AT mit לקח bezeichnet ${ }^{471}$. Bei diesem Verb sind die Obergänge von der wörtlichen Bedeutung "nehmen, wegnehmen" zu der juristischen fließend, vor allem in dem Fall, wenn der Mann Subjekt und die Frau Akkusativobjekt ist. Die Textsorte (z.B. Gesetzestexte) wie auch ein spezifischer Kontext können die juristische Bedeutung "heiraten" ( $\equiv$ eine Frau auf Dauer in die Gemeinschaft des Gatten aufnehmen) anzeigen. Zur Präzisierung wird לקח aber üblicherweise durch weitere Bestimmungen zu einer Reihe von Formeln ausgebaut ${ }^{472}$. Wenn wir so zwischen נאף als punktuelle Verletzung der ehelichen Besitzrechte des Mannes und negativ qualifiziertem לקח - unter den eben genannten Bedingungen - als längerfristiger Verletzung unterscheiden, dann greift die Unterscheidung bei einer Reihe von Fällen, die bisher vorschnell unter den Tatbestand "Ehebruch" subsu-

468 Vgl. SCHÜNGEL-STRAUMANN, Der Dekalog, 48f A 35.

469 Vgl. RICHTER, Recht, 128 A 23 ; SCHULz, Todesrecht, 16.

470 So CHOLEWINSKI, Heiligkeitsgesetz, 279.

471 Vgl. CHOLEWINSKI, Heiligkeitsgesetz, 298.

472 Wenn A für den Gatten und B für die Gattin steht, gelten folgende Typen der Formulierung:
A לקח B (z.B. Lev 18,17f);
A לקח B ל + ePP (z.B. Ex 21,10);
A אשה (z.B. Lev 21,14b);
A לקשה (z.B. Dtn 25,5);

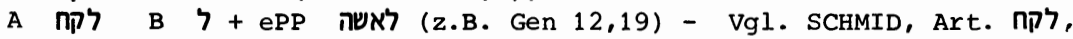 THAT I, 875-879, 877 unter 3d; SCHARBERT, Ehe, 215-217. 
sumiert wurden. Die illegitime Aneignung der Frau des Nächsten gehört zum Thema von zwei der drei Ahnfraugeschichten. Für Gen 12,19 und 20,2b.3b ist die juristische Denotation gesichert 473 . Ebenso veranschaulicht die Batseba-Geschichte vor allem in der Bewertung von 2 Sam 12,4.1obß nicht den Tatbestand "Ehebruch", sondern den von "widerrechtlicher Aneignung der Frau des Nächsten" 474. In den Gesetzbüchern stoßen wir auf den gleichen Tatbestand. Dtn 23,1 verbietet das Nehmen der Frau des Vaters und Lev 20,21 das Nehmen der Frau des Bruders 475.

Vom "Besitzverhältnis" Mann - Frau und vom eng umgrenzten Tatbestand von נאר her ergibt sich für den Dekalog eine "Gesetzeslücke". Die Beispiele aus den Erzählungen und Kodizes akzentuieren die Fehlanzeige. Die bestehende "Gesetzeslücke" hat der Dekalog mit dem Prohibitiv "du sollst die Frau deines Nächsten nicht begehren" ausgefüllt. Dieser verbietet die widerrechtliche Aneignung auf Dauer. Mit diesem Verständnis kann die Eigenständigkeit der Prohibitive gewahrt und das Problem ihrer Zuordnung ohne störende Oberschneidung gelöst werden 476 .

473 Für diese beiden stellen vgl. jetzt WEIMAR, Redaktionsgeschichte des Pentateuch, 12.59.105. In Gen 12,15 wird Sarai in den Harem des Pharao aufgenommen. Die dritte Ahnfraugeschichte verschiebt ihren vergleichbaren Tatbestand in Richtung des okkasionellen Beischlafs. Der Grundtext deutet ihn an in Gen 26,7, wo die Bewohner des Ortes nach der Frau Isaaks fragen, und eine redaktionelle Bearbeitung redet in V.1ob Klartext: "Beinahe hätte einer der Leute mit deiner Frau geschlafen (שכב ת)". Zu Literarkritik und Alter der dritten Ahnfraugeschichte WEIMAR, Redaktionsgeschichte des Pentateuch, 79-102; zur Problematik ihrer eherechtlichen Deutung SCHULZ, Todesrecht, 99-113; Kritik an SCHULz bei SCHMITT, $\mathrm{Zu}$ Gen 26,1-14, 149-156.

474 SCHULZ, Todesrecht, 31-34, bes. 33 konstatiert zwar das Fehlen des Rechtsterminus נאר, stört sich aber nicht daran, weil er auf den vermeintlichen Todesrechtssatz 2 Sam 12,5.13f fixiert ist und darin die Rechtsfolge des Straftatbestandes "Beischlaf bzw. Ehebruch" sieht. In 2 Sam 12,5 liegt ein partizipialer apodiktischer Rechtssatz vor und für VV.13f ist die Abhängigkeit vom Todesrecht nicht nachzuweisen, vgl. LIEDKE, Rechtssätze, 122.128 A 5.140. JACKSON, Theft, $146 \mathrm{f}$ erfaßt den Tatbestand genauer und stellt die Genese dar: Davids Verbrechen begann mit Beischlaf bzw. Ehebruch, 2 Sam 11,4f, in dessen Folge Batseba schwanger wurde. Daraufhin wurde der Mord an Urija arrangiert. Nach dessen Tod machte David Batseba zu seiner Frau, 2 Sam 11,27. Natan bewertet anschließend den ganzen Vorgang als widerrechtliche Aneignung (s.o.): "The offence of David - his only offence - was that of wife-stealing, the stealing of a person not sui iuris". Zur Literarkritik von 2 Sam 12,1-14 DIETRICH, Prophetie, 127-132.

475 Zur Frage, ob in Lev 20,21 die Leviratsehe von Dtn 25,5-10 aufgehoben wird, s. CHOLEWINSKI, Heiligkeitsgesetz, 298f; zu weiteren Stellen mit verbotenem לקח in H vgl. ELLIGER, Leviticus, 240 A 16. 
Wir haben die Aussageabsicht des Prohibitivs grob rekonstruiert und müssen nun erklären, warum diese auf der Ebene der Textoberfläche mit einem Prohibitiv von nמד realisiert wurde. Warum wurde kein Prohibitiv mit נשא gemäß dem einschlägigen Tatbestand "Frauenraub" (Ri 21,23) gebildet? Warum wurde dasselbe Verb nicht formelhaft für eine "Frau holen/heiraten" eingesetzt nach Art von Rut 1,4 und der eherechtlichen Terminologie beim Chronisten 477 . Warum wurde der eherechtliche Terminus לקח nicht verwandt, zumal er sich vom Tatbestand her nahelegte ${ }^{478}$ ? Die in den Fragen durchgespielten Möglichkeiten deuten zugleich eine Antwort an. Der Gebrauch der Termini לקח und נשא in juristischer Verwendung hätte einigen Formulierungsaufwand verlangt, um sicherzustellen, daß sich der Prohibitiv unzweideutig an den erwachsenen Mann richtet. Denn je nach Formulierung durch Anschluß weiterer adverbialer Ergänzungen kann ein Prohibitiv mit einem der beiden Verben entweder den Vater oder den erwachsenen Sohn ansprechen. Der Vater nimmt für seinen Sohn eine weibliche Person zur Frau (vgl. z.B. Gen 24,3.37) oder das angeredete Du nimmt für sich eine weibliche Person zur Frau ${ }^{479}$. Die beiden Verben zwingen zur Präzision und blähen den Prohibitiv notgedrungen auf, so daß er sti-

476 Der Versuch von EERDMANS, die Überschneidungen zu vermeiden, indem er für חמד / die Spezialbedeutung "sich das Herrenlose zueignen" annimmt, bürdet der verbbedeutung zuviel auf und läßt sich bei den Einzelvorkommen nicht durchhalten - EERDMANS, Theol. Tijdschrift 35, 1901, 93; DERS., orsprong, 26. - Kritik schon bei WILDEBOER, Theol. Studien, 116ff; MATTHES, Der Dekalog, 35-4o und KÖNIG, Deuteronomium, 90 .

KESZLER, Problematik des Dekalogs, 11-13, bes. 13 bezieht das Diebstahlverbot auf Kleinbesitz und das Begehrensverbot auf Großobjekte, nämlich Personen und Großvieh, verwickelt sich damit aber in Widersprüche, weil er zugleich im Diebstahlverbot auch den Menschenraub eingeschlossen sieht.

Die Erklärungen von COATS , Covet, $238 f$ und GORDON, Note, 2o8f sind von RICHTER, Recht, 13 of A 28 kritisiert und von JACKSON, Liability, $209 f$ ausführlich widerlegt worden.

KLEIN, Verbot, $168 f$ ad d zieht die Trennungslinie zwischen "Stehlen" und "Begehren", indem er im "Stehlen" ein "Wegnehmen im Verborgenen" mit "Schläue" ausgedrückt findet, im "Begehren" ein "Wegnehmen mit Macht". Er ahnt die Unterscheidung, ohne sie definieren und belegen zu können. WALLIS, Art. Thn, 1026-1029 weist nur den inneren Widerspruch im Dekalg, kann ihn aber nicht auflösen. Alle genannten Versuche kranken daran, daß sie von der Priorität der Exodusfassung ausgehen.

477 Vgl. SCHARBERT, Ehe, 221-223.

478 Ein Beispiel für einen solchen Prohibitiv bietet Jer 16,2 im Befehl Jahwes an Jeremia: לא תקח לך אשה!

479 S.०. A 478 oder Dtn 21,11 und vgl. mit den Formeln in A 472 . 
listisch aus dem Rahmen des Dekalogkontextes herausfällt und sprachlich nur mit Mühe aufzufassen ist. Mögliche Synonyma von לקח, die weibliche Personen zum 0bjekt haben können wie z.B. גזל und ${ }^{480}$, tragen Konnotationen mit sich, die an der vorliegenden Stelle unerwünscht sind. Entweder spezialisieren sie die Art und Weise der Aneignung, was einer intendierten Allgemeingültigkeit widerspricht, oder nähern sich der Bedeutung von גנב an, was wiederum Probleme mit der Oberschneidung provoziert. Wir halten darum eine alte Vermutung von Herrmann für angebracht:"(Darf man vielleicht annehmen), da $\beta$

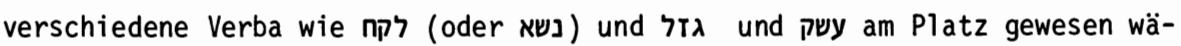
ren, daß der Gesetzgeber aber an deren statt das eine thn setzte, das sie und noch andere umfassen konnte, wenn der Zuhörer eben aus nמד den Weg zu den verschiedenen, auf die Aneignung ... zielenden Handlungen heraushörte" 481 ?

Dem Gesetzgeber waren solche Zusammenhänge durchaus bewußt, wie der Fall der schönen Kriegsgefangenen belegt, Dtn 21,11. Der siegreiche Israelit sieht (ראה) unter den Gefangenen eine Frau von schöner Gestalt, er gewinnt

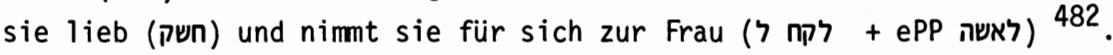
Hier wird ein Vorgang beschrieben, den in Erstreckung tמד allein in sich aufnimmt, aber in der Emotion negativ einfärbt.

Unter den besonderen Bedingungen des Dekalogs wie knappe Form, lückenlose Erfassung des angezielten Tatbestandsbereiches (illegitime Aneignung der Frau des Nächsten) und damit eng verknüpft eine weitreichende, offene Formulierung - unter diesen Bedingungen ist der Prohibitiv mit Thn eine gelungene Kreation.

\subsection{Die Uberschneidung wischen Diebstahlverbot und Begehrensverbot in bezug auf die Sachgüter}

Nach demselben $M$ uster behandeln wir nun die zweite Oberschneidung. Das transitiv-resultative גנב הגנב לא hat des Prohibitiven weiten Objektbereich: Personen, Tiere, Wertsachen und Gegenstände ${ }^{483}$. Darüber hinaus bestimmt das

480 גז: Gen 31,31 ; Ri 21,23; ЭUח: Ri 21,21 .

481 HERRMANN, Das zehnte Gebot, 75.

482 Zu חש s. WALLIS, Art. ששק, $280 f$.

483 Vgl. RICHTER, Recht, 128 A 23 und HAMP, Art. גנ, נג, bes. 44-46. 
Verb die Art und Weise des Vorgehens. Es legt sie in der Regel auf ein heim1 iches Beiseiteschaffen fest und unterscheidet sich darin von Synonyma wie גז $\cong$ rauben, die auf eine öffentliche gewaltsame Oberwältigung und Entwendung abheben. Im Vergleich mit גז sticht noch ein anderer entscheidender Unterschied hervor. Während nung von Immobilien einschließen kann ${ }^{484}$, schließt גנב sie aus und beschränkt sich auf Mobilien. Es wird z.B. nie mit Land und Grundstücken verbunden ${ }^{485}$. Schlechterdings ist es nicht vorstellbar, daß der Dekalog, nachdem er den Diebstahl von Mobilien verbietet, den von Immobilien ausspart. Von der Sache her ist dieser Tatbestand zu bedeutend; die Nabottradition 486 und prophetische Sozialkritik, wie die des 8. Jh. v.Chr., beweisen darüber hinaus seine Relevanz auf dem Felde gesellschaftlicher Konflikte.

Der ganze Alte Orient, ob in Amenemope, ob auf Kudurru-Grenzsteinen, ob in Gesetzesparagraphen ${ }^{487}$, kennt den Tatbestand unter dem Thema "Grenzverrückung". Das AT greift das Thema in der Form des Prohibitivs לא תסיג גבול רעך (Dtn 19,14a und die davon abgeleiteten Vetitive Spr 22,28; 23,10) und der Form des Partizipialsatzes מסיג גבול (Dtn 27,17; Hos 5,10) auf 488 . Die breite Streuung und das $z u$ erschließende relativ hohe Alter lassen vermuten, daß der Tatbestand auch in Prohibitivform dem Dekalog zur Verfügung stand. Hinzu kommt, daß der Prohibitiv metrisch und in Bezug auf Assonanz gut zum nahen Kontext paßt. Als Sperre gegen seine Obernahme muß sich dann seine exklusive Konzentration auf Land bzw. Grundstuicke ausgewirkt haben, wohingegen der Dekalog die Immobilien vom Haus her aufrollt. Ob darin eine Rücksichtnahme auf die wachsende Bedeutung gefestigter Städte unter der Monarchie zu Wort kommen, wie wir sie auch in der Sozialkritik der Schriftpropheten finden, kann hier nur vermutet werden 489.

484 לז $\lambda$ mit Immobilien: Gen 21,25: Brunnen; Mich 2,2: Äcker; Ijob 20,19: Haus; dazu SCHÜPPHAUS, Art. לז $\lambda$; JACKSON, Theft, 109.

485 Vgl. JACKSON, Theft, 113.115-118; DERS., Foreign Influence, $243 f$.

486 Vgl. BOHLEN, Nabot passim.

487 Vgl. RICHTER, Recht, 148; WAGNER, Rechtssätze, 37; OTTOSON, Art. גבול.

488 Anklänge in den Spr 15,25 und Ijob 24,2; dazu RICHTER, Recht, $108 \mathrm{f}$. 147-149.

489 WEBER hat das Novum des Dtn darin gesehen, daß es auf vielfältige Weise städtische Verhältnisse widerspiegelt, vgl. DERS., Aufsätze III, 71-76; zum dtn Sprachgebrauch "in deinen Toren" als Äquivalent für die Stadt und zum Problem "Antiurbanismus bei den Propheten"? FRICK, The City, 44ff.20off. 
Für einen Einsatz im Dekalogschluß bietet sich auch ein Prohibitiv mit ג an. Ohne Objekt taucht er in Lev 19,13a auf. Dort steht er in so enger Verbindung mit dem vorhergehenden Prohibitiv לא תעשק daß dessen personales Objekt "dein Nächster" für ihn elliptisch mitgilt. Sein Vorhandensein und sein relativ hohes Alter lassen sich aus den abhängigen Vetitiven Spr 22,22 und 28,24 sowie aus den Verbbelegen bei Jesaja erschließen ${ }^{490}$. Die eben genannten Belege gehören zu einer Gruppe von Stellen, an denen גזל sich mit einem persönlichen objekt verbindet und ein gegen diese Person gerichtetes Tun im Sinne von "jemanden berauben" bezeichnet ${ }^{491}$. Eine andere Gruppe verbindet גזל ebenso mit direktem Objekt, das hier dann das Geraubte bezeichnet ("etwas rauben"). Der Objektbereich schließt Mobilien wie Immobilien ein 492. Bezeichnenderweise verbindet sich ג גד in der ersten Bedeutung ("jemanden berauben") öfters mit עשק, einem terminus technicus für Bedrückung ${ }^{493}$. Beide Verben konzentrieren sich dabei auf die betroffenen Personen ${ }^{494}$. Uberblikken wir den Befund, dann fallen zwei Fakten auf: Die Gesetzeskorpora haben ein Interesse am Tatbestand "Bedrückung der Armen", das auch durch Prohibitive mit עשק ausgedruickt wird. Auf Grund der engen Verwandtschaft kann sich in einigen Fällen wie Lev 19,13 u.a. dieser Tatbestand mit dem von ג im Sinne von "Beraubung einer Person" verbinden. Daneben besitzen wir für einen Prohibitiv לא תגזל den Beleg Lev 19,13, die Hinweise aus den entsprechenden Vetitiven der Sprüche und Spuren in der Sozialkritik des Jesaja.

490 Jes 10,2 (3,14); - dazu ELIIGER, Leviticus, 248.257f und vor allem RICHTER, Recht, 149-151, allerdings ohne die notwendige Differenzierung zwischen den verschiedenen Bedeutungen von לTג, dazu s.u.

491 Lev 19,13 (s.o.); Dtn 28,29; Ri 9,25 (vgl. dazu JACKSON, Theft, 6 A 5); Jer 21,12 ; 22,3 ; Ps 35,10 ; Spr 22,22; 28,24; dazu SCHÜPPHAUS, Art. ל $\lambda, 1000$ und HAL I, 179. Jes 10,2 mit doppeltem Akkusativ (vgl. WILDBERGER, Jesaja I, 179) kann dieser Bedeutung zugeordnet werden. Die Konstruktverbindung von Jes 3,14 widerspricht ihr nicht.

492 Stellen bei SchÜPpHAUS, Art. Tג, 999; HAL I, 179 ad. 2 differenziert zu wenig.

$493 \mathrm{Vgl}$. Lev 19,13; Dtn 28,29; Jer 21,12; 22,3 (Ez 18,18; 22,29); Mich 2,2 beansprucht eine Sonderstellung (gegen RICHTERS, Einordnung, Recht, 149f): Die Stelle verwendet $\mathbf{T} \boldsymbol{\lambda}$ in der $\mathbf{z w e i t e n}$ Bedeutung "etwas rauben" und trennt ל $\lambda$, von durch ein anderes Verb. das die Konstruktion elliptischer Parallelsätze fortführt. Damit scheidet Mich 2,2 aus der Reihe der oben genannten Stellen aus.

494 Vgl. die Aufstellung bei RICHTER, Recht, 149 und vor allem die Prohibitive mit קשy in den Gesetzeskorpora: (Ex 22,20.21 mit anderem Verb); Dtn 24,14 (MT ist beizubehalten); Lev 19,13; dazu noch Jer 7,6 und Sach 7,10. Das Alter von קשy mit personalem objekt belegen Am 4,1; Hos 5,$11 ; 12,8$. 
Auch von diesen Belegen her bleibt es beim Tatbestand "Beraubung einer Person". Wir schließen daraus, daß in der Rechtsüberlieferung der Prohibitiv von eben diesem Tatbestand besetzt war. Der Dekalog hat darum gewußt und es respektiert. Obwohl die zweite Bedeutung von ג גזל ("etwas rauben") die Bildung eines Prohibitivs mit Tatbestand "gewaltsame und widerrechtliche Aneignung von Immobilien" erlaubte, hat der Dekalog darauf verzichtet. Vielleicht war ihm auch das ג inhärierende Gefälle von überlegenem Täter zu dem unterlegenen Opfer zu speziell, richtet er sich doch an die Gemeinde der freien Vollbürger, die vor dem Gesetz ausnahmslos gleichrangig sind.

Die besonderen Produktionsbedingungen des Dekalogs haben auch hier die Lexemwahl gelenkt. Ausschlaggebend war der angezielte Tatbestand "widerrechtliche Aneignung vom Immobilienbesitz des Nächsten". Ihn galt es, so neutral und allgemeinguiltig wie möglich, zu formulieren. Die Rücksicht auf schon bestehende, ehrwürdige Prohibitive, die aber für die gewünschte Aussage begrenzt funktionstüchtig waren, ließ eine andere Formulierung suchen. Ob dafür Ex 34,24ba und Mich 2,2 als Inspirationsquelle oder nur als stützende Parallele in Frage kommen, kann hier nicht entschieden werden. Der Prohibitiv von Ex 34,24ba mit indefinitem Subjekt und 3. pers. sing. verbietet den Nachbarn des Wallfahrers das Antasten der verlassenen Liegenschaften 495. Mich 2,2 geißelt die Immobiliengier der oberschicht. Beide verwenden die Basis ${ }^{496}$. Im Dekalog war diese Basis für den vorhergehenden Prohibitiv vergeben. Deshalb wurde das passende Synonym אוה/tD-Stamm für den zweiten Prohibitiv gewählt.

Wenn wir die gewonnene Unterscheidung zwischen dem Diebstahl- und dem zweiten Begehrensverbot voll anwenden, dann wird von ihr auf jeden Fall die mögliche Grundstufe der Besitzreihe in der Deuteronomiumfassung gedeckt, die das "Haus" des Nächsten nennt; das "Haus" würde dann eine Besitzeinheit im Sinne von Wohnhaus und dazugehöriges Grundstück bezeichnen. Eine mögliche zweite Stufe mit erweiterter Besitzreihe "das Haus deines Nächsten, sein Feld und alles, was deinem Nächsten gehört" würde im Rahmen einer Immobilienliste verbleiben, wenn die Schlußformel nicht exakt das Mobiliar neben den Immobilien benennt, sondern im üblichen Stil der Besitzreihen die Reihe abschließt und nur die Vollständigkeit der vorher aufgezählten Güter sichert.

495 S.o. und vgl. HALBE, Privilegrecht, $167 \mathrm{f}$.

496 Vgl. die Verbindung der Basis Thn mit Immobilien in den Konstruktverbindungen: Am 5,11: begehrenswerte Weinberge; Jer 3,19: Jahwes kostbares Land: Jer 12,10: Jahwes kostbares Erbteil. 
Auf jeden Fall stören die weiteren Auffüllungen der Reihe: "Rind und Esel" "Sklave und Sklavin". Diese hatten ja schon bei der syntaktischen und semantischen Prüfung der Reihe Verdacht erregt, sekundär eingetragen zu sein.

Nach Ausweis von Ex 21,37 und 22,3, den Paragraphen über Viehdiebstahl, sind "Rind und Esel" Objekt von גנב und zählen zu den Mobilien. Sie gehören in die Immobilienliste nicht hinein 497.

Den Sklavendiebstahl behandelt das alttestamentliche Recht nicht. Ob dieses Delikt auftrat, weil das Institut der Sklaverei in Israel nicht so ausgebaut war wie in den altorientalischen Nachbargesellschaften, bleibt Vermutung. Die altorientalischen Gesetzeskorpora wie CE $\S 40$ und $C H \S 7$ ordnen Sklavenund Viehdiebstahl nebeneinander. Die oben genannten alttestamentlichen Besitzlisten stellen die Sklaven neben das Vieh. Daraus läßt sich schließen, daß die Sklaven auch in Israel zu den Mobilien zählten und auch deswegen in einer Immobilienliste am falschen Platz sind ${ }^{498}$.

Es ist anzunehmen, daß ein Redaktor von der Schlußformel der ihm vorliegenden Immobilienreihe ausging und mechanisch die aus den Gesetzbüchern bekannten und gängigen Besitzgruppen "Sklave und Sklavin" - "Rind und Esel" einschob, ohne auf die besonderen Erfordernisse des Dekalogs zu achten. Nun erst entsteht der Eindruck, als ob das Diebstahlverbot auf Kleinbesitz und das zweite Begehrensverbot auf Großbesitz zielt.

Indem die primäre Deuteronomiumfassung die rechtliche Sonderstellung der Frau betont und dem Verhältnis Mann - Frau zwei Prohibitive widmet, teilt sie vor allem das ehe- und familienrechtliche Interesse der deuteronomischen Gesetzgebung. Mit ihrem Bemühen, den Bereich des Privateigentums lückenlos zu schützen, erweist sie sich solidarisch mit der Sorge altorientalischer Gesetzeskorpora; sie zeigt darin einen Konfliktbereich an, der sich ebenso in der Sozialkritik der Propheten wie in den vereinzelten Bestimmungen des Dtn (vg1. 15,1-6.7-11; 19,14; 21,15-17) widerspiegelt.

497 Zu Viehdiebstahl und zum Problem des Verhältnisses zueinander bei den eben genannten Paragraphen s. JACKSON, Theft, 130-138; HAMP, Art. 2נג, 45f; BOECKER, Recht und Gesetz, $144 \mathrm{f}$.

498 Zum Sklavendiebstahl vgl. JACKSON, Theft, 118-120. 
2.7 Die Polysyndese (Dtn 5,17-21) gegen die Asyndese (Ex 20,2-17)

in der Prohibitivverknüpfung

\subsubsection{Forschungsmükblick}

Diese Differenz ist schon immer notiert worden ${ }^{499}$, wurde aber kaum erklärt, sondern in ihrer Bedeutung eher heruntergespielt ${ }^{500}$. Am traditionellen Urteil, die Exodusfassung sei älter als die Deuteronomiumfassung, hat sie also nichts geändert. Gerstenbergers Vermutung, die Deuteronomiumfassung binde mit ihrer Syndese die Kurzprohibitive stärker zusammen und verrate darin höheres Alter, blieb die Ausnahme ${ }^{501}$. Auch für alle folgenden Exegeten ändert sich nichts am Gefälle von Ex 20 zu Dtn 5 hin. Lohfink ${ }^{502}$ hat als erster die Kompositionswirksamkeit der Polysyndese erkannt und für seine These von einem späteren Sabbatdekalog eingesetzt. Sachgerecht interpretiert er die Polysyndese als "Blockbildung" mit Asyndese nach vorne und syndetischer Reihe. Die Stichwortverbindungen des Sabbatgebotes zum Anfang und Schluß des Dekalogs stellten dieses Sabbatgebot "irgendwie in die Mitte des Dekalogs". Der Block der Kurzprohibitive verweise auf eine "zentralbetonte Konfiguration aus 5 Aussageblöcken", die in der Abfolge von I Jahweverehrung (5,6-10 - lang), II Namen Jahwes (5,11 - kurz), III Sabbat (5,12-15 - lang), IV Eltern (5,16 - kurz) und V sittliche Gebote (5,17-21 - lang) das Sabbatgebot ins Zentrum rücke. Nun sind Stichwortbeziehungen vom Sabbatgebot zu Anfang und Schluß des Dekalogs vorhanden, aber sie sind von zu punktueller und zugleich differenter Art, daß sie den ganzen Dekalog auf das Sabbatgebot ausrichten können ${ }^{503}$. Die auf den ersten Blick beeindruckende "zentralbetonte Konfiguration" scheitert an der Relativität der Begriff "lang" und "kurz" 504 . Mittmann 505 übernimmt die Lohfinksche Beobachtung der Blockbil-

499 So von KöNIG, Dekalog, 377.

500 Vgl. STAMM, Dekalogforschung, 7; ebenso REVENTLOW, Gebot, 24.

501 DERS., Wesen, 73 A 2.

502 DERS., Dekalogforschung, $25 \mathrm{ff}$.

503 Die Stichwortbeziehung von Dtn 5,15 zum Dekaloganfang 5,6 besteht in der Herausführungsformel. Während 5,6 einen bestimmten Typ von Herausführungsformel im Buch Dtn bietet, vertritt 5,15 einen Mischtyp mit Anleihen an einer anderen Form der Herausführungsformel, vgl. PLÖGER, Deuteronomium, $111 \mathrm{f}$. Die Beziehungen zum Dekalogschluß bestehen in den Wortpaaren "Sklave und Sklavin" sowie "Rind und Esel". Im Sabbatgebot gehören sie zu einer erweiterten Kultteilnehmerliste unter Einfluß von Ex 23,12, im Dekalogschluß dagegen gehören sie zu einer Besitzliste, was die unterschiedlichen enklitischen Personalpronomina anzeigen. 
dung. Unter dem Einfluß von Gese ${ }^{506}$ sieht er im Block der Prohibitive einen Hinweis auf den Wechsel der Aussageform als Ordnungsprinzip und kommt daher zu einer dreiteiligen Komposition: Verbot (5,7-11), Gebot (5,12-16) und Verbot (5,17-21). Die Abstraktion suggeriert nur eine planvoll durchgebildete Struktur. Denn der erste Teil ist gestört durch den Wechsel der Redeformen von Jahwe- zu Menschen- bzw. Moserede und der zweite Teil kann gar nicht auf eine Aussageform festgelegt werden, da das umfangreiche Sabbatgebot die verschiedensten Aussageformen enthält.

Somit kommt der Forschungsrückbiick zu dem Ergebnis, daß eine Balance oder symmetrie der Teile dem Textumfang nach nicht herzustellen ist ${ }^{507}$. Die Binnenstruktur des Dekalogs ist einmal bestimmt durch den Wechsel der Rede: Jahwerede, Menschenrede, neutraler Teil der Prohibitive ohne Bezug zu Jahwe weder in dritter noch in erster Person. In der Deuteronomiumfassung deckt sich dieser letzte Teil mit dem polysyndetischen Block. Die Dreierteilung nach den redenden Personen aber stößt sich mit der thematischen Einteilung. Denn das Thema der Jahwerede (das vereinigte Fremdgötter- und Bilderverbot) wird über die Jahwerede weiter hinausgeführt. Die Jahweverehrung kommt auch im Verbot des Namensmißbrauches und im Sabbatgebot zur Sprache, die aber zum Teil der Menschenrede gehören. Da rein ästhetische und syntaktisch-stilistische Einteilungsprinzipien versagen und mit thematischen Gesichtspunkten nicht zu harmonisieren sind, vermuten wir, daß die einzelnen Gebote in ihrer Textlänge nicht abgezählt, sondern gewogen werden wollen. Demnach steht in der Deuteronomiumfassung dem polysyndetischen Block von sechs Geboten eine asyndetische Reihe von vier Geboten gegenüber. Auf der Ebene der Einzelgebote legt die Deuteronomiumfassung eine Zweiteilung nahe mit der Zäsur nach dem Elterngebot. Die asyndetische Exodusfassung bleibt vorerst außer Betracht.

$5 \circ 4$ Zählt man die Worte der einzelnen Blöcke, dann steht das Sabbatgebot mit 64 Worteinheiten an der Spitze; ihm folgen die Jahweverehrung mit 59, die sittlichen Gebote mit 27, das Elterngebot mit 22 und das Namensmißbrauchverbot mit 17 . Wenn Sabbat und Jahweverehrung als "lang" gelten, dann rangieren die sittlichen Gebote unter den "kurzen" Blöcken und es bietet sich die Abfolge von: lang-kurz - lang-kurz - kurz.Die Dekalogkomposition sperrt sich gegen symmetrische Einteilung.

505 DERS., Deuteronomium, 143-145.

506 Vgl. GESE, Der Dekalog als Ganzheit, 78 A 56.

507 Vgl. NIELSEN, Zehn Gebote, 32f; ETTISCH, Symbolik, bes. 211f; seine These, daß auf jeder Tafel der ganze Dekalog gestanden habe, lehnen wir ab. 


\subsubsection{Anmerkungen zur Stilistik des Polysyndetons}

Bei der Stilform der Anapher, unter inhaltlichem Gesichtspunkt auch Priamel genannt, wird die Verbindung von aneinandergereihten Sätzen durch die asyndetische Wiederholung desselben Wortes am Anfang jedes Satzes geleistet ${ }^{508}$. Wir treffen diese Stilfigur an in Großreihen ${ }^{509}$ wie in Kleinreihen ${ }^{510}$. Bei den Kleinreihen kann die Syndese hinzutreten, wenn eine Gruppe durch Schlußsyndese als Dreiergruppe dargestellt werden soll. Auf den Dekalog übertragen bedeutet das: Die Reihe der Kurzprohibitive ist schon durch das Stilmittel der Anapher zusammengebunden. Die Syndese muß sekundär dazugesetzt worden sein, um die Reihe als eigenständige Gruppe bzw. als autarken Block erscheinen zu lassen, der von der Reihe der vorausgehenden Gebote abgehoben werden will; in dieser Reihe stehen die Gebote asyndetisch ohne Anapher nebeneinander ${ }^{511}$. Insofern bestätigt sich Lohfinks Urteil, daß die Blockbildung im Dienst einer Komposition steht, die dem Dtn-Dekalog nachträglich übergestuilpt wurde. Nur daß die Komposition auf eine Zehnerreihe zielt, die im Verhältnis vier zu sechs zweigeteilt ist. Das Faktum sekundärer Komposition konvergiert mit der bekannten Feststellung, daß die Vereinigung von Fremdgötter- und Bilderverbot durch die pronominalen Rückverweise in V.9a ebenso nachträglich vorgenommen wurde 512 .

\subsubsection{Das Verhältnis von Deuteronomium- und Exodusfassung}

Mittlerweile ist die Frage akut geworden, ob die Komposition der zweigeteilten Zehnerreihe auf eine ältere Exodusfassung oder auf eine in Dtn 5 verborgene Vorstufe des Dekalogs übertragen wurde. Im letzteren Falle bliebe die Exodusfassung sekundär gegenüber einer bearbeiteten Deuteronomiumfassung. Wir votieren für die zweite Möglichkeit, vor allem von der Gravitation der bisherigen Erklärung der synoptischen Differenzen her. Für die spätere Exodusfassung war die Auflösung der ihr vorgegebenen Zweiteilung (asyndetische

508 Dazu BÜHLMANN/SCHERER, Stilfiguren, $27 \mathrm{f} .61 \mathrm{f}$.

509 Die Beispiele: Lev 18,7-16(17). - dazu jetzt: HALBE, Inzestverbote, bes. 69; Dtn 27,15-26; 28,3-6.16-19.

510 Vgl. Dtn 22,9-11; mit Schlußsyndese: Dtn 16,19; Lev 19,15a.26.

511 Das erste Gebot besteht aus dem Fremdgötter- und Bilderverbot, die sowohl durch pronominalen Rückverweis in v.9a wie durch die Rahmung der Selbstvorstellungsformel vereinigt wurden. Auf das erste Gebot folgen die verschiedenen Gebotseinleitungen des Namensmißbrauchverbotes, des Sabbat- und Elterngebotes.

512 Vgl. ZIMMERLI, Das zweite Gebot, 240-242. 
Reihe von Geboten und syndetischer Block der Prohibitive) und damit die Rückkehr zur ursprünglichen Asyndese eine Notwendigkeit. Sie hatte das Bilderverbot aus seiner sekundären Verklammerung mit dem Fremdgötterverbot gelöst und dadurch die Rahmenelemente zum Annex des nun sehr umfangreichen Bilderverbots gemacht. Im Gegenzug war das zweifache Begehrensverbot zu einer Gebotseinheit gestaltet worden. Von der vorliegenden Deuteronomiumfassung waren die Zehnzahl der Gebote und die Zäsur nach dem Elterngebot vorgegeben. An beiden Vorgegebenheiten hielt die Exodusfassung fest. Der Kompromiß zwischen ihrer Novellierung und der Bindung an die Vorlage bestand darin, die strukturierende Abfolge von asyndetisch-syndetischer Verkoppelung der Gebote aufzuheben. Sie war für die eigene Komposition überflüssig, ja störte; denn bei ihrem Dekalog - einer asyndetischen Abfolge von zehn Geboten - besorgte die Mathematik die Strukturierung. Sie teilte die festliegende Zehnzahl in zwei Hälften von je fünf Geboten, wobei die Zäsur auf der alten Stelle nach dem Elterngebot erhalten blieb (Fremdgötter-, Bilder-, Namensmißbrauchverbot, Sabbat-, El terngebot/Tötungs-, Ehebruchs-, Diebstahl-, Falschzeugnis- und Begehrensverbot). Hier liegt dann auch der Grund dafür vor, daß die priesterschriftliche Literatur an der Zweitafeltradition festhält.

\subsubsection{Belege für die Zweiteilung des Dekalogs}

Als Bestätigung der Zweiteilung führen wir aus der inneralttestamentlichen Wirkungsgeschichte des Dekalogs (hier: der Deuteronomiumfassung) zuerst Lev 19,2-4 an. Die ältere wie jüngere Forschung ist sich über das Faktum der $\mathrm{Pa}-$ rallelität von Lev 19,2-4 zum Dekalog einig. Die Parallelität wird dahingehend präzisiert, daß der Dekalog das Vorbild darstellt, nach dem die Verse Lev 19,2-4 gestaltet wurden ${ }^{513}$. Darüber hinaus ist ein Trend festzustellen, der von Elligers Meinung ( $\mathrm{PH}$ habe hier vorgegebenes Material verarbeitet) wegführt zu den jüngeren Autoren (hier liege eine Neuformulierung durch eine exilische Redaktion des Heiligkeitsgesetzes vor, die inhaltlich und formal den Dekalog nachahmt, genauer: den ersten Teil bzw. die erste Tafel des Dekalogs vom Fremdgötterverbot bis zum Elterngebot kopiert). In der Dekalogparallele fehlt das Namensmißbrauchverbot. Aber es lag schon vor in V.12 und konnte deshalb ausfallen, als 19,2-4 mit den Prohibitiven VV.11ff verklammert wurde.

513 Vgl. ELLIGER, Leviticus, 245.252.254.256; JAGERSMA, Lev 19, 74-80; CHOLEWINSKI, Heiligkeitsgesetz, 44-54. 
Die Kopie des ganzen ersten Teils ist gewollt und kein Zufall der Textentstehungsbedingungen von Lev 19, denn bei der Erstellung von 19,2-4 wurden bewußt Doppelungen zu vorgegebenem Material in Kauf genommen wie im Fall des Sabbatgebotes aus V.30 und im Fall des Elterngebotes V.32 514.

Lev 19,2-4 gehört zur Wirkungsgeschichte des Dekalogs (näherhin: der Deuteronomiumfassung). Die freie Nachahmung konzentriert sich auf den ersten Teil bzw. die erste Tafel des Dekalogs. Sie belegt dadurch zweierlei: Der Dekalog wird als zweiteilige Einheit rezipiert. Deren Zäsur liegt nach dem Elterngebot ${ }^{515}$. Der nächste Beleg für die Zweiteilung des Dekalogs ist die Vorstellung von den zwei Gesetzestafeln. Sie hat soviel Eigengewicht, daß wir sie gesondert behandeln.

\subsubsection{Die Vorstellung von den zwei Gesetzestafeln}

Diese Vorstellung belegt nur die Zweiteilung ohne Auskunft über die Schnittstelle. Wir sind daran interessiert, in welcher Weise die Tafeln mit dem Dekalog in Beziehung stehen oder gebracht wurden und durch wen das geschah. Ober die Tafeln ist mehrfach geschrieben worden ${ }^{516}$. Methodisch gehen wir von der Beobachtung aus, die Perlitt akzentuiert als die "schmale und geschlossene Oberlieferung des (Tafel-)Motivs" 517 in der Sinaiperikope und ihren Parallelen im Dtn, kommen aber zu entgegengesetzten Analyseanweisungen. Während Perlitt von der terminologischen Differenzierung in der Bibel wenig erhofft 518 , sehen wir darin gerade einen Ansatzpunkt; denn es muß ja auffallen, wie auf engem Raum unterschiedliche Termini nebeneinandergestellt werden, ohne sie zu verschmelzen (vgl. Ex 31,18; Dtn 9f; 1 Kön 8,9). Im übrigen ist dieser Weg schon eingeschlagen worden, indem man die Terminologie eines priesterlichen Redaktors abhob ${ }^{519}$ und die älteste Schicht des Tafelmotivs rekonstruierte ${ }^{520}$. Was noch fehlt, ist die sichtung des Tafelmotivs

514 Das "Elterngebot" von Lev 19,32 kommt mit der "klassischen" Formulierung darin überein, daß in beiden Formen die versorgung und ehrfürchtige Behandlung der alten Eltern integriert ist.

515 Zum Zusammenhang von Eltern- und Sabbatgebot vgl. die späte Redaktion in Ez 22,7-8; dazu HOSSFELD, Untersuchungen, 136-140.

516 Vgl. LEHMING, Versuch, 32-4o; ETTISCH, Symbolik, 211-215; PERLITT, Bundestheologie, 203-216; ZENGER, Tafeln vom Sinai, (Lit.!); HAAG, Buch des Bundes; OTTO, Mazzotfest, 274ff.344-351; LORETZ, Gesetzestafeln, 159-161.

517 DERS., Bundestheologie, 206f.

518 DERS., Bundestheologie, 207.

519 So LEHMING, Versuch, 33f; PERLITT, Bundestheologie, 207 A 1; ZENGER, Tafeln vom Sinai, 101 . 
in der dtn/dtr Theologie ${ }^{521}$. Wir gruppieren die verschiedenen Tafelbezeichnungen und erheben die damit verbundenen Vorstel lungen 522.

Die älteste Gruppe nennt die Tafel לחת האבן (Ex 24,12;31,18). Jahwe oder Gott hat sie beschriftet (Ex 23,$12 ; 31,18$ ). Mose wirft sie aus seinen Händen (מידו; Q) und zertrümert sie unten am Berge (Ex 32,19).

Ein priesterlicher Redaktor spricht von den שני לחת העדת. Er betont dabei die Zweiheit (Ex 31,$18 ; 32,15 ; 34,29$ ), dehnt sie sogar auf die Vorder- und Rückseite aus (Ex 32,15b) und besteht auf göttlicher Autorschaft der Tafeln wie der Beschriftung (Ex 32,16$)$. Mose hält die beiden Tafeln in seiner Hand (Ex 32,15; 34,29) 523 .

Eine weitere Gruppe hat ihr Spezifikum gerade darin, daß sie zwei Termini nebeneinanderstellt: לוחת האבנים an erster und לוחת הברית an zweiter Stelle (Dtn 9,9.11; 1 Kön 8,9 BHS). Darüber hinaus treten beide Termini je einmal

$520 \mathrm{Vgl}$. ZENGER, Tafeln vom Sinai, passim; er weist die Schicht dem Jehowisten zu, vgl. DERS., Sinaitheophanie, 164. Die Anfragen oder Einwände gegen ZENGERs Vorschlag, die Tafeln in der ältesten Schicht als himmlische Bürgerlisten des Jahwevolkes zu verstehen, betonen die Differenz ספischen den Tafelstellen und der Erwähnung der Bürgerliste, dem von Ex 32,32 (so HAAG, Buch des Bundes, $25 \mathrm{~A}$ 9); oder sie weisen die betreffenden Tafelstellen durchweg als sekundär aus ohne verbindung zur Grunderzählung von Ex 32 und besonders Ex 32,32 (so LORETZ, Gesetzestafeln, 160). Der Nachweis, daß die betreffenden Tafelstellen nachträglich eingeschoben wurden, überzeugt literarkritisch nicht; ja, die Parallele von Ex 32 in Dtn $9 f$ legt eine Zugehörigkeit zum Grundtext von Ex 32 nahe. Ferner verschiebt die These des Einschubs nur das Problem. Wer und warum hat ein Redaktor die betreffenden Tafelstellen so eingeschoben, daß der vorliegende Text einen Zusammenhang mit dem ספר nahelegt? Sowohl von den Tafeln wie von dem ספר wird festgehalten, daß Jahwe sie beschrieben hat. Semantisch ist der Begriff "Tafel" von den ספר in der Grundbedeutung "Schriftstück oder Inschrift" nicht so weit entfernt, vgl. Jes 30,8 und THAT II, 165. Wir halten deswegen an ZENGERs ältester Tafelschicht und ihrer plausiblen Verbindung mit Ex 32,32 fest. Der Kritik von LORETZ an OTTOs überlieferungsgeschichtlicher Hypothese zum Verständnis Lade - Dekalog schließen wir uns rückhaltlos an.

521 PERLITT, Bundestheologie, 207 A 1.212, verweist auf "Fährten", die er aber nicht aufnimmt.

522 Die Bezeichnung הלחת wird nicht eigens aufgeführt, da sie auf vorher eingeführte und präzisierte Tafeln durch den definiten Artikel zurückweist - gegen PERLITT, Bundestheologie, 209.

523 Für Ex $32,15 \mathrm{a}$ steht die Zugehörigkeit zu einem priesterlichen Redaktor durch die Tafelbezeichnung außer Zweifel; aus syntaktischen Gründen (vgl. ZENGER, Sinaitheophanie, 84) ist V.15b demselben Redaktor zuzuschlagen. Für eine P-Hand spricht vor allem die für die Priestergrundschrift typische Stilform dex "short-circuit inclusion"- eine Inklusion, bei der die betreffende Einheit mit demselben Element beginnt und endet. Dieses Stilmittel arbeitet mit dem grammatischen Chiasmus wie hier in V.15b; dazu vgl. MCEVENUE, The Narrative Style, 43f. Der anschließende v.16 
einzeln auf: לוחת האבנים in Dtn 9,10 und לחת הברים in Dtn 9,15. Widersprüchlich bleibt das Verhältnis zur Zweiheit: In Dtn 9,9 fehlt die Zahlenangabe. In Dtn 9,10.11.15.(17); 1 Kön 8,9 ist sie vorhanden. Für diese Gruppe wird interessanterweise zweimal in Dtn 9,15.17 festgehalten, daß Mose die Tafeln auf seinen beiden Händen trägt. Nur eine Literarkritik zu Dtn 9 kann die Spannungen auflösen.

Die letzte Gruppe fällt durch ihre relativ breite Streuung und durch die Konstanz ihrer Elemente auf. Ihre Tafelbezeichnung lautet: שני לחת אבנים (Ex $34,1.4(2 x)$; Dtn 4,$13 ; 5,22 ; 10,1.3)$. Die Zweiheit ist obligatorisch. Mose hält die beiden Tafeln in seiner Hand (Ex 34,4b; Dtn 10,3). Die Tafeln werden von Jahwe mit dem Dekalog beschrieben (Ex 34,1; Dtn 4,13;5,22;10,4). Der Dekalog umfaßt "zehn Worte" (Dtn 4,13;10,4). Bei dieser Gruppe also finden wir die Ordnungsvorstellung von den zweiteiligen "zehn Worten" 524.

Innerhalb der dtn/dtr Behandlung des Tafelmotivs fällt Dtn $9 f$ eine Schlüsselrolle zu. Die Gruppierung der Tafelbezeichnungen (vor allem die dritte und vierte Gruppe) bietet einen ersten Einstieg in die Literarkritik der Kapitel, die uns helfen soll, die Aufeinanderfolge und das Verhältnis der verschiedenen Vorstellungen zu erkennen.

\subsubsection{Exkurs: Literarkritik zu Dtn 9.7b-10.11}

\subsubsection{Vorbemerkungen}

Die Unterbrechunq der Paränese zwischen 9,7a und 10,12ff durch eine Erzählung im Ich-Stil mit Mose als Sprecher macht die Abgrenzung dieses Textes unproblematisch.

Als Erzählung beansprucht der Text für sich eine temporale Progression. Widersprüche und Spannungen in dieser Ordnung fordern die Literarkritik heraus. Deshalb ist eine Wahl zwischen den beiden Möglichkeiten, hier: zeitliche

zeichnet sich durch zwei parallele Kasus-pendens-Konstruktionen aus, wobei der Schlußsatz V.16bß wiederum eine Inklusion mit הלחת beabsichtigt. ZENGERs Verdachtsmomente gegen eine Zugehörigkeit von V.16 zu V.15b fallen nicht ins Gewicht (DERS., Sinaitheophanie, 84). Die unterschiedliche Form des Demonstrativums המה V.16 ergibt sich aus der In-Pause-Stellung. Der Aramaismus Y ח (V.16) spricht nicht gegen eine Zugehörigkeit $\mathrm{zu}$ einem P-Redaktor.

524 Die umkämpfte Stelle Ex 34,28b mit einem weiteren Vorkommen der "zehn worte" bleibt hier vorerst außer Betracht. 
Abfolge - dort: juristisch-theologisches Ordnungsprinzip nicht als exklusive Alternative im Sinne eines entweder - oder" 525 , sondern im Sinne eines "sowohl - als auch" aufzufassen.

Ferner gehen wir von der Prämisse aus, die von vielen Exegeten festgehalten wird, daß der vorliegende Text Dtn 9,7b-10,11 eine von Ex 32 abhängige $\mathrm{Pa-}$ rallele darstel1t ${ }^{526}$. Ohne den Vergleich zu weit voranzutreiben und dadurch Ex 32 zum Maßstab der Analyse von Dtn $9 f$ zu machen 527 , kann man voraussetzen, daß beide Texte in der Abfolge bedeutenderer Ereignisse übereinstimmen. Neuere literarkritische Analysen von Ex $32{ }^{528}$ kommen im Falle von Ex $32 \mathrm{zu}$ einem Grundtext mit folgendem Duktus: Herstellung des Gußbildes, während Mose oben auf dem Berge weilt; Herabsteigen des Mose vom Berg und sein Dazwischentreten mit Zerstörung von Tafeln und Kalb; Aufstieg des Mose mit Fürbitte für das Volk und Entlassungsbescheid Jahwes. Die Parallele Dtn 9f mit Mose als Erzähler wird notwendigerweise die Ereignisse aus seiner Sicht darstellen. Die Erzählung beginnt deswegen mit seinem Aufstieg und nicht mit der Herstellung des Gußbildes. Von dieser erfährt der Hörer bzw. Leser nur indirekt über den Hinweis Jahwes an Mose und über die bestätigende Feststellung des Mose nach dem Abstieg. Von dieser eben angezeigten Prämisse her erwarten wir einen Grundtext mit einer Ex 32 analogen Abfolge des Geschehens. Versuche wie in der ältesten Literarkritik des Dtn 529 und gedämpfter in neueren Untersuchungen ${ }^{530}$, den Text in mehrere Stränge aufzuspalten, sensibilisieren zwar für die eklatanten Doppelungen zu Beginn der Erzählung, müssen sich aber daran messen lassen, inwiefern sie einen einheitlichen, flüssigen und in seiner Vollständigkeit plausiblen Grundtext bieten. Vorschläge, den Grundtext von Dtn $9 f$ als Retrospektive zu betrachten, die den Beweis für die These 9,4-6 antritt und bis 9,24 reicht ${ }^{531}$, kann das

525 So LOHFINK, Hauptgebot, 211-215; BRAULIK, Testament des Mose, $47 \mathrm{f}$.

526 So z.B. VON RAD, Deuteronomium, 55; VALENTIN, Aaron, $269 f$.

527 Vgl. die Bemerkungen von LOHFINK, Hauptgebot, $208 f$ A 9.

528 ZENGER, Sinaitheophanie, 77-87.103f.164; DERS., Exodus, 287f A 117; VALENTIN, Aaron, 205-303.

529 Dargestellt bei LOHFINK, Hauptgebot, 207-209.

530 So bei VON RAD, Deuteronomium, 55f und SEITZ, Deuteronomium, 51-69.

531 Vgl. dazu LOHFINK, Hauptgebot, $211.216 f$ mit den dort genannten Vertretern und neuerdings BUIS- LECLERCQ, Deutéronome, $88 \mathrm{f}$. 
Eigengewicht des Paradigmas "Horeb" in der Aufzählung von Orten, an denen Israel straffällig wurde, nicht erklären. Darüber hinaus bliebe in einem solchen Grundtext die Frage nach der Reaktion Jahwes offen, die aber gleich zu Anfang der Erzählung in 9,8 aufgeworfen wird.

Die folgende Literarkritik will knapp die vorliegende Erzählung analysieren und konzentriert sich mehr auf die begründete Differenzierung des Textes und weniger auf komplexe redaktionskritische Zuweisungen im Rahmen des dtn/dtr Schrifttums.

\subsubsection{Prüfung der Logischen Kohärenz}

Immer schon aufgefallen sind die beiden Doppelungen der Tafelübergabe (V.10 und V.11) sowie der Rede Jahwes (V.12 und neu eingeleitet VV.13f).

Der Fürbittakt des Mose vor Jahwe (VV.18f) - aller Wahrscheinlichkeit nach oben auf dem Berg - steht in Spannung zu den vorausgehenden Versen VV.15-17, die vom Abstieg des Mose und seinen Aktionen am Fuße des Berges berichten. Ebenso zerreißt er die aus Ex 32,19f bekannte Abfolge von Zertrümerung der Tafeln und der Verbrennung des Jungstiers. Der Vergleich zu Beginn ("wie beim ersten Mal" V.18) und das Zitat aus 9,9, den 40-tägigen Aufenthalt betreffend, zielen auf den ersten Bergaufenthalt des Mose in $9,9 f 532$.

Die Fürbitte für Aaron $(9,20)$ hängt sich an die vorausgehende Fürbitte für das Volk an und erweist sich darin als Nachtrag. Außerdem wird nur für einen Einzelnen Fürbitte geleistet anstatt für das ganze Volk wie in der restlichen Erzählung.

Die Verse 9,22-24 sind ohne erzählerische Verbindung zum Horebgeschehen in 9,21. Das Itinerar der Orte sprengt den Rahmen der bisherigen Horebereignisse.

In 9.25-29 findet eine erneute Fürbitte vor Jahwe statt, wobei der einleitende V.25 die Beziehung zum Fürbittakt von 9,18f herstellt. Von einem Aufstieg des Mose wird nach 9,21 nichts berichtet. Allerdings trägt 10,10 nach, daß Mose sich zur Zeit der Fürbitte oben auf dem Berge aufhält 533 .

532 Im Unterschied zu LOHFINK, Hauptgebot, 218 A 36, der an Dtn 5,22-31 denkt. Das Sparsamkeitsprinzip veranlaßt aber, zuerst im Rahmen dieser Erzählung von Dtn $9 f$ zu verbleiben.

533 Auf den schlechten Anschluß von 9,25ff nach 9,22-24 hin weist auch SEITZ, Deuteronomium, 52 . 
Der Abschnitt 10,1-5 berichtet von einer neuen, eigenen Bergbesteigung des Mose, um die zweiten Tafeln von Jahwe mit dem Dekalog beschriften zu lassen. Zum vorausgehenden $(9,25-29)$ wie nachfolgenden Kontext $(10,10)$ steht der $A b-$ schnitt in Spannung, weil Mose sich anfangs schon auf dem Berg aufhält und deshalb keinen neuen Aufstieg braucht und nachher mit dem Abstieg unnötigen Aufwand treibt, statt für den Schlußakt 10,10f oben zu bleiben. Der Verfasser dieses Abschnitts scheint für den eigenen Auf- und Abstieg nicht von Dtn 9f, sondern von Ex 34 her unter Zwang zu stehen.

Der Itinerarbericht 10,6f und die Levitennotiz 10,8f fallen durch ihr Thema und durch ihre anderen Interessen aus dem Rahmen der Erzählung heraus.

Der Schlußabschnitt der Erzählung 10,10f knüpft mehrfach an den vorausgehenden Kontext über 10,1-9 hinweg an. Mose häit sich auf dem Berge auf. Dieser Bergaufenthalt wird durch einen Vergleich als zweiter charakterisiert und mit der Zeitangabe "40 Tage und 40 Nächte" auf den ersten Bergaufenthalt in 9,9.11 bezogen. Der in 9,18f vorausgesetzte Bergaufenthalt bietet sich als Bezugspunkt nicht an, da er sich selbst schon als wiederholte, also zweite Fürbitte auf dem Berge versteht ${ }^{534}$. Die in 10,10b berichtete Erhörung setzt ein Fürbittgebet voraus. Der Rückverweis "auch dieses Mal" zielt auf 9,19b, wohingegen die nächste erreichbare Fürbitte in 9,25-29 zu finden ist ${ }^{535}$. Hier scheint der Schlußabschnitt selbst nicht spannungsfrei bzw. in den Rückbezügen eindeutig zu sein.

\subsubsection{Prüfung der syntaktisch-stizistischen Kohärenz 536}

Der Vers 9,7b will als Oberschrift verstanden werden. Er nennt Start- und Zielpunkt einer temporal-lokalen Entwicklung 537 und qualifiziert abschliessend den Prozeß mit einem Durativ (Suffixkonjugation von היה + Partizip zur

534 Im Unterschied zu LOHFINK, Hauptgebot, 213 A 24; die von ihm, ebd., $214 \mathrm{f}$, beschriebenen stilistischen Struktursignale (die Zeitangabe, die Erwähnung des Fastens und des Feuers) mögen auf der Ebene des Endtextes funktionieren. Für die Literarkritik fallen zuerst ihre jeweilige Individualität in syntaktischer und lexikalischer Gestaltung auf; dazu s.u.!

535 Vgl. LOHFINK, Hauptgebot, 213 A 24; VON RAD, Deuteronomium, 55.57; SEITZ, Deuteronomium, $51 \mathrm{f}$.

536 Die semantisch-syntaktischen Sprachvergleiche zu Dtn 9,7b-10,11 bei MINETTE DE TILLESSE, Sections, 56-63 und LOPEZ, Analyse littéraire, 549 sind hilfreich, aber in ihrer Beschränkung auf den pauschalen Nachweis dtr. Sprache für unsere Analyse zu global angelegt.

537 Zu den lexikalischen Parallelen vgl. LOPEZ, Analyse littéraire, 18. 
Bezeichnung eines generellen Sachverhaltes in der Vergangenheit). Der Numeruswechsel (MT) kann wegen der thematischen Kohärenz nicht schichtungsspezifisch ausgewertet werden. Er signalisiert den sekundären Oberleitungscharakter des ganzen Verses von der Paränese im Singular zur Anrede der Erzählung im Plural.

Vers 8 knüpft an V.7b syndetisch an. Die betont vorangestellte Ortsangabe verursacht die Inversion, die durch Narrativ mit abhängigem Finalsatz weitergeführt wird. Das ablaufende Schema "Sünde Israels, Zorn Jahwes, Strafe" 538 verleiht dem Vers eine über einen Erzählanfang hinausführende Reichweite. Er umgreift das ganze Horebgeschehen. Daher rührt sein schon festgestellter Uberschriftcharakter ${ }^{539}$. Im Verhältnis zu V.7b hat er die Funktion, das Horebgeschehen als erstes Paradigma einer Reihe von analogen Fällen einzuführen.

In V.9 wird durch die vorgezogenen Infinitivsätze ein relativer Neueinsatz der Erzählung erreicht. Mose gibt gleich zu Beginn den Zweck des Aufstiegs und dadurch auch das Tehma der Erzählung bekannt: die Obernahme der Steintafeln. Diese werden in asyndetischer Apposition zu Bundestafeln ernannt. Ein Rückverweis erinnert an den Bundesschluß von Dtn 5,2.

V.10 gibt sich wie die erzählerische fortsetzung von V.9, isoliert aber die erste Tafelbezeichnung von V.9 und setzt die Zahlangabe "zwei" davor. Die überfüllt wirkende dreifache adverbiale Bestimmung am Ende von V.10 (am Berg, mitten aus dem Feuer, am Tage der Versammlung) gehört nach Ausweis der Parallelen in Dtn 5,22 und 10,4 zum Stil des Redaktors.

Das formelhaft erstarrte ויהי zu Beginn von V.11 markiert einen Neueinsatz innerhalb der Erzählung. Zusammen mit der Zeitangabe bestimmt es die Konstruktion des Verses. Die Zeitangabe ebenso wie die zweifache Tafelbezeichnung greifen auf V.9 zurück. Somit schließt sich V.11 an V.9 an 540 . Die Zahlenangabe vor der ersten Tafelbezeichnung wird aus dem sekundären V.10 übernommen.

In der Jahwerede von V.12 fällt der für das Dtn singuläre Fall auf, daß Mose Subjekt der Herausführung aus Agypten ist.

Die zweite Jahwerede VV.13f konkurriert mit der ersten. Im Unterschied zu den Redeeinleitungen von 9,12 und 10,11 bietet sie ein zusätzliches לאמר.

538 Vgl. LOPEZ, Analyse littéraire, 18.

539 So LOHFINK, Hauptgebot, 211 A 18 und BRAULIK, Testament des Mose, 48.

540 Ebenso SEITZ, Deuteronomium, 54. 
Die beiden Narrative in $9,15 a \alpha$ entsprechen dem einleitenden Doppel-Imperativ der Jahwerede von 9,12 und sind identisch mit der Einleitung von Ex 32,15. Die Parenthese 9,15aß.b zeigt in ihren beiden nominalen Umstandssätzen ein Interesse an Theophaniephänomen, das der bisherigen Erzählung unbekannt ist. Dazu greift sie die zweite Tafelbezeichnung auf und verbindet sie mit der Zweizahl 541.

In V.16 stellt Mose unten am Berg fest, was Jahwe V.12b angesagt hatte. Ansage und Feststellung entsprechen sich chiastisch ${ }^{542}$. Damit erweist sich die Jahwerede V.12 im Grundtext fest verankert, ihre Konkurrentin VV.13f dagegen als sekundär.

Die Narrativkette von V.17 entspricht in ihren beiden letzten Gliedern der von Ex 32,19b. Das Objekt des ersten Narrativs הלחת weist mit seinem definiten Artikel auf die vorausgehenden termini technici. Von den sekundären Versen bzw. Versteilen VV.10.11.15 her halten wir auch hier die Zahlangabe בשני für sekundär. Das Verb nann auch den Akkusativ regieren (vgl. Dtn 22,28).

Der Fürbittakt VV.18f wird sowohl durch den einleitenden Vergleich "wie beim ersten Mal" als auch durch die abschließende Feststellung der Erhörung "auch dieses Mal" als Wiederholung charakterisiert.

Die adverbiale Bestimmung "in jener Zeit" am Schluß von V.20 unterstreicht dessen Charakter als Einschub 543.

Inversion und Frontstellung des attributiv ergänzten Akkusativobjektes in V.21 dienen der "juristisch-theologischen Qualifizierung" 544 . Die Abfolge der Aktionen zur Vernichtung des Kalbes folgt der von Ex 32,20 , entspricht aber in der einzelnen lexikalischen Füllung der Zerstörung der Kultgegenstände unter Joschija 2 Kön 23,6.(15) 545.

Der Abschnitt VV.22-24 beginnt wie V.8 und nennt eingangs drei Orte. Das Verb V.8a taucht in V.22 im Durativ von V.7b auf zur Bezeichnung eines mehrmaligen individuellen Sachverhalts in der Vergangenheit ${ }^{546}$. V. 24 schließt Aufzählung der Paradigmen ab mit zweifacher Erinnerung an v.7b durch identischen Durativ und Nennung des (zeitlichen) Ausgangspunktes 547.

541 Auch VALENTIN, Aaron, 273 A 1 äußert Bedenken gegenüber der Ursprünglichkeit der Parenthese.

542 Nachweis bei SEITZ, Deuteronomium, 55.

543 Vgl. PLÖGER, Deuteronomium, 218-225, bes. 223; SEITZ, Deuteronomium 51.

544 So LOHFINK, Hauptgebot, 212.

545 Vgl MINETTE DE TILLESSE, Sections, 58ff; LOPEZ, Analyse littéraire, $22 \mathrm{f}$. 
Die komplexe Gestaltung von V.25 ${ }^{548}$ ergibt sich aus dem Zwang, den Fürbittakt von VV.26-29 dem von VV.18f zuzuordnen; die letzteren Verse verstehen sich aber selbst schon als Wiederholung, so daß ein einfacher Rückverweis nicht ausreicht. Die Determination des temporalen Akkusativs ("die vierzig Tage und Nächte") zielt auf den Relativsatz mit abhängigem KausalSatz: Mose fiel vor Jahwe nieder genau so vierzig Tage und Nächte, wie er vor ihm niedergefallen war bei der Gelegenheit, da Jahwe die Vernichtung angedroht hatte.

Die zu VV.26-29 parallelen Fürbittgebete (Dtn 3,24f; Ex 32,11-13; Num 14, 13-19 ${ }^{549}$ ) bieten punktuelle Analogien, bewahren aber ihre individuelle Struktur. In V.26b macht sich der zweite asyndetische Relativsatz mit Herausführungsformel verdächtig. Die nahen Parallelen Dtn 7,8;13,6 und Mich 6,4 zeigen dagegen zwei syndetische Parallelsätze mit der Herausführungsoder Heraufführungsformel an erster und dem "Loskauf aus dem Sklavenhaus" an zweiter Stelle. Der Relativsatz V.26b wurde also dazugesetzt. Der erste Relativsatz V.26a gehört zur Gruppe von isolierten Vorkommen der Aussage über den Loskauf 550. Die Bitte, der Väter zu gedenken (V.27), nennt zuerst eine Bezeichnung der Patriarchen + Personalsuffix und fügt in Apposition die Patriarchennamen hinzu. Darin entspricht sie dtn/dtr Sprachstil 551. Gegenüber der nächsten Parallele Ex 32,13 fehlt dem Gedenken an die Patriarchen der Hinweis auf den Jahweschwur. Da dies die einzige von 21 Stellen des Dtn ist, der bei namentlicher oder pauschaler Erwähnung der Patriarchen der Jahweschwur fehlt ${ }^{552}$, macht sich V.27a verdächtig, zumal das Fürbittgebet in V.28 nur mit der Verheißung Jahwes an Israel argumentiert. Die Bitte wurde wohl dazugesetzt, um stichwortartig an den Vätereid zu erinnern. Die auffällige Umschreibung von Agypten in V.28 mit "das Land, aus dem du (Jahwe)

546 Die Unterscheidung individueller-genereller Sachverhalt stammt von GROSS, Verbform, 4f. Die übergänge zwischen mehrmalig individuellem und generellem Sachverhalt sind fließend.

547 Vgl. LOHFINK, Hauptgebot, 210f; VON RAD, Deuteronomium, 56.

548 VALENTIN, Aaron, 271 bezeichnet sie als "stilistisch wenig befriedigende Wiederholung des Themas 'Sünde am Horeb'"mit Rückgriff auf 9,18f.

549 Vgl. BRAULIK, Testament des Mose, 48.

550 Dtn 15,$15 ; 21,8 ; 24,18$ - weitere Stellen in den Listen bei WEINFELD, Deuteronomy, 326; ebenso STAMM, Art. פדה, THAT II, 405.

551 Vgl. Dtn 1,$8 ; 6,10 ; 9,5 ; 30,20$ - Ausnahme Dtn 34,4 ohne "Väter". Außerhalb des Dtn findet sich an vergleichbaren Stellen (Gen 26,3b.24; 28 , 13; Ex 32,13) die umgekehrte ordnung. Zu den Väterverheißungen SKWERES, Rückverweise, 86ff.210; zur Wendung "Gott deines Vaters" WEIMAR, Berufung, 151-153.

552 Stellen bei SKWERES, Rückverweise, 88 . 
uns herausgeführt hast" entspricht stilistisch der nachfolgenden Zielangabe "das Land, das er innen zugesagt hat". Der erste Teil des Volkszitats hat seine nächste Verwandte in Bezug auf Konstruktion und lexikalische Füllung in Num 14,16a, der zweite Teil in Dtn 1,27 und Ex 32,12 553 . Der V.29 greift rahmend Aussagen aus der Einleitung des Fürbittgebetes in V.26 auf. Der Gebrauch der Herausführungsformel verrät den Redaktor von V.26b.

Der Abschnitt 10,1-5 stellt sich als Einheit dar. Die aus 9,20 bekannte Formulierung "in jener Zeit" sorgt zu Beginn für losen und darin sekundären Anschluß 554 . Die Beziehungen dieses Abschnitts nach Ex 34,1.4; Dtn 4,13 und 5,22555 lassen die Konturen eines Redaktors erkennen. In unserer Erzählung ist seine Spur auf Grund der engen Verwandtschaft mit 10,4 auch in 9,10 zu entdecken ${ }^{556}$. Er kann kontextgerecht eigene Formulierungen variieren. So regiert דבר/D-Stamm mal die Präposition (4,12;5,22;10,4), mal die Präposition עם $(5,4 ; 9,10)$. In 9,10 nimmt er Rücksicht auf das כרת ברית עם im vorausgehenden Vers, zumal für inn nach Ausweis von 4,13 Dekalog und Bund identisch sind. Desgleichen kann er seine Tafelbezeichnung שני לחת אבנים unter Druck der Umgebung zu שני לוחת האבנים verändern.

Ebenso ist er für die isolierte Verwendung der ursprünglich in 9,9 paarig auftretenden Tafelbezeichnungen verantwortlich (vgl. 9,10.15b) und führt konsequent, angestachelt von seiner Tafelvorstellung, die "Zweiheit" der Tafeln ein (9,10.11.15b.17). Oberhaupt dürfte die ganze Parenthese 9,15aß.b auf inn zurückgehen, denn die seltene Rede vom "Berg, der im Feuer brennt" $(4,11 ; 5,23 ; 9,15)$ stammt wohl aus seiner Feder. In $10,5 a$ übernimmt er $9,15 a$

553 Vgl. LOPEZ, Analyse littéraire, 24f; SKWERES, Rückverweise, 166-171. Wir stimmen SKWERES zu, wenn er den Bezugstext für Dtn 9,28 in Ex $3,8 \mathrm{~J}$ ausmacht (zur Quellenzuweisung jetzt: WEIMAR, Berufung, 87ff). Wir bezweifeln allerdings die zeitliche Vorordnung von Num 14,13-16 als"frühdeuteronomisch". Die Crux liegt in der Ambivalenz von Formulierungen, die auf den ersten Blick dtn/dtr aussehen, dann aber signifikant von der im Buch Dtn gesetzten Sprachnorm abweichen.

Wie diese Abweichung $\mathrm{zu}$ bewerten ist, ob frühdeuteronomisch oder für manche jehowistisch, ob spät - bzw. nachdeuteronomisch oder für manche Signum der Pentateuchredaktion, dafür fehlen noch tragfähige Kriterien. Auf jeden Fall reicht die Bezeichnung "deuteronomistisch" angesichts ihrer mittlerweile angewachsenen Bandbreite nicht mehr aus.

554 Dazu PLÖGER, Deuteronomium, 223; LOPEZ, Analyse littéraire, 25.

$555 \mathrm{Vgl}$. oben unter 2.7.5.

556 Ein gründicher Vergleich der Stellen Dtn 5,$22 ; 9,10 ; 10,4$ bei SKWERES, Rückverweise, $28 f$. 
Die Einschübe $10,6 \mathrm{f}$ und $10,8 \mathrm{f}$ bestätigen bei diesem Analyseschritt ihren Nachtragscharakter. 10,6f fällt mit seinem Personenwechsel in die 3. Person völlig aus der Anrede der Moseerzählung heraus und bezeichnet das "Volk" als "Söhne Israels".

Bei 10,8f tritt die Anrede nicht in Erscheinung. Ebenso spricht die Einleitung mit "in jener Zeit" für den Nachtragscharakter 557.

Der Schluß 10,10f knüpft syndetisch an die Fürbitte 9,25-29* an. Die Inversion ( $w^{\mathrm{e}}=\mathrm{x}$-qatal) will keinen Progreß ausdrücken, sondern eine Begleithandlung zum vorlaufenden Fürbittakt schildern ${ }^{558}$. Die sekundäre Rückbindung der Erhörung ("auch dieses Mal" in V.10b) an 9,19b steht hier zwischen dem Bericht von der Erhörung und seiner asyndetischen Explikation in V.10bß. Deren Inversion wird durch die feststehende Verwendung von אבה als negiertem Hilfszeitwort verursacht ${ }^{559}$. Der singuläre Numerus im ePP des Infinitivs nötigt nicht zu literarkritischer Scheidung; er läßt sich aus der Anpassung an die folgende Rede vom Volk in der Einzahl verstehen (V.11a) 560 . Der Doppelimperativ mit desemantisiertem Bewegungsverb an 1. Stelle 561 in der Einleitung des Jahwebefehls V.11 erinnert an die gleiche Konstruktion von Dtn 9,12 und darüber hinaus an Ex 32,34. Ebenso dürfte die dortige Zielangabe des Führungsbefehls ("Geh, führe das Volk, wohin ich dir aufgetragen habe") die hiesige Ausgestaltung von V.11b mit dem Väterschwur angeregt haben ${ }^{562}$. Diese Ausgestaltung konkretisiert sich in einer Kombination von zwei Landnahmeverben 563 mit dem Väterschwur und einem final angeschlossenen Landgabesatz. Die nächste Parallele ist der zweifach geschichtete Vers $1,8 b^{564}$.

557 Zum Inhalt von 10,8f s. SKWERES, Rückverweise, 188-191.

558 Dazu s. GROSS, Verbform, 33.

559 Dazu GERSTENBERGER, Art. אבה, 23; Dtn 10,10 gehört zu den Ausnahmen ohne $\zeta$ beim anschließenden Infinitiv.

560 Zweifel am sekundären Charakter hat selbst MINETTE DE TILLESSE, Sections, 63.

561 Dazu RICHTER, Grammatik, $44 \mathrm{f}$.

562 Der Literarkritik von ZENGER und VALENTIN zu Ex 32 folgend (vgl. A 528), rechne ich Ex 34,34* zum Grundtext des Kapitels aus der Hand des Jahwisten. SKWERES, Rückverweise, lo9f kommt zu anderen Zuweisungen, aber zu derselben Abhängigkeit der Dtn-Stelle von Ex 32,34.

563 Dazu LOHFINK, Hauptgebot, $81 \mathrm{f}$.

564 Zur Schichtung s. MITTMANN, Deuteronomium, 19f. Die Konstruktionsparallelen sind: zwei Landnahmeverben + Väterschwur: Dtn 6,$18 ; 8,1$; ein Landnahmeverb + Väterschwur + finaler Landgabesatz: Dtn 31,7; Jos 1,6; eine barockausgebaute und zerlegte Form in Dtn $11,8 \mathrm{f}$. 


\subsubsection{Prüfung der semantischen Kohärenz}

Die Differenzierung des internen Sprachgebrauchs genießt Vorrang vor der redaktionskritischen Zuweisung. Der Obersichtlichkeit wegen werden die Beobachtungen in der Reihenfolge des vermuteten Grundtextes aufgeführt.

Den Grundtext von Dtn $9 f$ und Kap. 5 verbinden die Rede vom Berg ${ }^{565}$ und die Formel כרת ברית עם ePP in Dtn 5,2 wie in 9,9. Die Obernahmen aus dem Tetrateuch stechen ins Auge: 9,9 zitiert die aus Ex 24,18b bekannte Aufenthaltsdauer des Mose auf dem Berg und erweitert diese um das Motiv des Fastens. Der eingeschobene Vers 9,10 trägt eine Beschreibung der Tafeln nach, die aus Ex $31,18 b$ stamt.

Signifikant ist das Wortspiel mit der Wurzel שחת. Das Volk handelt verderblich (תחש/D-Stamm in 9,12). Daraufhin droht ihm das Verderben durch Jahwe, das Mose durch seine Fürbitte abwendet (שח/H-Stamm in 9,26 und 10,10). Demgegenüber umschreibt eine Reihe von sekundären Versen das Verderben durch Jahwe mit שמד/H-Stamm (9,3.8.14.19.20.25).

Die für das Dtn singuläre Herausführung aus Ag̣pten in 9,12 mit Mose als Subjekt legt sich von Ex 32 her nahe ${ }^{566}$. Die dortige Verwendung der "Heraufführungsformel" mußte unter der einseitigen Vorliebe des Dtn der "Herausführungsformel" weichen 567 . Damit übernahm die Stelle den Formelgebrauch des Elohisten in Ex 3,10f ( $v$ gl. noch Ex 19,17a), den auch der Jehowist in Ex $14,11 b$ kopiert ${ }^{568}$.

Der Rückverweis von 9,12.16 zielt auf den Dekalog ${ }^{569}$, näherhin auf das Bilderverbot, wie es der asyndetische V.12bß erläutert. Zwei Beobachtungen legen das nahe. Der Satz formuliert im Unterschied zu seinem Pendant in 9,16 nicht mit der auf das Konkrete abhebenden Konstruktverbindung מסכה - wie wir es auch von Ex 32,4.8 her erwarten -, sondern nur mit dem indirekten 0bjekt מסכה. Er gleicht sich damit an die allgemeine Formulierung des Bilder-

565 Vgl. Dtn 5,4.5.22-9,9f.15.21; 10,1-5.10.

566 Ex 32,1 gehört mit Sicherheit zum (jehowistischen) Grundtext des Kapitels (vgl. ZENGER und VALENTIN - dazu A 528). Ex 32,7 ist zusatz zum Grundtext und Ex 32,23 bleibt in der zugehörigkeit umstritten.

567 Dazu SKWERES, Rückverweise, 168 A 157 (Lit.!).

568 Vgl. VALENTIN, Aaron, 219 A 3; für die Zuordnung der Stellen jetzt WEIMAR, Berufung, 160 und 311 A 148.

569 Vgl. BRAULIK, Ausdrücke für "Gesetz", 49f; SKWERES, Rückverweise, $52 f$. 
verbots aus dem Dekalog an. Der Wechsel von פסל zu מסכה ist unter anderem vom Grundtext von Ex 32 her vorgegeben und bedeutet überdies keine trennende Variation, da מסכה oufters zusammenstehen 570.

Zweitens kommen das Bilderverbot und V.12bß darin überein, daß עש sowohl einen Akkusativ (die Skulptur) wie ein Präpositionalobjekt regiert (עשה + $\boldsymbol{3}+\mathrm{ePP} \leqq$ Subjekt). Die Formulierungshilfe von Hosea (Hos 13,$2 ; 8,4.6$ ) und der Einfluß von Ex 32,1.23.31 sind mit Händen zu greifen ${ }^{571}$. In V.15a kopiert der Grundtext wiederum für den Abstieg des Mose Ex 32,15a In der Rede von den Tafeln, die Mose aus seinen beiden Händen wirft, steht der Grundtext der Erzählung von Ex 32,19 nahe ${ }^{572}$. Für die Redeweise von der "Sünde" unterscheidet Lopez 573 den Gebrauch von und den von טußn außerhalb desselben wie hier in Kap. 9. Diese Unterscheidung läßt sich weiterführen.

Während der sekundäre Vers 9,18 die figura etymologica bevorzugt ${ }^{574}$, formuliert der Grundtext in 9,16 nur mit dem Verb und in 9,21 mit der Verbindung von חשאת + Letztere Wendung mag durch den Kontext inspiriert sein, drückt aber auf jeden Fall die unterschiedene Eigenständigkeit des Grundtextes aus.

570 Dtn 27,15; Ri $17,3 f ; 18,14.18 .20$; Neh 1,14; Jes 42,17 .

571 Die Parallelen lauten für die Wendung מסהה: Hos +4 + 4 + ePP 4 , ; 13,2; 1 Kön 14,9 (מסכ) ; 2 Kön 17,16; Neh 9,18 (עגל מסכה + mit מסכה als Objekt: Lev 19,4; Ex 34,17; mit אלהי זהב abjekt: Ex 20,$23 ; 32,31$; vgl. $32,1.23$.

Die Parallelen für die Wendung פשע + Ex 20,4// Dtn 5,8; Dtn 4,16.23 (Lev 26,1).

Nach unserer Meinung ist Dtn 9,12 fest im Grundtext der Moseerzählung 9,7-10,11* verankert und braucht keine Herleitung von Ex $32,7 f$, wie SKWERES, Rückverweise, $52 \mathrm{f}$ annimmt. Auf Grund der hier gemachten Literarkritik ist die zuweisung des umstrittenen Abschnitts Ex 32,714 neu zu verhandeln. Die Kategorisierung "dtr" reicht nicht aus, vgl. A 553. Der ganze Abschnitt Ex 32,7-14 - unabhängig von v. 9 weicht gelegentlich von dtn/dtr Sprachnorm ab. Die Entscheidung, in welche Richtung dieses Faktum zu interpretieren ist, in Richtung protodeuteronomisch oder in Richtung Pentateuchredaktion, scheint nach wie vor offen, $\mathrm{vgl}$. das Kurzreferat über bisherige Einordnungen bei VALENTIN, Aaron, 235f; LOHFINK, Ex 32,7-11.13-14; SKWERES, Rückverweise, $166-171$.

572 S.oben unter 2.7.5.

573 DERS., Analyse littéraire, 2of; vgl. KOCH, Art. KUח, 864 und KNIERIM, Art. אun, 542.

574 חטא ח Dtn 9,18; 1 Kön 14,16.22; 15,30; 16,13.19.26; 2 Kön 21,17; vgl. חטא חטא ח DUח 19,15; Ex 32,30f. 
Während der Grundtext in 9,26 für die Fürbitte פלל/td-Stamm einsetzt, benutzen 9,18.25 ( $\mathrm{vgl}$. noch Esr 10,1) נפל/td-Stamm. Dieser Gebetsgestus wird dabei von einer Begleithandlung zum Konkurrenzbegriff des "Fürbitte-leisten" angehoben. Das erhellt aus der konstatierten Erhörung in V.19b und aus V.18b. der wie beim Verb פלל den Grund für die Fürbitte mit der Präposition y einführt.

Die in der dtn/dtr Literatur beliebte Verbindung der Wurzel קשה 575 taucht hier in 9.6.13 auf. Der Grundtext bietet dagegen in 9,27 das Hapaxקשי העם Iegomenon In der Fürbitte 9,28 argumentiert Mose mit einer Landverheißung Jahwes an Israel. Dem Sprachgebrauch des Dtn entsprechend wird auf diese Verheißung mit דבר/D-Stamm verwiesen, in Absetzung vom Jahweschwur an die Patriarchen mit שבע/N-Stamm. Der Rückverweis zielt auf den Bezugstext Ex 3:8, der zur jahwistischen Mose-Berufung gehört ${ }^{576}$. Das Thy der Begleithandlung in 10,10 mit seiner lokalen Präposition bezeichnet hier ein "SichAufhalten" und steht in Korrespondenz zu dem ישב von 9,9, der Einleitung der Erzählung 577 . Der vergleichende Rückverweis, der sich anschließt, setzt darum im Grundtext den zweiten Bergaufenthalt des Mose (Fürbitte) in Beziehung zum ersten (Empfang der Tafeln).

Außerhalb des Grundtextes kann der Sprachgebrauch in den restlichen Versen weiter unterschieden werden. 9,7b nennt das Land des Auszugs das "Land Ägypten" : während 9,12.26 nur von "Agypten" sprechen ${ }^{578}$. 9,8.20 verwenden für das Erzürnen Jahwes über jemanden, ihn zu vernichten, das Verb אנף/tD-Stamm, wohingegen 9,19 für eine analoge Konstruktion קצ/G-Stamm wählt. Die Herausführungsformeln mit Jahwe als Subjekt in 9,26b.29 gehören zu dem von Plöger herausgestellten 2. Typ von Herausführungsformeln im Buch Dtn ( יהוה + H-Stamm + מצרים + adverbiale Bestimmungen) 579 .

575 Die Verbindung hat die Form einer Konstruktverbindung oder eines Verbs mit objekt; die Stellen bei WEINFELD, Deuteronomy, 341; VAN DER WOUDE, Art. קשה, 691 .

576 Zum Rückverweis SKWERES, Rückverweise, 166-171; zur quellenkritischen Zuordnung WEIMAR, Berufung, $87 \mathrm{ff}$.

577 So LOHFINK, Hauptgebot, 213 A 24; AMSLER, Art. Thy, 330.

578 PLÖGER, Deuteronomium, 107-112 ordnet die unterschiedliche Bezeichnung bestimmten Formulierungen der Herausführungsformel zu.

579 Vgl. A 578. 
Der literarkritischen Analyse war die Aufgabe gestellt, die Verflechtung der verschiedenen Tafelvorstellungen im Schlüsseltext Dtn 9,7b-10,11 zu entwirren. Deshalb kommt es der literarkritischen Hypothese darauf an, das Gegenüber von Grundtext und späteren Bearbeitungen herauszustellen, ohne sich auf redaktionskritische Zugehörigkeit und Abfolge einzelner Bearbeitungen festzulegen; denn dafür reicht das begrenzte Textkontinuum im komplexen Buch Dtn nicht aus.

Der Grundtext des abgegrenzten Textes 9,7b - 10,11 umfaßt folgenden Textbestand: 9,9.11f (ohne "die zwei").15a .16f (ohne "die zwei").21.26a.27b28; 10,10-11 (ohne "auch dieses Mal"). Dieser Grundtext zeichnet sich aus durch relativ enge Anlehnung an den Grundtext von Ex 32 sowohl im Duktus als auch gelegentlichen Formulierungen bis zu Zitaten. An Querverbindungen zu Dtn 5 fielen die durchgängige Rede vom "Berg" und die Formel "einen Bund schneiden mit uns/euch" auf. Die gegenüber dem Grundtext von Ex 32 verschobene Akzentsetzung ergibt sich einerseits aus der Stilisierung der Erzählung aus der Sicht des Mose und andererseits aus ihrem juristisch-theologischen Interesse ${ }^{580}$. Dieses offenbart sich vor allem in der Vorrangstellung der Tafeln. Die jehowistischen Lebens- und Steintafeln werden vom Grundtext zu Bundestafeln ernannt. Dadurch wird erst auf dieser Stufe der Tafeltradition die Erzählung vom Goldenen Kalb zum Paradigma des Bundesbruchs. Dabei spielt nur der Titel der Tafeln eine Rolle; sie werden von Jahwe ausgehändigt, um anschließend zerbrochen zu werden; zu ihrem Inhalt sagt der Grundtext nichts. Die Funktion des Mose erfährt eine Aufwertung: Er ist offizieller Empfänger der Bundestafeln. Er konstatiert den von Jahwe angezeigten Gebotsverstoß und qualifiziert inn als Bundesbruch durch den rechtswirksamen Akt des Zerbrechens der Tafeln "vor ihren Augen". Er erwirkt durch seine Fürbitte die Verschonung des Volkes. Im Unterschied zum Grundtext von Ex 32 (vor allem V.32) wirft Mose nicht seine eigene Person in die Waagschale, sondern argumentiert amtlicher, als ein Bundesmittler, mit der von Jahwe geschaffenen Existenz des Volkes und der Kontinuität der bisherigen Erlösungsgeschichte. Der Erfolg der Fürbitte kommt stärker als in Ex 32 zum Vorschein: Die Erhörung wird eigens berichtet und von zukünftiger Strafe wie in Ex 32,34 ist keine Rede mehr.

$580 \mathrm{Vgl}$. unter vermittlung mit der obigen Literarkritik die Charakterisierung bei LOHFINK, Hauptgebot, 211-213. 
Die zum Grundtext sekundären Verse lassen sich zu Gruppen ordnen, ohne daß das Verhältnis der Gruppen zueinander und ihre Abfolge hier geklärt werden können.

Eine erste Gruppe (9,13f.18f.25.26b.29; 10,10bß (auch dieses Mal) verstärkt die Rolle des Mose als Fürbitter: Sie führt in einer eigenen Rede den Vernichtungsbeschluß Jahwes ein, mit dem er unmittelbar auf die Sünde reagiert ( $V .13 f)$. Sie stilisiert die gesamte Erzählung zu einem dreifachen Fürbittakt des Mose um. Sowohl durch die Rede ("laß von mir ab!" V.14) wie durch die Rückverweise zu Anfang und Ende des Einschubs VV.18f erweckt sie den Eindruck, der erste Bergaufenthalt des Mose sei von der Fürbitte bestimmt. Zwischen das Zerbrechen der Tafeln und die Vernichtung des Jungstiers schiebt sie eine zweite Fürbittaktion ein. Die einzige Fürbitte des Grundtextes bearbeitet sie und deutet diese zum dritten Akt um.

Die zweite Gruppe von Versen (9,7b.8.22-24) überblickt den gesamten Wuistenaufenthalt Israels und macht das Horebgeschehen zum Anfangsglied einer Kette von Vergehen gegen Jahwe an verschiedenen Orten des Weges ins Gelobte Land.

Die dritte Gruppe $(9,10$; die Zahlenangabe "die zwei" vor den Tafeln in VV. 11.17; V.15aß.b; 10,1-5) entwickelt das Tafelmotiv weiter. Bei ihr werden die Tafeln mit dem Dekalog verbunden, der selbst zum Inhalt des Bundes avanciert. Der Dekalog umfaßt jetzt genau "zehn Worte", die auf zwei Tafeln verteilt sind. Die beiden Vorgänger innerhalb der Tafeltradition, der Jehowist und unser Grundtext von Dtn 9f, kennen eine unbestimmte Mehrzahl von Tafeln in den beiden Händen des Mose. Von nun an wandert die "Zweiheit" zu den Tafeln, die Mose nur mehr in einer Hand hält. Das gilt sowohl für den Redaktor dieser Verse wie für einen bzw. den priesterlichen Redaktor. Da der Dekalog wegen seiner Dignität auf Dauer verkündet und von Jahwe selbst (für alle Zeiten) festgeschrieben wird, kann er nicht durch den Bundesbruch am Horeb hinfällig werden. Konsequenterweise wird er nach der (letzten) Fürbitte des Mose in identischer, alter Herrlichkeit erneuert und in der Lade hinterlegt.

Von dieser Gruppe von Versen laufen Querverbindungen zu anderen Stellen des Dtn und zum Tetrateuch, so daß man hier den Zipfel einer Redaktionsschicht zu fassen bekommt, die u.a. daran interessiert ist, das Verhältnis der 
"Rechtskorpora" wie Dekalog, Bundesbuch und Privilegrecht in Ex $34 \mathrm{zu}$ regeln. Doch gilt das nur als vorläufiger Hinweis.

Ober den sekundären Charakter der späteren Einschübe wie 9,20;10,6f.8f ist sich die Forschung weitgehend einig ${ }^{581}$.

\subsubsection{Resultat}

Der Exkurs hat unsere obige Vermutung bestätigt: Das Polysyndeton der Deuteronomiumfassung gehört zur Wachstumsgeschichte des Dekalogs innerhalb des Deuteronomiums.Es belegt nicht die Priorität der Exodusfassung, sondern die nachträgliche Bearbeitung des Dekalogs am selben Ort (Dtn 5). Die Exodusfassung bearbeitet wiederum das schon entwickelte Endstadium des Deuteronomiumdekalogs und übernimmt auf ihre Weise die dort angebrachten Ordnungsvorstellungen bzw. die Binnensystematik des Dekalogs: Zehn Gebote auf zwei Tafeln mit der Zäsur nach dem Elterngebot.

\subsection{Gesamtergebnis des synoptischen Vergleichs}

Der Obersichtlichkeit und Knappheit halber wird das Gesamtergebn is thetisch entfaltet:

1. Der synoptische Vergleich analysiert den Endtext der beiden Dekalogfassungen und behandelt sie jeweils als individuelle Ganzheiten.

2. Der Vergleich führt dazu, das traditionelle Gefälle vom Exodusdekalog zum Deuteronomiumdekalog hin umzukehren. Alle Differenzen zwischen beiden Fassungen lassen sich als gewollte Eingriffe erklären.

3. Die ältere Deuteronomiumfassung zeigt vom Endtext her Wachstumsspuren, die eine oder mehrere Vorstufen erahnen lassen. Der Endtext stellt sich dar als eine Komposition von "zehn Worten" oder "zehn Geboten", die im Verhältnis 4 : 6 zweigeteilt ist. Die Komposition wirkt kopflastig durch das stark ausgebaute erste Gebot. Fremdgötter- und Bilderverbot sind darin zu einer Einheit verbunden ( $\mathrm{V} .9 \mathrm{~b})$ und gerahmt (VV.6 und $9 \mathrm{f}$ ). Der erste Teil der Komposition besteht aus dem vereinigten Hauptgebot, dem Verbot des NamensmiBbrauchs, dem umfangreichen Sabbat- und dem Elterngebot. Der zweite Teil stellt sich dar als eine syndetische Reihe von sechs Prohibitiven, die gegenüber den Geboten des ersten Teils relativ kurz gehalten sind.

4. Die jüngere Exodusfassung versteht sich als Novelle der Deuteronomiumfassung aus der Hand des Pentateuchredaktors. Ihre Komposition ist ein KompromiB zwischen novellierender Absicht und quasi-kanonischer Dignität

581 Vgl. BUIS/LECLERCQ, Deuteronome, 92f; LOHFINK, Hauptgebot, 209.216; VON RAD, Deuteronomium, 56; SEITZ, Deuteronomium, 51; BRAULIK, Testament des Mose, $47 f$. 
ihrer Vorlage. Die Einheit von Fremdgötter- und Bilderverbot sprengt sie auf und fusioniert im Gegenzug die beiden letzten Gebote der Deuteronomiumfassung $\mathrm{zu}$ einem Begehrensverbot. Sie entscheidet sich für konsequente Asyndese und erhält dadurch eine durchlaufende Reihe von zehn Geboten mit der Einleitung V.2 als Vorspruch, mit einem überlangen Bilderverbot, einem von der Vorlage her umfangreichen Sabbatgebot und einem gewichtigen abschließenden Begehrensverbot. Weil der priesterliche Redaktor mit Hilfe des Tafelmotivs an der Zweiteilung der Zehnerreihe festhält, ergibt deren Anwendung die Aufteilung in zwei Pendanten mit der Schnittstelle wiederum nach dem Elterngebot.

5. Die Wirkungsgeschichte der beiden Dekalogfassungen legitimiert den obigen Ansatz. Die beiden Dekalogfassungen wurden später nicht genetisch hintereinander, sondern simultan nebeneinander gelesen. Dadurch ergab sich eine grundlegende Spannung: Von der Sache, vom Anspruch eines Grundgesetzes her ist gefordert, daß der Dekalog nur in einer authentischen Fassung existiert. Faktisch aber bietet das AT davon zwei. Die verschiedenen religiösen Gemeinschaften haben diese spannung auf ihre je eigene Weise gelöst und sich aus den beiden biblischen Kompositionen eine einzige katechetische Fassung erstellt, je nach kontingent historischen Konstellationen und mit verschiedenen theologischen Gründen. Angesichts dieser Schwierigkeit ist die Suche nach der einen richtigen Zählung der Gebote hinfällig geworden 582 .

582 Vgl. REICKE, Die zehn Worte. Im Unterschied zu ihm sehen wir den Widerspruch, der die verschiedenen zählungen provoziert hat, nicht im Gegensatz zwischen Dekaloginhalt und zehnzahl - den haben beide Fassungen je für sich gelöst -, sondern in der Spannung zwischen dem einen Grundgesetz in zwei. Fassungen; vgl. dazu bes. REICKE, Die zehn Worte, $1-8$. 


\section{KAPITEL 3}

Der Dekalog im Kontext der Sinaitheophanie

\section{$3.1 \quad$ Einleitung}

Der synoptische Vergleich hat den Exodusdekalog als späte Novelle des älteren Deuteronomiumdekalogs erklärt. Wenn wir uns nun dem Kontext der jeweiligen Dekalogfassungen zuwenden, impliziert dieses Ergebnis die Arbeitshypothese einer späten, wahrscheinlich durch den Pentateuchredaktor vorgenommenen Einsetzung des Exodusdekalogs in die Erzählung der Sinaitheophanie. Da die Einfügung eines so bedeutenden Textes nicht nur eine punktuelle Verankerung im nahen Kontext verlangt, sondern die Frage nach seinem Verhältnis zu den übrigen Gesetzesmaterialien am Sinai wie Bundesbuch, Kultgesetzgebung und "Privilegrecht Jahwes" aufwirft, weitet sich die Aufgabenstellung aus auf die Profilierung von Redaktionsschichten, die zusammen mit bestimmten Gesetzesmaterialien auch ihre Konzeptionen in die Sinaitheophanie eintrugen. Hier soll der Nachweis geführt werden, daß die obige Arbeitshypothese manche der traditionellen Schwierigkeiten innerhalb der Sinaitheophanie erklären hilft. Die verschiedenen Positionen der Forschung bis 1971 hat Zenger in seiner "Sinaitheophanie" aufgearbeitet und zusammengefaßt 1 . Für die weitere Literatur verweisen wir auf die kursorische Literarkritik der Kap. Ex 19,1 - 20,21; 24,1-18 bei Mittmann ${ }^{2}$ und auf die mehr oder min-

1 DERS., Sinaitheophanie, 12-45 und die Tabelle 207-231; ferner DERS. in den Anmerkungen zu den betreffenden Texten in: Exodus.

2 DERS., Deuteronomium, 145-159. MITTMANN erweitert die bisherige Literarkritik um eine Reihe wertvoller Beobachtungen, aber sein Analysekonzept, eine durchlaufende elohistische Grundschicht mit mehrstufigen redaktio- 
cer flächigen Analysen bei Otto und Halbe sowie auf McCarthys Literarkritik aus der Vogelschau ${ }^{3}$. Eine Reihe von Aufsätzen zu Einzelproblemen der Sinaitheophanie kommt hinzu ${ }^{4}$ und daneben jüngst die literarkritischen Anmerkungen zu bestimmten Passagen bei Weimar ${ }^{5}$.

Wir gehen aus von der opinio communis der Exegeten, daß der Dekalog mit dem ursprünglichen Zusammenhang der Theophanieschilderung in Ex 19 nicht fest verknüpft ist, sondern sekundär bzw. lose in diesem Zusammenhang eingefügt wurde ${ }^{6}$. Strittig ist, wer den Dekalog eingeschaltet hat: Der Elohist, ein deuteronomisch-deuteronomistischer Redaktor oder eine noch spätere Hand, wenn man nicht mit Noth die Beantwortung der Frage für unmöglich hält ${ }^{7}$. Die obige opinio communis erlaubt uns, mit den Erwägungen beim unmittelbaren Kontext des Exodusdekalogs einzusetzen.

\subsection{Die Dekalogeinleitung in Ex 19,25 und 20,1}

Wenn man für Ex 19,25 nicht jede Erklärung aufhebt, indem man ihn zum Fragment erklärt ${ }^{8}$, bleibt nur übrig, ihn vom Vorausgehenden zu verstehen. Demnach berichtet V.25a vom Abstieg des Mose zum Volk. Darin bietet er die Ausführung von zwei Befehlen zum Abstieg in V.21 und V.24. Beide Befehle, wie überhaupt der gesamte Redeabschnitt VV.21-24, sind abhängig vom Auftakt V.2ob, wo Jahwe den Mose auf die Spitze des Berges beordert und Mose hinauf-

nellen Erweiterungen, zeigt erst am Ende den PferdefuB, vgl. S. $158 f$. Er verzichtet auf eine konsequente literarkritische Hypothese, indem er einen großen Teil der redaktionellen Einschübe nicht zuweist bzw. identifiziert. Seine E-Version weist nach eigenen Angaben gewisse Spannungen auf. Zum Schluß präsentiert er in Ex 24,10-11a noch den Splitter einer sogenannten jahwistischen Parallelversion, ohne deren minimalen Umfang und ihr Auftauchen gerade an dieser stelle aufzuhellen.

3 OTTO, Mazzotfest, 254-279; HALBE, Privilegrecht, 27o-340; MCCARTHY, Treaty, 243-276.

4 So ZIMMERLI, Erwägungen; HAAG, Buch des Bundes; SCHÜPPHAUS, Volk Gottes; NICHOLSON, Interpretation; DERS., Antiquity; DERS., The Origin; DERS., Decalogue; PATRICK, The Covenant; FUHS, Sehen, 258-271; MOSIS, Syntaktischer Aufbau; RUPRECHT, Erzähltradition.

5 WEIMAR, Berufung, bes. $180 \mathrm{ff}$ und das Stellenregister $396 \mathrm{f}$.

6 Vgl. dazu NOTH, Exodus, 124 und die ausführliche Erörterung bei PERLITT, Bundestheologie, 90-92.

7 DERS., Exodus, 124.

8 So NOTH, Exodus, 129; ROST, Gesetz, bes. 13 A 12; MITTMANN, Deuteronomium, 150 . 
steigt. Der Abstieg des Mose in V.25a ist notwendig, da Mose nach Angabe von 20,20 wieder unten beim Volk sein muß, um es anzusprechen. Die redaktionskritische Einstufung von V.25a hängt ab vom Entscheid der Frage, welchem Abstiegsbefehl er korrespondiert. Zenger sieht ihn als Fortsetzung von V.24, den er wie die Vorgängerverse VV.2ob.21.23 dem Jehowisten zuweist ${ }^{9}$. Aber V.24 gehört nicht in den Zusammenhang der Verse 2ob.21.23. Die Redundanz des Abstiegsbefehls, die Thematik (Zutritt von Aaron zu Jahwe) und syntaktisch-semantische Parallelen zu V.22, der auch nach Zenger die Verbindung von V.21 mit V.23 unterbricht ${ }^{10}$, raten dazu, beide Verse aus dem Abschnitt VV.20b-25a herauszunehmen ${ }^{11}$. Wir rechnen also V.25a zu den Versen 2ob.21.23, die der Hand des Jehowisten entstammen. Die Verse 22 und 24 teilen wir späten, (unterschiedlichen) priesterlichen Redaktionen zu 12 .

Für Ex 19,25b gibt es nur die Alternative: Entweder ist der Halbvers Schlußsatz einer Kette von erzählenden Sätzen oder er ist kataphorische Redeeinleitung zu einer direkten Rede. Semantisch 1äßt אמר im Unterschied zu דבר/D-Stamm nur das Zweite zu 13. Dann aber konkurriert die Redeeinleitung V.25b mit der von 20,1. Darüber hinaus zeigt sich ein gravierender Unterschied. V.25a legt für V.25b den Sprecher und Adressaten fest: Mose redet zum Volk ${ }^{14}$. Dagegen spricht in 20,1 Elohim zu nicht genannten Adressaten. Wie sind Konkurrenz und Widerspruch der beiden Redeeinleitungen aufzulösen? Textverlust nach V.2515 oder Einschätzungen wie "verunglückter Versuch, einen Ausweg der erzählerischen Situation zu finden, in die man durch V.20 geraten war" 16 ,bieten keine erstzunehmenden Lösungen. Auch die Verteilung auf zwei dtr Schichten bei gleichbleibender Funktion, Einlei-

9 DERS., Sinaitheophanie, 64.104f.110.17o-172.209f.

10 DERS., Sinaitheophanie, 63 und Exodus, $284 \mathrm{f}$ A 106.

11 Vgl. MItTMANN, Deuteronomium, 150.

12 Dazu mehr s.u.

13 So ZENGER, Sinaitheophanie, 64; ROST, Gesetz, 13; MITTMANN, Deuteronomium, 150 und die Wörterbücher: THAT I, 213; ThWAT I, 354 .

14 Nach zENGER, Sinaitheophanie ist "nicht ganz klar, wer Subjekt der Notiz ist". Aber da der Text keinen Subjektwechsel anzeigt und die Adressatenangabe von V.25b auf V.24a zurückweist, besteht über das Subjekt von אמר kein Zweifel.

15 So ROST, Gesetz, 13 A 12.

16 MITTMANN, Deuteronomium, 150. 
tung zum Dekalog zu sein ${ }^{17}$, scheitert am Unterschied der Sprecher; ferner kommen beide Redeeinleitungen als Einleitungen zum Dekalog, der Jahwerede par excellence, in Bezug auf Theologie und Formulierung für eine dtr Hand nicht in Frage. Es bleibt nur die Möglichkeit, mit einem überlegten redaktionellen Eingriff im vorliegenden Text zu rechnen. Ein Redaktor - weder der Jehowist noch ein Deuteronomist - hat die ihm in 19,25b vorgegebene Einleitung zu einer Moserede durch den Einsatz von 20,1 umfunktioniert zu einer Einleitung für eine Rede Elohims an das Volk. Strukturell betrachtet besteht seine neue Einleitung nun aus drei Teilen: Der erste, übernommene Teil V.25b gibt den Adressaten an, wohingegen er den Sprecher noch im Dunkeln läßt. Der zweite Teil ("und es sprach Elohim alle diese Worte") offenbart den Sprecher und nennt den Titel der Rede. Der dritte Teil, der erstarrte infinitivus constructus von (לאמר) אמר), dient der unmittelbaren oberleitung zur direkten Rede. In bezug auf die strukturellen Besonderheiten wie Dreiteiligkeit, Nennung des Adressaten im ersten und danach des Subjektes im zweiten Glied fällt eine bezeichnende Parallele auf, nämlich die redaktionell überarbeitete Bucheinleitung Lev $1,1{ }^{18}$, hinter der Weimar ${ }^{19}$ den Pentateuchredaktor vermutet. Die Frontstellung von אמר und der Numeruswechsel von pluralen Adressaten in 19,25b Singularanrede des Dekalogs mußten in Kauf genommen werden. Demnach kann man die Crux der Dekalogeinleitungen genetisch erklären. Der Jehowist hat nach dem jahwistischen Vers 19,20a seinen Abschnitt 19,2ob.21.23 eingefügt und mit 19,25 übergeleitet zum elohistischen Faden in 20,20a.21 (ohne die Redeeinleitung). Ein priesterlicher Redaktor hat diesen vorgegebenen Zusammenhang nach der Einleitung zur Moserede an das Volk aufgespalten. Die Stelle war inm wichtig. Nach der Theophanie wird das Volk zum ersten Male über Mose von Elohim angeredet. Nur hier an vornehmster Position kann der Dekalog öffentlich verkündet werden.

Die Analyse von Ex 20,1 soll diese Hypothese erhärten und präzisieren. Unser Redaktor hat in 20,1 mit Rücksicht auf den Kontext selbständig formuliert, so daß wir von diesem Vers Aufschlüsse über ihn erwarten können. Unabhängig voneinander haben Zenger und Rost auf die in ihrem Kontext singuläre Formulierung von 20,1 aufmerksam gemacht ${ }^{20}$. Der Vers setzt in der Rede-

17 ZENGER, Sinaitheophanie, 173.210.

18 Vgl. NOTH, Leviticus, 12; ELLIGER, Leviticus, $26 f$.

19 DERS., Berufung, 148 A 13.

20 ZENGER, Sinaitheophanie, 64; ROST, Gesetz, 12-14; ZENGER, Sinaitheophanie 109f.173.210 teilt den Vers seiner (zweiten dtr) Bundesbuchschicht zu; 
einleitung das ungebräuchliche Tבר/D-Stamm ein. Der bei diesem Vers geforderte, präpositional angeschlossene Adressat fehlt. Das direkte Objekt "alle diese Worte" dient meist mit dem Rückverweis auf vorher wörtlich zitierte Rede, hier wird es als einführender Titel eingesetzt ${ }^{21}$.

Schließlich wird das Subjekt Elohim genannt. Rost hat den Autor erahnt, ohne inn zu identifizieren, wenn er darauf hinweist, daß das "Reden Jahwes (דבר)" charakteristisch für die Priesterschrift ist. Worauf schon oben hingewiesen wurde, bestätigt sich: 20,1 entspricht im Aufbau der Einleitungsformel , וידבר יהוה אל משה לאמר , die in der priesterschriftlichen Literatur als gängige Einführung gesetzlicher Bestimmungen auftritt ${ }^{22}$. Das Fehlen der Adressaten wurde oben schon aus den Besonderheiten des Kontextes erklärt, die der priesterliche Redaktor zu bewältigen hatte. Im Gebrauch des Titels zeigt sich der Redaktor als treuer Schüler des Deuteronomium, das die דברים zum terminus technicus des Dekalogs machen kann, so daß der Verwendung als einführender Titel nichts im Wege steht. Es bleibt, die auffälligste Besonderheit zu erklären: Warum wird das Subjekt Elohim genannt? Der vorauslaufende Kontext spricht durchgehend von Jahwe; der nachfolgende Dekalog will Jahwerede schlechthin sein. Darin liegt gerade das Wahrheitsmoment der hartnäckigen Zuweisung von 20,1-17 an den Elohisten oder an einen jüngeren Zuwachs zu dieser Geschichtserzählung, daß sie diese Besonderheit unterstreicht und nicht anders auffangen kann als durch Einordnung in den Bereich von $E^{23}$. In der Pentateuchkritik hat bei der Herauslösung der E-Anteile der Gottesname immer eine entscheidende Rolle gespielt. Im komplexen Kontext der Sinaitheophanie ist auf dieses Kriterium nie verzichtet worden, wenn auch das Maß seiner Anwendung strittig blieb. Es drängt sich der Eindruck auf, daß in jüngeren Stellungsnahmen zur Sinaitheophanie dem Gottesnamen als Kriterium wieder stärkeres Gewicht zugemessen wird 24 .

Zwei Extreme gilt es zu vermeiden: die mechanische Anwendung, die der Individualität der betreffenden Texte nicht gerecht wird, und die Annahme eines

ROST, Gesetz,bleibt bei der traditionellen zuweisung an E.

21 Vgl. zur üblichen Verwendung: Ex $19,7 \mathrm{~b} ; 24,8$; Num 16,$31 ; \operatorname{Dtn} 4,30 ; 9,10$; 12,$28 ; 30,1 ; 32,5$ und die Behandlung bei ZENGER, Sinaitheophanie, 64 A 41 . 42 .

22 Vgl. RENDTORFF, Die Gesetze, 67ff; ROST, Gesetz, 16-19; DERS., Bemerkungen, 39-60.54-59.

23 Vgl. die jüngeren Zuweisungen bei: 2IMMERLI, Erwägungen, 178-181; ROST, Gesetz, 12ff; SCHÜPPHAUS, Volk Gottes, 20of; MITTMANN, Deuteronomium, 156; SMEND, Entstehung des AT, 84. 
Promiscue-Gebrauchs, die jene Individualität nicht erfaßt, weil sie mit beliebiger Variation rechnet und auf eine Erklärung des Wechsels verzichtet ${ }^{25}$. Von daher scheint die Zuweisung von 20,1 zum Bereich von E berechtigt, würde nicht ein kleiner, aber wichtiger Unterschied zur Differenzierung zwingen, auf den Zenger aufmerksam gemacht und den Mittmann bestätigt hat, ohne daraus Konsequenzen zu ziehen ${ }^{26}$. Die Verse 20,1.19 verwenden die Gottesbezeichnung אלהים ohne Artikel, die übrigen Vorkommen 19,3a.17.19; 20,20a.21; $24,11 b$ versehen sie mit dem Artikel.

Wir prüfen nun die zweite Gruppe in knappem Durchgang auf ihre literarische Zugehörigkeit. 19,3a wird traditionellerweise von einer großen Anzahl von Exegeten dem Elohisten zugeschrieben ${ }^{27}$. Neuerdings hat Weimar 19,2b $+3 a$.bd dem Elohisten abgesprochen und der Schlußredaktion des Pentateuch zugeteilt, die von $19,1(\mathrm{Pg})$ überleitet zu ihrem Redeabschnitt VV.3bß-6 ${ }^{28}$. Weimars Argumente stechen die alten literarkritischen Gründe nicht aus. Die Doppelung in $V .2 b$ zu V.2ar, die Nennung eines expliziten Subjekts in V.2b, nachdem in V.2a drei Sätze darauf verzichten, die Bezeichnung dieses Subjektes als "Israel" im Unterschied zu den "Söhnen Israels" in V.la und V.3bß und schließlich der Numeruswechsel zum singularischen Prädikat - diese vier Gründe fordern eine Abtrennung des V.2b von dem vorhergehenden Zusammenhang. Es spricht nichts dagegen - wie gehabt - in V.2b den Anfang der elohistischen Sinaierzählung zu erblicken, zumal v.3a daran schließt und den Gottesnamen mit dem Artikel erwähnt. In V.2b wird nur das verklammernde שלהים auf den Pentateuchredaktor zurückgehen. V.3a bietet mit seiner Inversion keinen "betonten Neueinsatz der Erzählung", sondern mit we = x-qatal eine vom Narrativ in V.2b abhängige Begleithandlung ("Israel lagerte dort..., während Mose zu dem Gott hinaufstieg") ${ }^{29}$. Auch die Redeeinleitung V.3ba muß dem Elohisten nicht abgesprochen werden ${ }^{30}$. Die Wahl des Lexems קרא (

24 Man vergleiche etwa die Akzentverschiebung von PERLITT, Bundestheologie, $91 \mathrm{f} .181 \mathrm{zu}$ MITTMANN, Deuteronomium, 152.155f und bei SCHÜPPHAUS, Volk Gottes, $198 \mathrm{ff}$.

25 Mit SCHMIDT, Exodus, 108 und SMEND, Entstehung des AT, 82 halten wir die Anwendung des Kriteriums im Verein mit sprachlich-sachlichen Argumenten für angemessen.

26 ZENGER, Sinaitheophanie, 67; MITTMANN, Deuteronomium, 151.

27 Vgl. ZENGER, Sinaitheophanie, 148-163 und seine Tabelle, 207.

28 DERS., Berufung, 148 A 17 und 180 A 108.

$29 \mathrm{Vgl}$. GROSS, Verbform, 33; anders WEIMAR, Berufung, 180 A 108.

3o Vgl. die Literarkritik bei ZENGER, Sinaitheophanie, 57.101. 
über eine bestimmte Distanz hinweg) macht die nachfolgende Ortsangabe plausibel. Einzig der Wechsel im Gottesnamen stört. Dabei ist die Nennung des Subjekts syntaktisch nicht unbedingt nötig. Sie wird wahrscheinlich auf den Redaktor zurückgehen, der die elohistische Redeeinleitung für die Eröffnung seines Einschubs 19,4-8 umbaute ${ }^{31}$.

Die nächste Stelle mit אלהים + Artikel Ex 19,17 wird einstimmig E zugeteilt ${ }^{32}$. Dafür ist 19,19 wieder umstritten. Eine Mehrzahl von Exegeten votiert für E. Zenger jedoch stößt sich am Unterschied von קלת V.16 (E) בקול V.19b und teilt deswegen auf in V.19a (E) und V.19b (Je). Aber V.19 muß als Einheit verstanden werden. Der asyndetisch angeschlossene V.19b mit seinen beiden $x$-yiqtol-Sätzen bezeichnet eine wiederholte Nebenhandlung in der Vergangenheit, die gleichzeitig zur Haupthandlung im Narrativ von V.19a verläuft ${ }^{33}$. Ohne V.19a hängt V.19b in der Luft; umgekehrt läßt V.19a ohne V.19b die Klimax der Erzählung vermissen. Die seltene, absolute Angabe קול) בקול) außerhalb der häufigen Konstrukt- und Attributverbindungen will sich auf keines der akustischen Begleitsignale der Theophanie festlegen, weder auf den Donner (V.16) noch auf den Posaunenschall (V.19a). Darum existiert keine Spannung zu vorhergehendem E-Kontext. Mit 19,19 steuert die elohistische Schilderung der Sinaitheophanie auf ihren Höhepunkt zu ${ }^{34}$.

31 Zur kontroversen Analyse des Abschnitts Ex 19,10-15 vgl. ZENGER, Sinaitheophanie, 59f; MITTMANN, Deuteronomium, 147f; WEIMAR, Berufung, 180f A 109. Auf sie muB hier nicht eingegangen werden, nur sei angemerkt, daB die von WEIMAR vorgeschlagene Interpretation von $19,11 \mathrm{~b}-$ 15 als redaktioneller Einschub durch wiederaufnahme von 19,11a in 19, 15a sich nicht empfiehlt, da sie die Abfolge von Befehl vv.10f* und Ausführung VV.14f* zerstört (vgl. den Wechsel der Sprecher von V.11a zu v.15). Ambivalent bleibt die variation der Zeitangabe in v.15 gegenüber der von v.11a. Schwierigkeiten macht bei gleicher Zuweisung der VV. 13b.16a.19a zu E die unterschiedliche Bezeichnung der Hörer.

32 Zum sekundären Charakter von V.16b und der Ortsangabe "aus dem Lager heraus" in V.17a vgl. ZENGER, Exodus, 284 A 106 und WEIMAR, Berufung, 181 A 110.

33 Vgl. BERGSTRÄSSER, II, 7b.

34 WEIMAR, Berufung, 181 A 109.110 hält in V.16aB die Erwähnung des Posaunentons und den ganzen V.19a für redaktionelle Bildungen. Damit fällt der ganze V.19 für seinen Elohisten aus. Allerdings nennt er keine Gründe für die Ausgrenzung dieser Textteile und gibt auch nicht die Redaktionsschicht an, zu der sie gehören sollten. 
Ex 20,20a wird unisono dem Elohisten zugerechnet ${ }^{35}$; ebenso $20,21^{36}$. Weit abgeschlagen taucht in Ex 24,11b die letzte Stelle innerhalb der Sinaiperikope mit אלהים auf. Allein schon inre Position fordert eine Sonderbehandlung. Abweichend von vielen Exegeten teilen wir sie dem Elohisten nicht zu und begründen das weiter unten.

Insgesamt fällt für Kap. Ex 19 und 20 ein konstanter und geschlossener Gebrauch von אלהים mit Artikel auf, der "den Gott schlechthin" bezeichnet und am plausibelsten dem Elohisten zugeschrieben wird. Von diesem Hintergrund hebt sich der Gebrauch von אלהים ohne Artikel in 20,1.19 ab, zumal kein Grund angegeben werden kann, warum der Elohist von seinem Stil hätte abweichen sollen. Jahwist und Jehowist kommen für die beiden Stellen nicht in Frage; letzterer formulierte in 19,20-25* anders, und schließlich unterbrechen die VV.20,1ff - wie oben aufgezeigt - seinen Zusammenhang. Auch dtr Redaktoren scheiden als Autoren aus. Für sie ist der Dekalog Inbegriff der

35 Ex 20,2ob dürfte wegen logischer und syntaktisch-stilistischer störungen der Kohärenz mit V.2oa sekundär sein; vgl. MITTMANN, Deuteronomium, 151; WEIMAR, Berufung, 181 A 111.

36 Nur WEIMAR, Berufung, 181 führt den Vers nicht mehr für $\mathrm{E}$ an. Dahinter mag wohl sein Interesse stehen, die Theophanie am Berge zum Finale der elohistischen Exodusgeschichte umzustilisieren und den E-Fragmenten eine durchgehende Konzeption zu unterlegen (vgl. 182-190). Deswegen eliminiext WEIMAR konsequent alle lokalen Elemente, die auf einen Berg außerhalb ̈̈gyptens verweisen und der Theophanie ein Eigengewicht verleihen. Abgesehen von den literarkritischen Schwierigkeiten "vor ort" und den noch nicht durchgespielten verschiebungen innerhalb einer Gesamthypothese zur Sinaiperikope rechtfertigt sich m.E. eine solche Reduktion nur, wenn sie durch exakte, möglichst randscharfe Entsprechungen, strukturelle klammern und Verweise kompensiert wird, d.h. wenn der Rest-Text in seiner Geschlossenheit und Harmonie unmittelbar evident ist. Ohne auf die Crux der unterschiedlichen Gottesnamen der reduzierten E-Theophanie selbst einzugehen (Ex 19,1011a.16a* ; 20,2oa), ergeben sich eine Reihe von Gravamina: An Entsprechungen zwischen dem Finale und der Ouvertüre in Ex 3 (insbesondere 3,10) ergeben sich genau genommen nur ein paar Worte (der Auftrag an Mose: "Geh zum Pharao bzw. zum Volk" und das Herausführen durch Mose). Die Theophanie erwähnt Ägypten mit keinem Wort, so daß die Gleichsetzung der beiden Herausführungen (Mose führt die Söhne Israels aus Ägypten heraus / Mose führt das Volk heraus) nicht sicher ist. Daneben zeigt selbst die reduzierte Theophanie Spuren von Eigenständigkeit, die in einer elohistischen Exodusgeschichte überhängen: Die rituellen Anweisungen und das Faktum der Theophanie an einem nun nicht näher bezeichneten, aber vorausgesetzten ort, wo sich der Elohim aufhält.

Das Anliegen WEIMARs soll dadurch nicht geschmälert werden. Mit ihm (Berufung, 181 A 112) verzichten wir auf die Identifizierung weiterer E-Anteile in Ex 33 und 34 . 
Jahwerede und das Wort אלהים entweder nur Appellativum oder Apposition zum beherrschenden Jahwenamen ${ }^{37}$. Die oben schon aufgenommene Spur weist in Richtung der priesterschriftlichen Literatur. Von ihrem Kontext her kann das Phänomen erklärt werden. Die $\mathrm{Pg}$ systematisiert ihre Geschichtsdarstellung auf verschiedene Weise. Sie trennt nach Ausweis von Ex 6,2 und dem korrespondierenden Vers Gen 17,1 zwischen einer Patriarchen- und Mosezeit anhand der verschiedenen Gottesnamen bei identischem Träger, für die Patriarchenzeit Elohim/El-Šaddaj, für die Mosezeit Jahwe ${ }^{38}$. Im ersten Teil ihrer Geschichtsdarstellung von der Schöpfung (Gen 1,1) bis zur offenbarung des Jahwenamens an Mose (Ex 6,2) gebraucht sie durchgehend den Gottesnamen Elohim ohne Artikel ${ }^{39}$. In dieser Phase kann sie an besonders herausgehobenen Stellen das Sprechen Elohims mit דבר/D-Stamm qualifizieren ${ }^{40}$. Vor allem kann Elohim während dieser Zeit mit Einzelpersonen wie mit Gruppen in unmittelbaren Sprechkontakt treten ${ }^{41}$. Ab Ex 6,2 bleibt dieser unmittelbare Kontakt nur auf Mose (und gelegentlich Aaron miteingeschlossen) beschränkt. Jahwe spricht die Menschen nur mehr über die Vermittlung des Mose an; auch wenn er das Volk direkt anredet, bleibt Mose dazwischengeschaltet ${ }^{42}$. So zeigt sich neben der Periodisierung der Geschichte mit Hilfe der Gottesnamen noch die Charakterisierung durch den Sprechkontakt: Elohimzeit mit unmittelbarer Anrede - Jahwezeit mit durch Mose vermittelter Ansprache. Damit ist das Dilemma herausgearbeitet, in das der Dekalog den priesterlichen Redaktor bringen mußte. Der Dekalog als unmittelbare Jahwerede an das Volk widersprach der Systematik der pg für die Epoche der Jahwe-Mose-Zeit, der Volksgeschichte. Unser Redaktor löste den Knoten mit den Mitteln der Pg und griff für diesen Sonderfall auf die Offenbarungsform der Frühzeit zurück. Darum redet am Sinai trotz Jahwe-Mose-Zeit Elohim das Volk unmittelbar an. Mose wird dabei nicht übergangen. Seine Rückkehr vom mittlerweile theophanen Gott löste die Dekalogverkündigung aus.

37 Vgl. LOHFINK, Gott, 101-103.

38 Vgl. WEIMAR, Untersuchungen, 78-95.

$39 \mathrm{Zu}$ den Ausnahmen S. WEIMAR, Untersuchungen, $86 \mathrm{~A} 18$.

4o Es handelt sich um ein gebietendes bzw. rechtswirksames Sprechen Elohims: Gen 8,$15 ; 17,3$. Letztere Stelle leitet die Einsetzung der Abrahamברית ein; dazu W. GROSS, Bundeszeichen, $111 \mathrm{f}$. Hinzu kommt Ex 6,2; zu den besonderen Bedingungen dieses Verses 5 . WEIMAR, Untersuchungen, $78 \mathrm{ff}$.

41 Mit Noach: Gen 6,13; 8,15; 9,17; mit Noach und seinen söhnen: Gen 9,1.8; mit Abraham: Gen 17,1.3.9.15; mit Jakob: Gen 35,10.11; mit Mose: Ex 6,2. Vgl. Ex 6,6ff; $14,1-2\left(R^{P}\right) ; 16,11 f ;$ Num $14,26.28$. 


\subsection{Der Dekalograhmen in Ex 20,18 - 21}

Die Exegese dieses Abschnitts der Sinaiperikope steht seit langem unter zwei Prämissen, die jeweils noch eigene Spielarten aufweisen. Zuerst wird der Abschnitt im großen und ganzen als ein geschlossener Block betrachtet und dem Elohisten zugewiesen ${ }^{43}$. Diese Ansicht hat Zenger widerlegt, indem er auf die logisch-semantische Spannung von 20,19 zu 20,20 hinwies 44 . V.20 gibt nicht die Antwort auf die Bitte des Volkes an Mose in V.19; beide Verse trennt der Gebrauch des Gottesnamens,d.h.אלהים ohne (V.19) bzw. mit Artikel VV.2of (s.o. unter 3.2). Da V.19 zur Identifizierung des redenden Subjekts (3. pl.) von V.18 abhängig ist, sind die VV.18f und VV.2of zu trennen. Die Aufteilung des Blocks zwingt auch zu neuen Zuweisungen. Die zweite Prämisse geht davon aus, daß der Dekalog und die nachfolgenden VV.18f sich nicht vertragen. Die Gründe für die postulierte Unverträglichkeit lassen sich in etwa so zusammenfassen: Die VV.18f greifen über den Dekalog hinweg auf die Theophanieschilderung in Kap. 19 zurück ${ }^{45}$. Die betreffenden Verse geben kein Echo auf eine erfolgte Dekalogverkündigung. Sie bieten keine zu erwartende "Willigkeitserklärung des Volkes" (Zimmerli). Die Einsetzung des Mose zum Mittler und die Bitte "nicht soll Gott mit uns reden" implizieren nicht eine Konsequenz aus dem Dekalog, sondern die Ankündigung des noch erfolgenden göttlichen Redens ${ }^{46}$.

Diese Beobachtungen führten zu zwei Deutungen. Die ältere stammt von Kuenen und feiert das 100-jährige Jubiläum ${ }^{47}$ : Ursprünglich folgte der Dekalog auf 20,18-21; er wurde dann aber umgestellt, damit diese Verse die Brücke schlagen vom Dekalog zum sekundär eingeschalteten Bundesbuch. Vor allem spricht das Sparsamkeitsprinzip gegen eine solch komplexe Umstellungshypothese ${ }^{48}$. Deshalb wird gegenwärtig überwiegend mit einer sekundären Interpolation des Dekalogs vor den VV.18f gerechnet ${ }^{49}$. Die oben gemachten

43 So NOTH, Exodus, 124.135; ZIMMERLI, Erwägungen, 179-181;SCHÜPPHAUS, Volk Gottes, 198f; OTTO, Mazzotfest, 261f; HALBE, Privilegrecht, 273f; NICHOLSON, Decalogue, 423; SMEND, Entstehung des AT, 84; RUPRECHT, Erzähltradition, 172 .

44 DERS., Sinaitheophanie, 66f; zustimmend, wenn auch mit anderen Konsequenzen MITTMANN, Deuteronomium, 151 A 68.

45 NOTH, Exodus, 124.135; PERLITT, Bundestheologie, 92 A 5; ZIMMERLI, Erwägungen, 180; ZENGER, Sinaitheophanie, 66; NICHOLSON, Decalogue, 423.

46 So wieder MITTMANN, Deuteronomium, 151.

47 Vgl. NICHOLson, Decalogue, 423 A 2; zuletzt bei MITTMANN, Deuteronomium, 151.156. 
Beobachtungen zur Unverträglichkeit des Dekalogs mit 20,18f sind ambivalent bzw. nicht zwingend. Wir gehen vom vorliegenden Endtext aus und verfolgen eine Linie, die sich bisher punktuell andeutete, aber noch nicht ausgezogen wurde: die Interpretation der VV. $18 f_{\text {von }}$ Dtn 5 her ${ }^{50}$.

Die Konstruktion des V.18 mit waw copulativum + Subjekt + Partizip + Narrative von $V .18 \mathrm{~b}$ ist aufzuschlüsseln als partizipialer Hintergrundsatz für individuellen - hier länger andauernden - Sachverhalt in der Vergangenheit, den die Narrativsätze von V.18b im Vordergrund weiterführen ${ }^{51}$. Die nochmalige Nennung des Subjekts beim ersten Narrativ erklärt sich aus der Kette der vier determinierten Akkusativobjekte ${ }^{52}$. Der Numeruswechsel im Subjekt ist schon in der elohistischen Vorlage beim Obergang von V.2oa nach V.21 vorhanden. Von der Syntax her verbietet sich eine literarkritische Aufspaltung des Verses ${ }^{53}$. Die Konstruktion ist der von Dtn 5.23 (יהי) mit inf. constr. + Narrativ) analog und verweist auf eine bedeutende Aussage des ganzen Kapitels Dtn 5 überhaupt. Theophanie und Dekalogverkündigung gehören untrennbar zusammen ("mitten aus dem Feuer hat Jahwe geredet"). Ex 20,18 übernimmt die Konzeption von Dtn 5 und greift deshalb auf die Theophaniephänomene zurück. Der Vers sammelt die jahwistischen und elohistischen Theophanieelemente ${ }^{54}$ und erweitert sie um "die Blitze", die wir aus dem Bundesschluß Jahwes mit Abraham Gen 15,17 und von der Eröffnungsvision Ezechiels Ez 1,13 her kennen. Im Unterschied zu Ex 19,4.21 hat das Verbum ראה 20,18 die Bedeutung "wahrnehmen", die visuelle wie akustische Ein-

48 Dahingehend sprechen sich aus: PERLITT, Bundestheologie, 91 A 4; ZIMMERLI, Erwägungen, 180 und SCHÜPPHAUS, Volk Gottes, 199.

49 So NOTH, Exodus, 124.135; PERLITT, Bundestheologie, 91f; ZIMMERLI, Erwägungen, 181; NICHOLSON, Decalogue, $427 \mathrm{ff}$.

5o PERLITT, Bundestheologie, 92 A 5: "Zu 20,2-17 besagt 20,18-21 nur etwas, wenn man von Dtn 5 her kommt". ZENGER weist die verse seiner zweiten dtr Bearbeitung, der Bundesbuchschicht zu, in: Sinaitheophanie, 110. 116.175.212. Vgl. CHILDS, Exodus, 372f; NICHOLSON, Decalogue, 424.427f; SKWERES, Rückverweise, $76 \mathrm{f}$ vergleicht Ex 20,19 mit Dtn 5,$25 ; 18,16$, ohne auf die erste Stelle weiter einzugehen. Zuletzt RUPRECHT, Erzähltradition, 172 .

51 Vgl. BERGSTRÄSSER, II $13 \mathrm{f}$ und GROSS, Verbform, 73f. Der Vers ist zu übersetzen: "Als das ganze Volk sah ..., da fürchtete sich das Volk...". zur Konjektur des ersten Narrativs vgl. ZENGER, Sinaitheophanie, 66; MITTMANN, Deuteronomium, 151 A 66; BHS zur Stelle.

52 So ZENGER, Sinai theophanie, 66.

53 Wie bei NOTH, Exodus, 135 und bei MITTMANN, Deuteronomium, 151.

54 Wie oft unterstrichen wurde. ZENGER, Sinaitheophanie, 66 weist darauf hin, daß der definitive Artikel der Akkusativobjekte diese als bekannt voraussetzt. 
drücke einschließt ${ }^{55}$. Gegenüber dem selteneren Tר in 19,16.18 56 schwenkt 20,18b zum geläufigeren ירא Die redaktionelle Akkumulation der Theophanieelemente, das Abweichen vom Sprachgebrauch der Umgebung ${ }^{57}$, der thematisch-stilistische Einfluß von Dtn 5 und die Verbindungen nach Gen 15 und Ez 1 sprechen für eine sehr späte Redaktion. Das Thema von 20,19, die Bitte des Volkes um Mittlerschaft des Mose, weil das unmittelbare Reden Gottes nur unter Todesgefahr auszuhalten ist, verrät den Einfluß der Schilderung der Horebtheophanie im Deuteronomium (Dtn 4,33;5.25-27;18.16) und zwar sowohl im Inhalt wie in bezug auf die Position im Aufriß der Schilderung nach Dekalogverkündigung und Theophanie.

Diese wichtige Parallele ist deswegen so schwer zu erkennen, weil die Zeitangaben, die in der Horebtheophanie den Zusammenhang von Dekalogverkündigung und Bitte des Volkes verdeutlichen,wie das Verb סיסף( fortfahren) und das Adverb עוד (Dtn 5:25;18,16), hier fehlen. Das mag zu Lasten eines mehr thetisch ausgerichteten Erzählens gehen. Auf jeden Fall bleibt die Parallele bzw. die analoge Dramaturgie durch die Abfolge der Sätze im vorliegenden Endtext gesichert. Der Elohist kennt in 19,19 nur ein absolutes Reden des Mose ohne Präpositionalobjekt, hier dagegen spricht Mose mit dem Volk (דבר/D-Stamm + עם (דבר), was seltener ist als das geläufige und auch im Dtn vorherrschende אבר + 58 . Das Gleiche begegnet uns im Falle, daß Jahwe Subjekt von דבר und das Volk der Adressat ist. Das Dtn bevorzugt dabei אל + Ausnahmen bilden nur Dtn 6,5 und 9,10 60. Vor allem Dtn 5,4 wird für Ex 19,9;20,19.22 prägend gewesen sein. Hier wie dort soll der intime Sprechkontakt Jahwes mit seinem Adressaten hervorgehoben werden. Schließlich ist das Verständnis der Bitte in V.19a ("sprich du mit uns, und wir wollen hören") kontrovers. Soll nur die Hörfähigkeit des Volkes bekundet werden 61 oder klingt die Konnotation "gehorchen" mit, so daß es sich um eine "Willigkeitserklärung" oder Selbstverpflichtung des Volkes handelt?

55 Vgl. Dtn $5,24 \mathrm{~b}$.

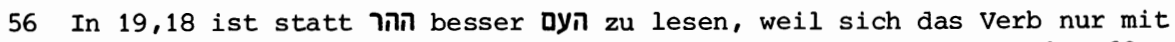
lebendigen Subjekten verbindet, so MITTMANN, Deuteronomium, 149 A 62 und ThWAT III, 180; anders WEIMAR, Berufung, $181 \mathrm{~A} 110$.

57 Vgl. vor allem den Sprachgebrauch in den jehowistischen Anteilen VV. $19,16 \mathrm{~b} .18 \mathrm{bB} .21$.

58 Vgl. die folgenden Stellen: $\operatorname{Dtn} 1,1.3 .45 ; 4,45 ; 5,27 ;(18,18) 27,9$; 31,$1 ; 32,45$ und Ex 19,6.

59 Die Vergleichsstellen: Dtn 1,$6 ; 4,12.15 ; 5,22 ; 10,4$.

60 Dtn $5,24 b$ hat את + את דבר. 
Die syntaktische Abfolge von Imperativ und syndetischem Kohortativ der Gruppe legt eher ein Verständnis im zweiten Sinne nahe ${ }^{62}$. Zudem will das Volk auf Mose, den Repräsentanten Jahwes, hören, was hier im Kontext der Gesetzesverkündigung soviel bedeutet wie tun, was Jahwe sagt und will 63 . Die vergleichbaren Selbstverpflichtungen des Volkes sind entweder zweiteilig 64 oder bevorzugen - einteilig - das Verb ${ }^{65}$. Der einfache Gebrauch von שמע ohne präpositionale Ergänzung außerhalb der Verbreihen für Gesetzesbeobachtung, aber in dieser Bedeutung findet sich im Dtn nicht ${ }^{66}$. Somit weist auch in 20,19 der vom Dtn und inm nahestehenden Passagen signifikant abweichende Sprachgebrauch auf einen späten Redaktor, der in eigener Formulierung die Horebtheophanie nachahmt.

Alle Beobachtungen und Argumente zu Ex 20,1.18f konvergieren in demselben Resultat: Der Exodusdekalog, die priesterliche Novellierung des Deuteronomiumdekalogs, ist von einem priesterlichen Redaktor überlegt in die jehowistische Schilderung der Sinaitheophanie eingesetzt worden. Bei der Rahmung seines Dekalogs, d.h. bei der Verknuipfung mit der Sinaitheophanie, nahm unser Redaktor die Auffassung von der Horebtheophanie aus dem Dtn zum Maßstab. Zugleich berücksichtigte er den nahen Kontext; ebenso behielt er

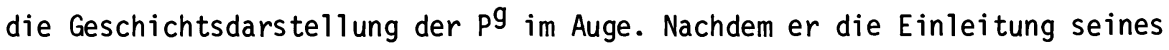
Einschubs an die jehowistische Redeeinleitung in 19,25b angebunden hatte, verfaßte er am Schluß ein Pendant in 20,20a, um mit dieser Redeeröffnung in die jehowistische Sinaitheophanie zurückzuleiten, die in 20,20a.21 dem Elohisten das Wort erteilt. Für die Entscheidung, wo der Dekalog eingeschoben werden sollte, waren unter anderem programmatische Zwänge maßgebend. Der Dekalog verlangte die unmittelbare Verkündigung an das Volk. Deshalb wurde er eingeschaltet, bevor in der Vorlage das Volk zum ersten Male nach dem Kommen Gottes angeredet wird. Diese Verkündigung sollte noch innerhalb der Sinaitheophanie vor sich gehen, deshalb die Einschaltung vor dem elo-

61 So MITTMANN, Deuteronomium, 152.

62 Vgl. GK § 108d.

63 Vgl. SCHULt, Art. עמש, THAT II, 980.

64 Mit der Consecutio:עמע: - שמה - Dtn 5,27 (6,3); Jer 35,10 und mit der auffälligen Umkehrung: Ex 24,7 (dazu mehr s.u.).

65 Die Stellen: Ex 19,8; 24,3; Num 32,31; Dtn 30,12f; Jos 1,$16 ; 9,24 ; 2$ Kön 10,5 ; Jer 18,$12 ; 42,3.5 ; 44,17$; Neh 5,12 .

66 Vgl. LOHFINK, Hauptgebot, 64-68. 
histischen $A b s c h l u ß$ und deren Interpretation des Kommens Elohims. Schließlich sollte Mose beteiligt werden, wenn auch nicht als erster Sprecher.

\subsection{Die Einleitung und die Bearbeitung des Bundesbuches}

Gemeingut der Exegeten ist die Ausgrenzung der zum Bundesbuch sekundären Einleitung Ex 20,22f. Vom Elohisten in 20,20a.21 grenzt sie sich ab durch andere Gottes- und Volksbezeichnung. Vom nachfolgenden Altargesetz in 20, $24 \mathrm{ff}$ unterscheidet sie sich durch den durchgehenden Plural der Anrede, der beide Verse zusammenbindet ${ }^{67}$. Strittig ist die Einheitlichkeit der beiden Verse ${ }^{68}$ und vor allem deren Zuweisung ${ }^{69}$. Wir prüfen deshalb Stück für Stück und beginnen mit der Redeeinleitung in V.22a, die mit ihren Eigenheiten bisher zu schnell übergangen wurde. Sie setzt sich zusammen aus der Redeeinleitung("Jahwe sprach zu Mose"), dem Redebefeh1 lahwes an Mose ("so sollst du zu den Söhnen Israels sprechen")und der in V.22b folgenden direkten Jahwerede. Sensibilisiert vom Dekalog, wo den Angaben der Redeeinleitung über Sprecher, Obermittler und Adressaten dogmatische bzw. juristische Relevanz zukommt, muß die Bundesbucheinleitung auffallen. Offensichtlich spricht Jahwe jetzt nicht mehr direkt, unmittelbar zum Volk, sondern über das Medium Mose. Aber die Zwischenschaltung des Mose hat wiederum ihre eigene Qualität. Sie wird durch einen eigenen Redebefehl thematisiert. Solches Betonen der "Botenrolle" kennt man von der prophetischen Literatur. Von ihr her aber würde man nach Einleitung und Redebefehl vor der direkten Jahwerede die Botenformel erwarten. Die ist hier weggefallen. Auf ein strukturanaloges Phänomen ist Rendtorff bei der Analyse des Formelguts in den

67 Vgl. NOTH, Exodus, 140f; ZENGER, Sinaitheophanie, 68; HALBE, Privilegrecht, 441.

68 SCHÜPPHAUS, Volk Gottes, 199 trennt zwischen V.22a (E) und VV.22b.23 (dtr); MITTMANN, Deuteronomium, 157 hält 20,22aB-23b $\alpha$ für dtr wegen der stilistischen Übereinstimmung mit dem dtr Abschnitt 19,3b-9; V. $23 \mathrm{bB}$ macht er zur Glosse; RUPRECHT, Erzähltradition, 158 spaltet auf in 20,22 (dtr) und 20,23-25.

69 Neben grundsätzlicher Skepsis gegenüber jeglicher Einordnung bei NOTH, Exodus, $139 \mathrm{f}$ und bei PERLITT, Bundestheologie, $158 \mathrm{~A} 1$ findet man: Zuordnung zu einer mit $\mathrm{E}$ verbundenen "Covenant Code Source" bei PATRICK, The Covenant, 145-157; HALBE, Privilegrecht, 501-503 ordnet die verse seiner SchluBredaktion des Bundesbuches (Ausbaustufe II) der frühen Königszeit zu. NICHOLSON, Decalogue, 428-433 plädiert für einen dtr Redaktor, der Dekalog und Ex 20,22f einsetzt; ZENGER, Sinaitheophanie, 109f.117.213 sieht seine zweite dtr Redaktion ("Bundesbuchschicht") am Werk. 
Gesetzen der Priesterschrift, insbesondere des Heiligkeitsgesetzes gestossen 70: Einleitungsformel - "Weitergabebefehl" - direkte Jahwerede. Rost hat das Nebeneinander von Einleitungs- und Weitergabebefehl mit nachfolgender Jahwerede interpretiert: "Denn wenn von Jahwe gesagt wird:לידבר ו... דבר ... לאמר : so wird von Mose mit den gleichen Worten berichtet, לאמר oder ואמרת, und dann wird ein Gesetz oder eine Forderung mitgeteilt, deren Erfüllung Jahwe nun nicht von Mose, sondern von den Israeliten oder gelegentlich auch von Aaron und seinen Söhnen nach inm erwartet. Mose ist demnach zwischengeschaltet, eine Art Relaisstation, die Empfangenes unverändert - und das scheint durch die Wiederholung des לאמר . לבר betont werden zu sollen - weitergibt" 71. Die nächsten Verwandten zu V.22a (Narrativ von כוt mit den "Söhnen Israels" als Adressat) finden sich in der priesterschriftlichen Literatur ${ }^{72}$. Die Variationen אמר und sowie andere Spezifika mögen für die literarkritische Differenzierung innerhalb des P-Schrifttums eine Rolle spielen, ändern aber nichts an der konstanten Struktur: Moses Mittlerstellung wird thematisiert. Er muß sich aber vor seinem Publikum nicht mit der Botenformel legitimieren. Durch

70 DERS., Die Gesetze, $68 \mathrm{ff}$.

71 DERS., Bemerkungen, 58; vgl. ebd., 54-59 und DERS., Gesetz, 16-19.

72 Hier die Belege: Ex 3,15: Der entscheidende Vers 3,15b, der die direkte Jahwerede bringt, gehört zu einer sehr späten Redaktion nach SCHMIDT, Exodus, 132f, die WEIMAR, Berufung, $47 \mathrm{f} .344 \mathrm{f}$ als $\mathrm{RP}$ identifiziert. Ex 19,3b knüpft an die elohistische Redeeinleitung mit anderem Verb im Narrativ an und hat לאמר vor dem Redebefehl, dürfte aber mit v.3bB zum Pentateuchredaktor gehören (mehr dazu s.u.). Lev 2o,1ff hat die gewöhnliche Einleitungsformel mit דבר und stellt die Adresse vor das Verb des Redebefehls; zu weiteren Besonderheiten vgl. ELLIGER, Leviticus, $268 \mathrm{f}$.

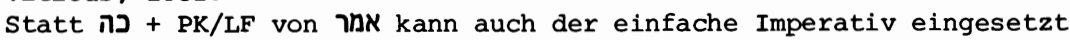
werden: Ex 6,2.6 (Pg); 33,5.2ENGER, Sinaitheophanie, 88f signalisiert zwar das Fehlen der "Ausrichtung des Jahwebefehls durch Mose an das Volk", hebt aber auf die spezifische übermittlungsform nicht ab und teilt Ex 33,5f der ersten dtr Bearbeitung zu, a.a.O., 111.193.224. WEIMAR, Berufung, 339 weist zumindest die ortsangabe in $33,6 \mathrm{R}^{\mathrm{P}} \mathbf{z u}$; darin kann ein Hinweis darauf gesehen werden, daß $R^{P}$ wohl an beiden versen Spuren hinterlassen hat. Lev 21,1ff nennt andere Adressaten und baut den Redebefehl weiter aus. Seine direkte Jahwerede ist durch 21,8 gesichert; zu den Besonderheiten vgl. ELLIGER, Leviticus, 280. Hinzu kommen: Num 14,26. (27a) ( $\mathrm{Pg}$ oder $\mathrm{P}^{\mathrm{S}}$ ); als einzige Ausnahme im Bereich der dtn-dtr Literatur noch Dtn 1,42 (vgl. auch Dtn 2,2.4-6 mit הות/D-Stamm). Statt des Imperativs von אמר kann der von דבר verwendet werden: Ex 12,1.3ff; zur Literarkritik innerhalb 12,1-14 vgl. WEIMAR, Hoffnung auf zukunft; Ex 31,12 ff $\left(R^{P}\right)$. 
ihn und nur durch inn spricht Jahwe direkt zu den Adressaten seiner Rede. D.h. der Mittler Mose steht mit seinem Monopol und seinen medialen Fähigkeiten über dem prophetischen Boten auf Seiten Gottes. Die Prononcierung der mosaischen Vermittlung erscheint spiegelbildlich in den priesterlichen Rückverweisen ${ }^{73}$. Dieses priesterliche Modell der Obermittlung des Jahwewortes hebt sich $a b$ von dem der dtn-dtr Literatur im weiten Sinne. Jahwe spricht zu Mose und über bzw. hinter Mose taucht das Volk als der angezielte Adressat der Gottesrede auf. Die Vermittlung wird nicht eigens hervorgehoben, weder durch einen Redebefeh1 noch durch die Botenformel. Mose fungiert als Vertreter des Volkes, als primus inter pares. Er und das Volk zusammen sind die Adressaten. D.h. Mose steht als Mittler mehr auf Seiten des Volkes. Die einschlägigen Stellen bieten eine Redeeinleitung (Narrativ von אמר mit Jahwe als Subjekt und Mose als Adressat) und dann die direkte Rede Jahwes an das Volk, sei es im Singular, sei es im Plural ${ }^{74}$. Dieser Befund gibt literarkritische Hilfestellung und läßt folgende Entscheidung zu: Entweder enthäit Ex 20,22a den dtr Redebeginn in V.22a $\alpha$, der in V.22aß priesterlich bearbeitet wurde, oder V.22a wurde ganz von einem priesterlichen Redaktor formuliert.

Auf die im Kontext der Sinaitheophanie auffällige Vorstellung von V.22b ist schon öfters hingewiesen worden ${ }^{75}$. Das $x$-qatal in Haupt- und Objektsatz verweist auf die zurückliegende Dekalogmitteilung, wo Jahwe/Elohim mit dem Volk unmittelbar geredet hat ${ }^{76}$. In der Verbindung von V.22b mit dem Dekalog ist dem Urteil von Nicholson voll zuzustimmen 77 . Wenn der De-

73 Die Belege: Ex 9,35 ( $R^{P}$ nach ZENGER, Exodus, 103); Ex 35,29 ( $\mathrm{R}^{\mathrm{P}}$ ); Lev $8,36\left(\mathrm{Pg}^{\mathrm{g}}\right) ; 26,46(\mathrm{H})$; Num $10,13\left(\mathrm{PS}^{\mathrm{S}}\right) ; 15,23\left(\mathrm{P}^{\mathrm{S}}\right) ; 17,5\left(\mathrm{R}^{\mathrm{P}}\right) ; 27,23\left(\mathrm{P}^{\mathrm{g}}\right)$; und die späten Zusätze: Jos 14,$2 ; 21,8$.

74 Zuerst die Stellen mit singularischer Anrede an das Volk: Ex 34,10-12 (mit seinem fließenden Übergang vom angeredeten Mose zum angeredeten Volk im "Privilegrecht Jahwes"; dazu mehr s.u.); Num 21,34 (nach NOTH, Numeri, 145 dtr; vgl. GROSS, Bileam, 330 A 110); Dtn 2,9; 2,17 (mit רב) + 18; 2,31; 3,2 (vgl. PLÖGER, Deuteronomium, 26f und MITTMANN, Deuteronomium, 66 A 12 ).

Stellen mit pluralischer Anrede an das Volk: Ex 16,28 (dtr nach ZENGER, Exodus, 279 A 89); Dtn 2,2f; 2,9 (Redeeinleitung) + 13a; 2,17 (Redeeinleitung) + 24; und mit Josua als Angeredeten anstelle des Mose: Jos 4,1b3 (dtr nach OTTO, Mazzotfest, 36-40.57); 6,2-5 (mit Wechsel von Singular und Plural, vgl. OTTO, Mazzotfest, 79-81).

75 Vgl. stellvertretend NOTH, Fxodus, $141 \mathrm{f}$.

76 Deshalb wird auch hier wie in 20,19 das דבר mit verbunden.

77 DERS., Decalogue, 428-433. 
kalog und sein Rahmen aber von einem priesterlichen Redaktor stammen, dann kann der Rückverweis in V.22b nicht einem dtr Redaktor zugeschrieben werden. Zugleich stehen damit auch die festgestellten Beziehungen zu Ex 19,3b. 4 und zum Dtn, insbesondere zu Dtn 4,36, in Frage, die bei der Zuweisung eine Rolle gespielt haben ${ }^{78}$. Der Satz von V.22b ist dem von 19,4a ähnlich, aber eben nur ähnlich. Bei ראה liegt verschiedene Bedeutung vor, in 19,4 "(visuelles) sehen", in V.22b dagegen "(akustisches) wahrnehmen" 79. Der Bedeutungsunterschied erzeugt eine unterschiedliche Syntax in der Fortsetzung. 19,4a führt das objekt des Sehens mit einem Relativsatz ein ${ }^{80}$; v.22b wählt einen Objektsatz mit כי. Auch die Vorstellung in V.22b entspricht nicht ganz der des Dtn. Die "Leit-Vorstellung" des Dtn zur Horebtheophanie lautet: Jahwe hat mitten aus dem Feuer mit Israel gesprochen ${ }^{81}$. Sie kann dann in audiovisuelle Wahrnehmungsakte zerlegt werden, nämlich in das "die Stimme Hören" und das "Feuer Sehen" 82 , die schließlich wie in Dtn 4,36 noch durch Ortsangaben voneinander abgehoben werden (vom Himmel die Stimme - auf Erden das große Feuer) ${ }^{83}$. V.22b übernimmt keine der im Dtn vorgegebenen Sprachklischees, sondern wählt aus. Im übrigen besteht Verwandtschaft zu dem "Rufen vom Himmel her" in Gen 21,17; 22,11.15, das Weimar ausnahmslos dem Pentateuchredaktor zuschreibt ${ }^{84}$. Die Aussage des V.22b, daß in der Dekalogverkündigung der transzendente Gott seinem Volk in außergewöhnlicher Weise nahegekommen ist, wurde vom Dtn vorbereitet und nach hier Ex 20,22 in eigener Weise übertragen. Wenn für 20,18f und 20,22aßb derselbe Redaktor verantwortlich ist, muß noch die verschiedene Volksbezeichnung erklärt werden. Der Redaktor kann beide verwenden und sich jeweils dem Kontext anpassen, wobei die "Söhne Israels" die inm geläufigere Bezeichnung ist ${ }^{85}$.

78 So bei zENGER, Sinai theophanie, 109f; MITTMANN, Deuteronomium, 157; NICHOLSON, Decalogue, 428-430; PATRICK, Covenant, 148.

79 Vgl. CAZELLES, Etudes, 39.

80 Parallelen in: Dtn 29,1 und Jer 44,2 .

81 Die Belege: Dtn 4,12.15.33; 5,4.22.26; 9,10; 10,4 .

82 Vgl. Dtn 5,23-25; 18,16 .

83 Vgl. BRAULIK, Rhetorik, 72.

84 DERS., Berufung, 36 A 53; 149 A 18.

$85 \mathrm{Vgl}$. $\mathrm{Pg}$ in Ex 6,7 und 7,4 (dazu WEIMAR, Untersuchungen, 220 A 281) sowie das Nebeneinander in Lev 9. 
Hat man sich in V.23 einmal von der fehlleitenden masoretischen Verseinteilung freigemacht ${ }^{86}$, dann sticht die ausgewogene chiastische Konstruk tion des Verses ins Auge ${ }^{87}$. In puncto Thema, Numerus und Aufbau hat sie ihre nächsten Parallelen in Lev 19,4a und 26,1aa, was mitnichten für "eine besonders altertümliche Formulierung des Bilderverbotes" spricht ${ }^{88}$ und sich gegen jede literarkritische Aufspaltung sträubt ${ }^{89}$. Gegenüber dem Singularverständnis in Ex 32,31 handelt es sich hier um die Vielzahl der Silber- und Goldgötter, was auf die spätere, vor allem exilisch-nachexilische Götzenbilderpolemik hindeutet ${ }^{90}$. Die Stoßrichtung des Verses geht gegen die Herstellung von Götzen und deren Verehrung in Konkurrenz zu Jahwe. Deshalb spielt das Verständnis der Präposition אתי eine so große Rolle ${ }^{91}$. Wir entscheiden uns für die lokale Bedeutung, weil unser Redaktor freiformulierend sowohl auf das Fremdgötter- wie auf das Bilderverbot Rücksicht nimmt und hier mit der Präposition אתי die Konkurrenzaussage des ersten Dekaloggebotes zum Ausdruck bringt.Wir haben also in V.23 eine wohl konstruierte Neuformulierung des Bilderverbotes vor uns. Ihr erster Teil verbietet Götzenbilder von der Warte Jahwes her - nicht neben ihm, nicht in Konkurrenz wie die Fremdgötter. Ihr zweiter Teil verbietet Götzenbilder von der Warte der Verehrer her - nicht Herstellung von Götzen für sich selber. Thema (Betonung des Bilderverbots), Ausführung (freie Verarbeitung des Hauptgebotes) und Stil (Numerus und Chiasmus) votieren für einen priesterlichen Redaktor.

Zum Problem "Einleitung ins Bundesbuch" zählt auch das Verhältnis von Altargesetz 20,24-26 und Oberschrift 21,1. Das im Kern sehr alte Altargesetz braucht hier in seinem stufenweisen Wachstum vorerst nicht zu interessieren ${ }^{92}$. Nur welcher Art ist seine Bindung an das in $21,2 \mathrm{ff}$ vorhandene Kor-

86 Ebenso CAZELLES, Études, 39f; ZENGER, Sinaitheophanie, 68 A 56.

87 Vgl. CAZELles, Etudes, 40.

88 So BOECKER, Recht und Gesetz, 118.

89 So MITTMANN, Deuteronomium, 157 A 87.

9o Dazu: Hos 8,4 und vor allem Dtn 29,16; Jes 30,22a; 31,$7 ; 40,19 ; 46,6$; $\mathrm{Hab} 2,19 \mathrm{~b}$; Ps 115,4 ; 135,15 .

91 Alternativen des Verständnisses: Entweder relational "was mich betrifft" - so CAZELLES, Études, 40 und VALENTIN, Aaron, 257 A 1 - oder lokal "neben, außer, entgegen" - so HAL 97 und PREUSS, Art. את, ThWAT I, 486.

92 Grundlegend dazu: CONRAD, Altargesetz, 8-20; HALBE, Privilegrecht, 441-444; BOECKER, Recht und Gesetz, 124-129. 
pus des Bundesbuches? Ist es sekundär vor die Oberschrift 21,1 gesetzt worden ${ }^{93}$ ? Oder hat die Oberschrift schon immer das Altargesetz als Prolog von den eigentlichen Rechtssätzen abgehoben, korrespondierend zu den rahmenden Bestimungen des Kultrechts in 23,14-19 94 ? Oder ist der Grundtext des Altargesetzes mit der Grundschicht des Bundesbuches von Anfang an verbunden gewesen und kam die Oberschrift erst mit der Einschal tung von 21,122.19 und dem Ausbau der (erweiterten) Grundschicht zum heutigen Rechtsbuch hinzu ${ }^{95}$ ? Das Problem von Position und Funktion der Oberschrift kann nicht allein durch Zuordnung zu Teilblöcken aufgehellt werden, sondern durch Erörterung der Beziehungen zum vorliegenden Kontext. Es git, alle Beobachtungen zu 21,1 zu sammeln.

In der Konstruktion entspricht 21,1 dem geläufigen Typ von Ober- oder Unterschriften zu Gesetzesmaterialien ${ }^{96}$. Das waw-copulativum zu Beginn oft übersehen - will die Oberschrift an den vorausgehenden Text anschliessen und verhindert einen absoluten Anfang. Besonders fällt das stilfremde "Du" auf am Anfang des nachfolgenden kasuistischen Abschnitts 21,2ff. Es kann nur aus dem "Du" am Anfang der Anrede im Altargesetz 20,24-26 hier eingedrungen sein 97 . Die Oberschrift 21,1 kann dafür nicht verantwortlich gemacht werden, denn sie kennt nur einen pluralischen Adressaten. Das deutet darauf hin, daß sie zu ihrem Kontext nicht ursprünglich dazugehört, obwohl sie sich einfügen will. Bevor sie eingeschoben wurde, waren Altargesetz und kasuistische Gesetze an der Nahtstelle 21,2 miteinander verbunden. Die Fremdheit der Oberschrift im Kontext steigert sich, wenn man bedenkt, da $B$ der Adressat der Vorschriften sowohl im "Ihr" wie im "Du" schon angeredet wird. Warum schwenkt man in die Situation der Beauftragung zurück und 1äßt dadurch 21:1 zur Bundesbucheinleitung 20,22 in Konkurrenz treten? Der Sprecher der Oberschrift, nämlich Jahwe, beauftragt sein Gegenüber, Mose,

93 So NOTH, Exodus, 142.

94 So BOECKER, Recht und Gesetz, 118.124ff.

95 So HALBE, Privilegrecht, 499.500-502.

96 Die Konstruktion (Nominalsatz bestehend aus einleitendem Demonstrativpronomen + Ausdruck für Gesetz mit erläuterndem Relativsatz) taucht auf: z.B. im therschriftensystem des Dtn oder Ex 19,6;35,1; Lev $23,4.37 ; 26,46 ; 27,34$ u.a.

97 So richtig BOECKER, Recht und Gesetz, 136. 
einer Gruppe die משפטים vorzulegen, obwohl dieselbe Gruppe schon unter dem Anspruch von Vorschriften steht. Die seltene Wendung שים לפני mit einem Ausdruck für Gesetz begegnet noch in Ex 19,7 und Dtn 4,44. Daß die im juristisch-strengen Sinn auf die kasuistischen Rechtssätze des ersten Teils des Bundesbuches zielen ${ }^{98}$, kann angesichts der Stilmischung mit den (apodiktischen) Todesrechtssätzen im ersten Teil und angesichts der Unsicherheit über die Reichweite der Oberschrift bezweifelt werden. Hier ist wohl eher der verschleifende Sprachgebrauch des Dtn anzusetzen, wobei außerhalb wie innerhalb einer Reihe "das ganze von Moses promulgierte Gesetz" bezeichnet ${ }^{99}$. Die Konkurrenz in der Funktion zu 20,22aß wie der abweichende Sprachgebrauch lassen hinter 21,1 keinen priesterlichen, sondern einen dtr Redaktor vermuten. Das gibt die Richtung an, die Position der Oberschrift zu erklären. Für einen vom Dtn herkommenden Redaktor mußte der V.20,24b des Altargesetzes, der seinerseits - wahrscheinlich vordeuteronomisch - zum Grundtext hinzugefügt wurde, einen Stein des Anstoßes bilden. Die distributive Aussage("an jedem Ort") widerspricht der Kultzentralisation 100 . Eine Form, das widerständige Altargesetz zu immunisieren mitsamt seinem V.24b, war die Oberschrift 21,1 . Sie suggeriert, daß das eigentliche Bundesbuch jetzt erst beginnt, d.h. daß die verbindlichen Vorschriften nun erst anheben. Das Altargesetz wird zum Vorbau. Die oben offengelassene Alternative zur Einleitung des Bundesbuches kann nun entschieden werden. Vom vorliegenden Endtext her schälen sich zwei Bearbeitungen der Bundesbucheinleitung heraus. Die ältere ist eine dtr Redaktion. Sie knüpft an die elohistische Sinaiperikope an und leitet in 20,22a a das Bundesbuch ein. Die Abfolge Redeeinleitung ("und es sagte Jahwe zu Mose") und direkte Rede Jahwes an das Volk entspricht der oben erarbeiteten Struktur dtn-dtr Reden Jahwes über Mose an Israel. Auf die Redeeinleitung folgte also bei dieser Redaktion das Altargesetz unter Einschluß von V.24b $\left(20,24-26^{*}\right)$.

98 So LIEDKE, Rechtssätze, $96 f$.

99 Nach BRAULIK, Ausdrücke für "Gesetz", 61.

100 Das Jל Konstruktverbindung verlangt distributives Verständnis, vg1. CONRAD, Altargesetz, 5-7; HAL 452 und trennt gerade diesen vers von der dtn Zentralisationsformel, vgl. ROSE, Ausschließlichkeitsanspruch. 77-87, bes. 85 A 1 - anders: WEIMAR, Berufung, 345f, bes. A 36. Den Gegensatz heben in jüngerer zeit hervor: VON RAD, Deuteronomium, 64; CONRAD, Altargesetz, 11f; HALBE, Privilegrecht, 377 und BOECKER, Recht und Gesetz, 127. 
Vor der Einarbeitung in die Sinaiperikope waren im Bundesbuch Altargesetz - in welcher Form auch immer - und kasuistischer Block miteinander verknüpft. Die dtr Redaktion trennte die Naht auf und schob eine weitere Oberschrift zusätzlich zu ihrer Redeeinleitung ein. Das dazwischenliegende Altargesetz wurde nun zu einem Vorbau. Letzteres kann präzisiert werden. Flankiert von der Redeeinleitung und der Oberschrift kann die Jahwerede im Altargesetz ihr "Du" der Anrede gar nicht in Richtung Volk entfalten. Das Altargesetz bleibt in der Gesprächssituation zwischen Jahwe und Mose gefangen; es wird zu einer historischen Vorschrift an Mose, die dieser auch in Ex 24,4f nach der Verkündigung des Bundesbuches (leidlich) ausführt. So wurde die Konkurrenz zur dtn Kultzentralisation geschickt ausgeschaltet.

Diese Hypothese viird dadurch gestuitzt, daß die Zusätze VV.25b.26b die Vorschriften des Altargesetzes mit der (späteren) historischen Wirklichkeit auszugleichen suchen und auf ihre Weise die Schwierigkeiten mit dem Altargesetz widerspiegeln 101. Ferner spielen Dtn 27,5b-6 und Jos 8,30-35 auf das Altargesetz an, ohne darauf zurückzuweisen ${ }^{102}$; indem nun Mose für die Vorschrift verantwortlich zeichnet, wird das Jahwegebot des Bundesbuches ignoriert.

Auf die dtr Redaktion folgt die jüngere priesterliche Bearbeitung der Bundesbucheinleitung. Sie gestaltet in V.22aß die dtr Redeeinleitung nach ihrem Schema um. Mit V.22b setzt sie das Bundesbuch in ein Verhältnis zu ihrem Dekalog: dort unmittelbare Rede Jahwes/Elohims an Israel - hier durch Mose vermittelte Rede im Bundesbuch. V.23 konzipiert sie in freier Verarbeitung der ersten Dekaloggebote als ihre Ouvertuire zum Bundesbuch.

Da eine priesterliche Bearbeitung des Bundesbuches auffälliger erscheint als eine dtr Redaktion, soll in einem kurzen Testlauf erwogen werden, ob jene weitere Spuren hinterlassen hat ${ }^{103}$. Kriterien der Identifizierung sind die für das Bundesbuch singulären Injunktive/Prohibitive im Plural 20,23; 22,30 und 23,13. Man kann vermuten, daß darin der Stil eines Autors bzw. Redaktors durchschlägt, der vergleichbar der Hauptredaktion des Heiligkeitsgesetzes 104 konsequent die Plural-Anrede einsetzt. Halbe hat die

101 Vgl. zuletzt HALBE, Privilegrecht, 443.

102 Dazu MERENDINO, Untersuchung, 194-207.

103 Es sei hier ausdrücklich auf den akribischen Durchgang durchs Bundesbuch bei HALBE, Privilegrecht, 391-5o5 verwiesen; vgl. auch BOECKER, Recht und Gesetz, 116-124.

104 Vgl. CHOLEWINSKI, Heiligkeitsgesetz, $137 \mathrm{f}$. 
Verwandtschaft beider Verse detailliert beschrieben ${ }^{105}$ und sie zu Angelbzw. Konstruktionspunkten seiner Ausbaustufe I des Bundesbuches gemacht. Sein in jedem Fall bedenkenswertes Verfahren zielt auf die Entdeckung und Auswertung von kompositionswirksamen Struktursignalen. Dafür hält er das System "Bundesbuch" (Ex 20,22-23,19) geschlossen und erhebt aus diesem System die immanente Struktur. Ein solches Verfahren ist in gewissem Sinne notwendig - auch um die Komplexität zu steuern -, muß aber durch folgenden Gesichtspunkt ergänzt werden: Das Bundesbuch steht nun einmal im Kontext der Sinaiperikope und ist irgendwann von irgendwem mit bestimmten Interessen dorthin gesetzt und vielleicht in dessen Nachfolge von weiteren Redaktoren des Pentateuch mit neuen Aspekten bearbeitet worden. D.h. es ist neben der Berücksichtigung von Struktursignalen nach Verklammerungen mit dem Pentateuch zu fragen. Dieser Gesichtspunkt soll paradigmatisch an 22.30 und 23,13 durchgespielt werden.

Beide Verse verbindet die "Satzstruktur" 106 mit inrer Dreigliedrigkeit, bestehend aus "prinzipieller Vermahnung", Prohibitiv und einer davon abhängigen "inhaltlich fast tautologischen Schlußwendung". Weitere "Kongruenzen im Detail" kommen hinzu,wie die syntaktische Verknüpfung (Syndese Syndese - Asyndese), das Aufscheinen des Sprecher-Ichs im ersten Glied und der Plural der Anrede. Die erste Divergenz (22,30 endet positiv, 23.13 negativ) mag entweder Kontextrücksichten entspringen oder durch die lexikalische Füllung bedingt sein, denn 23,13 verwendet einen Prohibitiv in dritter Person. Die zweite Divergenz (Numeruswechsel zum Singular 23,13bB) kann ebenso erklärt werden, indem der Autor sich an den nachfolgenden Text (Anrede im Singular) anpaßt 107 oder durch Numeruswechsel den Schlußpunkt setzt. Auf jeden Fall haben wir einen Autor vor uns, der mit dem Wechsel von Injunktiv zu Prohibitiv, von Syndese zu Asyndese Gebotsreihen gruppieren kann und für den der Numeruswechsel stilistische Funktion übernimmt. Für beides lassen sich Parallelen aus dem Heiligkeitsgesetz finden 108 . Bei aller Konvergenz der stilistischen Mittel divergieren beide Verse in

\footnotetext{
105 DERS., Privilegrecht, 423-440.500.

106 Folgendes nach HALBE,Privilegrecht, $423 \mathrm{ff}$.

107 So HALBE, Privilegrecht, 454 A 8.

108 Gebotsreihen mit Wechsel von Injunktiv und Prohibitiv: Lev 19,9f (Asyndese beim letzten Glied); 19,15 (Asyndese beim letzten Glied); 19,17 (Asyndese beim 2. Glied); 23,22 (Asyndese beim letzten Glied). Gebotsreihen mit stilistisch bedingtem Numeruswechsel: Lev 19,15 (Asyndese nach dem 1. Glied); 19,19 (Asyndese nach dem ersten und zweiten Glied).
} 
ihrer Aussage. Hier isoliert Halbe zu Unrecht das erste Glied und interpretiert es pauschal als "prinzipielle Vermahnung". Dabei handelt es sich in 22,30 um konkrete Vorschriften, die an passender Stelle eingefügt wurden. Das Thema "Heiligkeit von Personen" und das Verbot, Zerrissenes zu essen, hängen nach Ausweis der Parallelen sachlich zusammen ${ }^{109}$. Dagegen besitzt 23,13 inhaltlich einen ganz anderen Anspruch und eine größere Reichweite. V.13a bezieht sich auf die gesamte bis 20,22 zurückreichende Jahwerede. Der Injunktiv verwendet שמר in seltener Formulierung ${ }^{110}$. Er läßt einen warnenden Unterton mitklingen. V.13ba gebraucht die Wendung Stamm בשם, die überwiegend in exilisch-nachexilischen Texten auftaucht ${ }^{111}$. Der priesterliche Redaktor verarbeitet hier wiederum in seiner freien $\mathrm{Ma}$ nier das erste Dekaloggebot. Die Betonung des "Namens" kommt seiner Namenstheologie (s.0. 2.5.6) entgegen. V.13 korrespondiert damit seiner Bundesbucheinleitung 20,22f. Mit solcher Rahmung trennt er aber den Festkalender 23,14-19 ab und schiebt inn aus dem Zentrum an die Peripherie des Bundesbuches.

Er kann sich das leisten, weil er schon zuvor in Ex 12,14-20 eine eigene Verordnung über das Mazzenfest eingefügt hat und später in Lev 23 die Neuordnung des gesamten Festkalenders übernimmt.

\subsection{Exkurs zu Ex 19,3-9}

Der Aufweis zweier jüngerer Bearbeitungen des Bundesbuches (dtr und priesterliche Redaktion) macht Mut, einen so neuralgischen Text der Sinaiperikope wie Ex 19,3-9* mit der Arbeitshypothese zu untersuchen, auch in diesem Abschnitt auf beide Redaktionen zu stoßen. Es besteht ein breiter Konsens, daß Ex 19,3b-8 von nicht quellenhafter Eigenständigkeit ist und in den Kontext der Sinaiperikope eingeschoben wurde. Fraglich ist der Umfang des Abschnitts, besonders seine Ränder in VV.3.8f und seine Einheitlichkeit. Heftig umstritten ist die Zuweisung. Die Nähe zur dtn/dtr Literatur wird allgemein zugestanden, nur die Differenz gegensätzlich bewertet ${ }^{112}$. Oben unter

109 Vgl. Dtn 14,21a; Lev 17,15; 22,8; Ez 4,14; 44,31 - dazu CAZELLES, Études, 85; NOTH, Exodus, 152; WAGNER, Art. טרף, ThWAT III, 378.

110 שמר/N-Stamm + $ב$ in: Dtn 24,8; 2 Sam 20,10; Jer 17,21; Mal 2,15f; vgl. Ri 13,13 mit in - dazu CAZELLES, Etudes, 96.

111 Zu den Parallelen siehe VAN DER WOUDE, Art. שם, 952; die nächste Parallele zu diesem versteil in Jos 23,7 stamm von DtrN nach SMEND, Entstehung des AT, 118. 
3.2 haben wir vermutet, daß die elohistische Redeeinleitung 19.3ba durch Einfügung des Jahwenamens zur Einleitung der jetzt folgenden Rede umgebaut wurde. In V.3bß.4 können sich nach den Ausführungen unter 3.4 zwei Schemata der Redeübermittlung überlagern: Das dtn-dtr Schema (Jahwe redet über Mose direkt zum Volk) und das priesterliche Schema (Jahwe redet durch das Medium Mose ( $v g l$. Weitergabebefehl) direkt das Volk bzw. die Söhne Israels an). Der Redebefehl V.3bß verwendet אמר und steht damit in leichter Spannung zu V.6 אבר) und den Wendungen in Verbindung mit דברים in VV.7.8, die die Vermittlerfunktion des Mose kennzeichnen. Die Verdoppelung des Redebefehls mit $T$ J/H-Stamm ist insofern auffällig ${ }^{113}$, weil נגד hier keine indirekte Rede einleitet, sondern mit אמר parallel läuft und inm nachfolgt, statt wie üblich ihm vorauszugehen ${ }^{114}$. Wahrscheinlich wurde der zweite Redebefeh 1 dazugenommen, um zu Beginn der Sinaitheophanie die Vermittlertätigkeit des Mose hervorzuheben, wie es ebenso in V.9b geschieht. Die singuläre Parallelisierung der Adressaten "Haus Jakob" und "Söhne Israels" ist innerhalb des Pentateuch (vgl. Gen 46,27 PS) noch am ehesten einem priesterlichen Redaktor zuzutrauen 115.

In V.4 erinnert Jahwe Israel daran, daß es bei einer Folge von drei Ereignissen Augenzeuge war ${ }^{116}$. Die stilistisch-semantische Nähe von V.4a zum Dtn steht fest und wird auch zugegeben ${ }^{117}$. Für V.4b will McCarthy die Parallele Dtn 32:11 nicht anerkennen, weil sie als Gedicht keine sichere redaktionskritische Zuweisung zulasse. Die bisher übersehene Parallele Dtn 1,31a ${ }^{118}$ kann die Zweifel beheben. Für V.5a $\alpha$ ist neben der unbestrittenen

112 Für prä- oder protodeuteronomische Autoren treten in neuerer zeit ein: ZIMMERLI, Erwägungen, 175f; PATRICK, Covenant, 145ff; MCCARTHY, Treaty, 270-273. Für deuteronomistisch halten den Abschnitt: PERLITT, Bundes theologie, 167-181; ZENGER, Sinaitheophanie, 58f.109f.167f.207f ("Bundesbuchschicht"); MITTMANN, Deuteronomium, 146f.157f. Priesterliche Redaktion nehmen an: CAZELLES, Alliance, 70.78f; WEIMAR, Berufung, 148 A 17.343 A $24.356 f$.

113 Zur Verbform vgl. GROSS, Verbform, 39f A 80.

114 Vgl. zur gewöhnlichen Abfolge die Beispiele: Gen 45,26; 47,1; 48,2; Num 11,27; 1 Sam 23,1; 2 Sam 11,5. Der hier vorliegenden Abfolge ähnlich sind: Jes 44,7 mit דבר. Zur Semantik vgl. WESTERMANN, Art. Tגנ.

115 Vgl. PERLITT, Bundestheologie, 169f; CAZELLES, Alliance, $78 f$.

$116 \mathrm{Zu}$ Consecutio vgl. MOSIS, Syntaktischer Aufbau, 6 A 16.

117 So PERLITT, Bundestheologie, 17of und MCCARTHY, Treaty, 270.

118 Nach MITTMANN, Deuteronomium, $36 \mathrm{f}$ ein "Einschiebsel". 
dtr Parallele Ex 15,26 noch Ex 23.22a maßgebend; für diese Stelle ist ein protodeuteronomischer Autor mehr als fraglich 119 . Der invertierte Verbalsatz V.5aß expliziert die Forderung von V.5a ${ }^{120}$. Seine Parallelen hat Zenger erörtert, die alle auf späte Autoren verweisen ${ }^{121}$. Umgekehrt reicht die Pg-Parallele Gen 17,9f nicht aus, den hiesigen Abschnitt einem priester1ichen Redaktor zuzuschreiben ${ }^{122}$, zumal mit 1 Kön 11,11 ein dtr. Redaktor an den einschlägigen Stellen beteiligt ist ${ }^{123}$. Die folgenden Sätze in VV. 5b.6a sind von Vorgaben aus dem Buch Dtn bestimmt. Das gilt einmal für die Verbindung der Themen "Israel als Krongut Jahwes" und "Israel als $\mathrm{hl}$. Volk" 124 . Die viel verhandelten Abweichungen (absoluter Gebrauch von סגלה statt Konstruktverbindung mit עa als nomen regens - גור für Israel statt עגל vermögen die Beweislast für protodeuteronomische Abfassung des Abschnitts nicht zu tragen. Im Dtn konkurrieren zwei Aussageketten: Der Nominalsatz "ein hl. Volk bist du für Jahwe, deinen Gott" (Dtn 7,6; 14,2.21; vg1. 26,19) und die von der Bundesformel her inspirierte Konstruktion mit לי ל ל ל ל "für Jahwe zu sein/werden zu einem Eigentumsvolk" (Dtn 7,6; 14,2; 26,18; vgl. 28,9). Beide können die Konstruktion mit היה + adverbielle Näherbestimmung im Titel beeinflußt haben, die die VV.5ba.6a bestimmt (vgl. auch Dtn 26,19b) 125 . Das spricht für Verarbeitung deuteronomischer Vorgaben in unseren Sätzen und nicht für deren Vorläufer-Status. Die Ausgrenzung von VV.5bß.6a als "Einschub im Einschub" oder von V.6a als isolierter Nachklapp hinter dem $A b s c h l u ß$ von $V .5 b ß 126$ mißversteht die Konstruktion der beiden Sätze und folgt der Versabtrennung der Masoreten. Mosis hat mit guten Gründen nachgewiesen, daß beide Sätze eine kongeniale Erläuterung der vorausgehenden Apodosis sind, die mit explikativem כי eingeleitet wird ${ }^{127}$. Weil der Schluß in V.6b einen Satztyp verwendet (vgl. Ex 21.1), der im Dtn Redeab-

119 Vgl. ZENGER, Sinaitheophanie, 71; WEIMAR, Berufung, 326 A 32 "Nachgeschichte der dtr. Überlieferung".

120 Dazu MOSIS, Syntaktischer Aufbau, 6 A 19.

121 DERS., Sinaitheophanie, 58.

122 So bei CAZELLES, Alliance, 79.

123 Zur Einordnung von 1 Kön 11,11 s. NOTH, Könige, 246 und WÛRTHWEIN, 1 Könige, 134.

124 Vgl. HULST, Art. םע/7וג, THAT II, 307-314.

125 MOSIS, Syntaktischer Aufbau, 23-25, bes. A 69 erklärt mit dieser Konstruktion den Wegfall des nomen regens $ם$.

126 So PERLITT, Bundestheologie, 176 und MITTMANN, Deuteronomium, 147.

127 DERS., Syntaktischer Aufbau, 12-17. 
schnitte einführt und erst bei $P$ auch abschließt, will Cazelles P-Verfasserschaft annehmen. Er übersieht dabei die Vorläufer dieses Gebrauchs in Dtn 5,22 und 26,16. Wir können auch hier im Einflußbereich des Dtn verbleiben. Bei VV.7.8 hat Zenger auf das auffällige Desinteresse an Orts- und Umstandsangaben beim Vorgang der Obermittlung hingewiesen ${ }^{128}$. Das Auf und $A b$ gerade des Mose in den alten Sinaitheophanien 129 "verflacht" hier in VV.7f zu einem Hin und Her des Mittlers. Das entspricht dem völligen Fehlen der Raumkategorien Oben und Unten in der Horebtheophanie von Dtn 5 (vgl. besonders Dtn 5,5). In der lexikalischen Füllung der beiden Verse gibt es nichts, was den vom Dtn gesteckten Rahmen sprengt ${ }^{130}$. Die $A 1$ testen vertreten das ganze Volk. Ihr Auftauchen muß nicht für $P$ sprechen ${ }^{131}$, sondern erinnert an Dtn 5,23. So zeigt der Durchgang durch die Verse 4-8 also deren Einheitlichkeit und bestätigt - virtus in medio - ihre Einstufung als dtr Redaktion. Will man dabei weiter differenzieren, dann spricht vieles für eine der späteren dtr Redaktionen.

Für V.9 lauten die"Gretchenfragen": Kann er einer der alten Quel len zugeschlagen werden? Wenn nicht, in welchem Verhältnis steht er dann zu VV.4-8? Zum Jahwisten 132 steht er ebenso in Spannung 133 wie zum Elohisten, zu dem er nach 19,2b.3a.ba ${ }^{*}$ weder logisch noch semantisch paßt. Für den Jehowisten, der $J$ und $E$ verbindet, würde eine Zuteilung von V.9 sofort eine Konkurrenz der Redeeinleitungen in V.3b ${ }^{*}$ (E) und V.9 (Anfang) bedeuten, da er zwischen den beiden Versen keinen Text bietet; im übrigen ist inm eine solche Ankündigung wie V.9a nicht zuzutrauen, da sie in seinen Anteilen an der Sinaitheophanie nicht aufgegriffen wird (vgl. z.B. 19,20b.21.23.25).

128 DERS., Sinaitheophanie, $58 f$.

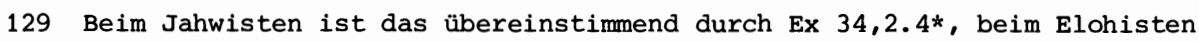
durch Ex 19,3a und beim Jehowisten durch Ex 19,2ob gesichert.

130 Vgl. MCCARTHY, Treaty, 271 A 56.

131 So CAZELLES, Alliance, 79.

132 So wieder HALBE, Privilegrecht, 274-278.

133 Dazu ZENGER, Rezension, 280 zu HALBEs Privilegrecht: "(Halbes JFaden weist folgene Spannungen auf): 19,9a kündigt Jahwe an, daB er 'im Dunkel der Wolke zu Mose kommen will'; in 19,19 ändert sich aber das Medium, der Modus und der Ort des Kommens Jahwes: 'er steigt herab auf den Berg Sinai im Feuer'; selbst 34,5 läßt sich nicht glatt als Erfüllung von 19,9a verstehen, weil. hier vom 'Herabsteigen in der Wolke' (nicht im Dunkel der Wolke!) die Rede ist". Hinzukommt, daß in 19,9 das Volk zum Ohrenzeugen, in 34,10 dagegen zum Augenzeugen der Taten Jahwes werden soll. 
Da ohne Not keine protodeuteronomische Erzählschicht postuliert werden soll, bleibt nur die Anbindung an VV.4-8. Von diesen Versen her verlangen vier Phänomene bei V.9 eine Erklärung: die neue Redeeinleitung, die thematische Verschiebung weg von der Beziehung Jahwe - Israel in VV.4-8 zu dem Verhältnis Jahwe - Mose unter Beteiligung von Israel in V.9a, der logische Bruch von V.9a nach V.9b, die variierte Wiederholung von V.8b in V.9b mit demselben Verb, das im zweiten Redebefehl von V.3bß auftaucht.

Die Lösung, V.9 doch VV.4-8 zuzuschlagen ${ }^{134}$, kann die obigen Phänomene nicht erklären. Die Interpretation von V.9b, sei es als Oberleitung, sei es als "zusammenfassende Notiz der Einheit" schafft keinen Ausweg ${ }^{135}$. Der Vorschlag, VV.3b-8a.9b als Grundtext der Einheit anzusehen, in den dann V.8b als vorbereitende Oberleitung zur sekundären Aussage V.9a eingeschoben wurde ${ }^{136}$, verstößt gegen das Sparsamkeitsprinzip. Ein Redaktor hätte in diesem Fall den ort für seinen Einschub so gewählt, daß er den Abschluß vor seinem Einschub vorwegnehmen und zusätzlich noch eine neue Redeeinleitung verfassen muß ${ }^{137}$. Es bleibt keine andere plausible Lösung als in V.9 das typische Paradigma einer "Kuhl'schen Wiederaufnahme" zu sehen ${ }^{138}$. Ein (weiterer) Redaktor respektiert die Integrität des inm vorliegenden Textes VV.4-8. Er bindet seine neue Information (V.9a) an diesen Text an, indem er dessen Schluß (V.8b) nach seiner Interpolation wiederaufnimmt (V.9b), ohne Rücksicht auf logische Kohärenz. D.h. die entscheidende Aussage liegt in V.9a. Die Zentrierung auf die VV.4-8 bleibt erhalten. Die Anspielung in V.9b auf den Redebefehl V.3bß beabsichtigt Rahmung, ohne das Gerahmte zu tangieren. Die Ansage der Theophanie gibt deren Elemente frei wieder und nennt nur Mose als Adressaten, was im Kontext der Sinaitheophanie singulär ist. Der Zweck der Veranstaltung - mit derselben Konjunktion eingeführt wie im sekundären Vers 20,2ob liegt in der Legitimation der Rede Jahwes mit Mose; es geht um den intimen

134 Vgl. NOTH, Exodus, $126 f$ und ZENGER, Sinaitheophanie, 59.102.

135 Auch ZENGERs revidierter Vorschlag, Exodus, 284 A 106, V.9a stamme von Je und V.9b sei "redaktionelle Wiederaufnahme des Fadens von V.8 in der Funktion der überleitung zu V.10", schafft neue Probleme bei der zuweisung (s.o.) und mißdeutet die redaktionelle Technik der Wiederaufnahme.

136 So CAZELLES, Alliance, 76f und MITTMANN, Deuteronomium , $146 \mathrm{f} .157$.

137 Mit Recht ablehnend MOSIS, Syntaktischer Aufbau, 5 A 15.

138 Andeutungsweise bei RUPRECHT, Erzähltradition, 155. 
Redekontakt zwischen Jahwe und Mose (דבר עם und nicht דבר אל unter 3.3), der die Quelle der Gesetzesverkündigung ist; Mose selbst wird uber seine Funktion, also indirekt legitimiert ${ }^{139}$. Das Verb שמע regiert hier die Präposition 2 und nicht einen Akkusativ - wohl ein Hinweis darauf, daß die Konnotation "gehorchen" mitschwingt. Wenn das Volk gehorsam hört, schenkt es auch Mose sein Vertrauen und zwar für immer. Im Unterschied zu Ex 4,8f. 31a ${ }^{140}$ geht es hier wie in Ex 14,31b um das Vertrauen des Volkes auf Personen (אמן/H-Stamm+ב) - auf Jahwe und ("auch") auf Mose. Alle Parallelen übersteigend häit der Glaube auf Dauer an. Der Dekalog ist hier nicht im B]ick. Er legitimiert sich ipso facto selbst mit seiner Unmittelbarkeit. Hier geht es um die endgültige Legitimation der mosaischen Gesetzesvermittlung, die die Sinaitheophanie beherrscht.

Die heuristische Arbeitshypothese hat sich bewährt. Zwei Redaktionen sind im Abschnitt 19,3-9* beteiligt: eine dtr Redaktion mit Schwerpunkt auf dem Bundesverhältnis Jahwe - Israel 19,3ba.4-8 und eine priesterliche Redaktion ad maiorem Mosis gloriam, ihre Vorgängerin umrahmend in 19,3bß.9.

\subsection{Der Abschnitt Ex 24,1-11}

Auszugehen ist von der weithin anerkannten Tatsache der Eigenständigkeit der beiden Teilstücke VV.3-8 und VV.9-11. Für die VV.1-2 sind die Schwierigkeiten bisher da und dort genannt, aber noch nicht durchgearbeitet worden. Hilflosigkeit besteht in bezug auf ihre Position und Funktion wie auf ihre Zuweisung. Einigkeit besteht darüber, daß in V.3 Mose von einer Gebotsmitteilung Jahwes kommt und diese Rede Jahwes sich nicht auf die Befehle der VV. 1-2, sondern auf das Bundesbuch bezieht. Der anerkannt sekundäre Zusatz V.3ar ("und alle משפטים") stammt dann von einem Redaktor, der in den "Worten Jahwes" den terminus technicus für den Dekalog sieht, sie also nicht mehr auf das Bundesbuch auslegt und deswegen das Bundesbuch unter dem aus 21,1 bekannten Begriff משפטים hier anführen muß ${ }^{141}$. Nach unserer Hypothese zum Dekalog und seiner Einfügung ist darin der priesterliche Redaktor zu ent-

139 Vgl. MOSIS, Syntaktischer Aufbau, 9 A 26.

$140 \mathrm{zu}$ Einstufung $\left(R^{P}\right)$ und Interpretation, wenn auch mit leichten internen Widersprüchen,WEIMAR, Berufung, 265.350.

141 Die Position vertreten: NOTH, Exodus, 160; PERLITT, Bundestheologie, 194; ZIMMERLI, Erwägungen, 182f; ZENGER, Sinaitheophanie, 74; HAAG, Buch des Bundes,22f; NICHOLSON, Interpretation, 78; MITTMANN, Deuteronomium, 152f; RUPRECHT, Erzähltradition, 164 . 
decken, für den in 20,1 die דברים zum Titel des Dekalogs geworden sind. Wenn V.3 auf das Bundesbuch - in welcher Ausdehnung auch immer - zurückgreift, kommt er hier nach VV.1-2 zu spät ${ }^{142}$; er fordert unmittelbaren Anschluß an seinen Bezugstext. Das läuft darauf hinaus, daß die VV.1-2 die ursprüngliche Verbindung zwischen Bundesbuch und 24,3 stören. Andererseits betrachtet man gerne die VV.3-8 als sekundären Einschub in den Zusammenhang der VV.1-2.9$11{ }^{143}$. Nur warum sollte der Interpolator den eigenen Zusammenhang (Bundesbuch - 24,3) zerreißen, um den vorgegebenen Zusammenhang (VV.1-2.9-11) zu zerhacken? Aus dieser Zwickmühle ist so schnell nicht herauszukommen, weder dadurch, daß man VV.1-2* dann doch der Schicht von 24,3 ff zuschlägt ${ }^{144}$, noch dadurch, daß man mit Verlust der ursprünglichen Einleitung zu VV.9-11 rechnet und die VV.1-2* einem weiteren Redaktor anlastet ${ }^{145}$. Wir schieben die Behandlung des Problems bis zum Schluß auf und beginnen mit VV.3-8.

Ex 19,7 und 24,3 haben denselben Verfasser, was die identische Sequenz der Handlungen bei leichter Variation in den Formulierungen belegt ${ }^{146}$. Die seltene Kombination von ספר-DSamm mit "Gesetzen" verrät den Einfluß der Psa1mensprache ${ }^{147}$. Der dazugehörige V.4a $\alpha$ berichtet von der Niederschrift der Worte durch Mose ohne Angabe des Wohin. Will man altorientalische Parallelen vergleichen, dann gehört die Notiz vom Aufschreiben von Verträgen naturgemäß zu den "Abschlußriten" von Vertragsschlüssen ${ }^{148}$. Analog haben die Notizen, die von einem Aufschreiben durch Mose berichten, gegenüber ihrem jeweiligen Kontext abschließende Funktion ${ }^{149}$. Im Vergleich mit dem Dekalog bzw. einer bestimmten dtr Sicht vom Dekalog hat der Unterschied zum Bundesbuch einiges Gewicht: Der Dekalog ist Rede Jahwes und wird von diesem selbst

142 Vgl. die Problematisierung bei PERLITT, Bundestheologie, 194 und ZENGER, Sinaitheophanie, 73 A 64 .

143 So NOTH, Exodus, 157f; PERLITT, Bundestheologie, 192; ZIMMERLI, Erwägungen, 182; SCHMIDT, Alttestamentlicher Glaube, 46f; RUPRECHT, Erzähltradition, 164 .

144 So ZENGER, Sinaitheophanie, 177.215f.

145 So andeutungsweise bei NOTH, Exodus, 159f; ausgeführt bei NICHOLSON, Interpretation, 78-80.

146 Vgl. PERLITT, Bundestheologie, 192; ZENGER, Sinaitheophanie, 74; WEIMAR, Berufung, 356fA 72 .

147 Die Belege: Ps 2,7; 50,16; 119,13 - KüHLEWEIN, Art. רפ, 169.

$148 \mathrm{Vgl}$. zum "Document clause" MCCARTHY, Treaty, 63.84.116f.196.

$149 \mathrm{Vgl}$. folgende Stellen in ihrem Kontext: Ex 17,14 (dtr mit vielen auch VALENTIN, Aaron, 146-150.197; abweichend WEIMAR, Berufung, 359f A 82). Mose schreibt den Sieg über Amalek in ein nicht näher bezeichnetes Buch; darauf folgt der Altarbau ohne Opfer. Ex 34,27f, Mose schreibt 
auf zwei Tafeln aufgeschrieben. Das Bundesbuch dagegen ist nach Ex 24,3.4a a Rede Jahwes, die Mose aufschreibt. Auf diesen Unterschied werden wir später zurückkomen.

Mit guten Gründen werden in neueren Analysen die VV.4aß. $5^{*}$ aus ihrer Umgebung herausgelöst und als Erzählschicht gedeutet, die dieser Umgebung zeitlich vorausliegt ${ }^{150}$. Die Bestreitung der Ausgrenzung bleibt in allgemeinen Betrachtungen zur Einheit stecken und bekundet mehr den Willen der Autoren zur harmonischen Ganzheit als das Wahrnehmen der Spannungen in der Textbasis ${ }^{151}$. Bei V.6 ist seine Zugehörigkeit zur Erzählschicht strittig. Perlitt streift alle Bundesassoziationen ab und macht den Vers zur "selbstverständlichen Fortsetzung und Vervollständigung" des Opferrituals ${ }^{152}$. Zenger trennt inn vom Opfer und weist inn seiner ersten dtr Bearbeitung zu ${ }^{153}$. Seine Argumente gewinnen in der Akkumulation: Blutritus ohne die "jungen Männer" und ohne die Mazzeben, keine Angabe über die Herkunft des Blutes. Perlitt überzieht seine Ablehnung der Bundesassoziationen und Ruprecht hat in seinem Einspruch recht ${ }^{154}$. Die singuläre Teilung des Opferblutes in zwei Hälften ( $V .6)$ tendiert auf die singuläre Doppelbesprengung in $V .6$ und $V .8$, die sich gerade darin vom üblichen Opferritual unterscheidet ${ }^{155}$. Hier wird der gewöhnliche Ritus, bei dem der Altar mit dem Blut des Opfertieres besprengt wird, auf zwei Partner hin modifiziert ${ }^{156}$. Logisch gehören also V.6 und V.8

das Privilegrecht Jahwes auf (weiteres s.u.). Dtn 31,9.24: Mose schreibt die Tora, das Dtn, in ein nicht näher bezeichnetes Buch; nach Dtn 31,26 soll dieses "Buch der Tora" neben der Bundeslade deponiert werden. Dtn 31,22: Mose schreibt das Moselied auf. Jos 8,32: Später dtr Rekurs auf die Niederschrift des Gesetzes durch Mose.

150 So PERLITT, Bundestheologie, 195ff; ZENGER, Sinaitheophanie, 74f.120147 rechnet die Schicht zum Jahwisten; MITTMANN, Deuteronomium, 152.154 votiert für den Elohisten.

151 Vgl. PATRICK, Covenant, 15of; MCCARTHY, Treaty, 266-269.

152 DERS., Bundestheologie, 198-200.

153 DERS., Sinaitheophanie, 75.179.216.

154 RUPREC̣T, Erzähltradition, 165-167.

155 Dazu vor allem ANDRE, Art. קר, ThWAT II, 687.

156 Die einzigen analogen Riten mit Blutapplikation an Menschen, die Priesterweihe Ex 29,20f; Lev 8,23f.30 und die Reinigung eines Aussätzigen Lev 14,14.25,können hier Deutungshilfen geben, vgl. RUPRECHT, Erzähltradition, ebd. und ELLIGER, Leviticus, 119.189. 
zusammen ${ }^{157}$. V.7 scheint den Ablauf des Blutritus zu unterbrechen ${ }^{158}$.

Löst man ihn heraus, entsteht beim obergang von V. 6 nach V.8 eine Redundanz des Subjekts Mose, der nun in V.8 ohne Grund genannt wird, obwohl seit V.6 kein Subjektwechsel vorliegt, der eine erneute Nennung notwendig machte. Mit V.7 aber wird die explizite Nennung des Subjekts plausibel. Das spricht für einen Autor von V.6 bis V.8. Die "Unterbrechung" durch V.7 ist gewollt. $v .7$ selbst bestätigt das. Zu schnell wird er auf $v .3$ bezogen ${ }^{159}$ und dabei wird zu erklären versäumt, warum der Verpflichtungsakt wiederholt wird. Das gibt nur Sinn, wenn er zum Ritual als integrierender Bestandteil dazugehört und der Autor der VV.6-8 das Angebot von V.3 ausschlug. Was dort offen gebl ieben war, wird nun vorgeführt: Mose hat "das Bundesbuch" zur Hand. Statt wie in Ex 19,7 und 24,3 dem Volke die jeweils gerade gesprochenen Jahweworte vorzulegen, schärft er hier den Inhalt des Buches ein ${ }^{160}$. Auf die einmuitige Antwort aus 19,8 und 24,3 wird hier verzichtet. Die Selbstverpflichtung gebraucht statt einem zwei Verben und dazu noch in ungewöhnlicher Reihenfolge. Entweder hat der priesterliche Redaktor mit Ruicksicht auf 20,19 נשמע hier dazugesetzt oder unser Autor gebraucht שמע wie wie unterschiede von V.3 und V.7 sprengen den Rahmen von Variationen bei ein- und demselben Autor. Die Deuterede des Mose in V.8 ist nach typisch dtn-dtr Schema aufgebaut. Das Nomen ברבת Koder Konsuktverbindungen mit ihm als nomen rectum werden durch einen Relativsatz mit כרת erläutert ${ }^{161}$. Die seltenere Präpositionalverbindung in $V .8 b ß 162$ hebt zum Schluß noch einmal die Grundlage des Bundes hervor.

So kommen wir zu dem Resultat, daß wir neben einer älteren dtr Bearbeitung des Bundesbuches in 24,3.4aa eine jüngere dtr Redaktion in 24,6-8 vor uns

157 PERLITTs Einwand, Bundestheologie, 199-201, V.8 spreche nur von "dem Blut" und nicht mehr von der "Hälfte des Blutes" wirkt angesichts der Singularität des Ritus übersubtil und übersieht die Inversion in $\mathrm{V} .6 \mathrm{~b}$ (die eine Hälfte in die Schalen - die andere Hälfte aber an den Altar). Es bleibt also noch das Blut in den Schalen, das Mose in $\mathrm{V} .8$ versprengen kann. Zur weiteren Erläuterung jetzt ZENGER, Sinaitheophanie, 75.

158 So ZENGER, Sinaitheophanie, 75.

159 Vgl. PERLITT, Bundestheologie, 192; ZENGER, Sinaitheophanie, 75.

160 Vgl. zur Wendung in 24,7aß noch Dtn 5,1 (mit רבד); 31,1 und 2 Kön $23,2$.

161 Relativsatz nach dem Nomen: Dtn 4,23; 29,11.24; 31,16 ; 1 Kön 8,21; 2 Kön 17,15.38; Jer 11,10; 31,32f. Relativsatz nach Konstruktverbindung: Dtn 9,$8 ; 28,69$.

162 Vgl. noch Ex 34,27 und mit Anspielung auf Ex 24,6-8 der Ps 50,5. 
haben, die vom vorliegenden Text angeregt einen eigenen zweiseitigen Bundesschlußakt berichtet. Bei der Zuweisung zu einer dtr Redaktion weitet sich ipso facto der Blick über den Pentateuch hinaus bis nach 2 Kön $22 f$ hin. Damit offenbart sich ein Konflikt, der durch den Titel "Bundesbuch" angezeigt wird. Diese Bezeichnung taucht nur hier und in 2 Kön $23,2 f .21$ auf. Bei aller Skepsis und bei allen tiefreichenden Auslegungsunterschieden kommen die Exegeten, die sich mit 2 Kön $22 f$ beschäftigen, doch zu der Annahme, daß das"Buch der Tora" oder das "Bundesbuch" von 2 Kön $22 f$ mit dem Dtn in Verbindung zu bringen ist ${ }^{163}$. Dann stehen das "Bundesbuch" in Ex 20-23 und das Dtn in Konkurrenz. Die Konkurrenz ist nur so aufzulösen, daß innerhalb der dtr Redaktionen deren jeweiliges Alter bzw. Verhältnis zueinander bestimmt wird. Es spricht einiges dafür, Ex 24,6-8 als späte dtr Redaktion einzustufen. Bei 2 Kön 22f, insbesondere 2 Kön 23,1-3, ist der Kampf um das richtige Verständnis gerade wieder mit aller Grundsätzlichkeit aufgebrochen, so daß sich vorerst kein Konsens abzeichnet ${ }^{164}$. Wir tendieren aber zur Vermutung, daß 2 Kön 23,1-3 älter ist als Ex 24,6-8. Ergo hat der letztere Abschnitt das Dtn als "Bundesbuch" entthront und ins zweite Glied versetzt, d.h. zum Deuteronomium im wörtlichen Sinne gemacht.

Zu der nun folgenden Behandlung von 24,9-11 ist eine methodische Vorbemerkung notwendig. Für die neuere Analyse dieser allerseits zugestandenen kritischen Verse ist es kennzeichnend, daß sie diese in sträflicher Weise von ihrem Kontext isoliert und dann erst interpretiert. Symptomatisch erscheint das Ausweichen vor einer eingestandenen schwierigen Literarkritik in die oberlieferungsgeschichte, das bevorzugte Operieren mit dem schwammigen Begriff "Tradition" und das Unterdrücken der Kontextfragen. Die eingangs ge-

163 Vgl. WÜRTHWEIN, Josianische Reform, 395f; DIETRICH, Josia, 32 A 86; ROSE, Bemerkungen, 60; HOFFMANN, Reform, 198.

164 Unterschiedliche Einstellungen zum deuteronomistischen Geschichtswerk führen zu diametral entgegengesetzter Wertung der Beobachtungen. So rechnet DIETRICH mit einer vordeuteronomistischen Schicht nahe an den Ereignissen selbst, die nacheinander durch DtrG, DtrP, DtrN bearbeitet wurde. In 2 Kön $22 \mathrm{f}$ bezweifelt er die Trennung in einen Fund- und einen Reformbericht (DERS., VT 27, 1977, 32 A 87). Über die Zuweisung von 23, 1-3 ist er sich nicht schlüssig (DERS., Josia, 31 A 84). WÜRTHWEIN rechnet 23,1-3 zum Höhepunkt und Abschluß des Fundberichtes aus der Hand von DtrG "siebzig oder mehr Jahre nach Josia", einer historischen Tendenzerzählung oder einer Legende(DERS., Josianische Reform, 406-412). HOFFMANN rechnet mit einem kunstvoll komponierenden Dtr und leugnet jegliche Schichtung (DERS., Reform, 192.200-203). ROSE hält eine vordtr schriftliche Gestalt von 2 Kön $22 f$ für illusorisch und erkennt höchstens das Huldorakel 22,19f für alt an (DERS., Bemerkungen, 54). Offensichtlich kann angesichts dieser Alternativen hier keine Entscheidung geboten werden. 
nannten Schwierigkeiten mit den Versen 24,1-2 und damit die Fragen nach der Einleitung dieses Abschnitts werden nicht geklärt. Welcher Redaktor kann diese alte und urtüliche Tradition gerade an dieser Stelle der Sinaitheophanie auf diese vertrackte Art eingebracht haben? Welches Ziel hatte er dabei im Auge? Solche Fragen sind bisher zu kurz gekommen. In signifikanter Weise verrät die Diskussion um die ursprünglich am Geschehen beteiligten Personen den Ansatz. Mit Naturnotwendigkeit pendelt sie sich darauf ein, daß anfangs nur die Altesten die Akteure waren. Es ist genau jene Gruppe, die gerade noch zu den Pluralverbformen von 24,1 of paßt, aber vor allem die geringste Kontextbelastung aufweist. Der umgekehrte Weg, daß vielleicht dem Hauptakteur Mose weitere Personen und Personengruppen zugesellt werden, wird kaum erwogen. Forschungsgeschichtlich allerdings verdient diese Phase der Isolierung von 24,9-11 Verständnis. Sie entspringt der Not, die betreffenden Verse quellenkritisch zu orten. Bei Noth kündigt sich diese Phase an. Er erklärt Ex 19,24a.(b) zum Fragment, das "ganz isoliert und ohne Folge dasteht". Ex 24,1-2 bieten kaum mehr den ursprünglichen Wortlaut und scheinen "nicht sehr sachgemäß formuliert"; in ihnen aber "steckt noch der ursprüngliche Gottesbefehl zum Aufstieg der Abordnung auf den Berg", zu der "in einem frühesten Stadium nur die Gruppe der siebzig nicht mit Namen genannten Altesten gehörte". Für die Zuordnung zur Quelle E spricht nicht der Kontext der Quelle, sondern nur der Gottesname $24,11 b^{165}$. Während Zimmerli sich anschließt ${ }^{166}$, zieht Perlitt die Konsequenzen. Er verzichtet auf die Identifizierung einer Quelle und isoliert 24,1a.9-11 zu "einer literarisch alten und theologisch wenig redigierten Schicht" 167 . Auf seinen Spuren wandeln Nicholson und in gewisser Weise auch noch Ruprecht ${ }^{168}$. Die einzigen, die eine Verkoppelung mit dem Kontext versuchen, sind Zenger und Mittmann ${ }^{169}$.

165 Soweit NOTH, Exodus, 129.157-160.

166 DERS., Erwägungen, $184 \mathrm{ff}$.

167 DERS., Bundestheologie, 181-19o.

168 NICHOLSON diskutiert ausführlich in seiner Aufsatzreihe (s.o. A 4) die neuere Literatur. Ausgangspunkt aller seiner überlegungen ist die These (passim): "Ex 24,9-11 is a separate unit of tradition within the Sinai pericope. "Weitgehend schließt sich FUHS, Sehen, 258-271 an NICHOLSON an. RUPRECHT bricht mit der traditionellen Einstufung als alt, bleibt aber bei der methodischen Prämisse der Isolierung, indem er Ex 24,1a.9-11 zum Erzählfragment macht. Dafür präsentiert er wie einen deus ex machina seinen Erzähler aus der Zeit des babylonischen Exils. SCHMIDT, Alttestamentlicher Glaube, 44-47 wiederholt im wesentlichen NOTH.

169 ZENGER, Sinaitheophanie, 76f.110.178.216f votiert für den Jehowisten, muß dann aber schwerwiegende Spannungen in Kauf nehmen. Die jehowistische Überleitung $z u$ Ex 32 in 24,12-15* setzt Mose unten am Berge voraus 
Wir beginnen mit dem Korpus VV.1of, um vom Zentrum her Einblick zu gewinnen. Hinter die von Perlitt gewonnene und von Nicholson bestätigte Einsicht darf man nicht zurückfallen, daß es hier primär um Gottesschau geht, auf die ein Mahl folgt. Eine ungebührliche Aufwertung des Mahles, womöglich die Stilisierung zum Bundesmahl, rückt die Peripherie in die Mitte, was Nicholson zu Recht kritisiert hat als "der Schwanz wackelt mit dem Hund" 170 . Für die Gottesschau lautet die Kernfrage: Wie ist die Doppelung V.1oa und V.11b zu bewerten? Perlitt hat auf sie aufmerksam gemacht, sie aber wegen der "Traditionsverschränkung der Gottesbezeichnungen" nicht literarkritisch ausgebeutet ${ }^{171}$, im Gegensatz zu Mittmann ${ }^{172}$. Perlitt hat Gefolgschaft gefunden ${ }^{173}$. Nicholson fängt die Doppelung stilistisch auf und erklärt sie mit einem Parallelismus membrorum zwischen V.11b einerseits und VV.10a+1la andererseits. Konsequenterweise tritt er für Synonymität zwischen ראזה ein ${ }^{174}$. Diese Lösung verfehlt den Duktus der Schau, weil sie deren Beschreibung nicht berücksichtigt. Umgekehrt betont Mittmann die Differenz: ראה als direkte Gottesschau gegen als visionäre Gottesschau ${ }^{175}$. Angesichts der Theophanieschilderung nach dem Verb ראה in 24,10 und im Blick auf die Rolle dieses Verbs in den Visionsberichten wirkt der Gegensatz konstruiert Von entscheidender Bedeutung ist, wie die Schilderung der Gottesschau aufgebaut ist. Auf den Narrativ von V.1oa folgen zwei Nominalsätze 177 in V.1ob,

und erteilt den Befehl zum Aufstieg, obwohl er kurz vorher schon oben ist. Die Vielzahl der Gottesnamen ebensow wie die lokale Unbestimmtheit fallen für den Jehowisten auf. Zu ZENGERs Zuweisung von 24,1-2 s.o. A 144. Die Schärfe, mit der der Jehowist den Berg abriegelt und den Zugang für das Volk verweigert Ex 19,13.21.23, paßt kaum zu der Abordnung, die in 24,9-11 Jahwe sehen darf. NICHOL.SON, The Origin, $152 \mathrm{f}$ hat ZENGERs Vorschlag mit vagen Argumenten abgelehnt; NICHOLSON zustimmend FUHS, Sehen, 259 ; MITTMANN, Deuteronomium, $153 f$. 158 trennt literarkritisch in 24,10.11 a J und 24,9.11b Teil der Grundschicht aus der Hand von E, dazu s.u.

170 DERS., Interpretation, 86.

171 DERS., Bundestheologie, $184 \mathrm{f}$.

172 Vgl. A 169.

173 ZENGER, Sinaitheophanie, 76; FUHS, Sehen, 264, ohne die Beziehungen der beiden Sätze zueinander klären zu können. Das hat zur Folge, daß bei FUHS die semantische Bestimmung von הrn - worauf es ihm ja ankommt völlig verschwimmt und vom Kontext her aufgeblasen wird; DERS., Sehen, 27 of.

174 DERS., The Origin, 149f.158 A 17.

175 DERS., Deuteronomium, $153 \mathrm{f}$.

176 vgl. JEPSEN, Art. הזח, 834. 
darauf ein invertierter Verbalsatz V.11a und eine Kette von drei Narrativen in V.11b. Wo beginnt die Schau und wo hört sie auf? In welchem Verhältnis stehen der erste Narrativsatz und die folgenden beiden Nominalsätze? In den prophetischen Visionsberichten und davon abhängig in den Traumschilderungen eröffnet ראה (G- oder H-Stamm) oder ein äquivalenter Ausdruck + והנה die Beschreibung des Geschehenen, die durch partizipiale oder reine Nominalsätze wiedergegeben wird ${ }^{178}$. Seltener ist die Einführung der Schau durch ראה mit Objektakkusativ und partizipialer Ergänzung ${ }^{179}$. Der in 24,10 vorliegenden, sehr raren Kombination von Verbalsätzen mit beschreibenden Nominalsätzen kommt der Höhepunkt der Berufungsvision Ezechiels in Ez 1,27f nahe ${ }^{180}$. Da im Ezechielbuch die Vision durch eine eigene Einleitung aufgebaut und mit korrespondierender Ausleitung abgebaut werden kann ${ }^{181}$, ist für Ex 24, lof Ahnliches zu vermuten. Die Einleitung in V.1oa korrespondiert der variierten Ausleitung in V.11b. Das eingerahmte Korpus VV.1ob.11a umfaßt dann den Inhalt und das Geschehen der Schau ${ }^{182}$. D.h. Ein- und Ausleitung haben primär stilistische Funktion; sie bezeichnen nicht den Akt einer Gottesschau "in the most direct manner" (Nicholson), denn die Auserwählten werden Jahwes überhaupt nicht ansichtig. Die "Keuschheit der Beschreibung", die schon immer aufgefallen war, muß unterstrichen werden. Alles, was von Jahwe gesehen wird, befindet sich unter seinen Füßen. Es muß daher offen bleiben, ob Jahwe auf "dem Gebilde aus lapislazulifarbenem Glasurziegel" steht ${ }^{183}$, oder ob er darauf thronend sitzt ${ }^{184}$. Jahwes Transzendenz ist hier gesteigert, weil er

177 Das setzt ein elliptisches Verständnis von v.1obß voraus; ebenso möglich ist das Verständnis dieses Verteils als weitere Apposition zum vorhergehenden מעשה, so bei RUPRECHT, Erzähltradition, 146 A 22.

178 Vgl. VETTER, Art. ראה, THAT II, 697-699 und GROSS, Verbform, 72.

179 Vgl. z.B. 1 Sam 28,13; 1 Kön 22,17.19; Jes 6,1ff; Am 9,1.

180 Ohne die Zusätze (vgl. ZIMMERLI, Ezechiel, 8) beschreibt 1,27 in chiastischer Konstruktion mit ראה die zweigeteilte Gestalt des Thronenden (vgl. ZIMMERLI, Ezechiel, 30.56f und KEEL, Jahwe-Visionen, 260-263).

181 Vgl. Ez 1,4 in Beziehung zu 1,28b (die Problematik der Unterschrift im Stil priesterlicher Gesetze $1,28 \mathrm{aB}$ kann hier übergangen werden); ebenso Ez 8,1f in Beziehung zu 11,24; zum AbschluB der Berufungsvision insgesamt in 3,12-15 vgl. ZIMMERLI, Ezechiel, $41.82 \mathrm{f}$.

182 RUPRECHT, Erzähltradition, 146 scheint der gleichen Auffassung, wenn er das waw des ersten Nominalsatzes explikativ ("und zwar") versteht. FuHS, Sehen, 261 spricht im Falle des V.10a von "Einleitung der Visionsschilderung", bleibt im Folgenden aber unentschlossen.

183 So KEEL, Jahwe-Visionen, 260.

184 So RUPRECHT, Erzähltradition, 146-151. 
selbst nach oben entrückt und von seinem Bereich nur mehr die untere Abgrenzung geschaut wird - sehr wenig im Vergleich auch mit verhaltenen Visionsschilderungen der Propheten. Bei dieser Interpretation verhalten sich ראה und zueinander synonym, ein Zeichen späteren Sprachgebrauchs ${ }^{185}$. Hensel 186 ist mit zwei gewichtigen Argumenten für die Spätdatierung eingetreten: Das Stilmittel des vagen Vergleichs ohne tertium comparationis wird in den Visionen des Ezechiel eingesetzt, um zu betonen, daß Jahwe sich der Anschaulichkeit entzieht. Und Edelsteine werden im AT erst von der Exilszeit an genannt ${ }^{187}$. Im übrigen ist der Unterschied zwischen der sogenannten "direkten Gottesschau" in Ex 24,9-11 gegenüber der Verborgenheit Gottes in den alten Theophanien von Ex 19 überzogen worden und hat illegitimerweise zur Frühdatierung ("vormosaischer Ursprung") geführt ${ }^{188}$. Die Isolierung des Abschnitts hat den Blick auf den Kontext verstellt, sonst hätte der ungezügelte Blick des Volkes auf die Erscheinung des כבוד יהוה bei pg in Ex 24,17 und Lev 9,24 vor solchen Einschätzungen warnen müssen ${ }^{189}$. Der wegen der Verneinung invertierte Verbalsatz von V.11a gehört zur Gottesschau 190. Sein hapaxlegomenon אצילים taugt nicht zur Datierung, dafür um so mehr die Wendung "seine Hand (feindlich) ausstrecken gegen". Die chronistische Wiedergabe der Perez-Usa-Ätiologie von 2 Sam 6,6-8 191 in 1 Chr 13,9f streicht heraus, wie sich Usa an der $h 1$. Lade vergreift und "stante pede" von Jahwe getötet wird ${ }^{192}$. Dieser Sprachgebrauch - wenn auch mit Subjektwechsel könnte V.11a beeinflußt haben, zumal wenn טהר "Glanz" (V.10b) mit "Heiligkeit" identisch wird ${ }^{193}$. Somit taucht hier neben dem Grundsatz "wer Gott

185 Vgl. JEPSEN, Art. הTח, ThWAT II, 834.

186 Vgl. das Referat seiner Dissertationsthesen bei RUPRECHT, Erzähltradition, 143-146.

187 Die einzige Ausnahme Gen 2,12 (vgl. RUPRECHT, Erzähltradition, 145 A 19) bestätigt die Regel, weil der Vers wahrscheinlich auf den Pentateuchredaktor zurückgeht, so WEIMAR, Redaktionsgeschichte des Pentateuch, 117.

188 So bei NICHOLSON, Interpretation, 95; Antiquity, 69; The Origin, 159.

189 Vgl. Ex 16,7; 33,18-23; Jes 35,2; 66,18.

190 RUPRECHT, Erzähltradition, 141 will ihn als "eingeschobene Reflexion" gleichsam in Parenthese setzen, die durch Wiederaufnahme in $\mathrm{V} .11 \mathrm{~b}$ eingebunden wird. Aber das gleichbleibende Subjekt (Gott) und der Rückverweis im ePP verklammern ihn genügend mit der Schau.

191 Vgl. SCHICKLBERGER, Ladeerzählung, 129-149.

192 Der Sprachgebrauch der dtr Verse Ex 3,20; 9,15 läuft anders.

193 So KEEL, Jahwe-Visionen, 260 A 351. 
sieht, stirbt" die Warnung auf "wer mit dem Heiligen in Berührung kommt, steht unter Lebensgefahr".

Nach obiger Auffassung bietet V.11b den zweiten Teil der Inklusion bzw. den diese Schau ausleitenden Rahmen. Bei dem vielumkämpften Anschluß "und sie aßen und tranken" gilt es, zwei Extreme zu vermeiden. Er kann nicht als terminus technicus für ein Bundesmahl reklamiert werden ${ }^{194}$. Andererseits darf er nicht zur Bedeutung "sie lebten bzw. überlebten" verflacht oder eingeebnet werden ${ }^{195}$. Der Ort (auf dem Berg unter Jahwe), die beteiligten Personen (die Leiter Israels) und die Gelegenheit (anläßlich der Gottesschau) geben dem "Essen und Trinken" eine offizielle, kultische Note. Ex bezeichnet die würdige Vollendung der Begegnung Jahwes mit den Volksvertretern in einem Festmahl und besiegelt die darin zum Ausdruck kommende Gemeinschaft 196 . Bei der hier vertretenen und weiter angezielten Spätdatierung gehen 24,9-11 die Opfer und der Bundesschlußakt von 24,3-8 voraus, so daß das Festmah1 diese vorausgehenden Riten integriert und insofern den Abschlüssen in Ex 18, 12b und Lev 9,24 nahekommt. Die stereotype Anweisung des Dtn, vor Jahwe zu essen und sich mit der ganzen Familie vor Jahwe $z u$ freuen, übernimmt die gleiche Funktion 197. Die engen Beziehungen von Ex 24,9-11 nach Ex 18,12 hat Perlitt herausgearbeitet ${ }^{198}$. Der entscheidende Vers 18,12 b gehört gemäß neueren literar- und redaktionskritischen Analysen aller Wahrscheinlichkeit nach zur Pentateuchredaktion ${ }^{199}$, was die bisherige Spätdatierung von Ex 24,9-11 unterstuitzt. Lev 9,24 kommt unserer Stelle nahe, nicht durch lexikalische Anklänge, sondern durch die analoge Funktion der Aussage. Nach Aarons erster Opferhandlung sanktioniert die Erscheinung der כבוד יהוה den Gottes-

$194 \mathrm{Zu}$ den Argumenten PERLITT, Bundestheologie, 186-190; NICHOLSON, Interpretation, 84-88.

195 So in seinen "retractationes" vorhergehender Positionen NICHOLSON, The Origin, 148-150.

196 Wir schlieBen uns damit der ausgewogenen Mittelposition von SCHMIDT, Alttestamentlicher Glaube, 46 und vor allem von SMEND, Essen und Trinken, 455-457 an, ohne deren Datierungen zu übernehmen.

197 Vgl. SMEND, Essen und Trinken, 457.

198 DERS., Bundestheologie, $188 \mathrm{f}$.

199 Vgl. ZENGER, Exodus, 282f A 100 und den Durchgang durch 18,1-12 bei WEIMAR, Berufung, 26-29, bes. 29 A 28 und 358f. Zu den Problemen mit $18,12 \mathrm{a}$ und zum beteiligten Personal s. VALENTIN, Aaron, 385-391 ebenso mit Tendenz zu einer späten Einordnung. 
dienst. Das Volk ist Augenzeuge und antwortet abschließend mit Jubel und Proskynese. Das "Essen" übernimmt an dieser Stelle das "vor Jahwe ausgehende Feuer", so daß auf ein Mahl des Volkes verzichtet werden kann. Lev 9,24 stammt aus der Hand von $\mathrm{P}^{S}$, der die $\mathrm{pg}^{\mathrm{g}}$ in V.24b erweitert ${ }^{200}$.

Nimmt man die Einleitung 24,1a hinzu, dann fällt die Fülle der Gottesnamen auf: Jahwe 24,1a; Gott Israels 24,10a; der Gott (schlechthin) 24,11b. Dieses Faktum allein spricht nicht unbedingt für eine der alten Quellen ${ }^{201}$. Man hat den Eindruck, daß der Titel "Jahwe, der Gott Israels" zerlegt 202 und um das aus Ex 19 bekannte Appellativum "der Gott" angereichert wurde. Mit Blick auf Ex 3,15 und 18,12b, für die wahrscheinlich der Pentateuchredaktor verantwortlich ist, spricht einiges dafur, inn selbst oder einen ihm nahestehenden priesterlichen Redaktor auch hier am Werk zu sehen.

Vom Korpus der Schilderung ausgehend können nun die noch ausstehenden Fragen der Kontextverklammerung und der beteiligten Personen angegangen werden. Oben ist darauf hingewiesen worden, daß die Prämisse vom hohen Alter im Verein mit der Isolierung der "Tradition" zur Reduzierung der beteiligten Personen auf die Gruppe geführt hat, die einerseits die pluralischen Verbformen des Korpus abdeckt und andererseits am wenigsten den Kontext einbringt, so daß das hohe Alter nicht tangiert wird ${ }^{203}$. Dieser Ansatz führt faktisch dazu, auf die Einleitung des Korpus in 24,1-2* und 24,9 zu verzichten. Der Preis scheint zu hoch bezahlt. Der Grundsatz "Namen ohne Funktion soll man nicht trauen" 204 mag bei Texten mit Differenzierung und Spezialisierung von Funktionen seine Berechtigung haben. Nur vom Korpus der Schilderung her

$200 \mathrm{Vgl}$. ELLIGER, Leviticus, $121 \mathrm{ff}$.

201 Vgl. RUPRECHT, Erzähltradition, 139.

202 Zum Titel vgl. die Parallelstellen: Gen 33,20 (E) hat "El, der Gott Israels" - "Jahwe, der Gott Israels" in Ex 5,1 (Je); die nachjehowistischen Zusätze in Ex 32,27 und 34,23 sowie Num 16,9 ( $\left.P^{S}\right)$.

203 Die Weichen hat NOTH, Exodus, 158 gestellt. Ihm folgen: mit Anfragen ZIMMERLI, Erwägungen, 184ff; PERLITT, Bundestheologie, 183; SCHMIDT, Alttestamentlicher Glaube, 45; NICHOLSON, Antiquity, 70-79 in differenzierter Auseinandersetzung mit NOTH und einer neueren Begründung; FUHS, Sehen, 262; VALENTIN, Aaron, 394-402. Einen vorsichtigen Einspruch erheben: MITTMANN, Deuteronomium, 153 A 73 und RUPRECHT, Erzähltradition, 162-164. Vgl. PERLITT, Bundestheologie, 183 und NICHOLSON, Antiquity, 78. 
wird keine andere Funktion verlangt als die, ein pluralisches Subjekt abzugeben. Wer mit diesem Kriterium die Aufzählung von 24,1a.9 aussieben will, begibt sich auf Glatteis.

Einleitung 24,1a und Ausführung 24,9 1assen jedesmal auf eine singularische Verbform mehrere Subjekte in einer Aufzählung folgen ${ }^{205}$. Diese Syntax erklärt sich vielleicht daher, daß in beiden Fällen das zuerst angeredete und genannte Subjekt, Mose, die Hauptperson ist, der die anderen Personen zugeordnet werden. Die Aufzählung ordnet in Gruppen: Mose und Aaron; dann Nadab und Abihu und die 70 Altesten. Die in ihrer Zugehörigkeit umstrittene Gruppe "Nadab und Abihu" taucht innerhalb des Pentateuch nur an Stellen des priesterlichen Schrifttums auf ${ }^{206}$. An all diesen Stellen wird sie wie hier gegenüber ihrem Kontext - auch in Reihungen - als eigene Gruppe herausgehoben. Mit der ersten Gruppe "Mose und Aaron" verbindet sie in priesterlichen Traditionen das gleiche Schicksal. Alle vier vergehen sich und sterben innerhalb der Wüstenzeit. Die Beziehung von Nadab und Abihu zu Aaron ist auch ohne ihre Beschreibung als Söhne allein schon durch ihre Position in der Reihe gegeben. Oberblickt man das gesamte Personal von 24,1a.9 und vergleicht es mit einschlägigen Stellen aus dem Pentateuch, dann kommen zwei Fundorte aus dem Rahmen des Dtn dem hiesigen Bild recht nahe (Dtn 27,1 und $31,9)$ : insofern sie den $A 1$ testen neben Mose Leitungsfunktion zubilligen. Kongruenz ergibt sich aber vor allem bei einigen Parallelen aus dem priesterlichen Schrifttum. Auf Ex 18,12 wurde oben hingewiesen. In Lev 4,15 treten sekundär die Altesten als Vertreter der Gemeinde beim Sündopfer hervor 207. Eine jüngere, auf die $\mathrm{pg}$ folgende Schicht in Lev 9,1f 208 bietet die folgende Befehlskette: Mose beruft Aaron und seine Söhne und die Altesten Israels. Strukturell stimmt die Abfolge mit der von Ex 24,1a.9 überein. Somit spricht nichts für literarkritische Operationen, aber alles für die Autorschaft einer späten Hand, die dem Mose das "üppige Gefolge" zugesel1t, um in einem repräsentativen Querschnitt alle Leitungsämter an der Gottesschau zu beteiligen.

Es besteht Konsens darüber, daß 24,1-2 nicht einheitlich ist. V.2 fällt mit seinem Befehl in dritter Person aus der Redesituation heraus. Solch jussi-

205 Vgl. ZENGER, Sinaitheophanie, 73.76.

206 Die Belege: Ex 6,23; 28,1; Lev 10,1-5; Num 3,2.4; 26,60f.

$207 \mathrm{Vgl}$. ELLIGER, Leviticus, 62.67.70.

208 Vgl. ELLIGER, Leviticus, 123f.128f. 
vischer Stil kennzeichnet wiederum priesterliche Autoren ${ }^{209}$. V.1b wird in 24,9-11 nicht wörtlich aufgegriffen. Man könnte inn aber in den Ablauf der Gottesschau integriert sehen, weil dort die Distanz zu Jahwe betont wird; darüber hinaus paßt er sich der Redesituation von V.1 ein. Wenn er zu V.la dazugehört, könnte er V.2 provoziert haben, insofern er Mose mit den anderen Personen auf Distanz hält und darin Ex $19 f$ widerspricht. V.2 stellt dann die "ranggemäße Standordnung" wieder her ${ }^{210}$. Oder V.1b fungiert als Oberleitung zu V.2 und zielt auf die Begleitung, die sich von ferne niederwerfen sol1, während Mose allein Zugang erhält. In jedem Fall sucht V.2 den Ausgleich mit Ex 19f. In den gleichen Zusammenhang verweist das Faktum, daß bei beiden Versen Jahwe von sich in dritter Person spricht ${ }^{211}$. Das wex-qatal der Redeeinleitung 24,1 kann sowohl das Moment der Vorzeitigkeit 212 ausdrücken wie den Gegensatz von vorausgehender offizieller Gesetzesverkündigung zu nun erfolgender privater Anweisung an Mose hervorheben ${ }^{213}$. Die Stellung dieser Verse zwischen Bundesbuch und dessen dtr Rahmung in 24,3. $4 a \alpha$ (s.o.) wird verständlicher, wenn wir den parallelen Vorgänger dieses Aufstiegsbefehls in 19,24 einbeziehen. Innerhalb des jehowistischen Kontexts 19,2ob.21.23.25 fallen die VV.22.24 auf ${ }^{214}$. Gegenüber der anonymen Automatik der Bestrafung(19,13a.21) greift in VV.23.24 Jahwe persönlich. ein. Die VV.21.23 sichern, daß das Volk unterschiedslos dem Berge fernbleibt VV.22.24 dagegen behandeln den Zutritt neuer Personen, der Priester und Aarons. In V.23 schließt sich Mose noch ins Volk ein, in V.24 agiert er vom Volk getrennt. Schließlich warnt V.24 nach VV.21.23 zum dritten Male vor einem Durchbruch des Volkes. Die Redewendung פרץ (Jahwe-Subjekt) + + + ePP (Menschen) in V.22.24 stammt wohl aus der Perez-Usa-Atiologie 2 Sam 6,6-8, die uns schon begegnete ${ }^{215}$, und erinnert an die Lebensgefährlichkeit des Heiligen, wenn Personen sich ihm unbefugt nähern.

Der V.24 - wenn man ihn nicht zum Fragment erklärt und damit jeder Erklärung enthebt - hat seine Existenzberechtigung allein darin, daß Jahwe Mose

209 Vgl. z.B. Ex 12,3ff; 14,2.15; 25,1f u.a. - dazu ROST, Bemerkungen, 58; zur weiteren Analyse von 24,2 s. ZENGER, Sinaitheophanie, $73 \mathrm{f}$.

210 So MITTMANN, Deuteronomium, 152.

211 Vgl. Ex 19,11b; 19,21f.24; dazu PERLITT, Bundestheologie, 182 und ZENGER, Sinaitheophanie, 72.

212 Vgl. die übersetzung bei ZENGER, Sinaitheophanie, 177.

213 Vgl. MITTMANN, Deuteronomium, 152.

214 Vgl. MITTMANN, Deuteronomium, 150. 
befiehlt, herunterzusteigen, um mit Aaron zusammen wieder aufzusteigen ( $V$. 24a). Der Rest des Verses konzentriert wiederholend selbständige Wendungen wie "zu Jahwe durchbrechen" (V.21, und "auf den Berg Sinai hinaufsteigen" (V.23) zu dem einen Ausdruck "nicht durchbrechen, um zu Jahwe aufzusteigen" 216 . Der V.24 gibt also nur einen Sinn, wenn man inn im Blick auf 24 , 1.9-11 versteht.

V.22 erwägt den Zugang der Priester zu Jahwe unter der conditio sine qua non der persönlichen Heiligkeit. Nach Ausweis der Parallelen beschreibt der Partizipialsatz mit נג/G-Stamm und den Priestern als Subjekt deren kultische Funktion 217 . Obwohl V.22 mit V.24 eng verwandt ist, stammen beide nicht von einer Hand. Der Zusatzcharakter wird in V.22 deutlicher als in V.24 218 . Und "die Priester" - Subjekt von V.22 - gehören in V.24 nicht ursprünglich zum Vers. Ihre ambivalente Position zwischen den Halbversen entlarvt das Wort und darüber auch V.22 als Einschub in Abhängigkeit von V.24 219. 19,22 hat Beziehungen zu 24,2 durch das Verb נגש, wie auch gegenläufig 24,2 auf 19,24 anspielt (a עלה / Volk). Der Eindruck drängt sich auf, daß das spätere Schicksal von Nadab und Abihu aus Lev 10,1ff in den Zusätzen 19,22 und 24,2 hereinspielt.

Das Rätsel um die befremdliche Position von 19,24 und 24,1 löst sich auf. Der priesterliche Redaktor, der 24,9-11 an das Bundesbuch mit seinem Bundesschlußritus anheftete, hat die Gottesschau mit zwei Befehlen nach vorne in der Theophanie verankert. Als Anknüpfungspunkte boten sich nur das jeweilige Ende der beiden Redekontakte Jahwes mit Mose innerhalb der Theophanie an: erstens das Ende des Dialogs 19,20b-24 und zweitens das Ende der Mitteilung des Bundesbuches ${ }^{220}$. Als später Redaktor zwingt er uns in die Sehweise eines Herausgebers, der die ihm vorliegende Textmasse verarbeitet und strukturiert. Wir vermuten den Grund seiner Bemühungen in einem Interesse an analoger Dramaturgie bzw. verwandten Abläufen der Theophanie oder schon besser der

215 Vgl. die Parallelen in: $2 \operatorname{Sam} 6,8 ; 1 \operatorname{Chr} 13,11 ; 15,13$; und oben Ex 24,11a.

216 Vgl. MITTMANN, Deuteronomium, 150.

217 Dazu MITTMANN, Deuteronomium, 150 A 65 und die Parallelen: Ex 28,43; 3०,20; Lev $21,16-24$; Num 4,19 .

218 Vgl. ZENGER, Sinaitheophanie, 63. Das unterschiedliche Pronominal-Suffix bei der Präposition 2 W.22b.24b ergibt sich aus der unterschiedlichen Position im Satz, vgl. JoúoN, $\S 103 f ;$ es bedingt für sich genommen keine literarkritische Trennung.

219 Dazu im Einzelnen ZENGER, Sinaitheophanie, 64. 
Theophanieliturgie. Die Sinaitheophanie beginnt mit der Erscheinung Jahwes (Ex 19 ), führt dann zu Gesetzesverkündigung mit Dekalog und Bundesbuch (Ex 20-23). Darauf antworten die Opfer und Bundesschlußriten (Ex 24,3-8). Die Liturgie schließt mit der Gottesschau durch die Volksführer auf dem Berge (Ex 24,9-11). Analog dazu wird die Kultgesetzgebung gerahmt bzw. in einer Liturgie eingesetzt und eingeweint 221 . Diese Liturgie beginnt mit der Erscheinung des כבוד יהוה (Ex 24,15-18). Darauf folgen die Begründungen und Einrichtung des Heiligtums (Ex 25-40) sowie die Opfervorschriften (Lev 1-8). Der Abschluß wird erreicht mit Lev 9, dem Opfer diesmal durch Aaron und seine Priestersöhne. Zum legitimierenden Finale erscheint die כבוד יהוה vor allem Volk (Lev 9,23-25). Ohne diese Spur weiter zu verfolgen, scheint neben der punktuellen Evidenz des Einzelabschnitts auch die mögliche Konzeption und leitende Absicht für einen oder mehrere priesterliche Redaktoren in Ex 19,(22).24; 24,1a(b).(2).9-11 zu sprechen.

\subsection{Das VerhäZtnis des Dekalogs zum Privilegrecht}

Im Folgenden kommt es nur darauf an, anhand der Rahmungen des Privilegrechts (Ex 34,12-26) zu prüfen, in welchem Verhältnis diese Gesetzessammlung zum Dekalog steht. Zur Rahmung gehören schon gleich die Einleitung des Kapitels V.1 Befehl und V.4 Ausführung. Ober die bis ins Einzelne gehenden Entsprechungen in 34,1.4a .b zu Dtn 10,1-5 und damit über die Identität der Redaktoren kann kein Zweifel bestehen ${ }^{222}$. Was Dtn 10,1-5 in der IchRede des Mose berichtet, setzt $34,1.4^{*}$ in den neutralen Erzählstil der dritten Person um. Der dtr Redaktor stellt mit seinem Eingriff die Weichen für das von ihm gewünschte Verständnis von Kap. 34. Seine Leitvorstellungen bezieht er vom Dtn her, näherhin von Dtn $9 f$. Er knüpft geschickt an die jehowistische Tafelvorstellung in Ex 24,$12 ; 31,18^{*}$ und in dem jehowistischen Grundtext von Ex 32 insbesondere Ex 32,19 an 223. Durch inn wird Ex 34 zur Erzählung von der Bundeserneuerung nach dem Tanz ums Goldene Kalb. Von Bun-

$220 \mathrm{Daß}$ in 19,24 nicht das gesamte Personal von 24,1 auftritt, mag mit der Sorge vor Utberlastung des Nachbartextes zusammenhängen. Auf jeden Fall sind mit Mose und Aaron die wichtigeren Figuren eingeführt. Die Beziehungen von 19,24 und 24,1 sind so dicht, daß sich eine redaktionskritische Trennung nicht empfiehlt.

221 Vgl. WESTERMANN, Herrlichkeit, $118 \mathrm{ff}$.

222 S.oben 2.7.5 und 2.7.6.5; zur Literarkritik vgl. ZENGER, Sinaitheophanie, 94f.199.226f.

223 Die priesterlichen Tafelparallelen in Ex $31,18^{*} ; 32,15 f^{*}$ (s.0. 2.7.5) waren für ihn noch nicht vorhanden. Damit widersprechen wir der Behandlung und Zuweisung von 34,1-4 bei HALBE, Privilegrecht, 279-286, bes. $284 \mathrm{f}$. 
deserneuerung am Sinai aber konnte erst die Rede sein, nachdem die Erzähltradition von Ex 32 (Grundtext) durch die Interpretationsfilter von Dtn $9 f$ gegangen war. Die jehowistische Tafelvorstellung war so offen und diesem Redaktor auch so nahe, daß er in Ex 32 die Tafeln betreffend nicht einzugreifen brauchte. Ex $34,1.4^{*}$ reichten inm aus, rückgreifend umzudeuten und vorgreifend die Leser-/Hörererwartung auf erneuerte Tafeln mit denselben Worten auszuspannen.

Eine bedeutende Rolle spielt die Einleitung ins Privilegrecht VV.10f. Halbe hat sie ausführlich und mit Akribie behandelt ${ }^{224}$, so daß wir uns in der Auseinandersetzung mit ihm sowohl auf ihn stützen wie auf ihn konzentrieren können. Wesentlich für Halbes Interpretation und Datierung des nachfolgenden Privilegrechts ist die Oberzeugung, daß VV.10-11a von struktureller Einheit und literarischer Einheitlichkeit sind. Die dreigliedrige Rede stellt in ihrem ersten Teil (V.10a) das zukünftige Handeln Jahwes dar. Dieses Handeln ruft Erkenntnis des Volkes hervor - dargestellt im zweiten Teil (V.10b). Die Erkenntnis wiederum zielt auf Entscheidung, wie sie im dritten Teil (V.11a) der Imperativ fordert. Die dreigliedrige Redeform entstammt einem kultischen "Sitz im Leben", was vor allem die Heimat der "Erkenntnisaussage" nahelegt. Halbe wischt zu schnell Zengers Einwände gegen die Zusammengehörigkeit von V.10a und V.10b beiseite ${ }^{225}$. V.10b verschiebt die Akzente der Ankündigung. Aus dem Volk des Mose ("dein ganzes Volk") wird "das ganze Volk, in dessen Mitte du (Mose) bist". Dadurch wird die Person des Mose aufgewertet. Der Wechsel von der Langform des selbständigen Personalpronomens in V.10a zur Kurzform in V.1ob stört auf so engem Raum. In V.loa vollbringt Jahwe Wundertaten vor dem Volk, in V.lob ist furchtgebietend das, was Jahwe "mit dir" tun wird. Unabhängig von dem Entscheid, wer in dem "Du" des Präpositionalobjekts angesprochen ist (Mose oder schon das Volk im Hinblick auf das "Du" des nachfolgenden Imperativs mit anschließendem Privilegrecht) fallen die unterschiedlichen Präpositionen bei הנy auf,obwohl es beide Male anscheinend um dasselbe Handeln Jahwes geht. Auch diese Akzentverschiebung von der neutralen Augenzeugenschaft beim Handeln Jahwes zur Rolle des in das Handeln involvierten objekts bleibt auffällig. Entscheidend aber ist vor allem die Frage, ob in V.1ob überhaupt eine "Erkenntnisaussage" vorliegt, die in der

224 DERS., Privilegrecht, 55-96.

225 DERS., Privilegrecht, 271 A 2:"gekünstelte Aufspaltung". Dazu ZENGER, Sinaitheophanie, $96 \mathrm{f}$. 
Konzeption Halbes die Vermittlung übernimmt zwischen angesagter Zukunft aus Jahwes Hand und dem Ruf zum Gehorsam im "heute". Der Entscheid hängt

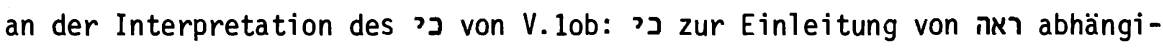
gen Objektsatzes (so Halbe) oder emphatisches כי כur Einleitung eines selbständigen Satzgefüges. Beim Verständnis als objektsatz gibt schon dessen weit entfernte Stellung vom Hauptverb zu denken, die durch den dazwischentretenden Relativsatz hervorgerufen wird. Unhaltbar ist Halbes Interpretation in bezug auf den abschließenden Relativsatz (V.1obß). Er schwebt völlig frei in der Luft, denn die "Erkenntnisaussage" kommt mit ihrem objektsatz an ihr Ende. Einschlägige Parallelen mit "Erkenntnisaussage" bieten nach dem Objektsatz immer einen neuen Satzbeginn, keinen abhängigen Nebensatz ${ }^{226}$. Das כי von V.10b leitet ein neues Satzgefüge ein. Das Demonstrativpronomen הוא bezieht sich nicht anaphorisch auf das "Werk Jahwes", sondern kataphorisch auf den nachfolgenden Relativsatz 227 . Wenn in V.1ob keine "Erkenntnisaussage" vorliegt, macht der Hauptsatz mit ראה eine Aussage über den Seh-Akt des ganzen Volkes und erscheint wie eine Verdoppelung des in V.loa implizierten Sehens ("vor deinem ganzen Volk"). Er will offensichtlich V.loa aufgreifen und zugleich in neue Bahnen lenken. Das Volk soll nicht nur Augenzeuge außergewöhnlicher und einmaliger Wundertaten werden, sondern soll über Mose sehen, was Jahwe mit Mose und ihm vorhat.

Der Kontext präzisiert:Das furchterregende Werk Jahwes sind Gesetz und Bund ${ }^{228}$. Die singuläre Diktion von V.loa trennt den Halbvers von der dtn-

226 HALBE, Privilegrecht, 57 A 13 weist auf Grammatiken und betreffende Artikel hin. Die Prüfung der Hinweise hat keine rechtfertigende Parallele ergeben. Umgekehrt betont der Kronzeuge MUILENBURG, Usages, 143 A 26, daß ein Verb, das durch Objektsatz mit 'כ verstärkt wird, am Ende eines Satzes steht.

227 Das'J kann Einleitung eines emphatischen Statements sein wie in 2 Sam 14,14; Num 23,23, vgl. noch Ex 2o,5b//Dtn 5,9b; Jes 43,3;oder es kann begründende Qualität haben, vgl. MUILENBURG, Usages, 145 Ziffer 8 und 10 sowie 147 Ziffer 15 .

228 HALBE, Privilegrecht, 58.271f betont zu recht, daß in v.1ob die Anrede an Mose hinübergleitet zur Anrede an das Volk, das im "Du" von 34,1126 angesprochen wird. Doch was hier in Ex 34 den Kontextzwängen einer Redaktion entspringt, die ab V.1ob umdeutet, kann nicht durch altorientalische Parallelen gerechtfertigt werden. Die außerisraelitischen Vertrāge der Hethiter mit Kontrahentenmehrheiten können die literarkritischen Konsequenzen für Ex 34,10 nicht aufheben. HALBE führt (271f A 2) drei Fälle auf. Im ersten Fall ist auf klare Kompetenzverteilung geachtet. Der erste Teil des Vertrages, den Suppiluliuma schließt, richtet sich singularisch an den Führer mit der Rechtsstellung eines Häuptlings (Hukkanaš), der zweite Teil wendet sich im Ihr-Stil an die Gruppe (die Leute von Hajasa). Im zweiten Fall (Vertrag mit Lab'u und den 
dtr Sprachwelt ${ }^{229}$. Bei V. lob nähern sich die Formulierungen dem Dtn an, wahren aber zugleich eine spezifische Distanz ${ }^{230}$. Nur noch einmal wird so deutlich wie in V.1ob betont, daß sich Mose inmitten des Volkes befindet - nämlich in Num 11,21a, einem wahrscheinlich jehowistischen Versanteil 231. Der V.11 zeichnet sich ebenso durch Nähe und Distanz zum Sprachgebrauch des Dtn aus. Die Belege sind öfters gesammelt worden und können hier knapp referiert werden. Der einleitende Imperativ von שמר/G-Stamm mit dativus commodi zeigt seine Singularität im Vergleich mit dem geläufigen und gleichkonstruierten Imperativ von שמר/N-Stamm ${ }^{232}$. Der nachfolgende partizipiale Promulgationssatz klingt dtn-dtr, offenbart aber bei näherem Zusehen seine Eigenheiten. Er gibt sich als Objektsatz zum Imperativ, während das Dtn שמר mit substantivischem Objekt konstruiert. Die üblichen Termini für Gesetz fehlen. Im Dtn spricht Mose den partizipialen Promulgationssatz, hier dagegen Jahwe 233.

Wenn der partizipiale Promulgationssatz die gerade geschehende Gebotsverkündigung meint, hat er in V.11a zusammen mit dem Imperativ kataphorische Qualität, ist also ganz auf die folgende Gesetzesverkündigung ausgerich-

Bewohnern von Tunip) redet der Vertragschließende den Vertragspartner an, indem er den Repräsentanten und seine Gruppe in einem Zuge hintereinander nennt und beide im "Ihr" zusammenschließt. Der Repräsentant hat wahrscheinlich die Rechtsstellung eines Bürgermeisters. Im dritten Fall soll die Gruppe ohne besonderen Repräsentanten sowohl im "Du" wie im "Ihr" angeredet werden. Das könnte eine Analogie zu Ex 34,10 sein, wo hinter dem "Du" des Mose dann die Gruppe auftaucht. Allerdings trägt die Parallele nicht. Bei dem angeführten Vertrag mit den Kaškäern sind die Numerussprünge fraglich. Erstens ist der Vertrag als Entwurf skizziert, also in gewisser Weise unfertig. Zweitens sind die Numerussprünge vom Urtext her fraglich, vgl. FRIEDRICH, Staatsverträge, 93f A 3. Die Vertragsskizze mit der egalitären Gesellschaft der Kaškäer legt doch nahe, im Vertragstext von der vorherrschenden Ihr-Anrede auszugehen. Nebenbei läuft Ex 34,10 in eine andere Richtung. Der Numerus bleibt, nur das "Du" weitet sich aus von der Einzelperson zur Gruppe, die erst allmählich in den Blick kommt. Den literarkritischen Konsequenzen zu 34,10 kann man kaum ausweichen.

229 Vgl. HALBE, Privilegrecht, $89 \mathrm{f}$.

$230 \mathrm{Vgl}$. HALBE, Privilegrecht, 90-94.

231 NOTH, Numeri, $74 \mathrm{f}$ hält den Halbvers für einen Zusatz zur Grunderzählung von Kap. 11, die nach ihm jahwistisch sein dürfte. Die Parallelangabe zu Num 11,21a in Ex 12,37b hält ZENGER, Exodus, 276 A 72 für jehowistisch; WEIMAR, Berufung, 58f A 115 dagegen nimmt Herkunft vom Pentateuchredaktor an.

232 Vgl. LANGLAMET, Israel, 321-350.481-507, bes. 329.

233 Vgl. LANGLAMET, Israel, 328-330; LOHFINK, Hauptgebot, 61f; HALBE, Privilegrecht, 94 A $43 a$. 
tet ${ }^{234}$. Der V.11b stört den direkten Zusammenhang zwischen der Einleitung V.11a und der Gesetzesverkündigung VV.12ff. Er ist als Zukunftsansage im Präsentativ zu interpretieren ${ }^{235}$. Halbe sieht darin die Kombination von Interjektion und Feststellungssatz und entdeckt so Formelemente der Rechtssprache. Er verkennt die Konstruktion. Alle von ihm stützend angeführten Beispiele - inner- wie außerisraelitisch - weichen in signifikanter Weise von der Konstruktion des Präsentativs in v.11b ab ${ }^{236}$. Für die Zugehörigkeit von V.11b zu einer dtr Redaktion ist neuerdings wieder Weimar eingetreten 237 . In der Kombination von Vertreibungszusage (mit גרש) und Völkerliste kommt dem Halbvers die dtr Parallele Ex 33,2 am nächsten 238.

Der zweite Teil der "Umrahmung des Privilegrechts" setzt ein mit einer neuen Redeeinleitung zu einer Jahwerede an Mose - ein Hinweis darauf, daß der Schreiber dieser Zeilen die vorhergehende Jahwerede als an das Volk gerichtet verstand. Der Imperativ regiert wieder den dativus commodi wie in $34,11.12$, was sich wegen der Beliebtheit der Konstruktion kaum schichtenspezifisch auswerten 1äßt. Besonderen Aufschluß gibt V.27b. Die Angabe am Ende des Verses "und mit Israel" klappt nach. Wie die Parallelen Ex 23,32 und Jer 31,31 zeigen, werden im Fall von zwei Präpositionalobjekten diese beide in die Wendung כרת ברית hineingenommen. Das sekundäre Interpretament sichert den Aussagegehalt des Grundtextes $a b$, daß Jahwe mit Mose einen Bund schließt, wobei Mose das ganze Volk vertritt ${ }^{239}$. Diesen Aussagegehalt gilt es durch Vergleich differenzierter ins Auge zu fassen, weil er bisher zu schnell eingeebnet wurde. Mose wird bei diesem Bundesschluß eine spezifische Rolle zugewiesen. Er steht als Bundespartner vor Jahwe. Auf der Partnerseite vertritt er das Volk. Einer solchen "Vertragssituation" kommt Dtn 5,2f sehr nahe. Hier spricht Mose vom Bund, den Jahwe am Horeb "mit uns" geschlossen

234 Das spricht gegen seine Position als Ziel der dreigliedrigen Redeform VV.1of bei HALBE, Privilegrecht, 56-59.

235 Grundlegend zur grammatischen Form: HUMBERT, La formule, 54-59.

236 Vgl. HALBE, Privilegrecht, 98-107.

237 DERS., Berufung, 323-329, bes. 326 A 31 zu HALBEs Einordnung.

238 Zur redaktionskritischen Einordnung von Ex 33,2 vgl. ZENGER, Sinaitheophanie, 193.223 und WEIMAR, Berufung, 325 A 27.

239 Die Vermutung von NOTH, Exodus, 219 bestätigt sich. PERLITT, Bundestheologie, 230 will den Zusatz festhalten, weil er an der dtr Verfasserschaft des ganzen Verses interessiert ist. HALBE, Privilegrecht, 333 hält die Sachaussage für entscheidend:Mose steht als Repräsentant Israels vor Jahwe. Trotzdem bleibt die Beobachtung für die redaktionskritische Einordnung wichtig. 
hat. Er schließt sich, den Sprecher, und das Volk in einer Gruppe zusammen. Mose und Volk stehen geschlossen auf der Partnerseite. Einen Schritt weiter geht jene Reihe von Stellen, an denen Mose als Sprecher den eben genannten Verbund aufgibt und aus der Gemeinschaft der Partner heraustritt. Er spricht jetzt vom Bund, den Jahwe "mit euch" geschlossen hat (vgl. Ex 24,8; Dtn 4, $13.23 ; 9,9 ; 31,16$, wo Jahwe nach Ausscheiden des Mose nur den Bund zwischen sich und Israel erwähnt). Offensichtlich gehört Mose nicht mehr zu den Partnern, sondern vermittelt eher zwischen zwei Partnern, Jahwe und Israel. Was sich bei diesem Formulierungen ankündigt, bringt die vierte Reihe von Stellen auf den Begriff (Dtn 28,69 und 29,9-14). Jahwe befiehlt dem Mose, den Bund mit Israel zu schließen. Also nicht mehr Jahwe, sondern Mose schließt nun den (Moab-)Bund. Die Abfolge der gereinten Stellen zeigt wie auf einer Meßlatte den langsamen Wechsel im Standort des Mose von der Partnerseite hinüber zur Seite des Bundesmittlers. An diesem Maßstab gemessen kann man den "Mose-Bund" von Ex 34,27 getrost als protodeuteronomisch einstufen.

Es besteht in neueren Analysen eine breite Obereinstimmung darüber, daß V.28 von V.27 abzutrennen ist. Er setzt sich in seiner Konzeption des Bergaufenthaltes von der jehowistischen Version in Ex 24,12a.18b ab und ist mit Sicherheit einer dtr Redaktion zuzutrauen. Die engen Beziehungen zu Dtn $9 f$ und $z u$ den eingangs behandelten dtr Versen 34,1.4aa.b lassen daran keinen Zweifel 240 . Wie geschickt bzw. schon trickreich der dtr Redaktor von Ex 34 gearbeitet hat, zeigt die Kontroverse um das Subjekt von ויכתב in V.28b. Der nahe Kontext von V.27 und V.28a her legt das Subjekt Mose nahe ${ }^{241}$. Der weitere Kontext, d.h. der Eingang des Kapitels, fordert mit logischer Konsequenz das Subjekt Jahwe ${ }^{242}$. Unserem dtr Redaktor war der Konflikt zwischen seiner eigenen Konzeption und der protodeuteronomischen Vorlage wohl bewußt. Er ließ das Subjekt deshalb in der Schwebe, je nachdem ob man mit kleiner oder großer Brennweite seine Zeilen liest. Denselben Mann kann man auch für Ex 34,27 verantwortlich machen. Unter dem Einfluß von Ex 32,31 (Grundtext des Kapitels) und Dtn 9,12 (Grundtext des Kapitels) hat er sein Bilderverbot neu formuliert und an der passenden Stelle nach dem Hauptgebot

240 Vgl. PERLITT, Bundestheologie, 2.30f A 4; ZENGER, Sinaitheophanie, 98. 201.230; HALBE, Privilegrecht, 272 A 6 vermutet sogar P-Verfasserschaft; der kommt aber erst im folgenden Vers 29 zu Wort.

241 So VALENTIN, Aaron, 284 A 1.

242 So ZENGER, Sinaitheophanie, 98.203. 
ins Privilegrecht eingeschoben ${ }^{243}$. Ohne den Anspruch zu erheben, die dtr Bearbeitung von Ex 34 vollständig erfaßt zu haben ${ }^{244}$, können dieser Redaktion zugewiesen werden: Ex 34,1.4a a.b.(9b).11b.17.27* ("und mit Israel").28. Das Hauptziel dieser Redaktion liegt auf der Hand. Das vorgegebene Privilegrecht mit seiner vorliegenden Rahmung konnte nicht übergangen werden, sondern mußte in eine weiter gesteckte Konzeption eingebracht werden. Eine dtr Redaktion, die den Tetrateuch mit dem mittlerweile angewachsenen Dtn verklammerte, mußte das Verhältnis des Privilegrechts innerhalb des "Mose-Bundes" von Ex 34 zu dem Dekalog innerhalb des "Horeb-Bundes" von Dtn 5.9f klären. Sie gestaltete nach dem Kalbsdienst von Ex 32 unter Einfluß von Dtn $9 f$ das Kap. 34 um zu einer Bundeserneuerung. Das Privilegrecht wurde nun zum zweiten, erneuerten Dekalog geadelt. Dieser Redaktor hat den Exegeten die Spur gelegt, im Privilegrecht einen Dekalog zu suchen. Dabei kam es inm zuerst darauf an, das Verhältnis von Dekalog und Privilegrecht zu bestimmen, und weniger darauf, die "Zehn Worte" abzuzählen. Für ihn waren Dekalog und "Zehn Worte" schon eine feste Größe.

Bei der Zuweisung von V.29 zu einem P-Redaktor herrscht weitgehend Obereinstimmung, wie ein Blick auf Zengers Tabelle zeigt ${ }^{245}$. Seine eigene Abtrennung von V.29aa empfiehlt sich nicht ${ }^{246}$. Die Beobachtungen sprechen gerade für die Zuweisung des ganzen Verses zu einem P-Redaktor. Die "short-circuitinclusion" in V.29a 247, die Redundanz in der expliziten Nennung des Subjekts "Mose" und die Variation in der Bergbezeichnung 248 sind verläßliche Hinweise auf seine Hand. Mit diesem Vers zeigt er sich als treuer Schuiler der dtr Redaktion von Ex 34. Er übernimmt deren Tafelvorstellung und über die Tafelvorstellung deren Verständnis von Ex 34 als Text der Bundeserneuerung mit einem erneuerten, zweiten Dekalog ${ }^{249}$. Dachte aber die dtr Redaktion an ihren Dekalog von Dtn 5.(9f), so hat der P-Redaktor natürlich den Exodusdekalog im Auge.

243 Die Ausführungen HALBEs, Privilegrecht, 216-219 werden damit integriert und zugleich modifiziert.

244 Vgl. dazu für die Textpartien außerhalb des Privilegrechts ZENGERs Analyse und innerhalb die Analyse von HALBE.

245 DERS., Sinaitheophanie, 230.

246 DERS., Sinaitheophanie, 98.

$247 \mathrm{Vgl}$. oben 2.7 .5 A 523.

248 Vgl. zu weiteren Bergbezeichnungen beim Pentateuchredaktor WEIMAR, Berufung, $338 f$. 
Zum Abschluß der Erwägungen zu Ex 34 sei eine zusammenfassende redaktionskritische Hypothese zur Integration und Bearbeitung des Privilegrechts gewagt. Ausgangstext ist der Dialog der jahwistischen Sinaitheophanie zwischen Jahwe und Mose in Ex 34,9a.10a250. Dieser die jahwistische Theophanie abschließende Dialog erklärt auch, weshalb die beiden Redeeinleitungen ohne explizite Nennung des Subjekts und ohne Adressatenangabe auskommen. Der Jehowist hat daran angeknüpft. Für seine Autorschaft spricht das durchgehend protodeuteronomische Gepräge seiner Aussagen und Formulierungen. Er greift in V.10b die jahwistische Ansage eines "Verheißungsbundes" auf und verschiebt die Akzente. War beim Jahwisten Mose der Empfänger von nicht adressierter Ansage künftiger Wundertaten Jahwes, so rückt Mose beim Jehowisten stärker in die Mitte und avanciert zum Partner Jahwes. Hinter Mose taucht das Volk auf, welches dieser vor Jahwe vertritt. Der "Verheißungsbund" des Jahwisten wandelt sich zum "Verpflichtungsbund" des Jehowisten. Mit V.1la leitet er über zum neuen Inhalt seines Bundes, dem in Jahwerede promulgierten Privilegrecht 34,12-26*. Nur zur Absicherung sei hier daran erinnert, daß damit keine Entscheidung über das hohe Alter der im Privilegrecht verarbeiteten Rechtsmaterialien getroffen ist. Es ist aber eine für die Interpretation nicht unwichtige Aussage über ihre Integration in die Sinaitheophanie gemacht. In V.27 offenbart der Jehowist seine Bundeskonzeption: Bundespartner Jahwes ist Mose und über Mose das Volk. Den Bundesinhalt machen die Worte des Privilegrechts aus. Dieses wird am Sinai mit dem Blick auf das zu erobernde Land promulgiert. Vom Jehowisten her wird der Sinai zum Ort der Verpflichtung bzw. des Gesetzes. Der Jehowist verknüpft Sinai - Mose - Bund - Gesetz zu einer Tradition, die in der dtn-dtr Bewegung aufblüht und ausstrahlt ${ }^{251}$. An dem jehowistischen Mose-Bund konn-

249 Der P-Redaktor versteht, worauf die ihm vorausgehende dtr Redaktion hinsteuert. Das Präpositionalobjekt אתו am Ende von V.29 kann sich nur auf Jahwe beziehen(vgl. ZENGERs interne Übersetzung in Sinaitheophanie, 203). Von Jahwe war "virtuell" zuletzt in V.28b die Rede. Will man das nicht anerkennen, muß man auf den Anfang von V.28 oder auf V.27 zurückgreifen, schafft damit aber einen überlangen Rückgriff.

250 Vgl. ZENGER, Sinaitheophanie, 96.10of.120ff.

251 Wir widersprechen damit der These HALBEs von den "Rahmenaussagen" in Ex 34,1oa .27 (DERS., Privilegrecht, 55.230-236.253-255). Was Rahmung im strengen Sinne bedeutet, zeigt das Privilegrecht in VV.12a.15a. An solche Konstruktion reicht die postulierte "Rahmung" nicht heran. Ihr widerstreitet die neue Redeeinleitung in V.27 - ein Zeichen dafür, daß der Jehowist bei der Einleitung vom Jahwisten abhängig war, am Ende seiner Einfügung aber frei schalten konnte. Verschiedene Verfasser erklären am besten die unterschiedliche Konstruktion der Angabe zum Bundschließen: in 34,1oa Präsentativ,zur Bezeichnung eines individuel- 
te eine dtr Redaktion des Tetrateuch nicht vorbeigehen. Sie mußte das Verhältnis von Sinai und Horeb oder von Jahwebund mit Mose und Jahwebund mit Israel oder von Privilegrecht und Dekalog klären. Ober die Interpretationshilfe von Ex 32 und Dtn $9 f$ integrierte sie das Privilegrecht als zweiten Dekalog innerhalb einer Bundeserneuerung. Sie umfaßt cum grano salis innerhalb von Ex 34 die oben genannten Verse. In die Fußstapfen der dtr Redaktion tritt schließlich eine priesterliche Redaktion in 34,29. Sie übernimmt auf ihre Weise die Tafelvorstellung, blickt aber damit auf den für sie zuständigen Exodusdekalog zurück.

\subsection{Thetische Zusammenfassung der Ergebnisse des Kapitels}

Die Abfolge der Thesen spiegelt die chronologische Reihenfolge der Redaktionsschichten wider, die in die vereinigte Sinaitheophanie des Jahwisten und Elohisten Gesetzesmaterialien integriert haben.

1. Der Jehowist knüpft an die jahwistische Verheißung vom Bund an (Ex 34,9a. 10a) und deutet sie um auf einen Bund mit Mose, dessen Inhalt das an Israel gerichtete Privilegrecht darstel1t: Ex 34,10b.11a.12-26*.27*.

2. Dtr Redaktoren bearbeiten vom Dtn her den Tetrateuch und modifizieren die jehowistische Sinaitheophanie:

Sie führen in Ex 19,3ba*.4-8 die Bundeskategorie ein, die als Filter der jehowistischen Sinaitheophanie vorgeschaltet wird. Nach dem AbschluB der elohistischen Sinaitheophanie in Ex 20,21 fügen sie das Bundesbuch ein, indem sie es wahrscheinlich auch zugleich bearbeiten: Ex 20,22aa.24-26*; 21,$1 ; 21,2-23,33 *$. Sie rahmen das Bundesbuch durch Rekurs auf ihre ouvertüre der Sinaitheophanie und wiederholen den Akt der Selbstverpflichtung des Volkes auf die gehörten Reden Jahwes. Mose hält die Reden schriftlich fest: Ex 24,3.4aa. Eine weitere dtr Redaktion knüpft an den jahwistischen Opferbericht (Ex 24,3aßץ.b.5*) an und baut ihn aus zum Bundesschlußritus: Ex 24,6-8.

Den jehowistischen Mose-Bund deuten sie um zur Bundeserneuerung des Horebbundes und ernennen das Privilegrecht zum erneuerten, zweiten Deka$\log$ : $\operatorname{Ex~} 34,1.4 a \alpha . b(9 b) .11 b .17 .27 * .28$.

3. Priesterliche Redaktoren - wahrscheinlich der Pentateuchredaktor - gestalten den Pentateuch. Mit dem Dtn gerät dabei der ältere Deuteronomiumdekalog an die Peripherie. Wegen seiner Dignität wird er nach vorne gezogen und an die spitze aller Gesetzesmaterialien der Sinaitheophanie

len zukünftigen Sachverhalts fortgeführt mit x-yiqtol (vgl. GROSS, Verbform, 80) - dazu absoluter, präpositionsloser Gebrauch der wendung כרת ברית; in 34,27 dagegen x-qatal zur Bezeichnung der Koinzidenz ( vgl. das sogenannte perfectum declarativum bei NOTH, Exodus, 219 und HALBE, Privilegrecht, 230 A 2) - dazu regiert dieselbe Wendung hier die Präposition את . Und schlieBlich - wie oben beschrieben - das andere Thema: in 34,1oa VerheiBung - in 34,27 Verpflichtung. 
gestellt. Die Redaktoren bearbeiten anfangs die dtr Ouvertüre der Sinaitheophanie und steigern die Rolle des Mose: Ex 19,3bß.9.

In Ex 19, (22). 24 bringen sie Klammern an für ihren Abschluß des ersten Teils ihrer Sinaitheophanie. In Ex 20,1-19.20* (nur mit der Redeeinleitung) schieben sie gezielt den Dekalog ein. In Ex 20,22aß.b bestimmen sie das Verhältnis von Dekalog und Bundesbuch. Mit Ex 20,23; 23,20 und 23,13 rahmen und bearbeiten sie das ihnen vorliegende Bundesbuch. In Ex 24,1-2 bringen sie ein zweites Klammerelement für ihr Finale des ersten Teils der Sinaitheophanie in Ex 24,9-11 an. In Ex 34,29 übernehmen sie die dtr Konzeption des Privilegrechts,allerdings mit Blick auf den von ihnen eingeschobenen Exodusdekalog. 


\section{KAPITEL 4}

Der Dekalog im Kontext der Horebtheophanie

\subsection{Einleitung}

Im Gang der bisherigen Untersuchung kommt es nun darauf an, die ältere Dekalogfassung in ihrem Kontext zu analysieren und von daher Aufschluß über die Heimat des Dekalogs zu erhalten. Durch die Entscheidung für die zeitliche Priorität der Deuteronomiumfassung ist die Option übernommen worden, daß die deuteronomische Bewegung entweder den Dekalog als erste übernommen oder selbst hervorgebracht hat. Der nahe Kontext des Deuteronomiumdekalogs ist Kapitel 5. Bevor wir dieses Kapitel unter die Lupe nehmen, soll das Koordinatensystem angegeben werden, das für die weiteren Beobachtungen gilt.

Das Urdeuteronomium ist mehr ein Postulat als ein mit exegetischem Konsens bestimmter Text. Einigkeit aber besteht darüber, daß der Kern des Gesetzes in den Kapiteln 12-26 das äl teste Material enthält. Prüft man die sogenannten vordeuteronomischen Texte, d.h. die von der deuteronomischen Sammlung aufgenommenen und verarbeiteten Rechtsvorlagen, so fällt zuerst ihr gesamtisraelitischer Aspekt auf. Der Bezug auf die Größe "Israel" ist sowohl in den Rechtskasus von 22,13-21 (VV.19.21) und 25,5-10 (VV.6.7.10) wie in den ursprünglichen Prohibitiven von 18,1a und 23,18 vorhanden. Er steckt in den Schlußwendungen des "paränetischen Gesetzes" 1 von 13,7-12 wie des Falls von 21,18-21. Die Angaben von 17,4.20 können ebenfalls sehr alt sein. Schließlich belegt die älteste Gruppe von Biartaformeln "Du sollst das Böse

1 Zu Terminus und Sache vgl. ROSE, Ausschließlichkeitsanspruch (Exkurs 1), 21-33. 
aus Israel wegschaffen" $(17,12 ; 19,13 ; 22,22)$ diesen Aspekt. Neben den expliziten Erwähnungen rangieren die Rechtsmaterialien, die überregionale, nationale Belange behandeln wie die Zentralisationsgesetze, das Amterrecht und die Kriegsgesetze 2 .

Während das Bundesbuch die unpersönliche Kasuistik und die anredenden, gebietenden Rechtssätze noch in sich geschlossen nebeneinander stellt, werden beide auch in den vordeuteronomischen Rechtsmaterialien ineinander verschränkt. Weil die Kasuistik von Natur aus die Anrede abweist, kann der Vorgang der Verschmelzung am besten an der Kasuistik der zivilrechtlichen Bestimmungen von Dtn 19-25 studiert werden. Die Anrede hängt sich einfach an (z.B. 22,22) oder sie übernimmt die Apodosis (z.B. 22,23f) oder sie durchdringt das ganze Gesetz wie im Fall der "paränetischen Gesetze" 13:2-6.712.14-16; 17:2-7. Damit wird die Redesituation - ein Sprecher wendet sich an ein "Du", sei es Individuum, sei es Kollektiv - zu dem Bindemittel schlechthin, das die unterschiedlichen Rechtsmaterialien zusammenhält. Im Unterschied zum Bundesbuch, zum Privilegrecht von Ex 34 und zu den priesterlichen Gesetzen fällt nun das Hauptcharakteristikum der Redesituation der vordeuteronomischen Materialien auf: Der Gesetzessprecher ist ein Mensch und nicht Jahwe! Die vordeuteronomischen Gesetzesmaterialien wie überhaupt das gesamte Gesetz Kap. 12-26 durchbrechen keinmal diese Stilform ${ }^{3}$. Der Unterschied kommt nicht von ungefähr. Es ist zu vermuten, daß sich darin ein besonderes Selbstverständnis der Gesetzessammlung äußert. Sie versteht sich von Anfang an nicht als weitere, neue Jahweanordnung neben anderen, sondern als abgeleitete Gesetzesverkündigung, die vorhandene Jahweanordnungen auslegt. Es liegt daher nahe, in dem anonymen Gesetzessprecher mit gesamtisraelitischem Publikum von vornherein Mose zu sehen. D.h. die literarische Fiktion der Moserede ist dem vordeuteronomischen Gesetzesmaterial nicht übergestülpt worden, so als ob sie eine bestimmte Praxis der Gesetzesverkündigung durch Priester, Leviten oder Propheten überformt und umdeutet, sondern ist von Anfang an dem vordeuteronomischen Material inhärent. Besser ausgedrückt: Das vordeuteronomische Material ist "ab ovo" im Namen dieser Fiktion gesammelt, bearbeitet und miteinander verbunden worden.

2 Vgl. die Gegenüberstellung Bundesbuch - Deuteronomium bei VON RAD, Gottesvolk, 19-27.

3 VON RAD, Deuteronomium, 15 A 2 nennt die Ausnahmen (Dtn 7,4; 11,13-15; $17,3 ; 28,20 ; 29,4 \mathrm{f})$. LOHFINK, Hauptgebot, $61 \mathrm{f}$, bes. A 7 sieht darin einen Hinweis auf die kultische Situation des Gesetzessprechers, in der Gott, Kultstifter (Mose) und Kultdiener in eins treten. Es empfiehlt sich, die Ausnahmen individuell zu erklären. Die einzige Ausnahme in- 
Die Mosefiktion sitzt ja tiefer im Herzen des Deuteronomium als es die expliziten Erwähnungen des Rahmens oder die verschiedenen Formeln, die auf eine bevorstehende Landgabe bzw. Landnahme blicken, erkennen lassen. So impliziert die Zentralisationsformel mit ihrer prospektiven Aussage ("der Ort, den Jahwe in Zukunft erwählen wird") die Mosefiktion 4 . Die Wachstumsstufen des Deuteronomium spiegeln also die Verdeutlichung und weitere Ausfaltung der Mosefiktion, die dem Material schon immer zugrunde gelegen hat, wider. Den Ursprungsort dieser Fiktion sehen wir in der jehowistischen Sinaitheophanie. Sie verknüpt zum ersten Male die Theophanie mit dem auf das (einzunehmende) Land ausgerichteten Privilegrecht von Ex 34. Sie weist Mose die entscheidende Rolle zu, Sprecher des Volkes und Vermittler von Bund und Gesetz zu sein. Demnach sind die deuteronomischen Sammler die Schüler und Propagandisten der jehowistischen Sinaikonzeption. Ihre Fiktion und die darin eingeschlossenen Gesetze wollen Konkretion der jehowistischen Konzeption sein. An der Wiege des Urdeuteronomium standen nicht nur Hosea und das Bundesbuch ${ }^{5}$ Pate, sondern gleichberechtigt neben ihnen der Jehowist. Damit ist die Entstehung und Entfaltung des deuteronomischen Gesetzes auf das 7. Jahrhundert anzusetzen - die für die deuteronomische Bewegung bevorzugt angenommene Epoche. Diese Sicht konvergiert mit einem neueren Vorschlag, der die literarische Arbeit der Verfasser des Deuteronomium stärker würdigt und sie als "Schreiber" am Königshof zu Jerusalem identifiziert ${ }^{6}$.

nerhalb des Gesetzeskorpus 17,3b entpuppt sich als redaktioneller Einschub, der mit seinem Rückverweis auf Dtn 4,19 zielt,wo Mose den Gestirndienst verbietet; also bestätigt die angebliche Ausnahme die Regel; vgl. SKWERES, Rückverweise, $72 \mathrm{f}$.

4 Dazu ROSE, AusschlieBlichkeitsanspruch, 81f. Die Belege aus dem Gesetzeskorpus Dtn $12,14.18 ; 15,20 ; 16,11 ; 17,8 ; 18,6 \mathrm{~b}$ gehören spätestens der deuteronomischen Sammlung an bzw. dem Deuteronomiker im Unterschied zu deuteronomistischen Redaktoren.

5 GemäB den Ausführungen im vorhergehenden Kapitel sind beim Bundesbuch zwei Phasen seiner Existenz zu unterscheiden. Die ältere Phase einer isolierten Existenz als Gesetzbuch, deren hohes Alter durch rechtsimmanenten Vergleich gesichert ist, und die spätere Phase der Integration und Bearbeitung innerhalb der Sinaitheophanie. Die Zäsur zwischen beiden Phasen wird durch eine deuteronomistische Redaktion markiert, die das Bundesbuch in die jehowistische Sinaitheophanie eingeschoben hat.

6 Vgl. WEINFELD, Deuteronomy, 158-178; zustimmend LOHFINK, Deuteronomy, 229-232. Er rechnet darin mit der Möglichkeit (230), daß der "kultische Dekalog" von Ex 34 die früheste Form des deuteronomischen Gesetzes darstellt. Ebenso DERS., Gott, 114. Zuletzt SKWERES, Rückverweise, 217-222. 


\subsection{Die Abgrenzung von Kap. 5}

Nach hinten ist der Zusammenhang von Dtn 5 durch den Neueinsatz von 6,4 deutlich abgegrenzt. Mit einer für Deuteronomiumfragen seltenen Kontinuität und Breite der Zustimmung gilt 6,4ff als der Beginn der ältesten Einleitungsrede zum Gesetzeskorpus 7 . Wenn 6,4 einmal Einleitung zum Gesetzeskorpus war, dann ist es aus dieser Position verdrängt worden, indem Dtn 5 davorgeschaltet wurde und weitere Texte wiederum vor Dtn 5 davorgesetzt wurden. Die Einheit Dtn $6,4-9^{*}$ gibt kein Echo auf eine vorausgehende Dekalogverkündigung vor allem dann, wenn "diese Worte" in V.6 sich auf VV.4b.5 beziehen und der anschließende präsentische Promulgationssatz sekundär eingeschoben wurde, vielleicht um aus dem Rückbezug auf VV.4b.5 nun einen Vorverweis auf die gesamte Gesetzesverkündigung zu machen ${ }^{8}$. Es ist allerdings schwer vorstellbar, daß eine alte Ausgabe des Gesetzeskorpus mit 6,4 eingesetzt hat, ohne daß durch eine Redeeinleitung oder Oberschrift der anonyme - im Grunde natuirlich bekannte - Sprecher expressis verbis genannt worden ist. Die Analogie zu anderen alttestamentlichen Buchanfängen fordert das Gleiche ${ }^{9}$. Eine solche Einleitung kann in 5,1 oder in 1,1 vermutet werden. Das führt zur Frage der Abgrenzung nach vorne. Hierzu hat Mittmann in seiner Hauptthese vertreten, daß die Horeberzählung in Dtn 5 den Schlußteil einer von 1,1 bis 5,31 bruchlos durchlaufenden Grundschicht bildet. Man könne nicht mehr - im Gefolge Noths - vom "Zusammenwachsen zweier heterogener Erzählungsblöcke" reden. Für Mittmann übernimmt der"Primärbestand von Dtn 1-5" die Funktion eines Prologs zum Gesetzeskorpus, während die Bezüge von Dtn 1-3(4) zum dtr Geschichtswerk erst auf der Ebene seiner zweiten pluralischen Ergänzungsschicht $\left(\mathrm{P}^{2}\right)$ in den Grundbestand eingetragen werden ${ }^{10}$. Im Rahmen unserer Untersuchung läuft das auf die Alternative hinaus:

7 Die obligaten Verweise auf die Meinung ALTs und NOTHs können wir uns hier sparen. Der Konsens soll nur durch jüngere Autoren belegt werden: PERLITT, Bundestheologie, 80; ROSE, AusschlieBlichkeitsanspruch, 140; MITTMANN, Deuteronomium, 6; BRAULIK, Testament des Mose, 36; LoHFINK, Gott, 108 A 30; DERS., Dekaloganfang, 105 A 21; LOPEZ, Deutéronome, $162 \mathrm{f}$.

8 Zur Literarkritik von 6,4-9* nun LOPEZ, Deutéronome, 164-167. Daß der Endtext von 6,6 sich nicht auf den Dekalog beziehen kann, den Jahwe und nicht Mose promulgierte, hat BRAULIK, Ausdrücke für "Gesetz", 49 nachgewiesen. Der Einschub steht wohl im Zusammenhang mit der Paraphrase zu 6,6-9 in $11,18-21$.

9 Vgl. NEUMANN, Hört, 91f; NIELSEN, Jahwe, 293 A 20.

10 MITTMANN, Deuteronomium, 164-169.177f. 
Ist Dtn 5 als Schluß des Prologs von Dtn 1,1 her zu lesen oder ist es eine Größe für sich, die mit Blick auf Dtn $6 \mathrm{ff}$ dem Gesetzeskorpus und seiner Einleitung vorgeschaltet wurde? Ich entscheide mich gegen Mittmann für die zweite Möglichkeit. Mittmanns Basisbeobachtungen zu den Parallelen in Wortwahl und Formulierung bei den Ecktexten seiner Grundschicht, Dtn 1 und 5, sind zu punktuell und vermögen die ihnen aufgebürdete Beweislast nicht zu tragen ${ }^{11}$. Mittmann kann nicht erklären, warum der Erzähler seiner Grundschicht im zweiten Teil zeitlich hinter den Anfang des ersten Teils zurückgreift. Er übersieht den thematischen und stilistischen Konnex der Horeberzählung mit der einige Kapitel weiter nachfolgenden Erzählung von den Bundestafeln, die in 9,7-10,11 eingeschoben wurde. Der Ort dieser Erzählung innerhalb der Einleitungsrede 5-11 orientiert Kap. 5 auf die nachfolgenden Kapitel hin. Die Parallelisierung von Kundschafter- und Horeberzählung verkennt beide. Die erste erzählt ohne Rekurs auf Gesetz und Bund. Die zweite erzählt vom Bund, um Gesetze mitzuteilen. Die weitere Auslegungstradition im Deuteronomium selbst votiert gegen Mittmann. Sowohl die Oberschriften $4,44 \mathrm{ff}$ wie die Paränese von 4,1-40 verstehen Dtn 5 als Text, der von Kap. 1-3 unabhängig ist ${ }^{12}$.

Das Uberschriftenkonglomerat 4,44-49 kann hier pauschal behandelt werden, weil es ursprünglich mit Kap. 5 wenig gemein hat. Die entscheidende Differenz liegt in der Bezeichnung Israels 13. 4,44-46 nennen den Adressaten "Söhne Israels", eine relativ späte Bezeichnung nach Ausweis der Parallelen ${ }^{14}$. Dagegen

11 MITTMANN, Deuteronomium, $165 \mathrm{f}$ nennt vier Parallelen: 1. Das Volk tritt mit seinem Anliegen an Mose heran $(1,22 / / 5,23 b)$ - er übersieht die Analogie auch $\mathrm{zu} \mathrm{4,11;} \mathrm{diese} \mathrm{Stelle} \mathrm{weist} \mathrm{er} \mathrm{seiner} \mathrm{ersten} \mathrm{Ergänzungsschicht}$ zu. 2.Jahwe hört die Äußerungen des Volkes $(1,34 / / 5,28)$ - er diskutiert nicht die Formulierungsparallelen in 4,12, vgl. ferner 4,33 und 26,7 . 3. Jahwe befindet die Initiative des Volkes für gut $(5,28)$ wie zuvor Mo$\overline{\mathrm{se}}(1,23)$ - die Wendung von 1,23 ( $1, \mathrm{~V} /$ Grundstamm) hat ihre echten $\mathrm{Pa}-$ rallelen z.B. in Jos $22,30.33$ und 1 Kön 3,10; Dtn 5,28 gebraucht dasselbe Verb im H-Stamm mit anders konstruierter Wendung;die wahre Parallele steht in Dtn 18,17. 4. Die Erwähnung der Zelte $(1,27 ; 5,30)$ - Zelte (Israels) werden im Dtn noch an anderen orten erwähnt (z.B. 16,7; vgl. 11,6), ohne daß man auf spezifischen Sprachgebrauch einer Schicht schließen kann. Solche Wortwahl muß nicht nur Zufall sein; sie kann aus verschiedensten Gründen kopiert werden. Die Zugehörigkeit zu einer Schicht läßt sich damit nicht beweisen, zumal wenn ein Teil der Parallelen nicht stimmt.

12 Das unterstreicht, BRAULIK, Literarkritik, $357 \mathrm{f}$ in seiner Auseinandersetzung mit MITTMANNs Analyse zu 4,1-4o.

13 Das hat MITTMANN, Deuteronomium, $130 \mathrm{klar}$ herausgestellt.

14 Die Parallelen: 1,3 (Vers mit anerkannt "priesterschriftlichem EinfluB"); 3,18; 10,6 (später Zusatz wiederum mit priesterschriftlichem Sprachgebrauch); 23,18 (wörtliche Bedeutung: Söhne - Töchter; gehört also nicht 
spricht die Umgebung $(4,1 ; 5,1 ; 6,3.4)$ - typisch für das Dtn - nur von (ganz) Israel. Konsens besteht über den Nachtragscharakter von 4,47-49. Diskutiert werden die zeitliche Priorität der beiden Oberschriften 4,44 und 4,45 und die Zugehörigkeit von 4,46 zu einer von beiden ${ }^{15}$. Das Problem kann vorerst auf sich beruhen. 5,1 ist als legitimer Einsatz einer Analyse gerechtfertigt. Mit Rücksicht auf die Besonderheiten der Deuteronomiumexegese - zum Handwerkszeug gehören umfangreiche Wortstatistiken und Formel tabellen - werden die verschiedenen Schritte der Kohärenzprüfung (thematische, syntaktisch-stilistische Kohärenz) für jeden Vers in einen Arbeitsgang zusammengezogen. Zur Debatte steht zuerst der Dekalograhmen 5,1-5.22-31.

\subsection{Der DekaZograhmen 5,1-5}

Die zweiteilige Redeeinleitung von 5,1 eröffnet die Erzählung. Sie entspricht einem Typ von Einleitung, der auch in den älteren Pentateuchquellen auftaucht, genau so wie er seine Parallelen im dtn/dtr Schrifttum hat. Nuancen zwischen Zuruf und Herbeizitieren durch den Sprecher werden mit den Präpositionen bei קרא ausgedrückt ${ }^{16}$. Der Adressat "ganz Israel" im pluralischen Sinne ist vordeuteronomisch in alten Gesetzen belegt ${ }^{17}$. Die Redeeinleitung zählt also zum Grundtext. Als Einleitung zum Urdeuteronomium mit Beginn in 6,4 könnte sie oder ihre Konkurrentin in 1,1 in Frage kommen, allerdings stört dann

dazu!); 24,7 (Glosse); 28,69 (Über-Unterschrift zum Moab-Bund); 31,19. 22f; vgl. 32,8 (Rahmen des Moseliedes); 32,49.51f; 33,1 (Hinführung und Einleitung zum Mosesegen); 34,8f (Priestergrundschrift).

15 Vgl. MITTMANN, Deuteronomium, 128-132; BRAULIK, Testament des Mose, 33. Die Hypothese von einem älteren (Dtn 4,$45 ; 6,1 ; 12,1$ ) und einem jüngeren Uberschriftensystem (Dtn 1,$1 ; 4,44 ; 28,69 ; 33,1$ ) - von LOHFINK wiederentdeckt in: BundesschluB, 32-56 und von SEITZ, Deuteronomium, 2344 ausgebaut - ist ein erster Schritt zur Differenzierung, kann aber nicht die erheblichen Unterschiede in Aufbau, Angaben zu Zeit und ort sowie in der Formulierung erklären.

Die Trias der Gesetzestermini von 4,45 ist mit der von 6,20 identisch $(6,17$ wandelt $a b)$ und verbindet diese Uberschriften mit der Einheit $6,20-$ 25*. Dann aber spricht 4,45 von den Israeliten im Plural und meint mit dem angeredeten "Du" in 6,20 jeden einzelnen israelitischen Vater. Das trennt diesen Abschnitt von 6,4-9*, wo das Kollektiv Israel mit seinen Söhnen angeredet wird. Diese Beobachtung will nicht den Bezug von $6,20-$ 25* nach 6,4-9* leugnen, widerrät aber doch einer frühen Verbindung beider Einheiten durch den deuteronomischen Redaktor, wie sie LOPEZ vorschlägt, vgl. Analyse, 504-508; Deutéronome, 174-176.

16 Vgl. Ex 3,4b (E); 12,21 (Je); Dtn 29,1; Jos 23,2 etc.

17 Der erste Beleg Dtn 13,12 zählt zum Grundtext von Kap. 13 - so zuletzt ROSE, AusschlieBlichkeitsanspruch, 18ff im Anschluß an SEITZ, Deuteronomium, 134. Ebenso kann 21,21b zum alten Kasus 21,18-21a a dazugehören, 
in ihrem Falle das pluralische Verständnis von Israel im Unterschied zum nachfolgenden singularischen Verständnis in $6,4 \mathrm{ff}$.

Der Höraufruf von 5,1: Die Höraufrufe im Buch Dtn sind von Neumann ${ }^{18}$ gründlich untersucht worden. Normalerweise markieren sie den Beginn eines neuen Redeabschnitts $(6,4 ; 9,1 ; 20,3 ; 27,9)$. Die Höraufrufe 4,1 und 5,1 scheren aus der Reihe aus, denn sie erweitern den Imperativ + Vokativ jeweils um ein Präpositionalobjekt bzw. um ein direktes objekt. Insofern als objekt ein oder mehrere Gesetzestermini fungieren, verschiebt sich die Bedeutung von שמע vom Hören zum Gehorchen ${ }^{19}$. Wenn שמע die Präposition mit einem Terminus für Gesetz regiert, so zeigt sich darin ein später Sprachgebrauch innerhalb des Dtn ${ }^{20}$. Davon ist שמע את + Gesetzestermini zu unterscheiden. Auch bei dieser Wendung ist die Konnotation "gehorchen" zu vermuten, wie der jeweilige Kontext der Parallelen belegt; nur könnte dieser Sprachgebrauch innerhalb des Dtn älter als der mit Präpositionalobjekt sein 21 .

Die eigenwillige Formulierung des Promulgationssatzes hat schon Lohfink hervorgehoben 22 . Das "Reden in die Ohren" vertritt hier das gewohnte Befehlen. Auf solche Weise wird Mose gegenüber Israel nur noch in 31,11 und im Rahmen des Moseliedes tätig $(31,28.30 ; 32,44 ; \mathrm{vgl}$. noch 2 Kön 23,2 und Jer 28,7). Der Befehl an Israel, die Gesetze zu lernen, steht hier absolut ohne die häufige hypotaktische Verklammerung mit dem Gott/Jahwe-Fürchten; darin kommt 5,1 nur noch $31,12 b$ am nächsten ${ }^{23}$. Der Rest des Verses (שמר לעשת) bietet die für das Dtn typische Verklammerung von שמר und 24.

während die Biartaformel eingeschoben scheint; vgl. HORST, Privilegrecht, 54f; MERENDINO, Gesetz, 246 entscheidet sich nicht.

18 DERS., Hört, 52-98. Seine syntaktischen und textlinguistischen Beobachtungen verdienen Gefolgschaft. Seine redaktionskritischen Zuweisungen folgen MINETTE DE TILLESSE, Sections, und sind darin zu grob.

19 Dazu NEUMANN, Hört, 63.89.98; ebenso LOPEZ, Analyse littéraire, 9.

20 Vgl. 4,$1 ; 11,13.27 f ; 18,19 ; 28,13$. Vgl. LOHFINK, Hauptgebot, $65 f$. und SEITZ, Deuteronomium, $266 \mathrm{f}$ A 51 .

21 Neben 5,1 noch $7,12 \mathrm{a}$ und 12,28 .

22 DERS., Hauptgebot, 150.

23 Die geläufigere Konstruktion verbindet למד Grundstamm (+ 7) mit dem Infinitivus constr. von ${ }^{\prime}$ in 4,$10 ; 14,23 ; 17,19(18,9) ; 31,13$.

24 Die Stellen bei LOHFINK, Hauptgebot, 68-70 und Tabelle III. Umfassend hat IANGLAMET, Israel, 328 A 44 die Parallelen aufgeführt. 
Wegen der Bedeutung des Wortpaares nקים / משפטים sollen hier einige Bemerkungen diesem Duo gewidmet werden ${ }^{25}$ : Im Unterschied zu Lohfink und Braulik geht man besser davon aus, daß die Syndese bei Reihungen typisch ist, wohingegen die Asyndese auffällt und jeweils erklärt werden muß. Textkritisch ist also beim MT zu bleiben. Lohfink betont das Prinzip der "variatio delectat" bei den Reihungen - Perlitt spiegelt die Not des Exegeten wider und spricht von "bestürzender Vielfalt" oder von "fast unkontrollierbarer Vielfalt" 25a. Es ist mit einem hohen Ausma 3 an verschleifendem Sprachgebrauch zu rechnen, vor allem dann, wenn die Reihen additiv erweitert werden. Aber sowohl die barocke Reihe wie die Variation durch Umstellung und andere synonyme Begriffe können einen schichtspezifischen Stil verraten; oder es ergeben sich Reihungen, wenn der Sprachgebrauch angrenzender Textbereiche sich überlappt, wie es Lohfink anhand der Reihungen von 26,16-19 demonstriert hat. 26

Der Literarkritiker wird immer versuchen, die beliebige Variation in der Kombination der Gesetzestermini zurückzudrängen und eine Schneise in das Dickicht zu schlagen, um einen Zugang zur je individuellen Stelle zu finden. Das Duo dient einmal als "Struktursignal" und umklammert die Paränese (5,1$11,32)$ wie das Gesetz $(12,1-26,16)$. Daneben taucht es in Triaden auf $(4,45$; $5,31 ; 6,1.20 ; 7,11 ; 26,17)$. Schließlich konzentriert sich sein Auftreten auf Kap. $4(4,1.5 .8 .14)$.

Gruppiert man im Blick auf die erläuternden Relativsätze, die sich an das Duo anhängen, oder im Blick auf die Hauptsätze, die das Duo einbinden, dann ergibt sich folgendes Bild: Mose befiehlt $(7,11)$ - Mose lehrt $(4,1.5$. $14 ; 5,31 ; 6,1)$ - Mose legt vor, wie er die Tora vorlegt $(4,8 ; 11,32)$ - Mose spricht $(4,45 ; 5,1)$ - Jahwe befiehlt $(6,20 ; 26,16)$ - ohne Hinweis auf irgendeine Gesetzesverkündigung 12,1. Die Zweiteilung in der Zuordnung ist offensichtlich: hier Jahwe - dort Mose mit dem Löwenanteil der Vorkommen. Die Stellen mit Jahwebezug erwähnen keine mosaische Vermittlung in welcher Form auch immer, ob als Sprecher, Lehrer oder Gesetzgeber. Die Stelle 6,20 ist durch ihren Bezug nach 4,45 an die Vorstellung von Mose als Sprecher gebunden; die Eltern sind für $6,20-25^{*}$ in die lehrende Funktion eingerückt. Dann

25 Grundlegend LOHFINK, Hauptgebot, 54-58 und BRAULIK, Ausdrücke für "Gesetz", 36-66; schließlich die umfassende Reihentabelle bei LIEDKE, Rechtssätze, 12-18.

25a LOHFINK, Hauptgebot, 54; PERLITT, Bundestheologie, 39.103.

26 DERS., Bundesformel, 542. 
verbleiben 12,1 und 26,16 , wo das Schweigen über Mose erklärt werden muß. 12,1 besitzt seine eigenen Schwierigkeiten und gibt für unseren Zusammenhang vorerst weniger her 27 . Aber 26,16 gibt Aufschluß ${ }^{28}$. Der Vers zeigt einige Besonderheiten, die aufgearbeitet werden müssen. Seiner syntaktischen Form nach ist er kein partizipialer Promulgationssatz, kommt inm aber sehr nahe. Nur an dieser Stelle verbindet sich das für Mose reservierte Partizip von צוה/D-Stamm mit dem Subjekt Jahwe ${ }^{29}$.

Gegenüber allen anderen Vorkommen mit dem Duo sind 26,16.17 und 7,11 die einzigen Passagen im singularischen Numerus. 26,17 und 7,11 zeigen durch ihre Reihung und ihren nahen Kontext den späteren Status an, sind also mit 26,16 nicht auf eine Stufe zu stellen. Das Demonstrativpronomen, das häufiger prädikativ gebraucht wird, tritt hier nicht gerade geschickt als Attribut zwischen die parallelen Termini ${ }^{30}$.Das kann eine Präponderanz der חקים Vorschriften des nahen Kontextes auf $(16,12 ; 17,19)$. Der Plural משפטים tritt im Gesetzeskorpus nicht auf, nur der Singular in der Bedeutung "Urtei1, Urteilsspruch, Rechtsanspruch". Das läßt zumindest für 26,16 die Vermutung Liedkes wahrscheinlich erscheinen, daß sich hier noch ein wissen um das Zusammenfließen zweier Rechtstraditionen zeigt, der von einer Autorität gesetzten משפטים nit des kasuistischen Rechts 31 . Entscheidend ist, daß 26,16 mit seinen Besonderheiten der jehowistischen Vorlage in Ex 34,11a nahekommt. Demnach repräsentiert 26,16 die älteste Stelle den archimedischen Punkt -, an der die deuteronomische Konzeption konkreter und reflex aufscheint: Jahwe befiehlt Satzungen und Rechtsnormen, Mose aber muß davon berichten. Das Dtn kreist in immer neuen Anläufen um dieses Problem des Zusammenspiels der beiden Größen und versucht, es auf den Begriff

27 Eine genaue Analyse bei MERENDINO, Gesetz 13-18. MERENDINO selbst hält sein Ergebnis aus der Analyse (dreistufiges Wachstum: $1 a \alpha+b+1 a ß$ ) in der Synthese nicht durch und rechnet mit zwei Stufen: deuteronomischer Redaktor (1aa+b), danach dtr Redaktor (1aß); vgl. a.a.0., 45.57 .

28 Die jüngste Analyse bei ROSE, Ausschließlichkeitsanspruch, 1o1f ver bleibt an der Oberfläche.

29 Vgl. PERLITT, Bundestheologie, 103 A 1 und BRAULIK, Ausarücke für "Gesetz", 42 A 6 .

3o Vgl. BRAULIK, Ausdrücke für "Gesetz", 55 A 3 und DE VRIES, Development, 303. Im Unterschied zu letzterem halte ich 26,16 für älter als 12,1 .

31 Vgl. LIEDKE, Rechtssätze, 185. 
zu bringen. Von 26,16 ist das Duo nach vorne über die Vermittlung von 12,1 übernommen worden und avancierte zur Vorzugsbezeichnung für das mosaische Gesetz, das Deuteronomium 32.

Der Höraufruf stellt sich als Gehorsamsaufruf für das mosaische Gesetz heraus. Seine Verbindungen laufen nach $7,12 \mathrm{a} ; 12,1.28$ und $31.11 .12 \mathrm{~b}$. Im Kontext der Horeberzählung kommt er zu früh, denn die mosaische Gesetzesverkündigung soll ja erst durch die Erzählung begründet werden; außerdem trennt ihn einiges vom Sprachgebrauch in 5,31. Der Gehorsamsaufruf von 5,1 und die Horeberzählung gehören ursprünglich nicht zusammen.

Mit $\underline{5,2}$ (x-qatal) beginnt die Horeberzählung nach der Redeeinleitung von 5,1 . Der Sachverhalt wird verfehlt, wenn der Vers des Wir-Stils wegen einer Wir-Redaktion zugeteilt wird ${ }^{33}$. Mose berichtet vom Bundesschluß am Horeb. V.2 verwendet die juristische Formulierung כרת / ברית / und ubernimmt damit auch den Sprachgebrauch Hoseas (Hos 2,20;12,2). Im Dtn wird dieser Sprachgebrauch zum Signum der Horeb-berît ${ }^{34}$. Dagegen kann die Wendung כרת auch die Moab-berît einschließen ${ }^{35}$. Ebenso wie bei Hosea wird nur in 5.2 und 9,9 (Grundtext!) von der ברית absolut ohne differenzierende Beigaben durch Suffixe, Konstruktverbindungen ("Bund Jahwes") oder Demonstrativpronomina geredet. Indem sich Mose in das "wir" einschließt, steht er auf der Seite der Partner Jahwes, noch nicht als Bundesmittler außerhalb des Volkes. Wir sahen bereits darin einen Hinweis auf die Nähe von 5,2 zum Bundesschluß des Jehowisten in Ex 34,27. Was die Ortsbezeichnung bzw. den Programmnamen Horeb angeht, kann 5,2 die älteste Stelle sein und das Urheberrecht beanspruchen 36 .

32 Die Ausdeutung des Duos auf Paränese und Gesetz insinuiert einen bestimmten Textumfang (Paränese Kap. 5-11, Gesetz Kap. 12-26). Sie empfiehlt sich weniger, weil die Paränese Gesetz und das Gesetz Paränese enthält. Für das Duo steht im Zentrum das Verhältnis der legitimierenden Autoritäten Jahwe und Mose.

33 So LOPEZ, Analyse littéraire, 9f; vgl. ebd., $34 f$ und DERS., Deutéronome, 164. Gegen eine solche einheitliche Redaktion spricht schon allein der häufige Sprecherwechsel in der Wir-Rede, d.h. die Wir-Rede ist an vielen Stellen zu finden, wo sie der Kontext verlangt; so auch in 5,2 ; in 6,4 z.B. den Wir-Anteil auszutrennen, zerstört den Gehalt der Aussage. Vgl. dazu LOHFINK, Gott, 109 A 33.

34 Vgl. Dtn 4,23;9,9; 29,11.24 und ebenso Ex 24,8 (dtr Redaktion) sowie 1 Kön $8,9.21$.

35 So in 5,$3 ; 28,69 ; 29,13 ; 31,16 . \mathrm{Vgl}$. den Jehowisten in Gen 15,18 und Ex 34,27 und schlieBlich 2 Kön 17,35; Jer 34,8; Ez 17,13. Die Wendung כרת/ברית/ל von $34,12.15$ und Dtn 7,2 kann hier übergangen werden.

Zu beidem PERLITT, Sinai, 3o2-322. 
Zu $\underline{5,3}$ hat Mittmann das Wichtigste ausgeführt ${ }^{37}$. Der Vers ist deutlich sekundär (Verschiebung des Sprachgebrauchs und der Vorstellungen). Er knüpft thematische und syntaktisch-stilistische Beziehungen nach Dtn 4,3f 38 und 29,13f. Den Redaktor plagt das Problem der dauerhaften Guiltigkeit des Bundes. Wie der Moabbund für die gegenwärtige und alle späteren Generationen gelten sol1, so hat auch der Horebbund seine dauernde Gültigkeit nicht verloren, weil die Väter der von Mose angesprochenen Generation durch ihren Abfall zum Baal-Peor und dem daraufhin erfolgten Tod aus dem Bund ausgeschieden sind.

Zu Recht hat Mittmann (ebd.) die Zugehörigkeit von 5,4 zum Grundtext der Horeberzählung verteidigt. Mose setzt sich vom "Wir" in 5.2 ab und geht in die Distanz des "Ihr" von 5,4. Der Vers präludiert die spätere Unterscheidung des Kapitels. Das Volk erfährt nur den Dekalog unmittelbar, die weitere Weisung über den Vermittler Mose dagegen behält seine Jahwe-unmittelbare Position. Abgesehen von Kap. 5 kommt darin das Mittlerproblem des Dtn zum Ausdruck, das sich in den verschiedensten Schichten findet. Mose kann sich in ein- und demselben Kontext mit dem Volk zusammenschließen und zugleich sich von inm trennen.

So solidarisiert er sich mit dem Volk im Bekenntnis zum einen Jahwe $(6,4)$ und distanziert sich anschließend vom Volk im Gebot der Gottesliebe $(6,5)$ - keiner hat bisher hier literarkritisch zu trennen gewagt. In 5,2 gehört er in den Bundesschluß, in 9,9 (Grundtext, der zur selben Schicht wie 5.4 zählt) steht er außerhalb. In 4,5 spricht er als Gesetzeslehrer von "meinem Gott", anschließend kehrt er im "Wir" des Bekenntnisses und des Gebetes zum Volk zurück $(4,7)^{39}$.

Der unmittelbare Jahwekontakt des Volkes wird zweifach beschrieben. Die Bestimmung פנים בפנים unterscheidet sich von der geläufigeren פנים אל פנים, meint aber das gleiche 40 .

37 DERS., Deuteronomium, 132f, bes. A 7.

38 Mit BRAULIK, Literarkritik, 376 rechne ich V.3b zu vV.3f dazu; der singularische Numerus von V.3b kann durch die distributive Redeweise veranlaßt sein.

39 Vgl. BRAULIK, Weisheit, $182 \mathrm{f}$.

40 Die ersteist Hapaxlegomenon, die zweite: Gen 32,31 (Je) - WEIMAR, Berufung, 255-259 hat Gen 32,23-33 zuletzt analysiert (Lit.!) und schreibt sie dem Jehowisten zu. Die Ätiologien V.29b und v.31b sowie V.33 weist er dem Pentateuchredaktor zu. Das mag für v.33 angehen, aber nicht für die Namensätiologien $v .29 \mathrm{~b}$ und $v .31 \mathrm{~b}$, die thematisch und semantisch anders mit dem Grundtext verbunden sind. In V.29b ist zwar das "mit den 
Während an den älteren Stellen wie Gen 32,31 und Ri 6,22 Einzelpersonen mit Jahwe in unmittelbaren Sichtkontakt treten, wird hier der unmittelbare Sprechkontakt hervorgehoben. Dem dient auch die seltenere Verbindung von דבר /D-Stamm mit der Präposition עם 41 . Möglich ist, daß die Betheltradition sowohl nach Hos 12,5 wie nach Gen 32,31 (Je) auf 5,4 Einfluß ausgeübt haben. Die Ortsangabe "auf dem Berg, mitten aus dem Feuer" nimmt Ex 19,13b (E?) und Ex 19,18a (Je) auf, ordnet die Vorgaben aber dem Sprechkontakt unter.

Thematisch steht $\underline{5,5}$ dem Vorgängervers diametral entgegen ${ }^{42}$. Als eine $\mathrm{Pa}-$ renthese (Partizipialsatz mit Zeitangabe) wird der Vers eingeschoben, um am Horeb die Mittlerfunktion des Mose zu verankern und damit zu begründen. Nun steht das Volk auf einmal unten am Berg und wagt nicht aufzusteigen, weil es sich vor dem Feuer fürchtet. Der Vers widerspricht Ex 19,13b: paßt aber fugenlos in die Situation wie sie Dtn 4,11 beschreibt. Die Verbindungen zwischen Dtn 4,10-15 und 5,5 werden verstärkt durch stilistische und semantische Parallelen. Sowohl in 4,14 wie in 5,5 wird die Zeitangabe nachgestellt; in 4,13 wie in 5,5 wird $T$ /H-Stamm verwendet, um die feierliche Verkündigung $z u$ unterstreichen. 43

Die Satzstellung betont die Hauptaussage des Verses: die Position des Mose. Steht nach 5,31 und 10,10 (Grundtext) Mose auf dem Berg bei Jahwe, so nimmt er hier eine Mittlerposition ein zwischen Jahwe und Volk. Wie im diplomatischen Protokoll gibt die räumliche Position die juristische Stellung an. Wie sie funktioniert, demonstrieren Ex 19,7 und 24,3: Mose pendelt zwischen Jahwe und Volk. Diese Parallele legt nahe, daß die betreffende dtr. Redaktion der Sinaiperikope mit der von Dtn $4,10-14^{*}$ und 5.5 in Verbindung steht.

Man geht den Versionen in die Falle, wenn man für 5,5 den MT aufgibt, Mose hier die"Worte Jahwes" verkünden läßt und auf diese Weise einen Widerspruch

Menschen" Einschub, der Rest des Halbverses wie auch V.31b sind bei Je zu belassen. - Weitere Stellen: Ri 6,22 (alte Erzählung); Dtn 34,10 $(d t r) ; \operatorname{Ex~33,11~(RP);~Ez~20,35;~vgl.~die~Wendung~"Aug'~in~Auge"~Num~14,~}$ 14 (dtr) und Jes 52,8. WESTERMANN, Genesis I/2, 624-635 rechnet mit einer jahwistischen Grundlage 32,23-26a.27.3o-31a*.32. VV.26b.33 gehören als späteste zusätze zusammen. VV.28f stehen P zeitlich nahe. V.31b soll eine ältere Ortsbenennung verdrängt haben. Eine Zuweisung dieses Einschubs nimmt WESTERMANN nicht vor.

41 Dtn 5,4;9,10; Gen 29,29; 31,24.29; Ex 19,9; 20,19; Num 11,17 und Hos 12,5 .

42 Vgl.VON RAD, Deuteronomium, 40; PERLITT, Bundestheologie, 81; MITTMANN, Deuteronomium, 132 A 1; SEITZ, Deuteronomium, 49. 
zu Dtn 4,13 und 5,22 konstruiert ${ }^{44}$. Der Redaktor hat gezielt den Singular "Wort Jahwes" gewählt. Auf ihn - wie wir noch sehen werden - gehen ja sowohl 4,13 wie 5,22 zurück. Darum kam für inn der Plural nicht in Frage, denn er hätte ja bedeutet, daß der Dekalog durch Mose vermittelt wurde eine Aussage, die für das ganze Dtn, die Deuteronomisten und sogar den Pentateuchredaktor ( $v g l$. Ex 20) unmöglich ist. Die Mittlerfunktion des Mose zeigt sich auch beim Dekalog - aber hier durch Weitergabe der Tafeln. Darum bezeichnet in 5,5 der prophetische terminus technicus דבר יהוה die gesamte mosaische Horebverkündigung. Dazu gehört an erster Stelle das Bundesbuch, das von diesem Redaktor in die Sinaitheophanie integriert wurde - es ist Jahwewort, vermittelt und aufgeschrieben durch Mose (Ex 24,3.4a a) - dazu gehört wohl auch das deuteronomische Gesetz. Für diesen Redaktor ist der Horeb Stiftungsort tragender Institutionen des Gottesvolkes. Wie das mosaische Mittleramt, so kann er auch die vierte Gewalt im Verfassungsentwurf, nämlich die Institution der Prophetie (Dtn 18,14-20), aus den Horebereignissen ableiten!

\subsection{Der DekaZograhmen 5, 22-31}

Der $\underline{V} .22$ versteht sich seiner Konstruktion nach (vorangestelltes Akkusativobjekt mit rückweisendem Demonstrativpronomen, vgl. 13,1) als Rahmen, der die Dekalogverkündigung abschließt. An seinem sekundären Charakter gibt es keinen Zweifel ${ }^{45}$. In 5,4 spricht Jahwe unmittelbar mit dem Volk (אבר/DStamm + (אל + דבר), obwohl es sich um dieselbe Dekalogmitteilung handelt. War vom Adressaten des Dekalogs bisher nur in Suffixen die Rede ("mit uns" 5,2; "mit euch" 5,4) und wird er später in 5.28 von Jahwe als "dieses Volk" bezeichnet, so qualifiziert ihn V.22 als "eure Versammlung". Erst am Ende der Horeberzählung wird Mose auf Bitten des Volkes und mit Zustimmung Jahwes zum Vermittler der weiteren Gesetze gemacht. In V.22 übernimmt Mose schon vorgreifend diese Rolle durch Obernahme der Tafeln. Da$z u$ ist er nur aufgrund von 5,5 in der Lage. Der Vers präsentiert den Dekalog

43 Vgl. zu den Beobachtungen PLÖGER, Deuteronomium, 222 und LOPEZ, Analyse littéraire, 11. Dtn 5,5 gebraucht על עit der Präposition ב (vgl. Dtn 1, 22; 29,22) im Unterschied zum Gebrauch mit adverbialem Akkusativ in:

Dtn $1,24.41 .43 ; 3,27 ; 9,9$ (Grundtext); 10,1.3; 30,12; 32,50.

44 So SEITZ, Deuteronomium, 49 und LOPEZ, Analyse littéraire, 11. MITTMANN, Deuteronomium, 161.174.183 versteckt sein Mißverständnis hinter falscher Zuweisung. PERLITT, Bundestheologie, 8of hält sich bedeckt. Deutlich gegen den MT BRAULIK, Ausdrücke für "Gesetz", 46. 
als beabsichtigte und von vornherein fertige Urkunde, die verkündet, aufgeschrieben und übergeben wird. Er verrät nichts von der späteren Erklärung und Differenzierung der mündlichen Rede in unmittelbare (Dekalog) und vermittelte Rede (mosaisches Gesetz). Der Vers trägt soviele neue Nuancen ein, daß sie systematisch behandelt werden müssen.

1. Der Redaktor stilisiert Israel zur Gemeindeversammlung ${ }^{46}$ :

Aus der kriegerischen Gemeinde Jahwes des vordtn Gemeindegesetzes Dtn 23,29 wird hier eine friedliche Gemeinde Israels, die alle einschließt, Männer, Frauen, Kinder und sogar den "גר" 47.

Stiftungstag und Stiftungsort dieser Gemeinde ist der Horeb mit der Obergabe von Dekalog und Deuteronomium (משפטים (מקים) an Mose. Das zeigt der Redaktor verbal an in 4,10 ( $\mathrm{vgl}$. 31,12a) oder mit suffigiertem Nomen in 5,22 (vgl. 31,20) oder mit dem erinnernden Kürzel יום הקהל von 9,10;10,4;18, 16. Regelmäßige Wiederholungen der Versammlung zeigt $31,12 a$ an.

2. Der Redaktor baut die Theophanie aus:

Die Theophanieelemente aus dem alten Tempelweihspruch 1 Kön 8,12 (Wolkendunkel) und der Bergtheophanie des Elohisten Ex 19,16 (Wolke) und Ex 20,21 (Wolkendunkel) werden aufgegriffen und mit den Theophanieelementen des Jehowisten verbunden wie Wolke, Feuer und Finsternis ${ }^{48}$. Dabei bilden "Wolke und Wolkendunkel" ein festes Paar ${ }^{49}$, das zur Trias mit wechselndem dritten Element erweitert werden kann ${ }^{50}$. In Reverenz gegenüber 5,4 hat unser Redaktor seine Trias von 4,11 auf 5,22.23a verteilt. Aus der Stimme Jahwes $(5,25.26)$ wird hier die "laute Stimme" $(5,22 a)$. D.h. der Redaktor steigert sowohl die akustischen wie visuellen Phänomene der Horebtheophanie und ist dabei auf eine Balance der Wahrnehmungsakte bedacht, wie vor allem sein Kurzbericht von der Horebtheophanie in $18,16 \mathrm{ff}$ zeigt.

46 Vg1. MÜLLER, Art. קהל, 615.

47 Vgl. die Betonung des 3 in Dtn 5,22; 31,20; Jos 8,35; 1 Kön 8,14.22. $55.65 ; 12,3$ und die Auflistungen in Dtn $31,12 \mathrm{a}$ und Jos 8,35.

48 Ex 13,21f (Wolken- und Feuersäule); 14,20 (Wolke und Finsternis); 19, $18 \mathrm{a}$ (Feuer).

49 (Dtn 5,22); Ez 34,12; Joel 2,2; Zef 1,15; Ps 97,2.

50 Dtn 4,$11 ; 5,22 f ;$ Ps $97,2 f ;$ vgl. 2 Sam 22,10-13. Komplexere Reihen: Joel 2,2 und Zef 1,15 . 
3. Der Redaktor grenzt den Dekalog randscharf $a b$ :

Einmal grenzt er den Dekalog ein durch sein יסף , mit dem er auf dem Wege zum Kanonprinzip ist ${ }^{51}$. Zum anderen wird der Dekalog wie eine Rechtsurkunde schriftlich niedergelegt, im wörtlichen Sinne petrifiziert. Wie im Alten Orient üblich, soll die schriftliche Niederlegung von Gesetzen (und Berichten) deren Unverletzlichkeit und ewige Gültigkeit garantieren 52 . Indem der Redaktor den Dekalog mit den Steintafeln verbindet ${ }^{53}$, bringt er inn in Analogie zum weltberühmten Vorbild der Gesetzesstele des Hammurabi, allerdings mit einem gravierenden Unterschied: Den Dekalog hat Jahwe selbst geschrieben.

Die Kongruenz von 5,22b mit 4,13b; 9,10; 10,1-5 1äßt keinen Zweifel an der durchgehenden Redaktionsschicht $z u$. Eine wichtige Frage meldet sich hier wieder verschärft zu Wort: Warum hat der Redaktor zur Abgrenzung der Dekalogoffenbarung das Medium gewechselt: von der Mündlichkeit zur Schriftlichkeit? Das liegt in der Natur der Gesetze und ihrer Gültigkeit - wie es die altorientalische Kultur fordert - und darin äußert sich der Einfluß des Jehowisten aus Ex 34,27 . Wichtig wird ein dritter Grund. Die deuteronomische Unterscheidung von mittelbarer und unmittelbarer Jahwerede reicht für das Verhältnis Dekalog - dtn Gesetz aus. Sie taugt nicht mehr, wenn weitere Gesetze oder "Kodizes" hinzugezogen werden, die ebenfalls Jahwerede präsentieren und bei übergreifender Konzeption zu Dekalog und Deuteronomium in ein Verhältnis gesetzt werden muissen.

Somit muß eine komplexe Systematik für die verschiedenen Gesetzesammlungen geschaffen werden. Die Schriftlichkeit erlaubt dabei eine weitere Differenzierung: Das Bundesbuch - Jahwerede, die Mose aufschreibt (Ex 24,4); das Privilegrecht Ex 34 - der nach dem Bundesbruch erneuerte Dekalog (Ex 34,28); der Dekalog - Jahwerede von Jahwe aufgeschrieben; das dtn Gesetz - Moserede von Mose aufgeschrieben (Dtn 31,9.24-26).

Der Vers 23a setzt neu ein ${ }^{54}$. Der definite Artikel bei קול, Die Angabe "aus der Finsternis" und die Parenthese "der Berg im Feuer brennend" (Dtn 4,11;

51 Er gebraucht Das Kanonprinzip setzt den H-Stamm desselben Verbs mit Präposition und menschlichem Subjekt ein, vgl. Dtn 4,2; 13,1; Koh 3,14 und Spr 30,6; Jer 26,2 .

52 Vgl. zum Kodex Hammurabi MÜHL, Untersuchungen, 9of.122f. Ferner SMITH, Statue of Idrimi, Zeile 92-98. Grundsätzlich wird der Fluch auf den herabgerufen, der das Denkmal/die Schrift verändert oder zerstört. Zu den Implikationen dieser Verknüpfung s.o.unter 2.7.6.5. 
$9,15 a ß+b) 55$ belegen denselben Redaktor von 5,22, der zusammen mit seiner Rahmung des Dekalogs $(5,5+5,22)$ auch den Neueinsatz gestaltet hat.

Mit V.23ba erreichen wir wieder den Grundtext. Daß eine Rede ohne Schluß durch den nächsten Narrativ beendet wird, ist geläufig ${ }^{56}$ und gehört hier zur Aussage des Kapitels. Jahwe hört auf zu reden, weil das Volk ihn unterbricht und über Mose, seinen Stellvertreter, interveniert. Die Glosse V.23bB ist wohl aus 29,9 hier eingedrungen bzw. eingeschoben worden 57 .

In V.24a beschreibt das Volk sein Theophanieerlebnis. Der Halbvers ist chiastisch aufgebaut 58 . Interessant ist die Erwähnung der"Herrlichkeit Jahwes": weil sie innerhalb des Dtn nicht mehr erwähnt wird. Kommt hier ein Echo an aus den alten Pentateuchquellen? Obergeht man die priesterlichen Erwähnungen der כבוד יהוה, dann verbleiben nur Ex 33,18.22 und Num 14,21f. Letztere Stelle ist als deuteronomistisch verdächtig ${ }^{59}$. Die Exodusstelle wird unterschiedlich eingestuft ${ }^{60}$. Möglich ist, daß die jehowistischen Anteile Ex 33 , 18.21a.22 den Grundtext in V.24a beeinflußt haben. Der hätte dann das Privilegrecht des Mose demokratisiert.

V.24b widerspricht dem Kontext, was wiederholt notiert wurde ${ }^{61}$. Er konstatiert positiv, daß der Mensch lebt, weil Gott mit inm spricht. Der nachfolgende Kontext VV.25f rechnet mit Todesgefahr, wenn Gott spricht. Gegenüber

54 Die Konstruktion $2 \boldsymbol{T}+\boldsymbol{J}$ + Inf.constr.) leitet häufiger zum Kontext relative Erzählanfänge ein, vgl. Gen 12,14; Dtn 31,24f - futurisch gewendet: Dtn 20,2 .

55 Vorbild dieser Wendung kann Ex 3,2b sein - nach WEIMAR, Berufung, 33-35. 210, Vorlage des Jehowisten und ältester Beleg der Wendung.

56 Vgl. Dtn $1,20-22 ; 4,10 f$.

57 Dazu MITTMANN, Deuteronomium, $137 \mathrm{f}$.

58 Die Glosse "und seine Größe" zerstört die Balance. Sie trägt einen terminus in die Theophanie, der sonst die Macht Jahwes beim Auszug demonstriert; vgl. 4,$34 ; 9,26 ; 11,2 ; 26,8 ; 34,12$. Signifikanterweise gebraucht $V .24 a$ den Aufmerksamkeitserreger 1ה, während Kap. 1.2.4 den Imperativ האר bevorzugen.

59 Vgl. zuletzt die Analyse von Num $13 f$ bei MITTMANN, Deuteronomium, 42-55, bes. 55 .

60 WESTERMANN, Art. כבד, 808 hält den zusammenhang Ex 33,18-23 für spät (auf keinen Fall J oder E). ZENGER, Sinaitheophanie, 93.148ff.197f.255f differenziert und sieht in Ex 33,18.21a.22 E am Werk. Die Ausdehnung der Bergtheophanie des Elohisten bis nach Ex 33 ist zu bezweifeln (s.0.); dann bleibt noch die Notlösung, dem Jehowisten die Versanteile zuzuweisen. Für diese Mittelposition spricht die Unmittelbarkeit des Kontaktes Jahwe - Mose und die Kongruenz zwischen Jahwe und seinem כבוד. Eine pauschale Zuweisung an $P$ muB mit der Literarkritik von Ex 33,12-23 und mit der Differenzierung in der Vorstellung selbst fertig werden. 
V.24a gebraucht er ראה nicht wörtlich im Sinne von "mit den Augen sehen", sondern im Sinne von "wahrnehmen, erkennen". Dann wechselt דבר/D-Stamm ein weiteres Mal die Präposition, nach a und אל את jetzt 62.

Das Horebereignis wird zum Paradigma vor der gesamten und für die ganze Menschheit: Der Mensch lebt durch das Wort Gottes bzw. Jahwes. Diesen Kernsatz macht die Meditation 8,2-6 zum Ziel ihrer Aussage ${ }^{63}$. Der Wüstenmarsch während der vierzig Jahre wird zum Test auf das Leben mit dem Dekalog. Der Test gelang. Der Wüstenaufenthalt ist Vorbild für ein Leben nach dem lebensspendenden Gesetz bzw. Dekalog.

V.25a steht in Spannung zu V.25b, weil er die Befürchtung des Volkes, zu sterben, doppelt. Außerdem trägt er ein neues Motiv ein, das "fressende Feuer", das Jahwe selber ist. Das Motiv stammt aus 9.3 und gehört in die Kriegsschilderung. In 9,3 zeigt es den für die Feinde (Israels) schrecklichen Charakter Jahwes. 4,24 wendet den gefährlichen Charakter Jahwes gegen Israel und in diesem Sinne setzt ihn auch V.25a ein.

Ursprünglich hat das ועת aus V.25a direkt zu V.25b übergeleitet. Das Volk erhebt Einspruch. Die Fortsetzung der unmittelbaren Jahwerede bedeutet Tod. Der Einspruch wendet den alten Grundsatz, daß Gott sehen den Tod bedeutet, auf die akustische Wahrnehmung der Gottesworte an ${ }^{64}$. V.25b entspricht darin 5,4 .

V.26 entspricht in seiner Konstruktion den Unvergleichlichkeitsaussagen von 4,7f, die Braulik im Anschluß an Labuschagne beschrieben hat ${ }^{65}$. Die rhetorische מי-Frage läßt den Sachverhalt samt Attribution dem Vergleichssatz vorausgehen. In diesem Fall ist die Aussage des Relativsatzes irreal. In V.26 wird die Konstruktion durch $x$-qatal auf das vergangene Ereignis der Horebtheophanie angewandt; deshalb auch der irreal gemeinte abschließende Narrativ. Das Forum solcher Unvergleichlichkeitsaussagen ist universal. Das

61 Vgl. SEITZ, Deuteronomium, 46 mit Berufung auf HEMPEL; ebenso MITTMANN, Deuteronomium, 138.

62 Darin zeigt sich Verwandtschaft mit priesterlichem Sprachgebrauch, der auf diese Weise auf den intimen Gesprächskontakt zwischen Jahwe und einem Menschen abhebt; zu den stellen vgl. ROST, Bemerkungen, 54f A 6 . Der priesterliche Sprachgebrauch von Ex 19,9 und 20,19 folgt anderen Gesetzen (s.o. Kap. 2).

63 LOPEZ, Analyse littéraire, 508f hat den überlegten Aufbau der Einheit 8,26 nachgewiesen. Ihre konzentrische Struktur kreist um V.3b: "Der Mensch lebt nicht vom Brot allein, sondern von all dem, was aus dem Munde Jahwes herausgeht, lebt der Mensch".

$64 \mathrm{Vgl}$. Gen $32,31 \mathrm{~b}$ (s.o. A 4o); Ri 6,22f; 13,22; Ex 19,21 (Je); 33,20 (thetische Formulierung-Zuweisung fraglich); Lev 16,2 ; Num 4,20; Jes 6,5 . 
sterbliche Fleisch wird dem lebendigem Gott entgegengesetzt. Das Attribut "lebendig" hebt auf die gefährliche Vitalität Gottes ab, die sich sonst gegen Fremdgötter und Fremdvölker richtet ${ }^{66}$. In $v .26$ geht es um das Wunder, das Israel angesichts der bedrohlichen Lebendigkeit Gottes (innerhalb der Horebtheophanie) überlebt hat. Die engsten Beziehungen knüpft der Vers neben denen zu 4,7f auch noch zu 4,32-34, wo sich derselbe Horizont mit analogen Wendungen entfaltet ( $\mathrm{vgl}$. bes. 4,33 ). V.26 sprengt also den Rahmen des Grundtextes.

Die VV.27f bilden einen bruchlosen Zusammenhang. Interessant ist die Differenzierung bei den Verben des Sagens. Das Verb אמר behält auch im Dtn seinen Bezug auf die wörtliche Rede ${ }^{67}$. Dem Wunsch des Volkes gemäß soll in Zukunft nur Mose die wörtliche Mitteilung Jahwes hören (V.27). Der gesamte Obermittlungsvorgang von Jahwe zu Mose und von Mose zum Volk wird mit דבר/ D-Stamm umschrieben (V.27b). Die Selbstverpflichtung des Volkes weicht signifikant von späteren Belegen ab ${ }^{68}$.

Mit formelhaftem ימימן eingeleitet, überrascht V.29 mit einem Wunsch. Der Vers verrät sich durch seinen Sprachgebrauch als sekundär ${ }^{69}$. V.29a bietet eine "gemischte Reihe" 70 , deren Parallelen relativ späten Sprachgebrauch repräsentieren. Die häufig mit der Gottesfurcht verbundene Zeitangabe "alle Tage" 71 hat sich hier an die Gesetzesbeobachtung angehängt - wiederum ein Zeichen weiter fortgeschrittenen Sprachgebrauchs ${ }^{72}$. Der Segenshinweis mit Generationenreihe hat seine nächste Parallele in Dtn 12,28 - die Abweichungen zeigen den fortgeschrittenen Sprachgebrauch an. Die frappanteste Parallele den ganzen Vers betreffend, trotz einiger Varianten - bietet die Neue-BundWeissagung aus Jer 32,39 (Jer D). Es ist also gut möglich, daß spätere deuteronomistische Bearbeitungen, sei es des DtrG oder des Jeremiabuches, sich

65 DERS., Weisheit, 18of (Lit.!) - DERS., Rhetorik, 23.

66 Vgl. THAT I, 554; ThWAT II, $891 \mathrm{f}$.

67 Vgl. SKWERES, Rückverweise, $21 \mathrm{f}$.

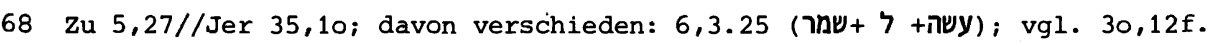
Für die Konstruktverbindung קול (v.28) plädiert LABUSCHAGNE, Art. 632 für die Bedeutung "Nachricht/Kunde".

69 Auch MITTMANN, Deuteronomium, 139 trennt ihn ab. Schwierig bleibt die Zuweisung; punktuelle Wortvergleiche helfen hier wenig!

70 Zur Bezeichnung und Sache LOHFINK, Hauptgebot, 71f. Die Parallelen: 6,2; 8,6 (umgekehrte Reihenfolge); 10,12 (stark ausgebaut und von der Regel abweichend; 13 (dito); 17,19; 28,58 (umgekehrte Reihenfolge); 31,12b.

71 Dtn 4,$10 ; 14,23 ; 31,13$; Jos 4,$24 ; 1$ Kön 8,40; Jer 32,39 (Jer D).

72 Vgl. 11,1; 2 Kön $17,37$. 
in Dtn 5 verankert haben. Sucht man nach einem bestimmten Text im Dtn selbst, dann kommt wegen der Betonung des Herzens und des Gehorsams am ehesten 8,2-6 in Frage. Der Vers 29 gebraucht mit "alle meine Gebote" einen der häufigsten Gesetzestermini des Dtn 73 und unterscheidet sich dadurch von 5,1.31. Wir versuchen, der Bedeutung nahezukommen, indem wir sein Vorkommen nach identischen Kontexten gruppieren.

Der Plural מצות wird immer entweder durch Suffix oder durch Konstruktverbindung auf Jahwe bezogen. Er betont also immer Jahwes Urheberschaft, unterscheidet aber von sich aus nicht bei der Obermittlung der Gebote. Wegen dieser Neutralität ist er gut geeignet,den Gesetzesgehorsam einzuschärfen, muß aber jeweils vom Kontext her darauf festgelegt werden, welche bestimmten Gesetze denn nun eigentlich gemeint sind.

Eine erste Gruppe von Stellen verwendet den Plural als Akkusativobjekt zu שמר und tendiert dazu, Reihungen zu bilden, die den Gesetzesgehorsam einschärfen oder "gemischte Reihen" sind, die einen Verbalausdruck personaler Beziehung zu Gott enthalten ${ }^{74}$. Die zweite Gruppe entwickelt mehr Profil. Sie beginnt mit der Aufforderung, auf Jahwes Stimme zu hören und fordert dann den Gehorsam ( שמר und/oder עשה ), betont die Gesamtheit der Gebote (כל) und schließt ab mit einem partizipialen Promulgationssatz. Dieser stellt sicher, daß es sich bei dem Plural dieser Gruppe um das gesamte mosaische Gesetz, d.h. das Deuteronomium handelt ${ }^{75}$. Die dritte Gruppe stellt den Plural zu yמ bzw. zu שמע אל und rängt ebenfalls einen partizipialen Promulgationssatz an 76. Die umfassende Allgemeinheit des Plurals מצות fördert seine vielfache Verwendung. In den Unterschieden zwischen den Gruppen kann sich schichtspezifischer Sprachgebrauch verraten.

Der Grundtext kommt wieder zu Wort in 5,30f. Die Aufforderung Jahwes an Israel, zu den Zelten zurückzukehren, variiert den bekannten Kriegsbeendigungsruf "ein jeder zu seinen Zelten"! 77.

73 Vgl. BRAULIK, Ausdrücke für "Gesetz", 56-60.

74 Die erste Gruppe: 5,$10 ; 7,9 ; 6,17 ;-5,29 ; 8,2.6 ; 13,5 ; 26,17 \mathrm{~b} .18 \mathrm{~b} ; 28$, $9 b ; 30,16$.

75 Die zweite Gruppe: 13,$19 ; 27,10 ; 28,1.15(45) ; 30,8.10$.

76 Die dritte Gruppe: Mit שמר : שמע אל 4 :2b.40; mit $(11,13) .27 .28$; 28,13.

77 Vgl. KоCH, Art. אהל, 130 - die dtn Fiktion wird deutlich am Unterschied zu "ein jeder zu seinem Haus" in Dtn 20,5-8; 1 Kön 22,17. 
Auffällig an beiden Versen ist, wie wenig auf die Ortsumstände, d.h. die Raumvertikale Rücksicht genommen wird. Das kennzeichnet den gesamten Grundtext und ebenso den Grundtext der Erzählung vom Bundesbruch in Dtn 9f. Die Sonderstellung des Mose kommt räuml ich zum Ausdruck. Mose und Volk werden getrennt. Mose steht bei Jahwe - ein Reflex auf die Sinaitheophanie (vgl. Ex $20,21 \mathrm{E} ; 34,2.5 \mathrm{aß} \mathrm{J} ; 33,21 \mathrm{a} \mathrm{Je}$ ?). V.31 verteilt die verschiedenen Aufgaben: Jahwe spricht zu Mose (beim Horebereignis) - Mose soll in Zukunft das Gesetz lehren - das Volk soll dieses Gesetz im Lande erfüllen. Die Konzeption der Horeberzählung vollendet sich, indem abschließend die Unterschiede von Dekalog und mosaischem Gesetz bestimmt werden. Der erste Unterschied betrifft den Ort der Promulgation. Der Dekalog stammt vom Horeb und ist die älteste, d.h. ehrwürdigste Gesetzesoffenbarung.

Das mosaische Gesetz wird später promulgiert. 5,31 nennt keinen Ort. 28,69 wird das später nachholen. Der zweite Unterschied betrifft die Art der Offenbarung: Der Dekalog ist direkte Jahwerede - das mosaische Gesetz ist vermittelte Jahwerede. Das bedingt keine Abstufung der Verbindlichkeit, denn alle Gesetze gründen in Jahwes Befeh1, sind somit "Gebote Jahwes" (s.o.) 78 . Der dritte Unterschied betrifft den Gültigkeitsbereich: Der Dekalog gilt universal(vgl.8,2-6); das wird erhellt aus dem Gegensatz zum mosaischen Gesetz.Denn dieses gilt für Israel im Gelobten Land. 5,31 betont mehr das unterschiedene Nebeneinander von Dekalog und mosaischem Gesetz - ein Hinweis dafür, daß sich die Konzeption erst herauszubilden beginnt. Das Verhältnis der als unterschieden etablierten Größen steht noch nicht im Blick.

Von besonderer Bedeutung ist die Trias in 5,31. Sie verbindet den Singular מצוה mit dem bekannten Duo חקים / משפטים in einer syndetischen Reihe. 7,11 kopiert 5,31 und 6,1 interpretiert den Vers, beide hängen also von 5,31 ab. Diese Stelle hat also die Trias hervorgebracht ${ }^{79}$. Der schmucklose Singular in 17.20 sowie der suffigierte Singular in 26,13 bezeichnen das jeweils im Kontext angegebene Gesetz (Königsgesetz und Zehntabgabe). In 31,5 legen der Rückverweis und der nahe Kontext den Ausdruck "das ganze Gesetz" auf die mosaischen Bestimmungen (Verhalten gegenüber den Landesbewohnern) von Dtn 7 und 20 fest ${ }^{80}$. In 15,5 und 19,9 mit fast identischer Konstruktion(כמר לעשות + + partizipialer Promulgationssatz) legen das Demonstrativpronomen sowie

78 Dazu BRAULIK, Weisheit, $171 \mathrm{f}$.

79 Die weitere Analyse baut auf den Ausführungen von BRAULIK, Ausdrücke für "Gesetz", 53-56 auf.

8० So SKWERES, Rückverweise, 73-75. 
die Position im Text den Singular מצוה auf die Vorschriften des Kontextes fest. In 27,1 ist die Konstruktion analog. Hier sorgt die Anfangsposition zu Beginn des Kapitels für Ersatz des Demonstrativpronomens, auch hier gilt der Singular für die Vorschriften des konkreten Kapitels.

Im Zusatzvers 6,25 tragen das Demonstrativpronomen und der relative Umstandssatz 81 eine Ambivalenz ein. Es kann das mosaische Gesetz gemeint sein, aber ebenso die Verpflichtung der Eltern, die Kinder zu unterweisen. Die paränetischen Schemata von 8,1 und 11,8 (das ganze Gesetz + partizipialer Promulgationssatz) beziehen den Singular auf das mosaische Gesetz; das gilt auch für das ähnlich konstruierte Bedingungsgefüge 11,22-25. Im Panegyrikus auf "dieses Gesetz" (+ partizipialer Promulgationssatz) 31,11-14 ist der Singular in seiner Reichweite schwer einzugrenzen.

Der Oberblick erlaubt doch einige Rückschlüsse: Beim Großteil der Stellen unter ihnen die ältesten Vorkommen der Belege wie 17,$20 ; 26,13$ - bezieht sich der Singular auf die Vorschriften des nahen Kontextes. Dieses Faktum bietet eine plausible Erklärung dafür, daß der Singular normalerweise keine Reihen mit anderen Worten für Gesetz bildet. Demgegenüber setzen die Stellen mit umfassendem Bezug auf das mosaische Gesetz voraus, daß der Singular entschränkt wurde. Das hat 5:31 besorgt, indem es den Singular in typisch dtn Manier syndetisch zu dem Duo חקים / משפטים addierte, das selbst als Zusammenfassung des Gesetzeskorpus durch 26,16 und 12,1 ausgewiesen war.

Der Landsatz in der Form von V.31b 82 - wie überhaupt - kommt eigentlich nur singularisch vor. Den Zwang zum Singular demonstriert 12,1a (Perfekt statt Partizip) mitten im pluralischen Kontext. Die erste Stelle mit pluralischem Landsatz ist 5.31 (vgl. noch Jos 1,11). Damit zeigt der Grundtext gerade im Bereich stereotyper Formulierungen gegenüber den älteren Schichten im Gesetzeskorpus und im Rahmen des Dtn seinen fortgeschrittenen Sprachgebrauch an.

\subsection{Die Parönese $5,32-6,3$}

Die VV.32f springen abrupt ohne Oberleitungspartikel von der Jahwerede in die Moserede 83 und zeigen schon dadurch ihren sekundären Charakter an. Die

81 Dazu SKWERES, Rückverweise, 55-57.

82 Dazu PLÖGER, Deuteronomium, $79 \mathrm{ff}$ und DIEPOLD, Israels Land, 81; die Stellen: 9,6 ; $(12,1) 19,2.14(21,1) ;-15,4 ; 25,19 ;-17,14 ; 19,1 ; 26,1$.

83 Vgl. VON RAD, Deuteronomium, 44; MITTMANN, Deuteronomium, 139 (dort ältere Literatur). 
Eingangsmahnung nimmt den Schluß von 5,1 auf. Der folgende Umstandssatz rekurriert auf 5,31b. Was Jahwe dort befohlen hat, schärft Mose hier ein. Es schließt sich eine stereotype Metapher an ${ }^{84}$. Das "paränetische Schema" von דרך mit הלר/ב verbunden ${ }^{85}$. Die Ausnahmen von der Regel bieten 5,33;13,6 und 2 Kön 22,2 , das wie VV.32f beide Wegmetaphern hintereinanderschaltet und ebenso vom "ganzen Weg" spricht. Der Segenshinweis ist hier besonders ausgebaut. Die dreifache Zusage von Leben, Wohlfahrt und langem Leben ist singulär. Es hat den Anschein, als ob die Segenshinweise von 4,1b und 4,40 hier konzentriert bzw. zusammengezogen werden. Die übliche Verbindung vom "Langmachen der Tage" auf der אדמה ist hier unter dem Druck des Kontextes aufgegeben ${ }^{86}$. Wie im dtr 1 Kön 3,14 verknüpft 5,33 den Wandel auf dem Wege mit dem Langmachen der Tage.

Insgesamt ist deutlich geworden, wie der Sprachgebrauch dieser beiden Verse den Rahmen des Dtn und seiner Formulierungsregeln sprengt und sich Sprachklischees des dtr Geschichtswerkes nähert (z.B. 2 Kön 22,2; 1 Kön 3,14).

6,1 ist die nach 5,31 erwartete Brücke zur mosaischen Gesetzesverkündigung. Das belegen das waw zu Anfang, der Oberschriftcharakter und die Aufnahme der Trias aus 5,31. Die Differenzen aber zeigen, daß dieser Brückenvers sekundär an 5,31 angefügt wurde. Wiederum verdient der MT den Vorzug vor den Versionen. Die Konstruktion des Nominalsatzes mit Demonstrativpronomen im Singular (vgl. dagegen Z.B. 4,45; 12,1) will von vornherein die Trias aus 5,31 modifizieren. Die Asyndese vor dem Duo behandelt dieses als Apposition, das den Singular מצוה erläutert, von der Absicht des Redaktors her aber ersetzt. Für inn ist das Duo die bevorzugte Bezeichnung des mosaischen Gesetzes, und so lenkt er hier geschickt den Grundtext in seine Sprachbahnen. Der Rest des Verses ist mit 4,14 bis auf konstruktionsbedingte Varianten völlig kongruent. Die Identität der Redaktoren steht damit fest ${ }^{87}$. Die Landgabeformel aus 5,31b ersetzt er durch die von ihm bevorzugte Landnahmeformel mit עבר (vgl. 4,14) 88 .

$84 \operatorname{Dtn} 2,27 ; 17,11.20 ; 28,14$; Jos 1,$7 ; 23,6 ; 2$ Kön 22,2 .

85 So BRAULIK, Ausdrücke für "Gesetz", 50 .

86 Vgl. noch: Dtn 4,26b; 17,20 (Jes 24,31); Ri 2,7.

87 Vgl MITTMANN, Deuteronomium, 139f.163; LOPEZ, Analyse litteraire, 17.

88 Parallelstellen: 11,8.11 - Präzisierung durch Jordanüberschreitung: $(9,1$ als Inspirationsquelle); 4,26; 11,$31 ; 31,13 ; 32,47$; Jos 1,11 ; vgl. Num 33,51f; 35,10f - Landnahmeformel mit בוא: (Ex 34,12 Je); Dtn 4,5; 7,1; 11,29 . 
Wenn 6,1 auf der Ebene seines Redaktors die Oberleitung von der Horebtheophanie zum Urdeuteronomium in $6,4 \mathrm{ff}$ war, dann hat sich später wieder eine Paränese dazwischengedrängt, die mit ihrem Singular auf 6,4ff hin gravitiert. Sie bietet eine enervierende Vielfalt von Formeln und häuft sie auf, um Mahnung und Segenshinweis zu verstärken ${ }^{89}$. Zwar ähnelt die Abfolge von Gottesfurcht und Gesetzesgehorsam in V.2a der von 5,29, aber weicht auch davon ab. Die Kombination von Finalkonjunktion mit ירא (x-yiqtol) findet sich noch im dtr 1 Kön 8,40, die suffigierte Reihe von Gesetzestermini (מצות / חקות) findet sich noch in 1 Kön 11,38 90. Der zu erwartende partizipiale Promulgationssatz ist durch eine Generationenfolge erweitert (Vater, Sohn und Enkel), die in dieser Weise noch in Dtn 4,9.25 auftritt, allerdings dort in ein Satzgefüge eingebunden. Die Zeitangabe "alle Tage deines Lebens" hat wieder bezeichnende Parallelen 91. Der Segenshinweis V.2b fällt hier schmal aus; inn wegen seines "promissorischen Charakters" vor V.3 mit seiner neuen Paränese als sekundär abzutrennen, rechnet zu wenig mit der Möglichkeit der assoziativen Verknüpfung im Anschluß an "die Tage des Lebens" 92 . Der Höraufruf in V.3 präludiert 6,4 und erinnert an 5,1. Er ist hier völlig in die Aufforderung zum Gehorsam eingebunden. Das finale אשר mit Segenshinweis auf Wohlfahrt findet sich nur noch 4,40. Der Mehrungswunsch, der im Numerus aus dem Kontext herausfällt, könnte von den dtr oder nach-dtr Heilsweissagungen des Jeremiabuches Jer 3,$16 ; 23,3$ her beeinflußt sein ${ }^{93}$. V.3b hat seine besonderen Schwierigkeiten, auf die wir hier nur aufmerksam machen ${ }^{94}$.

Die Paränese 6,2f hinterläßt den Eindruck, daß späte Schichten des dtr Geschichtswerkes und vielleicht der dtr Bearbeitung des Jeremiabuches Formulierungen, die innen wertvoll sind - und die wir in ihrer Tragweite noch nicht voll erfassen -, hier eingetragen haben. Auf diese Weise haben sie dem Horebereignis bzw.Dtn 5 ihre Reverenz erwiesen.

\subsection{Ergebnis der Literarkritik zum Dekalograhmen}

Die intensive redaktionelle Bearbeitung von Dtn 5 belegt den Stellenwert dieses Kapitels innerhalb der dtn-dtr Theologie; es ist aber zugleich mit

89 LOPEZ, Analyse littéraire, $17 \mathrm{f}$ hat sich mit seiner formelvergleichenden Methode die meiste Mühe gegeben. Wir greifen auf ihn zurück.

90 Nach DIETRICH, Prophetie, 87, DtrN.

91 Neben Dtn 17,19; 1 Kön 11,34; 15,4f; 2 Kön 25,29.30 - alle Stellen aus den Königsbüchern nach DIETRICH, Prophetie, 142f, DtrN.

92 So MITTMANN, Deuteronomium, 140; allerdings argumentiert man auf schwankendem Boden. 
den im Dtn komplexen Problemen der Schichtung belastet. Die Literarkritik zu Dtn 5 hat keinen Tatbestand ergeben, das Kapitel von Dtn 1-3 her zu verstehen; umgekehrt zeigt der Grundtext wie seine Bearbeitungen Verbindungen zum Grundtext von 9,7-10,11 und dessen Bearbeitungen. Wir übernehmen deshalb die alte These vom Zusammenhang der Horeberzählung mit der Tafelerzählung 95 und modifizieren sie: Ein- und derselbe Autor hat sowohl den Grundtext von Dtn 5 wie den von Dtn $9 f^{96}$ verfaßt. Als Grundtext des Dekalograhmens hat sich herausgestel1t: 5,1 (mit seiner Redeeinleitung).2.4.5 (nur mit der Oberleitung וערה ).23bß.24a.25a (nur.27-28.30-31. Der Grundtext verarbeitet die Sinaitheophanie des Jehowisten und stellt seine Horebtheophanie von Anfang an unter die Bundeskategorie, ohne sie weiter auszufalten. Wichtig ist für inn die Mitteilung des Dekalogs. Seine Rolle im Bund - im Unterschied etwa zu 4,13 (Bund ミDekalog) - wird nicht weiter präzisiert; allerdings läßt die Erzählung an seiner konstitutiven Funktion keinen Zweifel. Das Verhältnis des Dekalogs zur nachfolgenden mosaischen Gesetzesoffenbarung wird bestimmt. Dabei tritt mehr ihre jeweilige Eigenständigkeit als ihr Zusammenspiel in Erscheinung. Der Dekalog ist Horeboffenbarung. Er besitzt die unüberbietbare Dignität unmittelbarer Jahwerede ans Volk. Sein universaler Guiltigkeitsbereich ergibt sich aus dem Gegensatz zum mosaischen Gesetz, das im Gelobten Land gilt. Das mosaische Gesetz tritt als Zusatzoffenbarung auf, die auf Einspruch des Volkes notwendig wurde. Jahwe hat den Einspruch akzeptiert und die Vermittlung des Mose angenommen. Am Horeb hat nur Mose die Zusatzoffenbarung empfangen mit dem Auftrag, sie in Zukunft zu lehren. Die Zusatzoffenbarung versteht sich als umfassendes Gebot (Jahwes) unter Einschluß der Satzungen und Rechtsnormen von 12,1-26,16. Sie wendet sich an das Volk/Israel und gilt für das von Jahwe übergebene Land.

Die relative Chronologie der weiteren redaktionellen Bearbeitungen des $\mathrm{Ka}$ pitels ist mit erheblichen Unsicherheiten beschwert. Die karge und abstrahierte Erzählweise des Kapitels gibt wenig textinterne Hilfestellung. Die

93 Vgl. noch $\operatorname{Ex~} 1,7$ ( $\left.P^{g}\right)$ und $D$ tn 8,$1 ; 30,16$ in anderer Formulierung.

94 Sie werden ausführlich erörtert bei MITTMANN, Deuteronomium, 140 A 28 und bei SKWERES, Rückverweise, $165 \mathrm{f}$.

$95 \mathrm{zu}$ dieser These SEITZ, Deuteronomium, $46 \mathrm{f}$ mit Verweis auf PUUKKO und HEMPEL. Zu deren Konzeption das Referat bei LOERSCH, Deuteronomium, 41. 53-55. LOHFINK, Hauptgebot, 216-218.282.290 geht von einer kultischen Sonderexistenz der beiden Texte aus und betont ebenso den zusammenhalt der Erzählungen.

96 Nach den Darlegungen von 2.7.6.5 umfaßt der Grundtext von Dtn 9f: Dtn $9,9 \cdot 11 \mathrm{f} .15 \mathrm{a} \alpha \cdot 16 \cdot 21 \cdot 26 \mathrm{a} \cdot 27 \mathrm{~b}-28 ; 10,10-11$. 
punktuellen Erweiterungen vor allem in der Paränese zwingen zu intensivem Textvergleich. Kriterium der Chronologie bleibt dann nur die Schichtung der Paralleltexte, und die ist gerade für das Dtn umstritten.

Der Gehorsamsaufruf von 5,1 entwickelt besondere Verbindungen zum Abschnitt 31,9-11.12b 97 (die Betonung von "[ganz] Israel" - das Rufen bzw. Reden in die Ohren der Israeliten - das Lernen von Satzungen und Rechtsnormen bzw. der Tora - das Tun [שמר לעות [שות der Gesetze). Ich rechne mit einer Zusammengehörigkeit der beiden Stellen, wenn nicht sogar mit derselben Schicht.

Die folgende, spätere Redaktion gewinnt ein starkes Profil. Sie umfaßt innerhalb der Horeberzählung die Verse 5,5.22.23a und 6,1. Sie stilisiert das Horebereignis zum Gründungsdatum für die Mittlerschaft des Mose. Sie verstärkt die visuellen und akustischen Elemente der Theophanie. Auf ihrer Stufe wird der Dekalog zur schriftlichen Urkunde, die auf zwei Tafeln von Jahwe niedergelegt wird. Jetzt umfaßt der Dekalog genau zehn Worte. Für die mosaische Gesetzgebung bevorzugt sie das Duo חקים / משפטים; diese Bezeichnung wird mit der mosaischen מצוה idenfiziert. Am Horeb hat Mose den Auftrag zur Lehre der Gesetze erhalten. An den Horeb wird auch die Stiftung der Versammlung Israels gelegt. Israel versteht sich nun als eine um das Gesetz versammelte Gemeinde. Einen ihrer Schwerpunkte hat diese Redaktion in Kap. 4. Wir konnten Verbindungen nach $\underline{4,1}^{98}$ und vor allem nach $\underline{4,10-14^{*}}$ feststellen. Neben dem Theophaniebericht setzt sie dort die berît Jahwes mit den Zehn Worten gleich und stellt innen die mosaischen חקים / gegenüber. In der Tafelerzählung hat sie ebenso deutliche Spuren hinterlassen: 9,10.15aßb; $\underline{10,1-5}^{99}$. Sie hat dort ihre Tafelvorstellung eingetragen und konsequenterweise den Bundesbruch zur Bundeserneuerung mit identischem zweiten Dekalog umgestaltet. Auf ihre Fährte stießen wir im Prophetengesetz $18,16 \mathrm{f}$, so daß wahrscheinlich der ganze Abschnitt 18,14-20 auf ihr Konto geht. Schließlich hat sie 31,9-13 bearbeitet, indem sie 31,12a einschob (vgl. 4,10) und $\underline{31,13}$ anhängte (vgl. 4,10.13). Hier liegt der Grund, sie ihrer obigen Vorgängerin nachzuordnen.

97 PERLITT, Bundestheologie, 115-128 stuft den Abschnitt Vv.9-13 als "frühdtr Beleg" ein. Zur Literarkritik innerhalb des Abschnitts ebd., 116. 120 A 4.

98 Zur Diskussion um V.1b zuletzt BRAULIK, Literarkritik, 359.

99 S.o. unter 2.7.6.5. 
Ihr sammelndes Interesse an traditionellen Theophanieelementen, ihre Betonung der Mittlerschaft des Mose sowie das Interesse an seiner Tätigkeit als Gesetzesschreiber und vor allem ihre Rücksichtnahme auf das Bundesbuch (s.o. zu Dtn 5,5.22) lassen in ihr die entscheidende dtr Redaktion der Sinaiperikope vermuten. Sie schickt in Ex 19,4-8 ihren Vorspann voraus (vgl. das suffigierte b $\mathrm{b}^{\mathrm{i}} \mathrm{t}$ Ex 19,5 mit Dtn 4,13$)$, sie integriert das Bundesbuch Ex 20 , $22^{*} .24-26 ; 21,1-23,33^{*} ; 24,3-4 a \alpha$ und funktioniert schließlich mit Hilfe ihrer Tafelvorstellung das Privilegrecht zum zweiten Dekalog um Ex 34,1.4*.28.

Die beiden nächsten Redaktionen hängen eng mit Schichtungen innerhalb von Kap. 4 zusammen: 5,3 zeigt Verwandtschaft mit 4,3f und 29,13f 100 . 5,26 verweist auf 4,7f und 4,32-34. Da die Verse 4,3-8 aller Wahrscheinlichkeit nach eine Einheit bilden ${ }^{101}$, sind 5,3 und 5,26 zusammenzunehmen. 5,25a verbindet sich mit 4,24. Insofern 4,24 mit seinem kriegerischen Bild von Jahwe enge Verwandtschaft zu 4,34 hat, gehört auch 5,25a zur selben Redaktionsschicht (trotz des Numerusunterschiedes). Der Einschub 5,23bß zielt auf 29,9. 29,9 steht mit 29,13f in Verbindung - und insofern schließt sich der Kreis nach 4,3-8. Summa summarum: 5,3.23bß.25a.26 gehören zu einer späteren Redaktion, die sich in 4,3-8.24.32-34 zu Wort meldet.

5,24b steht mit 8:2-6 in enger Beziehung. Diese letztere Einheit verbindet sich mit 4,36 durch das seltene Thema der Unterweisung durch Jahwe. 5,29 kann mit 8,2-6 zusammenhängen ${ }^{102}$, so daß 5,24b und 5,29 zu einer Redaktion gehören. Ihre Zuordnung zu ihrer Vorgängerin hängt von der Einordnung von 4,36 ab.

$100 \mathrm{Zu}$ den literarkritischen Problemen in Kap. 29 PERLITT, Bundes theologie, 23-30.

101 MITTMANN, Deuteronomium, 116-118.125f weist sie seiner pluralischen Ergänzungsschicht $\mathrm{zu}\left(\mathrm{Pl}^{2}\right)$. BRAULIK, Literarkritik, 380 unterstreicht die thematischen und formulierungsmäBigen Verbindungen zwischen VV.1-8 und 32 -4o. Im Unterschied zu ihm (ebd., 373f), halte ich 4,3-8 für sekundär und eigenständig gegenüber 4,10-14*. Die Formulierungsunterschiede gerade zwischen V.5 und V.14 sind zu groß für einen Verfasser (eigener Rückverweis, der redundant wäre, wenn derselbe Verfasser dasselbe Ereignis noch einmal berichten würde; eigene Formulierung des Auftrags, die Gesetze entsprechend bzw. dann zu tun; die Wendung בקרב הארץ bleibt auffällig; der Gebrauch der Landnahmeformel mit בוא, während der Redaktor in 4,14 und 6,1 die mit

102 Die Zusammenhănge zwischen 8,2-6 und 5,29: Betonung des Herzens, vgl. 8,2.5; der Zusammenhang von Gottesfurcht und Befolgen der מצות יהוה, vgl. $8,2.6$. 
In den zusätzlichen Paränesen melden sich die Schichtungen des deuteronomistischen Geschichtswerkes zu Wort: Die ältere Paränese 5,32f läßt auf DtrG und die jüngere $6.2 \mathrm{f}$ eher auf DtrN schließen 103.

\subsection{Schichtungen innerhalb des Dekalogs}

\subsubsection{Einleitung und Forschungsrückblick}

Der synoptische Vergleich hat in dieser Untersuchung die Konzentration auf den älteren Deuteronomiumdekalog erlaubt. Die Analyse seines näheren Kontextes ermöglichtnun, eine der klassischen Probleme der Dekalogexegese anzugehen, den Sprecherwechsel innerhalb des Dekalogs von Jahwerede zur Menschenrede. Wenn man sich auf eine Urdekaloghypothese sowohl der älteren Literarkritik wie der jüngeren Formkritik einläßt - sie bestimmt nach wie vor in weitem Maße das Verständnis des Dekalogs -, dann erfaßt der Sprecherwechsel einerseits die kurzen einleitenden Rechtssätze der Einzel gebote wie im Fall des Namensverbotes (im Unterschied zu Fremdgötter- und Bilderverbot), andererseits die Erweiterungen der Rechtssätze wie im Fall des Namen-, Sabbat- und Elterngebotes (im Unterschied zu den Erweiterungen im Bilderverbot). Die Urdekaloghypothese verführte von Anfang an dazu, die Erweiterungen großzügig und pauschal abzuhandeln. Das Problem des Sprecherwechsels verschwand im Orkus der Wissenschaft. Die Frage nach den Ursachen für die unterschiedliche Erweiterung spielte keine Rolle. Man verwies höchstens auf den langen Prozeß punktueller Anhängsel oder auf die Zufälligkeiten der Dekalogpredigt, die im Laufe der Zeit zu allerlei Anlagerungen an den Urdekalog führte. So konnte die ältere Literarkritik des Dekalogs den Sprecherwechsel im Namenverbot noch hinnehmen und ihn in der Erweiterung desselben Verbots anzeigen, allerdings ohne irgendwelche Konsequenzen zu ziehen ${ }^{104}$. Mit der Einführung formkritischer Methoden in die Dekalogexegese durch H. Schmidt ${ }^{105}$ steigt die Sensibilität in diesem Punkt. Der Sprecherwechsel wird im Fall der Begründung beim Namenverbot notiert, im einleitenden Prohibitiv wird er wegdiskutiert. Im Objekt des Prohibitivs ist Jahwe kein nomen rectum, sondern

103 Vgl. 5,32f mit 1 Kön 3,14 (DtrG) und 2 Kön 22,2 (DtrG) - dazu VEIJOLA, Königtum, 48. Zu 6,2f vgl. 1 Kön 8,40 (DtrN) und 1 Kön 11,38 (DtrN) dazu VEIJOLA, a.a.0., 89 A 44 und 120 A 21 .

104 Vgl. z.B. DILLMANN, Exodus, 233.

105 DERS., Mose, 79.87. 
Zitat; die Apposition"dein Gott" wird deshalb ersatzlos gestrichen. Schmidts Rekonstruktion des Namenverbotes wirkt bis heute nach 106 . "Literarkritiker" wie Meinhold und Noth verzichten auf einen Urdekalog, können daher auch weniger belastet auf den ganzen Dekalog blicken und den Sprecherwechsel hervorheben ${ }^{107}$. Die formkritisch orientierte Exegese hakt dagegen beim Namenverbot ein. Hier steht für sie der Sprecher der Prohibitive in Frage und über den Sprecher die ursprüngliche Heimat der Prohibitive. Ist der Prohibitiv des Namenverbotes ein Hinweis auf einen menschlichen Sprecher des Urdekalogs, also auf eine Gesetzessammlung, die sekundär in den Kult integriert wurde? Oder gilt der Urdekalog von Anfang an als Jahwerede, die nur in der Vermittlung bzw. Predigt auch zur Er-Rede abgewandelt werden konnte. Oder muß man zwischen Prohibitiven in Ich- und Er-Rede unterscheiden mit jeweils verschiedenem Sitz im Leben ${ }^{108}$ ? Gerstenberger hat den Sprecherwechsel akzentuiert. Die sozialen Prohibitive stehen außerhalb der Jahwerede, weil sie dem patriarchalischen Sippenethos entstammen. Ihre Verknüpfung mit der Jahwerede geschah im Kult. Die religiösen Gebote sind Bundesbestimmungen; ihre Heimat ist der Kult, wie die Einbettung in Jahwerede deutlich macht, die Verkoppelung beider wurde also sekundär vorgenommen ${ }^{109}$. Perlitt hat Gerstenbergers Unterscheidung übernommen und literarkritisch präzisiert: Produzent der religiösen Gebote im Dekalog ist die dtn Theologie; sie hat diese in eine Gottesrede eingekleidet und mit den sozialen Prohibitiven verknüpft ${ }^{110}$.

106 Wie er streichen die Apposition aus dem ursprünglichen Namenverbot (in chronologischer Reihenfolge): RABAST, NIELSEN, FOHRER, GESE und SCHUNGEL-STRAUMANN.

107 MEINHOLD, Der Dekalog, 15 setzt den Dekalog spăt an; er hălt die ErPassagen für priesterliche Laienbelehrung, die von der dtn Schule mit den Ich-Passagen zum Ganzen des Dekalogs zusammengearbeitet wurde. NOTH, Exodus, $129 \mathrm{f}$ vermutet eine sekundäre Beeinflussung des Dekalogs von der Ich-Rede der Dekalogeinleitung her.

108 Während für REVENTLOW, Gebot, $44 f$ die dritte Person im Namenverbot keine Rolle spielt, obwohl er das Verbot in unmittelbarer sachlicher Verbindung zu einleitenden Selbstvorstellung Jahwes sieht, votieren RABAST, Das apodiktische Recht, 37 und PHILLIPS, Criminal Law, 56 für ursprüngliche Jahwerede auch im Namenverbot. Entgegengesetzt entscheidet sich NIELSEN, Zehn Gebote, 35.7of.99-101. Der Urdekalog existierte zuerst als Gesetzessammlung und wurde sekundär durch die levitischen Kreise des Dtn in Jahwerede umgesetzt. FOHRER, Recht, 136.138-140 plädiert für eine analoge Abfolge: Das Namenverbot weist darauf hin, daß Jahwe auch die Gottesgebote ursprünglich nicht gesprochen hat und daß die Jahwerede sekundär übergestülpt wurde nicht im Kult, sondern durch den Kompositeur des Dekalogs, der auch die Einleitung voranstellte (wahrscheinlich der Elohist). Andeutungsweise ähnlich SCHMIDT, Überlieferungsgeschichtliche Erwägungen, 202. 
Solche formkritische Betrachtung des Dekalogs macht den Sprecherwechsel unübersehbar - und darin liegt ihr Verdienst. Allerdings steht sie trotz Zertrümerung der Zehnernorm noch im Banne der Urdekaloghypothese. Sie beschränkt ihre Betrachtung auf die einleitenden Gebots- und Verbotssätze; der Sprecherwechsel in den sogenannten Erweiterungen wird nicht erwogen; dadurch kommt die Komposition und über die Komposition die Individualität der Einzelgebote nicht in den Blick. Eine Zweiteilung des Dekalogs in Gottesrede mit religiösen Bestimmungen und Sammlung von (sozialen) Prohibitiven liegt schief, weil sie die Ebenen wechselt. Im Bereich der zweiten Tafel decken sich Prohibitiv und die Gattung Gebot: Jeder Prohibitiv ist zugleich ein Gebot. Die erste Tafel bietet einen weit komplexeren Tatbestand: zwei Prohibitive, die zugleich je ein Gebot sind. Beide Gebote sind bruchlos in eine Gottesrede eingebettet. Dann folgt ein Prohibitiv mit Begründung in Menschenrede, dann eine Komposition unter anderem mit den verschiedensten grammatikalischen Befehlsformen wiederum in Menschenrede - sie steht für ein Gebot. Die Tafel schließt mit einem motivierten Befehl, dem letzten Gebot der Tafel in Menschenrede. Gerade für die erste Tafel müssen also die Beschreibungsebenen sauber getrennt werden ${ }^{111}$. Formkritische Vergleiche und Rückschlüsse auf die Genese der Dekalogkomposition sind erst dann erlaubt, wenn innerhalb des Dekalogs das Verhältnis der Gruppen von Einzelgeboten restlos geklärt ist, wenn der Gesamttext als spannungsfreie Texteinheit etabliert ist. Insofern ist die Literarkritik zum Einzeltext (Deuteronomi umdekalog) voll auszuschöpfen, bevor die Formen- und Gattungskritik zum Zuge kommt. Nachdem der synoptische Vergleich unter 2.7 die Zehnernorm und die Tafeleinteilung als sekundär überformende Ordnungsvorstellungen erklärt hat, steht nun die Einteilung der Redeabschnitte durch Sprecherwechsel zur Debatte 112 . Demnach sind drei Bereiche voneinander zu trennen: der Bereich der Jahwerede (5,6-10), der Bereich der Menschenrede (5,11-16) und der neutrale Bereich ohne Bezug zu Jahwe, weder in erster noch in drit-

110 DERS., Bundes theologie, 84-102.

111 Die Einheit "Gebot" wird im Dekalog sowohl durch einen autarken Satz (Prohibitiv) wie durch eine Folge von Sätzen realisiert. Die Verknüpfung der "Gebote" geschieht entweder durch Alliteration in stereotypen Satzanfängen oder durch Syndese bzw. asyndetische Reihung oder durch kompositionstechnische Mittel wie pronominaler Rückverweis und umrahmende Jahwerede. Die "Gebote" innerhalb der Menschenrede stehen asyndetisch hintereinander.

112 JEPSEN, Beiträge, 285.298f, LESTIENNE, Les dix "paroles", 494 und CHILDS, Exodus, 394 zeigen den Sprecherwechsel als Gegebenheit des Gesamtdekalogs, beschreiben ihn aber nicht exakt und kommen zu keiner Erklärung. 
ter Person (5:7-21) 113. Ob die Dreiteilung für den Dekalog konstitutiv ist oder sekundär zustande kam und dann in welcher Kombination, kann aus dem Deuteronomiumdekalog allein nicht entschieden werden. Der Verweis auf parallele Gesetzeskorpora trifft auch nur wieder Einzeltexte mit individueller Problematik. Hilfestellung gibt der nahe Kontext von Dtn 5. Der Grundtext des Kapitels hat den Dekalog in die Schilderung der Horebtheophanie eingeführt und ihn als unmittelbare Jahwerede von aller weiteren vermittelten Jahwerede abgehoben. Unabhängig davon, wie man den Numeruswechsel zum Singular des Dekalogs interpretiert, ob als Signum einer festen Vorlage oder als Fiktion, es ist nicht vorstellbar, daß der Grundtext das zum Unterscheidungskriterium erhebt, was im Dekalog selbst nicht deutlich dargestellt wird, nämlich Jahwerede zu sein. Für den Grundtext des Kapitels kam also beim Dekalog nur die Kombination des ersten und dritten Bereichs in Frage; andernfalls hätte er die Unmittelbarkeit nicht zum Unterscheidungskriterium des Dekalogs erheben können. Die Rede von Jahwe in dritter Person innerhalb des Dekalogs war aber für den Redaktor von 5,5.22.23a; 6,1 möglich, ja nötig; er nahm auf die Jahwerede des Bundesbuches Rücksicht, wie die Rückverweise im Sabbat- und El terngebot belegen. Für ihn hat Jahwe am Sinai schon gesprochen; am Horeb muß er darauf Bezug nehmen. Das Unterscheidungskriterium der Unmittelbarkeit kommt nicht mehr in Frage. Er weicht auf das Medium der Schriftlichkeit aus und behauptet auf diese Weise den absoluten Vorrang des Dekalogs. Der Grundtext begründet mit der Unmittelbarkeit den Vorrang des Dekalogs vor dem mosaischen Gesetz. Der besagte Redaktor verteidigt den Vorrang des Dekalogs mit der schriftlichen Autorschaft Jahwes gegenüber dem Bundesbuch, dem Privilegrecht und der mosaischen Tora. Inm wurde oben die Zehnernorm und die Tafelaufteilung zugewiesen. D.h. dieser Redaktor hat den Dekalog erst zum Dekalog im vollen Sinne gemacht, indem er neue Gebote einfügte und vorliegende Gebote neu gruppierte. Im folgenden sollen mit $\mathrm{Hilfe}$ dieser Hypothese die Einzelgebote des zweiten Bereichs (5,11-16) analysiert und interpretiert werden.

\subsubsection{Das Verbot vom MiBbrauch der Jahwenomens $(5,11)$}

Das Verbot besteht aus einem Prohibitiv mit begründendem כ-Satz. Die Begründung konstatiert mit extratemporalem $x$-yiqtol die Strafverfolgung durch Jahwe. Als Objekt des regierenden Verbs in der Begründung fungiert ein Rela-

113 Vgl. ZENGER, Sinaitheophanie, 65f. 
tivsatz, der den Tatbestand mit denselben Worten beschreibt wie der Prohibitiv. Die Verknüpfung von Prohibitiv mit Begründung durch die Konjunktion כist gerade im dtn Gesetz häufig belegt ${ }^{114}$. Auffällig sind die typisch dtn Appositionen "dein Gott" beim nomen rectum, "Jahwe" im Objekt des Prohibitivs und der Umbruch von der Anrede des Prohibitivs zur unpersönlichen Feststellung der Begründung. Letzterer legt sich aus mehreren Gründen nahe: Die Begründung mit dem für das Dtn singulären נקה/D-Stamm greift auf den Jahwehymnus Ex 34,6f (bes. V.7ba) zurück, den auch die Jahwerede in Dtn 5, $9 b .10$ verarbeitet hat. Der dortige Prototyp legt eine unpersönliche Formulierung nahe ${ }^{115}$. Ebenso setzen mehrere weisheitliche Sentenzen dasselbe Verb im N-Stamm ein, um für ein bestimmtes Verhalten die Vergeltung (durch Jahwe) anzudrohen ${ }^{116}$. Beziehungen zur älteren Weisheit sind gerade für das Dtn nicht abzustreiten. Sie liegen auch für Dtn 5,11 nahe, denn dessen syntaktisch engste Parallele Dtn 16,19 (// Ex 23,8) verrät weisheitliche Herkunft ${ }^{117}$. Da der Prohibitiv keine eindeutige Parallele kennt ${ }^{118}$, also keinen Vorgänger besitzt und das ganze Satzgefüge im Rahmen dtn Formulierung verbleibt, zwingt nichts zu einer Trennung von Prohibitiv und(sekundärer) Begründung, sondern spricht vieles für durchgehende Abfassung durch unseren Redaktor. Das Fehlen eines Rückverweises plädiert ebenso für Neuschöpfung. Die wortreich - wiederholende Begründung zeigt den starken Einfluß des weisheitlichen Mahnspruches 119.

Da der Vers einer späteren dtr Redaktion des Dtn zugehört, kann das Vorfeld innerhalb des Dtn sondiert werden, das der Formulierung des Namenverbotes vorausliegt. Zuerst ist die dtn/dtr Namenstheologie zu bedenken. Während die theologischen Wörterbücher dahin tendieren, eine eigenständige "Theologie des Namens" im Dtn zu leugnen ${ }^{120}$, schlägt momentan das Pendel zurück in

114 Dazu RICHTER, Recht, 107-115.116.132-136.

115 Ich stufe die Formel ונקה לא ינקה in Ex 34,7 als dem Redaktor vorgegeben ein. Sie wurde kopiert in Num 14,18 (dtr nach MITTMANN, Deuteronomium, 49-55) und $\mathrm{Nah} 1,3 \mathrm{a}$ (exilische Nachinterpretation nach JEREMIAS, Kultprophetie, 17f, bes. A 4).

116 Vgl. Spr 6,29;11,21; 16,5;17,5; 19,5.8 (28); 28,20 - dazu McKANE, Proverbs, 497.626 und VAN LEUWEN, Art. נקה.

117 Vgl. RICHTER, Recht, 114.155.

118 Ps 24,4 funktioniert als Parallele nur unter der Bedingung des MT und bei Gleichsetzung von נפש mit שם - dazu KOCH, Formgeschichte, 59 f. Ps $139,20 b$ lautet anders, vgl. BHS z.St.

119 S. RICHTER, Recht, $106 \mathrm{f}$.

120 So SEEBASS, Art. בחר, 599-602 und VON DER WOUDE, Art. שם, 953-955. 
Richtung Eigenständigkeit des Jahwenamens und damit zu berechtigter Rede von einer "Theologie des Namens". Die Argumentation stuitzt sich auf eine differenzierende Betrachtung der Zentralisationsformeln. Diese stellen nicht nur Variationen zur "Kundgabe des Jahwenamens" dar, sondern bleiben theologische Reflexion, indem sie zwischen Jahwe und seinem Namen unterscheiden. Ipso facto wird dem Namen eine Eigenständigkeit zugebilligt, die diese Unterscheidung erst ermöglicht ${ }^{121}$. Solche Namenstheologie hat das Namenverbot beeinflußt, auch wenn hier keine redaktionskritischen Zuweisungen der Belegstellen erfolgt sind. Einen deutlichen Hinweis gibt der Teil des Prophetengesetzes 18,14-20, den wir demselben Redaktor zuweisen, näherhin die VV. 18-20. Nach Art der legitimierenden prophetischen Berufungsberichte unterstreichen sie die Gegenständlichkeit des Gotteswortes: Jahwe gibt die Worte in den Mund des Propheten. Desgleichen betonen sie den konkreten Sprechakt ("ein Wort sprechen im Namen Jahwes"); das bestätigt eine Vermutung von Brongers, das "im Namen Jahwes" bedeutete hier mehr als "im Auftrag Jahwes"122, nämlich konkreter: "unter Verwendung des Jahwenamens". In bezug auf die priesterliche Tätigkeit spiegelt das dtn Gesetz eine Entwicklung wider, die - älter vom "Dienen im Namen Jahwes" redet $(18,5.7)$ und - später - dieselbe Tätigkeit mit "dienen und segnen im Namen Jahwes" $(10,8 ; 21,5)$ umschreibt. Mit Hilfe von Num 6,27 ist darunter der Sprechakt beim Segnen gemeint. Besonders einschlägig ist zum Schluß Dtn $28,58{ }^{123}$. In die geläufige Formel vom "Jahwe fürchten" wird in explikativer Asyndese ein zusätzliches neues Objekt "dieser herrliche und furchterregende Name" eingeschoben, singulär für das ganze Dtn. Dabei wird ein Epitheton, das sonst mit Jahwe verbunden ist (Dtn 7,21; $10,17.21)$ auf den Namen ubertragen.

121 ROSE, Ausschließlichkeitsanspruch, 77-94 spricht davon, daß die Langformen der Zentralisationsformel ("um seinen Namen dort wohnen zu lassen" "um seinen Namen dort hinzulegen") die Kurzformel ("der ort, den Jahwe sich erwählen wird") durch die Trennung zwischen Jahwe selbst und seinem Namen korrigieren. Innerhalb der Langformen konstatiert er eine Entwicklung. Eine jüngere dtr Schicht wechselt das Verb, statt שיםמן jetze "des breiteren Aussagehalts" wegen (a.a.0., 84) oder "weil die 'Ungewöhnlichkeit' des erwāhlten Ortes nach der zerstörung 587 ins Bewußtsein gedrungen ist" (a.a.o., 92 A 3). - HALPERN, Centralization Formula hebt mehr auf das Problem der Zentralisation ab als auf den "Namen Jahwes"; aber auch er unterscheidet zwischen der älteren Langformel mit שכן, die Konnotationen der Mobilität zulasse und die älteste Form der zentralisationsformel darstelle (a.a.o., 31.34f), wohingegen die jüngere Formel mit שים nach Ausweis der Parallelen im DtrG den Namen Jahwes stärker an Jerusalem binde (a.a.o., 32). Diese mehr lokale Differenzierung in den Langformeln impliziert ebenso eine wachsende Autarkie des "Namens", weil dessen lokale Bindung zunimmt.

122 DERS., Wendung, 7f - dazu paßt auch die "Proklamation des Namens Jahwes" in $\operatorname{Dtn} 28,10 ; 32,3$. 
Fazit: In den späteren Redaktionen des Dtn wird zunehmend die Eigenständigkeit des Jahwenamens betont und eine Tendenz zu einem dianoetischen Verständnis offenbart sich. Aus dieser Bewegung heraus wird das Namenverbot formuliert. Wie das Verb des Prohibitivs festlegt, geht es um das Aussprechen bzw. um die Verwendung des Jahwenamens.

Bei der weitverbreiteten Frühansetzung des Prohibitivs ist der Druck sehr stark, den Tatbestand zu konkretisieren ${ }^{124}$. Beliebt ist die Deutung auf Falschschwur bzw. Meineid hin. Dieses Verständnis bietet von der Sache her einige Vorteile. Denn das Delikt zeigt zwei Seiten: Einmal das gemeinschaftsschädigende Verhalten, zum anderen bedeutet es eine Beleidung Jahwes, der durch die Anrufung in das Vergehen verwickelt wird ${ }^{125}$. Wie die Position und die Formulierung anzeigen, hat das Namenverbot die theologische Komponente herausgelöst und zum Kern der eigenen Aussage gemacht. Durch die Stichwortassoziation über שוא nach Dtn 5.20 und Ex 23,1 hin schwingt im Namenverbot eine Verbindung zum juristischen Bereich mit. Ober diese Verbindung kann auch die Konnotation "Meineid" vorliegen. Nur ist das nicht die vom Namenverbot primär intendierte Aussage. Denn warum sollte der Redaktor die für diesen Tatbestand geläufige und gut bezeugte Formulierung "(im Namen Jahwes) falsch schwören" mit שבע im N-Stamm vermieden haben ${ }^{126}$ ? Diese Frage bringt uns auf eine interessante Fährte. Im ganzen Dtn schwört eigentlich nur Jahwe (Väterschwur); der Mensch darf zweimal in 6,13 und 10,20 "bei Jahwes Namen schwören". Hier steht die Wendung im Kontext von Verben für das Gottesverhältnis und bezeichnet umfassend das Bekenntnis zu Jahwe, hat also keine Verbindung zum Dekaloggebot ${ }^{127}$. Für den Redaktor und Autor des Namenverbotes konnte die Formulierung besetzt sein. Aber eine andere Erklärung drängt sich auf. Das dtn Gesetz zeigt ein auffälliges Desinteresse am Eid bzw. Meineid. Während das Bundesbuch in seinen prozeßrechtlichen Andeutungen sowohl den (einen) Augenzeugen kennt (Ex 22,9) ${ }^{128}$ und als ul-

123 Nach SEITZ, Deuteronomium, 298-302 gehört der Abschnitt 28,58-61 eng zu $17,18 \mathrm{f}$ und $31,9-11,12 \mathrm{~b}$. Die letzte Stelle haben wir einer Redaktion zugewiesen, die der hier behandelten vorausgeht.

124 JUCCI, La proibizione, 245-253 läßt die verschiedenen Deutungen Revue passieren.

125 Dazu GIESEN, Semantische Vorfragen, bes. 129-131.

126 Die Belege: Lev 5,22.24; 19,12; Jer 5,2; 7,9; Sach 5,3f; Mal 3,5; Ps 24,4 .

127 Vgl. LOHFINK, Hauptgebot, 79.

128 Dazu JACKSON, Essays, 167. 
tima ratio den Eid (Ex 22,7.10) oder ein Ordal (Ex 22,8) vorsieht, fehlen analoge Vorschriften im Dtn völlig. Nun schenkt das Dtn dem Prozeßrecht besondere Aufmerksamkeit ${ }^{129}$ und trotzdem erwähnt es keinen Eid. Der Eindruck drängt sich auf, daß das dtn Gesetz das Prozeßrecht reformiert, den Eid überflüssig und damit dem Meineid vorbeugen will. Die Zeugenregel (Dtn $17,6 ; 19,5)$ wie die wiederholte Vorschrift eines genauen Ermittlungsverfahrens (Dtn 13,15; 17.5; 19,18) sollen der Gefahr des Meineids zuvorkommen. Von daher ist zu schließen, daß der Autor des Namenverbotes den Tatbestand "Meineid" primär nicht im Blick hatte, denn er wußte um die Intentionen des dtn Gesetzes.

Auf diesem Hintergrund ist anzunehmen, daß es dem Redaktor von Anfang an um eine allgemeine Formulierung ging, die einen weiten Tatbestand abdeckt. Es geht um den Schutz des göttlichen Namens, wo immer er gebraucht wird, ob in der Prophetie, ob im Kult oder im privaten Alltag. Der "Name Jahwes" hat mittlerweile eine Eigenständigkeit erreicht, die sich ambivalent auswirkt. Zwar wird durch die Differenzierung zwischen Jahwe und seinem Namen die Freiheit Jahwes betont, aber sein Name wird verfügbarer. Der Gravitation zu dessen mißbräuchlicher Verwendung will das Namenverbot wehren. Aus dem adverbiell gebrauchten שוא ist bei der dünnen Bezeugung nicht viel Aufklärung zu gewinnen ${ }^{130}$. Vom dtn Kontext her kann damit der von Jahwe nicht autorisierte Gebrauch gemeint sein, sei es daß Jahwe zu einem konkreten Vollzug bzw. Aussprechen des Namens keinen Auftrag erteilt hat (Falschprophetie), sei es daß die Art der Verwendung und der Zweck vom dtn Gesetz nicht gedeckt sind.

\subsubsection{Das Sabbatgebot $(5,12-15)$}

Das Sabbatgebot ist oben unter 2.3 ausführlich besprochen worden. Hier geht es nun um seine Verankerung im Dtn und die Behandlung einiger Besonderheiten.

Der Infinitivus absolutus zu Beginn von Gesetzen bzw. Gesetzesabschnitten ist im dtn/dtr Schrifttum üblich 131 . Aus der doppelten Rahmung des Sabbatgebotes $(5,12 / / 5,15 b)$ fällt nur der finale und suffigierte Infinitivus

129 Siehe den Kasus von 13,13-19; den Musterprozeß 17,2-7; die Einrichtung eines Zentralgerichts $17,8-13$ und die Vorschriften zum Zeugen 19,15. 16-21. Vgl. auch Num 35,30.

130 SAWYER, Art. שוא, 883 tritt für die tbersetzung "zum Unheil, mißbräuchlich" ein. 
constructus mit minus taucht im Dtn nicht auf ${ }^{132}$. So besteht die Wahrscheinlichkeit, daß der Infinitiv mit Rücksicht auf die Exodusfassung, wo er in der Rahmung verankert ist, hier vom Pentateuchredaktor eingetragen wurde 133.

Der Kern des Sabbatgebotes liegt in der Satzgruppe VV.13f vor, die das zweiteilige Arbeitsverbot des Privilegrechts (Ex 34,21) und des Bundesbuches (Ex 23,12) verarbeitet. Der Ausbau zu einer Gruppe von vier Sätzen mit parallelem zweiten und vierten Satz will im dritten Satz, einem Nominalsatz, den Endpunkt des Zeitraums (hier den siebten Tag) definieren. Der vierte Satz (ein Prohibitiv) ist im Unterschied zum parallelen zweiten Satz (Injunktiv) durch Asyndese abgesetzt. Mit seiner Negation hebt er den Endpunkt vom vorausgehenden Zeitraum ab. Eine analoge Komposition bietet Lev 23,3; 25,3f. Diese Konstruktion ist mit ihren Parallelen zu vergleichen. In Frage kommen alle Stellen mit strukturell zweiteiliger Vorschrift zur Zeiteinteilung. Eine bestimmte Zeit sollst du tun ..., am Ende der Zeit sollst du tun .... Meist folgt darauf eine weitere Vorschrift zur Erläuterung ${ }^{134}$. Von allen Parallelen hebt sich das Sabbatgebot - es ist beim MT zu bleiben dadurch $a b, d a ß$ es im Nominalsatz zu Beginn des zweiten Teils den Endpunkt als Subjekt im status absolutus einfürt, während alle Parallelen dafür die Präpositionsverbindung "am siebten Tag/Jahr" einsetzen. Diese Besonderheit erklärt sich aus dem Anliegen des Sabbatgebotes: Der siebte Tag soll mit dem Sabbat identifiziert werden. Derselben Absicht dient die hier gleichfalls erstmalig vorkommende Konstruktverbindung יום השבת (s.0. unter 2.3.3). Die alte Anweisung "sechs Tage sollst du arbeiten (עבד)" (Ex 34,21) wird mit dem Ausdruck yשה מלאכה עשה Ex erläutert. Die in 23,12 angebotene Wendung מעשה wird vermieden, wahrscheinlich weil sie durch den Ausdruck "das Werk der Hände" gebunden ist, der in den späten Schichten des Dtn wie des DtrG in Konnex mit Götzenbilder gebracht wurde und deshalb anrüchig geworden ist ${ }^{135}$. Meistens entdeckt man in der Wendung עשה מלאכה priesterlichen

131 Vgl. Dtn 1,$16 ; 15,2 ; 16,1 ; 25,17 ; 27,1 ; 31,26 ;$ Jos 1,13 (dtr); Ex 13,3 (spät-dtr).

132 Die einzigen weiteren Belege des Verbs Dtn 15,19/H-Stamm und Dtn 32,51 (D-Stamm) kommen als Parallele nicht in Frage.

133 Dem priesterlichen Schrifttum ist die Heiligung eines Termins geläufig, vgl. THAT II, 605. Zur Abtrennung des Infinitivs auch REVENTLOW, Gebot, 55 (allerdings von anderen Voraussetzungen her); ebenso HULST, Sabbatgebot, 154.163f.

134 Die Parallelen: Ex 13,$6 ; 16,26 ; 31,5 ; 35,2$; Lev $23,3.8 ; 25,3 f$; Num 28 , 24f; Dtn 16,8. 
Sprachgebrauch ${ }^{136}$. Sie findet zwar in priesterlicher Literatur ihre größte Verbreitung, ist aber nicht auf sie beschränkt, sondern scheint eher auf Grund des Sabbatgebotes ihre breite Streuung erfahren zu haben 137 .

Der Sabbat gilt "für Jahwe, deinen Gott" - eine Redeweise, die von Ex 23,14 und vor allem von Dtn 16,1.10.15 her inspiriert ist.

In der anschließenden Kultteilnehmerliste fällt auf, daß der sonst an einigen Parallelen immer mitgenannte Levit fehlt ${ }^{138}$. Der $\lambda$ übernimmt wohl die Stellvertretung für die Trias der "personae miserabiles". Der Levit kann ausgefallen sein, weil die normierende Vorlage Ex 23,12b ihn nicht aufführt. Zugleich mag die exilische Situation und die Konzentration auf die Familie eine Rolle gespielt haben.

Die der Kultteilnehmerliste inhärente soziale Tendenz (s.0. 2.3.7) und die soziale Motivierung nach Art des vorgegebenen Arbeitsverbotes aus Ex 23,12b provozieren das dreiteilige Schlußschema des Sabbatgebotes. Durch Stichwortentsprechung (עבד) ist es an die Motivierung rückgebunden. Dtn 16,11f kann dabei Vorläufer und Stimulans gewesen sein 139.

Im Schlußschema läßt die Erinnerung an das Sklavendasein in Agypten die Erwähnung des Loskaufs (פדה) aus Agypten erwarten ${ }^{140}$. Der Redaktor ver-

135 Dtn 4,28; 27,15; 31,29; 1 Kön 16,7; 2 Kön 22,17 - Hos 14,4; Jes 2,8; 17,8 ; Mich 5,12; Je: 1,16; 25,6f; 32,30; 44,8 - zu den Konstruktverbindungen mit $T^{\top}$ im Dtn jetzt HALPERN, Centralization Formula, 28.

136 Zuletzt HALBE, Passa-Massot, 148 A 7.

137 Nicht leicht ist der jeweilige Bedeutungsgehalt von מלאכה zu bestimmen, der von schwerer Handarbeit ("Maloche") bis zu "Beschäftigung" und "Tätigkeit" reicht; vgl. SCHMIDT, Schöpfungsbericht, 156 A 4.5; CHOLEWINSKI, Heiligkeitsgesetz, 191 A 41. Zur Wendung שלאה מלאה: Verb und Objekt im vorpriesterlichen Sprachgebrauch: Gen 39,11; Dtn 16,8; 1 Kön 11,28 ; Jer 18,3 - priesterlicher Sprachgebrauch: Gen 2,2; Ex 31,14f; 35,$2 ; 36,2.4 .6$; Num 4,3. Die um כל erweiterte Wendung im vorpriesterlichen Sprachgebrauch: Dtn 5,13f; 1 Kön 7,14.40; Jer 17,22.24 - priesterlicher Sprachgebrauch: Lev 16,$29 ; 23,3.28 .30 f$; Num 29,7. Das Verb im NStamm im vorpriesterlichen Sprachgebrauch: Ri 16,11 - priesterlicher Sprachgebrauch: Ex 12,16; 31,15; 35,2; Lev 23,3; 11,32. Als Objekt eine Konstruktverbindung mit מלאכה nur im priesterlichen Sprachgebrauch: Ex 35,$35 ; 36,1.4 ;$ Lev $23,7 f .21 .25 .35 f$; Num $28,18.25 f$; 29,1.12.35.

138 Die Kultteilnehmerliste (vgl. oben unter 2.3.6 A 105): Dtn 12,12.18; $16,11.14 ; 26,11 \mathrm{~b}$ ( an dieser stelle sogar eigens sekundär an 26,11a angehängt).

139 MERENDINO, Gesetz, 135 weist 16,11aß dem dtn Redaktor zu; HORST, Privilegrecht, 120 rechnet dieselben Versteile zu seiner Redaktion D; CHOLEWINSKI, Heiligkeitsgesetz, $197 \mathrm{f}$ nimmt ebenso an, daß der Hinweis auf die Sklaverei durch die Aufzählung der personae miserabiles hervorgerufen wurde. 
פדה durch $\mathrm{x}$, 141.

Die Herausführung aus Agypten wird mit zwei adverbialen Bestimmungen näher beschrieben: "mit starker Hand" - "mit ausgestrecktem Arm". Wer ihren Ursprung ausfindig machen will, schlägt sich durch das Dickicht dtn/dtr Schichtungen ${ }^{142}$. Der Doppelausdruck ist im Dtn beheimatet; das Sabbatgebot hat inn übernommen und nicht geschaffen 143. Das isolierte "mit starker Hand" kommt in seinen Belegen dem Alter nach kaum über dtr Redaktionen hinaus ${ }^{144}$. Die Wendung "mit ausgestrecktem Arm" tritt nicht alleine auf, sondern geht neue Kombinationen ein. Ihre Belege reichen tiefer in dtr Schichten ${ }^{145}$.

140 Die eng verwandten Parallelen: Dtn 15,15; 24,18. Hinzu kommen jene Stellen, die פדה mit der ortsangabe "aus dem Sklavenhaus" verbincien (Dtn 7,8; 13,6; Mich 6,4). FLOSS, Jahwe Dienen, 56-63 schreibt Mich 6,4 jie erste Verknüpfung von פדה mit dem Sklavenhaus Ägypten zu - skeptisch dazu PREUSS, Art. KY?, 805. FLOSS übersieht die erstgenannten Stellen. Das Sklavendasein, Ägypten (das durch die Beiordnung negative Konnotationen erhält) und פדה werden zum ersten Male im Sklavengesetz des Dtn 15,15 verkettet (vgl. oben 2.3.7). Das ältere Gemeindegesetz dagegen Dtn 23,8b kann Ägypten noch im positiven Sinne erwähnen und zur Begründung anführen.

141 Vgl. LOHFINK, Dekalogfassung, 24.

142 Vgl. die Tabellen und Erläuterungen bei WEINFELD, Deuteronomy, 329; LOHFINK, Credo, bes. 29f; WEIMAR, Berufung, 329-331; PREUSS, Art. KY?, 813 .

143 Als älteste Stelle könnte Dtn 7,19 in Frage kommen (PERLITT, Bundestheologie, 59 A 3: dtn; LOPEZ, Analyse littéraire, 483ff.499.501: protodtn); 11,2 (?); $26,8 \mathrm{dtr} ; 4,34$ (dtr Redaktion nach der Grundschicht von Kap. 4 - vgl. oben 4.6); 1 Kön 8,42 (DtrN) // 2 Chr 6,32; Jer 21,$5 ; 32,21$ (beide Jer D); Ez 20,33 (red.); Ps 136,12.

144 Die vielfach den alten Pentateuchquellen zugewiesenen Belege stuft WEIMAR, Berufung, frühestens als dtr ein; die geprägten Wendungen sind dann von Dtn aus nach vorne in den Tetrateuch hineingetragen worden: Ex 3,19 und $6,1 \mathrm{ba}$ (dtr); 6,1bß (RP); 13,$9 ; 32,11$ (spät-dtr); Num 20, 20 (spät-dtr) - Singulär ist die Variation T בחזק Ex 13,3.14.16 (dtr?).

Im Dtn dürfte die älteste Stelle Dtn 7,8a (ohne ortsangabe) sein. Sie gehört zum Abschnitt 7,7.8a, der seine nächste Konstruktionsparallele in 9,28 hat; letztere stelle haben wir dem Autor des Grundtextes von Dtn 5 und 9 zugewiesen. Dtn 3,24 (vgl. 11,2) - nach MITTMANN, Deuteronomium, 93ff.183, $\mathrm{PL}^{1}$, sein erster Ergänzer der Grundschicht; 6,21 (späte dtr. Red. s.u.); 9,26b (Redaktion zur Grundschicht von Kap. 9f; mit 9,29 zusammenzunehmen, s.o. unter 2.7 .6 .5 ); 34,12 (nach-dtr);Jos 4,24 DtrG; Dan 9,15.

145 Die Kombination "mit großer Kraft und ausgestrecktem Arm": Dtn 9,29 (s.o. A 144); Jer 27,5; 32,17 (beide Jer D); 2 Kön 17,36 (DtrN). "Mit großer Kraft und starker Hand": (Dtn 4,37 - nach MITTMANN, Deuteronomium, 123.184 letzte Redaktion); Ex 32,11 (s.o.); Neh 1,10. 
Somit läßt sich das Sabbatgebot als geschlossene und überlegte Komposition erklären. Sie stammt aus der Hand eines dtr Redaktors. Sein Blick ist auf Privilegrecht und Bundesbuch gerichtet. Anregungen schöpft er aus dem dtn Festkalender in Kap. 16, den Zentralisationsgesetzen sowie aus Kap. 7.

Seine Hauptleistung liegt in der Fusion des Vollmondsabbat mit dem siebten Tag der Woche, der durch Arbeitsruhe gekennzeichnet ist. Also kam es ihm darauf an, die festlich - kultischen Implikate des Sabbat mit der Woche zu verknüpfen. Der vorexilische Sabbat ist charakterisiert durch den Besuch lokaler wie überregionaler Kultzentren, durch besondere kultische Aktivitäten am Heiligtum und durch festliche Versammlungen ${ }^{146}$. In Jerusalem wird er gleichfalls als Festtag am Tempel begangen und durch den Besuch des Königs im Tempel hervorgehoben 147. Auf der anderen Seite wird er nicht von der Kultzentralisation betroffen, denn wir entdecken auch nicht die Spur einer kultgesetzlichen Regelung zum Vollmondsabbat in den alten Gesetzeskorpora, geschweige denn in den vordtn/dtr Gesetzen. Daraus läßt sich vermuten, daß der Sabbat gegenüber dem Zusammenbruch im Exil widerstandsfähiger war, weil er kultgesetzlich nicht reglementiert und nicht an Jerusalem und seinen Tempel exklusiv gebunden war. Während die alten Wallfahrtsfeste obsolet geworden waren, konnte man mit dem Sabbat als dezentralisiertem Feiertag an die kultischen Traditionen vorexilischer Zeit anknüpfen. Das vermag die steile Karriere des neu konzipierten Sabbat in exilischer und nachexilischer Zeit zu erklären.

Die Auswirkungen des späten Sabbatgebotes sind in Dtn 16,3b.8 feststel1bar ${ }^{148}$. Beide Verse bzw. Versteile weisen Verwandtschaft mit dem Sabbatgebot auf, trennen sich aber zugleich von dessen Redaktionsschicht ab ${ }^{149}$. Sie

146 Vgl. 2 Kön 4,22f; Am 8,5; Hos 2,13; Jes 1,13.

147 Vgl. 2 Kön 11,5.7.9.14; 16,17f; Klgl 2,6 - dazu ROBINSON, The Origin, 1-112; STOLZ, Art. שבת, 865f.

148 Die eigene Terminologie, die an P erinnert, trennt beide Verse vom Kontext und verbindet sie. V.8 steht außerhalb einer in gewisser Weise konzentrischen Konstruktion von 16,1-7 und zeigt Spannungen zu V.3aß sowie V.7b. Beide Verse gehören zur vierten und letzten Redaktion von 16,1-7. Die Begründungen im Einzelnen gibt dazu HALBE, Passa-Massot, 148f.157f. 163.167.

149 Die Berührungspunkte: Die Rede vom "Land Ägypten" $(16,3 \mathrm{~b} / 5,15)$; der 6/7er Rhythmus $(16,8 / 5,13 f)$; die Wendung Uמכה מלאה $(16,8 / 5,13 f)$. - Die Unterschiede: זכר $(16,3)$ im Unterschied zu שמר (5,12); die Wendung "alle Tage deines Lebens" (16,3b vgl. 4,9; 6,2 etc.) $\neq$ "alle Tage, die (ihr) lebt" $(4,10 ; 31,13)$; die präpositionale Einführung des siebten Tages in 16,8 \# 5,14; der neue Terminus תצy (vielleicht weil der sabbat schon festge-

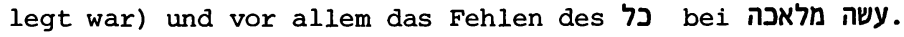


sind deshalb einer späteren Redaktionsschicht zuzuordnen, die aber unter Einfluß des Sabbatgebotes steht und dessen Rhythmus wie dessen Konzeption des siebten Tages auf das Mazzotfest anwendet ${ }^{150}$. Damit setzt der Proze $\beta$ der konsequenten "Sabbatisierung" der alten Feste nicht erst mit dem PSchrifttum ein, sondern nimmt in den späten dtr Redaktionen seinen Anfang (vgl. Dtn 16,8; Ex 13,6f). Dort wurde die neue Konzeption des Sabbat geboren und das Fundament für seine durchgreifende Wirkung gelegt, indem man das Sabbatgebot in den Dekalog aufnahm.

\subsubsection{Das Elterngebot $(5,16)$ \\ 4.7.4.1 Analyse der Komposition}

Vom Aufbau her prägt das Elterngebot eine strukturelle Zweiteiligkeit. Der erste Teil umfaßt die Einzelvorschriften mit dem Rückverweis. Der zweite Teil enthält den Segenshinweis mit zwei Finalsätzen und abhängigem Relativsatz. Die analog gebauten Parallelen aus dem Dtn können die Vorschrift grammatikalisch verschieden realisieren ${ }^{151}$. Ein absoluter Infinitiv als Stellvertreter eines finiten Verbs in Befehlsform findet sich unter den Parallelen nicht. Da er vom Kontext abhängig ist (in puncto Person, Modus, Tempus), ist ein solch isolierter absoluter Infinitiv mit parallelem Segenshinweis auch kaum zu erwarten. Vielfach steht er am Anfang von Befehlsketten ${ }^{152}$. Dabei

150 Dtn 16,8 ist geprägt durch das Fehlen einer Binnenbalance. In welchem Verhältnis stehen das Mazzot-Essen zur Arbeitsruhe? Das Kernproblem des Verses ist seine Zuordnung zu 16,1-7. Will der Vers ein Kontrastprogramm bieten - so HALBE, Passa-Massot, 149.167f: Ein neues Mazzotfest mit sechstăgigem Mazzot-Essen, Festversammlung und Arbeitsruhe am siebten Tag und vor allem Feier der gesamten Woche am Zentralheiligtum? Oder knüpft der Vers nur an 16,1-7 an und verschiebt die Akzente in Richtung eines neben dem Pascha gleichberechtigten Mazzotfestes: Feier des Pascha zusammen mit dem ersten Mazzottag am Zentralheiligtum, dann Rückkehr nach Hause und Essen der Mazzot für weitere sechs Tage mit AbschluB am siebten (real nun achten) Tag? - Vgl. die Andeutungen bei CHOLEWINSKI, Heiligkeitsgesetz, 179ff. Offen ist die Lokalisierung der Mazzotwoche von 16,8. Die behutsame Arbeitsweise dieser letzten Redaktion (vgl. 16,3b) muB dieser Vermutung nicht widersprechen. Im zweiten Falle wäre Dtn 16,8 noch näher verwandt mit dem dtr Abschnitt Ex 13,4-10, der ein eigenes Mazzotfest von sieben Tagen mit festlichem AbschluB am siebten Tage vorsieht. Vom Zentralheiligtum ist in den dtr Passa- und Mazzotvorschriften Ex 12,24-27a; 13,4-10 nicht die Rede, es sei denn, man will den Terminus an $($ Ex 13,6$)$ darauf festlegen.

151 Der Vergleich beschränkt sich auf Belege mit verwandtem Segenshinweis. Die Kombination von Imperativ und Finalsatz bieten: Dtn 4,1; 12,28 Injunktiv und Finalsatz: Dtn 22,7; 25,15 - Prohibitiv und Finalsatz: Dtn 12,25. Zu den weiteren Belegen mit Segenshinweis vgl. Tabelle $V$ in LOHFINK, Hauptgebot, $305 f$. 
kann er aber in seiner Position relativ unabhängig bzw. entfernt von nachfolgenden befehlenden Verbformen stehen. Die Parallelen gehören in diesem Fall überwiegend späteren Schichten des Dtn an 153. Will man in 5,16 einen absoluten Infinitiv identifizieren, dann wird er in seiner Qualität nicht durch das Elterngebot allein, sondern durch den weiteren Kontext festgelegt, insbesondere durch den parallelen Anfang des Sabbatgebotes ${ }^{154}$. Die Zugehörigkeit des Elterngebotes zum Block bzw. Einschub der Menschenrede (5,11-16) unterstuitzt diese Annahme. Die angegebenen Parallelen sprechen nicht dagegen. Da das Gebot der Elternehrung keinen alttestamentlichen Vorgänger besitzt, die Kombination von Einzelvorschrift und Segenshinweis dem Dtn geläufig ist ${ }^{155}$, spricht nichts gegen, aber vieles für eine Formulierung des gesamten Elterngebotes in einem Zuge. Wie kam es zur positiven (zweiteiligen) Formulierung des Gebotes, das ja auch als Prohibitiv mit Motivierung hätte ausgedrückt werden können? Der Rückverweis gibt direkt, und die Zugehörigkeit zu der Redaktionsschicht, die das Bundesbuch in der Sinaiperikope eingesetzt hat,gibt indirekt Aufschluß.Es kam dem Redaktor darauf an, die konkreten Vergehen von Ex 21,15.17 nicht zu selektieren, sondern ins Elterngebot zu integrieren. Er bildete deshalb aus der Vorlage keinen Prohibitiv, sondern wählte ein semantisch entgegengesetztes Lexem, das allgemein auf die gewünschte Haltung den Eltern gegenüber abhebt, ohne sich auf Konkretionen dieser Haltung festzulegen (s.0. 2.4.5). Dieser Tendenz zur abstrahierenden Allgemeinheit entspricht im Dtn der gegenüber dem Elterngebot ältere kasuistische Rechtsfall des störrischen Sohnes (Dtn 21,18-21aa). Dort wird der Straftatbestand durch Partizipien dargestellt, d.h. die grundsätzliche Leugnung der elterlichen Autorität und damit die Negierung der natuirlichen Eltern-Kind-Beziehung ${ }^{156}$. Prohibitive mit den dortigen Verben (מרה/סרר) tauchen im AT nicht auf und boten sich nicht an.

Weitere Motive zur Abfassung des Gebotes sind zu erwägen. Bei dieser späten Schicht des Dtn kann sich der Einfluß des weisheitlichen Mahnspruchs verstärkt haben ${ }^{157}$. Ebenso haben die älteren Gebotskompositionen in Dtn $22,6 \mathrm{f}$ und 25,13-15.16 ihren Einfluß ausgeübt.

152 Vgl. oben A 131 und GK $\S 113 a a$ sowie WATTS, Infinitive Absolute, bes. 143.

153 Die Belege: 2 Kön 3,16 (dazu SCHWEIZER, Elischa, 29f); Dtn 24,9; 25,17; 27,1 ; Jos 1,13 .

154 Vgl. mit dieser Argumentation JoÜoN, § $123 \mathrm{v}$.

155 Vgl. oben A 151; dazu noch: Dtn 16,20; 23,21 - ebenso DIEPOLD, Israels Land, 94 .

156 Vgl. o. 2.4.5 A 214 und BELLE FONTAINE, Rebellious son, 15f.17.19. 


\subsubsection{Erweiterung des Interpretationsrahmens}

Bis jetzt haben wir die Formulierung des Elterngebotes für sich betrachtet. Sie versteht sich selbst als zusammenfassende Interpretation der alten Todesrechtssätze aus dem Bundesbuch Ex 21,15.17. Das Gebot verlangt eine Haltung des Respekts den Eltern gegenüber. Worin sich dieser Respekt ausdrückt, bleibt offen. Auf jeden Fall werden verbale und handgreifliche Aktionen abgelehnt, die die elterliche Autorität untergraben. Unbeantwortet ist die Frage, warum der Redaktor das Elterngebot für seinen Dekalog auswählte und warum er inm die Schlußposition auf seiner ersten Tafel der Gottes-Gebote anwies. Mehr ins Exegetisch-Technische übersetzt lautet die Frage: Lassen sich aus dem Makrokontext des Dtn und aus dem nahen Kontext weitere Texte derselben Redaktion Aufschlüsse darüber gewinnen, was der Redaktor unter Eltern un Kindern verstand, und welche Funktionen oder Aufgaben er innen zuwies? Um das Spektrum möglicher Verhaltensweisen gegenüber den Eltern zu zeigen und um zugleich auch einen diachronen Parameter zu gewinnen, sollen die Stellungnahmen der Proverbienliteratur zur Eltern-Kind-Beziehung geordnet aufgeführt werden. Das Buch der Sprüche bietet zu diesem Problem das meiste Material; dazu verbleiben wir in einem überschaubaren Textbereich.

\subsubsection{Exkurs: Das Verhältnis der Kinder zu den EZterm im Buch der Sprüche 158}

Die Belege werden gleich zu Gruppen geordnet sowohl unter formkritischem wie inhaltlichem Aspekt.

Die erste Gruppe bietet zweiteilige Sprüche. Als Protasis stehen Partizipialsätze, die ein konkretes Verhalten gegenüber den Eltern beschreiben. In der Apodosis werden daraufhin Fol gen angedroht oder das Verhalten wird bewertet.

Spr 20,20 behandelt den Elternfluch oder die Schmähung (קלל/D-Stamm). Es ist der bestbezeugte Straftatbestand bezüglich der Eltern auch innerhalb Rechtskorpora ${ }^{159}$. Der Nachsatz droht mit den Folgen. Nahe verwandt ist

157 Einschlägig sind die strukturellen und inhaltlichen Parallelen: Spr $3,1 \mathrm{f} ; 4,10 ;(9,10 f)$.

158 Vgl. dazu RICHTER, Recht, 17of; ALBERTZ, Elterngebot, 364-369; ebenso GERSTENBERGER, Wesen, 117-130; DERS./SCHRAGE, Frau und Mann, 64-68.

159 Siehe den Todesrechtssatz in Ex 21,17; den apodiktischen Relativsatz Lev 20,9; den Fluchsatz Dtn 27,16 mit der allgemeineren Nebenform von קלל, nämlich קלה/H-Stamm; Ez 22,7 konstatiert in einem Gerichtswort dieses paradigmatische Vergehen. 
Spr 30,11; der Straftatbestand ist identisch. Der Partizipialsatz löst sich auf in einen asyndetischen Relativsatz, der das Geschlecht der Gottlosen beschreibt. In Spr 30,17 ist der Straftatbestand in einen asyndetischen Relativsatz gepackt (Verachtung und Spott für die alten Eltern). Die Folge des Vergehens wird die ehrlose Bestattung sein. In Spr 28,24 wird ein älterer Prohibitiv, der das Berauben (ג) von Abhängigen und Schwachen, d.h. das Vorenthalten von gerechtem Lohn und Versorgung bietet ( $v g 1$. Spr 22,22; Lev 19,13), zu einem Partizipialsatz umgeformt und auf die Eltern angewandt. Der Nachsatz bewertet die Tat. Der Vordersatz von Spr 19,26 formuliert partizipial wie mit finiter Verbform den Straftatbestand der Mißhandlung und Vertreibung der Eltern. Der Nachsatz gibt eine Bewertung. Die gesamte erste Gruppe blickt überwiegend auf den erwachsenen Sohn und beobachtet sein Verhältnis zu den alten Eltern.

Die zweite Gruppe präsentiert meist parallel gebaute Sentenzen, die das Ideal der Weisheit, nämlich den gerechten und weisen Sohn, mit dem Motiv der Elternfreude verbinden. Sein Gegenteil, der Tor, bereitet den Eltern Schaden und Verdruß ${ }^{160}$. Die Sentenzen schildern das Verhalten des Sohnes mit abstrahierender und stereotyper Terminologie. Konkretionen tauchen selten auf. Deswegen können die näheren Umstände im Verhältnis Eltern- Kind nicht angegeben werden. Stellen wie Spr 29,15.17 aber deuten die Verschiebung ins Pädagogische an: Die Eltern treten ihren jugendlichen Kindern als Erzieher gegenuiber und vermitteln Weisheit. Gelegentlich wird die Sentenz zu einem Konditionalgefüge $(23,15)$ oder Mahnspruch $(27,11 ; 29,17)$ aufgebrochen, was schon auf die folgende Gruppe hinweist.

Die dritte Gruppe zeigt Instruktionen bzw. Mahnsprüche (Imperativ oder Vetitiv + Motivierung) 161 . Sie leiten mit Vorl iebe Lehrreden und Spruchgruppen ein und fordern die Aufmerksamkeit des Hörers für die folgende Weisung. Die Eltern erziehen bei dieser Gruppe ihre jungen Kinder; sie vermitteln Erfahrungs- und Traditionswissen. Der junge Sohn und Schüler soll ihnen gegenüber aufgeschlossen, lernwillig und gehorsam sein.

160 Zur zweiten Gruppe gehören: Spr 10,1; 15,20;17,21.25; 19,13a; 23,15. $24 ; 27,11 ; 28,7 ; 29,3.15 .17$.

161 Zur dritten Gruppe gehören: Spr 1,$8 ; 4,1-3 ; 6,20-22(10,1$ als Stellvertreterin in Anfangsposition); $23,22(31,1 \mathrm{f})$. 
Von der ersten über Vermittlung der zweiten hin zur dritten Gruppe gibt es eine sachliche Verschiebung, gepaart mit einem diachronen Gefälle. Die ältere erste Gruppe betont die sozialen Tugenden. Der erwachsene Sohn soll auf die alten Eltern Rücksicht nehmen. Die jüngere dritte Gruppe konzentriert sich auf die Kindererziehung. Die jungen Kinder sollen das lebensnotwendige Wissen der Eltern übernehmen.

\subsubsection{Der Rechtskontext des EZterngebotes}

Ein analoges Gefälle läßt sich innerhalb der Gesetzeskorpora beobachten. In diesem Zusammenhang spielt die Spannweite des Elterngebotes selbst von Ex $21,15.17$ bis Dtn 5,16 eine Rolle. Hinzuzunehmen ist die jüngere Variante des El terngebotes in Lev 19,3 162 .

Im dtn Gesetz geben zwei Paragraphen des Familienrechts Auskunft über die Funktion und Rechtsstellung der Eltern: Der Paragraph über Vortäuschung von Jungfrauschaft bei Heirat 22,13-21 und der Fall der Gehorsamsverweigerung beim Sohn 21,18-21. In ersten Fall stehen die Eltern in der Blüte der Jahre; ihre Tochter befindet sich im heiratsfähigen Alter. Die Mutter ist in gewisser Weise an der Verhandlung beteiligt; sie ist also rechtsfähig. Beide Elternteile (vor allem der Vater) übernehmen die Funktionen eines Anwalts für ihre Tochter vor dem Altestengericht. Der zweite Fall zeigt beide Elternteile in gleichberechtigter Rechtsfähigkeit. Vater und Mutter sind physisch in der Lage, den widerspenstigen Sohn zu überwältigen und vor das Gericht zu schleppen. Es handelt sich also um einen Fall aus der Kindererziehung. Der schwer erziehbare Sohn steht im jugendlichen Alter; die Eltern haben noch die volle Verfügungsgewalt. Dem Redaktor des Elterngebotes lagen beide Fälle vor. Den Straftatbestand des "Nicht-Hörens / Nicht-Gehorchens" kennt er noch von anderer Stelle aus Dtn 17,12. Dort wird die Gehorsamsverweigerung gegenuiber dem Priester und dem Richter am Zentralgericht ebenso wie gegenüber den Eltern mit dem Tode bestraft. Diese Paragraphen muß der Redaktor gut kennen. Denn er beutet ihn für seinen Anteil am Prophetengesetz aus. Den Straftatbestand von 17,12 kopiert und variiert er in seinem Fall des Ungehorsams gegenüber dem prophetischen Wort in 18,19. Die Rechtsfolge

$162 \mathrm{Vgl}$. oben 2.7.4 A 513. Zur Interpretation noch ALBERTZ, Elterngebot, 355; JAGERSMA, Lev 19, 74-76; CHOLEWINSKI, Heiligkeitsgesetz, 259-262. Der Injunktiv gebietet die ehrfurchtsvolle scheu der jungen Kinder (deshalb auch vielleicht die Voranstellung der Mutter) vor den Eltern als Vermittler auch von religiösen Traditionen. 
mit Todesstrafe setzt er für seinen Fall des Falschpropheten ein in 18,20. Den Vorgaben aus dem dtn Gesetz wie dem Redaktor liegt an der Respektierung institutioneller und elterlicher Autorität.

Nun $1 a ̈ ß t$ sich nachweisen, daß die formal geschützte Autorität der El tern gerade bei diesem Redaktor in besonderer Weise aufgefüllt wird. Er stilisiert die Weitergabe von Gesetzen zu einer Vermittlung von Lehre. So betont er das Lehramt des Mose (Dtn 4,1.14;6,1). Im Gegensatz definiert er die Aufgabe der gegenwärtigen Generation von Israeliten: Sie selbst sollen lernen und als Eltern ihre Kinder lehren ${ }^{163}$. Im folgenden sollen Belege derselben Redaktion vorgeführt werden.

\subsubsection{Die Aufgabe der EZtern im Kontext der Redaktion des EZterngebotes}

Die erste Stelle Dtn 4,10 (s.0. 4.6) erzählt von der Horebtheophanie. Jahwe verkündet den Dekalog. Die Israeliten sollen ihn lernen und an ihre Kinder weitergeben. Die zweite Stelle Dtn 11,18-21* offenbart einen ähnlichen Vorgang ${ }^{164}$. Nur geht es hier um das mosaische Gesetz. Die gegenwärtige Gene-

163 Zwar heben die Vorgängerredaktionen auch schon darauf $a b$, allerdings nicht so pointiert und so konsequent wie dieser Redaktor. Dtn 5,31 (Grundtext von Kap. 5) zeichnet Mose als Lehrer. Eine frühe Redaktion von Dtn $5(5,1 \mathrm{~b} ; 31,12 \mathrm{~b})$ fordert die Israeliten auf, das mosaische Gesetz zu lernen. Ansteckung durch falsche Lehre und schlechtes Lernen bei den Nachbarvölkern wollen 18,9 und 20,18 unterbinden. Dtn 14,23b und 17,19 verschmelzen das Lernen der Gottesfurcht mit dem Gesetzesgehorsam und entsprechen darin dem Anliegen und der Terminologie unseres Redaktors, wie 4,10 und 31,3 zeigen. Dtn 4,5 erwähnt die Lehre des Mose in Anhängigkeit von 4,14; der Rahmen des Moseliedes 31,19.22 läBt Mose das Lied lehren. zu diesen Zusammenhängen s. BRAULIK, Weisheit, 17 of.

164 Die Forschung (vgl. LOHFINK, Hauptgebot, 235 und SEITZ, Deuteronomium, 87f) hat diesen Abschnitt als jüngeren Seitengänger von Dtn 6,6-9 ausgewiesen, der die alte Einleitung zum dtn Gesetz verarbeitet und in spezifischer Weise abwandelt. Der Abschnitt $11,18-21$ ist nicht einheitlich. Während die Wv.18-19a.21 ihr Modell kreativ variieren und pluralen Numerus haben, versucht der singularische Einschub Vv.19b.2o vor dem abschließenden Segenshinweis noch Fehlendes aus 6,7.9 wortwörtlich nachzutragen. Mose spricht. In für das Dtn singulärer Weise bezieht v.18 die דברים auf Mose (vgl. BRAULIK, Ausdrücke für "Gesetz", 45 A 3). Die Wendung "diese meine Worte" zielt kataphorisch auf das folgende mosaische Gesetz (vgl. etwas undeutlich LOPEZ, Deutéronome, 165 A 19). Die Verse übernehmen damit die gleiche Funktion wie der sekundäre Promulgationssatz in 6,6 (s.0.4.1 A 8), der von demselben Redaktor stammt. Der Abschnitt teilt sich in drei Teile auf. Der erste Teil (V.18) betont die Aufnahme der Moseworte durch die gegenwärtige Generation. Er zieht 6,6.8 zusammen und verstärkt die Aktivität der Angeredeten. Der zweite Teil (V.19a) unterstreicht das Lehren. Er wechselt das Verb zu 
ration bzw. die Eltern sollen es sich einprägen und dann die Söhne darin unterweisen. Auf diese Weise wird das lange Leben beider Generationen im zugesagten Land gesichert. In Dtn 31,13 trägt die Redaktion eigens nach, daß auch die nicht wissenden Kinder die "Worte dieser Tora" hören und lernen sollen ${ }^{165}$. Die Erweiterung der Vorlage 31,9-11 um VV.12a.13 verdoppelt den Lernvorgang. Aus den vormals Angeredeten wird die gegenwärtige El terngeneration mit Verantwortung für die unwissenden Söhne. Die Weitergabe der Tora ist darin impliziert, auch wenn sie expressis verbis nicht ausgeprochen wird.

Die Auffassungen dieser Redaktion haben spätere Bearbeitungen beeinflußt. Die verwandten Verse Dtn 4,9 und 6,2 (DtrN) erweitern die Tradentenkette auf drei Generationen. Die Horebereignisse sollen weiterverkündet werden, genau so wie sich die Generationen im Gesetzesgehorsam vereinen ( $\mathrm{vgl}$. Ex 10,2 ; Ps 44,2; 78,3f). Der hinter dem Moselied nachgetragene Abschluß 32,4547 verschärft sogar die Vermittlungsaufgabe der Eltern zur Befehlsgewalt den Kindern gegenüber ${ }^{166}$. Meiner Meinung nach gehört in diesen Zusammenhang auch der Abschnitt Dtn 6,20-25 ${ }^{167}$. Ober die Kinderfrage verankert ein Redaktor das "Lehramt der Eltern" in der gründenden Zeit der Wüste.

Th/D-Stamm und wandelt die Parataxe von 6,7 zur Hypotaxe. Beide Operationen verweisen auf den Utbermittlungsvorgang. Der dritte Teil (V.21) schlieBt beide Generationen im Segenshinweis zusammen. Für die Zugehörigkeit von 11,18-19a.21 zur behaupteten Redaktion sprechen folgende Gründe: Im Dtn sprechen nur 4,10 und 11,19 von einer Lehrfunktion der gegenwärtigen Generation. Die Hypotaxe mit $\rangle$ ist bei dieser Redaktion beliebt (vgl. 4,14; 6,1; 31,13). Der "Himmel" wird häufig erwähnt (vgl. $4,11.26 a ; 11,21)$. Die einmalige Variante vom "zahlreich sein der Tage" bezeugt die Beziehung zur Weisheitsliteratur $(11,21 / / \operatorname{Spr} 9,11)$. Und schließlich stimmt der Numerus noch überein.

165 Die fast wörtlichen übereinstimmungen dieses Verses mit Dtn 4,10.14.26a lassen an der Zugehörigkeit keinen Zweifel (vgl. oben unter 4.6).

166 Die genaueste Analyse des Abschnitts hat SEITZ, Deuteronomium, $34 f$ vorgenommen. Demnach kompiliert der Abschnitt insbesondere Texte der hier beschriebenen Redaktion.

167 Eine neue Untersuchung dieser Passage hat LOPEZ, Analyse littéraire, 504-508; DERS., Deutêronome, 174-176.183f vorgenommen. Ich stimme seiner Abtrennung von VV.22.23a.25 zu, halte aber weitere Ausscheidungen (vor allem wegen der Wir-Rede) für überflüssig. LOPEZ weist den Abschnitt dem dtn Redaktor zu. Ich halte diese Einstufung für zu früh (vgl. oben 4.2 A 15) . 6,20 ist durch die seltene singuläre Trias der Gesetzestermini mit 4,45 verbunden (vgl. noch 6,17). Schon allein diese Trias und deren freie Zusammenfassung in 6,24 spricht für einen späteren Redaktor, der das breiter gestreute Duo der "Satzungen und Rechte" großzügiger verarbeiten kann. Für Israel wird die späte Bezeichnung "Söhne Israels" $(4,45)$ gewählt, deshalb ist in 6,20f der einzelne Haus- 


\section{4.?.4.6 Resultat zum Elterngebot}

Wie in der späten Weisheit vermitteln bei diesem Redaktor die Eltern das Traditionswissen, das sie selbst empfangen und erlernt haben. Die Tradition hat sich im Dekalog und dem mosaischen Gesetz verfestigt. Vom nahen Kontext ein- und derselben Redaktionsschicht her darf man annehmen, daß das Elterngebot den Respekt vor innen als "Gesetzeslehrer" impliziert. Das Elterngebot ist also eine späte Formulierung, die sich bewußt allgemein ausdrückt, um sowohl die soziale Rücksicht auf die Eltern wie die Anerkennung ihrer Vermittlungsaufgabe zu integrieren. In der Zeit des Redaktors, dem Exil, sind die Institutionen zusammengebrochen, die profane wie religiöse Tradition gebunden und gepflegt haben. In diese für das Oberleben und die Identität des Volkes lebensgefährliche Lücke müssen die Eltern einspringen. Das erklärt zureichend die Bedeutung und Auswahl des Elterngebotes für den Dekalog und seine vornehme Position auf der Tafel der Gottesgebote. Mit der exilischen Spätansetzung schwächt sich auch das Rätsel der fehlenden Nachwirkung des Elterngebotes ab. Hier sei nur noch einmal verwiesen auf die späte Weisheit in Spr 1-9 sowie Mal 1,$6 ; \operatorname{Sir} 3,1-16 ; 7,27$ sowie auf das Buch Tobit 168 .

\subsubsection{Die Verschmelaung von Fremdgötter- und Bilderverbot durch 5,9a}

Mit Verweis auf den synoptischen Vergleich (2.1) resumieren wir die Prämissen zur Behandlung von 5,9a. Im Deuteronomiumdekalog bezieht sich 5,9a über das Bilderverbot in 5,8 hinweg auf das Fremdgötterverbot in 5,7. Die syn-

vater angesprochen, der seinen Sohn in das Gesetz einzuweisen hat. In dem Abschnitt fällt im Vergleich mit parallelen Credoformulierungen die finale Unterordnung der Hereinführung auf. LOPEZ, Analyse, 507 will sie mit der stilistischen Eigenart des dtn Redaktors erklären. Warum aber sollte der Stil des Redaktors gerade und nur an dieser stelle durchbrechen? Die Erklärung von LOHFINK, Hauptgebot, 161 bleibt angemessen, weil textgerecht. Mit der finalen Unterordnung der Hineinführung signalisiert der Abschnitt seinen standort: in der wüste, vor der Hineinführung! Das korrespondiert mit einer weiteren Besonderheit. Mose hat zwar das Amt des Sprechers inne $(4,45)$, aber Jahwe befiehlt die Gesetze direkt an die Adresse der Väter $(6,20.24)$. Es geht vor allem um deren Aufgabe, über die Gesetze Auskunft zu geben. Die Frage der Söhne aber entzündet sich am Tun bzw. Befolgen der Gesetze durch die väter.

$168 \mathrm{Vgl}$. ALBERTZ, Elterngebot, 364ff; für das Aufgreifen des Elterngebotes im Buche Tobit wird auf die demnächst erscheinende Münsteraner Dissertation von DESELAERS verwiesen: DERS., Tobit, Kap. I, Teil II, A 358 und jeweils zu den Stellen. 
taktische Form wie die Position des Halbverses ergeben sich aus seiner Funktion. Er soll die beiden vorausgehenden autarken Gebote zu einem Gebot verschmelzen. Der Halbvers lehnt sich an die Rahmung des Grundtextes $(5,6.9 b)$ an und arbeitet mit analogen stilistischen Mitteln. Die Klammer, die der Grundtext um die beiden Gottesgebote legt, wird noch enger gezogen.

Die Verschmelzung beider Gebote folgt mit logischer Konsequenz aus der bisherigen Arbeit der Redaktion. Sie kreiert ja den Dekalog: Sie führt die Zehnernorm ein - bei ihrem pädagogischen Interesse (Elterngebot!) kein Wunder. Die klassische Erklärung der Zehnzahl als mnemotechnisches Mittel der Unterweisung ist nach wie vor die beste. Die Redaktion führt die Tafeleinteilung ein. Ihre zweite Tafel enthält sechs Gebote, die sie durch Syndese verbindet ${ }^{169}$. Auf ihrer ersten Tafel erweitert sie den Grundtext beträchtlich durch drei neue Gebote. Um ihre Zehnernorm zu retten, muß sie Fremdgötter- und Bilderverbot vereinen. Dadurch vollzieht sie konsequent, was durch die Rahmung der Jahwerede im Grundtext schon angelegt ist, nämlich die Nachbarschaft von beiden Geboten.

5,9a ist die erste Stelle, die die ältere Reihung von 1. הוה . umkehrt, wahrscheinlich unter Einfluß des Privilegrechts Ex 34,14. Im Namenverbot und im Sabbatgebot haben wir ja beobachtet, daß der Redaktor Ex 34 nicht aus dem Auge verliert. Alle weiteren Parallelen der jüngeren Reihung gehören späteren Redaktionen an 170 .

Läßt sich die Vereinigung von Fremdgötter- und Bilderverbot nicht nur aus der Dekalogbearbeitung, sondern auch aus dem nahen Kontext der Redaktion plausibel machen? Das ganze Kapitel Dtn 4 nimmt der Formulierung nach das Fremdgötterverbot nicht auf. Wenn es von Fremdgöttern der Sache nach handelt, dann durch den Filter des Bilderverbots 171 . Diese Akzentverschiebung setzt logisch die Vereinigung beider voraus. Sie wurde von den an Kap. 4 beteiligten Redaktoren entweder schon vorgefunden oder selbst geschaffen. Wir

169 Wahrscheinlich schiebt sie auch in Dtn 5,21 mit Rücksicht auf das Sabbatgebot und vielleicht das Bundesbuch die in der Immobilienliste fremden Paare "Sklave/Sklavin" - "Rind/Esel" ein (vgl. oben 2.6.4.2.2).

17o Die Parallelstellen aus dem Dtn 4,19 und 30,17 sind der Formulierung nach miteinander verwandt. Beide hăngen von der obigen Dekalogredaktion ab; Ex 23,24a (spät-dtr, nach FLOSS, Jahwe Dienen, 247-275); 1 Kön 9,9 (DtrN); 2 Kön 21,3 (DtrG); Jer 22,9 (Jer D); zu den Reihungen vgl. oben 2.1 .

171 Dazu BRAULIK, Rhetorik, 44 A 112. 
halten unseren Redaktor und Dekalogbearbeiter für den, auf den die Grundschicht von Kap. 4 zurückgeht ${ }^{172}$. Er hat die Vereinigung beider Gebote im Dekalog bewerkstelligt und nimmt das auch in Kap. 4 auf. Das"vorangehende" Echo davon ist in 4,23aba.25aba zu vernehmen ${ }^{173}$. Die Warnung, die Horebberît, d.h. den Dekalog, nicht zu vergessen, wird konkretisiert mit dem Bilderverbot. Das Bilderverbot hat die Position des Ersten Gebotes eingenommen. Damit wird die Tendenz hinter der Vereinigung beider Gebote deutlich. Es geht nicht um Unterordnung des Bilderverbotes, sondern um dessen Erstplazierung (mindestens pari loco). Weil in 4,23.25 die Apposition zu פסל in gegenüber 5,8 umgekehrter Konstruktverbindung stilistisch glatter eingesetzt wird, sind die Ergänzungen zum Prohibitiv des Bilderverbots in 5,8 diesem Redaktor nicht zuzutrauen; es bestand für ihn auch nicht die Notwendig̣keit, sie nachzutragen. 174

172 Bisher wurde dieser Redaktion - in modifizierendem Anschluß an MITTMANN - 4,1.10-14*.26a zugewiesen, was sich vor allem aus den Querverweisen ergab (vgl. oben 4.6).

173 Die Paränese von 4,23 lenkt zum Schluß in 4,26a über. V.23ba und v.25ba sind fast identisch. Die wiederholung kann mit der intensiven Warnung vor dem Verstoß gegen das Bilderverbot erklärt werden. Die Formulierungen des Bilderverbots sind bescheiden gehalten im vergleich zur ausgebauten Terminologie von 4,16-18. Die Vv.12b.15-18 gehören zu einer weiteren Redaktion, die an die Theophanieschilderung der Grundschicht von Kap. 4 (unser Redaktor!) anknüpft und den Theophaniebericht für ihre neue Argumentation benützt. Es geht nicht mehr um die Weitergabe von Gesetzen "unter Blitz und Donner", sondern um die Art der Theophanie. Neu ist die Polemik gegen die Gestalt im Namen des Wortes. Für die zugehörigkeit von 4,23.25* zur Grundschicht spricht vor allem die Näherbestimmung der Horebberît in einer Konstruktverbindung (vgl. 4,23 mit 4,13 - s.o. unter 4.3). Der Relativsatz in v. 23 nimmt die Redeweise des Grundtextes von Dtn 5,9f (vgl. 5,2; 9,9) auf - auch das weist auf das Verfahren unseres Redaktors hin. Zum Kampf um Kap. 4 vgl. MITTMANN, Deuteronomium, 115-124; BRAULIK, Literarkritik, 351-378; jüngst: BEGG, The literary Criticism.

174 Wenn man keine Erweiterung in zwei Schüben annehmen will (vgl. ZIMMERLI, Das zweite Gebot, 235 A 3 und s.o. 2.1) und dadurch sich die Schwierigkeiten einhandelt, zwei Erweiterer zu identifizieren, kann man es mit einem Ergänzer versuchen. Als erster käme der Redaktor von 4,12b. 15-18 in Frage, weil er das Motiv für eine Ergänzung mitbringt, nämlich alle abbildbaren Lebewesen der Kreaturen ausdrücklich in den Prohibitiv einzubeziehen. Im Dekalog redet er verkürzt. Seine eigene Schwierigkeit in 4,17f, die vier Tiergattungen auf die drei Räume des Kosmos zu verteilen, vermeidet er. Es bleibt die Crux des syntaktischen Anschlusses der Relativsätze an die Apposition in 5,8. Daß der Redaktor flüssiger und präziser formulieren kann, zeigt er in 4,16-18. Dann verbleibt nur die Möglichkeit, $d a \beta$ er im Dekalog in verkürzender Redeweise zentrale Stichworte seiner eigenen Argumentation nebeneinandersetzt; vgl. die stilistische Analyse von 4,15-22 bei BRAULIK, Rhetorik, $35-47$. 
Nicht von ungefähr wäh1t der Redaktor das seltene Verb פסל für die Herstellung der beiden Steintafeln (Ex 34,1.4; Dtn 10,1.3) ${ }^{175}$. Darin mag eine polemische Anspielung an das Bilderverbot liegen. Es darf in der Welt keine andere greifbare Repräsentation Jahwes, kein Bild geben, es sei denn den in Stein gehauenen Dekalog.

\subsubsection{Ergebnis}

Die "klassischen" Spannungen im Dekalog (Sprecherwechsel, Wechsel von Negation zu Position bei den Geboten, unterschiedlich metrische Gestaltung, unterschiedliche Reihung etc.) haben sich großen Teils auflösen lassen durch die Hypothese einer umfassenden dtr Redaktion des Dekalogs, die den Dekalog erst zu den "Zehn Geboten" auf zwei Tafeln gemacht haben. Sie beschränkt sich nicht auf Ergänzungen eines "Urdekalogs", weil ihre Vorlage kein Dekalog ist und sie diesen erst herstellt. Sie bearbeitet eine vorgegebene Gebotsreihe. Dabei steht sie unter spezifischen Zwängen und verfolgt bestimmte Absichten. Inr Horizont umfaßt das Privilegrecht, das Bundesbuch und das dtn Gesetz. Im Dekalog gehören zu dieser Redaktion: V.9a in der Funktion, Fremdgötter- und Bilderverbot zu verschmelzen und sie so zum ersten der Zehn Gebote zu machen; VV.11-16 (Namenverbot, Sabbat- und Elterngebot); die waw copulativa der zweiten Tafel und wahrscheinlich die Auffüllung der Immobilienliste von 5,21 (Sklave/Sklavin - Rind/Esel). Einer nachfolgenden dtr Redaktion wird die Ergänzung des Prohibitivs in 5,8 zugewiesen.

\subsection{Die originale Komposition und mögliche Vorstufen}

Im Gang der Analyse wurden schrittweise Spannungen reduziert, so daß sich jetzt ein relativ spannungsfreier Grundtext ergeben hat. Er besteht strukturell aus zwei Teilen: einem gerahmten "Kopf" und einer asyndetischen Reihe von sechs Prohibitiven (Dtn 5,6-8a*.9b-10.17-21). Der konzentrische Aufbau des ersten Teils ergibt sich dadurch, daß die um die Apposition "dein Gott" erweiterte Selbstvorstellung von 5,6 in 5,9b wiederholt wird.

Zur sogenannten Hofal-Vokalisierung des zweiten Prohibitivs von 5,9a vgl. ZIMMERLI, Das zweite Gebot, 237 A 10 und LOHFINK, Dekaloganfang, 109 A 42. Die diachrone Linie der einschlägigen Stellen läuft von Dtn 13,3 (vor-dtn) über Dtn 5,9a nach Ex 23,24.

175 Das Verb kommt sonst nur in 1 Kön 5,32 (Tempelbau) und im sekundären Vers Hab 2,18 (Götzenbilder) vor; vgl. PERLITT, Bundestheologie, 213 A 3 . 
Beide Male wird sie durch erläuternde Sätze ergänzt, die die Aufgabe haben, das Subjekt der Selbstvorstellung näher zu beschreiben, in 5,6 durch einen Relativsatz und in 5,9b.10 durch eine weitere Apposition sowie zwei syndetisch zusammengebundene Partizipialsätze ${ }^{176}$. Die Rahmung umschließt ihr Zentrum, zwei asyndetisch aufeinanderfolgende Prohibitive. Wie stark der Kopf als selbständiges Element der Komposition gedacht ist, zeigt die konsequente Jahwerede. Sie dringt in den ersten Prohibitiv ein und duldet im zweiten Teil der Rahmung keine störende dritte Person, obwohl diese nahegelegen hätte, da die Einzelteile aus der kultischen Prädikation Jahwes stammen. Hier sind sie völlig in die Selbstprädikation eingeschmolzen ${ }^{177}$. Im zweiten Teil der Komposition wird die asyndetische Reihe von sechs Prohibitiven zusammengehalten durch die alliterierende Wiederholung der Negationspartikel. Auf drei Kurzprohibitive folgen drei durch objekte erweiterte Prohibitive, die durch das Leitwort yר in Präpositions- oder Konstruktverbindungen aufeinander bezogen sind. Das entscheidende Vorbild dieser Komposition findet sich im Privilegrecht von Ex 34, wie es Halbe in seiner ursprünglichen Fassung freigelegt hat: ein gerahmtes Hauptgebot oder Grundverpflichtung (Ex 34,12-15a) mit anschließenden Einzelbestimmungen (Ex 34, $18-26^{*}$ ) 178 . Gegenüber dem Privilegrecht von Ex 34 wirkt die Komposition des Dekaloggrundtextes glatter, ohne Kanten und eleganter. Die Zweiteiligkeit des Grundtextes ergibt sich auch aus einem weiteren Grund. Der "Kopf" redet das kollektive "Du", ganz Israel, an. Die Erwähnung der Herausführung aus Ägypten läßt daran keinen Zweifel aufkommen. Die beiden Prohibitive zum Verhältnis Jahwe - Israel erzwingen keine Anderung. Dagegen wenden sich die sechs Prohibitive des zweiten Teils an den Einzelnen. Der Aussagegehalt der Verben verhindert eine korporative Deutung ${ }^{179}$. Mit diesem Wechsel paßt sich der Grundtext in das dtn Gesetz ein, zu dessen Spezifika es gehört, in der Singularanrede zwischen Kollektiv und Individuum zu pendeln.

176 Die Rahmung ist immer wieder festgestellt worden, vgl. ZIMMERLI, Jahwe, bes. $37 \mathrm{f}$. Nur wurde sie nıcht ausreichend gewürdigt, weil man auf die Dekalogreihe fixiert war.

177 Der Umsprung in die dritte Person im Personalsuffix am Ende von V.10 wird unten geklärt.

178 DERS., Privilegrecht, 96-98.126f.138.146f.223-230.

179 Vgl. GERSTENBERGER, Wesen, $71 \mathrm{f}$. 


\subsubsection{Der erste Teil des Rahmens (Dtn 5,6)}

Er wird geprägt durch die Verbindung von Selbstvorstellung mit der Herausführung. Die Selbstvorstellungsformel mag ihren Sitz im Leben in der gottesdienstlichen Rechtsproklamation haben ${ }^{180}$, die Verbindung von Selbstvorstellungsformel mit Herausführungsformel halte ich für literarisch ${ }^{181}$. Sie deutet sich an in der authentisch hoseanischen Form der Selbstvorstellung (Hos 12,$10 ; 13.4$ ), die an die Selbstvorstellung die Apposition"dein Gott" anfügt und dann mit der Zeit-/Ortsangabe "vom Lande Agypten her" an den Exodus erinnert. Neben Hosea stand für Dtn 5,6 der jehowistische Vers Gen 15,7 Pate. Er spielt auf die Herausführung aus Agypten an und berichtet von Selbstvorstellung zusammen mit Herausführung im Kontext einer Theophanie wie Dtn 5,6 ${ }^{182}$. Dtn 5,6 dürfte also die Formel aus der Literatur geerbt haben. Das bedeutet, daß die kultische Verwendung des Dekalogs in seine Wirkungsgeschichte, aber nicht zu seiner Entstehung gehört ${ }^{183}$. Der Rahmen verlängert die Ortsangabe "aus dem Lande Agypten" mit der Konstruktverbindung "aus dem Sklavenhaus" 184 . Aus den 13 alttestamentlichen Parallelen können die nächstverwandten Parallelen eingekreist werden. Mit Rück-

180 ZIMMERLI, Jahwe, $26 \mathrm{f.38ff.}$

181 GROSS, Herausführungsformel, hat die obige Verbindung untersucht und als Formel 1 innerhalb der geprägten Vorstellung von der Herausführung klassifiziert. Im Anschluß an zIMMERLI vermutet er für seine Formel 1 priesterlich-kultischen Sitz im Leben. Für Gen 15,7 deutet er literarische Verbindung an, DERS., Herausführungsformel, 430-432.

182 In der zeitlichen Ansetzung von Gen 15,7 als protodeuteronomisch bzw. jehowistisch an den Anfang des 7. Jh.s scheint sich ein Konsens anzubahnen, vgl. PERLITT, Bundestheologie, 71-77; ihm folgend WESTERMANN, Genesis I,2, 265f; ebenso WEIMAR, Redaktionsgeschichte des Pentateuch, 52 A 153. Dieses Urteil bestätigt sich beim Vergleich von Gen 15,7 (in Bezug auf Selbstvorstellung mit Herausführung) mit seinen Parallelen. Im Unterschied zum Dtn (Dtn 5,6// Ex 20,2) besitzt die Selbstvorstellungsformel keine Apposition zum Prädikativ. Das selbständige Personalpronomen steht in Kurzform statt der im Dtn bevorzugten Langform (vgl. Gen 15,7 mit Ex 34,1ob Je). - Im Unterschied zum priesterlichen Sprachgebrauch (Lev 19,36; 25,38; 26,13; Num 15,41) verwendet Gen 15,7 den Singular statt des dortigen Plural in den enklitischen Personalpronomina. Schließlich fehlt beim Jehowisten die für die P-Literatur typische Akkusativpartikel; vgl. GROSS, Herausführungsformel, 431 .

183 Die späten Ps 5o,5.7ff.18ff und 81,4.9 geben ein Echo auf den Dekalog und können seine mittlerweile kultische Verwendung bezeugen. In Theologie und Einzelformulierungen sind sie unter anderem vom Dtn abhängig, vgl. JEREMIAS, Kultprophetie, 125-127.

184 Dazu: PLÖGER, Deuteronomium, 113 A 204; FLOSS, Jahwe Dienen, 56-63; PREUSS, Art. KYT, 805.811f. 
sicht auf die Häufigkeit d.h. den Schwerpunkt des Vorkommens und bei grober redaktionskritischer Zuweisung kann man sich auf die Belege innerhalb des Dtn konzentrieren und die außerdtn Belege als davon abhängig ausschalten ${ }^{185}$. Gerade das Dtn schildert den Aufenthalt Israels in Agypten als Sklavendasein ${ }^{186}$. Innerhalb der Parallelen im Buch Dtn steht die Frage an, ob die appositionelle Anfügung ursprünglich ist oder ob die Konstruktverbindung "Sklavenhaus" anfänglich zu einem eigenen Verb "loskaufen" gehört, das an drei Stellen zur Herausführung in Parallele steht (Dtn 7,8b; 13,6; Mich 6,4). Im letzteren Fall wäre die appositionelle Anfügung sekundäre Kontraktion der Parallelaussage 187 . Die Entscheidung ist schwierig zu fällen ${ }^{188}$. Sie läuft darauf hinaus, welcher Zusatz in Kap. 13, nämlich 13, 6 oder 13,11, Priorität beansprucht. Von anderer Seite kommt Hilfe. Unterscheidet man hinsichtlich der syntaktischen Verknüpfung der Herausführungsformel mit dem vorausgehenden Kontext, dann stehen die Stellen mit Relativsatz (Dtn $5.6 ; 6,12$ ) gegen diejenigen mit partizipialer Beiordnung (Dtn $8,14 ; 13: 6.11)$. Diese Unterscheidung kann über die diffizile redaktionskritische Zuweisung der Einzelstellen hinaus einen Parameter abgeben. Im Dtn läßt sich beobachten, daß in bestimmten Fällen bei gleichem Inhalt und analoger Aussage spätere Schichten die Tendenz haben, die Zeitsphäre zu verdeutlichen. Z.B. in den historisierenden Gebotseinleitungen haben die relativ älteren Schichten ki-yiqtol ${ }^{189}$. Die jüngeren Schichten setzen ein והיה 19avor 190 . Was dabei mit Blick auf die Zukunft stattfindet, läßt sich analog mit Blick auf die Vergangenheit beobachten beim Wechsel von partizipialer zur relativischen Ergänzung 191 . Demnach gehören die jüngeren $\mathrm{Be}-$ lege Dtn 5,6 und 6,12 zusammen. 6,12 gehört zum Abschnitt 6,10-13, seine redaktionskritische Einstufung und damit seine Beziehung zum Dekalog sind umstritten ${ }^{192}$. Wegen der in 6,10-13 implizierten Kriegsideologie - Israel

$185 \mathrm{Zu}$ den außerdtn Belegen zählen: Ex 13,3.14 (spät-dtr) $(20,2) ;$ Jos 24, $17 \mathrm{aB}$ (red.; dtr); Ri 6,8 (dtr); Mich 6,4 (exilisch); Jer 34,13 (Jer D).

186 Vgl. mit zeitlicher Priorität Dtn 15,15 und ferner: Dtn 5,15; 16,12; $24,18.22$.

187 FLOSS, Jahwe Dienen, $61 \mathrm{f}$ behauptet das, weil er Mich 6,4 für authentisch hălt. Skeptisch PREUSS, Art. KY?, 805.

188 Es stehen sich im Dtn gegenüber: 5,$6 ; 6,12 ; 8,14 ; 13,11-13,6 ; 7,8 \mathrm{~b}$.

$189 \mathrm{Zu}$ den historisierenden Gebotseinleitungen allgemein SEITZ, Deuteronomium, 95-97. Die Belege: $\operatorname{ttn} 7,1 ; 8,7 ; 12,20.29 ; 17,14 ; 18,9 ; 19,1$.

190 Die Belege Dtn 6,10; 11,29; 26,1 (vgl. 30,1; 31,21); ebenso Ex 12,25f; $13,1 \cdot 14$

191 Mit älterer partizipialer Ergänzung: Dtn 8,14; 13,6.11 - mit jüngerem Relativsatz: Dtn 5,$6 ; 6,12$; vgl. $7,8 \mathrm{~b}$ mit Narrativ. 
wird von Jahwe ins Land geführt und übernimmt dessen Einrichtungen; die Ureinwohner werden ausgetauscht ${ }^{193}$ - ordne ich $6,10-13$ später ein als $7,1-6^{*}$ und $8,7 \mathrm{ff}$ und halte es für frühdeuteronomistisch. Dtn 5,6 und 6,10-13 können redaktionskritisch auf einer Stufe stehen, eher rangiert 6,10-13 früher. Auf jeden Fall gehört der erste Teil des Rahmens nicht zu den vordtn Schichten des Dtn.

\subsubsection{Das Fremdgötterverbot (Dtn 5,7)}

Beim Fremdgötterverbot sind schon immer die fehlende ubereinstimmung der einzelnen sachparallelen Verbote und die Weiträumigkeit und Allgemeinheit der dekalogischen Formulierung aufgefallen ${ }^{194}$. Ein hohes Alter wird Ex 22,19 zugestanden. Der partizipiale Rechtssatz drückt sich konkret aus 195 . Ex 34,14a stammt aus dem Hauptgebot des Privilegrechts. Den protodtn Charakter des Verses hat Halbe nachgewiesen ${ }^{196}$. Hos 3,1 und 13,4 - sine ira et studio betrachtet - fordern keineswegs das Vorhandensein des Dekalogs 197. Die Ungebundenheit des Ausdrucks und die Einpassung in Hoseas Botschaft plädieren für dessen Verfasserschaft. Für den Plural "fremde Götter" in 3,1 brauchte es keinen Dekalog. Die restlichen, sonst angeführten Vorläufer des Fremdgötterverbots sind dem Dekalog nachzuordnen 198.

192 LOPEZ, Analyse, 491f; Analyse littéraire, 4o-42; Deutéronome, 18o-183 sieht im Verfasser von 6,10-13 den Bearbeiter von 8,7-18a. Er rechnet beide Texte zum vordtn Bestand. Der Autor von 6,10-13 hege eine Vorliebe für den Relativsatz und habe die partizipiale Ergänzung von 8, 14 in einen Relativsatz umgesetzt. Er sei mehr auf 8,7-18a hin ausgerichtet als auf den Dekalog. Der Dekalog bzw. die Einleitung sei mithin von 6,10-13 abhängig. LOHFINK, Dekaloganfang, 101f hält 6,10-15 für eine Paraphrase des Dekalogs, weil er diesen früh ansetzt. Für 8,7-20 erwägt er neuerdings eine exilische Ansetzung, da "vielleicht die Situation einer im fremden Land allmänlich wohlhabend gewordenen Diaspora angezielt ist" (ebd., 103f A 17).

Auffällig ist bei diesem Abschnitt das unterschiedliche setzen der Apposition in 6,12.13. Die Parallelen zu 6,13 wie 10,20 und 13,5 halte ich für später.

193 Vgl. LOHFINK, Art. סרם, 210.

194 Vgl. KNIERIM, Das erste Gebot, bes. 23f; SCHMIDT, Alttestamentlicher Glaube, 70.

195 Für HALBE, Privilegrecht, $417 \mathrm{f}$ wird Ex 22,19 Mittelpunkt des Bundesbuches in seiner Ausbaustufe II; dazu BOECKER, Recht und Gesetz, 121. zur Textkritik jetzt LOHFINK, Art. םר, $193 f$.

DERS., Privilegrecht, 119-122.

197 So WOLFF, Hosea, 76.

$198 \mathrm{Zu} \operatorname{Ex} 23,14$ (RP) s.oben 3.4; zu Ex 23,24 s.u.; Ps 81,10. ist vom Dekalog abhängig und spät, s.o. A 183. 
Der Prohibitiv von Dtn 5,7 ersetzt mit seiner Konstruktion das im Hebräischen nicht vorhandene Verb "haben". Zum Objekt wählt er die "fremden Götter", das entscheidende Stichwort im polytheistischen Referenzsystem des Dtn ${ }^{199}$. Im Verglei.ch mit den Parallelen fällt auf, daß die bevorzugten Verbindungen des Dtn wie "hinter anderen Göttern laufen", "anderen Göttern dienen" und "andere Götter anbeten" nicht aufgegriffen werden. Dabei sind alle drei Wendungen schon vordtn bezeugt, nämlich in den Straftatbeständen der "paränetischen Gesetze" von Kap. 13 (13,3.7.14) und des kasuistischen Paragraphen zum Musterprozeß $17,3 \mathrm{a} 200$.

Im Dtn haben diese Wendungen selbst schon einen allgemeinen Inhalt, indem sie zu Wendungen für das Gottesverhältnis werden und die umfassende und totale Bindung an Jahwe einfordern. In diesem Sinne haben sie sich auch in den späteren Schichtungen durchgesetzt. Nicht der Dekalogprohibitiv hat Einfluß ausgeübt, sondern die vordtn Straftatbestandsformulierungen, die leichter zu übernehmen waren als der schwerfällige Dekalogprohibitiv 201. Rückwirkend unterstreicht dieses Faktum die singuläre Form von Dtn 5,7. Gegenüber den hoseanischen Belegen mit den Baalen als fremden Göttern abstrahiert das Verbot bezüglich des objektes. Im Unterschied zu den älteren Fremdgötterverboten von Ex 22,19 und 34,14a verzichtet es auf jede kultische Konkretion der Verehrung. Schließlich reicht die allgemeine Bedeutung der oben genannten Wendungen nicht aus und der Prohibitiv verstärkt die Abstraktion zum inhaltsleersten und allgemeinsten Ausdruck des Gottesverhältnisses, zur Haben-Relation. Mit solcher Abstraktheit ist das Fremdgötterverbot einsam geblieben. In der Interpretation der abschließenden Präpositionsverbindung "mir zum Nachteil, zu meinen Lasten" schließe ich mich van der Woude an 202. Die Singularität des dekalogischen Fremdgötterverbotes spricht für gezielte Abfassung durch einen Autor, der selbst auf Vorgänger blickt, die das Gottesverhältnis auf den Begriff zu bringen versuchen. Hinweise für eine "Präexistenz" des Prohibitivs in einer Reihe haben sich nicht ergeben ${ }^{203}$.

199 So LOHFINK, Gott, 102 A 5 mit den 33 Stellen und ebd., 106.

200 Vgl. ROSE, Ausschließlichkeitsanspruch, 19-23.

201 Die Ausnahme bildet Ps 81,10. Zur allgemeinen Bedeutung von עבד s. FLOSS, Jahwe Dienen, 514ff.559-562.

202 DERS., Art. פנים, 459. Sein Verständnis bietet zwei Vorteile. Es ist breit bezeugt und besitzt eine Parallele aus dem Dtn $(21,16)$, wo es ebenso um eine spezifische Personenbeziehung geht.

203 Diese Annahme ist einfacher und sparsamer als das mühevolle Substraktionsverfahren bis zu einer hypothetischen Kleinreihe mit einem völlig rekonstruierten Urprohibitiv, so bei MÜLLER, Gott, bes. $136 f$. 


\subsubsection{Das Bilderverbot (Dtn 5,8)}

Um den historischen Ort und die Bedeutung des dekalogischen Bilderverbots zu beschreiben, sollen seine Varianten geordnet und sein Umfeld sondiert werden.

Geht man einmal von der Voraussetzung aus, daß das Bilderverbot in Parallele zum Fremdgötterverbot anfänglich für sich bestand, dann spielen die isolierten Vorkommen eine große Rolle.

Die erste Stelle Ex 20,23 stammt von RP 204 . Er interpretiert das dekalogische Bilderverbot als Verbot der Götzenbilder. In Korrespondenz zu seiner Ausleitung des Bundesbuches in Ex 23,13 (Fremdgötterverbot) schafft er eine Rahmung um sein Bundesbuch, indem er die zusammengehörigen beiden ersten Dekaloggebote variierend aufnimmt, nur jetzt dem Bilderverbot den ersten Platz in der Rahmung zuweist. Die zweite Stelle Ex 34.17 ist ein sekundärer Einschub in das Privilegrecht ${ }^{205}$. Geleitet vom Vorbild des Dekalogs schiebt ein dtr Redaktor den Prohibitiv hier hinein; er ist deswegen als isoliertes Verbot zu betrachten. Unter Verarbeitung von Ex 32,31 und Dtn 9,12 (vgl. Lev 19,4) wird die Herstellung gegossener Götterbilder verboten 206 .

In Lev 26,1 hat die Terminologie des Bilderverbots (vgl. Lev 19.4) das Fremdgötterverbot aufgesogen. Mit singulärer Differenzierung werden verschiedene Kultobjekte aufgeführt und perhorresziert. Jahwe steht den Nichtsen gegenüber. Das Verbot gehört in die späte Götzenpolemik.

Schließ1ich Dtn 27,15, eine anerkannt sekundäre Rahmenformulierung sowohl unter formkritischem wie inhaltlichem Gesichtspunkt ${ }^{207}$.

Im Vergleich mit dem dekalogischen Bilderverbot fehlt der dativus commodi beim Verb עשה (vgl. Dtn 4,25), das ein Doppelobjekt wie Ri 17,3f hat (Bild und Gußbild). Der Fluchsatz wertet im Stil der Toeba-Gesetze und erläutert in Anlehnung an Hos 13,2. Eine junge, spät-dtr Formulierung des Bilderverbots liegt uns vor.

\footnotetext{
204 S.o. unter 3.4.

205 Vgl. HALBE, Privilegrecht, 122-126.215-219.

206 S.o. unter 3.7.

207 Vgl. SCHOTTROFF, Fluchspruch, 222ff; zuletzt WALLIS, Vollbürgereid, $48 f$.
} 
Die isolierten Vorkommen des Bilderverbotes setzen den dtr bearbeiteten Dekalog voraus. Das Bilderverbot ist bereits mit dem Fremdgötterverbot vereinigt und nimmt mit inm die erste Stelle ein. Es kann von nun an isoliert aufgegriffen, sekundär nachgetragen oder herausgehoben vorangestellt werden. Die Formulierungen können auf beide Gebote anspielen.

In einer weiteren Gruppe von Varianten wird das Bilderverbot mit Varianten des Fremdgötterverbots zusammengespannt: Ex 23,24 verbietet, die Götter der landsässigen Fremdvölker zu verehren und die entsprechenden Kultgegenstände anzufertigen. Das Verbot wird fortgesetzt mit dem Befehl zu deren Vernichtung und zum Zerbrechen der fremden Mazzeben. Das Verbot gehört zu einer spät-dtr Redaktion 208. Lev 19,4 kopiert - wie schon oft betont - in eigenständiger Weise den Dekalog. Weitere Stellen wie Jer 1,16b;25,6 gehören zur dtr Bearbeitung des Jeremiabuches und 2 Kön 22,17 zu DtrP (einer Bearbeitung des dtr Geschichtswerkes). Keiner dieser Belege rangiert zeitlich vor dem dekalogischen Bilderverbot. Keine Stelle reicht im Alter über dtr Redaktionen hinaus. Markant ist die Variationsbreite der Formulierungen innerhalb der Varianten. Bei der letzten Gruppe ist am meisten konstant die strukturelle Verbindung der beiden Verbote, darauf die Verwendung des Leitverbs עשה. Starke Variation herrscht vor in der Wahl der Termini zur Bezeichnung der Kultgegenstände. Alter und Vielfalt der Varianten votieren eher für ein relativ jüngeres dekalogisches Bilderverbot, das seinen Einfluß in differenzierter Weise ausübt und mit konkurrierenden Formulierungen kämpft, als für eine ehrwürdige und alte Formulierung, die seit Jahrhunderten entweder in der Predigt verkündigt oder in der Lehre eingeschärft wird.

Nach den obigen Oberlegungen zur Komposition des Dekaloggrundtextes ist diesem das Privilegrecht vorgeordnet. Dort ist mit dem singulären Verbot, einen anderen Gott anzubeten (Ex 34,14), die Vorschrift zur Vernichtung fremder Kultmale verbunden (Ex 34,13a.b) ${ }^{209}$. Auch sachlich gehört die Un-

208 Mit FLOSS, Jahwe Dienen, 26of.275 gegen HALBEs vordtn Frühansetzung (Privilegrecht, 113.490). Das Fremdgötterverbot (V.24a ) übernimmt die spätere Reihung von 1. מוה 2. 2. der dtr Dekalogbearbeitung. Die Variante des Bilderverbots $(\mathrm{V} .24 \mathrm{a} B)$ verzichtet auf den dativus commodi (vgl. Dtn 4,25; 27,15) und verbietet grundsätzlich die Herstellung von Kultgegenständen. Die Vernichtungsvorschrift (V.24b) spielt auf Ex 34,13 an. Daß sie überhaupt hier auftaucht, verrät allein schon späte Entstehung, weil nun die Vernichtungsvorschrift des Privilegrechts und die Dekaloggebote zusammengesehen werden. 
duldsamkeit gegenüber den Kultsymbolen der Kulturlandgötter in den Einzugsbereich des dekalogischen Bilderverbots, weil es diese gerichtete Intoleranz in seiner umfassenden Grundsätzlichkeit impliziert. Ex 34,13 wurde vom Grundtext des Dekalogs nicht aufgenommen, wohl wegen fehlender Allgemeinheit der Aussage. Dtn 7,5 210 erweitert die Trias aus Ex 34,13 um die Vernichtung der Fremdgötterbilder. Die Stelle steht wohl unter Einfluß des dekalogischen Bilderverbots. Allerdings erzwingt der Kontext das Pluraletantum פסלים. Dtn 12,3 variiert 7,5. Die beiden letzten Stellen Ri 2,2 und Ex 23, $24 b$ sind spät (s.o.).

Zur Vorgeschichte des Bilderverbotes: Die Varianten des Bilderverbots und die sachverwandte Vorschrift zur Vernichtung fremder Kultmale haben in den Bereich vordtn, dtn/dtr und priesterlicher Literatur geführt. Chronologisch gelangt man damit in den Zeitraum vom 8. Jh. an abwärts. An dieser Stelle muß eine Beobachtung induziert werden, auf die schon öfters hingewiesen wurde. Unabhängig von der Frage, in welchem Maße der Jahwekult bildlos gewesen ist, hat man im praktischen Verhalten gegenüber einigen Kultsymbolen zwei Epochen voneinander abgehoben 211 . Die ältere Epoche zeigt einen unbefangenen Umgang mit Mazzeben (Jakobsgeschichte, jahwistische Sinaitheophanie in Ex 24,5; ferner Jos 24,26f). Sie erzählt ohne Bedenken von Götterbildern ( $\operatorname{Ri} 3,19.26 ; 8,24-27 a^{*} ; 17 f$ ), bringt Mose mit der ehernen Schlange in Verbindung (Num 21,4ff; 2 Kön 18,4) und duldet den Stierkult in Betel (1 Kön 12,26-30). Weder Elija und Elischa, noch Jehu, noch Amos haben gegen Betel in dieser Hinsicht Einwände. Dann erfolgt der Umschwung zu einer neuen Epoche. Die Unbefangenheit kippt um in Unduldsamkeit und eifert in scharfer Polemik, deren ältester Vertreter im Nordreich Hosea ist. Für das Südreich markiert diese Wende der jehowistische Grundtext von Ex 32 und vor allem die Kultreform des Hiskija ( 2 Kön 18,

209 Vgl. HALBE, Privilegrecht, 110-119. Ich folge seinen Beobachtungen, seiner vordtn Einstufung von Ex 34,13a(b), nicht aber seinen weiteren redaktionskritischen Zuweisungen.

210 Dtn 7,5 ist sekundärer Eintrag in den Basistext von Kap. 7. Ohne weitere Begründung referiere ich hier meine Auffassung der umstrittenen VV.1-11: 7,1 (ohne Völkerliste).2.6 ist Grundlage des Kapitels, eine Art "paräentisches Gesetz" mit Begründung zum Bannvollzog. VV.3.4.5 interpretieren den Bann sekundär. VV.7-8a erlăutern mit zwei parallelen Sätzen die Erwählung. VV.8b-11 knüpfen darạ an mit dem dreiteiligen Schema der Beweisführung; Aussageabsicht ist eine Neuinterpretation von Dtn 5 mit Dekalog und Auftrag an Mose zur Verkündigung seines Gesetzes.

211 Vgl, ZIMMERLI, Bilderverbot; SCHMIDT, Alttestamentlicher Glaube, 74-81; ROSE, Ausschließlichkeitsanspruch, 50-59; KEEL, Jahwe-Visionen, 37-45. 
4) 212 . Keel hat für die Entwicklung zum Bilderverbot folgende Entwicklung skizziert 213: Aus der nomadischen Vergangenheit bringt Israel keine Jahwebild-Tradition mit, darin vergleichbar mit anikonischen Kulten in den Randgebieten altorientalischer Hochkulturen. Im Kontakt mit Kanaan werden kanaanäische Götterbilder "jahwesiert". Dieser Prozeß wird dann aber als Oberfremdung abgelehnt. Der Ausschließlichkeitsanspruch Jahwes rebelliert und führt zum Bilderverbot.

Hosea kommt bei diesem Aufriß eine Schlüsselrolle zu. Er nimmt die Polemik gegen die Mazzeben auf (Hos 3,4; 10,1f). Darin ist er Vorläufer von Dtn 16, 21f. Die hiesigen Prohibitive mit ihren Ergänzungen 214 stimmen mit Hosea in der grundsätzlichen Ablehnung überein. Es geht nicht um Vernichtung fremder Kultsymbole, sondern Aschera und Mazzebe als solche werden verboten. Die Konkretisierung der Kultsymbole (Dtn 16,21f) kann aus Ex 34,13 stammen. Aus der dortigen Trias (fremde Altäre, Mazzeben und Ascheren) spart das prinzipielle Verbot bezeichnenderweise den Altar aus; als Altar Jahwes darf und muß er zentrales Kultsymbol bleiben. Hosea greift auf breiter Front die private wie öffentliche Herstellung von Götzenbildern an (Hos 4,17; 8,4f; $13,2 ; 14,9)$ und konzentriert seine Ablehnung auf den Jungstierkult von Betel (Hos $8,5 \mathrm{f} ; 10,5 ; 13,2$ ). Der von Jerobeam eingerichtete Jungstierkult von Betel blieb bis zu Hosea als orthodoxer jahwistischer Kult geachtet ${ }^{215}$. Sein Spezifikum war die Verbindung von Exodustradition mit dem Jungstierbild. Für Hosea hat sich diese Verbindung aufgelöst. Der Stier hat aufgehört, Repräsentant des Exodusgottes zu sein. Mit der Aufhebung der konstitutiven Verbindung wird das Kultbild zum Götzen. Die Bilderverehrung depraviert zu einem Symptom der Krise im Verhältnis Jahwes zum Volk. Sie liefert das Krankheitsbild der zugrundeliegenden Trennung Jahwes von Betel 216. Für Hosea mutiert die öffentliche wie private Bilderverehrung zum Baalsdienst. Deswegen kann er in einem Atemzug den Abfall zum Baal und die Bilderherstellung geißeln, d.h. den Verstoß gegen das erste wie zweite Gebot

212 Abgesehen von den Spuren der hiskijanischen Reform in Beerscheba und Stratum VII von Arad macht KEEL, Jahwe-Visionen, 44 A 74 auf die zunehmende Bilderfeindlichkeit aufmerksam, ablesbar an den hebräischen Siegeln im Übergang vom 9./8. Jh. zu denen vom 7./6. Jh.

213 S.o. A 211.

214 Vgl. RICHTER, Recht, 109f; ROSE, Ausschließlichkeitsanspruch, 5off.

215 Vgl. UTZSCHNEIDER, Hosea, 88-104.

216 Vgl. UTZSCHNEIDER, Hosea, 104.127f. 
konstatieren (Hosea $8,4 f ; 11,2 ; 13,1 f$ ). Die Alternative, ob Fremdgötteroder Jahwebilder abgelehnt werden, ist für Hosea unangebracht, denn die Jahwebilder sind zu Fremdgötterbildern geworden. Was hat die hoseanische Kultkritik ausgelöst? Eine bündige Antwort ist schwer zu finden. War es die Sorge des Propheten, Jahwe vom todgeweihten Betel und vom kranken Nordreich abzuziehen, um seine Verbindung zum Volk über den Untergang hinaus zu retten ${ }^{217}$ ? Oder war es der Gegenschlag des Pendels, die rigorose Abgrenzung mit ihrer Besinnung auf das Eigene, als Antwort auf die sich steigernde Anpassung an den Baalskult? Meldete sich der mit Füßen getretene Ausschließlichkeitsanspruch Jahwes zu Wort ${ }^{218}$ ?

Auf keinen Fall entsprang die hoseanische Wende seiner Besinnung auf das dekalogische Bilderverbot ${ }^{219}$. Umgekehrt: Das Bilderverbot Dtn 5,8 ist von Hosea her zu lesen. Der Prophet formuliert konkret, aus der jeweiligen Situation heraus. Er verrät an keiner Stelle die Normierung durch ein vorgegebenes Dekalogverbot. Dagegen läßt sich der Prohibitiv Dtn 5.8 mit dem Vorläufer Hosea besser erklären. Die Position des Prohibitivs neben dem Fremdgötterverbot ergibt sich aus der Vorgeschichte. Seit der Opposition gegen die fremden Kultsymbole (Ex 34,13) und seit der prinzipiellen Infragestellung der Bilder durch Hosea und Dtn 16,21f, ist die Bilderverehrung die nach außen gewendete "Kehrseite" der Fremdgötterverehrung geworden (vgl. Dtn $16,22 b)$.

Die Gestalt des Prohibitivs: Dtn 5,8 setzt das allgemeine עש ein und verbindet es mit dem dativus commodi. Darin zeigt sich der Einfluß Hoseas (vgl. Hos 8,4; 13.2) und die Verbindung zu den Grundtexten von Ex 32.31 und Dtn $9,12.16^{220}$. Gibt das Verb schon wenig Information über Herstellung und Material des Kultobjektes, so wird das durch das objekt in Dtn 5,8 keineswegs kompensiert im Unterschied zu Hosea, Ex 32 und Dtn $9 f$. Das hoseanische Lieblingswort für Götterbilder 221 (= tote Gebilde) wird nicht übernommen, weil wahrscheinlich die polemisch-persönliche Note störte. Das

217 SO UTZSCHNEIDER, Hosea, $127 \mathrm{f}$.

218 So ROSE, Ausschließlichkeitsanspruch, 53f; KEEL, Jahwe-Visionen, 44.

219 SO ZIMMERLI, Bilderverbot, 253.

220 zum Leitwort השy mit Kultobjekten vgl. die älteren Vorkommen in Ri $17,3 \mathrm{f}$; Hos 8,6; Ex 32,1.4.20 - zu den gegenüber Dtn 5,8 älteren, kultisch ausgerichteten Geboten mit dativus commodi vgl. Ex 34,22; Dtn 16,21f. Zum folgenden s. FLOSS, Jahwe Dienen, 156-163.

221 Hos 4,$17 ; 8,4 ; 13,2 ; 14,9$ - dazu WOLFF, Hosea, $115.178 f$. 
konkrete פסכה in 222 legt sich auf metallene Objekte fest,wohingegen diesem Punkt eine größere offenheit mitbringt ${ }^{223}$. Das Pluraletantum betont wie פסל den Dingcharakter, scheint sich aber durch seinen häufigen Bezug auf Bilder fremder Völker auf die Bedeutung "Fremdgötterbilder" einzugrenzen. Das wird bestätigt dadurch, daß es nie mit Verben der Herstellung verbunden wird. Fremdgötterbilder sind für Israel schon vorhanden; sie sind zu vernichten, damit sie nicht zur Versuchung werden.

Ergebnis: Dtn 5,8 verbietet in neutraler und allgemeiner Form die Herstellung eines geformten Kultbildes. Diesem Ziel dient die Lexemwahl im Verb wie im Objekt. Für die Jahweverehrung haben Bilder ihre Symboifunktion verloren. Sie garantieren nicht mehr die Nähe Jahwes, sondern ziehen von ihm ab. Die Alternative: Verbot der Jahwe- oder der Fremdgötterbilder stellt sich nicht. Wenn für Israel Jahwebilder verboten sind, dann a fortiori die Obernahme von Fremdgötterbildern. Jedes Gottesbild, das Israel herstellt oder verehrt, bedeutet Abfall von Jahwe. Vorhandene Fremdgötterbilder sind zu vernichten. Das dekalogische Bilderverbot verbleibt im Rahmen des Jahwekultes. Seine Radikalität richtet sich nicht gegen jegliches Bild und nicht gegen die Gottesverehrung der anderen Völker. Deshalb kann ein späterer dtr Redaktor in Dtn 4,19 tolerant behaupten, daß Jahwe selbst den Völkern die Gestirne zur Anbetung zugeteilt habe. Die Polemik gegen den Bilderdienst als unsinnigen Götzendienst setzt erst später ein. Der Prohibitiv von Dtn 5,8 kennt keinen Vorgänger. Seine Formulierung entstammt einem Autor, der in einer bestimmten theologischen Tradition steht. Zu seinen Ahnen zählen Hosea, der Jehowist mit seiner Sinaitheophanie inklusive Privilegrecht und die eigenen dtn Vorgänger. Die Wirkungsgeschichte des Bilderverbots verläuft komplex. Die späteren Varianten zeigen individuelle Verarbeitung. Die Fluktuation in deren Formulierung belegt das reiche Angebot der Vorgaben aus der einschlägigen uberlieferung zum Bilderverbot.

222 Hos 13,2 ; Ex 32,4; Dtn 9,12.16; Ri 17,3f.

223 Diese offenheit wird allgemein notiert: ZIMMERLI, Das zweite Gebot, 558. BERNHARDT, Gott und Bild, 113 A 6; ELLIGER, Deuterojesaja, 74. Ursprünglich sei bei gס an Skulpturen aus Holz und Stein gedacht, vgl. Ri 17,3f mit dem möglichen Hendiadyoin"מסכה פסל Später könne פסל sogar das Metall einbeziehen. Wie die literarische Schichtung in Ri $17 f$ nahelegt, steigt פסל zum allgemeinen Oberbegriff auf, vgl. Ri $17,3 \mathrm{f} ; 18,14.17 .18 \mathrm{mit} \mathrm{Ri} 18,20.30 \mathrm{f}$. 


\subsubsection{Der zweite Teil des Rahmens (Dtn 5,9b.10)}

Zu seiner Struktur hat Halbe das Notwendige gesagt 224 . Zugrundeliegt ein eigenständiges zweigliedriges Prädikationsgefüge mit dem ersten Element "ein eifernder Gott", das im zweiten Glied den Eifer auslegt. Der älteste Beleg kann Ex 34,14b sein. Als Heimat oder Sitz im Leben vermutet Halbe die Abrenuntiation fremder Götter. Der Dekalog-Grundtext übernimmt die ursprüngliche zweiteilige Struktur und setzt sie in seine Rahmung ein. Im ersten Teil bleibt es bei dem Element vom "eifernden Gott". Im zweiten leiht er Prädikationen aus Ex 34,7 aus. Das zugrundeliegende Prädikationsgefüge erklärt den Anschluß mit emphatisch-begründendem כי, die asyndetische Reihung der beiden Elemente und schließlich die Position nach dem Hauptgebot. Die beiden Parallelen aus dem Dtn gehören zu späteren Redaktionen ${ }^{225}$.

Das zweite Element der Prädikation, die syndetischen Partizipialsätze, entfaltet den Eifer Jahwes zum Unheil wie zum Hei1 ${ }^{226}$. Der Dekalog-Grundtext ändert die Vorlage (Ex 34,7 ). Er rafft die Generationenreihe, setzt statt des spezifischen נצר das allgemeine עשה 227 und stellt die Partizipialsätze um, nicht so sehr weil ein Verbot eingeschärft wird und die Strafsanktion zunächst ausgesprochen wird ${ }^{228}$, sondern weil der Eifer Jahwes ausgelegt wird. In den betreffenden vorexilischen Texten wirkt er sich als strafendes Handeln gegen das abfallende Israel aus. Erst in exilisch-nachexilischen Texten kann er sich zugunsten Israels gegen andere Völker richten oder Israel direkt Heil schaffen ${ }^{229}$. Auf diesem Hintergrund fällt die positive Entfaltung im zweiten Partizipialsatz auf, da sie unerwartet auftritt. Sie

224 DERS., Privilegrecht, 134-140; vgl. BERG, Eifersucht, bes. 198-200.

225 Dtn 6,15a ist innerhalb der betreffenden Parallelen durch seine Eingliedrigkeit isoliert. Der singularische Einschub V.15a im pluralen Kontext VV.14.15b unterbricht das dreiteilige Schema von Abfall Israels, Zorn Jahwes und Untergang, vgl. Dtn $7,4(8,19) ; 11,16 f ; \operatorname{vgl}$. LOPEZ, Deutéronome, 169-171; LOHFINK, Dekaloganfang, 101f erklärt anders und votiert für Abhängigkeit vom Dekalog. Dtn 4,24 gehört zur zweiten Redaktion von Dtn 4, s.o. unter 4.6.

226 Die beiden standarduntersuchungen dazu: SCHARBERT, Formgeschichte; DENTAN, The literary affinities; dazu PERLITT, Bundestheologie, $85 \mathrm{f}$. 213-215.

227 Vgl. ZOBEL, Art. TDח, bes. 51.60.64.

228 So SCHARBERT, Formgeschichte, 134.

229 Vgl. BERG, Eifersucht, 211. 
ist wahrscheinlich aus der Vorlage übernommen worden, weil der Autor bei der grundsätzlichen Wesensbeschreibung Jahwes auf diese Seite seines Handelns nicht verzichten wollte.

Ein weiteres Problem ist die Verträglichkeit des Grundsatzes der solidarischen Haftung (Dtn 5,9b) mit dem der Individualvergeltung (Dtn 24,16). Nach dem Ansatz dieser Untersuchung berührt er das Schichtungsproblem innerhalb des Dtn und kann hier nicht aufgelöst werden. Doch kann einiges zur Entlastung aufgebracht werden.

Das Problem der Vergeltung wird vor allem in exilischer Zeit akut. Eine einfache lineare Entwicklung vom Grundsatz der solidarischen Haftung zu dem der Individualvergeltung ist nicht anzunehmen. Wie dicht beide Grundsätze nebeneinanderliegen, kann Ez 20 zeigen ${ }^{230}$. Innerhalb dtr Redaktionen sind die Stimmen geteilt. Die späte Paraphrase des Dekalogs in Dtn 7,8b-11 betont die Individualvergeltung gegen den Dekalog, wohingegen die dtr Bearbeitung des Jeremiabuches Jer 32.18 sich an den Dekalog anschließt (in Differenzierung zu Jer $31,29 b$, das auch Jer D zugewiesen wird).

Ein letztes Problem stellt sich bei den partizipialen Anfügungen am Ende von V.9b und V.1ob. Zur Debatte steht ihr syntaktischer Anschluß wie ihre Zugehörigkeit zum Dekalog-Grundtext. Die Grammatiken deuten die Partizipien mit $\zeta$ als Umschreibung eines Genitivs zum vorhergehenden Nomen und beziehen sie sinngemäß auf die Väter ${ }^{231}$. Dadurch zielt Jahwes Wirken auf die hassenden und liebenden Väter; die Partizipien stehen jeweils in thematischer Kongruenz zu ihren Vorgängersätzen. Scharbert und andere ${ }^{232}$ deuten die Partikel $>$ als Dativ zum "eifernden Gott"; die Partizipien beschreiben nun das Wirken Jahwes an jeder einzelnen Generation, insofern sie haßt oder liebt; die angefügten Partizipien individualisieren und korrigieren die solidarische Haftung der Vorgängersätze; sie sind deshalb Zusätze von der einzigen Parallele her, nämlich Dtn 7,8b-11. Der asyndetisch reihende Stil der Prädikation läßt die Entscheidung offen. Folgende Argumentation aus dem synop-

230 Der Grundtext von Ez 20 verkündet die Greuel der Väter und begründet damit das gegenwärtige Exil, vgl. Ez 20,4.23; die erste Bearbeitung in Ez 20,30f* korrigiert: Auch die gegenwärtige Generation sündigt mit dem gleichen "Wandel der Väter".

231 GK $\S 129$ e; JOÜON, § $130 \mathrm{ob}$.

232 DERS., Formgeschichte, $145 \mathrm{ff}$. 
tischen Vergleich kann hier weiterhelfen. Denn eine Differenz der Dekalogfassungen ist noch nachzutragen. Im Ketib des MT von Dtn 5,10b heißt es "seine Gebote" gegen Ex 20,6 mit "meine Gebote". Die Exodusfassung bietet sinngemä $B$ eine geschlossene Jahwerede. Der Wechsel zur Er-Rede liegt auf der Versgrenze von Ex 20,6 nach 20,7. Die Deuteronomiumfassung verlegt den Wechsel in den Vers 5.10b hinein. Wenn man dafür keine Verschreibung von jod zu waw annehmen will - eine häufig vorkommende Verwechslung -, bleibt nur die Erklärung, daß der Autor von Dtn 5,10b eine Oberleitung zur nachfolgenden Er-Rede schaffen wollte ${ }^{233}$. Das impliziert zweierlei: Für den besagten Autor oder Redaktor ist der Wechsel ein Problem, weil inm vorgegeben. Innerhalb seines Zusatzes verläßt er die Ich-Rede Jahwes und lenkt zur Er-Rede hinüber. Die Deuteronomiumfassung spiegelt deutlicher die Wachstumsphasen des Dekalogs, worauf schon hingewiesen wurde. Die Exodusfassung dagegen purgiert den Dekalogtext. Von der Deuteronomiumfassung her erweisen sich die partizipialen Anfügungen als sekundär. Der Verfasser von Dtn 7,8b11 hat seine dortige Korrektur des Dekalogs auch im Dekalogtext selbst umsichtig und behutsam verankert.

\subsubsection{Die Kurzprohibitive (Dtn 5,17-19)}

Die gängige Auffassung hört und liest in Hos 4,2 ein Echo auf den Dekalog. Das hat die Annahme zur Konsequenz, daß die Dekalogprohibitive sekundär durch absolute Infinitive nominalisiert werden. Nicht erklärt wird dabei, warum Hosea diese bestimmten Prohibitive selektierte, warum er nur drei zitiert, für seine beiden ersten Infinitive vom Dekalog abweicht und darüber hinaus auch noch solche Infinitive wählt, die in ihrem Verhältnis zueinander und in ihrer Bedeutung dunkel sind ${ }^{234}$. Der erste Infinitiv bzw. das erste Vergehen erscheint in keiner Prohibitivreihe; das zweite nur in Lev 19,11 .

Vom bisherigen Gang der Analyse ergibt sich das Gegenteil. Der Dekalog-Grundtext setzt die absoluten Infinitive von Hos 4,2 in Prohibitive um und wählt aus. Diese Auffassung gründet auf drei Argumenten:

233 Vgl. KÖNIG, Deuteronomium, 88 und DERS., Stilistik, 255.

234 Zur Bedeutung s.o.2.5.4; die syntaktische Auffassung der fünf absoluten Infinitive schwankt. Die Grammatiken (GK $\S 118 \mathrm{ff}$; BERGSTRÄSSER, II, 12 I) kommen von Jer 7,9 her und fassen die absoluten Infinitive interjektional auf.WOLFF, Hosea, 81 versteht sie als Subjekt eines Verbalsatzes mit dem Verb von Hos $4,2 \mathrm{~b} \alpha$ als Prädikat. 
Hos 4,2 stammt von Schülern des Hosea, die die verstreute Verkündigung des Meisters (Hos 6,7ff; 7,1ff; 10,4) überschriftartig für die Kap. 4-11 zusammenfassen 235 . Hos 4,2 blickt also nicht auf den Dekalog, sondern auf die Verkündigung Hoseas. Dadurch werden Auswahl und Zusammenstellung der Infinitive plausibel.

Das AT belegt an einigen Beispielen nicht die Anspielungen an den Dekalog, sondern die Karriere eines Korpus von drei Vergehen (Töten, Stehlen, Ehebrechen - wenn auch mit wechselnder Reihenfolge), die aus Hos 4,2 ausgewählt und als geschlossene Gruppe überliefert werden: Jer 7,9; Ijob 24,1315; (Ps 50,18ff, mit möglichem Rekurs auf den schon existierenden Deka$\log )$.

Eine Schlüsselrolle fällt Jer 7:9 zu. Neuere Analysen heben in Jer 7 einen Grundbestand von einer dtr Bearbeitung ab ${ }^{236}$. In Jer 7:9 läuft die Grenze zwischen beiden mitten durch die Reihe von 6 absoluten Infinitiven. In seiner syntaktischen Verknüpfung bezeugt der Vers, daß die Gruppe der ersten drei Infinitive als eigenständiges Korpus empfunden wird, an das die weiteren Infinitive mit jeweils eigenem Präpositionalobjekt syndetisch angehängt werden. Der vierte Infinitiv zeigt ein Delikt an, "falsch schwören": das das ganze Dtn aus prozeßtechnischen Gründen (s.o.) vermeidet. Der Formulierung nach kann der Infinitiv durchaus eine jeremianische Schöpfung sein, vgl. Jer 5,2 237. Die beiden nächsten Infinitive entstammen der dtr Bearbeitung des Jeremiabuches. Sie wurden wahrscheinlich durch die zweifache Ausrichtung des vierten Delikts (gegen Jahwe und gegen den Nächsten) provoziert. Jer 7,9 ist eine individuelle Bildung und verrät weder in Zahl noch in Auswahl einen spezifischen Einfluß des Dekalogs; selbst die dtr Ergänzungen schöpfen aus dem großen Sprachreservoir dtn/dtr Tradition. Verzichtet man darauf, auf Biegen und Brechen hier Dekalogeinfluß aufzuspüren, dann bezeugt der (jeremianische) Grundtext in V.9a* die Selektion einer Dreiergruppe aus Hos 4,2. Die schwer verständlichen beiden ersten Infinitive der Hoseastelle werden durch eine sachparallele eig̣ene Formulierung

\footnotetext{
235 Andeutungsweise bei CARDELLINI, Hosea; vor allem JEREMIAS, Hosea, bes. 49 .

236 Vgl. RICHTER, Recht, 58f; THIEL, Redaktion, 103-119; ROSE, Ausschließlichkeitsanspruch, 213-246.

237 Dazu THIEL, Redaktion, 185f und MEYER, Jeremia, 55-65. Die weiteren Parallelen außerhalb des Jeremiabuches sind von Jeremia abhängig.
} 
ersetzt. Wir gewinnen damit einen wichtigen Zeugen für das analoge Verfahren des Dekalog-Grundtextes. Wie Jer $7,9^{*}$ zapft er entweder selbst dieselbe Quelle an oder baut auf Jer 7.9* auf. Nur wandelt er sekundär die Infinitive in Prohibitive um. Erst bei diesem Schritt haben ihm wohl kleinere Prohibitivgruppen als Modell vorgeschwebt.

\subsubsection{Die durch Objekte erweiterten Prohibitive (Dtn 5,20 - 21)}

Der Gebrauch von ב ענה / als juristischer terminus technicus ist mehrfach vordtr belegt ${ }^{238}$; sogar ein Prohibitiv ist darunter,allerdings mit schwer verständlicher Präpositionsverbindung Ex 23,2239 . Die zum Prohibitiv 5,20 sachlich und der Wahl der Lexeme nach einschlägigen Parallelen bieten keinen gleichwertigen Verwandten ${ }^{240}$. Gerstenberger ${ }^{241}$ rechnet den Prohibitiv unter die Einzelgänger. Ich führe ihn auf den Kompositeur des Grundtextes zurück. Wie Hos 4,2 und Jer $7,9^{*}$, aber mit abweichender Formulierung will er den Rechtsbereich schuitzen und das falsche Zeugnis vor Gericht unterbinden. Die nächsten beiden Prohibitve sind im synoptischen Vergleich als Kunstbildungen nachgewiesen worden ${ }^{242}$. Sie verbieten allgemein alle Pläne und Machenschaften, die dazu führen, sich die Frau des Nächsten auf Dauer anzueignen oder dem Nächsten seinen Immobilienbesitz streitig zu machen und schließlich zu entwenden.

Das dtn Gesetz ersetzt in mehreren Schichten den älteren Begriff yר durch den Verwandtschaftsterminus אח. Dadurch dehnt es die Clansolidarität auf genetisch nicht so eng verbundene Mitglieder des gesamten Volkes aus. Dieser Sprachgebrauch ist daran interessiert, soziale und politische Gegensätze zu nivellieren und eine Gesellschaft von Brüdern zu schaffen 243. Die letzten drei Prohibitive kehren zum älteren Begriff y zurück. Darin mag eine archaisierende Tendenz liegen. Entscheidend ist aber wohl der Gehalt von $y$, der nicht nur den Volksgenossen, sondern darüber hinaus jeden

238 Vgl. 1 Sam 12,3; Dtn 19,16.18; Hos 5,5; 7,10 und daneben noch Spr 25, $18 \mathrm{~b}$.

239 Dazu RICHTER, Recht, 121 (Zusatz!).

240 Vgl. Spr 24,28a Vetitiv mit anderem Verb und anderem nomen rectum beim Zeugen; Spr 25,18b Partizipialsatz mit anderem nomen rectum beim Zeugen; Ex 23,1b Vetitiv mit eigener Formulierung; Ex 23,1a Prohibitiv mit Übereinstimmung in einem Lexem (שוא); s.o. unter 2.5.4.

241 DERS., Wesen, 88.

242 S.o. unter 2.6.4.2. 
beliebigen Mitmenschen, dem man gerade begegnet, bezeichnet ${ }^{244}$. Der Verfasser des Grundtextes wählt auch hier wieder die Formulierung unter dem Aspekt der entschränkten Allgemeinheit.

\subsubsection{Exkurs: Die These von der Umsetzung des Dekalogs in die Kasuistik der vordtn Biarta-Gesetze}

Ihr Urheber ist J. L'Hour, ihr Propagandist Lohfink ${ }^{245}$. Die These setzt den Dekalog früh an und macht inn zur Basisurkunde für fast alle vordtn Biarta-Gesetze. Diese greifen die einzelnen Dekaloggebote auf und legen sie in konkreter Kasuistik aus. Die These erscheint plausibel, weil sie den Dekalog als Grundgesetz einem einflußreichen Grundbestand dtn Gesetze vorordnet und eine immer schon vermißte Systematik anbietet. Ihre Schwächen liegen im Korpus der Biarta-Gesetze selbst und in deren Verbindung zum Dekalog. L'Hour 246 selbst macht darauf aufmerksam, daß Aquivalente für das Namenverbot, das Sabbatgebot und das Begehrensverbot fehlen. Allein diese Fehlanzeige reißt eine empfindliche Lücke in die Geschlossenheit der Systematik. Die behaupteten Kongruenzen zwischen Dekaloggeboten und Biarta-Gesetzen kommen entweder nur sehr punktuell oder überhaupt nicht zustande 247 . Das zweite Gravamen richtet sich gegen die Geschlossenheit des Biarta-Korpus selbst. Diese kommt bei L'Hour nur durch harmonisierende Texteingriffe zustande. So hat die Biarta-Schlußformel dreimal die Form "du sollst das Böse aus Israel ausrotten" $(17,12 ; 19,13 ; 22,22)$. Damit wendet sie sich an den Einzelnen, während sich die häufigere Schlußformel "du sollst das Böse aus deiner Mitte ausrotten" an das Kollektiv wendet. Nebeling ist der einzige, der daraus die notwendigen literarkritischen Konsequenzen zieht ${ }^{248}$. Offensichtlich ist die an den Einzelnen gerichtete

243 Vgl. JENNI, Art. ח א, $102 \mathrm{f}$.

244 Vgl. KÜHLEWEIN, Art. עา, 789f.

245 L'HOUR, Législation; LOHFINK zuletzt in neueren Veröffentlichungen: DERS., Gott, 104 A 18; DERS., Deuteronomy, 229-232, bes. 230; DERS., Dekaloganfang, 104 A 19; vgl. auch ROSE, Ausschließlichkeitsanspruch, 33-38, bes. 37f A 6 .

246 DERS., Législation, 26 A 2.

247 Im Fall des ersten Gebots haben nur der Fall des apostatischen Propheten 13,2-6 und der Musterproze $\beta$ 17,2-7 punktuelle Kongruenzen ("fremde Götter") - die anderen Fälle 13,7-12.13-18 müssen zu Biarta-Gesetzen rekonstruiert werden. Beim Tötungsverbot hat der dazugehörige Rechtsfall 19,11-13 keine Lexemverbindung zum Dekalog; diese muß über den Kontext importiert werden. Im Fall des Lügenzeugen 19,16-19 überwiegen die Differenzen. Bei 21,1-9 zeigen sich keine Berührungspunkte, 
Form noch nicht so in die Mosefiktion der Rede an ganz Israel eingeschmolzen (vgl. Ri 20,13).

Jüngst hat Kaufmann eine nur ähnliche,weil weitergehende These vertreten ${ }^{249}$. Das gesamte dtn Gesetz stamme von einem einzigen Autor. Dieser Autor habe den vollständigen Dekalogtext übernommen und zum Gerüst für seine Gesetzessammlung gemacht, die nun dem Modell gemäß einen kunstvoll aufgebauten, ausgeweiteten Dekalog darstelle. Kaufmanns Gegenvorschlag zu den in dieser Arbeit vertretenen Ansichten verzichtet auf literarkritische Differenzierung innerhalb wie außerhalb des Dekalogs. Stine Zuordnung von Dekaloggeboten und größeren Passagen des dtn Gesetzes importiert die Bezüge von aussen und erspart sich, die Abgrenzung der Einzelteile und ihre Berührungspunkte aus dem Text selbst zu entwickeln.

\subsubsection{Der Numeruswechsel vom Rahmen zum Dekalog-Grundtext}

Das leidige Numerusproblem spitzt sich in Dtn 5 auf die Frage zu: Ist der Numeruswechsel Zeichen für ein echtes oder fingiertes Zitat? Nimmt man ein echtes Zitat an und wertet den Numeruswechsel literarkritisch aus, dann wird der Dekalog-Grundtext in Dtn 5 als schon fertiges Produkt sekundär mit einem pluralisch abgefaßten Rahmen umgeben. Aus dieser Annahme ergeben sich weitere Fragen: Wie ist der Dekalog-Grundtext entstanden? Wo hatte er seinen Sitz im Leben bis er über Dtn 5 ins Dtn aufgenommen wurde? Welche Hinweise, die Dtn 5 zeitlich vorausliegen müssen, gibt es dafür, daß der Dekalog-Grundtext ein ursprüngliches Eigenleben geführt hat? Warum blieb sein singularischer Numerus für seine nächste Umgebung folgenlos?

Die zweite Hypothese rechnet mit einem fingierten Zitat. Der Autor des Grundtextes von Dtn ist auch der Verfasser bzw. Kompositeur des DekalogGrundtextes. In bezug auf den Numeruswechsel verzichtet die zweite Hypothese auf eine rein literarkritische Auswertung. Bisher wurde in dieser

ebenso im Fall des störrischen Sohnes 21,18-21. Die familienrechtlichen Fälle 22,13-21.22.23-27 sollen sich ans Ehebruchsverbot bzw. Begehrensverbot (bei der Frau) anschließen. Es fehlen aber Lexem-Brücken. Schließlich ist 17,8-13 im Dekalog nicht unterzubringen und die Kongruenz von 24,7 mit dem Diebstahlsverbot kommt nur über die Alt'sche Interpretation dieses Prohibitivs zustande.

248 DERS., Schichten, A 510; ausführliche Kritik an L'HOURs These, ebd., 404ff ; 1136, mit dem Hauptargument, daß L'HOUR nicht erklären kann, weshalb die allgemeingültigen Gebote des Dekalogs so stark auf konkrete Einzelfälle eingeschränkt werden. Vgl. weiter SEITZ, Deuteronomium, $131 \mathrm{f}$. 
Arbeit jeder Numeruswechsel individuell erklärt sowohl unter Abwägen seiner möglichen literarkritischen als auch stilistischen Bedeutung. D.h. die Entscheidung im Fall des ambivalenten Numerus kann nur durch zusätzliche Kriterien herbeigeführt werden. Die zweite Hypothese braucht also weitere Argumente:

Die Weichen zum Singular stellt der Kompositeur, indem er für die Einzelgebote das Modell des Prohibitivs wählt und seine Großreihe nach dem Muster kleinerer Prohibitivreihen zusammenstellt. Statistisch gesehen hat bei den Prohibitiven der Singular das Obergewicht 250. In diachronem Aufriß überwiegen in den älteren Korpora wie Bundesbuch, Privilegrecht und auch dtn Gesetz die Singularprohibitive, wohingegen im Heiligkeitsgesetz sich mehr und mehr die Pluralform durchsetzt ${ }^{251}$. Die Singularform der Prohibitive gewährt der Komposition des Grundtextes einen weiteren Vorteil. Sie erlaubt den bruchlosen ubergang vom kollektiv gemeinten Singular im Kopf-Teil des Grundtextes zur singularischen Bedeutung der nachfolgenden Reihe von sechs Prohibitiven.

Das Sparsamkeitsprinzip, der Numeruswechsel als begründetes Stilmittel und das Gewicht der Prohibitivüberlieferung votieren für die zweite Hypothese. Demnach ist der Autor der Grundtexte von Dtn 5 und $9 f$ auch der Kompositeur des Dekalog-Grundtextes. Die Einstufung in die Schichtungen des Dtn fällt schwer. Mit Vorbehalt ist seine Einordnung als früh-dtr Autor möglich.

\subsubsection{Ergebnis}

Der Dekalog-Grundtext ist eine individuelle Komposition. Sie besteht aus einem gerahmten "Kopf-Teil" und einer nachfolgenden Prohibitivreihe. Für die zweiteilige Gesamtkomposition stand das Privilegrecht Ex 34,12-26* Model1. Die Prohibitive des zweiten Teils werden aufgereiht und zusammengesetzt nach dem Muster kleinerer Prohibitivgruppen. Die Reihe der Kurzprohibitive bildet das Kompositionszentrum. Sie entstammt der Infinitivreihe von Hos 4,2. die entweder bereits durch den selektierenden Filter von Jer 7.9 gegangen ist oder nach Art von Jer 7,9 als Dreiergruppe übernommen und

249 DERS., Deuteronomic Law, 105-158.

$250 \mathrm{Vgl}$. GERSTENBERGER, Wesen, 71.76.

$251 \mathrm{Zu}$ den wenigen Pluralprohibitiven im Dtn: PEUCKER, Dtn 12,26, 47; zum Heiligkeitsgesetz: GERSTENBERGER, Wesen, 72 A 2. 
sekundär in Prohibitive umgesetzt wird. Die restlichen drei, durch Objekte erweiterten Prohibitive sind Kreationen des Kompositeurs, der von den Kurzprohibitiven ausgehend mit eigenen Verboten Gesetzeslücken schließt.

Die Absicht, allgemein und grundsätzlich zu formulieren, beherrscht die gesamte Komposition. Der Rahmen des "Kopf-Teils" entfaltet eine Kurz-Theologie von Jahwe in Tat und Wesen.

Fremdgötter- und Bilderverbot wehren den Hauptgefahren für das exklusive Verhältnis Jahwe - Israel: konkurrierende Götter und der Jahwe-Beziehung abträgliche Bilder. Die anschließenden sechs Prohibitive regeln die Beziehungen von Mensch zu Mitmensch. Die vorgegebenen Tatbestände der Kurzprohibitive (Töten - Ehebrechen - Stehlen) werden ergänzt. Die Rechtsprechung für ein Unrecht anfälliger und deshalb von den Rechtstraditionen mit Sorge betrachteter Lebensbereich - soll vor falschem Zeugnis geschützt werden. Der Frau wird ein weiterer Prohibitiv gewidmet. Neben dem einzelnen, punktuellen Ehebruch werden alle Pläne und Machenschaften verboten, die darauf abzielen, sich die Frau des Nächsten auf Dauer zu eigen zu machen. Schließlich wird der Bereich des Eigentums erneut berücksichtigt. Neben dem Stehlen als Entwenden von Mobilien des Nächsten untersagt der letzte Prohibitiv die widerrechtliche Aneignung von Immobilien des Nachbarn. Weitere semantische Analysen können hịer nicht erfolgen, aber ein Raster ist dafür angeboten.

Der Dekalog-Grundtext gehört zu einer umfassenden Revision der vorgegebenen jehowistischen Sinaitheophanie, die in den zusammengehörigen Grundtexten von Dtn 5 und $9 f$ vorgenommen wird. Das Privilegrecht Ex 34 mit seinem Einfluß auf die dtn Gesetzgebung (vgl. Dtn 7,16; daneben 12,2f.29.31; 14,21b; 26,1-11) wird in seiner Funktion eines Basistextes abgelöst durch den Dekalog-Grundtext. Dieser übernimmt nun die Aufgabe eines universalen, dauerhaft gültigen Grundgesetzes vor allen konkreten einzelnen Rechtsverordnungen. Was im Einzelnen zur Herausbildung und Formulierung dieser neuen juristischen Metaebene geführt hat, kann hier nicht verfolgt werden und bleibt weiteren redaktionskritischen Forschungen zum Dtn überlassen, die auch dann die historische Entstehungssituation des Dekalog-Grundtextes genauer einkreisen können. Die um die Sammlung und Systematisierung von Rechtsmaterialien bemühte dtn/dtr Bewegung mag sich zur Konzeption eines "modernen" Grundgesetzes gedrängt gefühlt haben. Andererseits können die Erfahrungen von Diaspora und die drohenden Anzeichen oder die ersten Berührungen mit dem Exil zur Definition der Basisbestimmungen für den Bund Jahwes mit Israel geführt haben, weil die herkömmlichen Bundesbestimmungen nicht mehr zu befolgen bzw. zu leben waren. 


\section{KAPITEL 5}

\section{Biographie des Dekalogs}

(anstelle eines Schlußwortes)

5.1 Zu den Ahnen des Dekalog-Grundtextes zählen das Privilegrecht Ex 34 und Hos 4,2 über die Vermittlung von Jer 7,9. Daneben liefern kleinere Prohibitivreihen das Muster für seine Komposition.

5.2 Im Rahmen einer Revision der jehowistischen Sinaitheophanie für das Dtn (Grundtext von Dtn 5 und 9f) komponiert ein früh-dtr Autor den DekalogGrundtext. Er gestaltet eine Gebotsreihe mit dem Anspruch eines universalen und dauerhaft gültigen Grundgesetzes und stellt sie vor das paränetisch eingeleitete dtn Gesetz. Sein Dekalog-Grundtext umfaßt: Dtn $5,6-8 a^{*} \cdot 9 b^{*} \cdot 10 a \cdot 17-21^{*}$.

5.3 Ein späterer dtr Redaktor baut den Grundtext aus zu den "Zehn Geboten". Er vereinigt Fremdgötter- und Bilderverbot, fügt drei neue Gebote ein (Namenverbot, Sabbat- und El terngebot) und prägt dem Dekalog seine ZweiTafel-Vorstellung auf. Er schiebt das Bundesbuch in die Sinaitheophanie und bearbeitet diese vom Dtn her. Zugleich deutet er das Privilegrecht Ex 34 um zum zweiten "Zehn-Wort", das nach dem Bundesbruchvon Ex 32 neu erstellt wird. Diese dtr Redaktion zieht Spuren von Ex 19 bis quer durch das ganze Dtn.

Innerhalb des nun fertigen Dekalogs zählen zu dieser Redaktion: VV.9a. 11-16; Anteile von V.21 und die waw copulativa der zweiten Tafel. 
5.4 Im Zuge einer weiteren Redaktion mit Schwerpunkt in Dtn 4,12b.15-18 wird der Prohibitiv des Bilderverbotes Dtn 5,8 von dort her ergänzt. Der Redaktor von Dtn 7,8b-11 trägt seine individualisierenden Korrekturen in den Dekalog ein: Ende V.9b und V.1ob.

5.5 Bei der Herstellung des Pentateuch gerät das Dtn mit dem Dekalog an die Peripherie. Der Pentateuchredaktor erweist dem Dekalog seine Reverenz und setzt ihn nach vorne (Ex 20) an die Spitze aller Gesetze der Sinaitheophanie, die er zugleich neu gestaltet. Dabei novelliert er die ihm vorliegende ältere Deuteronomiumfassung. Er behält die Zwei-Tafel-Vorstellung bei, ordnet aber innerhalb des Dekalogs neu an. Unter seinen verschiedenen Maßnahmen sind zu nennen: Die Verselbständigung des Bilderverbots, die neue Sabbatbegründung, die Fusion der Begehrensverbote und andere Anderungen.

Der Dekalog hat seine Wurzeln im Dtn. Seine Laufbahn beginnt in der Horebtheophanie und vollendet sich in der Sinaitheophanie des Pentateuch. 


\section{LITERATURVERZEICHNIS}

\section{Vorbemerkung}

Für Reihen, Zeitschriften etc. wurden die üblichen Sigel verwendet. Neuere Abkürzungen richten sich nach der Internationalen Zeitschriftenschau für Bibelwissenschaft und Grenzgebiete 25 (1978/79).

Die Anmerkungen nennen den Verfasser-Nachnamen, das Hauptstichwort des Titels und die Seitenangabe. Das Literaturverzeichnis gibt das Hauptstichwort in Klammern vor dem vollen Titel an.

AHLSTRÖM, G.W., (Art. תग) Art. Tית, ThWAT II, 1975, 564-569.

ALBERTZ, R., (Persönliche Frömmigkeit) Persönliche Frömmigkeit und offizielle Religion, Stuttgart 1978.

- (Elterngebot) Hintergrund und Bedeutung des Elterngebotes im Dekalog, ZAW 90 (1978) 348-374.

ALT, A., (Ursprünge) Die Ursprünge des israelitischen Rechts (1934), Kl. Schr. I, 278-302.

- (Verbot) Das Verbot des Diebstahls im Dekalog (1949), Kl. Schr. I, 333340 .

- (Anteil des Königtums) Der Anteil des Königtums an der sozialen Entwicklung in den Reichen Israel und Juda (1955), Kl. Schr. III, 348-372.

- (Mich 2,1-5) Micha 2,1-5. ГH / ANA $\triangle A \Sigma M O \Sigma$ in Juda (1959), Kl. Schr. III, 373-381.

AMSLER, S., (Art. Thn) Art. Thח, THAT II, 1976, 328-332.

ANDRÉ, G., (Art. קר) Art. Tרו, ThWT II, 1975, 686-689.

ANDREASEN, N.E.A., (Sabbath) The old Testament Sabbath, SBL Dissertation Series 7, Missoula 1972.

- (Recent Studies) Recent Studies of the old Testament Sabbath, ZAW 86 (1974) 453-469.

ANDREW, M.E., (Falsehood) Falsehood and Truth, Interpr 17 (1963) 425-438.

ANGERSTORFER, A., (Schöpfergott) Der Schöpfergott des AT, Regensburger Studien zur Theologie 20, Frankfurt 1979.

AUERBACH, E., (Moses) Moses, Amsterdam 1953.

- (Das Zehngebot) Das Zehngebot - allgemeine Gesetzes-Form in der Bibel, VT 16 (1966) 255-276.

BACH, R., (Bauen) Bauen und Pflanzen,in: Studien zur Theologie der alttestamentlichen tberlieferungen, FS G.v. Rad, Neukirchen 1961, 7-32.

BALTZER, K., (Bundesformular) Das Bundesformular, WMANT 4, Neukirchen 1960.

BARTH, C., (Elterngebot) Das Elterngebot (12. Sonntag nach Trinitatis), GPM 33 (1978) 330-335.

BEER, G., (Exodus) Exodus, HAT I,3, Tübingen 1939.

BEGG, C., (The literary Criticism) The literary Criticism of Deut 4,1-4o, ETL 56 (1980) 10-55. 
BELLEFONTAINE, E., (Rebellious Son) Dtn 21,18-21. Reviewing the case of the rebellious son, JSOT 13 (1979) 13-31.

BERNHARDT, K.H., (Gott und Bild) Gott und Bild. Ein Beitrag zur Begründung und Deutung des Bilderverbots im Alten Testament, Berlin 1956.

BERG, W., (Eifersucht) Die Eifersucht Gottes - ein problematischer Zug des alttestamentlichen Gottesbildes?, BZ NF 23 (1979) 197-211.

BERGER, K., (Gesetzesauslegung) Die Gesetzesauslegung Jesu, WMANT 40, Neukirchen 1972 .

BERSTRÄSSER, G., (II. Teil) Hebräische Grammatik, II. Teil: Verbum, Hildesheim 1962.

BERTHEAU, E., (Die sieben Gruppen) Die sieben Gruppen mosaischer Gesetze in den drei mittleren Büchern des Pentateuchs, Göttingen 1840.

BEYER, K., (Althebräische Syntax) Althebräische Syntax in Prosa und Poesie, in: Tradition und Glaube, FS K.G. Kuhn, Göttingen 1971, 76-96.

BEYERLIN, W., (Herkunft) Herkunft und Geschichte der ältesten Sinaitraditionen, Tübingen 1961.

- (Bundesbuch) Die Paränese im Bundesbuch und ihre Herkunft, in: Gottes Wort und Gottes Land, FS H.-W. Hertzberg, Göttingen 1965, 9-29.

BOECKER, H.J.,, (Recht und Gesetz) Recht und Gesetz im Alten Testament und im Alten Orient, Neukirchen 1976.

BOHLEN, R., (Nabot) Der Fall Nabot, TTSt 35, Trier 1978.

BOLLE, W., (Bodenrecht) Das israelitische Bodenrecht, Berlin 1940.

BOTTERWECK, G.J., (Dekalog) Form- und überlieferungsgeschichtliche Studie zum Dekalog, Conc 1 (1965) 392-401.

- (בrt. בהמה Art. ThWAT I, 1972, 523-536.

BRAULIK, G., (Ausdrücke für "Gesetz") Die Ausdrücke für "Gesetz" im Buch Deuteronomium, Bib 51 (197o) 36-66.

- (Testament des Mose) Das Testament des Mose. Das Buch Deuteronomium, Stuttgarter Kleiner Kommentar AT 4, Stuttgart 1976.

- (Weisheit) Weisheit, Gottesnähe und Gesetz. Zum Kerygma von Deuteronomium 4,5-8, in: FS W. Kornfeld, Wien 1977, 165-197.

- (Rhetorik) Die Mittel deuteronomischer Rhetorik erhoben aus Deuteronomium 4,1-40, AnBib 68, Rom 1978.

- (Literarkritik) Literarkritik und archäologische Stratigraphie. Zu S. Mittmanns Analyse von Dtn 4,1-40, Bib 59 (1978) 351-378.

BRICHTO, H.Chr., (Problem) The Problem of "Curse" in the Hebrew Bibel, Philadelphia 1968.

BRONGERS, H.A., (Wendung) Die Wendung בשם / Im Alten Testament, ZAW 77 (1965) 1-19.

- (Zehnzahl) Die Zehnzahl in der Bibel und in ihrer Umwelt, in: Studia Biblica et Semitica, FS T.C. Vriezen, Wageningen 1966, 30-45.

BÜHLMANN, W. - SCHERER, K., (Stilfiguren) Stilfiguren der Bibel, BiBe 10, Fribourg 1973.

BUIS, P. - LECLERCQ, J., (Deutéronome) Le Deutéronome , Paris 1963. 
CALOZ, M. , (Ex XIII, 3-16) Ex XIII, 3-16 et son Rapport au Deutéronome, RB 75 (1968) 5-62.

CARDELLINI, I., (Hosea) Hosea 4,1-3. Eine Strukturanalyse, in: Bausteine Biblischer Theologie, FS G.J. Botterweck, Bonn 1977, 259-27o.

CARMICHAEL, C.M., (Deuteronomy) The Laws of Deuteronomy, London 1974. CAZELles, H., (Etudes) Etudes sur le Code de $1^{\mathbb{2} A}$ Alliance, Paris 1946.

- (Décalogue) Les Origines du Décalogue, Eretz-Israel 9 (1969) 14-19.

- (Allicance) Alliance du Sinai, Alliance de l'Horeb et Renouvellement de 1 'Alliance, in: Beiträge zur alttestamentlichen Theologie, FS W. Zimmerli, Göttingen 1977, 69-79.

CHARLES, R.H., (Decalogue) The Decalogue, Edinburgh 1923.

CHILDS, B.S., (Exodus) Exodus. A Commentary, London 1974.

CHOLEWINSKI, A., (Heiligkeitsgesetz) Heiligkeitsgesetz und Deuteronomium, AnBib 66, Rom 1976.

CLARK, W.M., (Animal Series) The Animal Series in the Primeval History, VT 18 (1968) 433-449.

COATES, J.R., (Covet) Thou shalt not covet, ZAW 52 (1934) 238 f.

CONRAD, D., (Altargesetz) Studiem zum Altargesetz Ex 20,24-26, Marburg 1968.

CONRAD, J., (Die junge Generation) Die junge Generation im Alten Testament, Arbeiten zur Theologie 42, Stuttgart 1970.

CRÜSEMANN, F., (Widerstand) Der Widerstand gegen das Königtum, WMANT 49, Neukirchen 1978.

CRÜSEMANN, F. - THYEN, H., (Mann und Frau) Als Mann und Frau geschaffen. Exegetische Studien zur Rolle der Frau, Gelnhausen 1978.

DEISSLER, A., (Grundbotschaft) Die Grundbotschaft des Alten Testaments. Ein theologischer Durchblick, Freiburg 1972.

- (Gott) Ich bin Dein Gott, der dich befreit hat. Wege zur Meditation über das Zehngebot, Freiburg 1975.

DELITzSCH, Fr, , (Genesis) Neuer Commentar über Genesis, Leipzig 1887.

DENTAN, R.C., (The Literary Affinities) The Literary Affinities of Ex 34,6f', VT 13 (1963) 34-51.

DESELAERS, P., (Tobit). Das Buch Tobit. Studien zu seiner Entstehung, Komposition und Theologie, OBO, Freiburg-Schweiz-Göttingen 1981.

DEXINGER, F., (Garizimgebot) Das Garizimgebot im Dekalog der Samaritaner, in: Studien zum Pentateuch, FS W. Kornfeld, Wien 1977, 111-133.

DIEDRICH, F., (Anspielungen) Die Anspielungen auf die Jakob-Tradition in Hosea 12,1-13,3. Ein literaturwissenschaftlicher Beitrag zur Exegese früher Prophetentexte, fzb 27, würzburg 1977.

DIEPOLD, P., (Israels Land) Israels Land, BWANT 95, Stuttgart 1972.

DIETRICH, M. - LORETZ, O., (Soziale Struktur I) Die soziale Struktur von Alalah und Ugarit. I: Die Berufsbezeichnungen mit der hurritischen Endung - huli, wo 3 (1966) 188-205. 
DIETRICH, M. - LORETZ, O., (Soziale Struktur II) Die soziale Struktur von Alahah und Ugarit. II: Die sozialen Gruppen hupse - namê, hanniaḩhe ekư, ehele - Sūzubu und marjanne nach Texten aus Alalah̆ IV, wO 5 (1969) 57-93.

- (Soziale Struktur V) Die soziale Struktur von Alalah und Ugarit. V: Die Weingärten des Gebietes von Alalah im 15. Jahrhundeřt, UF 1 (1969) 37-64.

DIETRICH, M. - IORETZ, O. - SANMARTIN, J., (KTU) Die keilalphabetischen Texte aus Ugarit, AOAT 24/1, Neukirchen 1976.

DIETRICH, W., (Prophetie) Prophetie und Geschichte. Eine redaktionsgeschichtliche Untersuchung zum deuteronomistischen Geschichtswerk, FRLANT 108, Göttingen 1972 .

- (Josia) Josia und das Gesetzbuch, VT 27 (1977) 13-35.

DILLMANN, A. - RYSSEL, V., (Exodus) Die Bücher Exodus und Leviticus, KeH 12, Leipzig 31897.

DONNER, H., (Die soziale Botschaft) Die soziale Botschaft der Propheten im Lichte der Gesellschaftsordnung in Israel, OrAnt 2 (1963) 229-245.

DONNER, H. - RÖLLIG, W., (KAJ) Kanaanäische und aramäische Inschriften, Bd. I: Texte, Wiesbaden 31971; Bd. II: Kommentar, Wiesbaden 21968; Bd. III: Glossare, Indizes, Tafeln, Wiesbaden 21969.

DRIVER, G.R. - MILES, J.C., (Assyrian Laws) The Assyrian Laws, Oxford 1935.

- (Babylonian Laws) The Babylonian Laws, Vol. I, Legal Commentary, Oxford 31960; Vol. II, Transliterated Text - Translation - Philological Notes Glossary, Oxford 21960 .

DÜRR, L., (Wertung des Lebens) Die Wertung des Lebens im Alten Testament und im antiken orient, Münster 1926.

EBERHARTER, A., (Der Dekalog) Der Dekalog, Münster 1929.

EERDMANS, B.D., (Theol. Tijdschrift) Theologische Tijdschrift 35 (1901) 93.

- (Oorsprong) Oorsprong en vetekenis van de "tien woorden", ThT 37 (1903) 19-35.

EISING, H., (Art. זכר ) Art. ThWAT II, 1975, 571-593.

EISSFELDT, O., (Goethes Beurteilung) Goethes Beurteilung des kultischen Dekalogs von Ex 34 im Lichte der Pentateuchkritik (1966),Kl. Schr. IV, 221-230.

- (Sohnespflichten) Sohnespflichten im Alten Orient (1966),Kl. Schr. IV, 264-270.

ELLIGER, K., (Leviticus) Leviticus, HAT I.4, Tübingen 1966.

- (Deuterojesaja) Deuterojesaja, 1. Teilband, Jes 40,1-45,7, BK XI, 1, Neukirchen 1978.

ERLANDSSON, S., (Art. Tנה ) Art. ThWAT II, 1975, 612-619.

ETTISCH, E.E., (Symbolik) Die monotheistische Symbolik der Bundestafeln, VT 14 (1964) 211-215.

EWALD, H., (Geschichte) Geschichte des Volkes Israel, Bd. 2, Göttingen 31865 . FENSHAM, F.C., (Son) The Son of a Handmaid in Northwest Semitic, VT 19 (1969) 312-321.

FLoSS, J.P., (Jahwe Dienen) Jahwe Dienen - Göttern Dienen, BBB 45, Bonn 1975. 
FOHRER, G., (Hiob) Das Buch Hiob, KAT 16, Gütersloh 1963.

- (Recht) Das sogenannte apodiktisch formulierte Recht und der Dekalog (1965), in: Studien zur alttestamentlichen Theologie und Geschichte, Berin 1969, $120-148$.

- (Jesaja I) Das Buch Jesaja, 1. Bd., Zürcher Bibelkommentare, Zürich 21966 .

- (Propheten Bd. 7) Die Propheten des Alten Testaments, Bd. 7 Prophetenerzählungen, Gütersloh 1977.

FREEDMAN, D.N. - LUNDBOM, J., (Art. רור) Art. רור, ThWAT II, 1974, 181-194.

FRICK, F.S., (The City) The City in Ancient Israel, SBL Dissertation Series 36, Missoula 1977.

FRIEDRICH, J., (Staatsverträge) Staatsverträge des Hatti-Reiches in hethitischer Sprache, 1. Teil, MVÄG (1926) 1, Leipzig 1926; 2. Teil MVÄG (1930) 1, Leipzig 1930.

FUHS, H.F., (Sehen) Sehen und Schauen. Die Wurzel הTn im Alten Orient und im Alten Testament, fzb 32, Würzburg 1978.

- Qādeš - Materialien zu den Wüstentraditionen Israels, BN 9 (1979) 54-70.

GALLING, K., (Präfekten) Assyrische und Persische Präfekten in Gezer, PJB 31 (1935) 75-93.

- (Liste) Die Liste der aus dem Exil Heimgekehrten, in: Studien zur Geschichte Israels im persischen Zeitalter, Tübingen 1964, 89-108.

GAMBERONI, J., (Elterngebot) Das Elterngebot im Alten Testament, BZ NF 8 (1964) 161-19o.

GEFFKEN, J., (Einteilung) Utber die verschiedene Einteilung des Dekalogs, Hamburg 1838.

GERSTENBERGER, E., (Wesen) Wesen und Herkunft des "Apodiktischen Rechts", WMANT 20, Neukirchen 1965.

- (Covenant) Covenant and Commandment, JBL 84 (1965) 38-51.

- (Weisheit) Zur alttestamentlichen Weisheit, VerkF 14 (1969) 28-44.

- (אבה (אבה Art. THAT I, 1971, 20-25.

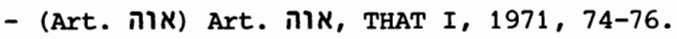

- (Art. Thח) Art. Tמח, THAT I, 1971, 579-581.

GERSTENBERGER, E. - SCHRAGE, W. , (Frau und Mann) Frau und Mann, Biblische Konfrontationen, Bd. 1013, Stuttgart 1980.

GESE, H., (Der Dekalog als Ganzheit) Der Dekalog als Ganzheit betrachtet (1967), in: Vom Sinai zum zion. Alttestamentliche Beiträge zur biblischen Theologie, München 1974, 63-80.

GESENIUS, W. - BUHL, F., (Handwörterbuch) Hebräisches und aramäisches Handwörterbuch über das Alte Testament, Berlin 171962 .

GESENIUS, W. - KAUTZSCH, E., (GK) Hebräische Grammatik, Hildesheim 281962.

GIESEN, G., (Semantische Vorfragen) Semantische Vorfragen zur Wurzel שבע "Schwören", in: Bausteine Biblischer Theologie, FS G.J. Botterweck, Bonn, 1977 , 127-143. 
GoldmanN, S., (The Ten Commandments) The Ten Commandments, Chicago 1956. GORDON, C.H., (Note) A Note on the Tenth Commandment, JBR 31 (1963) $208 f$. GRESSMANN, H., (Mose) Mose und seine Zeit. Ein Kommentar zu den Mose-Sagen, FRLANT 18, Göttingen 1913.

GROSS, H., (Zur Wurzel Tכ) Zur Wurzel Tכ, BZ NF 4, 1960, 227-237.

GROSS, W., (Bileam) Bileam. Literar- und formkritische Untersuchung der Prosa in Num 22-24, StANT 38, München 1974.

- (Herausführungsformel) Die Herausführungsformel - Zum Verhältnis von Formel und Syntax, ZAW 86 (1974) 425-453.

- (Verbform) Verbform und Funktion wayyiqtol für die Gegenwart? Ein Beitrag zur Syntax poetischer althebräischer Texte, ATS 1, St. Ottilien 1976.

- (Bundeszeichen) Bundeszeichen und Bundesschluß in der Priesterschrift, TTZ 87 (1978) 98-115.

GUNKEL, H., (Die israelitische Literatur) Die israelitische Literatur, Neudruck Darmstadt 1963.

GUNNEWEG, A.H.J., (Geschichte Israels) Geschichte Israels bis Bar Kochba, Stuttgart 1972 .

HAAG, H., (Der Dekalog) Der Dekalog, in: Moraltheologie und Bibel, AM 6, Paderborn $1964,9-38$.

- (Buch des Bundes) Das "Buch des Bundes" (Ex 24,7), in: Wort Gottes in der Zeit, FS K.H. Schelkle, Düsseldorf 1973, 22-30.

HALBE, J., (Privilegrecht) Das Privilegrecht Jahwes, Ex 34,10-26, FRLANT 114, Göttingen 1975.

- (Passa-Massot) Passa-Massot im deuteronomischen Festkalender. Komposition, Entstehung und Programm von Dtn 16,1-8, ZAW 87 (1975) 147-168.

- (Inzestverbote) Die Reihe der Inzestverbote Lev 18,7-18, ZAW 92 (1980) $60-88$.

HALLO, W.W. - TADMOR, H., (Lawsuit) A Lawsuit from Hazor, IEJ 27 (1977) 1-11.

HALPERN, B., (Centralisation Formula) The Centralisation Formula in Deuteronomy, VT 31 (1981) 20-38.

HAMP, V., (Art. גנג) Art. Tנג, ThWAT II, 1974, 41-47.

HEMPEL, J., (Schichten) Die Schichten des Deuteronomiums. Ein Beitrag zur israelitischen Literatur- und Rechtsgeschichte, Leipzig 1914.

HERRMANN, J., (Das zehnte Gebot) Das zehnte Gebot, in: Beiträge zur Religionsgeschichte und Archäologie Palästinas, FS E. Sellin, Leipzig 1927, 69-82.

HERRMANN, S., (Das "apodiktische Recht") Das "apodiktische Recht". Erwägungen zur Klärung dieses Begriffs, MJO 15 (1969) 249-261.

- (Geschichte Israels) Geschichte Israels in alttestamentlicher Zeit, München 1973.

HERTZBERG, H.W., (Samuelbücher) Die Samuelbücher, ATD 1o, Göttingen 31965. HOFFMANN, H.D., (Reform) Reform und Reformen. Untersuchungen zu einem Grundthema der deuteronomistischen Geschichtsschreibung, ATANT 66, zürich 1980. 
HOFFNER, H.A., (Art. בית) Art. ThWAT I, 1972, 629-638.

HOLZINGER, H., (Exodus) Exodus, KHC 2, Tübingen 1900.

HORST, F., (Privilegrecht) Das Privilegrecht Jahwes. Rechtsgeschichtliche Untersuchungen zum Deuteronomium, in: Gottes Recht, TB 12, München 1961, 17-154.

- (Zwei Begriffe) Zwei Begriffe für Eigentum, in: Verbannung und Heimkehr, FS W. Rudolph, Tübingen $1961,135-156$.

HOSSFELD, F.L., (Untersuchungen) Untersuchungen zu Komposition und Theologie des Ezechielbuches, fzb 20, Würzburg 1977.

HUMBERT, P., (La formule) La formule hébraique en hineni suivi d"un participe, in: Opuscules d'un Hebraisant, Neuchâtel 1958, 54-59.

HULST, A.R., (Sabbatgebot) "Bemerkungen zum Sabbatgebot", in: Studia Biblica et Semitica, FS. T.C. Vriezen, Wageningen 1966, 152-164.

HYATT, J.Th., (Exodus) Exodus (New Century Bibel), London 1971.

IRSIGLER, H., (Einführung) Einführung in das biblische Hebräisch, ATS 9/I, St. Ottilien 1978.

JACKSON, B.S., (Theft) Theft in Early Jewish Law, Oxford 1972.

- (Witnesses) "Two or Three Witnesses", in: Essays in Jewish and comparative Legal History, Leiden 1975, 153-171.

- (Liability) Liability for mere Intention in Early Jewish Law, in: Essays in Jewish and comporative Legal History, Leiden 1975, 202-234.

- (Foreign Influence) Foreign Influence in the Eraly Jewish Law of Theft, in: Essays in Jewish and comparative Legal History, Leiden 1975, 235-249.

JACOB, B., (Exodus) Das zweite Buch der Tora. Exodus (Hrsg. von E.J. Jacob), Mikrofilm, Jerusalem 0.J.

JAGERSMA, H., (Leviticus 19) Leviticus 19. Identiteit- Beverijding Gemeenschap, SSN 14, Assen 1972.

JENNI, E., (Begründung des Sabbatgebotes) "Die theologische Begründung des Sabbatgebotes im Alten Testament", ThSt 46, Zürich 1956.

- (Art. nא) Art. חא, THAT I, 1971, 98-104.

- (Art. בביות) Art. THAT I, 1971, 308-313.

JEPSEN, A .. (Beiträge) Beiträge zur Auslegung und Geschichte des Dekalogs, ZAW 79 (1967) 277-304.

- (Art. הTn) Art.הזn, ThWAT II, 1976, 822-835.

JEREMIAS, J., (Kultprophetie) Kultprophetie und Gerichtsverkündigung in der späten Königszeit Israels, WMANT 35, Neukirchen, 1970.

- (Hosea) Hos 4-7, in: Textgemäß, FS E. Würthwein, Göttingen 1979, 47-58.

JIRKU, A., (Das weltliche Recht) Das weltliche Recht im Alten Testament, Gütersloh 1927.

JOỦON, P., (Joüon) Grammaire de l'Hëbreu biblique, Roma 1923.

JUCCI, E., (La proibizione) Es 20,7. La proibizione di un uso illegitimo

del Nome di Dio nel Decalogo, Bibo 20 (1978) 245-253.

JUNKER, H., (Deuteronomium) Das Buch Deuteronomium, EB, Bonn 21954. 
KAISER, O., (Formular) Zum Formular der in Ugarit gefundenen Briefe, ZDPV 86 (1970) 10-23.

KATZENSTEIN, H.J., (The Royal Steward) The Royal Steward, IEJ 10 (1960) 149154.

KAUFMAN, S.A., (Deuteronomic Law) The Structure of the Deuteronomic Law, Maarav 1 (1978/79) 105-158.

KEEL, O., (Jahwe-Visionen) Jahwe-Visionen und Siegelkunst, sBS 84/85, Stuttgart 1977 .

KELLER, C.A., (Art. קלל) Art. Tלל II, 1976, 641-647.

KESZLER, W., (Problematik des Dekalogs) Die literarische, historische und theologische Problematik des Dekalogs, VT 7 (1957) 1-16.

KIESOW, K., (Jesajabuch) Exodustexte im Jesajabuch, OBO 24, Göttingen 1979.

KIPPENBERG, H.G., (Typik) Die Typik antiker Entwicklung, in: Seminar: Die Entstehung der antiken Klassengesellschaft, suhrkamp taschenbuch wissenschaft 130, Frankfurt 1977, 9-61.

- (Religion) Religion und Klassenbildung im antiken Judäa, StUNT 14, Göttingen 1978.

KLEIN, H., (Verbot) Verbot des Menschendiebstahls im Dekalog, VT 26, 1976, 161-169.

KLOPFENSTEIN, M.A., (Lüge) Die Lüge nach dem Alten Testament, Zürich 1964.

- (Art. בT) Art. ITJ, THAT I, 1971, 817-823.

- (Art. כשח Art. THAT I, 1971, 825-828.

- (Art. שקר, THAT II, 1976, 1010-1019.

KNIERIM, R., (Das erste Gebot) Das erste Gebot, ZAW 77 (1965) 20-39.

- (Sünde) Die Hauptbegriffe für sünde im Alten Testament, Gütersloh 21967.

- (Art. KUn) Art. KUn, THAT I, 1971, 541-549.

KOCH, K., (TempeleinlaBliturgien) TempeleinlaBliturgien und Dekaloge, in: Studien zur Theologie der alttestamentlichen Überlieferungen , FS G. von Rad, Neukirchen 1961, 45-60.

- (Formgeschichte) Was ist Formgeschichte?, Neukirchen 31974.

- (Art. אהל Art. ThWAT I, 1971, 128-141.

- (Art. KUn) Art. KUn, ThWAT II, 1976, 857-870.

KÖHLER, L., (Der Dekalog) Der Dekalog, TRu NF 1 (1929) 161-184.

KÖNIG, E., (Syntax) Syntax der hebräischen Sprache, Leipzig 1897.

- (Stilistik) Stilistik, Rhetorik, Poetik, Leipzig 1900.

- (Dekalog) Zur Erklärung und Geschichte des Dekalogs, NKZ 12 (1901) 363389.

- (Deuteronomium)Das Deuteronomium, KAT III, Leipzig 1917.

KREMERS, H., (Stellung des Elterngebotes) Die Stellung des Elterngebotes im Dekalog, EvT 21 (1961) 145-161.

KRISTENSEN, A.L., (Formulas) Ugaritic Epistolary Formulas, UF 9 (1977) 143158.

KRUYSWIJK, A., (Beeld) Geen Gesneden Beeld, Amsterdam, 1962. 
KUENEN, A., (Einleitung) Historisch-kritische Einleitung in die Bücher des Alten Testaments I, 1, Leipzig 1887.

KUHHLEWEIN, J., (Art. ספר) Art. THAT II, 1976, 162-173.

- (Art. עา ) Art. עา, THAT II, 1976, 786-791.

LABUSCHAGNE, C.J., (Art. Art. קול , THAT II, 1976, 629-634.

LANDE, J., (Formelhafte Wendungen) Formelhafte Wendungen der Umgangssprache im Alten Testament, Leiden 1949.

LANG, B., (Altersversorgung) Altersversorgung, Begräbnis und Elterngebot, ZDMG Suppl. III, 1, 1975,149-156.

LANGLAMET, F., (Israël) Israël et'l'habitant du pays'. Vocabulaire et formules d'Ex XXXIV, 11-16, RB 76 (1969) 321-350.481-507.

LAUSBERG, H., (Rhetorik) Elemente der literarischen Rhetorik, München 31967. LEHMING, S., (Versuch) Versuch zu Ex 32, VT 10 (1960) 32-40.

IEMAIRE, A., (Le Sabbat) Le Sabbat à l'époque Royale Israélite, RB 80 (1973) 161-185.

LESTIENNE, M., (Les dix "paroles") Les dix "paroles" et le Décalogue, RB 79 (1972) 484-510.

LEEUWEN, C. van, (Art. ננקה) Art. THAT II, 1976, 101-106.

LEWY, J., (Ursprung der Zehn Gebote) Auerbachs neuester Beweis für den mosaischen Ursprung der Zehn Gebote widerlegt, VT 4 (1954) 313-316.

L'HOUR, J., (Législation) Une législation criminelle dans le Deutéronome, Bib 44 (1963) 1-28.

- (Interdits) Les interdits to'eba dans le Deutéronome, RB 71 (1964) 481503.

LIEDKE, G., (Rechtssätze) Gestalt und Bezeichnung alttestamentlicher Rechtssätze. Eine formgeschichtlich-terminologische Studie, WMANT 39, Neukirchen 1971 .

LOERSCH, S., (Deuteronomium) Das Deuteronomium und seine Deutungen. Ein forschungsgeschichtlicher Utberblick, SBS 22, Stuttgart 1967.

LOHFINK, N., (BundesschluB) Der BundesschluB im Land Moab. Redaktionsgeschichtliches zu Dt 28,69-32,47, BZ NF 6 (1962) 32-56.

- (Hauptgebot) Das Hauptgebot. Eine Untersuchung literarischer Einleitungsfragen zu Dtn 5-11, AnBib 20, Rom 1963.

- (Höre Israel) Höre Israel! Auslegung von Texten aus dem Buch Deuteronomium, Düsseldorf 1965.

- (Dekalogfassung) Zur Dekalogfassung von DE 5, BZ NF 9 (1965) 17-32.

- (Bundesformel) Dtn 26,17-19 und die "Bundesformel", ZThK 91 (1969) 517553 .

- (Ex 32,7-11.13-14) Ex 32,7-11.13-14 (24. Sonntag des Jahres), in: Die alttestamentlichen Lesungen der Sonn- und Festtage, Lesejahr C 3, Würzburg 1971 , 47-60.

- (Credo) Zum "kleinen geschichtlichen Credo" Dtn 26,5-9, ThPh 46 (1971) 19-39. 
LOHFINK, N., (Gott) Gott im Buch Deuteronomium, in: La Notion biblique de Dieu. Ed. par J. Coppens (Bibliotheca Ephemeridum Theologicarum Lovaniensium 41), Gembloux 1976, 101-126.

- (Deuteronomy) Deuteronomy, in: The Interpreters Dictionary of the Bible Supplement, Nashville 1976, 229-232.

- (Unsere großen Wörter) Unsere großen Wörter, Freiburg 1977.

- (Dekaloganfang) Die These vom "deuteronomischen" Dekaloganfang - ein fragwürdiges Ergebnis atomistischer Sprachstatistik, in G. Braulik (Hrsg.), Studien zum Pentateuch, FS W. Kornfeld, Wien 1977, 99-109.

- (Art. ח Art. חרם ThW III, 1978, 192-213.

LOPEZ, F.G., (Analyse) Analyse littéraire de Deutéronome, V-XI, RB 84 (1977) 481-522; RB 85 (1978) 5-49.

- (Tradition) Deut., VI et la Tradition - Rédaction du Deutéronome, RB 85 (1978) 161-200; RB 86 (1979) 59-91.

LORETZ, O., (Rentenkapitalismus) Die prophetische Kritik des Rentenkapitalismus. Grundlagen - Probleme der Prophetenforschung, UF 5 (1975) 271-278.

- (Gesetzestafeln) Die steinernen Gesetzestafeln in der Lade, UF 7 (1977) 159-161.

- (Elterngebot) Das biblische Elterngebot und die Sohnespflichten in der ugaritischen Aqht-Legende, BN 8 (1979) 14-17.

LOWENTHAL, E., (Joseph-Narrative) The Joseph Narrative in Genesis, New York 1973.

LOZA, J., (Exode XXXII) Exode XXXII et la rédaction JE, VT 23 (1973) 31-55.

LURJE, M., (Studien) Studien zur Geschichte der wirtschaftlichen und sozialen Verhältnisse im israelitisch-jüdischen Reiche von der Einwanderung in Kanaan bis zum babylonischen Exil, BZAW 45, Gießen 1927.

MACALISTER, R., (Gezer) The Excavation of Gezer, Vol. I, London 1912.

MATHYS, F., (Sabbatruhe) Sabbatruhe und Sabbatfest. Uberlegungen zur Entwicklung und Bedeutung des Sabbat im Alten Testament, Thz 28 (1972) 241-262.

MATTHES, J.C., (Der Dekalog) Der Dekalog, ZAW 24 (1904) 17-41.

MAYER, G., (Art. אוה Art. ThWAT I,1971, 145-148.

MCCARTHY, D.J., (Treaty) Treaty and Covenant. A Study in Form in the Ancient oriental Documents and in the old Testament, AnBib 21, Rom 21978.

MCEVENUE, S.E., (The Narrative Style) The Narrative Style of the Priestly Writer, AnBib 50, Rom 1971.

MCKANE, W., (Proverbs) Proverbs (The old Testament Library), Philadelphia 21975 .

MCKAY, J.W., (Exodus) Exodus XXIII, 1-3,6-8. A decalogue for the administration of justice in the city gate, VT 21 (1971) 311-325.

MEIER, E., (Die ursprüngliche Form) Die ursprüngliche Form des Dekalogs, Mannheim 1846.

MEINHOLD, J., (Der Dekalog) Der Dekalog, Gießen 1927.

- (Zur Sabbatfrage) Zur Sabbatfrage, ZAW 48 (1930) 121-138.

MEISNER, O., (Der Dekalog) Der Dekalog. Eine kritische Studie I. Der Dekalog im Hexateuch, Halle 1893. 
MENDELSOHN, J., (Samuel's Denunciation) Samuel's Denuncitation of Kingship in the Light of the Akkadian Documents from Ugarit, BASOR 143 (156) 1722 .

MENES, A., (Die vorexilischen Gesetze) Die vorexilischen Gesetze Israels im Zusammenhang seiner kulturgeschichtlichen Entwicklung, BZAW 50,Gießen 1928.

MERENDINO, R.P., (Gesetz) Das deuteronomische Gesetz. Eine literarkritische, gattungs- und überlieferungsgeschichtliche Untersuchung zu Dt 12-26, BBB 31, Bonn 1969.

- (Untersuchung) Dt 27,1-8. Eine literarkritische und überlieferungsgeschichtliche Untersuchung, BZ NF 24 (1980) 194-207.

MERODE-DE-CROY, U. de, (Rolle der Frau) Die Rolle der Frau im Alten Testament, Conc 16 (1980) 270-275.

METTINGER, T.N.D., (Salomonic State) Salomonic State Officials. A Study of the Civil Government Officials of the Israelite Monarchy (Coniectanea Biblica. Old Testament Series 5), Lund 1971.

MEYER, J., (Jeremia) Jeremia und die falschen Propheten, OBO 13,Freiburg/ Schweiz-Göttingen 1977.

MILGROM, J., (Profane Slaughter) Profane Slaughter and a formulaic Key to the Composition of Deuteronomy, HUCA 47 (1976) 1-17.

- (A formulaic Key) A formulaic Key to the sources of D, Eretz-Israel 14 (1978) 42-47.123f.

MINETTE DE TILLESSE, G., (Sections) Sections "tu" et sections "vous" dans le Deutéronome , VT 12 (1962) 29-87.

MITTMANN, S., (Deuteronomium) Deuteronomium 1,1-6,3 literarkritisch und traditionsgeschichtlich untersucht, BZAW 139, Berlin 1975.

MORAN, W.L., (Background of the Love of God) The Ancient Near Eastern Background of the Love of God in Deuteronomy, CBQ 25 (1963) 77-88.

- (The Conclusion) The Conclusion of the Decalogue, CBQ 29 (1967) 543-554.

MORGENSTERN, J., (Covenant) The Book of the Covenant. Part. IV, HUCA 33 (1962) 59-105.

MOSIS, R., (Syntaktischer Aufbau) Exodus 19,5b.6a. Syntaktischer Aufbau und lexikalische Semantik, BZ NF 22 (1978) 1-25.

MOWINCKEL, S., (Décalogue) Le Décalogue. Etudes d'Histoire et de Philosophie Religieuses 16, Paris 1927.

MƯHL, M., (Untersuchungen) Untersuchungen zur altorientalischen und althellenistischen Gesetzgebung, Klio Beiheft 29 (1933), erweiterter Neudruck Aalen 1963.

MÜLLER, H.P., (Zur Verkündigung der Zehn Gebote) Zur Verkündigung der Zehn Gebote, WPKG 65 (1976) 518-535.

- (Art. קהל Art. ThAT II, 1976, 609-619.

- (Gott) Gott und die Götter in den Anfängen der biblischen Religion. Zur Vorgeschichte des Monotheismus, in: Monotheismus im Alten Israel und seiner Umwelt (Hrsg. O. Keel), BiBe 14, Fribourg 1980, 100-142.

MUILENBURG, J., (Usages) The Linguistic and Rhetorical Usages of the Particle J in the old Testament, HUCA 32 (1961) 135-160. 
NEBELING, G., (Schichten) Die Schichten des deuteronomischen Gesetzeskorpus. Eine traditions- und redaktionsgeschichtliche Analyse von Dtn 12-26, Diss. maschinenschriftlich, Münster 1970.

NEGRETTI, N., (Il Settimo Giorno) Il Settimo Giorno. Indagine criticoteologica delle tradizioni presacerdotali e sacerdotali circa il sabato biblico, AnBib 55, Roma 1973.

NEUMANN, P.K.D., (Hört) Hört das Wort Jahwes. Ein Beitrag zur Komposition alttestamentlicher Schriften (Schriften der Stiftung Europa-Kolleg 30), Hamburg 1975.

NICHOLSON, E.W., (Interpretation) The Interpretation of Ex 24,9-11, VT 24 (1974) 77-97.

-(Antiquity) The Antiquity of the Tradition in Ex 24,9-11, VT 25 (1975) 69-79.

- (The Origin) The origin of the Tradition in Ex 24,9-11, VT 26 (1976) 148160 .

- (Delalogue) The Decalogue as the direct Adress of God, VT 27 (1977) 422433.

NIELSEN, E., (Zehn Gebote) Die Zehn Gebote. Eine traditionsgeschichtliche Skizze, AThD 8, Kopenhagen 1965.

- (Jahwe) Weil Jahwe unser Gott ein Jahwe ist (Dtn 6,4f), in: Beiträge zur alttestamentlichen Theologie, FS W. Zimmerli, Göttingen 1977, 288301 .

NORTH, R., (Art. שTח) Art. שTח, ThWAT II, 1975, 759-780.

NOTH, M., (Exodus) Das zweite Buch Mose. Exodus, ATD 5, Göttingen 21961.

- (Leviticus)Das dritte Buch Mose. Leviticus, ATD 6, Göttingen 1962.

-(Numeri) Das vierte Buch Mose. Numeri, ATD 7, Göttingen 1967.

- (Könige) Könige I, BK IX, 1, Neukirchen 1968.

OHLER, A., (Israel) Israel, Volk und Land. Zur Geschichte der wechselseitigen Beziehungen zwischen Israel und seinem Land in alttestamentlicher Zeit, Stuttgart 1979.

OETTLI, S., (Deuteronomium) Das Deuteronomium, München 1893.

OTTO, E., (Mazzotfest) Das Mazzotfest in Gilgal, BWANT 107, stuttgart 1975. otTosson, M., (Art. גבול Art, Thwat I, 1972, 896-901.

OYEN, H. van, (Ethik) Ethik des Alten Testaments, Gütersloh 1967.

PARDEE, D., (Letters) Letters from Tel Arad, UF 10 (1978) 289-336.

PATRICK, A.T., (La formation littéraire) La formation littéraire et l'origine historique du décalogue, ETL 4o (1964) 242-251.

PATRICK, D., (The Covenant) The Covenant Code Source, VT 27 (1977) 145-157.

PERLITT, L., (Bundestheologie) Bundestheologie im Alten Testament, WMANT

36, Neukirchen 1969.

- (Sinai) Sinai und Horeb, in: Beiträge zur alttestamentlichen Theologie, FS W. Zimmerli, Göttingen 1977, 302-322.

PETERS, J.P., (The Ten Words) The Ten Words, JBL 6 (1886) 140-144. 
PETSCHOW, H., (Codex Hammurabi) Zur Systematik und Gesetzestechnik im Codex Hammurabi, ZA NF 23 (1965) 146-172.

PEUCKER, H., (Dtn 12,26) Deuteronomium Kap. 12-26 form- und rechtsgeschichtlich untersucht, Diss Greifswald 1962.

PHILLIPS, A., (Criminal Law) Ancient Israel's Criminal Law. A New Approach to the Decalogue, Oxford 1970.

PLAUTZ, W., (Eheschließung) Die Form der Eheschließung im Alten Testament, ZAW 76 (1964) 298-318.

PLÖGER, J.G., (Deuteronomium) Literarkritische, formgeschichtliche und stilkritische Untersuchungen zum Deuteronomium, BBB 26, Bonn 1967.

PREUSS, H.D., (Art. את) Art. ThWAT I, 1971, 485-500.

- (Art. חוה, ThWAT II, 1976, 784-794.

- (Art. KY?) Art. KY?, ThWAT III, 1981, 795-822.

RABAST, K.H., (Das apodiktische Recht) Das apodiktische Recht im Deuteronomium und im Heiligkeitsgesetz, Berlin 1948.

RAD, G. von, (Gottesvolk) Das Gottesvolk im Deuteronomium (1929) TB 48 (1973) 9-108.

- (Deuteronomium) Das fünfte Buch Mose. Deuteronomium, ATD 8, Göttingen 1964 .

- (Theologie I) Theologie des Alten Testaments I. Die Theologie der geschichtlichen Überlieferungen, München ${ }^{4} 1962$.

- (Genesis) Das erste Buch Mose. Genesis, ATD 2/4, Göttingen ${ }^{9} 1972$.

REICKE, B., (Die zehn Worte) Die zehn Worte in Geschichte und Gegenwart, Beiträge zur Geschichte der biblischen Exegese 13, Tübingen 1973.

RENDTORFF, R., (Die Gesetze) Die Gesetze in der Priesterschrift, FRLANT 62, Göttingen 21963.

REVENTLOW, H. Graf, (Gebot) Gebot und Predigt im Dekalog, Gütersloh 1962.

RICHTER, W., (Recht) Recht und Ethos. Versuch einer ortung des weisheitlichen Mahnspruchs, StANT 15, München 1966.

- (Grammatik) Grundlagen einer althebräischen Grammatik. A. Grundfragen einer sprachwissenschaftlichen Grammatik. B. Die Beschreibungsebenen: I. Das Wort (Morphologie) ATS 8, St. Ottilien 1978; II. Die Wortfügung (Morphosyntax) ATS 10, St. Ottilien 1979; III. Der Satz (Satztheorie) ATS 13, St. Ottilien 1980.

RIESENER, J., (Stamm Tבע) Der Stamm y im Alten Testament, BZAW 149, Berlin 1979.

ROBINSON, G., (The Origin) The Origin and Development of the Old Testament Sabbath. A Comprehensive Exegetical Approach, Dissertation Hamburg 1975.

ROSE, M., (AusschlieBlichkeitsanspruch) Der AusschlieBlichkeitsanspruch Jahwes. Deuteronomische Schultheologie und die Volksfrömmigkeit in der späten Königszeit, BWANT 116, stuttgart 1975. 
ROSE, M., (Bemerkungen) Bemerkungen zum historischen Fundament des JosiaBildes in II Reg 22f, ZAW 89 (1977) 5o-63.

ROST, L., (Schuld der Väter) Die Schuld der Väter, in: FS R. Herrmann, Berlin 1957, 229-233.

- (Gesetz) Gesetz und Propheten, in: Studien zum Alten Testament, BWANT 101, Stuttgart 1974, 9-38.

- (Bemerkungen) Bemerkungen zu dibbär, in: Studien zum Alten Testament, BWANT 101, Stuttgart 1974, 39-59.

ROWLEY, H.H., (Moise) Moise et le Décalogue, RH Phil Rel 32 (1952) 7-4o. RUDOLPH, W., (Jeremia) Jeremia, HAT I, 12, Tübingen 31968 .

- (Hosea) Hosea, KAT XIII, 1, Gütersloh 1966.

- (Micha) Micha-Nahum-Habakkuk-Zephania, KAT XIII, 3, Gütersloh 1975.

RÜCKER, H., (Die Begründungen) Die Begründungen der Weisungen Jahwes im Pentateuch, ETS 30, Leipzig 1973.

RUPPERT, L., (Josefserzählung) Die Josefserzählung der Genesis. Ein Beitrag zur Theologie der Pentateuchquellen, StANT 11, München 1965.

RUPRECHT, E., (Mannawunder) Stellung und Bedeutung der Erzählung vom Mannawunder (Ex 16) im Aufbau der Priesterschrift, ZAW 86 (1974) 269-307.

- (Erzähltradition) Ex 24,9-11 als Beispiel lebendiger Erzähltradition aus der Zeit des babylonischen Exils, in: FS Cl. Westermann, Göttingen $1980,138-173$.

SALONEN, E., (Höflichkeitsformeln) Die Gruß- und Höflichkeitsformeln in Babylonisch-Assyrischen Briefen, Studia Orientalia 38, Helsinki 1967.

SAWYER, J.F.A., (שצt. שוא (שוא) AHAT II, 1976, 882-884.

SCHARBERT, J., (Formgeschichte) Formgeschichte und Exegese von Ex 34,6f und seiner Parallelen, Bib 36 (1957) 130-150.

- (Ehe) Ehe und Eheschließung in der Rechtssprache des Pentateuch und beim Chronisten, in: G. Braulik (Hrsg.), Studien zum Pentateuch, FS W. Kornfeld, wien 1977, 213-225.

SCHICKLBERGER, F., (Ladeerzählungen) Die Ladeerzählungen des ersten SamuelBuches. Eine literaturwissenschaftliche und theologiegeschichtliche Untersuchung, fzb 7, Würzburg 1973.

SCHMID, H.H., (Schalom) Schalom "Frieden" im Alten orient und im Alten Testament, SBS 51 , Stuttgart 1971 .

- (Art. לקח Art. THAT I, 1971, 875-879.

SCHMID, H., (Mose) Mose. Überlieferung und Geschichte, BZAW 110, Berlin 1968.

SCHMIDT, H., (Mose) Mose und der Dekalog,in: EYXAPIETHPION . Studien zur Religion und Literatur des Alten und Neuen Testaments, FS H. Gunkel, FRIANT 36,1 , Göttingen 1923, 78-119.

SCHMIDT, W.H., (Überlieferungsgeschichtliche Erwägungen) UUberlieferungsgeschichtliche Erwägungen zur Komposition des Dekalogs, VTS 22 (1972) 201-220.

- (Schöpfungsgeschichte) Die Schöpfungsgeschichte der Priesterschrift, WMANT 17, Neukirchen 31973. 
SCHMIDT, W.H., (Alttestamentlicher Glaube) Alttestamentlicher Glaube in seiner Geschichte, Neukirchen 21975.

- (Exodus) Exodus, BK II, 2, Neukirchen 1977.

SCHмITT, G., (Zu Gen 26,1-14) Zu Gen 26,1-14, ZAW 85 (1973) 143-156.

SCHмITT, H.C., (Josephsgeschichte) Literarkritische Studien zur vorpriesterlichen Josephsgeschichte, Habil.-Schrift, Marburg 1975.

SCHMÖKEL, H., (Gebote) Biblische "Du-sollst"-Gebote und ihr historischer Ort, Z Sav RG Kanonistische Abteilung 36 (1950) 365-39o.

SCHNEIDER, H., (Der Dekalog) Der Dekalog in den Phylakterien von Qumran, BZ NF 3 (1959) 18-31.

SCHOTTROFF, W., (Gedenken) "Gedenken" im Alten Orient und im Alten Testament, WMANT 15, Neukirchen 1964.

- (Fluchspruch) Der altisraelitische Fluchspruch, WMANT 30, Neukirchen 1969.

- (Art. T) Art. ThAT I, 1971, 507-518.

- (Recht) Zum alttestamentlichen Recht, VuF 22 (1977) 3-29.

- (Amos) Der Prophet Amos. Versuch der Würdigung seines Auftretens unter sozialgeschichtlichem Aspekt, in: Der Gott der kleinen Leute (Hrsg. SCHOTTROFF-STEGEMANN), München 1979, 39-66.

SCHREINER,J., (Die Zehn Gebote) Die Zehn Gebote, Biblische Handbibliothek 3 , München 1966.

SCHÜNGEL-STRAUMANN, H., (Der Dekalog) Der Dekalog - Gottes Gebote?, SBS 67, Stuttgart 1973.

SCHUUPPHAUS, J., (Art. לTג) Art. לזג, ThWAT I, 1973, 999-1001.

- (Volk Gottes) Volk Gottes und Gesetz beim Elohisten, TZ 31 (1975) 193-210.

SCHULZ, H., (Todesrecht) Das Todesrecht im Alten Testament. Studien zur Rechtsform der Mot-Jumat-Sätze, BZAW 114, Berlin 1969.

SCHWEIZER, H., (Elischa) Elischa in den Kriegen, StANT 37, München 1974. SEEBASS, H., (Art. בחר (בחר ) ThWT I, 1972, 593-608.

SEGERT, S., (Glied) Bis in das dritte und vierte Glied, CV 1 (1958) 37-39.

SEIDL, Th., (Jeremia) Texte und Einheiten in Jeremia 27-29. Literaturwissenschaftliche Studie 1. Teil, ATS 2, St. Ottilien 1977.

Formen und Formeln in Jer 27-29. Literaturwissenschaftliche Studie 2. Teil, ATS 5, St. Ottilien 1978.

SEITZ, G., (Deuteronomium) Redaktionsgeschichtliche Studien zum Deuteronomium, BWANT 93, Stuttgart 1971.

SELLIN, E., (Geschichte I) Geschichte des israelitisch-jüdischen Volkes. 1. Teil. Von den Anfängen bis zum babylonischen Exil, Leipzig 1924.

SETERS, J. van, (Abraham) Abraham in History and Tradition, New Haven 1975.

SKWERES, D.E., (Rückverweise) Die Rückverweise im Buch Deuteronomium, AnBib 79, Rom 1979.

SMEND, R., (Essen und Trinken) Essen und Trinken - ein Stück Weltlichkeit des Alten Testaments, in: Beiträge zur alttestamentlichen Theologie, FS W. Zimmerli, Göttingen 1977 , 446-459. 
SMEND, R., (2. Mose 20,4-6) 2. Mose 20,4-6 (5. Sonntag nach Trinitatis), GPM 1978, 280-287.

- (Entstehung des AT) Die Entstehung des Alten Testaments, Stuttgart 1978.

SMITH, M., (Entwicklungen) Die Entwicklungen im Judäa des 5. Jh.v.Chr. aus griechischer Sicht, in: H.G. Kippenberg (Hrsg.), Seminar: Die Entstehung der antiken Klassengesellschaft, stw 130, 313-327.

SMITH, S., (Statue of Idrimi) The Statue of Idrimi, London 1949.

SMITTEN, W.Th. in der, (Art. רמור) Art. רמור, ThWAT II, 1977, 1036-1042.

STAMM, J.J., (Dreißig Jahre) Dreißig Jahre Dekalogforschung, ThR NF 27 (1961) 189-239.281-305.

- (Dekalogforschung) Der Dekalog im Lichte der neueren Forschung, BernStuttgart 21962 .

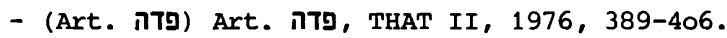

STAMM, J.J. - ANDREW, M.E., (Commandments) The Ten Commandments in Recent Research, SBTh II, 2, London 1967.

STECK, O.H., (Gen 12,1-3) Gen 12,1-3 und die Urgeschichte des Jahwisten, in: H.W. WOLFF (Hrsg.), Probleme biblischer Theologie, FS G. von Rad, München 1971 , 525-554.

- (Der Schöpfungsbericht) Der Schöpfungsbericht der Priesterschrift. Studien zur literarkritischen und überlieferungsgeschichtlichen Problematik von Gen 1,1-2,4a, FRLANT 115, Göttingen 1975.

STEUERNAGEL, C., (Deuteronomium) Deuteronomium und Josua, HK I,3, Göttingen 1900.

STOEBE, H.J., (Das achte Gebot) Das achte Gebot, WuD 3 (1952) 108-126.

- (Art. 210) Art. 210, THAT I, 1971, 652-664.

- (Samuelbücher) Das erste Buch Samuelis, KAT VIII, 1, Gütersloh 1973.

STOLZ, F., (שבחת) Art. שבת (AHAT II, 1976, 863-869.

STRACK, H.L., (Exodus) Exodus, München 1894.

STROMBACH, W., (Die Gesetze) Die Gesetze unseres Denkens. Eine Einführung in die Logik, München 31975 .

SZLECHTER, E., (Effets) Effets de la captivité en droit assyro-babylonien, RA 57 (1963) 181-192.

THIEL, W., (Redaktion) Die deuteronomistische Redaktion von Jeremia 1-25, WMANT 41, Neukirchen 1973.

- (Entwicklung) Die soziale Entwicklung Israels in vorstaatlicher Zeit, Dissertation zum Dr.sc.theol. ,Berlin 1977.

TITZMANN, M., (Strukturale Textanalyse) Strukturale Textanalyse, UTB 582, München 1977.

TSEVAT, M., (Biblical Sabbath) The Basic Meaning of the Biblical Sabbath, ZAW 84 (1972) 447-459.

UTZSCHNEIDER, H., (Hosea) Hosea. Prophet vor dem Ende, OBO 31 , Freiburg/ Schweiz-Göttingen 1980.

VALENTIN, H., (Aaron) Aaron. Eine Studie zur vorpriesterschriftlichen Aaronüberlieferung, ОВО 18, Freiburg/Schweiz-Göttingen 1978.

VAUX, R. de, (Institutions I) Les institutions de $1^{\circ}$ Ancien Testament I, Paris 21961 . 
VAUX, R. de, (Histoire) Histoire ancienne d'Israel. Des origines à la'installation en Canaan, Paris 1971.

VEIJOLA, T., (Königtum) Das Königtum in der Beurteilung der deuteronomistischen Historiographie. Eine redaktionsgeschichtliche Untersuchung, AASF B 198, Helsinki 1978.

VERMES, G., (Decalogue) The Decalogue and the Minim, in: In Memoriam Paul Kahle, BZAW 103, Berlin 1968, 232-240.

VETTER, D., (רזt. ראה ה ראה, THAT I., 1976, 692-701.

VRIES, S.J. de, (Development) The Development of the Deuteronomic Promulgation Formula, Bib 55 (1974) 301-316.

WAGNER, V., (Rechtssätze) Rechtssätze in gebundener Sprache und Rechtssatzreihen im israelitischen Recht. Ein Beitrag zur Gattungsforschung, BZAW 127, Berlin 1972.

- (Art. טרף) Art. Thwat III, 1978, 375-383.

WALLIS, G., (Jobeljahr-Gesetz) Das Jobeljahr-Gesetz, eine Novelle zum Sabbatjahr-Gesetz, MIO 15 (1969) 337-345.

- (Vollbürgereid) Der Vollbürgereid in Deuteronomium 27,15-26, HUCA 45 (1974) 47-63.

- (Art. Thn) Art. Thn, ThWAT II, 1976, 1020-1032.

WATTS, D.W., (Infinitive Absolute) Infinitive Absolute as Imperative and the Interpretation of Ex 20,8, ZAW 74 (1962) 141-145.

WEBER, M., (Aufsätze III) Gesammelte Aufsätze zur Religionssoziologie III. Das antike Judentum, Tübingen 61976.

WEIMAR, P., (Hoffnung auf Zukunft) Hoffnung auf zukunft. Studien zu Tradition und Redaktion im priesterschriftlichen Exodus-Bericht in Ex 1-12, Diss. Freiburg/Brsg. 1971/72.

- (Untersuchungen) Untersuchungen zur priesterschriftlichen Exodusgeschichte, fzb 9, Würzburg 1973.

- (Redaktionsgeschichte des Pentateuch) Untersuchungen zur Redaktionsgeschichte des Pentateuch, BZAW 146, Berlin 1977.

- (Freiheit) Zur Freiheit geschaffen. Aspekte des alttestamentlichen Freiheitsverständnisses, Biki 1979, 86-90.

- (Berufung) Die Berufung des Mose. Literaturwissenschaftliche Analyse von Exodus 2,23-5,5, OBO 32, Freiburg/Schweiz - Göttingen 1980.

- (Ijobnovelle) Literarkritisches zur Ijobnovelle BN 12 (1980) 62-80.

WEIMAR, P. - ZENGER, E., (Exodus) Exodus. Geschichten und Geschichte der Befreiung Israels, SBS 75, Stuttgart 21979.

WEINBERG, J.P., (Agrarverhältnisse) Die Agrarverhältnisse in der BürgerTempel-Gemeinde der Achämenidenzeit, in: J. Harmatta und G. Komoroszy, (Hrsg.), Wirtschaft und Gesellschaft im alten Vorderasien, Budapest 1976, 473-486.

WEINFELD, M., (Deuteronomy) Deuteronomy and the Deuteronomic School, Oxford 1972 .

WEINGREEN, J., (Case) The Case of the Blasphemer, VT 22 (1972) 118-123. WEINRICH, H., (Sprache in Texten) Sprache in Texten, Stuttgart 1976. 
WELlHAUSEN, J., (Composition) Die Composition des Hexateuchs und der historischen Bücher des Alten Testaments, Berlin 41963.

WESTERMANN, C., (כבד. (כבד. THAT I, 1971, 794-812.

- (Herrlichkeit) Die Herrlichkeit Gottes in der Priesterschrift (1971), in: Forschung am Alten Testament. Gesammelte Studien Band II, TB 55, München $1974,115-137$.

- (Genesis) Genesis, BK I,1, Neukirchen 1974; BK I,2, Neukirchen 1981.

- (Art. Tגנ) Art. Tגנ, THAT II, 1976, 31-37.

WHITLEY, C.F., (Covenant) Covenant and Commandment in Israel, JNES 22 (1963) 37-48.

WILDBERGER, H., (Jesaja) Jesaja,BK X,1, Neukirchen 1972;BK X,2, Neukirchen 1978.

WILDEBOER, G., (Theologische Studien) Theologische Studien 1 (1903) $116 \mathrm{ff}$.

WOLFF, H.W., (Amos) Dodekapropheton II, Joel und Amos, BK XIV,2, Neukirchen 1969.

- (Anthropologie) Anthropologie des Alten Testaments, München 1973.

- (Hosea) Dodekapropheton I, Hosea, BK XIV,3, Neukirchen 31976 .

WOUDE, A.S. van der, (Art. פנים) Art. פנים, THAT II, 1976, 432-460.

- (Art. קשה Art. THAT II, 1976, 689-692.

- (Art. שם) Art. שמם, ThAT II, 1976, 935-963.

WUNDERLICH, D., (Grundlagen) Grundlagen der Linguistik, Reinbek 1974.

WÜRTHWEIN, E., (Text) Der Text des Alten Testaments, stuttgart 41973.

- (Josianische Reform) Die Josianische Reform und das Deuteronomium, ZThK 73 (1976) 395-423.

- (1 Könige) Das erste Buch der Könige). Kapitel 1-16, ATD 11,1, Göttingen 1977 .

ZENGER, E., (Dekalogforschung) Eine Wende in der Dekalogforschung? Ein Bericht, ThRev 64 (1968) 189-198.

- (Sinaitheophanie) Die Sinaitheophanie. Untersuchungen zum jahwistischen und elohistischen Geschichtswerk, fzb 3, Würzburg 1971.

- (Tafeln vom Sinai) Psalm 87,6 und die Tafeln vom Sinai, in: Wort, Lied und Gottesspruch, FS J. Ziegler II, Würzburg 1972, 97-103.

- (Exodus) Das Buch Exodus (Geistliche Schriftlesung 7), Düsseldorf 1978.

- (Rezension) Rezension zu J. Halbe, Das Privilegrecht Jahwes Ex 34,10-26, ThRev 75 (1979) 277-280.

ZIMMERLI, W., (Das zweite Gebot) Das zweite Gebot (1950), in: Gottes offenbarung, TB 19, München 1963, 234-248.

- (Jahwe) Ich bin Jahwe (1953), in: Gottes offenbarung, TB 19, München 1963, $11-40$.

- (Erwägungen) Erwägungen zum 'Bund'. Die Aussagen über die Jahwe-berrt in Ex 19-34, in: Wort-Gebot-Glaube, FS W. Eichrodt, ATANT 59, Zürich 197o, 171-19o.

- (Bilderverbot) Das Bilderverbot in der Geschichte des alten Israel. Goldenes Kalb, eherne Schlange, Mazzeben und Lade (1971), in: Studien zur alttestamentlichen Theologie und Prophetie, TB 51, München 1974, 247-26o. 
ZIMMERLI, W., (Abraham) 1. Mose 12-25. Abraham, Zürcher Bibelkommentare AT 1.2, Zürich 1976.

- (Ezechiel) Ezechiel, BK XIII,1 und 2, Neukirchen 21979.

ZOBEL, H.J., (Art. TDN) Art. TDח, ThWAT III, 1979, 48-71. 


\section{REGISTER DER BIBELSTELLEN}

(in Auswahl und unter Berücksichtigung des Inhaltsverzeichnisses)

Gen

$1,24-26 \quad 46$

$1,26 \quad 51$

1,28

$2,1-3$

$2,2 \mathrm{f}$

2,2

2,3

3,6

12,19

15,2

15,7

15,16

15,17

17,1

$20,2.3$

$24,3.37$

30,30

50,23

Ex

3,15

6,2

6,8

6,13-20

$13,3-16$

13,3

$13,6 \mathrm{f}$

16

18,12

19

19,1

19,2

$19,3-8$

19,3

$19,4-8$

19,4

19,5

19,6

19,7

$19,8 \mathrm{f}$

19,8

19,9

19,16

19,17

19,18

19,19
46
51

34

35.40 .51 .52

51

52

98

134

94

264

31.32

173

171

134

135

94

28.32

\section{0}

171

67

31.32

41

41

252

56

199-201

283

168

168

185.190

$168.179 .185 f .190$

239

173.179 .186

$186 \mathrm{f}$

187

182.188 .191 .193

185

188

174.188-19o

174.227

169

174

169

19,20
$19,21-24$
19,21
19,22
19,23
19,24
19,25
20
20,1
$20,2-17$
20,4
20,5
$20,8-11$

20,8

$20,9 f$

20,10

20,11

20,12

20,16

20,17

20, 18-21

2o, $18 f$

20,18

20,19

$20,2 \circ f$

20,20

20,21

$20,22 f$

20,22

20,23

$20,24 \mathrm{ff}$

2o, 24-26

20,24

20,25

20,26

$21,1-23,33$

21,1

$21,2 \mathrm{ff}$

21,2

$21,7-11$

21,10

$21,12-17$

21,12

$21,13-14$

21,15
164-166

164

164-166.173

$203 f$

$165 \mathrm{f}$

164f. 2o2-2o4

164-166.175

284

165-168.170.175

141

$21.23 f .51$

2of. 24-27.32

$37-40.42$. $46.49 \cdot 51$ -

53.57

34-36.4of

$33 f$

42-46

$33-35.39 f .42 .50-52$

20.24.59-68

$75 f .80 .85 f$

42f.87-96.103.106

172

$172 f .175 .179$

$173 f$

20.170-175

172

170.172.175f

170.175f. 227

176.185

174-185. 239

180.183 .268

176

18 of. 239

182

183

183

239

180-182

18 of

181

115

120

$69 f$

69

70

69-72.253-256 


\begin{tabular}{|c|c|c|c|}
\hline 21,17 & $69-72.253-256$ & $34,12-26$ & $211.281 \mathrm{f}$ \\
\hline 21,37 & 140 & $34,12-15$ & 263 \\
\hline 22,3 & 140 & 34,13 & $269 f$ \\
\hline 22,9 & 45 & 34,14 & $25.260 .266 f .274$ \\
\hline 22,19 & $266 f$ & 34,17 & $209 f .268$ \\
\hline 22,30 & $183-185$ & $34,18-26$ & 263 \\
\hline $23,1-9$ & $79 f$ & 34,21 & $36-38.56 f$ \\
\hline $23,1-8$ & 80 & 34,24 & 111.130 .139 \\
\hline $23,1-7$ & 81 & 34,27 & $208-211.228$ \\
\hline $23,1-3,6-9$ & 80 & 34,28 & $209 f .239$ \\
\hline 23,1 & $79-81.246$ & 34,29 & 210.212 \\
\hline $23,2 f$ & 79 & & \\
\hline 23,2 & 278 & Lev & \\
\hline 23,7 & $79-81$ & 1,1 & 166 \\
\hline $23,10-11$ & 111 & 4,15 & 201 \\
\hline 23,11 & $45 f$ & $9,1 \mathrm{f}$ & $\begin{array}{l}201 \\
201\end{array}$ \\
\hline 23,12 & $36-38.43-49.52-$ & 9,24 & $199 \mathrm{f}$ \\
\hline & $57.115 f .248 f$ & 18,20 & 90 \\
\hline 23,13 & $183-185.268$ & $19,2-4$ & $144 \mathrm{f}$ \\
\hline 23,14 & 249 & 19,3 & 74.256 \\
\hline 23,24 & 269 & 19,4 & $180.268 f$ \\
\hline $23,31 \mathrm{f}$ & 55 & 19,11 & 276 \\
\hline 23,32 & 208 & 19,12 & 86 \\
\hline $24,1-2$ & 19 of .195.2oof & 19,13 & 138 \\
\hline 24,1 & $200-204$ & 19,19 & 46 \\
\hline 24,2 & $201 \mathrm{f} .204$ & 20,21 & 134 \\
\hline $24,3-8$ & 191 & 23,3 & 248 \\
\hline $24,3 f$ & 226.239 & $24,10-23$ & 85 \\
\hline 24,3 & $19 o f .193 .202$ & 25 & 126 \\
\hline $24,4 f$ & 183 & $25,3 f$ & 248 \\
\hline 24,4 & $191-193.202$ & $25,6 \mathrm{f}$ & 116 \\
\hline 24,5 & 192 & $25,44-46$ & 116 \\
\hline $24,6-8$ & $193 f$ & 26,1 & 180.268 \\
\hline 24,6 & 192 & $26,6 f$ & 46 \\
\hline 24,7 & $\begin{array}{l}193 \\
192\end{array}$ & $26,44-46.47-49$ & 42 \\
\hline $\begin{array}{l}24,8 \\
24,9-11\end{array}$ & 192 - & & \\
\hline $24, y-11$ & 204 & Num & \\
\hline 24,9 & 201 & 6,27 & 245 \\
\hline 24,1 of & $196 f .200$ & $13,1-14,38$ & 67 \\
\hline 24,11 & 170.197 .199 & 13,2 & 66 \\
\hline 31,17 & 51 & 13,32 & 67 \\
\hline 31,18 & 145 & 14,7 & 67 \\
\hline \multirow[t]{2}{*}{32} & 148.159 .210 .212 & $14,17 \mathrm{f}$ & 30 \\
\hline & 27 of. 283 & 14,18 & 27.32 \\
\hline 32,31 & 180.268 .272 & 22,18 & 94 \\
\hline 34 & $282 f$ & 24,13 & 94 \\
\hline 34,1 & $204 f .209 f .239$ & & \\
\hline 34,4 & 204 f.2o9f. 239 & $D$ tn & \\
\hline $34,6 f$ & $28 f .244$ & 1,1 & $217-219$ \\
\hline 34,7 & $27-32.274$ & 4 & 61 \\
\hline 34,9 & 211 & 4,1 & 238 \\
\hline 34,1 of & 205 & $4,3-8$ & 239 \\
\hline 34,10 & $205-207.211$ & 4,9 & 258 \\
\hline $34,11.12 .15$ & $\begin{array}{l}55 \\
207-211-222\end{array}$ & $4,10-14$ & 238 \\
\hline
\end{tabular}




\begin{tabular}{|c|c|c|c|}
\hline 4,10 & 257 & 5,26 & 23 of. 239 \\
\hline 4,12 & 284 & $5,27 f$ & 231.237 \\
\hline 4,13 & 228 & 5,29 & 231 f. 239 \\
\hline $4,15-18$ & 284 & $5,3 \circ f$ & $232-234.237$ \\
\hline 4,19 & 273 & $5,32 f$ & $234 f .240$ \\
\hline 4,23 & 261 & 5,33 & 65 \\
\hline 4,24 & 239 & 6,1 & $235 f .238 .243$ \\
\hline 4,25 & 261 & $6,2 f$ & 65.236 .240 \\
\hline $4,32-34$ & 239 & 6,2 & 64.258 \\
\hline 4,36 & 179.239 & $6,4-9$ & 217.219 \\
\hline $4,44-49$ & 218 & $6,4 \mathrm{ff}$ & 236 \\
\hline $4,44-46$ & 218 & 6,4 & 217.219 \\
\hline 4,44 & 182.219 & $6,10-13$ & $265 f$ \\
\hline 4,45 & 219 & 6,1 of & 113 \\
\hline 4,46 & 219 & 6,12 & 265 \\
\hline \multirow[t]{2}{*}{5} & 156.161 .173 .210$. & 6,13 & 246 \\
\hline & $236 f .281-283$ & $6,20-25$ & 219.221 .258 \\
\hline \multirow[t]{2}{*}{5,1} & $217.219-223$ & $7,1 \mathrm{f}$ & 55 \\
\hline & $237 \mathrm{f}$ & 7,5 & 270 \\
\hline 5,2 & 208 & $7,8-11$ & $275 f .284$ \\
\hline 5,2 & 156.223 .237 & $7,9 f$ & 29 \\
\hline 5,3 & 224.239 & 7,16 & 282 \\
\hline 5,4 & $174.224 f .237$ & $8,2-6$ & 239 \\
\hline 5,5 & $225 f .237 f .243$ & $8,12 \mathrm{f}$ & $112-115$ \\
\hline $5,6-10$ & 141.242 & $9 f$ & 145.148 .156 .160 .204 \\
\hline $5,6-8$ & 262.283 & & $210.237 .281-283$ \\
\hline 5,6 & $262-265$ & $9,7-10,11$ & 148.159 .218 .237 \\
\hline $5,7-21$ & 243 & $9,4-6$ & 148 \\
\hline $5,7-11$ & 142 & 9,7 & 147.15 of . 160 \\
\hline 5,7 & 24 & 9,8 & 151.160 \\
\hline 5,8 & $21-24.51 .261 f .284$ & 9,9 & 151.156 .159 \\
\hline $5,9-10$ & 262 & 9,10 & 151.156 .160 .228 .238 \\
\hline \multirow[t]{2}{*}{5,9} & 2 of. $24-27.30 .32 .244$ & $9,11 \mathrm{f}$ & 159 \\
\hline & $260-263.283 f$ & 9,11 & 151 \\
\hline 5,10 & $244.263 .283 f$ & 9,12 & $151.156 f .268 .272$ \\
\hline $5,11-16$ & $242 f .262 .283$ & $9,13 f$ & 151.160 \\
\hline 5,11 & 76.78 .141 & 9,15 & $152.157 .159 f .238$ \\
\hline $5,12-16$ & 142 & $9,16 \mathrm{f}$ & 159 \\
\hline \multirow[t]{2}{*}{$5,12-15$} & $38-40.45 .49 f .53 .56$ & 9,16 & $152.156 f .272$ \\
\hline & 141 & 9,17 & 152 \\
\hline $5,12-14$ & $33 f .37$ & $9,18 f$ & $149 f .152 .160$ \\
\hline 5,12 & $35 f .4 \circ f$ & 9,18 & 157 \\
\hline $5,13 f$ & 248 & 9,20 & 152.161 \\
\hline $5,14 f$ & $47-50$ & 9,21 & 149.152 .157 .159 \\
\hline 5,14 & $43-48.52$ & $9,22-24$ & 149.152 .160 \\
\hline 5,15 & $33 f .4$ of. 47 & 9,24 & 148 \\
\hline 5,16 & $20.63-74.141 .256$ & $9,25-29$ & $149 f$ \\
\hline $5,17-21$ & $141 \mathrm{f} .262 .283$ & 9,25 & 153.160 \\
\hline 5,20 & $75-80.84 f .246$ & $9,26-29$ & $153 f$ \\
\hline \multirow[t]{2}{*}{5,21} & $87.89 .96-103.106$ & 9,26 & $158-160$ \\
\hline & $113-116.262 .283$ & $9,27-28$ & 159 \\
\hline $5,22 f$ & 20 & 9,29 & 160 \\
\hline 5,22 & $226-228.238 .243$ & $10,1-5$ & 150.154 .160 .204 \\
\hline \multirow[t]{2}{*}{5,23} & $173.228 f .237-239$ & & 218.238 \\
\hline & 243 & $10,6 \mathrm{f}$ & 150.155 .161 \\
\hline 5,24 & $229 f .237 .239$ & $10,8 \mathrm{f}$ & 150.155 .161 \\
\hline 5,25 & 230.237 .239 & $10,10 f$ & 155.159 \\
\hline
\end{tabular}




\begin{tabular}{|c|c|}
\hline 10,10 & $149 f .160$ \\
\hline $10,12 \mathrm{ff}$ & 147 \\
\hline 10,20 & 246 \\
\hline $11,18-21$ & $257 f$ \\
\hline $12,2 \mathrm{f}$ & 282 \\
\hline 12,3 & 270 \\
\hline 12,29 & 282 \\
\hline 12,31 & 282 \\
\hline 13 & 267 \\
\hline 13,6 & 265 \\
\hline 13,11 & 265 \\
\hline 14,21 & 282 \\
\hline $15,1-6.7-11$ & 140 \\
\hline $15,12-15$ & 48 \\
\hline $15,12.17$ & 115 \\
\hline 16 & 251 \\
\hline 16,1 & 249 \\
\hline 16,3 & 41.251 \\
\hline 16,8 & $41.251 \mathrm{f}$ \\
\hline 16,10 & 249 \\
\hline $16,11 \mathrm{f}$ & 249 \\
\hline 16,15 & 249 \\
\hline 16,19 & 244 \\
\hline $16,21 \mathrm{f}$ & $271 \mathrm{f}$ \\
\hline 17,3 & 267 \\
\hline 17,12 & 256.279 \\
\hline 17,20 & 234 \\
\hline $18,14-20$ & 226.238 .245 \\
\hline $18,16 \mathrm{ff}$ & 227 \\
\hline $18,18-20$ & 245 \\
\hline 18,19 & 256 \\
\hline 18,20 & 257 \\
\hline 19,13 & 279 \\
\hline 19,14 & 137.140 \\
\hline $19,16-19$ & $84 f$ \\
\hline $20,5-7$ & $111.119-121$ \\
\hline 20,17 & 55 \\
\hline 21,11 & 136 \\
\hline $21,15-17$ & 140 \\
\hline $21,18-21$ & 253.256 \\
\hline $22,6 f$ & 63.253 \\
\hline 22,7 & 65 \\
\hline $22,8 f$ & 111 \\
\hline $22,9-11$ & 46 \\
\hline $22,13-21$ & 256 \\
\hline 22,22 & 133.279 \\
\hline 23,1 & 134 \\
\hline 23,9 & 32 \\
\hline 24,5 & 120 \\
\hline 24,8 & 56 \\
\hline 24,16 & 29.275 \\
\hline $25,13-15.16$ & 253 \\
\hline 25,15 & 64 \\
\hline $26,1-11$ & 282 \\
\hline 26,13 & 234 \\
\hline 26,16 & $222 f$ \\
\hline 27 & 90 \\
\hline
\end{tabular}

$\begin{array}{ll}27,15 & 268 \\ 27,16 & 72 \\ 27,17 & 137 \\ 28,30 & 111.120-122 \\ 28,31 & 45 f \\ 28,58 & 245 \\ 31,9-11.12 & 238 \\ 31,11 & 220 \\ 31,12 & 220.238 .258 \\ 31,13 & 238.258 \\ 32,45-47 & 258\end{array}$

Jos

24,13

113

$R i$

20,13280

$21,23 \quad 135$

Rut

$1,4 \quad 135$

$4,5.9 f \quad 123$

1 Sam

$8,11 \mathrm{~b}-17 \quad 92$

$25,5 f \quad 105$

2 Sam

$12,4.10 \quad 134$

$12,8 \quad 122$

1 Kön

$8,9 \quad 145$

$8,12 \quad 227$

2 Kön

$10,30 \quad 31 \mathrm{f}$

$15,12 \quad 31 \mathrm{f}$

$18,4 \quad 27$ of

$21,3 \quad 25$

22f 194

$22,17 \quad 269$

23,1-3 194

$25,12 \quad 125$

Esr

$2,65 \quad 116$

Neh

$4,8 \quad 122$

$5 \quad 125$

$5,3.11 \quad 110$ 
308

$\begin{array}{ll}7,4 \mathrm{f} & 126 \\ 7,67 & 116 \\ 9,25 & 113 \\ 10,32 & 126 \\ 11,1 \mathrm{f} & 126\end{array}$

Ez

$\begin{array}{ll}1,13 & 173 \\ 11,15 & 125 \\ 18 & 29 \\ 20 & 275 \\ 33,24 & 125\end{array}$

8

94

Hos

Ijob

$\begin{array}{ll}24,13-15 & 277 \\ 42,16 & 30.32\end{array}$

3,1

4,2

5,10

8,4

10,4

12,2

12,10

12,12

13,2

13,4

266

81f.272-278.281.283

137

272

$81 \mathrm{f}$

82

264

83

spr

19,14

123

19,26

255

20,20

254

22,22

138

137

22,28

23,10

137

28,24

138.255

$29,15.17 \quad 255$

30,8

83

30,11

255

30,17

255

31,16

110

Jes

5,8-10

$109 f$

13

122

$32,12 \mathrm{f}$

$59,3 f$

110

83

Jer

1,16

$6,11 \mathrm{f}$

269

7,9

121

277f. 281.283

25,6

269

121

$29,5 f$

29

$31,29 \quad 275$

31,31

32,15

208

110

32,18

$35,7.9$

29.275

110

39,10

125

52,16

125

Am

5,11

Mich

2,2

Sach

5,1-4

111

139

125

264.266 